

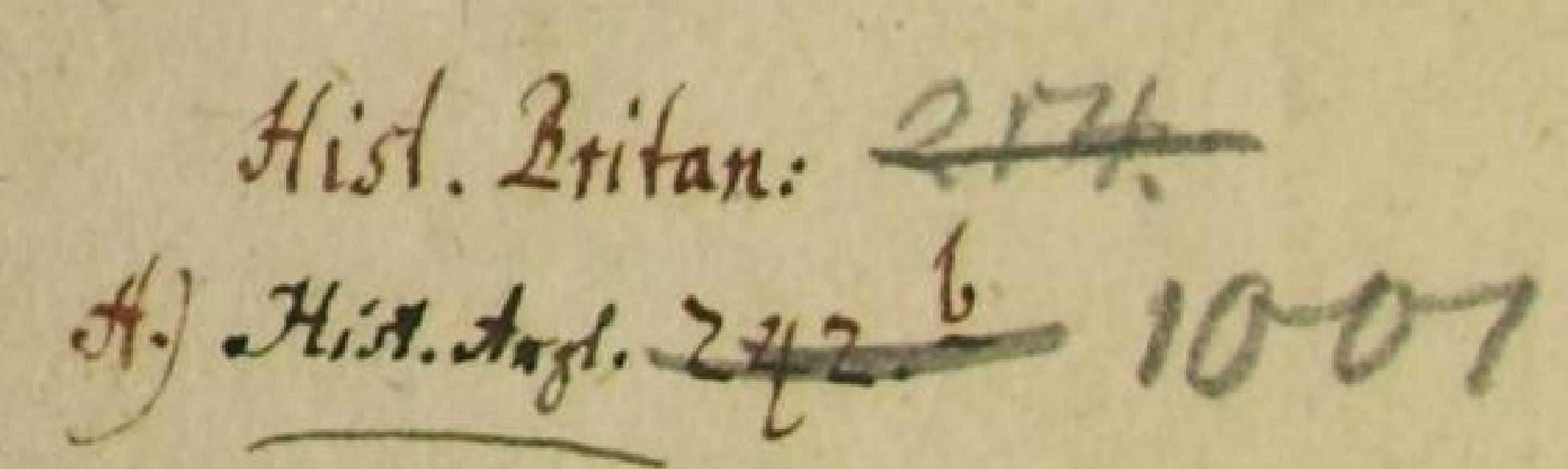






\section{T્t $\mathfrak{i}$ i eilles}

Deutfhen in England im $9 a b r \quad 1782$.

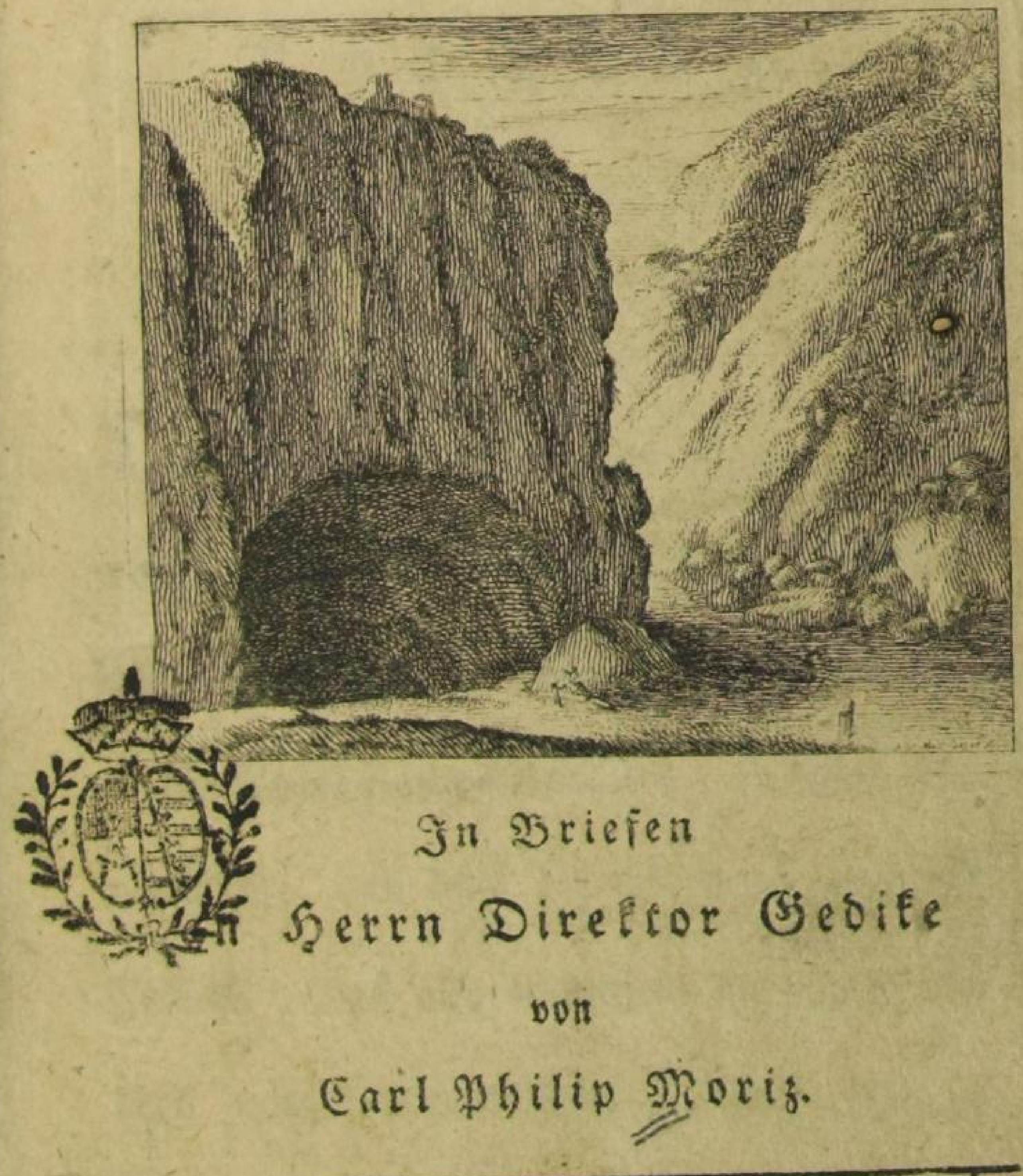

Serlin, 1783.

bey zriedrid Raures. 


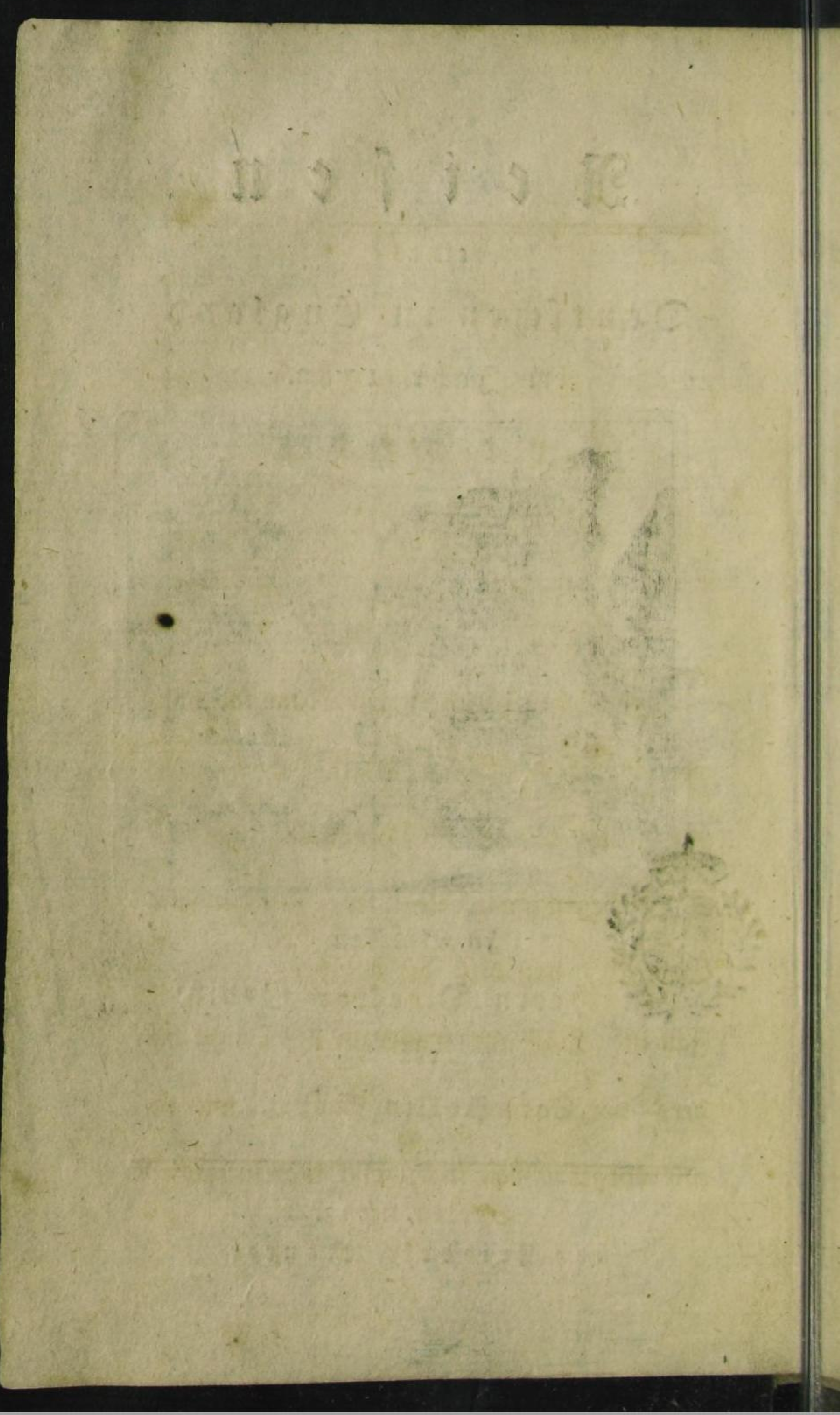




\section{$\mathfrak{B} \bullet \mathfrak{r} \mathfrak{r} \mathfrak{e}$}

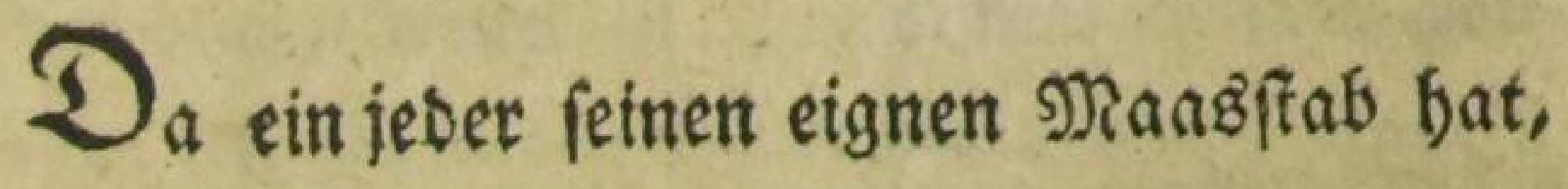
mornach ex bie Dinge auffer fich abmifit, und peinen eignen Gefichtspunft, woraus ex bie Begenftände betrachtet, fo folgt fefor

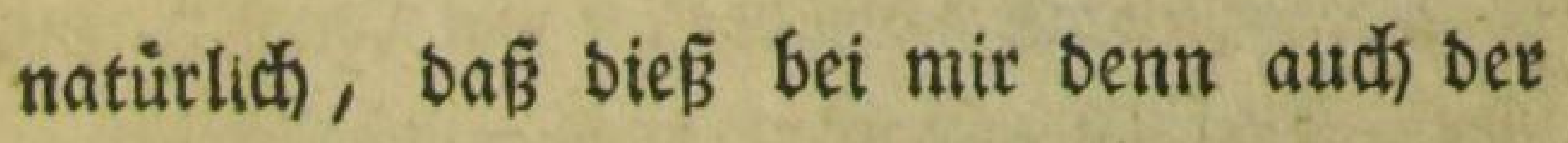
Sall iff. Dẩ alfo manchem bie Dinge ans bers vorgefommen fenn múfien, wie fie mir vorgefommen find, folgt eben fo naturs 
lid). in Crmanglung befrer linterbaltung, etwa mit biefem bucthe cine @tunbe ju vertúrgen, Den bitte ich um Beferjigung Diefer fursen Norrebe, und un Nachfictit für ben Eve joibler. 
2uf Der Ibemie ben 3 xfen Mab.

nolich, liebfter (S)..., befinde id mich zrot fajen ben gluidlichen Ufern bes gandes, bas zu

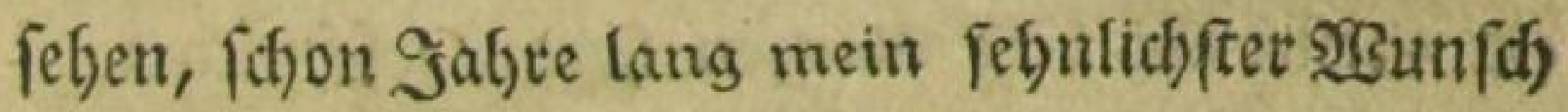
roar, und robin ich mich to oft in (Ssebanten getråumt habe. $30 t$ einigen Stunben Dåmmers ten nod) bie grúnen Şüget von England vor uns in blauer Ferne, ieste entfalten fie fid) von beis ben Seiten, wie ein boppeltes afmphytheater.

Die Sonne brid)t burd) bas Siemsif, uns vergúlbet wedjelsweife mit ifrem Sd)ein Gebú: The uno sgiefen am entfernten Ufer. Broei Daften ragen mit itgen Spişen aus ber Tiefe

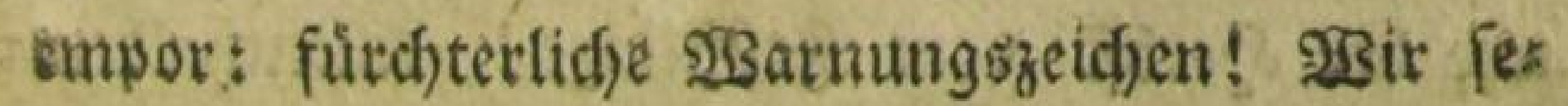
2. 


\section{$(2)$}

getin Gart an ber Sandbane vorbei, wo fo viet

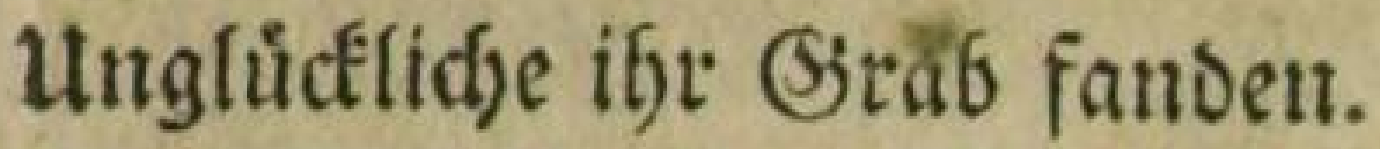

Эmmer enger ziegen fid bie Utfer zufammen: Die Gefaftr der Tieife if vorbei, und der forgen: freie Sienuß bebt an. Sigie ift bodh Dem Ments

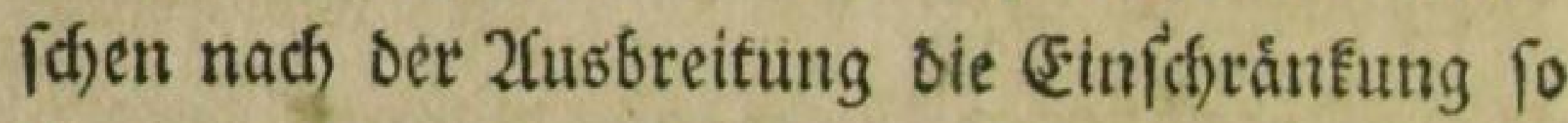

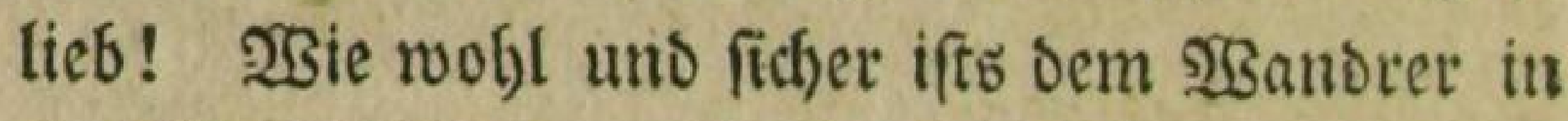
Der Eleinen Şerberge, Dem Seefabrer in Dem ges

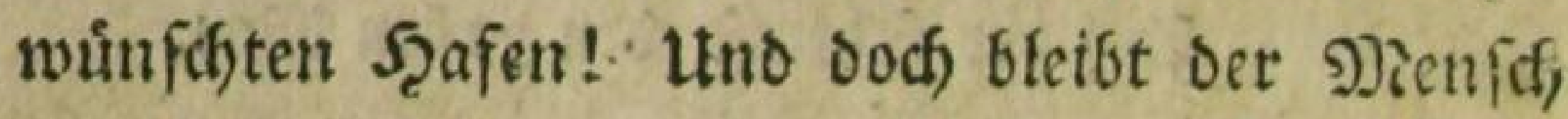
immer im (Engen, er mag nod) fo feffr im ten Feint ; felffit bas ungebeure Neer zieft fids um ifg $\mathfrak{z} u[a m m e n$, als ob es ifst in feinen Da: fen einfchliesenen wollte; um ifn ift beftándig nus ein Stúct aus dem Granzen feraurgeiffnitter.

2Iber Das iff ein ferrlicher 2 (4usfobnitt nus dem

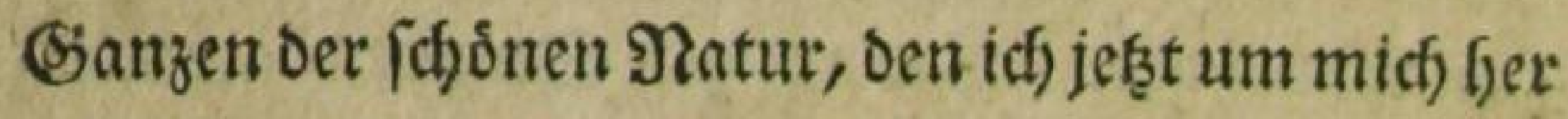
erblicfe. Die Themfevolf hin und her zerftreuter groper und fleiner Schiffe und Doste, bie ent? weber mit uns fortteegeln oder vor 2fnfer liegen; Die Şúgel an beiben Eeiten mit einem fo milben fanften Ssưn befleibet, wie id) nodh nirgenos fahe. Die reizenden Ufer ber Elbe, die ich verlié, werben von biefen $\mathfrak{t}$ fern úbertroffen, mie Der Şerbft vom Frtîtinge! Iflentyalben. 


\section{(3)}

Teh id) nidfts, als frudtbares uno bebautes \&ano, und bie lebendigen Sgecten, roomit die grúnet 2rseizenfetber eingejăant fino, geben der ganzen weiten Shur das ZUnéfen eines großen majeftátio

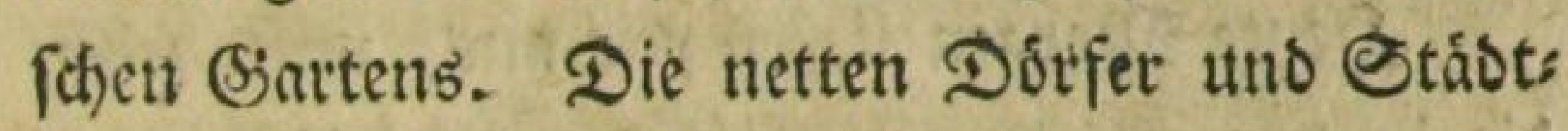

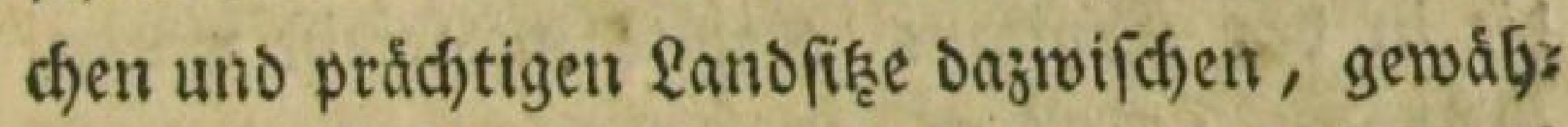

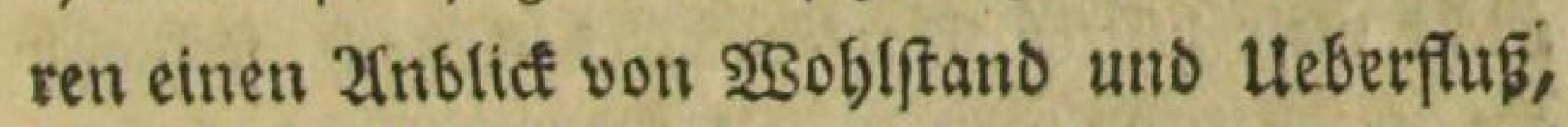

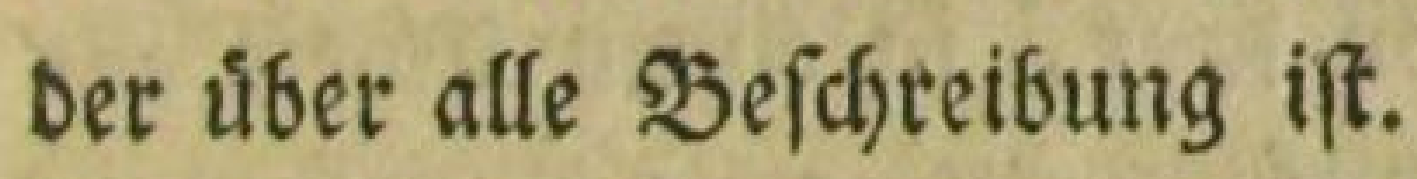

Insbefonbre idgón ift bie 2lusfidft nad) Gitas ve[ano, einem artigen Stábtcljen; bas einen bet Scligel binangebaut ift, und um weldhes Ders

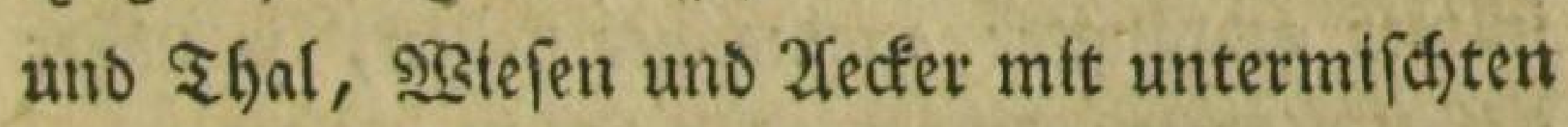

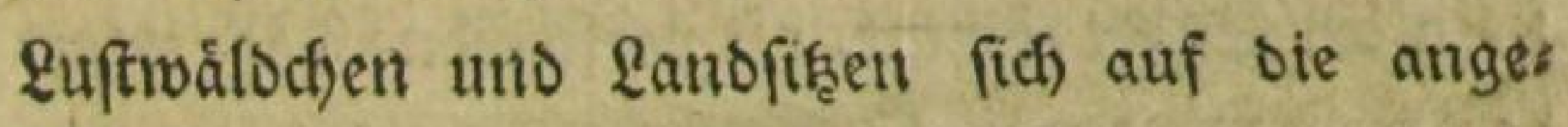

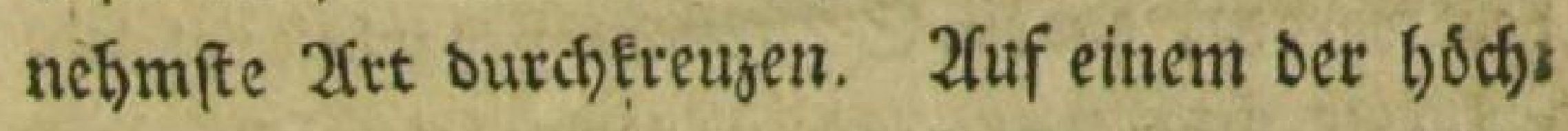

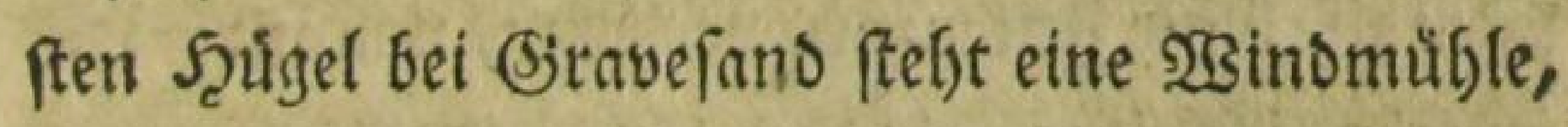
bie einen guten Gefictitspunft giebt, weil matt fie, nebfe einem Theile ber (segent, nud) weit Gin ouf Den Srummungen ber Effemle fieft. Zfber wie Denu fein iff, fo finto wir bei Seetrad)tung aller Diefer Echson: beiten auf bem Berbect nod) einem Febr faitten

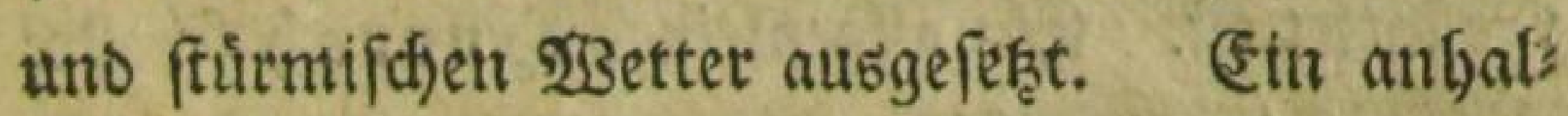

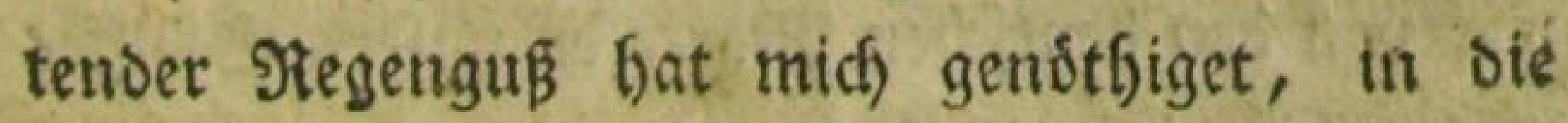
Rajúte ju gelgen, wo idh mir êne tr tibe Stundes 


\section{$(4)$}

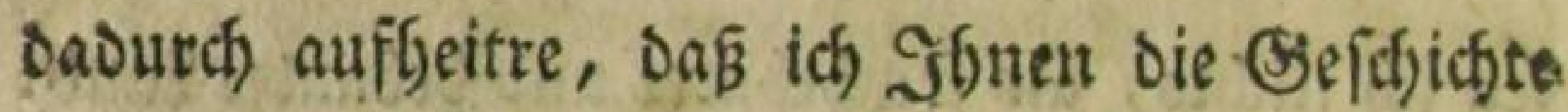
etner a ligenehmen beforeibe.

Sonbon, Den aten Juni.

Şeute Miorgen ließ̧en wir uns, unโer zelth, Die in Des Rapitans Rajúte mitgeteift waren, nidjt weit binter Dartford, Das nod Fechjef)n Deilen von Lonbon liegt, in einem Soote ans gand lę̧en. Diés thut man gemeiniglid, wenn man bie ₹Gemfe hinauf nad) Iondon fábrt, weil wegen ber erftaunlichen s)enge von Edjiffen, bie immer gedrăngter aneinander freben, je náfer man ber Stadt fommt, oft verifileone Tage erfor: bert werden, ege ein Sisiff fid durcharbeiten fautr. SBBer aljo feine Beit unmúg verlieren, uno andre Hins annefgmlidjefiten, als Das sftere Stiff(teben uno 2Inftoken des Schiffes vermeiden will, Der macht Die renigen Meilen bis \&onbon lieber zu\&ande, ets

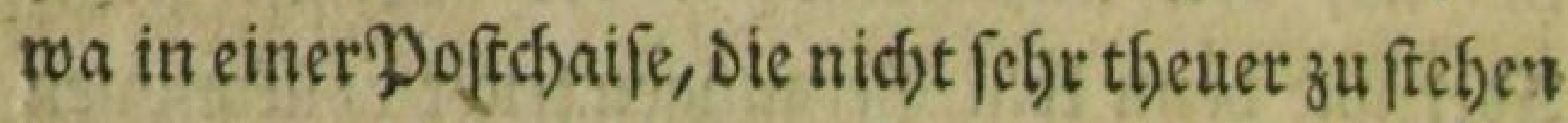
formmt, wenn úberdem jebesmal ibrer brei zufam: mentreten, welches Durch eine Parlamentsafte verftattet iff. (Fin allgemeines $\mathcal{S C}_{\text {, }} \mathfrak{r} \mathfrak{r} \mathfrak{a}$ ) (d)allte uns von ben beutichen Matrofen un[ers Sdjiffes nach), Die biefes von den (Englänoern angenoms. 


\section{( \&)}

men Gaben. Das Ufer, wo wit ausfiegen, twat rocis und freidigt. $3 i s$ Dartford musten wir zut

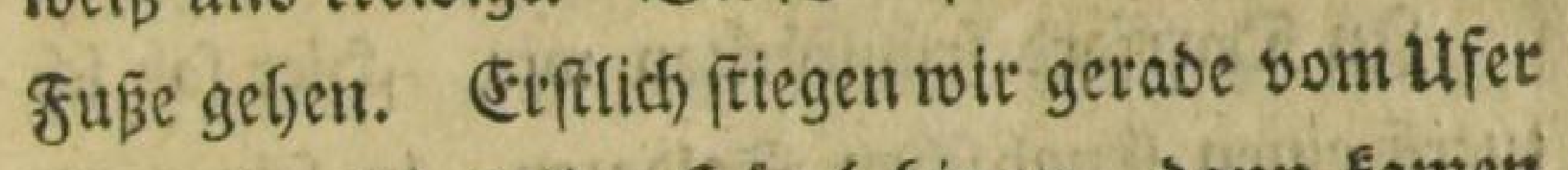
einen żiemlidh freilen Şągel f̧inan, Dann Eamen wir fogleid) an bas erffe Engliiche Dorf, wo mich bie aufferotbentlidje গettigeeit thi ber פauart Der

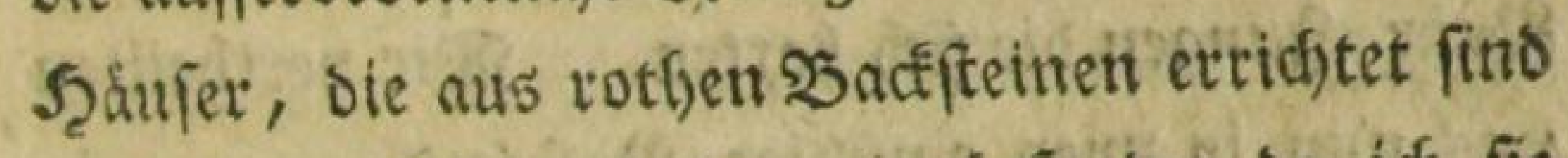
itho flache Dácher baben, ittsbefontere ba id fie nnit unferri Sauerbútteti verglid, in ein angenel): mes Erftaunen fertete.

Utho nun zogen wit wie eine Saravane mit unjern Stáben von einem Dorfe zuth andern : cinige Leute, die uns begegneten, foblenen uns

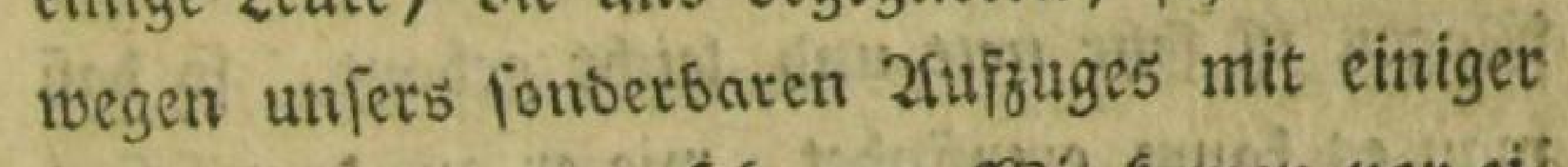
betrounderung anzulfeben. STSit fathen yor eil nem Esegolol vorbei, wo fich ein ₹rupp Bigeunet bet einem Setier um einen $\$$ aum gelagett batte. Iffein fo mie wir fortwomberten, warb ble Gee geno timmer fojonter uno fabsher. Die Eroe ift

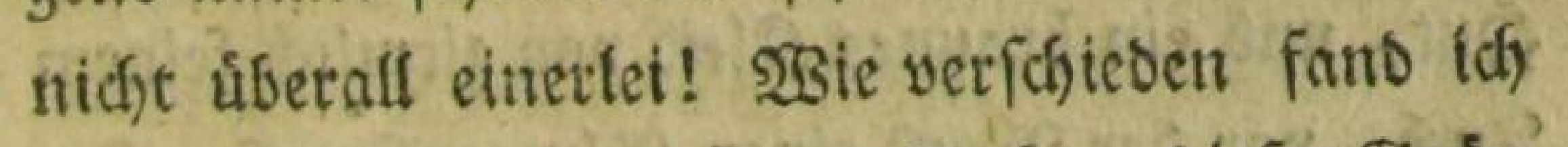
Diefe fetten uno frudgtbaren 2fecter, ofeefes Grún

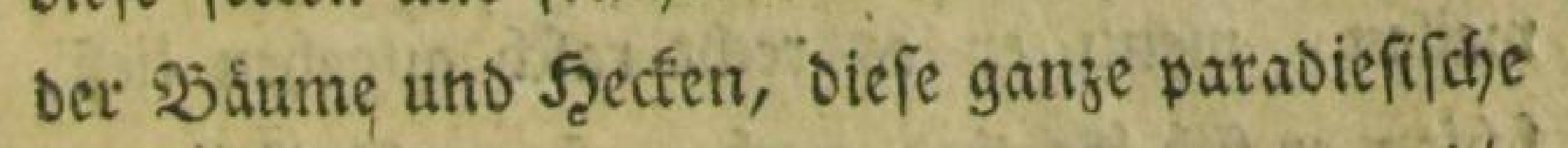
Giegent, wori ben unfergetr, und affer anbern bie

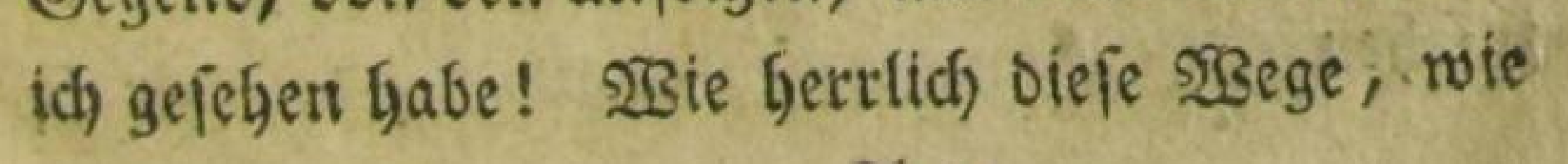

$x_{3}$ 


\section{(6)}

feft biés (Etoreid) unter mir; mit jedem Estritte

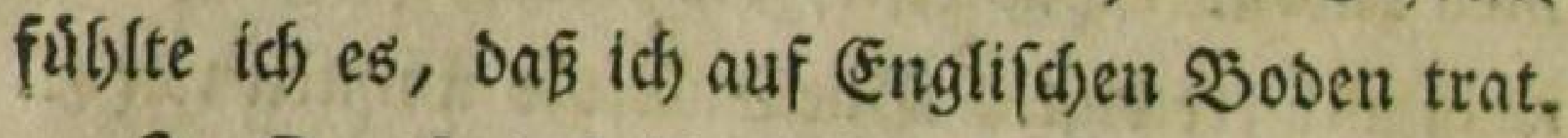

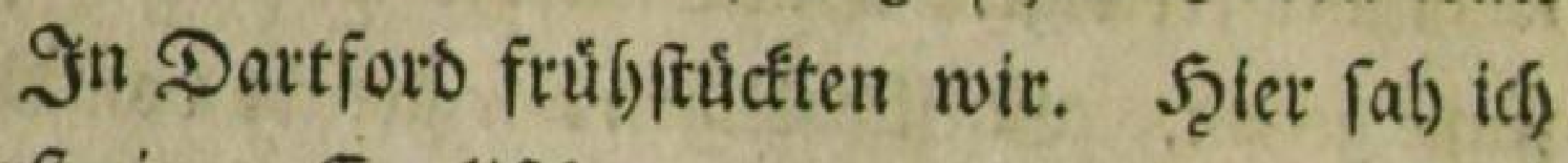
zuerff einen Engliffen Soldaten, in feiner ros then Diontur mit abgeidnittnen und vorn beruns tergetámmten Şaar, aud) auf ber Straße cin SDaar Saungen bie fich barten. STsir vertbeilten uns nun in grwey einfifige poftdjailen, wo in jeber orei Đerfonen, freilid) nidft alfzubequem

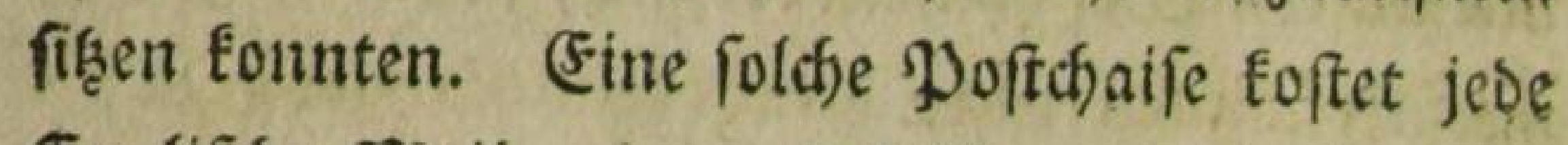
Englifhe गreile einen Schilfing. Sie iff mit unlern Extrapoften zu vergleiffen, weil man fie zu jeber Beit befommen faml. Zf fber ein follher

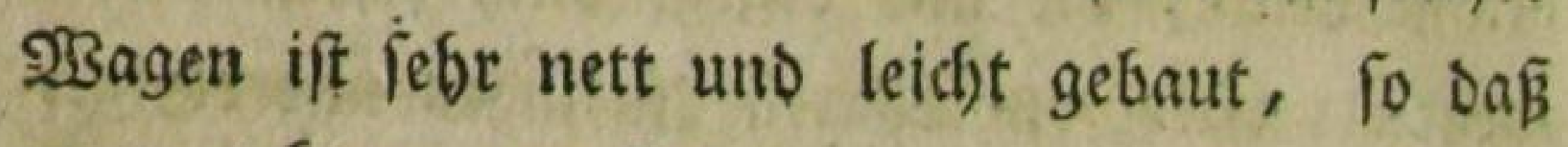
mant es Eaum empfindet, wie er aul Dem feften (eroreid fortroflt. Er bat vorit und an beiben

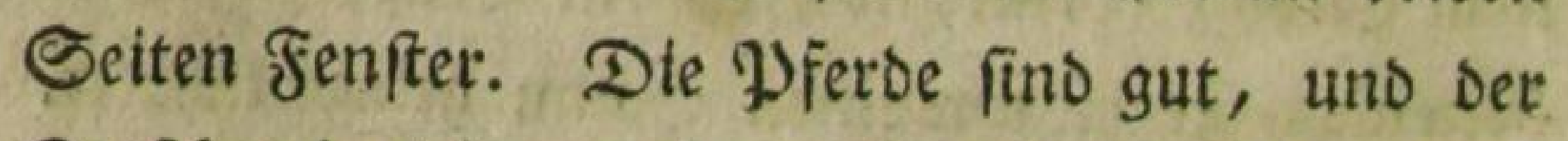
Siutififer jagt immer in vollem Trabe fort. Der unfrige trug abidinittnes Shaar, einen runben frut, und ein braunes Sileto von ziemlid, feinem

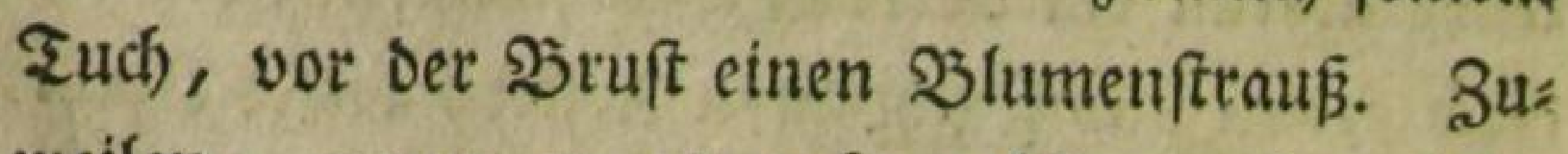

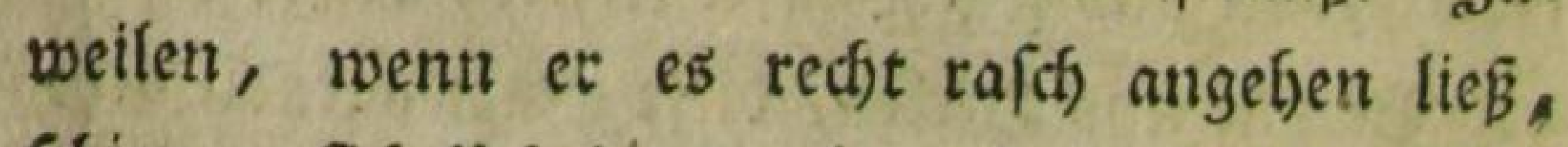

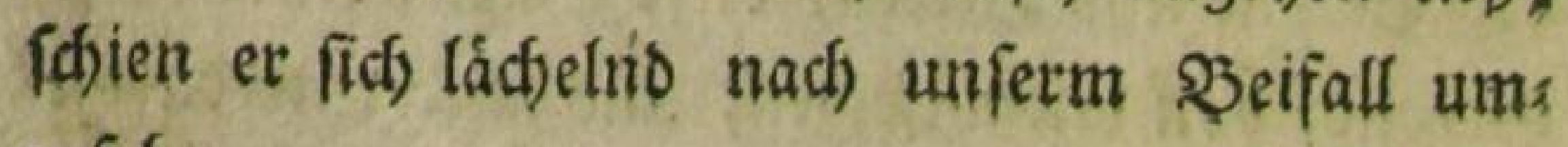
buegen. 


\section{( 7 )}

Und nun flogen bie Gertlichfien Lanb? fichaften, worauf mein 2linge fo gern ver: weilt hatte, mit Pfellfanelle vor uns vorbei;

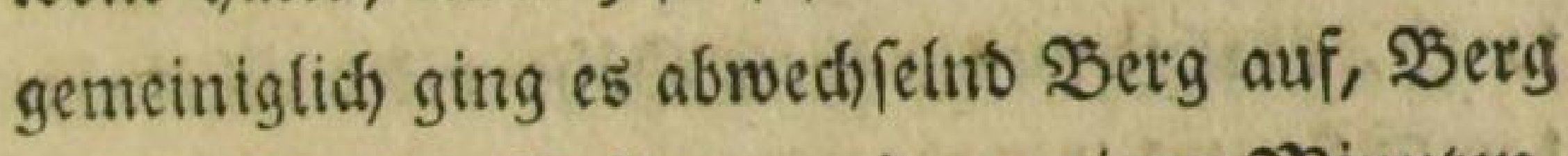
nb, $\mathfrak{W}$ alo ein, $\mathfrak{Z}$ ald aus, in wenigen Minuten. Dann fam einmal jut rechten Seite oie Themie wieder zum Borfhein mit allen ifjen Maften; benn ging es wieder burch reizende Stabte unt Distier. Şefonders fielen mir die erftaunlidy grop̧en Schilber auf, welche beim Eingange in bie Flecten uno Difrer, queer uifer bie Straß̧e an sinem balten hángen, ber von einem f̧aúe zum andern übergelegt ift. Dieß̉ giebt einige 2tefon: lich feit mit einem ₹gore, wofurr idf es auch ans fângliă bielt, allein fo ift es weiter nichts, als ein Zeichen, Das foier fogleich beim Eintritt in Den Dit ein Sarttyof fer. So famen wir bei Diefer fdnellenzlowed) felung fodd) ft mannichfaltiger Giegenftánde beinabe in einer 2fit von ß̧etáubung bis nalje vor Sireenwidh, uno mun

\section{Die 2(usficht von Sonoon.}

(5) zetgte fich im sicfen গRebel, Die Daul(s; firche hob fidf aus ber ungeheuren Dafle Eleine:

$$
\text { स } 4
$$




\section{( \& )}

ter Stebaude, wie ein Serg empor. Das 9) Jos nument, eithe thurmbolse runde Sáule, die jum

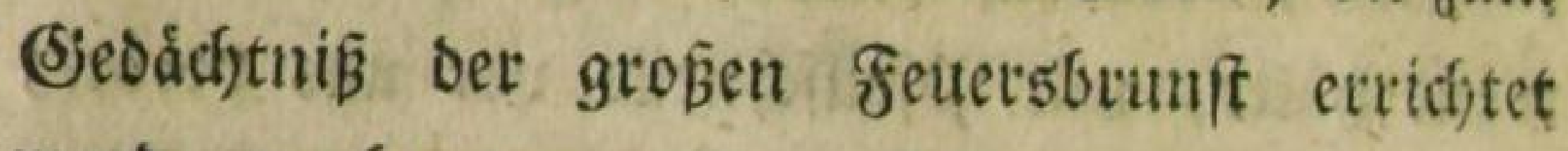

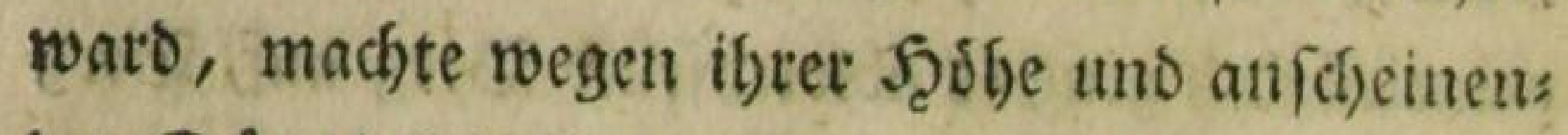
Den Dúnnigfeit einen ganz ungerobonten uno fon: berbaten 2tublicf.

23it nåberten uns mit grofer Sthnellig̨eit, uno bie Siegenfámbe verdeutlichten fict) alle 2(u: getrblicfe. Die Sieftminfterabten), Der ₹orver, ein Shurm, eine Sirche nach) Det anbern, tragten bervor; Shon founte mall die bohen runten Shyornfreine auf ben Scaufern unterfheiben,

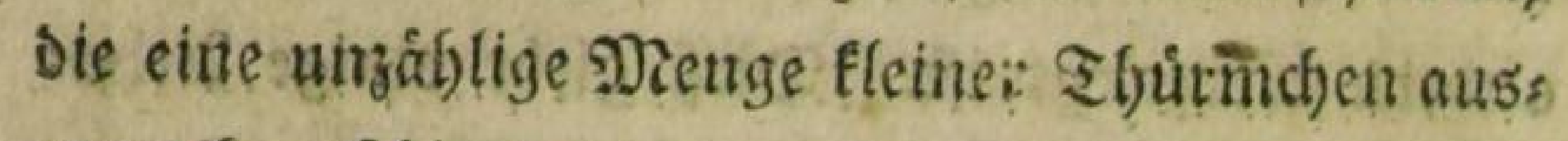
.̧umadjen fósienen.

3on Sireenwich) bis \&onbon wat bie Iands ftraße fichon weit lebljafter, als Die volfreichfte Strabe in Berlin, fo vief teitende uno fafternde Werionen, uno Fusganger begegneten uns. 2tud) etblicte man febon alfentbalben Şấfer, uno an ben Seiten waren in verbåltni nung Laternenpfale angebrací)t. TSa mir febr - auffiel, waren die vielen fente, oie ich mit Ditil: levi reiten fafe, unter denen fich einige von febet jugendidjen 2fufeben befanten. 2\$ohl oreimal 


\section{( 9 )}

murben twir bei fogenattnten Từnpilkes pDek S(hlagbaumen angebalten, itm einen Zoll abzu? tragen, Der fict) Dod) am (Ende suf einige Sdhils linge belief, of wir ifgn gleich nur in Supfermunze bezablten.

Enotidf famen wir at bie prafdstige şseft: minfter: Brtucte, Es ift, nils ob man ưber biefe Brucfe eine fieine Reife thut, fo mancherlen (jes genftánde eroficft man yon berfelben. Im Sons traft gegen die runde, moderne, majeftátifdse

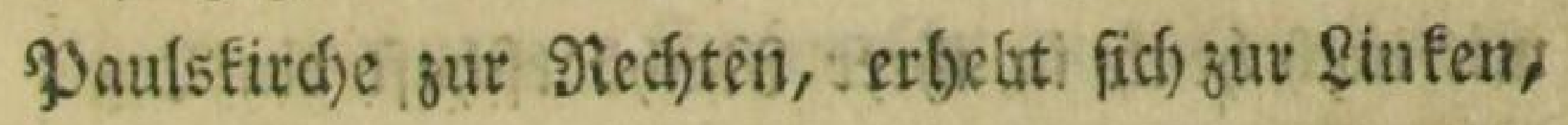
Die altfrántifd)e, langlid)te :seftminfterabten mit ibrem ungelyeuren fipisen Dadye. Sur rechten Seite bie Shemfe binunter, fiefot man bie Sjlack? friarsbraffe, Die biefer an Edfonlyeit nidjt viet

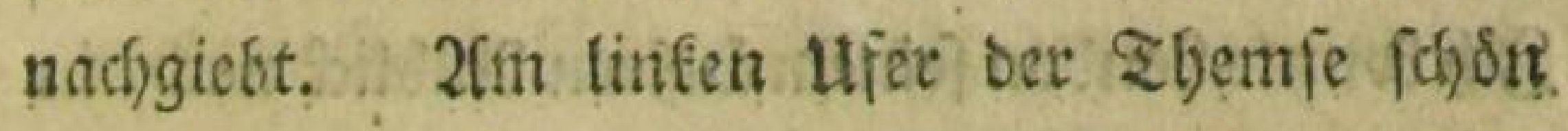
nit Sămen befef̧te Terraffen, uno bie neiter Giebaube, welthe ben Samen Zloelphi ; Suils bings fúfren. Zluf Der Themfe felloft eine grofie

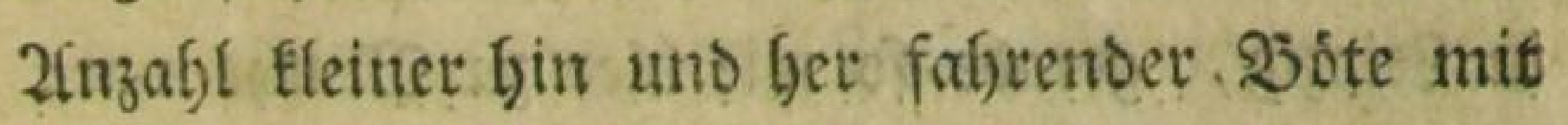
eirtem ग)aft uno Seeget, in weldhen fíd Derfos nen von allerlei Stande tifberfefen laffen, wo:

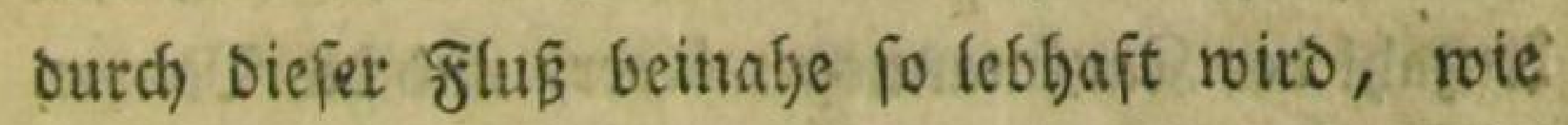
sine fononer Strạ̈e. Sirobe Sdyiffe fiét XI 


\section{( ro )}

man biet nicjt mefre, benn bie gebn am anberti Enbe ber Stabt nicft weiter als bis an bie Lond, ner Ştůcfe.

9. 2 Şir futbrent nun in bie Stabt åber (5)aring: ftoß uno ben Strano, nach eben ben 2roelphi:

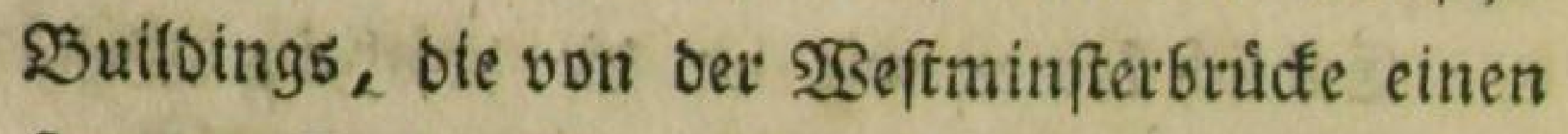
fo vortrefflichen Shrofpeft gaben: weil meine bei: ben Petígefábrten auf Dem Echiffe uno in ber Poftchaile, ein Paar junge Englänber, in oies. fer Ssegeno wohnten, uno fich erboten batten,

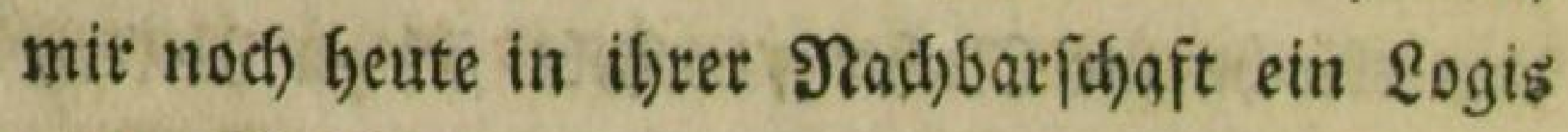
zo verichaffen.

3. In Dett Straßen woourch wit fufren, bes bielt alles ein ountles uno fofrwárgliches, abev Doch) Dabei groß̉es und majeftátifdes 2fufełen.

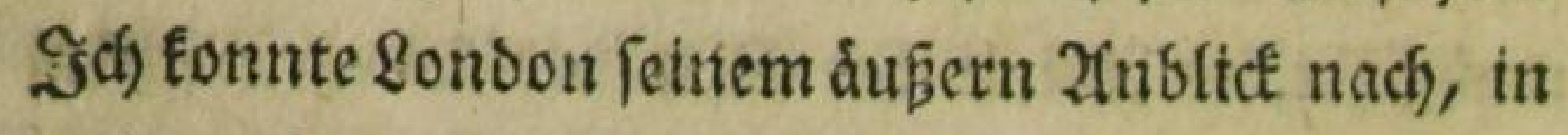
meinen Siebanten mit feiner Stadt vergleidhen, bie th jonft gefét)en batte. Sonberbar iff es, dā̄ mir olgngefábre vor fünf Jabren, beim erften (sintritt in Eeipztg, getaoe fo wie bier zu Matbe war:

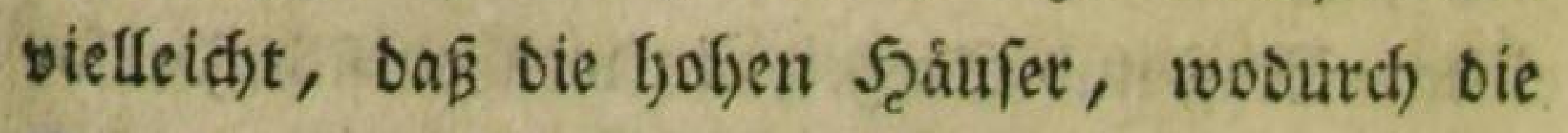
Etraßen zum รgeil verdunEelt werben, Die groß̧e Zfrzabl Der Raufmannsgewdiber, uno Die \$ienge

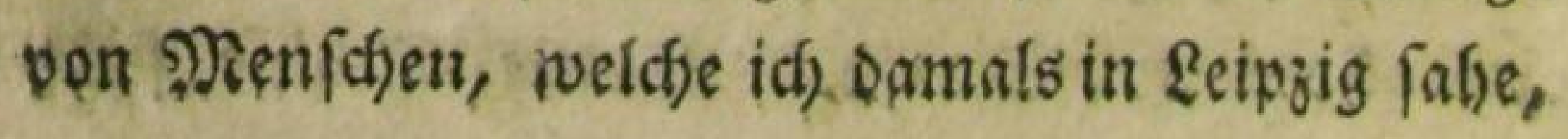




\section{(1)}

nit bem einige entfernte 2feffnlichfeit Gaben modften, was id) nun in Sonton um midh bet erbiicfte.

2flenthalben geben yom Strande nach ber

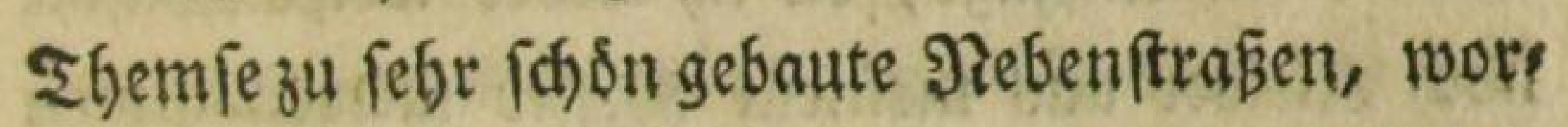
unter Die 2lDelphi ßuildings bei weiten Die fahons ften find. Unter biefen fútgrt wieder eine Nebens abtheilung, pder angrenzende Gegend Den Na: men Yort : Suildings, in weldsen Bjeorg Street befindlich ift, wo meine beiden Reifeger fáfirten wobnten. Es betridat in biefen fleinen Straben nach Der Themie zH, gegen das (jerwúg! yon गen[chen, $25 a g e n$ uno Pferden, reldhes Den Strand beftåndizg auf und nieber geljt, ? einmal eine jo angenelgme Stille, Daß̧ man gan aus Dem (Sieráufh Der Stabt entfernt fu fenn glault, welches man bod) wieder fo nabe bat.

(Es mod)te obngefäbr zebn oder elfulfr (et)n, Da mir hier anfamen. Madhoem mid) bie beiben Engländer nod) in ifrem \&ogis mit einem frút): fruck, Das aus Thee und Sutterbrod beftanb, bes mirtbet batten, gingen fie felbft mit mir in ifject शacjbaridjaft herum, um ein \&ogis für mich) zu Jushen, Das fie mir endidh bei einer Schneidera 


\section{( 12 )}

loittroe, oie ibtem Scaule gegenubber wobnte, fut Fechzelnn Schifling wochentlich, verichaften. (Fs wat auch fefre gut, oaß̧ fie mit mit gingen, denn

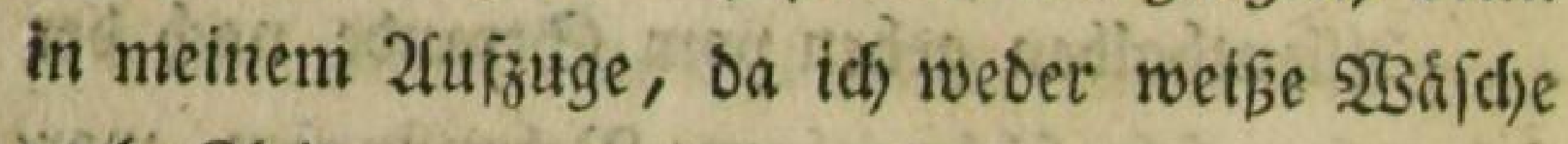
hod) Sleider aus meinem Soffer mitgenommen batte, wurroe id fagwerlich irgentroo untergetom: men fern.

- Es war mir ein fonderbares aber febrt ange: nebmes Ssefúbl, oaß̉ ich mich nun zum exftenmal unter lauter Finglaindern befano, unter \&euten, bie eine frembe Sprache, ftembe Sitten, uno ein frembes Rlima baben, uno mit benen id boch hun umgelen uns reven fonnte, als of to von Jugenb auf mit thenen etzogen rate. Es if ge:

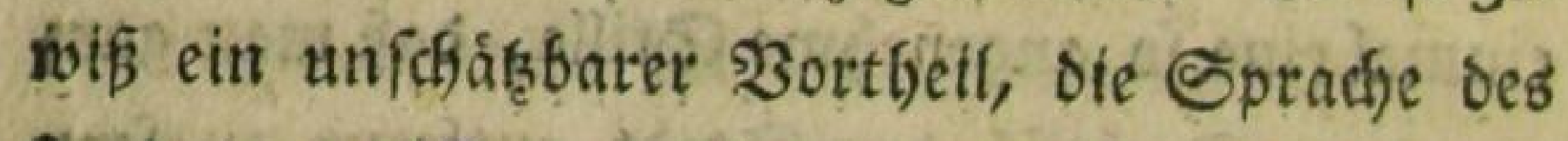

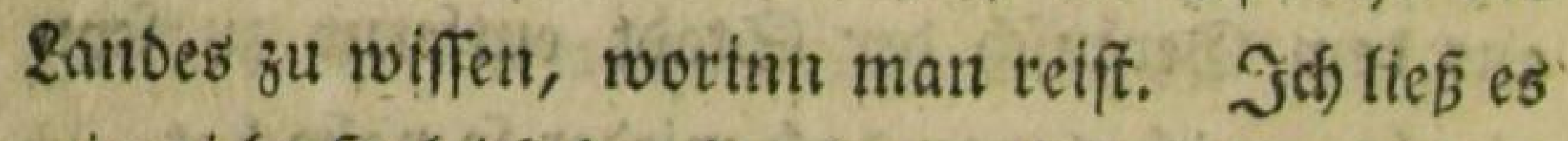

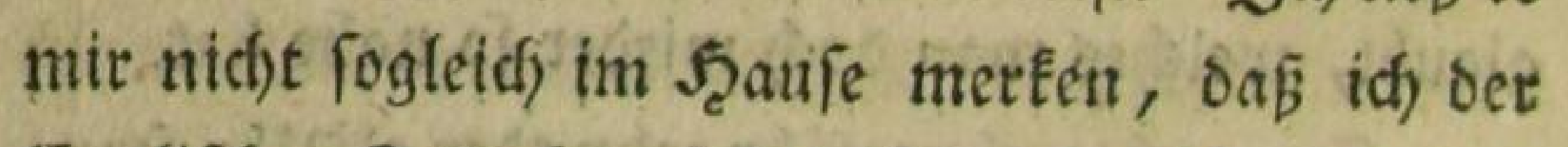
(Englifchen Spradje mådjtig len; je mebt id aber cebete, Deftomegr fans idh Siebe uns Sutrauen.

Jich beroobne nun ein groß̧es Sinmet untent an ber Eroe vorn Geraus, bas mit Eapeten und fursteppichen verfegen, uno felst gut msblint iff: Die Stúgle fint mit \&eder úberzogen, uno oie

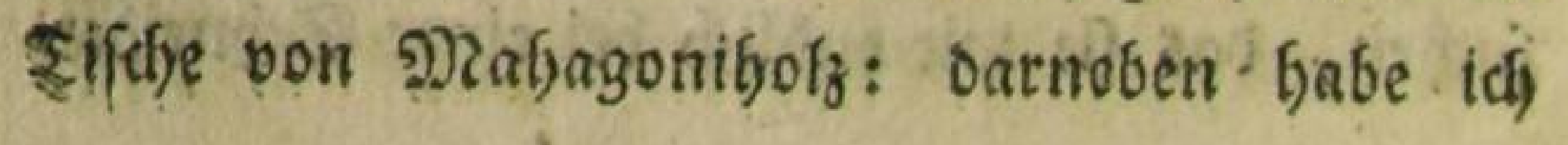




\section{(13)}

noch eine grobe Sammer. Nun fann id mid bier einrichten wie idf wilf, uno mir meinen elgs nen Thee, Saffee, Butter uno Brod halten, roozll mir meine Sisthth einen ver/d)lofinen glas. fernen Sdfrant in der Stube eingeraiumt hat.

Die Famille befteft nus Der Frau im Şaule,

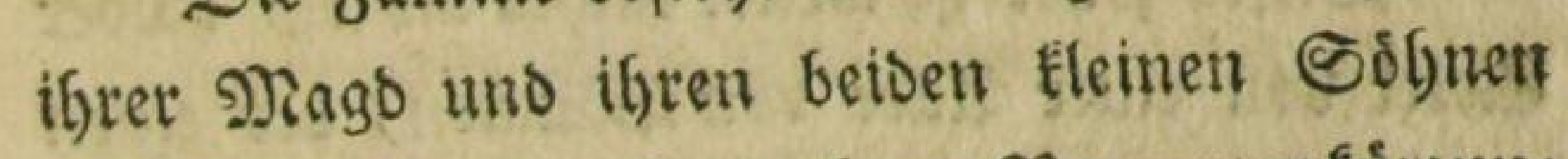

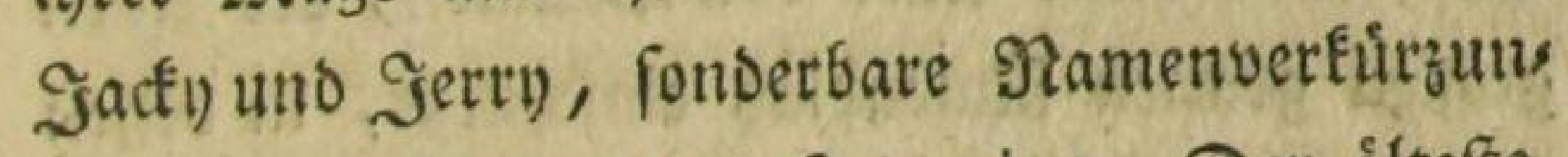
gen von Jobannes uno Jetemias. Der åltefte, Sncfiy, von zmolf Jabren, if ein feís leblyafter Ropf, und unterbált mich auf bie angenefimfte 2fit, inbem er mir von feitren వefácháfigungen in ber Sdjule erzáblt, uno fich yon mir wieder allerlen von Deutichland erzáblen lás̆t. Er meiß fein amo, aman, amas, ames, in eben folthen fingenven Tone wie unire getosthntichen Gd)ul: fuaben berzulasen. 2fls id) in feiner Siegenwart anfing irgeno eine frostiche Prelodie fur mich bu triflern, fabe er mich febr bedenflicf) und verwoun: Derno an, und erinnerte mich, daß̧ es Eonntag (ev). $u m$ ifsm Eein 2lergerniß zu geben, antwor: tete ich if)m, Daß ich bei ber 23erwirrung Der Rieife nicht auf Den ₹ag gemerft batte. (Er hat mid) Geute \$Jittag \{djon in Den St. James : \art 


\section{( 14$)$}

Sefúfet, bet nicht tweit von fier ift; unto mun bs? ten Sie denn etras von dem berúgmten

\section{St. James = Pare.}

Diefer Date ift weiter nicfts als ein balber Eirfel von einer Zfllee von \$áumen, ber eittent

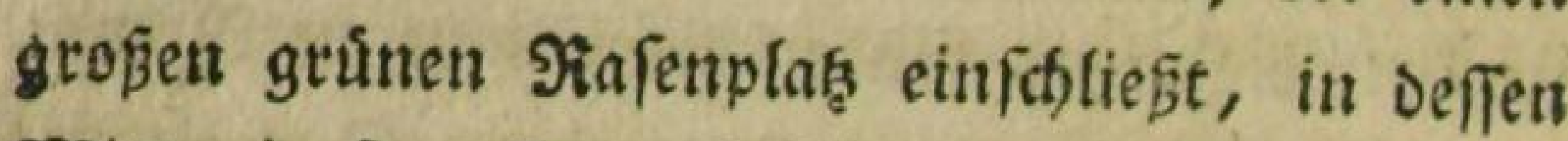
פittte cin fumpfigter ₹eid) befind(idf) iff.

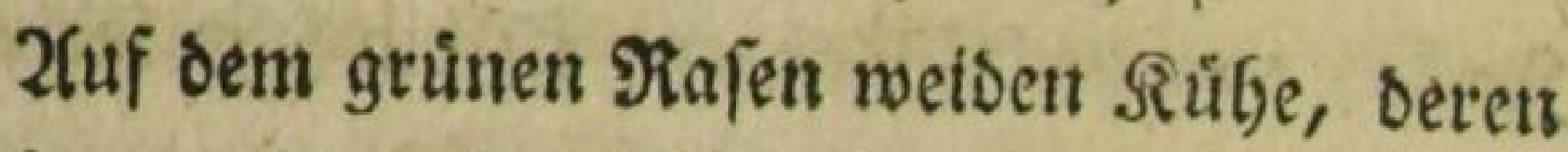
Dild man biel, fo frith, wie fie gemolfen wito, verfauft. In ben 2ffleen find Sănfe zum 2fuss

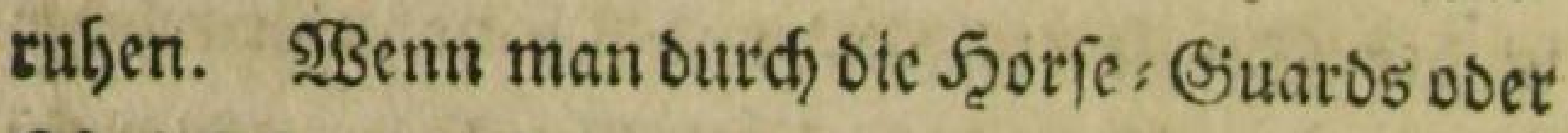
Sosniglide $253 a c h e$ zu Pferbe, weldje mit vers (chjeobnen Durdjgángen verfefen iff, in ben Dart tsmmt, fo if zur rediten Gette, St. Tames Walace, ober ote Rónigliche গeffibenz, wie befannt, stnes ber unanfetinlidffen Gebaude in Ronbon.

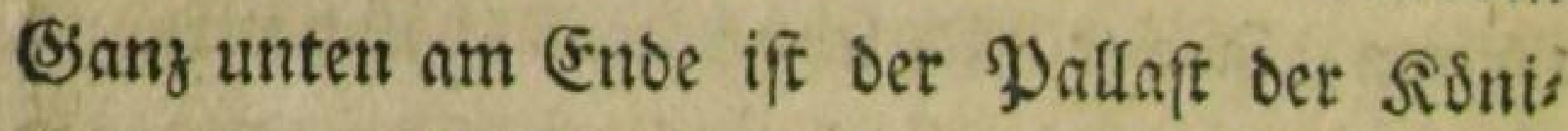
ginn, zwar fajón unb modern, aber boch féfie els nem Đrivatgebåude ábnlich. Lebrigens giebt es affentbalben um Gt. James : Ware felge prádftige

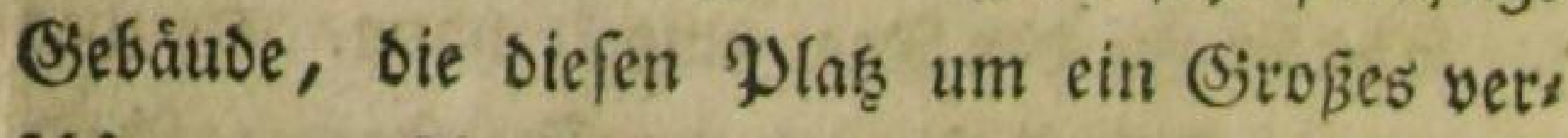
fagonetn. 2fuch ift vor bem Galben Cirfel, bet 


\section{( If)}

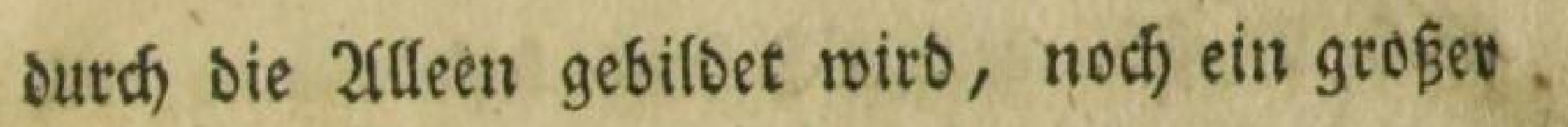
Shlafs, wo die łaarade geffellt mirt.

rssie wentig aber biefer fo betúfimte Đart mit un Darf id nifft erft jagen. Itno bod) madyt matt

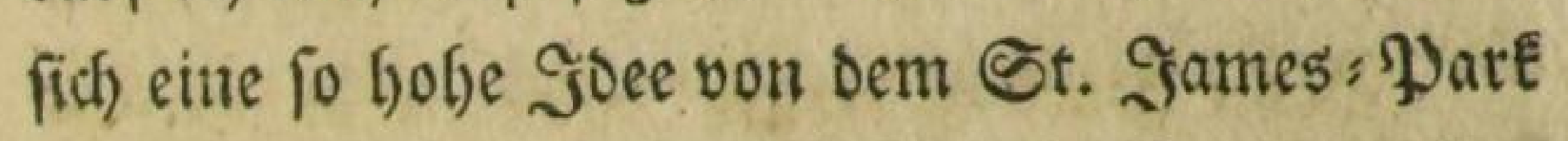

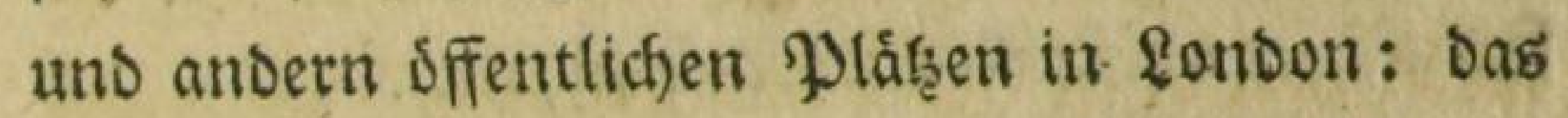
madft, weil fie mefre als bie unfern in Siomas nen uno Súdjern figuritt baben. Beinalje

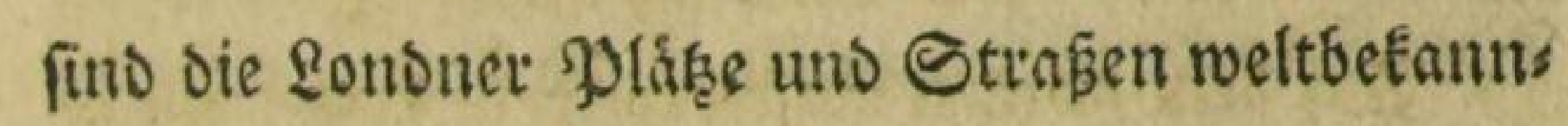
ter, als bie meiffen unfrer Stäbte.

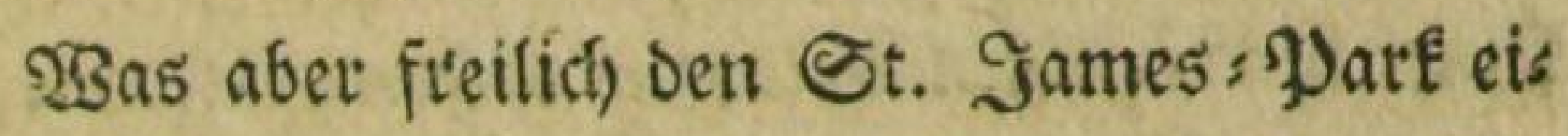
nigermaß̧en wieber ergebt, ift eine erftaunlthe Dienge von Dienichen, die gegen afbend bei \{chos nem 2 setter Darinn fpazieren geflt. So voll von Deenjchen find bei uns bie beften Spaziers gánge niemals, auds in ben fchónften Eoms mertagen nicht, als bjer beftándig im bidffen Gees Drănge auf uno niedergefen. Das \$ergnigen, midh) in ein folches (Sedránge faft lauter woblges fleideter uno fajóngebilbeter Đer fonen zu milchen, babe id bente 2rbend zum erffenmal gentoffen.

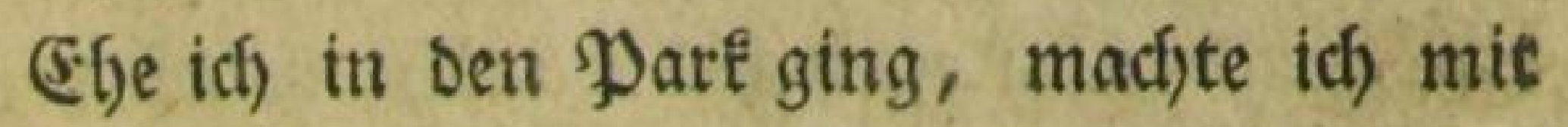
meinem §acty nod) einen andern Spajiergang, sey 


\section{(16)}

- mich mat feht wenige Sdfritte foftete, uino bods

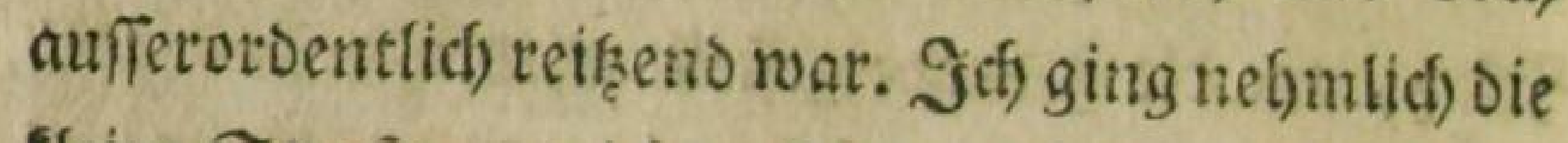
fleine Straß̧e, wo idf woljne, nadi Det Themie zu binunter, und ftieg, beinatye am Enbe berielben, fut linfen Seite nod) eintge Stuffen binab, die mich auf eine angenef)me mit Saaumen befergte Seraffe am ufer Der Slgemle fúbrten.

Bon Gievans batte idf) Den (id)dnfifen Zfublict, ben man fid) nur benten famt. $20 r$ mir lag oie Themie in ifrer Rrummung mit den ptáchtigen Schwibboggen ibret Şruden; S3efrninfter mit

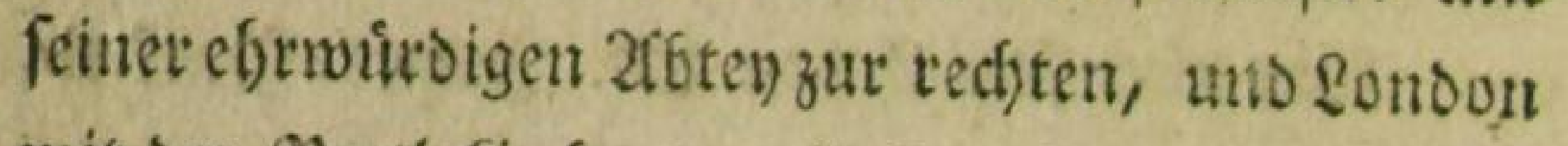
mit Der spaulsfirche ătir linfen Geite, bog fids mit bell hliern ber ₹lyemie vorwaits, uno am jen leitigen ufer lag SouthwerE, Das jeşt nud mit 3u \&onoon gerechnet wirb. Seier fonnte ids aljo bets nalje bie ganze Stadt, von ber Seite wo fie Der Themle jugewandt ift, mit einem slic úberfe. hen. Sticht weit von bier in biefer teizenben Gegend der Stabt hatte aud) Der bethifmmte (Sars: ricf feine 250 bmutitg. Diefen Spajiergang werbe

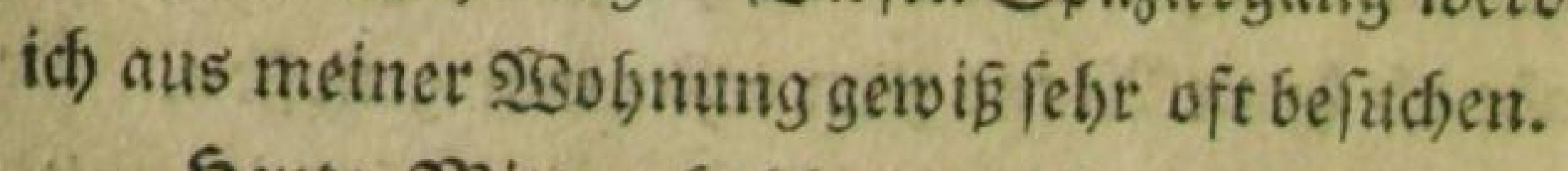

f̧eute Mattang bobften mid) meine beident Ethgländer in eit nabagelegnes Speifeisaus ab, 


\section{( 17 )}

wo wir für ein wenig Sallat uno SBraten einen Estilling, uno beinabe Gallb po viel an ben 2fufs wárter, nad) unferm Gelbe an neun bis zénn (sto Fojen, bejalfen muśten, und dod) folf es bjer

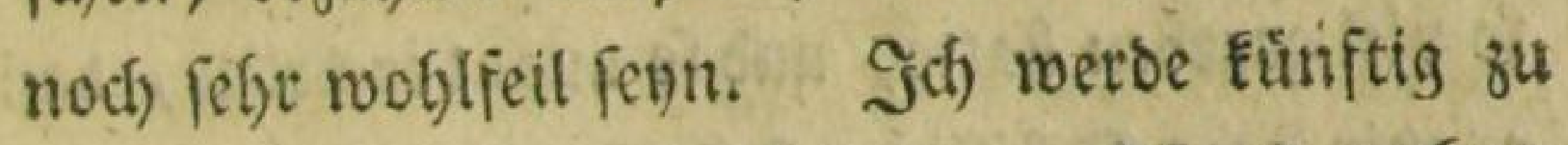

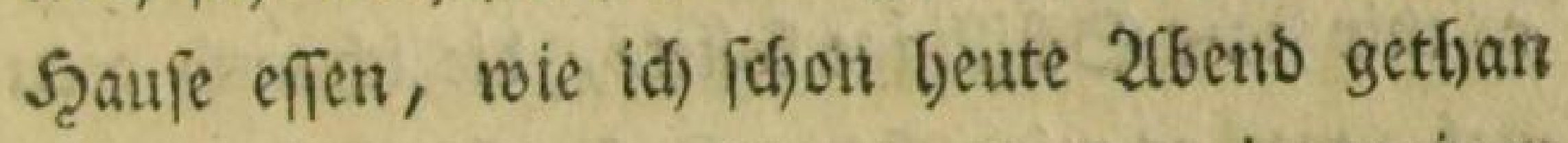

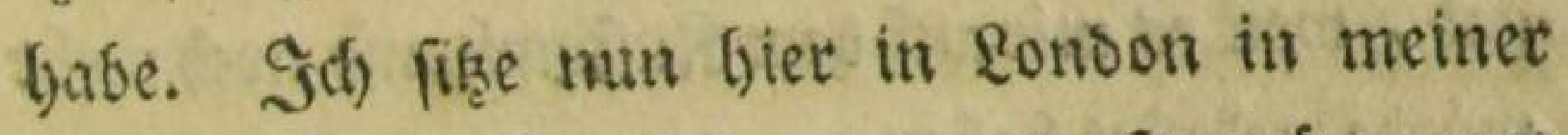
Etube beim Raminfeuter, und fo wáre nut Diefer Tag zu Enbe, ber erfet ben id) in Eng: lano zugebradst fabe, uno id) weis faum, of id es einen Tag nennen foll, wenn idf bebente, twas für mannid)faltige neue uno arffallende (Sicgenfránde in einer fo furgen Beit vor meitres Eecte vorúbergegangen finto.

Ronbon, Den sten Juni.

(Endlid), liebfer (5). ., bin idf einmal wies Det in Siufe, da id meinen Soffer und meine Eadhen vom Edfiffe gabe, Das erft geftern Siorgen angefommen iff. Sreil ich meinen Roffer nicht erfit wollte nad) Dem Suftom: oder Zollfaulfe bringen lafien, welda)es fel)r viele um(tande macht, (i) muşte icf) an Die (Sieridjtobienter und 2 ifitatos 


\section{( 18 )}

rett, weldfe' auf oas Schiff fament, bejablen. 2iss idf aber Den einen mit zreei Echillingen befrieots get batte, fo profeffitte ber andere wieder gegen bie 2 erabfolgung des Soffers, bis iff ifm ebenfo viel gegeben Gatte, und fo aud Der britte, baß 25 mir fed)s Sádillinge foffete, bie idf auch gern gab, weil es mir auf dem $\Re$ uftomboufe nuch mefar wúroe getoftet Gaben.

(Sleeid) am Ufer ber Tleme befanben fich

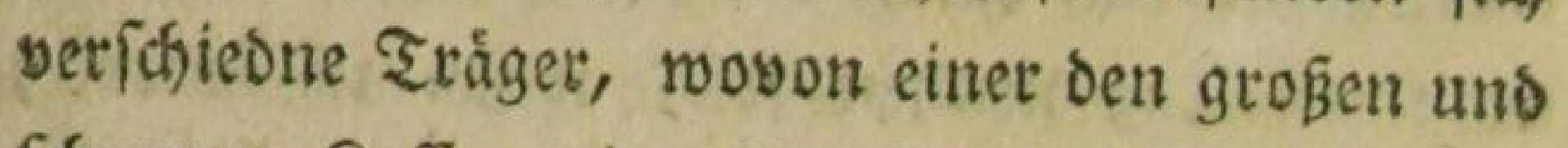
fofweren Soffer mit erffaunlicher Reidftigfeit auf Die Sd)ulter nabm, uno ifn fúr zroei ङchillinge fo weit trug, bis wir eine SRietgentidse trafer,

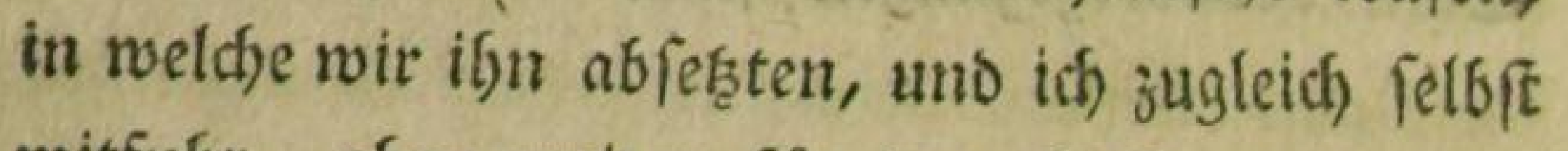
mitfulgr, obne weiter fúr ben Soffer befonders

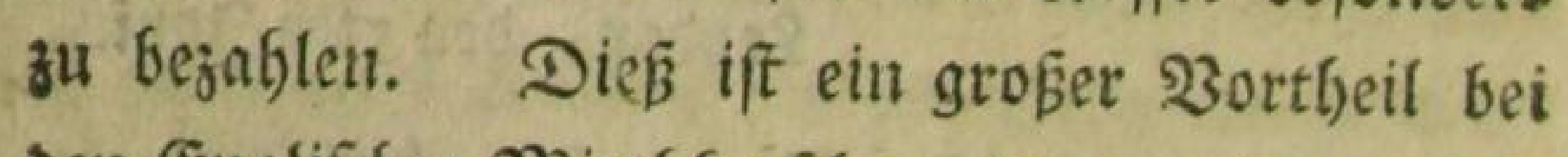

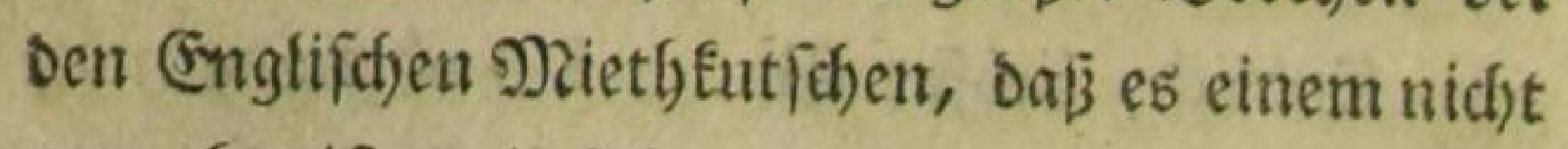
verwefyrt iff, mit fich) zu neflmen, was man will: man erjpart Dabei boppelt fo viel, als man einem ₹ráger bezablen múste, uno fábirt felber mit. Die 2Intworten uno Zlusorúcfe oer gemeinen \&ente

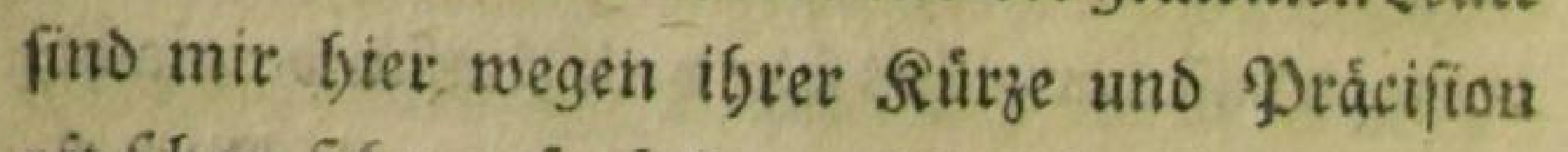

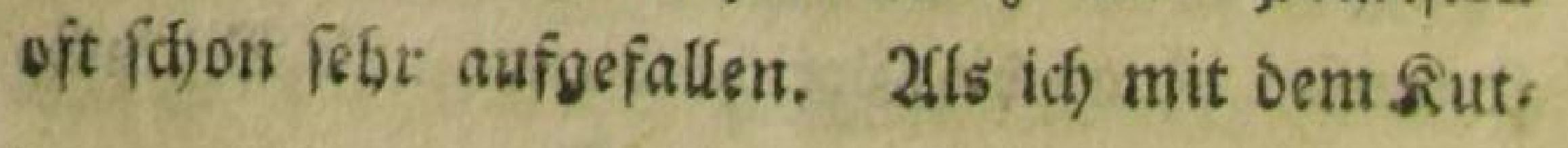




\section{(19)}

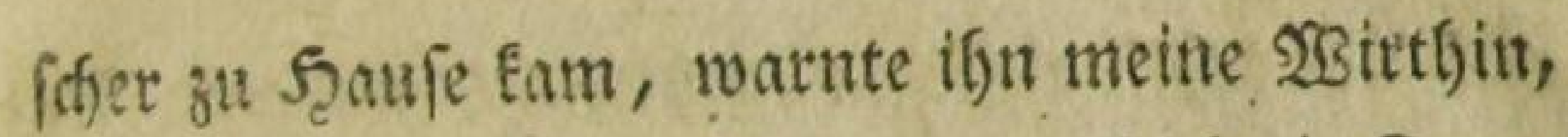
mit nidft zu viel ab̧ufurbern, weil idf eit frems Der fen: uno werm er audh fein Trtember wáre, antwottete ex, fo wuirbe idf ifm nidgt ju viel ab: forbern!

Decine Empferflungsfhreiben an cinen biefis gen . Raufmann, Die id) wegen der eiligen 2ffreife von STamburg nidst mitnefymen fornte, fint nun and) angeformmen, und haben mir viele beforgs: niffe wegen der Utmueciffétung meines (jolbes ev: (part, ich) Eann bieß nun míeber mit nach) Deut (d); Lano nefmen, und bort an ben Rortefponbenten Des hiefigen תaufmanns die Summe wieber ge: ben, Die mir berfelbe fiee im Englifachen Beflbe

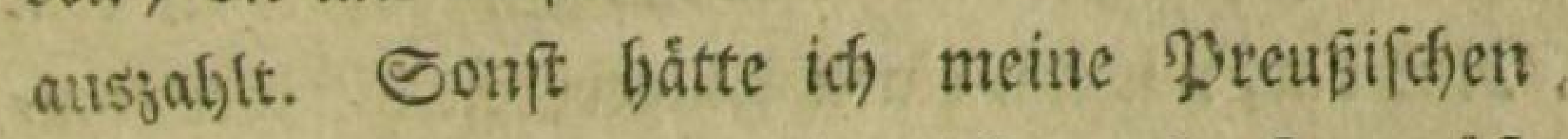

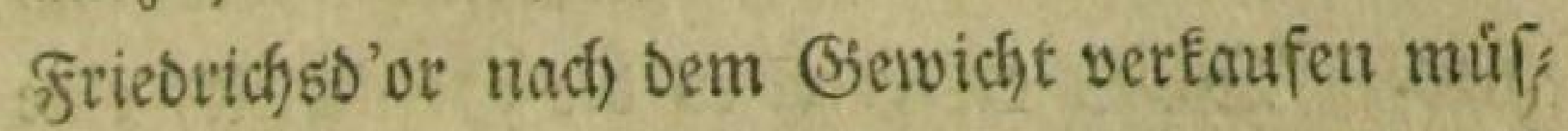
fen. Fúr einige foollandifde Dutfaten, bie iff swäfreno ber Zeit ausgeben mußte, befam ih) nidjt melge wie acht Gdjiflinge.

23on ben DRatrofenpreffen Gat bier ein Zfus: lánber nicht bas minbefte зu bejuirchten, vollenosswenn er fidf an feinen verbád)tigen Orten finden

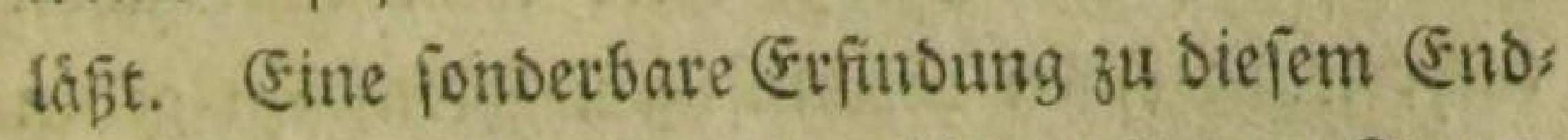
3weft iff ein Sdjiff, bă nidjt weit vom Tower

शू 2 


\section{( so )}

auf Towethifl auf bem Sande ftebt, uno mit Dia: ften und Subebsit verfeben ift. Einfältigen \&eus ten, bie etwa vom \&ande fommen und bier fee, Gen bleiben, um es anzugaffen, verfpricht mant, es fuir eine Sileinigfeit ju zeigen, uno pobals fie barinn fint, werben fie wie in einer Falle feft gefalten, und entroeder nach Ṡefinden ber $\mathfrak{u}$ t'm ftåne wieder losgelaffen oder zu Matrofen wegs: gentommert.

Sbar bequem Dáud)t einem Stremben ber mit breiten Steinen gepflafterte $\mathfrak{S}_{\mathrm{Seg}}$ an beiben Geis ten der Straß̧et, wo man vor ber entFef̧liçen Menge von Şagen und Rutichen auf Den Stra, Ben fo ficher ift, wie in feiner Stube; Denn fein Siab barf nur um einen Fingerbreit bimber fom, men. Sndeß erforbert es bie Sesflichleit, eine Dame, oder jemano, den man ebren will, nicht etwa wie bei uns, immer zur Siechten, fondern an ber Gette ber Scáufer (Wall-fide), es fẹ nun vibrigens die rechte oder bie linfe, geljen zu faffen, well diefe bie bequemfte uno fidherfte ift. פitten auf oer Straße wiro man in gonbon nicht leicht einen vernunftigen \$ienfd)en geben feben, ausgenommen, rein man queer úber 


\section{(21)}

muß , weld)es bev (5)aringfroß, und anders

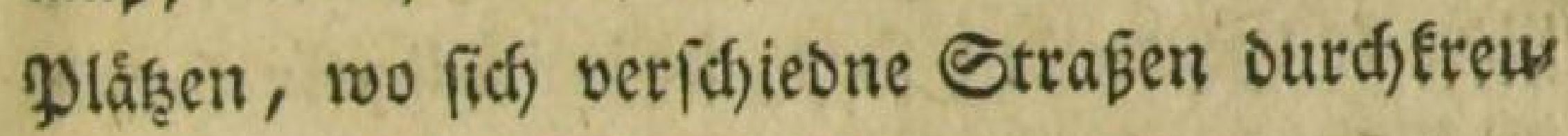
jen, wirflich gefäbrtich ift.

Seljr auffallend ift es, wenn man, befons Dets auf bem Etrande, wo ein Saufmannsges roslbe an bas andere ftosit, und oft Leute vor fefle verjafiesnem (Sierverbe in einem Şaule roohs nen, Die Şăler oft von unten bis oben, mit groß̧en, an aufgeljaingte Tafeln gemablten Sutfftaben, beféfieben fiefjt, 2(lles was in Dern Scaule lebt und webt prangt aud) mit einem Sdjilbe vor Der Thuire, und Da ift in Der That fein 'Sdulfflicfer, Deffen গafimen uno Sserverbe nid)t mit grofer goloner Sd)rift von jedermann

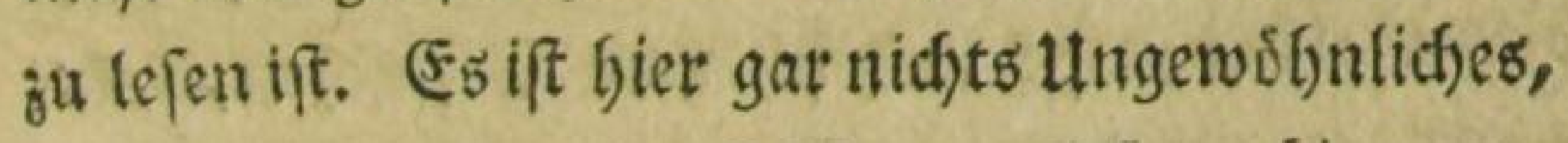
Ginter einander an ben Thüren zu lejen : Gier wers oen ßinder erzogen, fier Sd)ul) geflicft, fiet frembe Liqueurs verEauft, uno fier Begrábuiffe veranftaltet. Dealer in Foreign Spirituous Liquors, oder hier find frembe giqueure zu verfaufen if unter allen bie bánfigfte Stts (d)rift, bie id) gefunden babe. 2(uth) foll bie bes gierde zum zum פrantemeintrinfen, befonbers bi ben gemeinen Englándern auß̧erbrdentlid) wetr

: 3 


\section{( 22$)$}

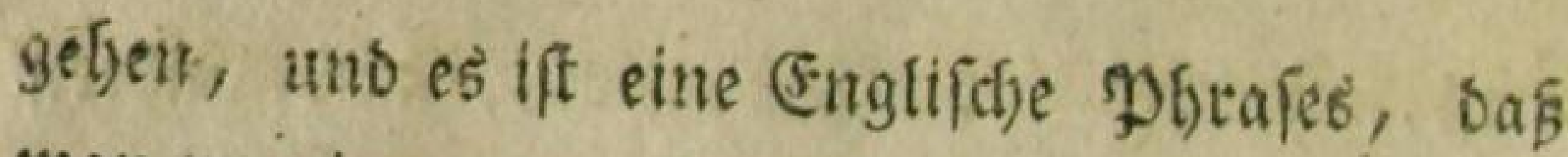
man woin jemantoen fagt, he is in liquor (er if in Bianterwein) wenn man bejeidnen will, bas

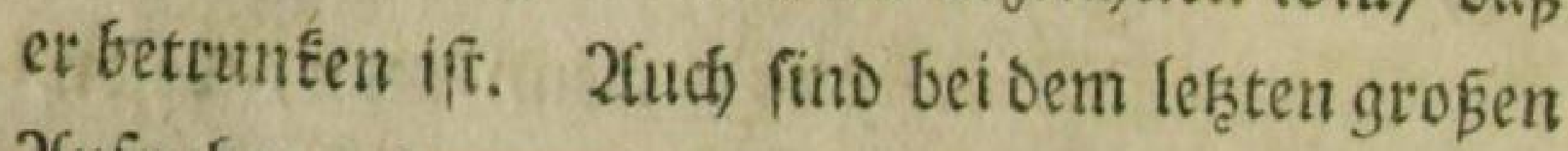
Zfuftulfre, ber nodh ję̧t immer der zweite ober britte Begenftand ift, morauf fidf die gewosbutis chen Ronverfationen zu lenten- pflegen, meft Dienj(hen bei Den' ausgeleetten Sitantweinsfấ:

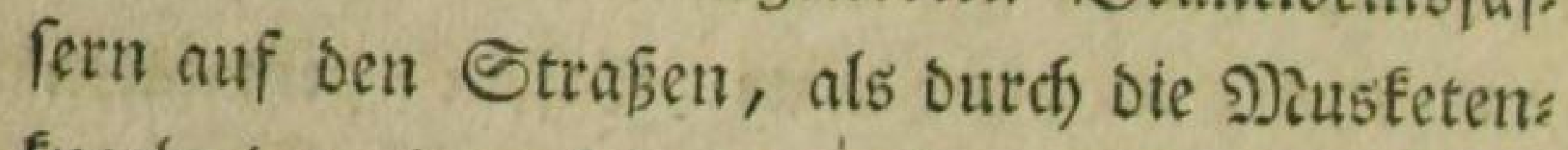
Eugeln Der eingerúcten Siegimenter, toot gefun. ben roorden.

So weit iff diefe Planr ₹age über gonoon Durchftetichen bin, babe idf, im (sangen genom:

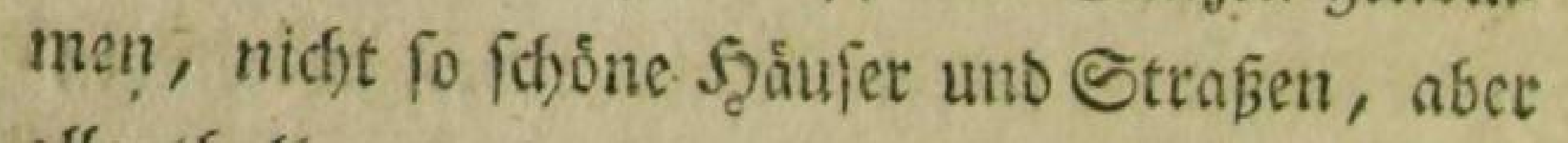

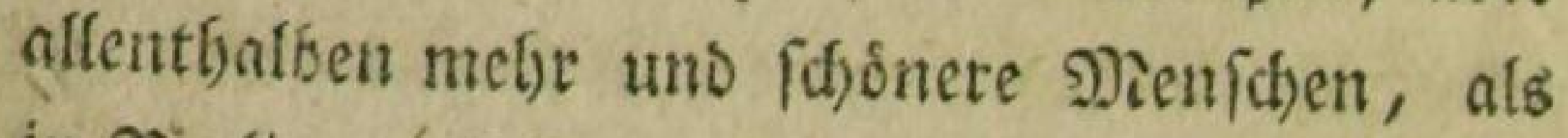
in Sertiut, gefebten. (55 madjt mir ein wabres 2etgnúgen, fo oft idf von (SGáringfto Strand htnauf, und fo weiter, vor der Daalb: firche vorbei, nach Der Rosniglichen jorre gehe,

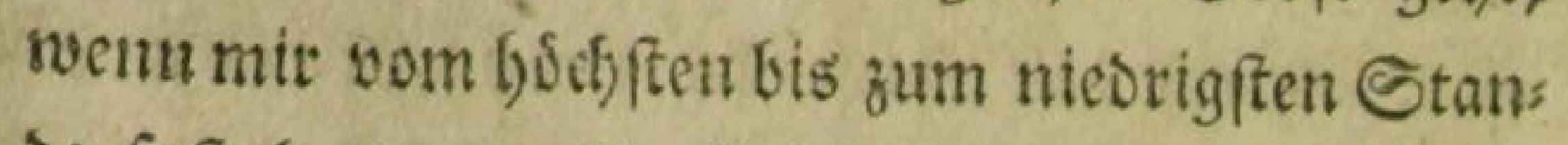
De faft lauter woblgeffaltete, reinfich gefleidete seute, in bififfen (scotainge begegnen, wo idf

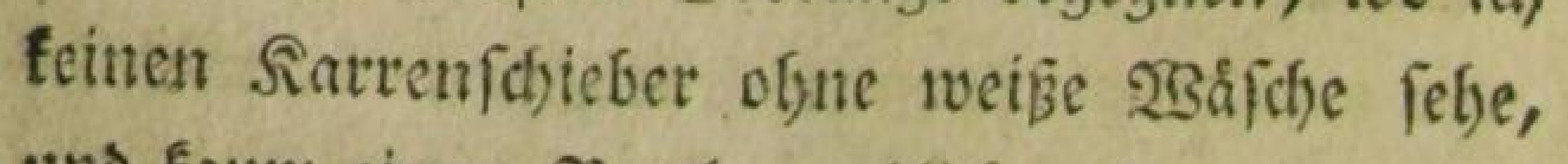
und Eaum einen Bettler erblicfe, Der unter leis 


\section{( 23 )}

neì zertumpten Siletoern nidft wenigftens eir teines f̧embe truige.

(sin fonderbarer 2finblick ift es, unter biefem

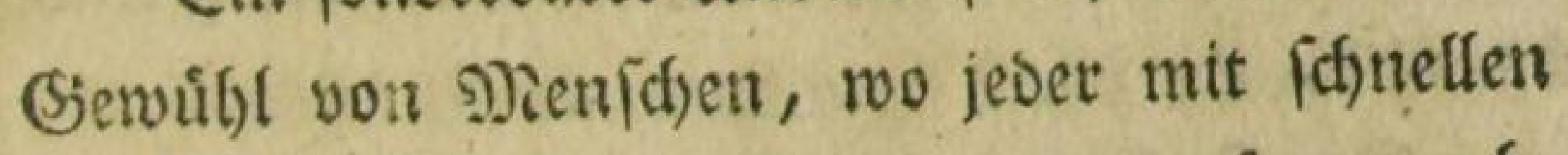
Edfyitten feinem (s)erwerbe ober \$ergnigen nad): gebt, uno fich allentbalben burchorángen uno

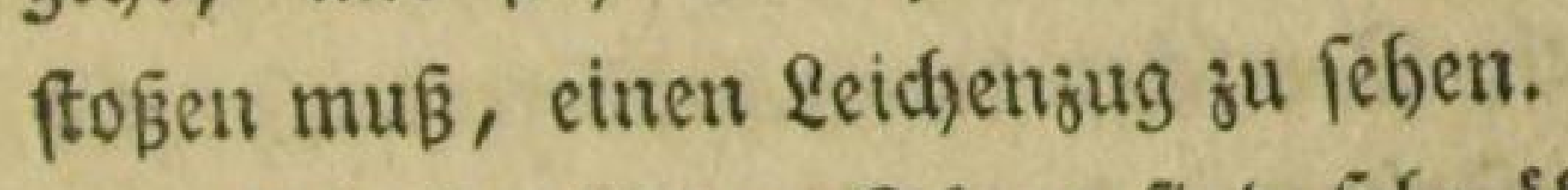

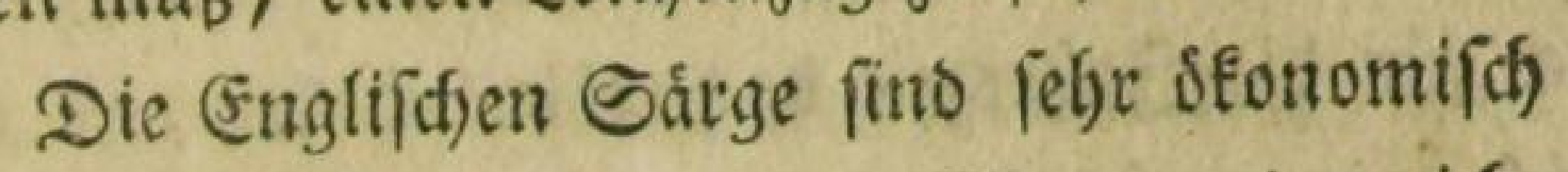

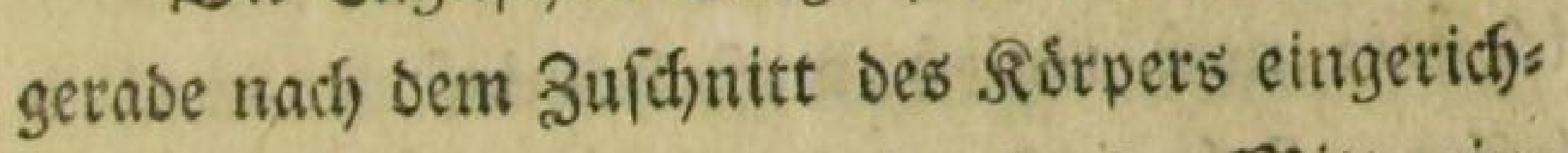
tet; fie fint platt, oben breit, in Der פaitte eins

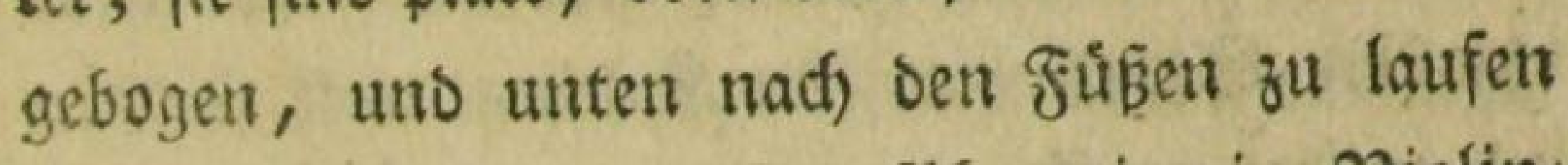
fie fipis zufammen, ofngefágr wie ein Siotin: Eaftert.

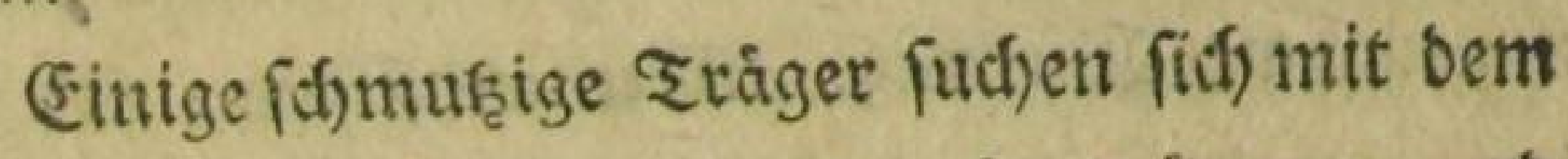
Earge, fo gut fie fómnen, burchłzutrángen, uno einige Srauerleute folgen. Hebrigens betum: mett man fich fo wenig darum, als ob ein frets ragen vorbeifúffre. Şet den Şegrábnitfen Der

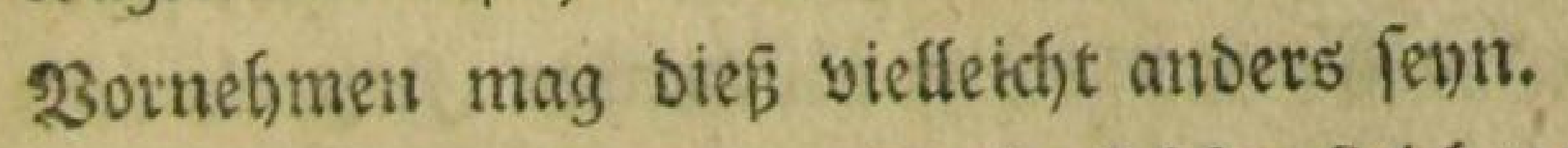

Uebrigens fómmt mir ein foldher \&eichenzug in einer grofenen volfereiden Staot immer befto

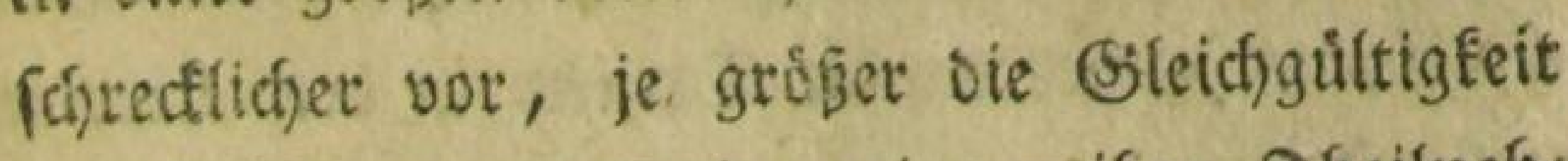

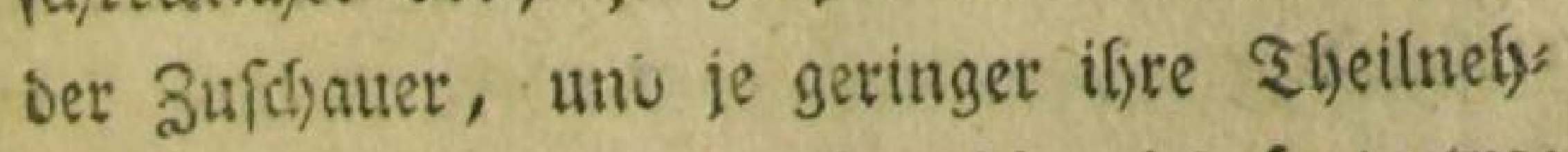
mung Dabet iff. Der \$senfdy wirs fortgetras 


\section{(24)}

3en, als ob et gat nichi ju den 4ifrigen gefbort Gatte. Jo einer fleinen Etadt oder Dorfe fernt ifn ein jeber, uns fein গalsme wito wenigftens gettannt,

Die Snfuenza, weldbe (th) in Sertin ver: lié, Gabe ich) bier wieder angetroffen, uns es fterben viele Nenf(hen Daran. Soch immer if es fuir bie Jabrazeit ungensobulich falt, fo Daß̧ id) mir noch tåglid mus Saminfeuer machen

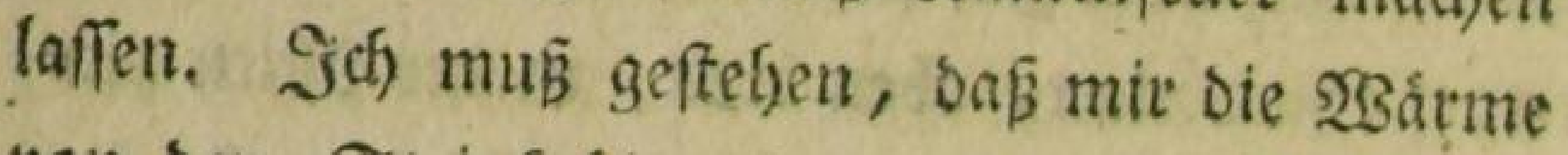
von ben Steinfoblen im Samine weit fanfter und mifber bortémmt, als dievon unfern Defen. 2luch) thut Det anblicte des Feuers feloft cine fefir angenefone 2 Sirkung. Tisx mus man fich bur ten, gernde und anbaltend bineinjufeben; denn oaljer fommen woht mit sie vielen jungen Gireife

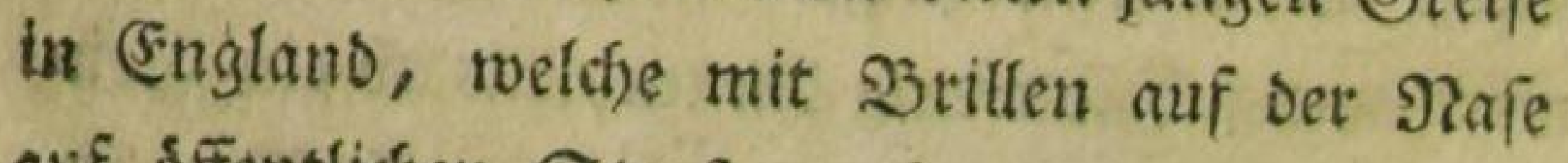
auf sffentlichen Straß̧en geben uno reiten; uns fid) alfo fdjon in ifgrer blütenden Jugeno oer. 230 blthat fir bas Gireifenalter bedies nen, Denn unter diefen Nafymen (the Bleffings of old Age) werben bie SBrillen in betr gaben verfauft: 


\section{( 25$)$}

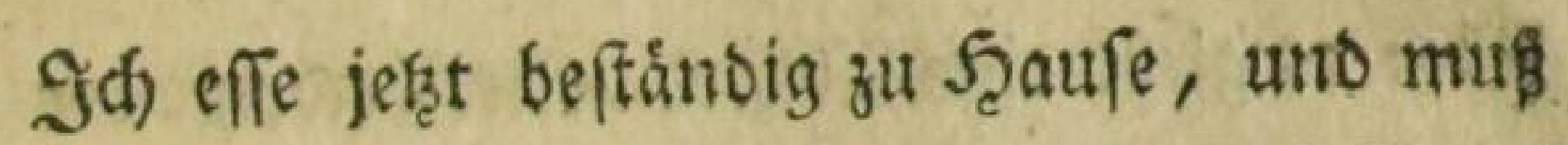

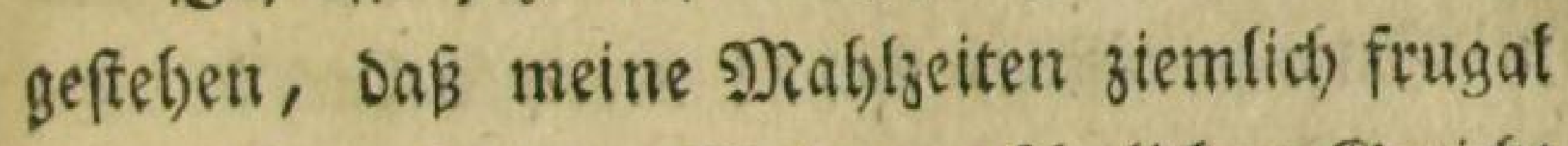

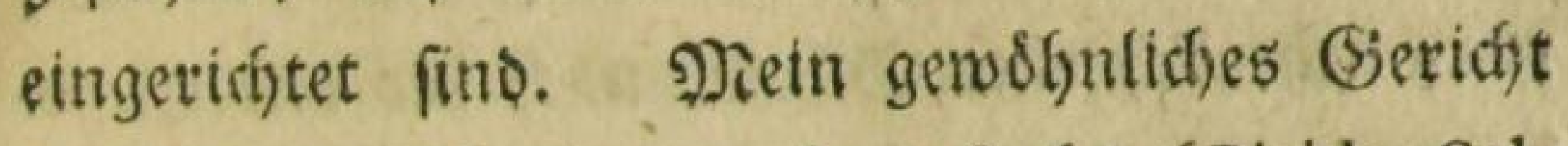
Des 2fbends ift eingemachter $\mathfrak{a} a d$ ) (Pickle Salmon) Den man mit Defl und (sfitig alts ber

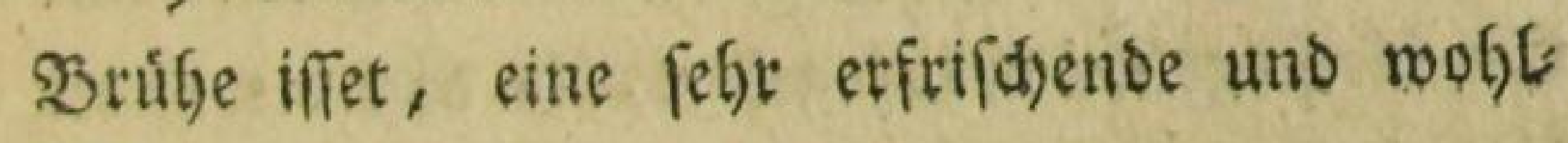
(a)mectende Speife.

Sgler in Englanb Raffee trinten will, Dem rathe idf allemal vorbetzulagen, wie viel इaffen man ifsm von einem Loth machen folf, fonft wirt or eine ungelyeure Menge braunes $\mathfrak{W}$ affer erthalten, weldjes ich mit aller (Erinnerung noefs nidjt habe vermeiden fónnen. Das idsone 2 Sets

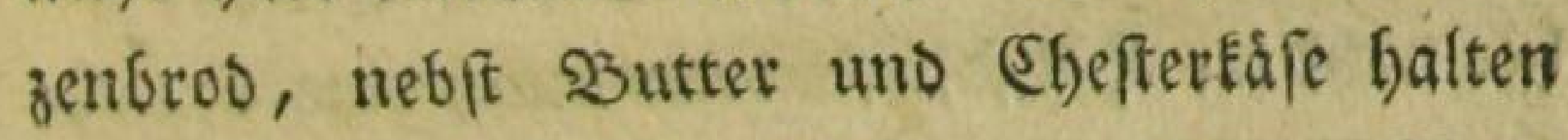
mid) für Die [partichen 9) Jittagsmablzeiten icfabs lo5. Denn bieje befteflen gemeinigfich aus einem Stúcf Galbgetodhten oder gebratnen Flei iche, und

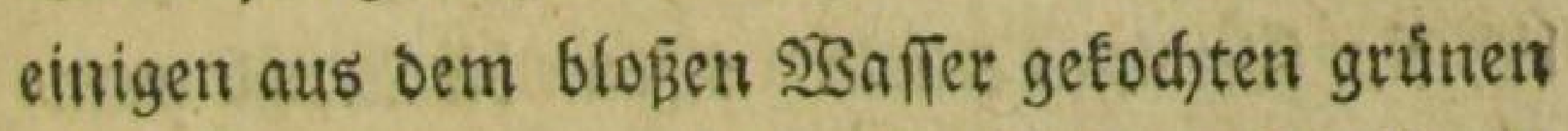
Soblbláttern, worauf eine Strúlge von s)él luno Sutter gegoffen wiro; Das iff mirtfich bie ges woffnliche 2frt, in England Die Gemule juzน vichten.

Die Şutterfóbeiben, weld)e zum Ihee geges

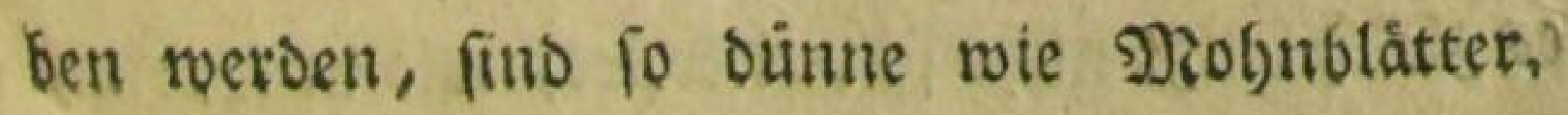
อง 


\section{( 26$)$}

2fber es giebt eine 2ftt, Sutterfcheiben am Sas minfeuter zu rôften, roeld)e unvergleichitid) ift. (5. roird nefymlith eine Scheibe nach Der andern fo lange mit einer Giabel ans Feuer geftectet, bis bie 3 utter eingezogen ift, alsoant wird int: mer bie folgende orauf gelegt, fo Daß̧ bie Sututs ter cine ganze $\mathfrak{a} a g e$ foldher Styeiben allmálig ourcfyieft: man nennt bieß einen ₹oaft.

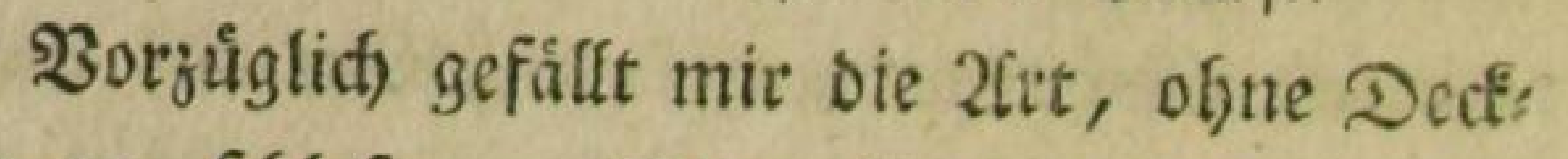
bette zu follafen. Maan liegt zrwifften zroet Settlafen, wovon bas obere bie Unterlage einer leichten wollenen Decke ifit, Die of ne zu britcten, finlånglich erwármt. Das Sd)ubpuşen gefdfies Get nicht im Staure, fonbern butch eine benadys batte \$erfon Deren Sienerbe dieß ift, uno bie alle Miorgen die Schuly aus bent Şaufe abbolet, und gereinigt wiederbringt, wofút fie wodbent:

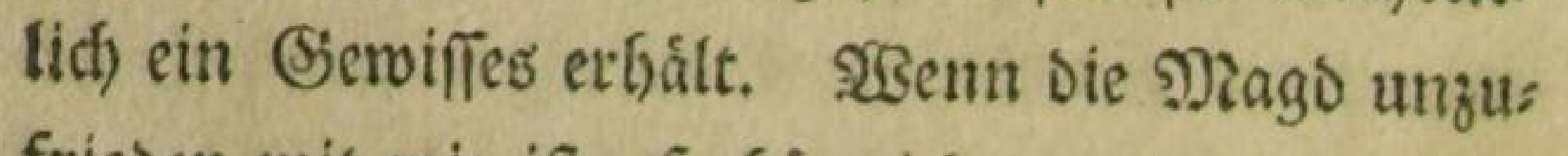
frieden mit mir ift, fo góre ich) zumeilen, dá̧ fie micf) Drauken the German, Den Deutichen nennt, fonft beife idy im Scaufe the Gentleman, oder Der f̧err.

Das Fabren habe idh ziemlich eingeftellt, ob es gleidh lange nicht fo viel foftet, wie in Şertin, 


\section{(27)}

indem if) Gier füt einen Sdjilling ůber eitre (Englis (4) Je Meile bin uno ber fabren fann, wofur ich Dott wenigftens einen Sjulden bezablen miste. Demofngend)tet aber eripart man felfir viel, wenn man ju fuse gefor, und fich mit fragen zu bes

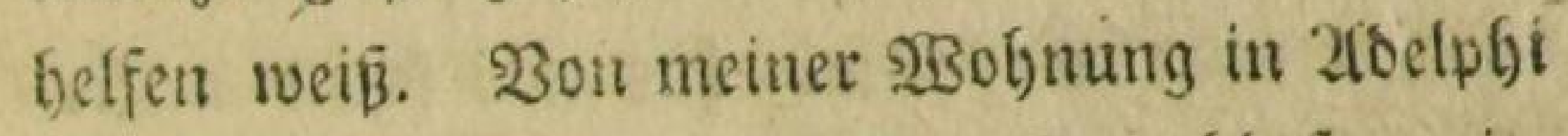
bis an bie Roniglidfe sodrfe, ift rooft fo weit, wie von einem (5nbe Serlins zum andern, und bĭ an ben Tower uno St. (Eatharins, mo bie Sififfe auf Der Themfe anfommen, ift woht noch einmal fo reit, uno bie fen 2 seg babe ich we: gen meines Roffers, Der now auf Dem Sififfe war, f(t)on zreimal zu Fuse gemactst.

2fls id den exften zrbent, wie es ounfel roard, zunidfeam, etfraunte id) úber bie bertiche Erlendhtung der Strapen, wogegen bie unfrige

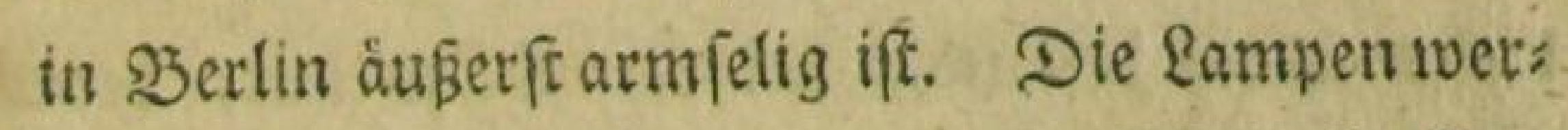
Den fison angeftedt, wenn es nod) beinabe ₹ng iff, uns bie gaternen fino fo oidje neben einan:

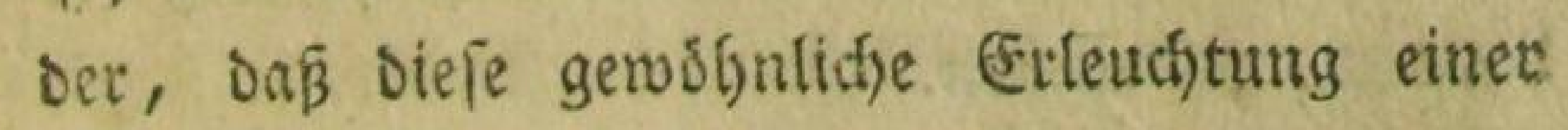
feiertichen Sflumination åhntict, fieltst, wofür fie aud) ein beutfcher Prinz lbielt, Der jum etftems mal nach Lonbon fam, uno im Ernft glauote, Das fie feinetwegen veranftaltet fè. 


\section{(28)}

Dell gten Juni $r 782$.

Scente babe ich in oer beutfdyen Sirche in Qubgatefill fur Seern Dुaftor 23 endeborn gepres

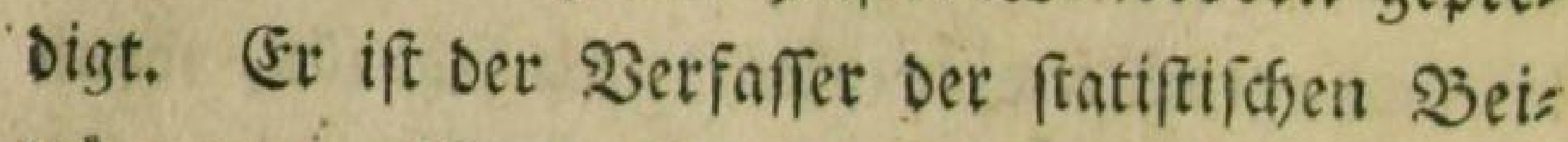
tråge zur nåbern Renntnis Ssroģbrittanniens.

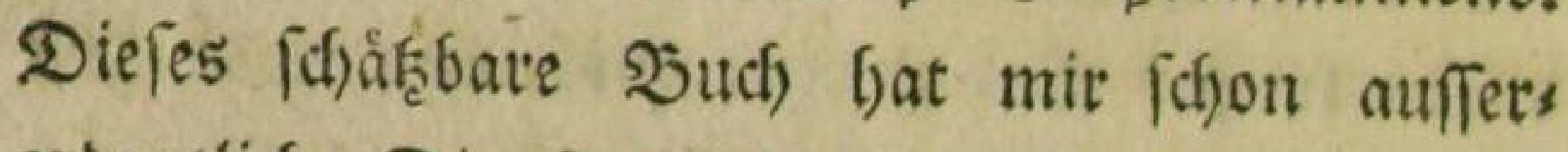
ordentliche Dienfie geleiftet, und idf mochte eis nem jeben ratben, der nad) England reifit, fich biejes South anzufdarfen, das um befto brauclys barer wits, weil man es bequem in der Tafefe tragen, und fith allentbalben Daraits Ratt)s ertjo:

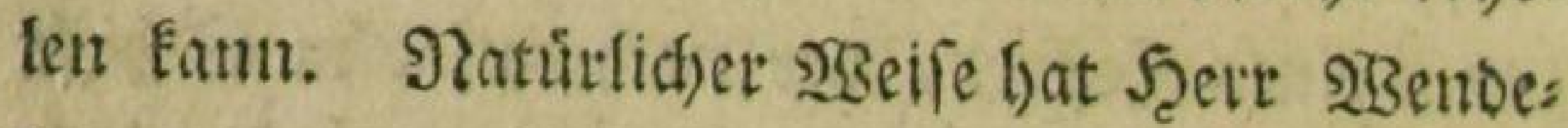
born, ber mun fichon eine getaume 3eit in (Eng: land lebt, mefsi und beffer beobadyten fonment, als alle biejenigetr, welche durdbreifen oder fich nut eine Eurze Zeit Dott nufbalten Eீnnen. STEet Diefes Sud) beftånoig bei ber f̧ano hat, bem witb fobwerlich etwas Semettenswertbes in und um \&onbon unt liberfaupt in ber 2 erfalfung bes Eandes, entwiffien.

Seetr STSendeborn lebt in গew : Inn bei Tem plebar, in einer philofopbifchen aber nicht unt

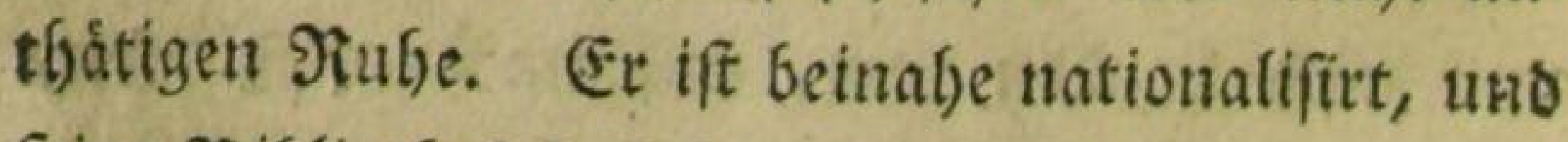

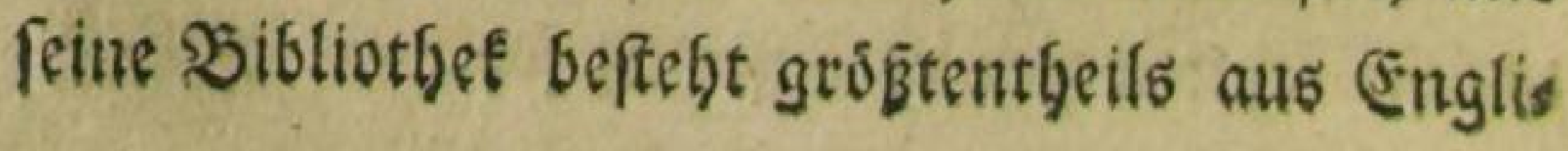




\section{(29)}

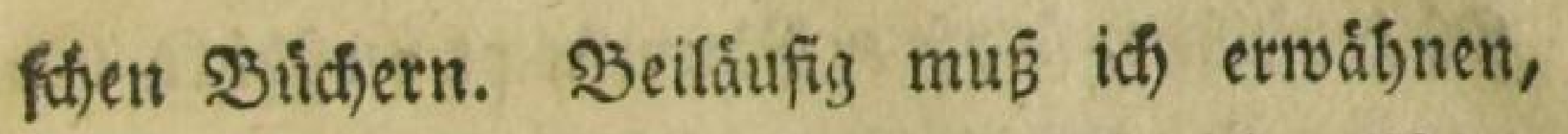

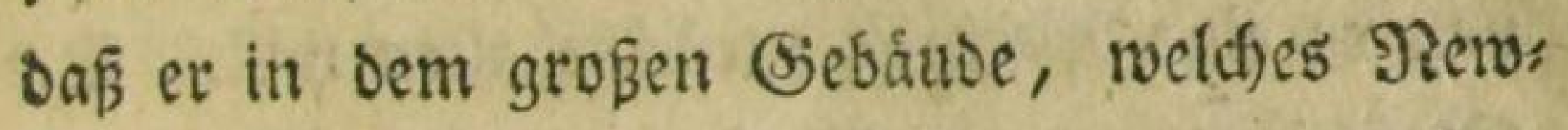

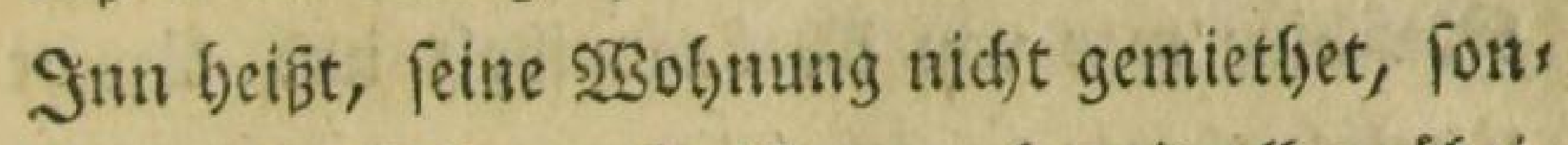
Deen gefauft hat: io iff es audh mit allen úbris

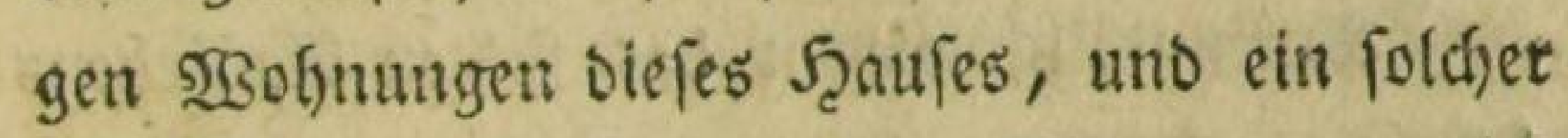
Sáufer von einigen Stuben unt Sammern, witro wie ein (Eigenthúmer betrad)tet, Det Şaus unt Szof bat, uno befigęt Das Reclit, bei Darlamentss roablen feine Etimme zu geben, wetur er feit Zfusländer ift, welches bei Sherrn $25 s e n d e b o r n$ ber Fall war, ber bemofingeaditet. auch vom

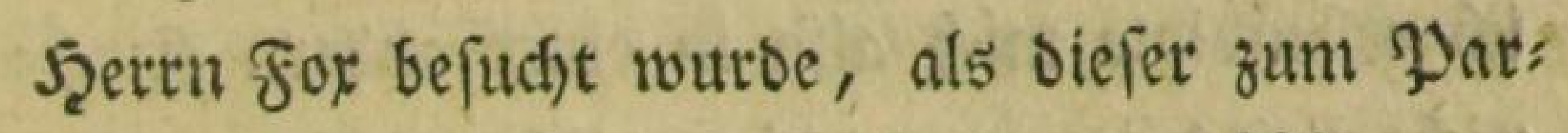

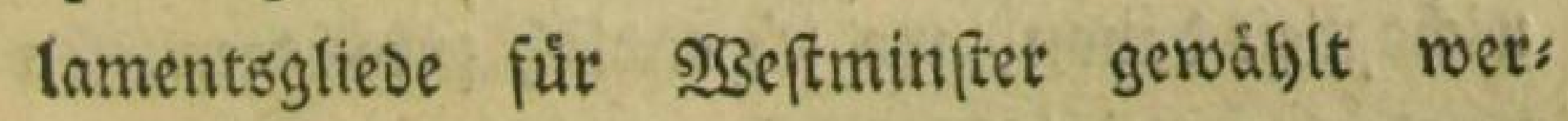
ben wollte.

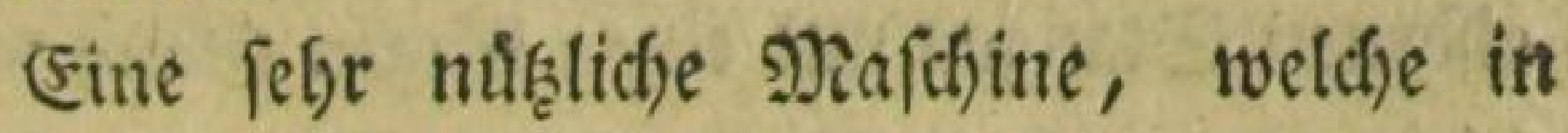
Deut/dlans nod nidgt fegle befannt iff, wenig: ftens nidft viel gebraudft wiro, habe idf juevit bei Şeern 2 Benteborn gefelen. Es ift biefes eine Dreffe, woourd, vermoge fefor ftarfer Staht: febern, etn befartiebnes Slatt papier auf ein anores unbeldyriebnes abgeotucte werben fann,

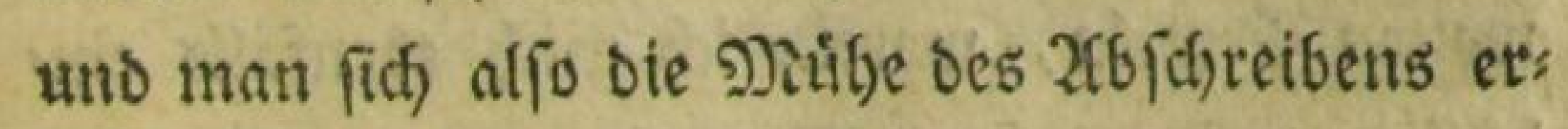

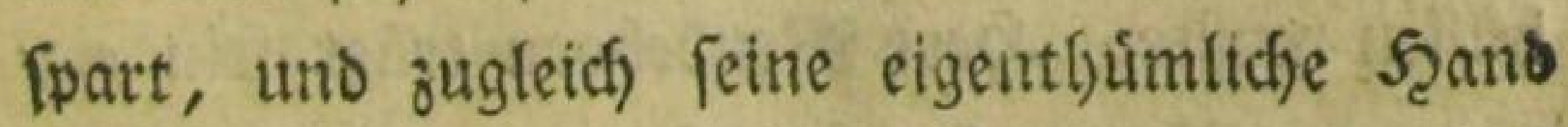
wervielfătigen Eann. Şert 2 sendecborn bedient 


\section{(30)}

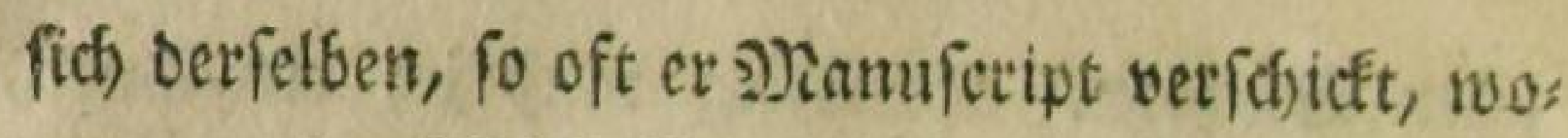
von er eine 2lbidrtift zutúctebegalten will. Die

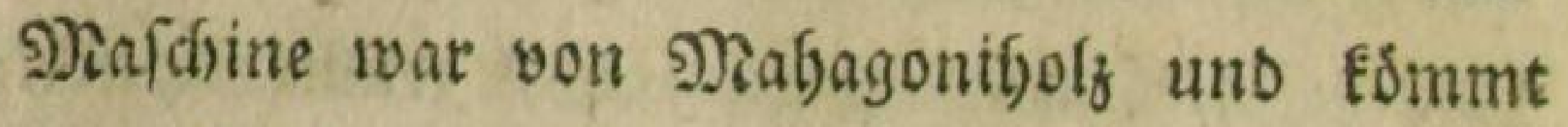
ziemfict) theuer zu ferben.

Sermutblich wegen bes fpaten 2fuffetefens ber Einmobner von \&ondon, nimmt der Bsottes: Dienfte erft um balb eilf feinen 2fnfang. Sath Gatte Geute \$rorgen-Şeren פSenteborn verfeblit,

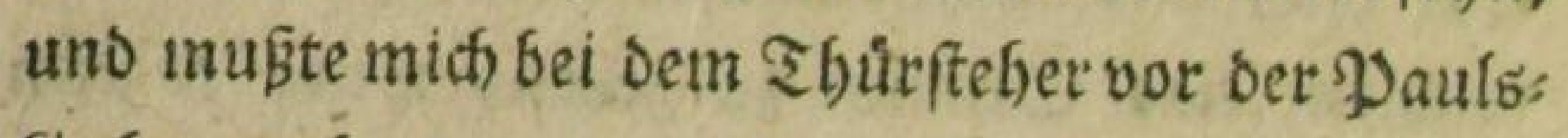
firche nach Der Deutiften Sirthe erfundigen, worinn idf presigen follte; Diefer wugte es nicht, ich erfundigte mich alfo in cinrer andern Sirche nidgt weit Davon, two id) entlid) zurechtgemiefent rurbe, und nachoem id ourdy eine Flour mit eifernen Stangen unb cinen langen (Bang binten binnus gegangen wat, endfich hach getade zu rect):

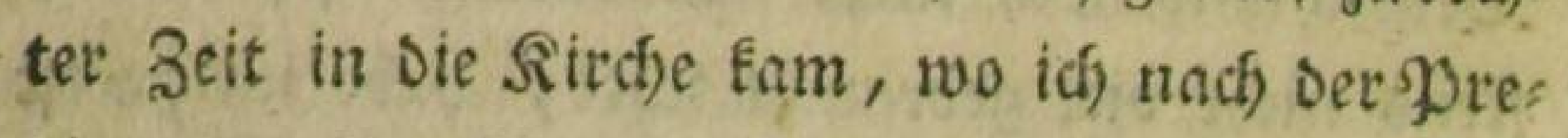
Digt eine Dantfagung fút bie glúdífiche 2fnfuuft uniers Sdififes in Rondon ablejen muşte. Die Deutchen झुresiger gefhen bier vólfig wie bie

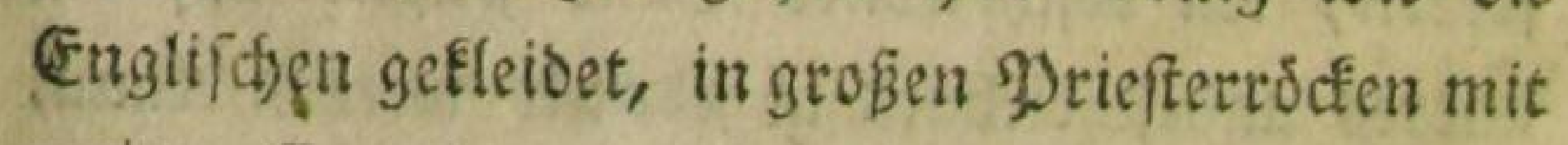
weiten (Eumeln, worein id) mich ebenfalls ein=

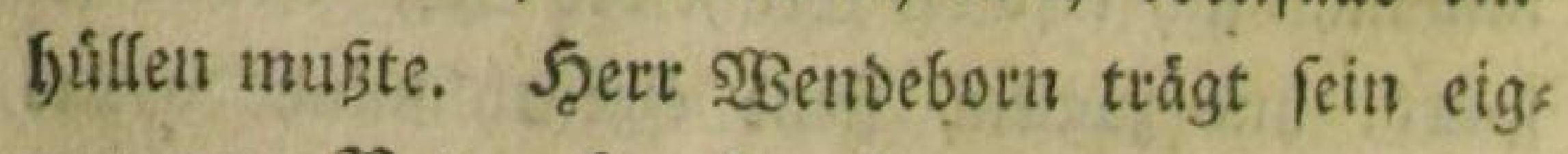
nes von Natur fraules Sagat, nach englifotę 


\section{( 31$)$}

23eife bas Toupe vorn beruntergefåmmt. Die

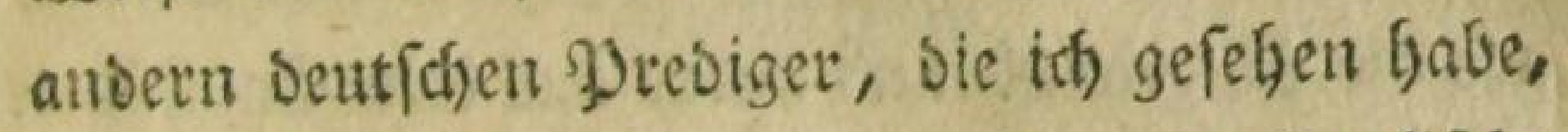
tragen Derticten, fo wie aucí) viele Englifine Ejeifflithe.

(S) fern babe id) unferm Siefandten bem (5) fen Sucn meine 2(ufwartung gemad)t, uno bie Simplicitát in feiner Rebensart Fę̧⿸丆⿰丨丶㇀ mid) in eine angenef)me Bermunbering. (Fr wofint in einem ganz gerofbulichen fofmalen Scaufe. Sein Se: fretâr wobnt oben, bei weldyem ich aud) Den Prew Bifásen Sonful (pract), Der ifyn gerade befuchte. Unten an Der (stoe rect)ter Scand ward id) unmit: telbar in bas Bimmer feiner (5rcellenz gefífret, olne bas idf Durd) eine 2(ntid)ambre gel)en Durfte. (er trug ein blaues Sileid mit rotbem 2fuffchlag uno Rragen. Bei einer ₹affe Raffee unterredeté er fich mit mir úber allerlei wifien/haftlidje (jes genfánde, und da ich) if̧m von dem groß̧en Streit íber ben "tacifmus uno Stacifmus etzáblte, ers flárte er fidh, als ein gebobruer Girteche fúr ben Stacifmus. \$erlangte barauf von mir, ifhn ofrie Umftånbe, wenn id) rooflte, zu befuchen, id můrbe ifgm willtemmen fentr. 


\section{$1(32)$}

feerr Qeonfardi, Der einige betannte Stúcte, als die Qäferichule und andre auts dem (Englifochen ths Deutiche riberferst bat, lebt bier, als Đotivat: mann, uno giebt Deutfden im Englifehen uno Englänoern im Deutfchen mit vieler (Siejdjicfflich) Eeit Unterrid)t, auch verfertigt er gegen ein jåtrt: licfjes Sieb)alt, Den altifel uon Englano, in Det Scamburgifchen neuen Zeitung, uno ift Logen: ineifter einer beutichen Ioge in Lonbon, uno gie: ptåfentant afler beutichen Rogen in Englano, wel:

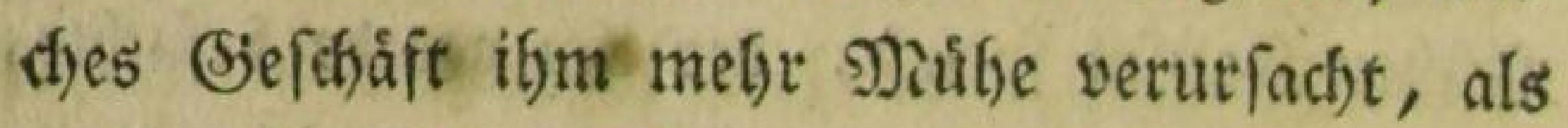
ps ifgm eintrablich ift: Dentr alles wenter fich at ifin. 2fuch ith warb von Syamburg aus an ifit empfoblen. (Et ift ein fet)e sienfferriger Mannt, uno hat mir ichon mancje Siefáligfeit erzeigt.

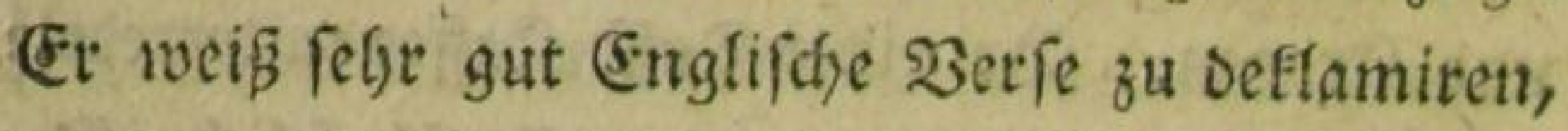
Ino rebet bie Sprache beinalje wie feine g)iutters fpradse, ouch ift er mit einer liebenswlitoigen

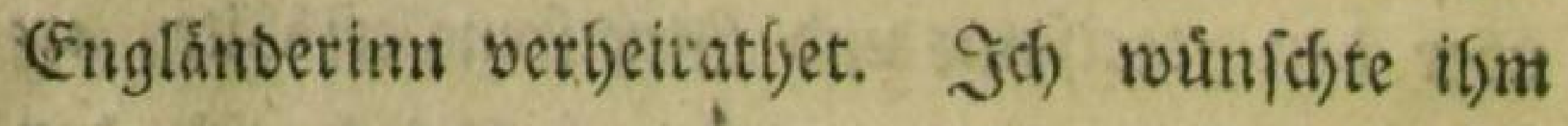
Das befre Sdjictjal von ber 2selt!

Nun forten Sie Denn andh etroas von bem berúbmten uns an fo vielen orten nadige: nlsmten

3aurb̨alf 


\section{( 33 ) \\ Baurf̨all.}

Seftern habe ich Baurthall zum erftenmale be fucht. 2Uus meinem Rogis in 2foelpbi : Suildings b)atte id) nidft weit zur 2 (3eftminfterbrúcte, wo immer eine groß̧e 2(nzahl von פjoten auf ber Themie befindlid) ift, bie jebem auf einen fu Sebote fteben, Der fidh fuit eitnen Sdifling oder Sirpence fahren laffen roill.

3on bier fubr id aljo bie Themie hinauf nach ミaurfall, wo man im ミorbeifabren zur finfen Seite \&ambeth uns Den alten \$allaft Des Silidsofs von (Santerburn liegen fiebet.

3autbafl if eigentlid) Der Nafyme eines flemen Dorfs, worinn Der Sarten eben biefes গamens befinofich ift. Naan zablt beum (Ein: gange einen Sdhilling.

I(d) fano beym (sintritt mirflid) einige 2(ef)"

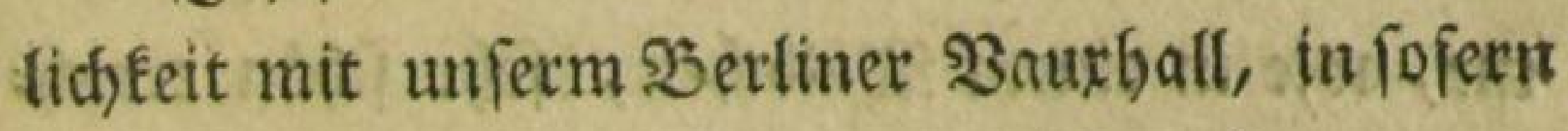
man fleines mit grópern vergleidjet fann, wes nigftens waten bie (Sänge, nebfit Den Piablereien

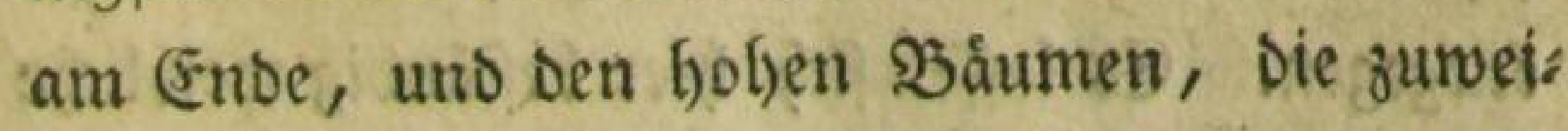
len an ber Seite berfelben einen $\mathfrak{S a l}_{\text {a }}$ ausmarjen,

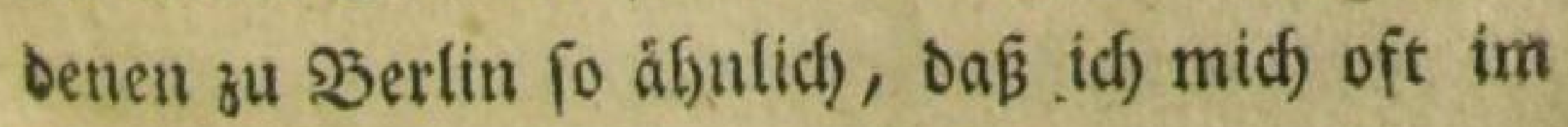
(s 


\section{( 34$)$}

Opagierengeben auf eine angenebme 2 frt tåuffs te, und vergaß̧, Daß̧ ích fo reit von biefer Staot entfernt war; insbefonoere, ba icfy einige ges bobrue Serliner, als ben Şertn Saufmann, Eplittgerber', nebfi mebrern bier antraf, mit benen ich ben 2lbend fefre angenebm jus Gractete.

Seth uno rieder, befonders in einem ber

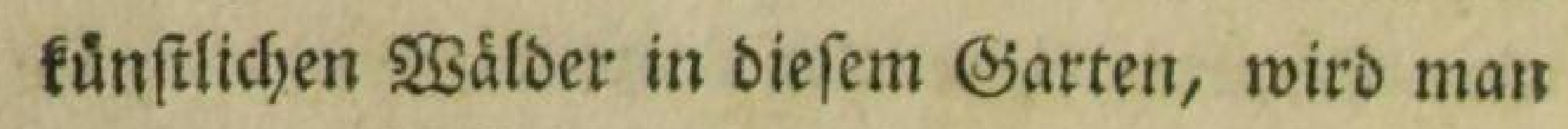

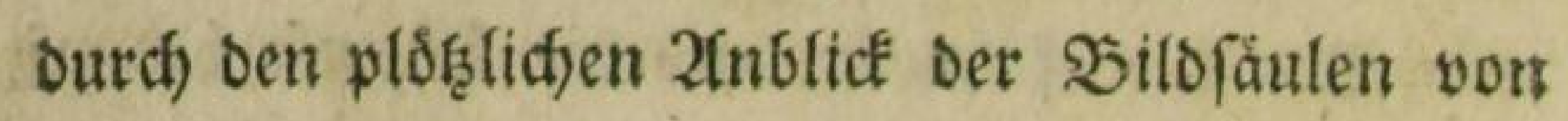

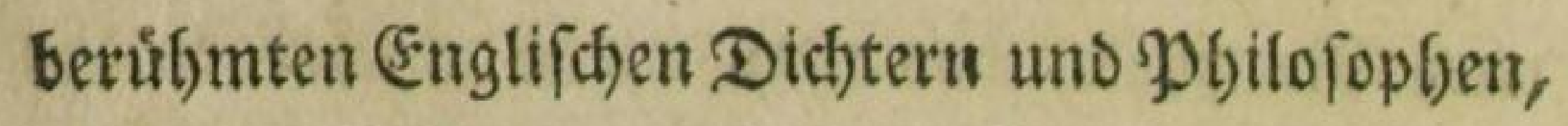
als z. B. Miltons, Thom ions und anderer angenebm liberraicht. $2{ }_{3 a s}$ mich am meiffen

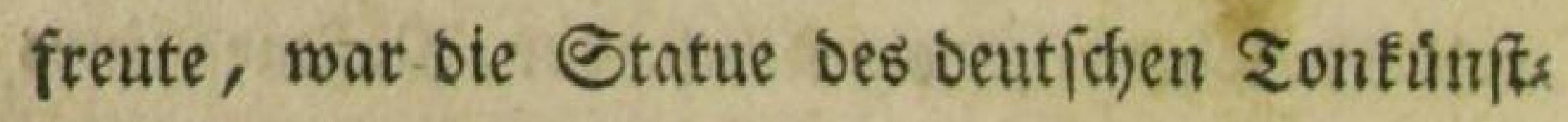
fers Şendel, welche vorn beinm (Eingange In Den Giarten nidjt reit vom Drchefter befind: Iidf ift.

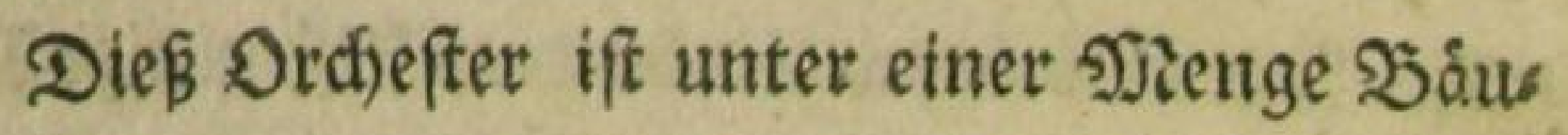

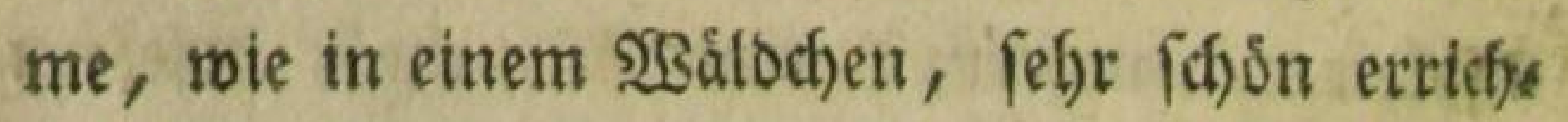
tet, uno gleid) benm (Fintritt in Den Ssarten (d)allt einem die $\mathfrak{B}$ ofal, uno Snftrumentalmufi? entgegen. (5s laffen fiđ hiet beftándig weiblidfe Sangerinaen boren. 


\section{( 35 )}

In der Nábe Des Dithefters find an Dêt Eeiten des Siartens fleine गijhen, mit Tifochen unb Sánten, worinnen gefpeíft wiro. Die Sainge vor benfelben, fo wie úberfaupt im Bat: ten, find beftönoig geotángt voll von s]ienfifen nus ben allerverfatedenften Ständen. Sch fpeişte Gier mit Dem spreupifícien Legationsfes fretår uno Seern Eplittgerber, nebfe noch eini: gen gebofyrnen Berlinern, uno was mich am meis ften wunberte, war bie Fredylyeit Der biefigen

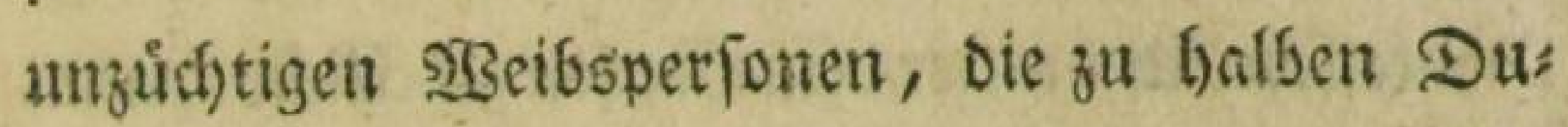
zenben mit ifren Suplerinnen anfirmen, roelcho fich fúr fich felber und fưr if)e (biefolge, auf die unverichåmtefte Şeife ein (S)las 2 sein nach bem andern ausbaten, daß̧ man ifnen nicht gut abs foblagen ourfte.

(Fin Englanber eilte feht fdjnelf vor unfrer Difiche vorbei, uno als ifin einer jeiner Sefannten fragte, woer finmolfe, fagte ex auf eine fo fomifch: roichtige 2frt, Die uns afle za Rachen mard):

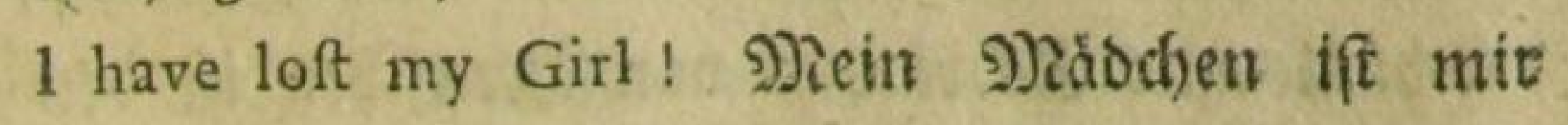
aus Dem (Seficht getommen! (Fs fdien, als of er es fudfte, roie man einen Szandichul) oder Stod fucht, ben man irgendrod ljat ftelgen laffer.

(S) $\rightarrow$ 


\section{( 36$)$}

Etwas fpat in die Nacht fatyen wit noch ein prád)tiges Sdjaufpiel in einem Theile des (Sartens, wo nach aufgerognem $3 o r b a n g e$ ourd) eine fuinftidse Jiafchine afuge uns ohe fo getåufd)t wurbe, Daß̧ man einen wuitflichen $2 \mathfrak{S a}$ af: ferfall von einem boben Felfen berab, zu felyen und zu boren glaubte. 2lls alles im Secorange

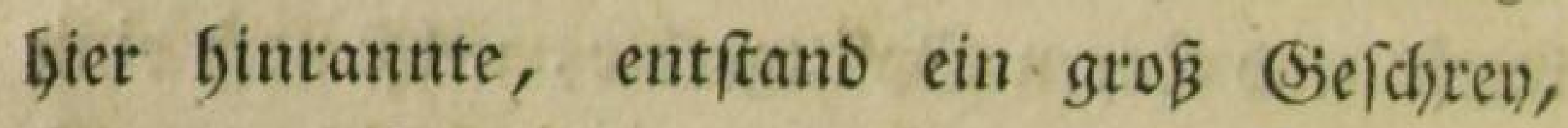
take care of your Pockets, nef)mt eure ₹aidfen

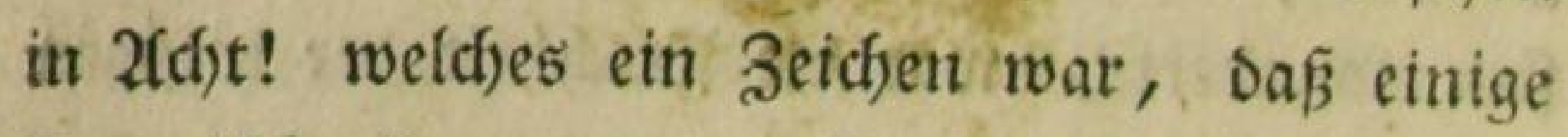

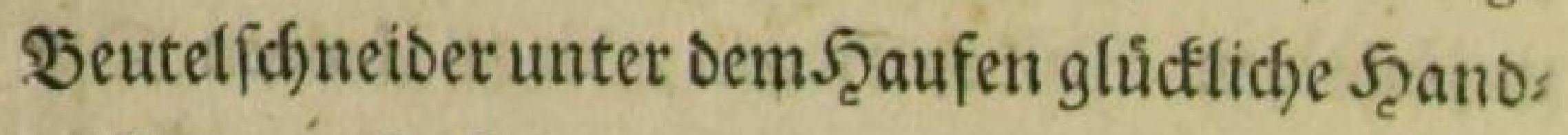
griffe gemad)t hatten.

Botžuglich gefiel es mir in oer fogenann: ren Siotunde, einem pråchtigen runben Sjebåube im Siarten, welches vermittelft fifoner Siron: leuthter uno grofer Epiegel auf Das fifonifte er ? leuchtet war, uno runs umfier mit vortrefflichen Siemåblden uno Sillofäulen prangte, mit oeren Betractutung man fich Stundenlang auf oie an: genefmfte 2fit bejchåftigen fann, wenn man bes Bemuibls uno (Sjedrănges von Mienfa)en in oen Euftgången Des (sartens múbe iff.

Unter Den (Siemåbloen ftellt cins bie Ueber: gabe einer belagerten Gtaot vor. WBenn man 


\section{( 37$)$}

Diés Siemáblde lange anfiebt, fo witro man bis 311 ₹franen baburch gerůfrt; Denn ber 2lusoruct Des hodd)ften (slenlos, Der an Berzmeiflung gráalzt, bei Den B̉elagerten, nebft der ångftlidyen Errwar: tung Des ungewiffen 2fusgangs, und was der Sie:

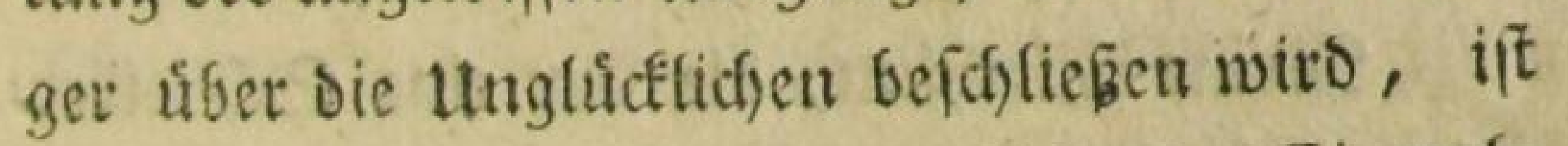
iit Dem (sieficht Der um (sinade flebenden Einwohy. ner vom Sreife bis auf Den Săugfing, Den feine 9) zutter emportåit, fo wabr uno naturlids zu

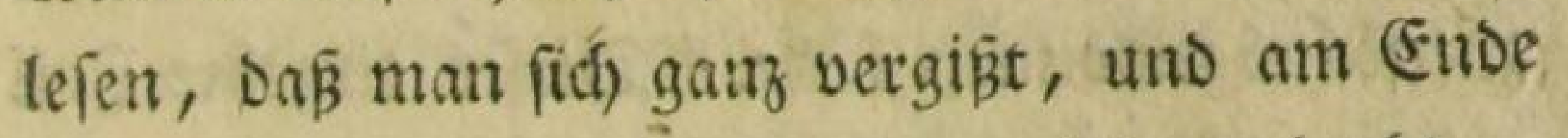
beinabe fein Ssemábloe mef)r zu fefjen glaubt.

2fuch fier findet man bie Șüften vorzúgli: d)er englifcher Schrifteftler runo umber an ben Eeiten aufgeftellt. So finbet Der $\mathfrak{B}$ ritte feinen Schactipear, goffe, sitton, Druben

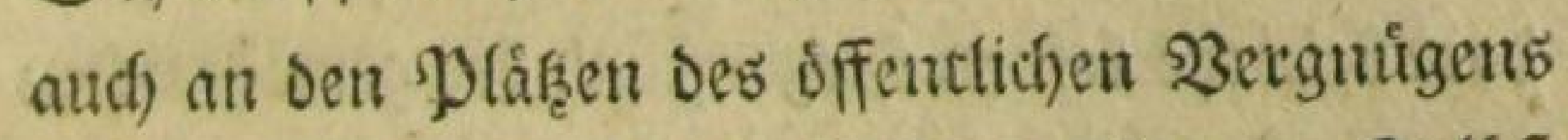
wieder, uno efret oa ifgr afndenfen. Selbfí Das Bolf lernt bieje গamen fenuen, und neunt fie mit (E) frfurd)t. In biefer Siotunde if aud) cin Ord)efter, worinn bei regnigten 2lbenden bie गafif aufgefúfut wito. Dod) genug von Bautball!

2lusgemadyt ift es, oaß̧ oie Englilichen Elal:

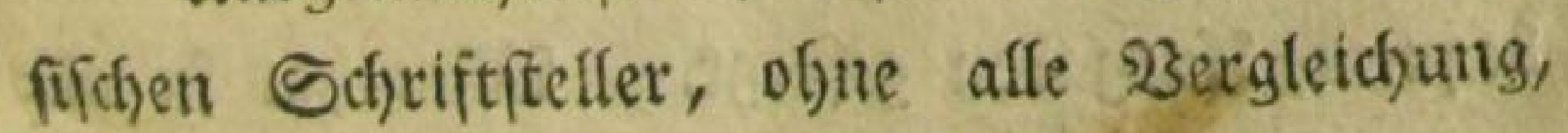
ह 3 


\section{(. 38 )}

Gåufiger gelejên reetben, als bie Deutichen, bie Gód)fens, außer Den Gielebrten, ber Mittelftanb, und faum biefer liefit. Die Englifchen ఇationals

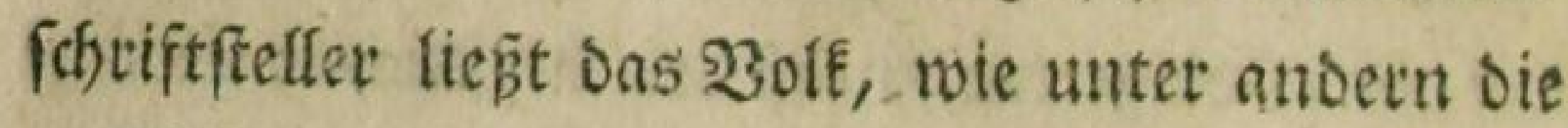
unzåbligen 2fufagen beweifen.

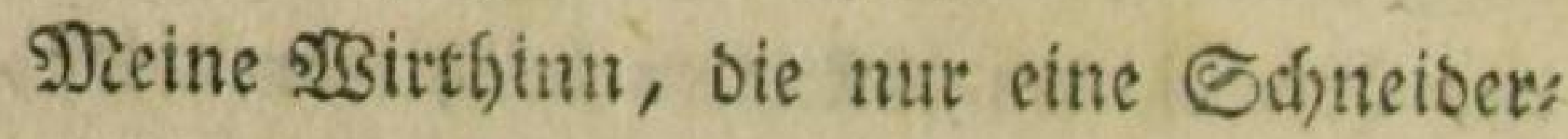

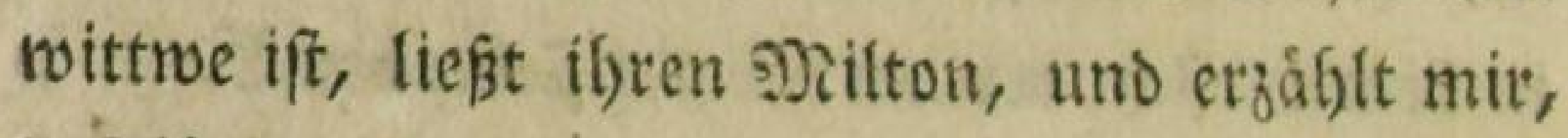
Dás ifer verfforbter Mamn, fie eben wegen ber guten Deflantation, womit fie Den Dilton fas, zuerff trebgeroonnen habe. Diejer cinzelne Salf rwútbe nichts berweifen, aifein idh habe faton meths tere Qeute von geringerm Stande geiptochen, Die alle thre פationalfictyifftfeller Eamuten uno theils gelefen fatten. Dies verebelt die niedern Etán=

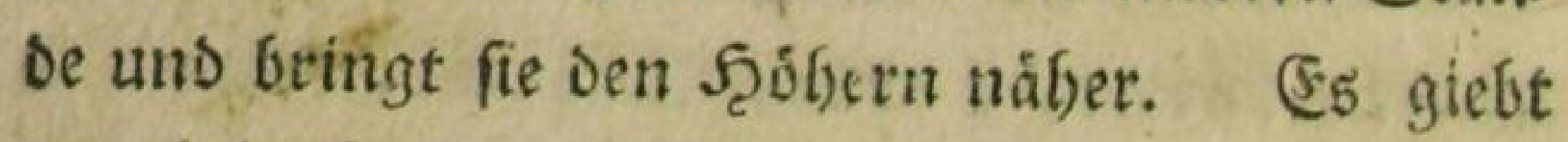
Dort beinalje feinen Giegenfand der gerwófinficfien Itnterrebung im hófgern Stande, wortúber bee nieore nicht audch mitfprechen fónnte. In Deutf(d): land iff feit Beflerten noch fein Didjternalyme eigentlidf) wieder im Niunve dę-23olf́s ge: welen.

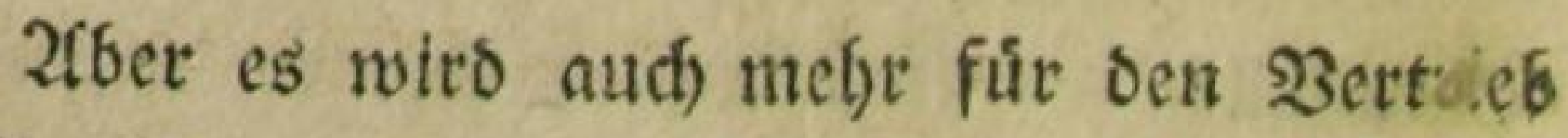
ber flafilichen Edyriftfferfer, fúr woblfeile uno bequęme 2fusgaben geforgt, झran bat fie alfe 


\section{(39)}

sebunbetr, in etner Folge in ₹af́chenformat, unb In welthem format fie einer baben will. Jith babe mir für zwey) Scintllinge einen Milton in Durosez in nieslicfem Franzband gefauft, ber fids

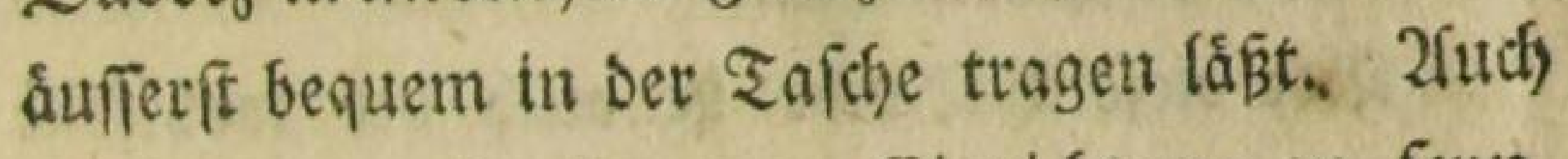
fojeinet es mit eine-gute (sintidytung fu fenn, Dấ bie Dutcher, weld)e am háufigften gelefen werden, grosiftentlgeils fichon febr fauber gebuw: Den fino, wenn man fie Eauft.

2lllentbalben auf Den Strapen trift man Intiquarien, die eimzelue Sticte von Schnte: fpear, uns andre Rleinigfeiten fuir einen \$)enny), ja zunvellen für einen F̧alfpenny), (einen Drenet nad) unferm (Selbe) verEanfen. Won einem Foldjen 2fntiquatius babe idf beibe Theile vom

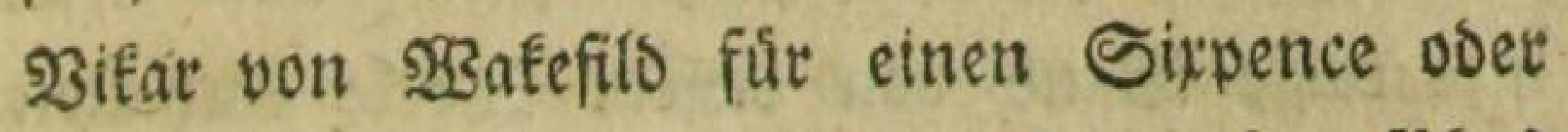
Galben Sdjifling (vier Sirvidjen ofngefáfir) gefauft,

T3ie aber unfie beutidje \&itteratur noch in Englano geidsąąt roiro, habe id unter andert aus Dem vorgebruften 2fvertiffement von einem Wuche gefégen, Dak unter Dem Titel the Entertaining Mufeum ober Complete Circulating Library, foroble eine seifge aller flafifichen Englifden 


\section{(40)}

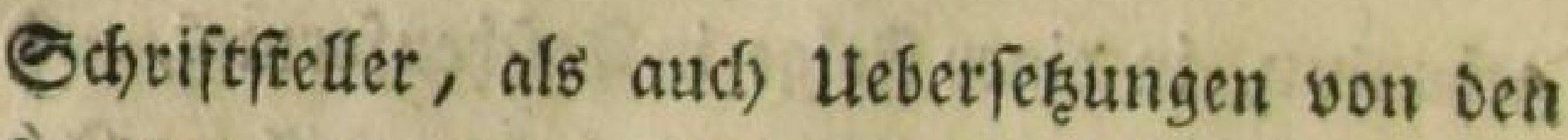
beculbmteften franzofilichen, fpanifden, italient: foren und felofi beutidjen (even german) Fiomanen enthalten folf.

3ei biejem Suche ift audh der moblfeile

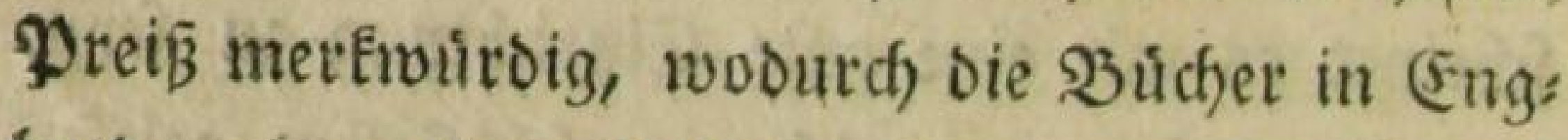

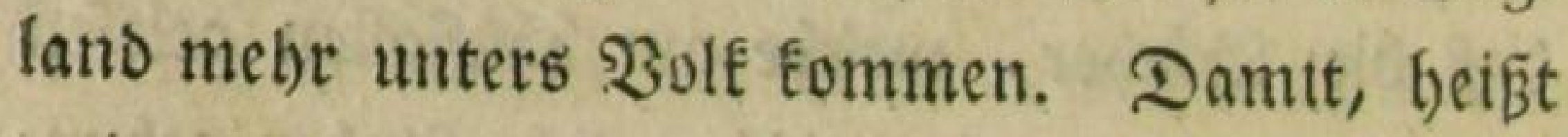
es in bein 2ivertiffement, jebermann im Stanide

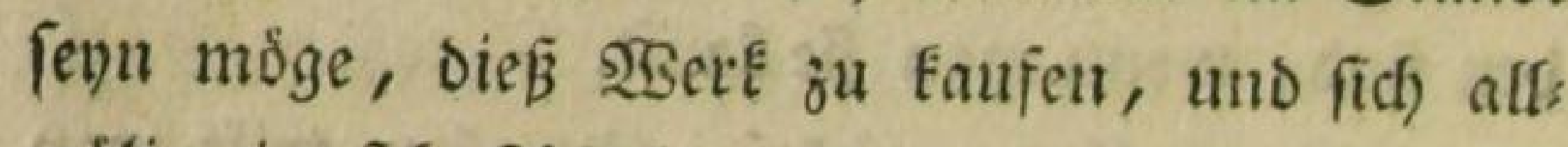

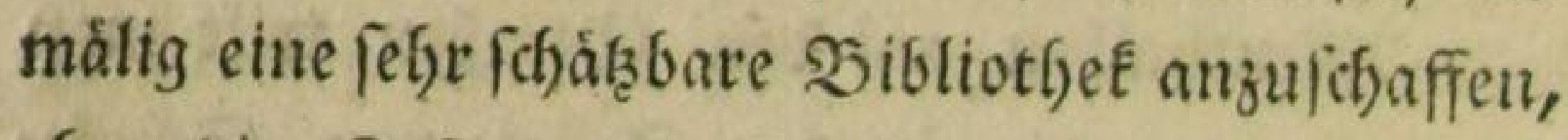
ofne die Soften gervabr zu werden, fo wiro wơchentlich ein Sándoden beraustommen, wels dhes geheftet einen Sirpence (vier (strofden,) uno gebunben, mit bem ₹itel auf bem Siucken, neun \$ence ( 6 (S)rolichen) foffet. Der zffie uno 26 fe 25 and von biefem 2 SEerfe entbaltent ben erfen uno zweiten ₹heil vom Ranoprediger son $23 a f e f i e l d$, Den ich eben von einem 2fntiqua: tius gefauft babe,

Die einzige Uleberferesung aurs dem Deut then,

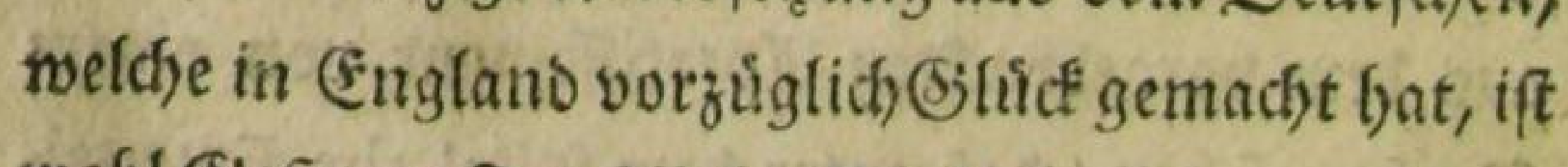

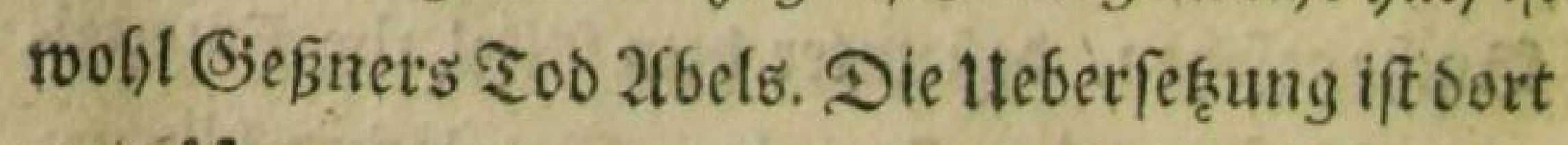
weit Sfter aufgelegt, wie in Deutfhland das Dris ginal. Nian bat fdfon bic acitzelsnte EDotion 


\section{$(41)$}

bavon, uno fie fifreibt fict ber Sorrede nact, yon einem fraueitzimmer her. Slop:

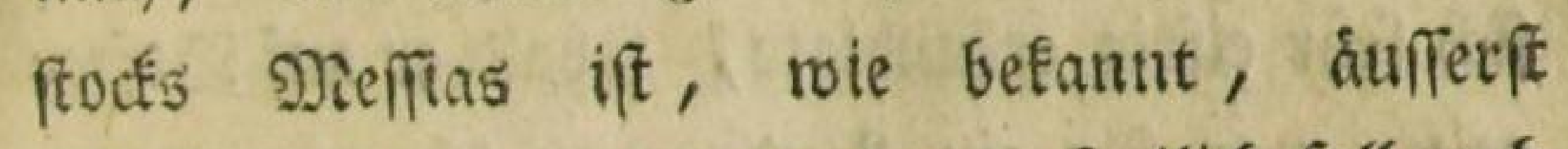
fiflectet aufgenommen worden; freilid, foll aud bie Ueberfersung Darnady fern, id Eann fie bier nicht zu Gefefidft befommen. Şere Şaftor 2 Şetr Deborn hat eine beutiche Epradilefiee fúr bie (Engs lánber, in Englifater Eprache gefortieben, die gut aufgenemmen iff. Nidft zu vergeffen iff,

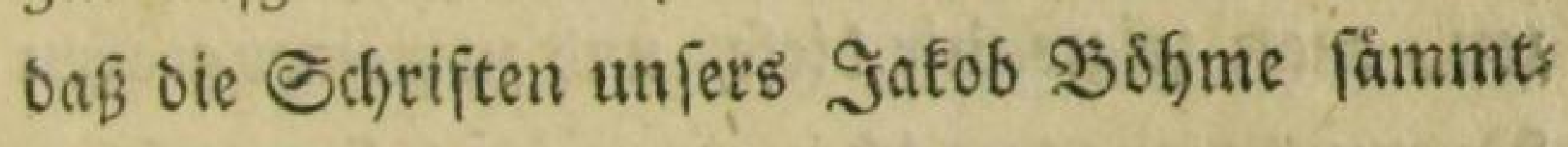

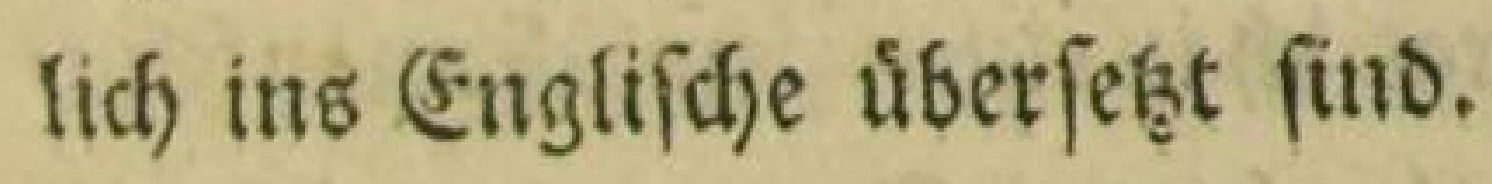

Eonoon, Den raten Suni.

So oft id von Ranelagh getjort Gatte, madfte id) mir bod) feine beutliche Borffeflung Davon. Jih bachte mit barunter einen (Sarten, etwa von andrer (Fintichtung wie 2 aurball, uns wer weißs was. Sieftern 2lbeno ging id) zu Fuße ginaus, um biefen ort bés 23ergnugens gu be: fudfen, verirrte midh aber nad) Elyeliea, no ids einen Sartenfdjieber traf, ber mich nidst nut

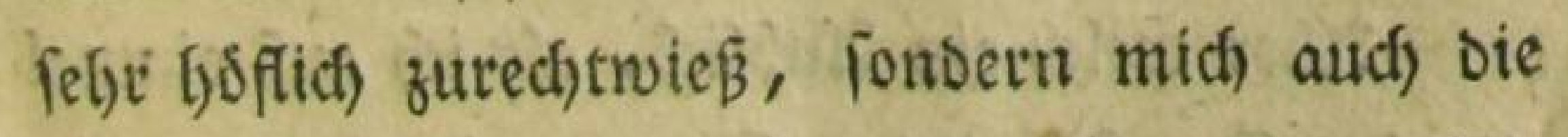
Strecte, die mir miteitnanber gingen, untew

ह 5 


\section{( 42$)$}

Gielt, und fief von mir febt viel son unferm King of Pruffia erzáblen ließs, nads weldjem et fidh) Febre eifrig ertundigte, fobalo er auf $\mathfrak{B}$ efras Beil, was fúr cin Lambsmann id́) wăte, von

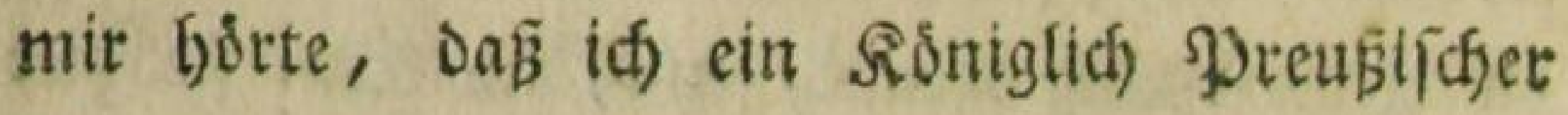
Untertian (eb).

So) langte alio in Tanelagh an, und nachs: Dem ich beim (Eingange meine balbe Sirone er: legt batte, fagte idh nad) Der Thuir zum (Shat: ten, man zeigte mir diefe, uno zu meiner grofient 2erwunderung trat if́) in einen ziemfich) unan fén lidjen, (d)wad) erleudfteten (sarten, wo id) mus mentge Perfonen antraf. (5s roabrte aud) ntabt lange, fo rutbe id) von etner jungen $\mathfrak{L a d y}_{1}$; bie on fpazteren ging, uno mir ofne Lmftănde ifjer ffrm bot, gefragt: marum th) bier fo cinfam

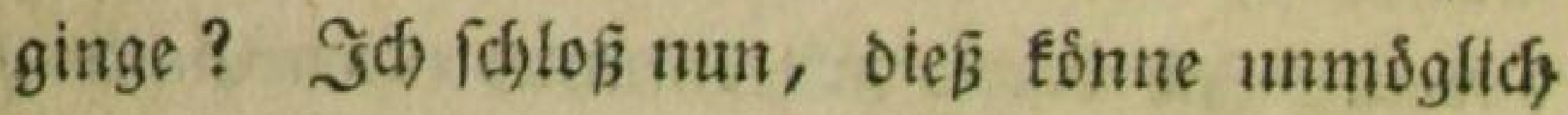
Das prådytige, gepriefue Ranelagh (enn, als id) nidjt weit von mir verfdjiedne \&eute in eine इhilte getsen fabe, benen ich folgte, um etwa baburch wiber ins fiete zu fommen, oder bie Siene zu veråndern.

2lbet welch ein 2inbficf, als id) auf einmal aus ber Dunfelbait des Gsartens in ein von vie: 


\section{(43)}

fen funbert Rampen erleudjetes ruttbes Giebande

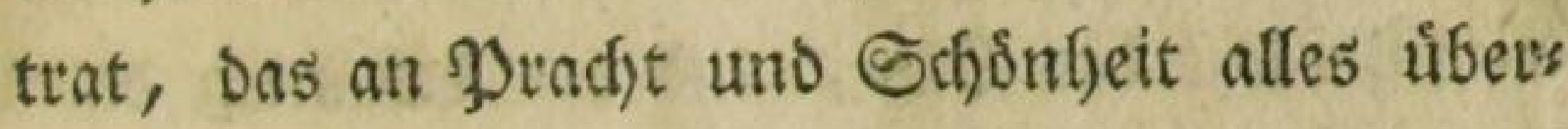
traf, was idf nodh Dergleidfen gefehen batte! Zflles war bier Strfelformig: oben eine Sbafferie mit abgetheilten Iogen, uno ouf einem Theil Detfelben eine orget mit einem fibsngebau ten Shore, won welchem Snftrumental: uns Bofalmufie Gerunterfhaflte; unter biefer Gial, lerie tuns umber fojon musgemabfte Nifichen fuir biejenigen, weldje (Evififdyungen zu fich nefmen wollen; Det F̧uß̧6oden mit Teppidjer belegt, in Der Mitte Deffelfen vier hofe ichnarze

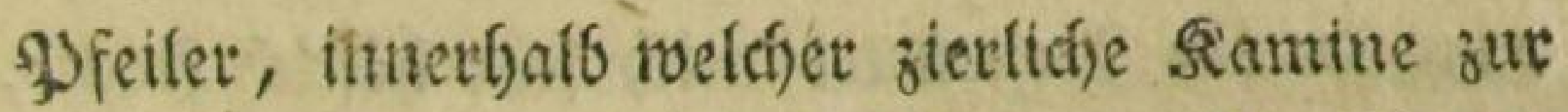
Bubereitung von Snffee, Thee und Pumich ans gebradt) find, und um weldye it bet Riundung

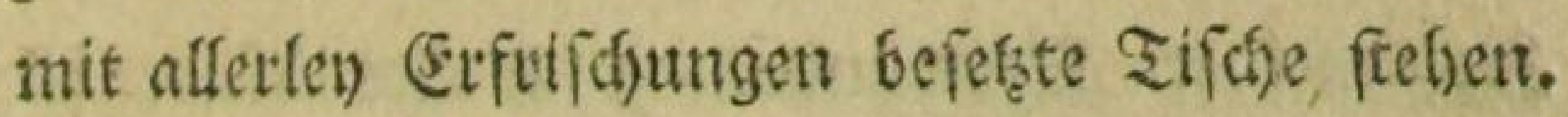
Itm biefe vier झffeiler Drelget fith mun bie ganze

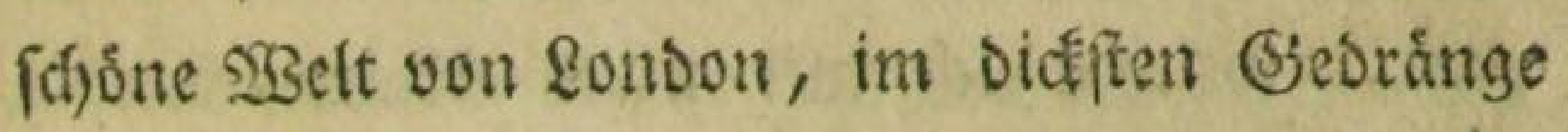
fwazieren getsens, wie eine bunte Epindel betum.

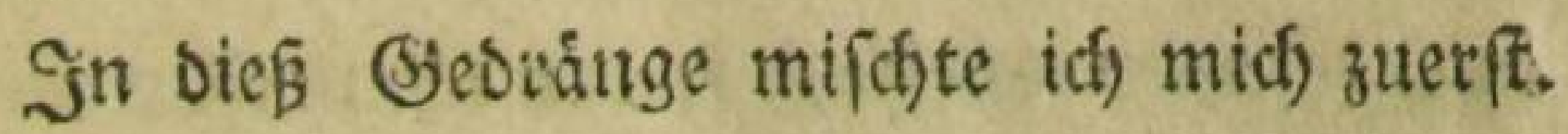

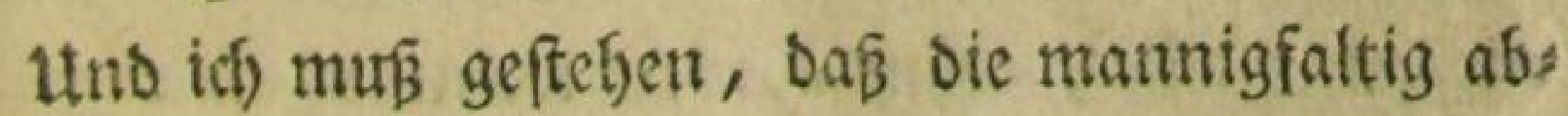
med) felnden (Siefid)ter, movon wirkfid) bei weitem die grobte 2fmzagt won blendender Sthongeit iff, 


\section{( 44$)$}

nebft Der Erleutitung, uno ber (Sitóse, Mrajeftát uno Pracht bes Stts, uno ber beftandig oabet forttonenden Niufif, eitten unbe(d)reiblich ange: nefimen (sinoruct auf bie phantafie mad)t, uno Daß̉ einem, Der Dieß zum erftenmal fiebet, obn: gefáf) fo Dabei zu Prutbe ifr, wie bei ben fecen: máfretyen, die er in feiner Sindbeit gelejen hat.

2fls ith) Des (Siebranges und Serumgebens im (Sirfel midoe war, feçzte id) mich) in elne ber Nifchen, um einige Ertfriforungen zu nefmen, und fabe aus diefer nun mit ग) und Giestange ber fróblicten forgenfreten 2 seft zu, als ein 2lufwaitter mich fef)e boflich fragte, was id) fuir (strififdungen verlangte, uno mit Das 2 erlangte in renig Miimuten brachte. 2ิu meiner Bermunderung wollte biefer für Die Etfriffungen fein (Sielo von mir annel): men, weldhes ich mir nicht eteláren founte, bis er mit fagte, baß alles fichon mit der balben STrone benm (Eingange bezahlt (ê), uno das ich nut befellen burfte, wenn ich noch etwas ge: nießzen wollte, ifm aber, menn es mir ge: fiele, ein fleines Trinf́gelo geben mod)te. Dié gab ich ibm fefgr gerne, weil ids fuir meine halbe 


\section{(45)}

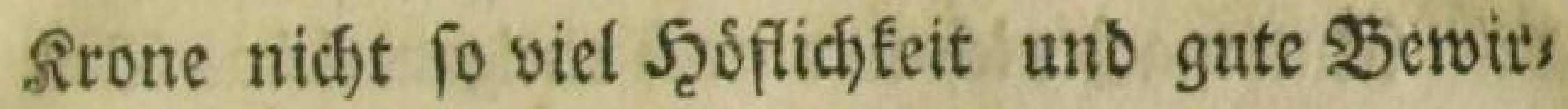
thung erwartet batte.

Sth) ging mun auf Die Sialletie, und fef̧te midh in eine Der Iogen, wo idh, wie ein etmfter Şeltbejhauer, auf Das beftándig im (Sirkel fich) umber orebende (Sienuifl Ginunterblicfte, uno Sterne, uno Droensbinber, framzofiliche Frifuten, uno ef)twuiroige Decúcfen, Das 2flter, uno bie Gutgend, Die Scobeit uno Den fimpeln ज) sittelftano im bunten (Sienimmel fich einander Durd) Ereuzett fabe. Ein Engländer, weldher fidf fu mir ge: fellte, zeigte mit Da auf mein Ṡejragen, Sprin: zen und Lords mit ungefeuren Sternen, womit fie Die ůbrige unanfef)nlichere \$ienge ver bunfelten.

Scier Drelten fich andre im ewigen (5ikfel berum, um zu Fehen uno gejeben zu werden; Dort verfammlete fid ein Trupp eifriger Dilet; tanten in Der Tonfonft vor bem ordbefter uns (d)maußste mit Den Sfyren, insés andre bei ben woblbedienten Sifden auf eine reellere 2frt iften ledszenden (Saumen erfrifden, und nod) andre, fo wie id), einfam auf Der (sallerie in bem SBin:

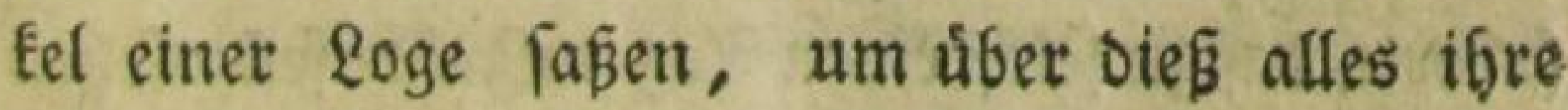
Betrad)tungen anzufteflen. 


\section{( 46$)$}

Glun machte ich) mit nodh eintgemal bas

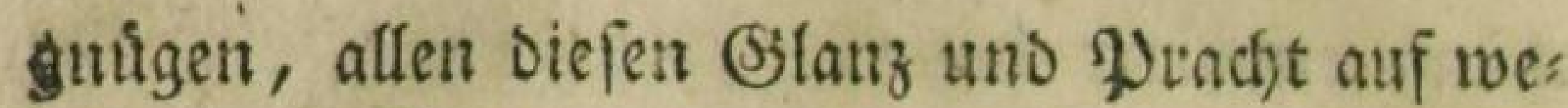
nige 2ugenblicfe mit Der Dunfelbeit Des (Siarten fu vertau[jhen, und mir bie angenef)me Uebers rafffung zu erneuern, bie mir mein erffer (Fin: tritt in bas Siebaube verurjactete. So bradjte (d) bier unter beftanoiger 2(bwech) jelung von ఇer: gnigen einige Stmben in bie Racht आn, wo bas (jeotrånge allmålig fich verminberte, uno idf bann audf eitie Sutfde nabm uns nach Szaufe fubt.

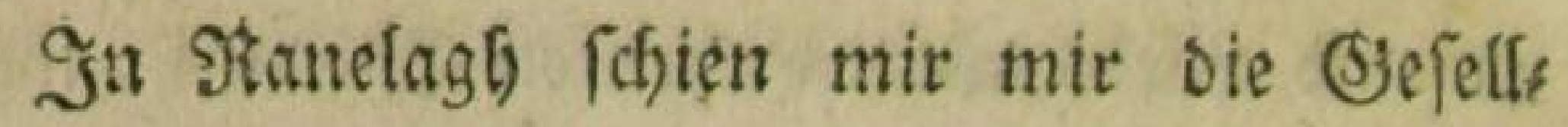
(6)aft ausgefud)ter uno feinet als in Bauxball zu fenn; Denn von geringem Stande getst nies manb bin, Der nidjt feinen beften Sdymud ans legt, uno es babutech bet feinen $253 e l t$ gleidf

thun futcht, menigfens fah id) unter ber gans zen SDienge feinen, Der nidjt feidene Strimpfe gettagen hâtte. Die ârmften Familien machen wes

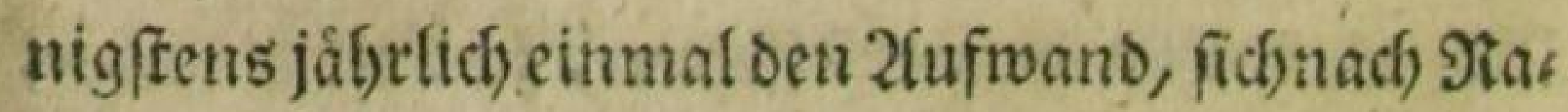
nefagh fab)ren zu lafien, wie meine 5 Sirtbinn ver: fioferte, Daß fie felbft einen Tag im Jafre feftzuferentr pilegte, an bem fie obufellbar math Panclagly 


\section{( 47 )}

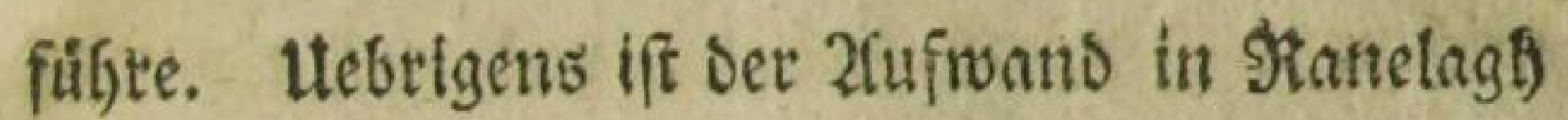
nid)t fo groß, wie in Baurfiall, wenn man auf ote (Erfriffoungen fiefret, benn wer im \$aurball zu 2lbend effen will, wie es die meiffen thun,

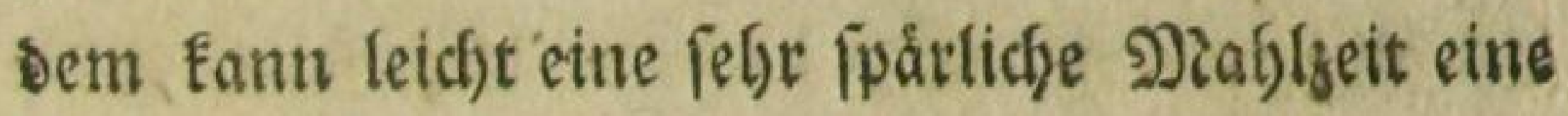
Galbe Suinee foffen.

\section{Das Sarlament.}

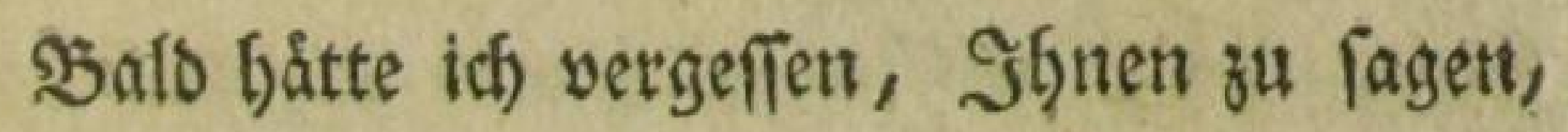
baş ich fáon im Parlament geweien bin, uno Doch) ift Dię̧ Das 2 Bidftigfte. Lino wean ich in (Englano aud) fonft nichts als bieś gefétyen Gátte,

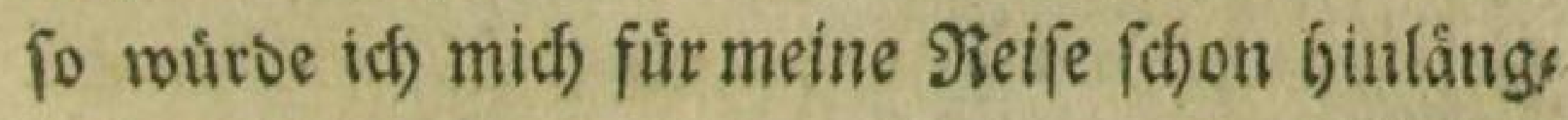
(ich) belobnt balten.

So wenig ich mich auch fonft um bie polis tifif) 2 selt befimmert habe, weil es bei uns

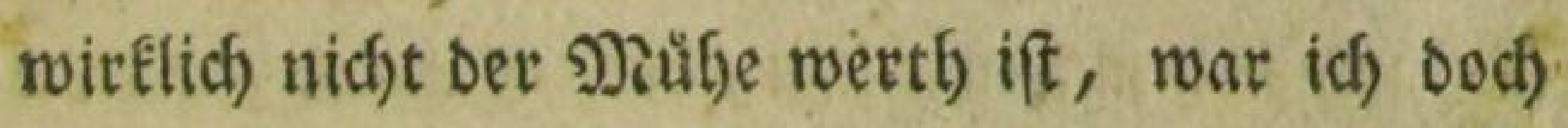
fel)e begierig, einer Parlamentsfiķung mit beia

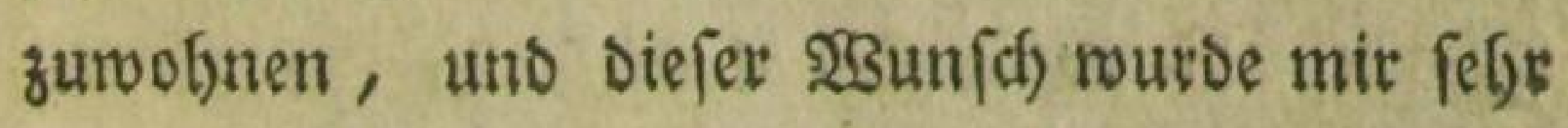
balb gevábrt.

2fn einem Nadfmittage um oret $\mathfrak{U}$ bt, wo

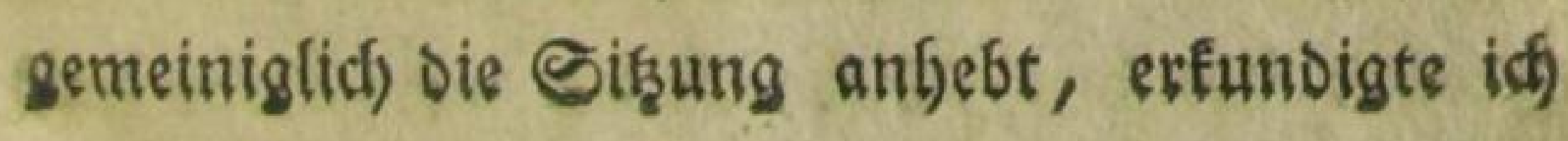




\section{$\therefore \quad(48)$}

mid) nach 2 Seftminfferthall, und rutroe von et: nem (Englänoer fehr hofflid furechtgemiejen, wie oenn bieß ůbertgaupt gefojieflet, man mag fra: gen, ween man wolle, fo das man fidf, wenn man nur cinigermaß̧en ber Eprache maít)tig iff, mit Leichter, Shúle burch ganz gonoon fin: Dent Eant.

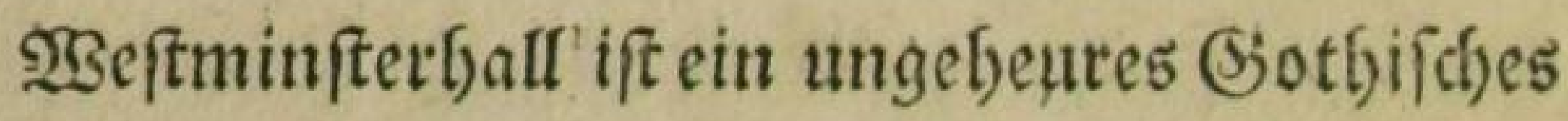
Gebátide, Defien Giemolbe nicht von Dुfeilern unterfuifect wirb; fatt beten fino aber an beiden Seiten bes (S)emslbes grope und unformlitbe aus Şolz geiduittene Engelofidpfe angebrad)t, Die Daffelbe zu tragen foreinen.

2Benn man buth biefe lange Scalle geft, fo fteigt man am Ende ein \$aar Stuffen binauf, uno fómmt zut linten Seite burch chen buneeln Sang, ins $\mathfrak{F}$ auts ber Gemeinen, Das unten eine großje boppelte Thlir bat, uno auf einer fleinen Ireppe formmt man zu ber (S)allerie für Dic Suj(jauet.

2lls idh das erftemal biefe Treppe finauf: ging, uno an bas (S)elander fam, fals idh bier ei. nen fefre feinen פiann in einem forwarzen Sleide frefen: Den id fragte, of ich auf bie (Salferie

fomment 


\section{(49)}

tommen burife? Er antwortete mir, ich mulfte von einem parlamentogliese beraufgebracht wer: Den, fonft Esnne có nidjt gejheben. Da idh nun nidgt die Efgre Gatte, ein Parlamentsglied zu fennen, und aljo misvergnigt wieder bie Treppe Ginunter ging, borte ich mir etroas von bottle of wine nadj/d)allen, Das id) mir (d)ledjter: bings nicht erflären fonnte, bis id) zu Şaule Eam, uno von meiner 2 Birtbinn boote, id batte bem feingeteibeten Manne eine balbe Rrone

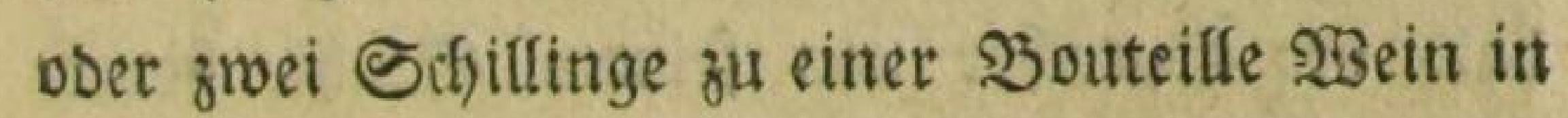

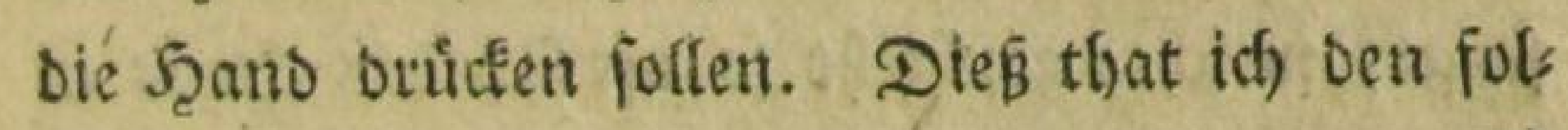
genden Tag, wo mir berfelbe Nann, Der mich vorljer abgewiefen fortte, nachoem tif) iffm nut gnei Sdyillinge in bie Scant gebrifift, febr bof:

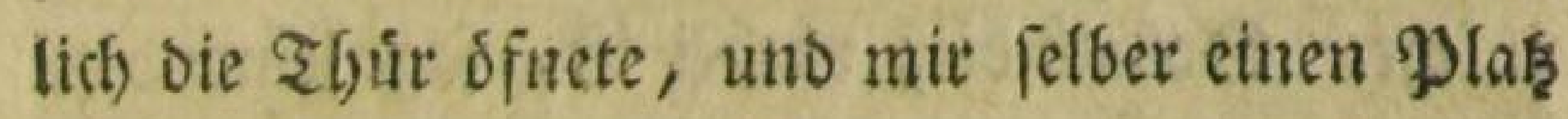
auf Der Bsallerie amvieß̧.

Uno nun fals ids allo zum erftenmale in eis nem giemlid) unanfefnnithen (sebaduve, Das einet

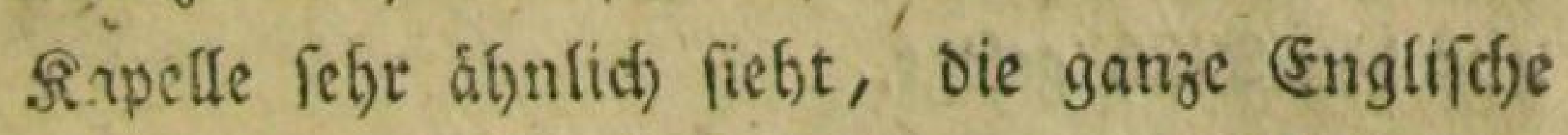
Nation in ifsen Sieptåfentanten verfammelt: Der Sprecher, ein âtrlicfer Mann, mit einer unget)euren 2fllongenperuble, in einem ffjrat: sent Drantel, ben Sgut auf Dem Sopfe, mit get 


\section{( so)}

tade gegenuiber auf einem etbabenen Stufle, bet mit einer fleitren Sanzel viel 2(ebnlichfeit hat, nut Das vorn bas Pulpet Daran fehlt; vor Dies fem Stuble ein ₹ifh), Der wie ein Zfitar auss fiebt, vor weld)em miederum zwei Mánner, welche

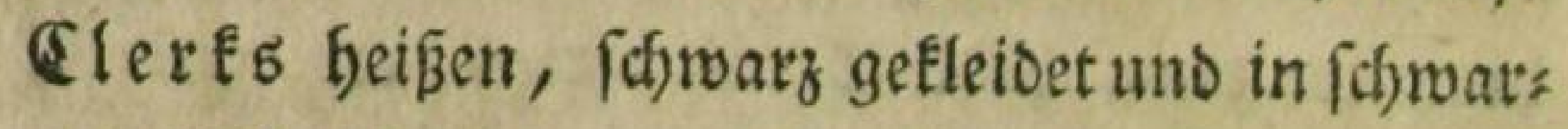
zen Månteln fiķen, uno auf relchem neben ben pergamentnen 2ften, ein groß̧er vergolbeter อ pter liegt, Der allemal reggenommen, uno in

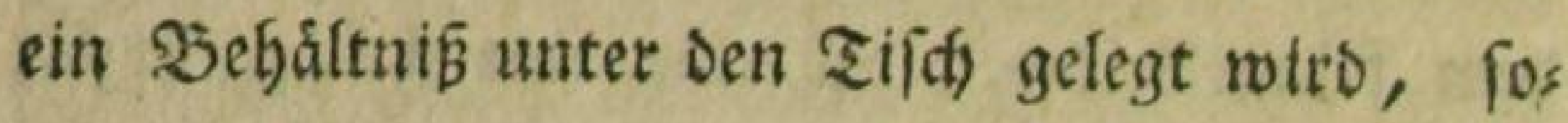
bals ber Sprecher von feinem Stuble berabs: fteigt, welcher gejchielst jo oft fid) Das Jeaus in eine fogenanute Rommittee oder blope Unterfus d)ung verwandelt, wåfyend weld)er es feine

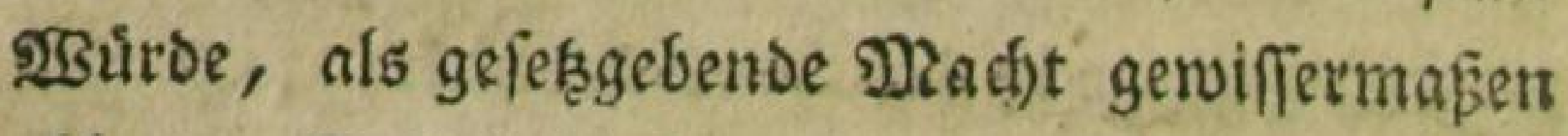
ablegt. Sobalo dießs vorbei ift, fagt jemano jut Dem Sprecher: mun fonnt thr eudh wieber bins feß̧en! und fobalo oer Sprecher feinen Stuhl befteigt, wiro aud Der Scepter wieber vor ifm auf Den ₹iich gelegt.

Ifn ben Seiten bes Şaufes runb umber unter

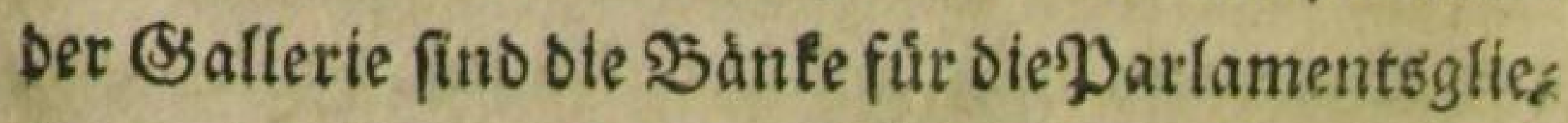
Der, mit grúnem Tuch) ausgeidflagen, immer cine bobger, als bie andre, wie unite Shore in sen 


\section{( $\{2\}$}

Sirthen, Damit berjenige, weldoer reber, Ins. mer uiber bie vor ifm figsenden wegiegen fann. (Sben fo fint aud Die Sjante auf ber Ballerie. Die \$orrlamentsglieber behalten thre Szulte auf,

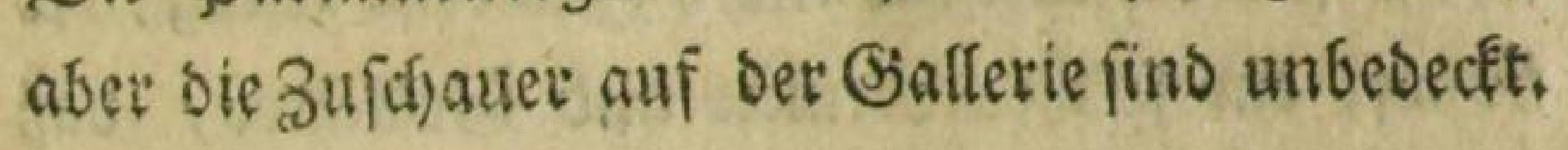

Die Parlamentsglieber im Untertgaufe has ben nichts Unter/f)eibendes in ibrer Sleibung; fie Eommen im theferrod und mit Stiefeln uns

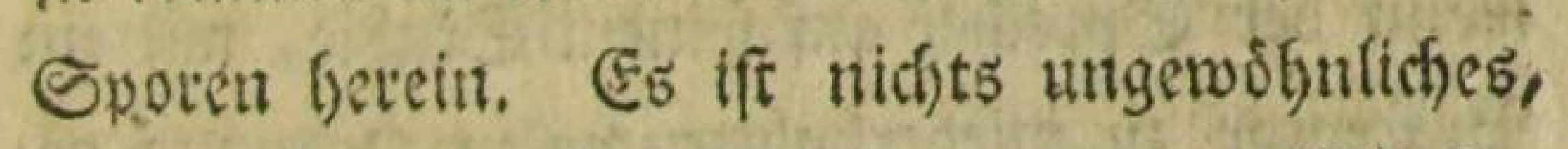
ein Parlamentsggtied auf einer von ben bånken ausgeftrectit liegen zu leflen, indés bie andern bebattiren. Einige fnaffen গuifie, andre eflen 2feppelfinen, oder yoas fonft die Gafreszeit mit fich bringt. Das (Fin: und Zfurgeben Dauert faft beftänstg, uno jo oft jemans binausgefen roilf, feefle er fich erft vor ben Sprectser, uns madjt ifgm feinen seeverenz, gleidsfam als ob er

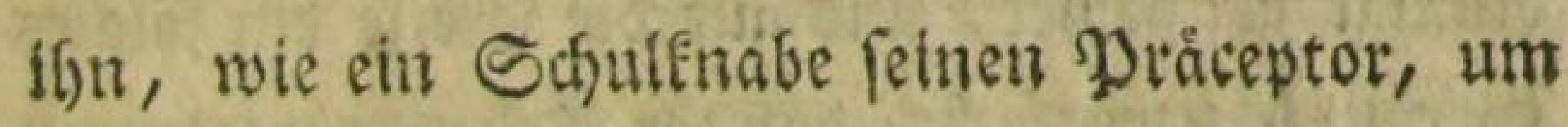
Evraubnis bittet.

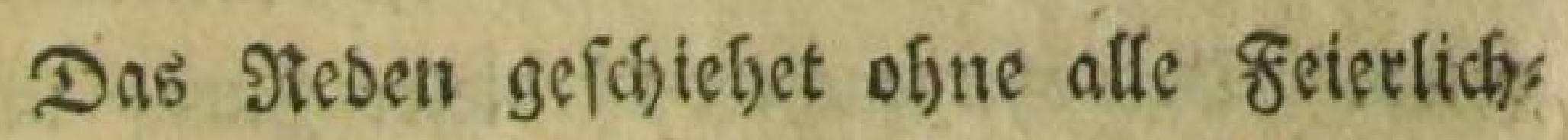
feit: einer freft blós von feinem Silze suf, nimmt feinen Şut ab, rendet fíd) gegen dew Eprecher, an ben alle গieden geridftet find, bes

(2) 2 


\section{( 52$)$}

bălt Şut und Stof in einer f̧and, und mit Dern ander macht er feine Bieften.

Fedet ciner fobledft, oder bat das, was er fagt, fúr- bie meiften nicht Intereffe genug, fo

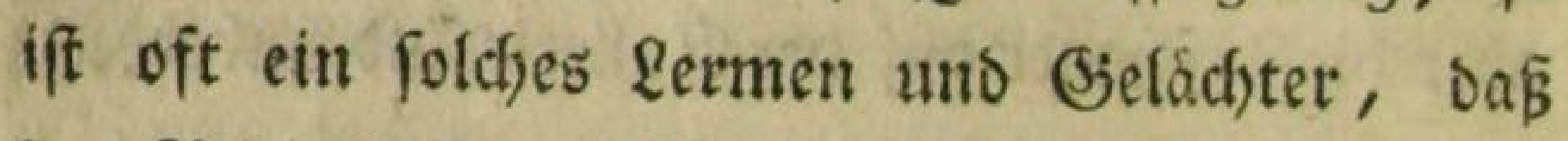

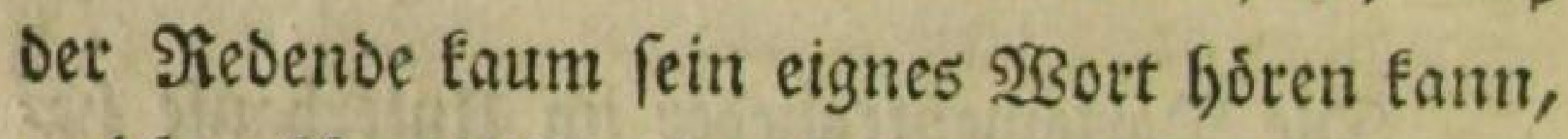

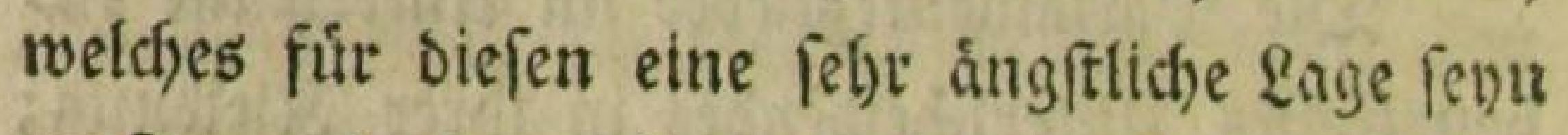

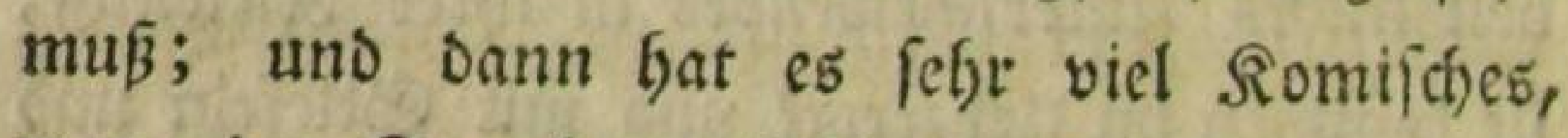
wenn ber Eprecber auf feinem Stulfle, wie ein Práceptor zu wiederbofittenmalen Sronung ge: bietet, invem er austuft, to Order, to Order! ofne bas eben viel barauf geachtet wirb.

Sobalo bingegen einer gut und zweectmásigig rebet, fo beerrfobt die áuber|fee Etille, uno einet nad) Dem andern glebt feinen Seifall baburdf fu erfennen, Daß er hear him! foót ifgn! ruft, weldses benu freilich oft vom ganzen feaufe auf einmal gefwielfet, und auf die 2 seife ein folches

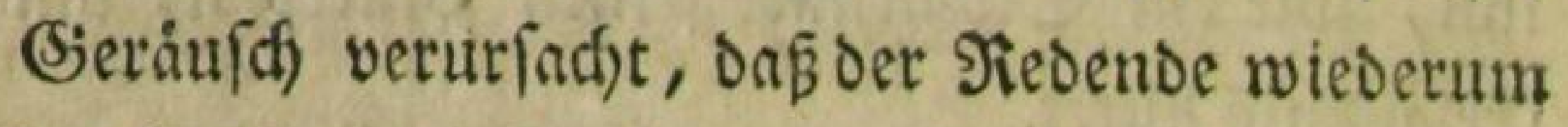
ourd) eben biefes hear him! oft unterbrocteen wirt. Demolngendjet if diefer Buruf immer eine grope 2lufmutterung, umo ith babe oft bemerft, Daß́ einer, Der mit einiger furchtfam, feit ober אálte z̧u reden anfángt, am Ende da 


\section{( 53$)$}

butch in cin foldjes Feuer geferst wito, onß́ ex mit einem Strome von Beredt[amétit [pricht.

253eil alle Fieben an ben Eprecher gerid): tet fino, fo fangen fie fid) immer mit $S$ it an, auf reldhe 2lutede Der Sprecher feinen Scut ein flein wenig abnimmt, ifgn aber fogleich

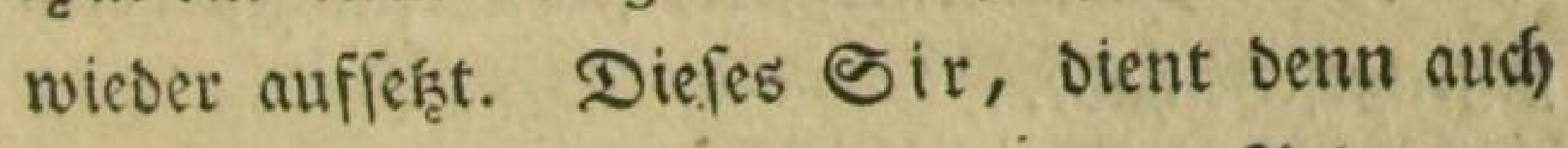
oftmals, die Ulebergånge in ben Sieben zu madjen, uno if ein gutes Sculfismittel, fobalo

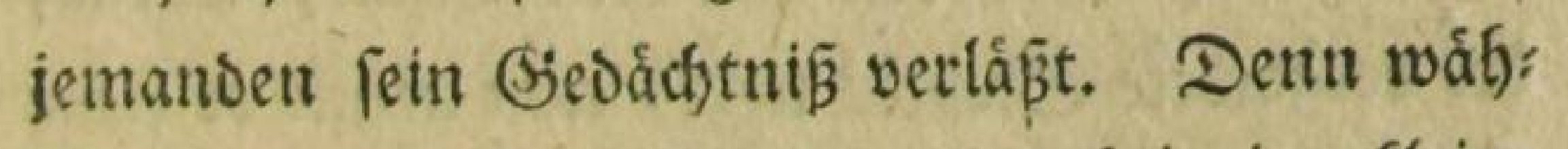
reno, Daß̧ er Sir lagt, und babei eine fleine \$aule macht, befinnt er fich aul bas Folgende. Dod) habe ich aud) gefeben, daßs einer am (Ende eine 2frt von Roncept aus bet ₹ajde ziefon muß̧te, wie ein Ranbibat, oer in ber Predigt ftecfeat bleibt: fonft werben bie Sieden nidjt abge: lejen. Diefe Sieden haben ebenfalls ifre Sies meinsorter, als z. \$. morauf in diefem Şauje

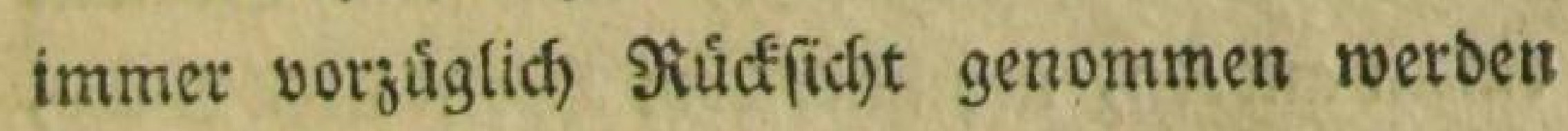
miffe, uno Dergleichen.

* (S)leich am erften Tage zeigte mir etn Engláu oer, ber neben mir auf ber Sjallerie fá̧, die vornefym[ten Sitglieder des \$arlaments, als

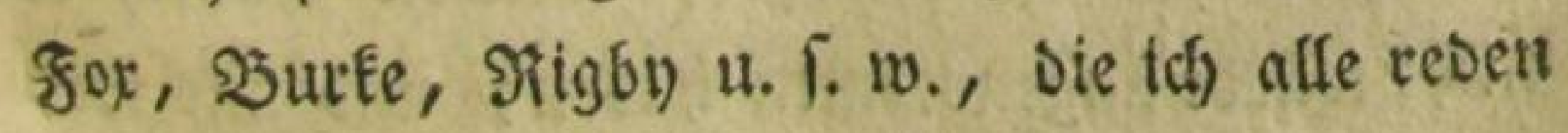

D 3 


\section{( 54 )}

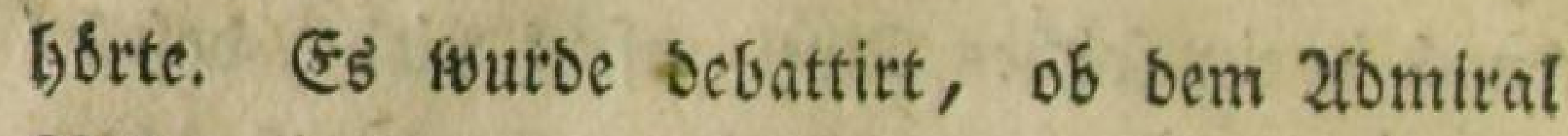

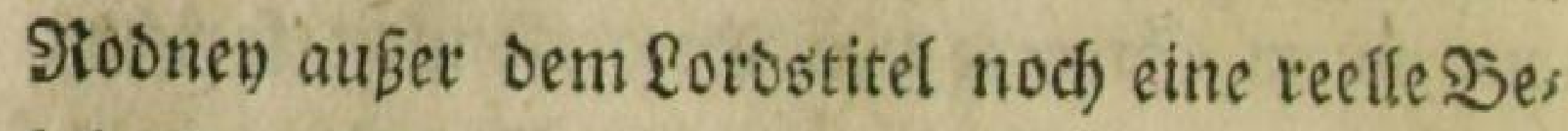
lobnung follte gegeben werben; zugleidy writbe For von bent jungen gorb Fielting vorgerwoveter,

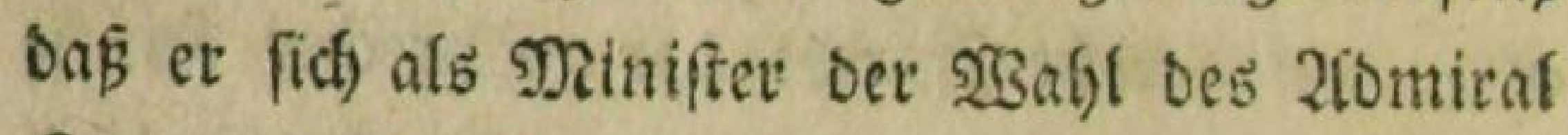

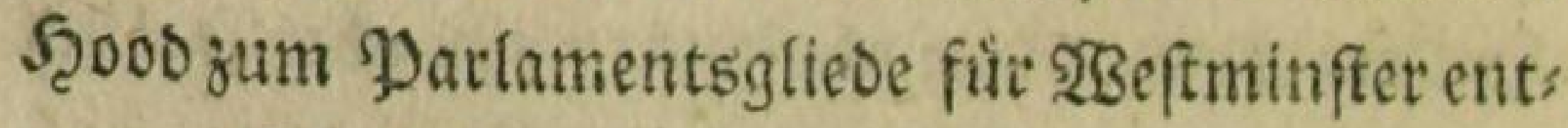
gegengefęç habe.

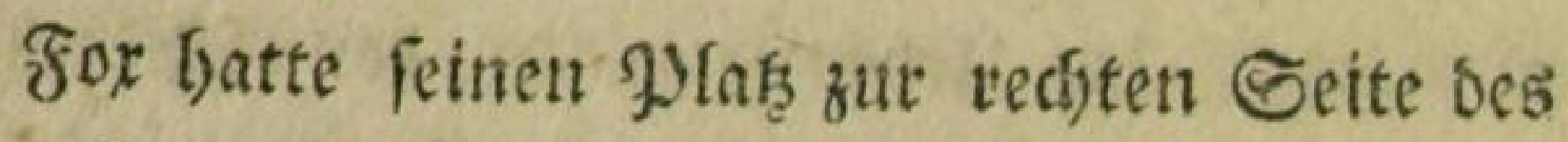
Sprechers, nidjt weit von bem Silaje, mornuf Der vergoldete Ecepter fiegt, nun nafjm er feine

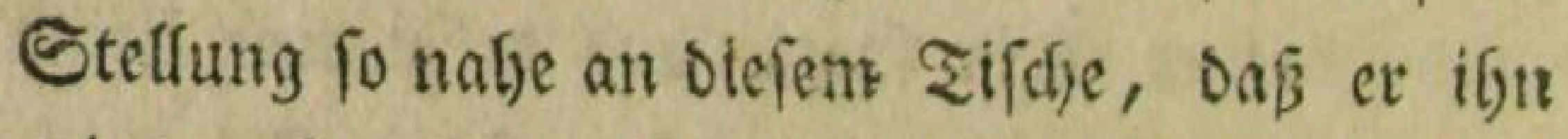
mit bet Sfant etreidfen, uno mandfen betzhais ten Echlag Darauf thun Eonnte, nachoem es der Ziffett feiner Fiede erforderte: Lüro wie er fidf nun gegen ben gorb Fielding vertbettigte, indem er bebauptete, daßj er fić) nitht als Minifer, fondern bloß als' \$orivatmann bies

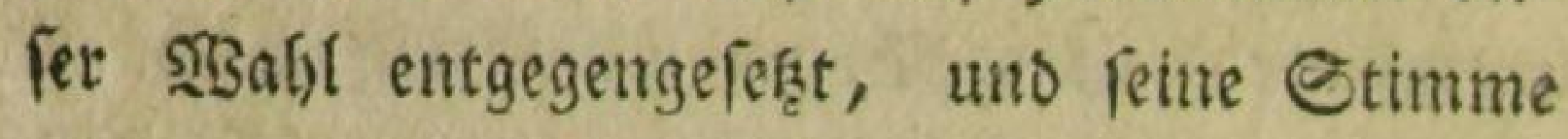

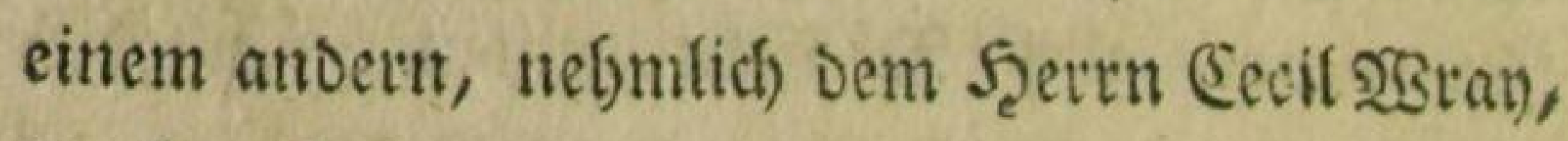
gegeven babe; uno oaj̉ ber Sisnig, oa er ifin zum Staatzjeftetár gemacht, feinen ₹aulfo mit ifm eingegangen fer, woourdy er feine Etimme ale Drivatmann vertobve, weldhen Eauld er tridt twútbe angenommen Gaben; und mit wels 


\section{( 52$)$}

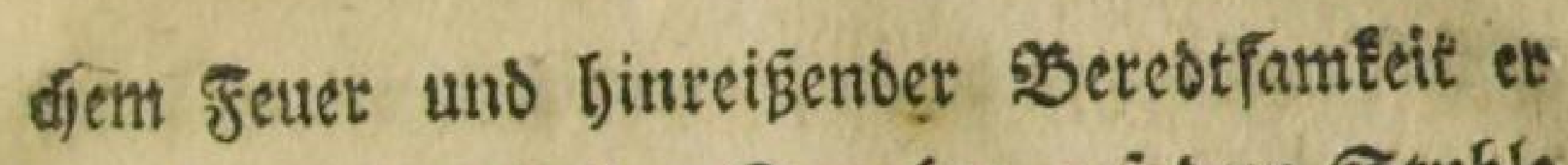
fprad); unb roie ber Sprecter auf bem Stuble

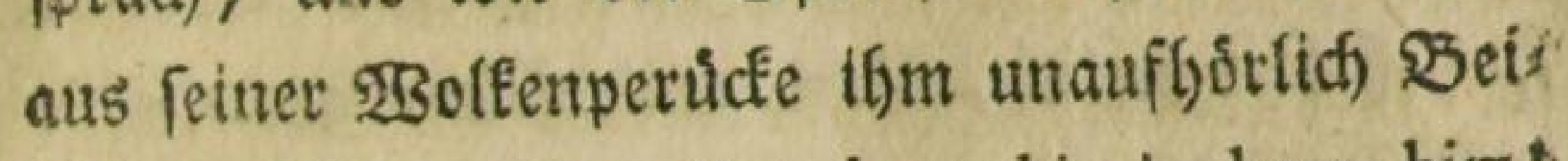
fall zunicfte, und alles hear him! hear him! thef, uns Speak yet! went es fabien, als wollte et aufgdten zu reden; und er auf die şelfe beis nafje zrwei Etunben nadjetinanber (prady, Das

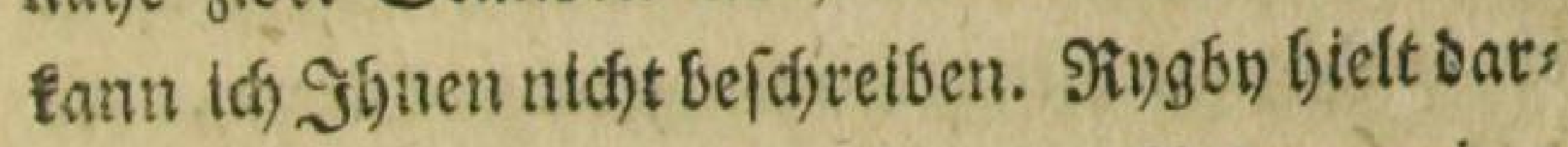
auf nod) cine furge aber fefre fauntgte gicoe, worint et \{agte, rwie wenig ber Globe \&oros oder \&adn'stttet

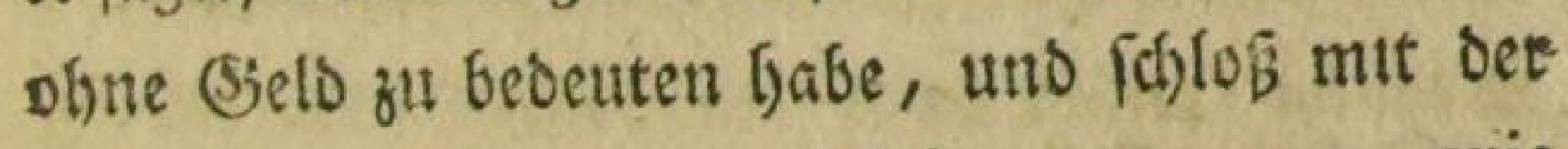
Yateinifchen Sentenz: infelix paupertas, quia ridiculos miferos facit, nachoem er vorber fefge fein bemertt hatte, man múfie evfit zu etfahten fuchen, of Der Zromiral siobnen niçt wieberum einige roldftige \$orien gemadht bâtte, weil ev alsoann eben feiner \$jclobnung an Gelbe mefre

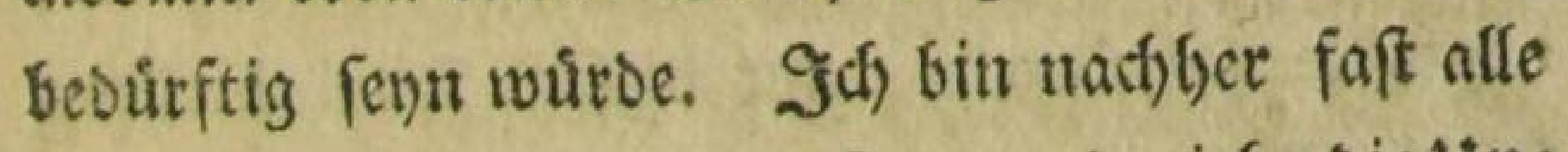

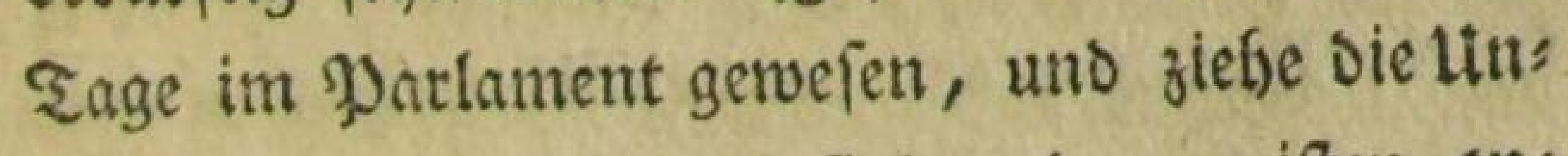
terfyaltung, bie id) bort finde, ben meiften ans seen $3 e r g n i g u n g e n$ yor.

For ift immer nod) bet bem 3 olfe fefre bes fiebt, of man gleid) unzuffrieben barúber iff,

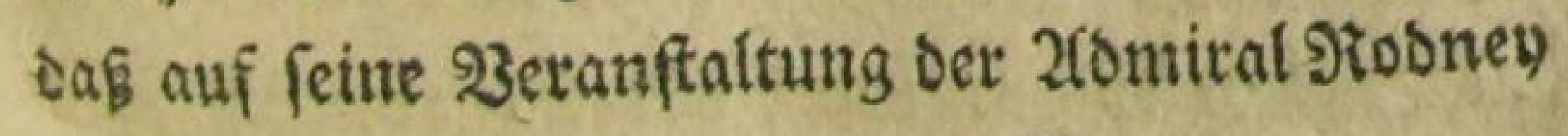

D 4 


\section{( 56$)$}

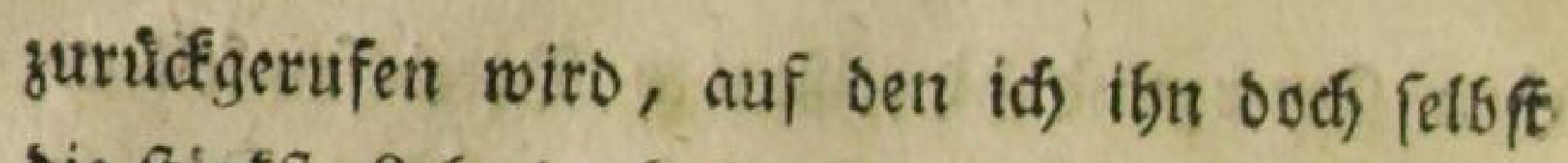
bie frárffe Qobrebe Gabe balten Góren. Egarlea

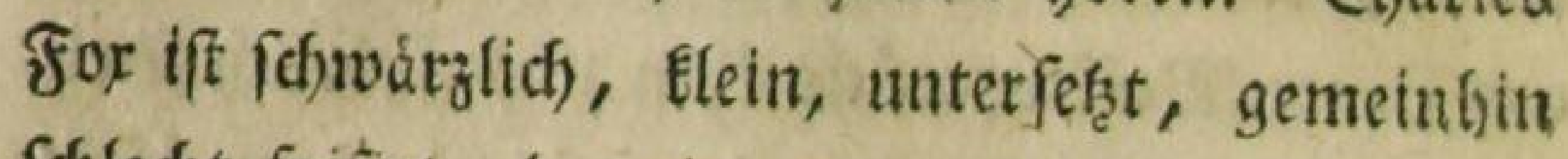

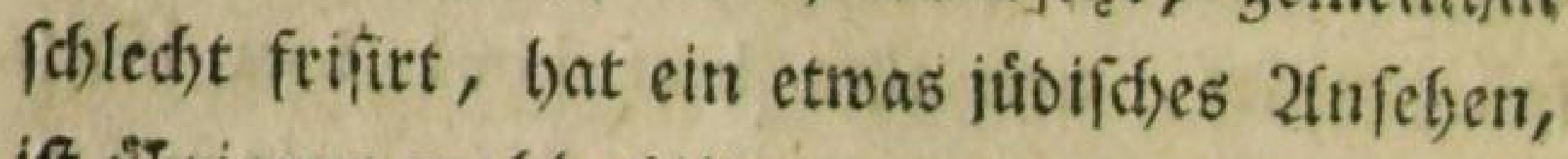

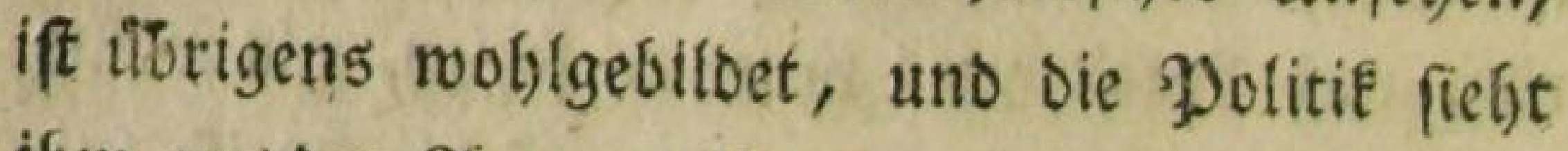
ifm aus Den 2fugen: Mr. Fox is cunning like a Fox babe idh hier oft fagen borren. Siute ift ein woff(gewact) fener langer getaber Miann, ber fofon etroas áltlich ausfiefft. Singbi ift ferje forpulent, und bat ein rotbes ftarkes (sefictit.

Sefbr auffallend waren mir bie offenbaren Seleidigungen und (Grobbeiten, welde fidf oft Die Darlamentsgliever einander fagten, indem Det eine z. $\mathfrak{b}$. auffortte zu reden, unb ber andre unmittelbar barauf anfing: it is quite abfurd $\mathfrak{u}$. f. w. Es ift bodfft ungereimt, was dee right honourable Gentleman, mit Diefen Sitel beefren

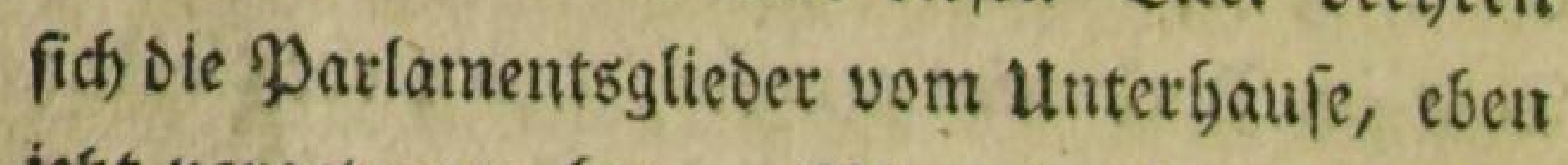
jef̧t vorgetragen bat. Niemals aber jagt, Der Eintichtung gemáä, jemand dem andern inธ Gie:

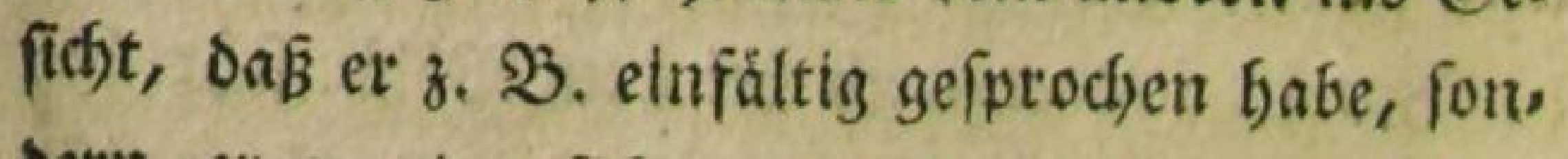
Dern er wendet fich, wie gewosbnlicf, zu Dem Sprecher, uns fagt, inderm er biefen anredet, 


\section{( 57 )}

oet right honourable Gentleman babe fefre eitle fáltig gefprodjen.

Selor fomifh fiefst es aus, wenn furveilen einer fpridft, uno ber anope die Sseftus dazu macht: wie ich oiés einmal bei einem alten efor: lid)en Sưrger bemerEte, Det fich felbft nid)t zu reben getraute, aber inde巨́ (ein গadbbar (prad), jebe nadyorucflidhe Sentenz deffelben mit einer eben fo nadjorucflid)en Geftifulation, wobei fein ganzer Rórper in \$ervegung geriet'), bezeid)nete.

Dft verirret fich Der (Sang Der Debatten in einen Priwatwortruechfel uno গisuerfanoniffe untereinander, wenn bié zu lange bauert, uno man z̆ fef̧r von Der Şauptfache abfómmt, fo roird man endlich Des Dings úberotúfị, uno es entfrebet eit allgemeines rufen: The queftion! The queftion! Dieß mus zumeilen offer wieder: bofit werden, weil immer einer gegen ben ans Dern nodh gern bas lefeste SGort haben will. (End: lid) aber fsmmt es Denn bod) fum Stimmetr, nno ber Sprecher fagt: wer fúr bie Sadje ift, Der fage ay, uno wer barwieder ift, lage no: Danu hort man ein verwirtes (Sief(d)ei von ay und no untereinander, Itno ber Gprecher fagt

D 5 


\section{( 58 )}

laşe entrueber: mir bäucht, es find mebt ay's als no's, oder, es find mefrer no's als ay's. Dent mifien aber alfe Zuidaner von ber Bjallerte ge: ben, und bas eigentliche Stimmen nimmt etfit feinen Infang. Die Jyarlamentsglieder fareient alsoant zu Der Sillerie finauf withdraw! with. draw! bis alle sufchaner entfernt fino. Dieje wetben folange th ein Simmer unten an oer Ireppe cingefpert, unb wenn bas Stimment vorbet iff, wieder binatifgelaffen. Seler habe idg mich ůber ben' \$Jutbrillen, felbft bei gefittetert Englåndern roundern múfien, mit welther Sies walt fie fich wieder aus ber Stube binausblaings ten, fobalo mur bie ₹húte gedfnet wutbe, um bie erfen zu fenn, ote wheder auf ber Sallerie antamen. 2fuf Dte Tseife fino roir zuweilen zreei bis oveimal von ber Sallerie fortgefdsidt, uno wieber binaufgelaffen wórder.

Unter ben Sulchauern giebt es Reute von allet: lei Stande, auch find beftánd tgid amen darunter:

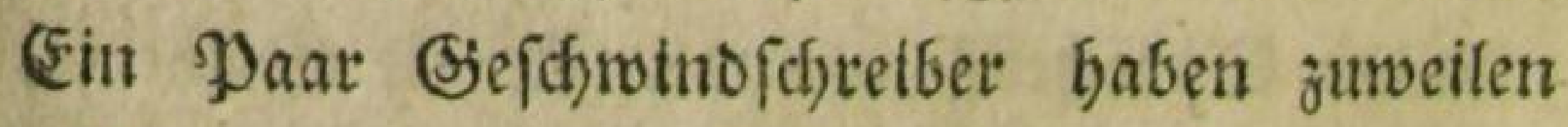
nic)t meit von mir gefeffen, bie auf eine etwas

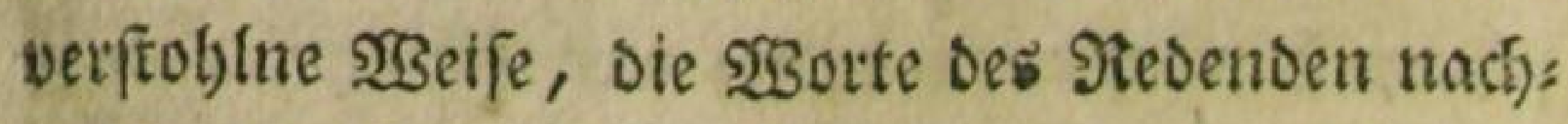
3ufdreiben fudjten, weldge benn gemeinigfich nodis 


\section{( 59$)$}

benfelben 2foeno gebrucit in Tefen fins. Bem muttlidi) werben biefe Reute von ben 2 erlegern oer Zattungen befotoet. Ethige गुerfonen giebt

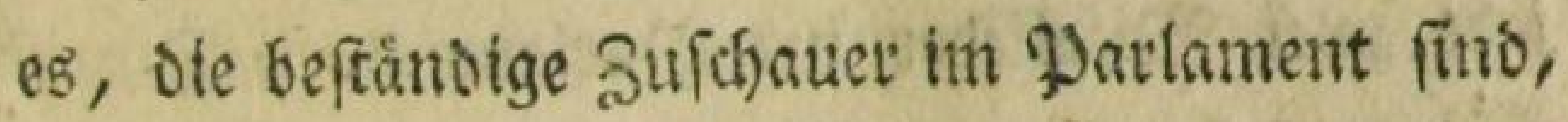
und fur eine ganze Sirgung eine Gruinee an ben

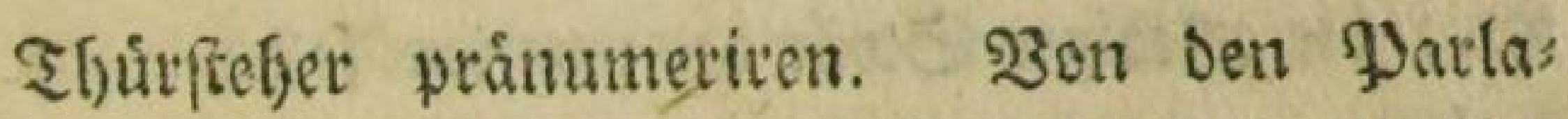

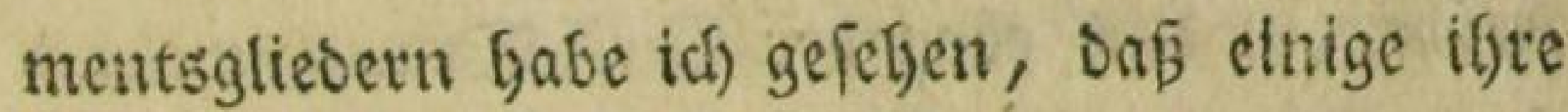
Sofrne, als junge Sinaben fofon mit in bies

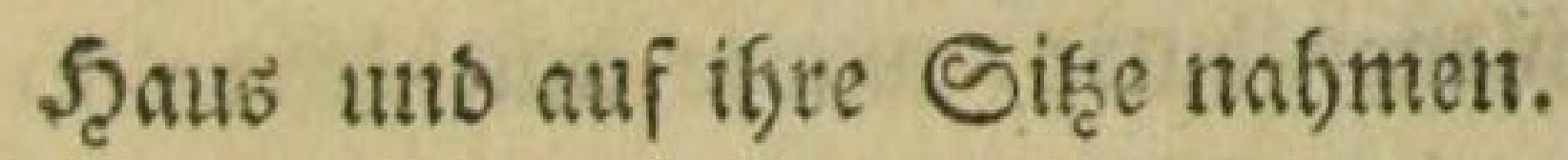

Ess ift im Boridalage gewefen, das im Obers

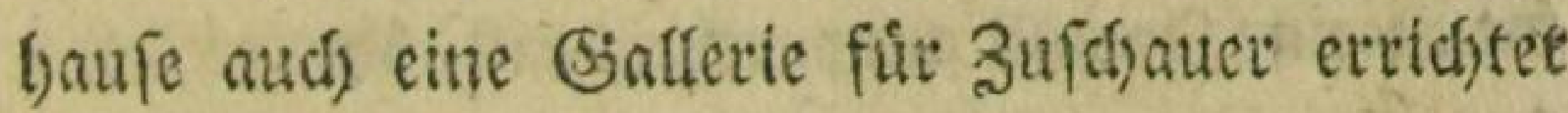
werben folle. Dies iff aber nićst zll Stande ges formmen. 2atud) gejetes in Oberbaufe fdjon fitts

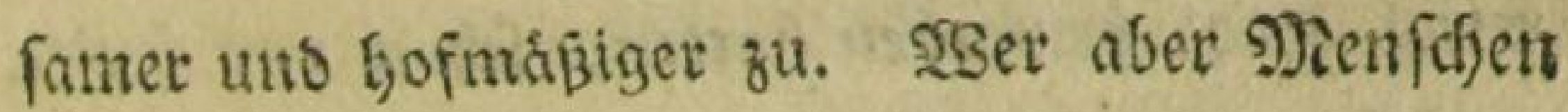
beobaditen, uno sie quffedsenbfen (SGaraftere in if) ren fáteffen 2feuferungen Betrachten wifl, bev gebe ins tunterfans!

ßergangnen Dienftang war Şângetag; es trat aber audf zugleid) citre njarlamentswabl: eins von beiben fonnte id) mar mit anfergen, ich zog oentu, wie naturtlich, ons leştre vor, indem ids nut in ber Ferne Die Tootenglocie jener Opfer Der Sierechtigkeit láuten hoirte. Serest befâteibe (id) Şgnen allo 


\section{(60)}

\section{Eine Parlamentstraḩl.}

Die Ståbte \&onbon unb 2 seftminfter fdjicfen jede zruei \$)itglieder ins \$arlament. For iff

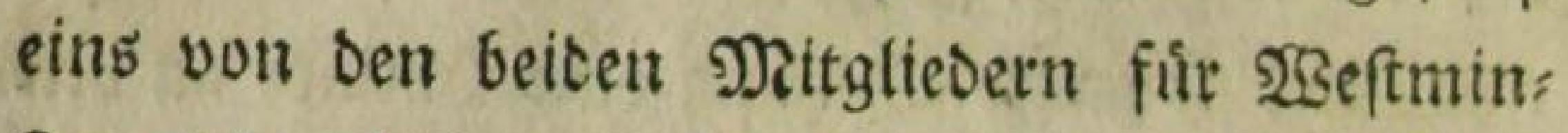
fter; Die erledigte Stelle bes zrweiten follte befeŗt werben. Und eben Der Cácil $\mathfrak{T}$ ran, welchen Fox, fatt des 2lomiral 5 zeod, Dem er entgegen wat, vorgefdjlagen batte, wutbe mun sffentlich gewåblt. Buveilen foll es bet foldjen 2 sablen, roenn eine Oppofitionspartlgei oa ift, blutige $\mathfrak{R}$ Sp fe fefen; bier war aber die $\mathfrak{3 a b l}$ fichon fo gut wie geicheljen, weil biejenigen, bie fich für Den 2ids, miral Şood berworben hatten, fidjon von frelen Stricten zurúcfgetreten waren, da fie fahen, ba ibr Botbaben nicft Durdjging.

Die $23 a f l$ gefdjabe in Soventgatden, einem grofen Diartplakge, unter freiem Şimmel. (5) war nehmlich) vor bem (Eingange einer Rirche, bie audh Die paulstirche beist, aber nidht mit Der Ratbeorale zu vetwed)feln ift, ein (seruift

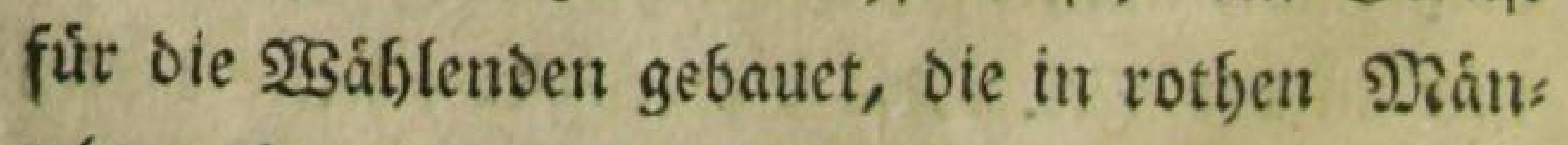
teln uno mit weiß̧en Stáben auf ůbereinander errichteten S̉ảnfen faß̧en: gauz oben wat ein 


\section{(61)}

Ctuffl fúr ben 'práfes: alles aber war nur bont

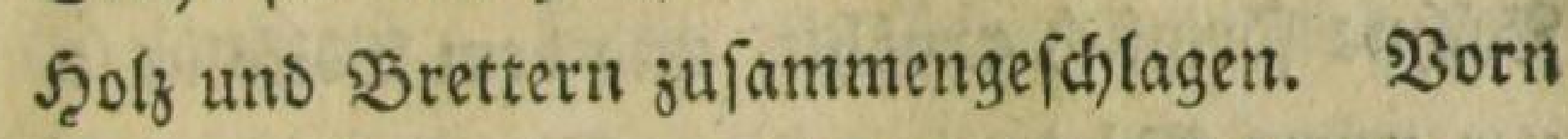

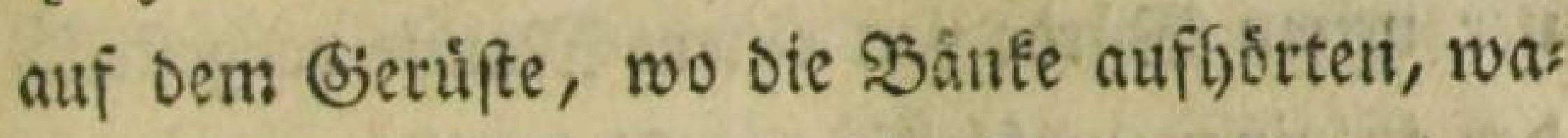
ren खiatten gelegt, uno bier ftanden biejenigen, weldhe zu Dem Bolfe redeten. Zluf Dem Ylake yor bem Geruffet batte fith eine Menge Bolfs

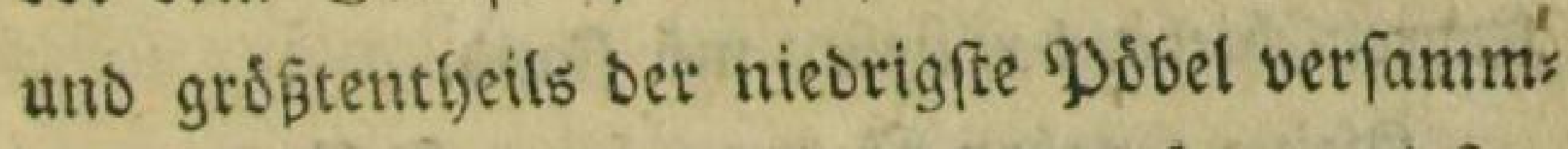
let. Dic Siesner bucteten fich tief vor biefem Şaufen, und rebeten ifgn allezeit mit bem ₹itel Gentlemen (edle Şúrger!) an. F̧err Eăcil IStray muşte vortreten und biefen Gientlemen mit Şano uno Mauno verppredjen, Feine $\mathfrak{P}$ flidf: ten, als ifre Reptafentant im Đartament auf Das getteufte zu erfüllen. Zfud entichulbigte et (iid) mit feiner Seeife uno Sitánflidefetet, baß̧ et nidft einem jeben unter ignen, wie es fiid) ge: bübte, feine 2fufwartung gemadit babe. Sos balo er anfing zu reoen, wat bie ganze Nenge fo frill rie bas tobende Nicer, wenn der Sturm fid) gelegt bat, uno alles tief,, wie im गुarlamente, hear him! hear him! uno fobald er aufgethort batte fut reven, evidfallte eiu allgemeines Scurraf) aus jedem गiunbe, uno jeder fofwenfte feinen

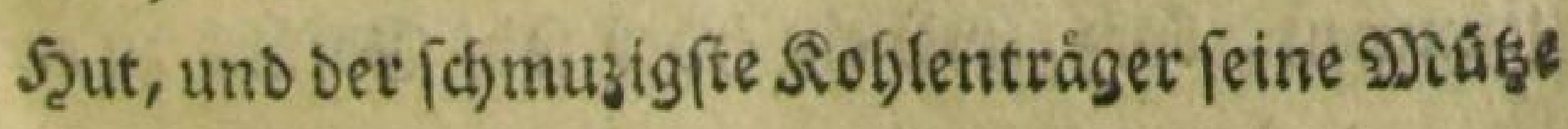
am Den Ropf. 


\section{$663)$,}

Et watd mun von ben Deputirten auf bet

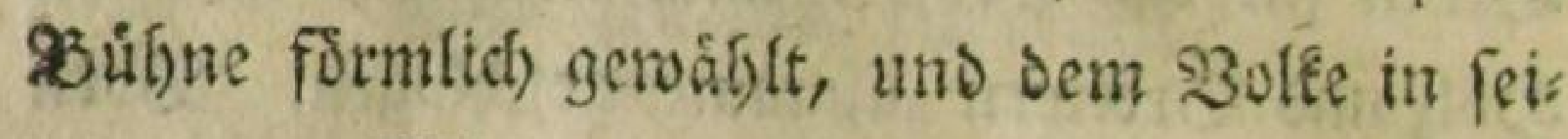

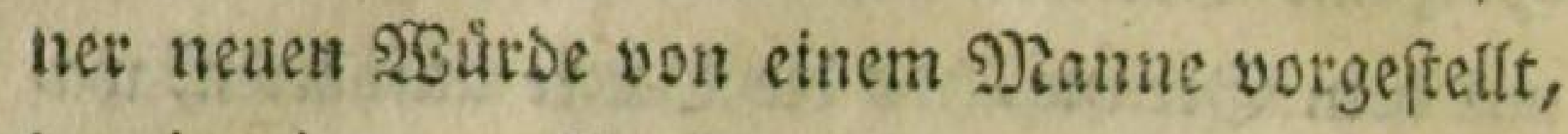
Det in einer moblgefétent siede ifym 4 mo bem פolfe Gific wuinjhte. Diefer Diann Gatte cine gute 2uibrede: he fpeaks very well! fagte ein Rartenfibieber Der neben mir frand.

Sileine Suben lingen fić) an (Sielander und Eaternenpfáble, uno als ob fie úberzeugt wäaren, baß auch) fie fohon mit angeredet wútden, forten fie aufmerEfam bem Diconet zu, uns bejeugten am (Ende auf gleiche 2 seife burch ein frendige Scutrah igren Sbeifall, inbem fie, wie bie (Et: wachjenen, ifre Szute um Den Ropf fofwenften.

Seier wadten alle Bilber yon Fom, Soria

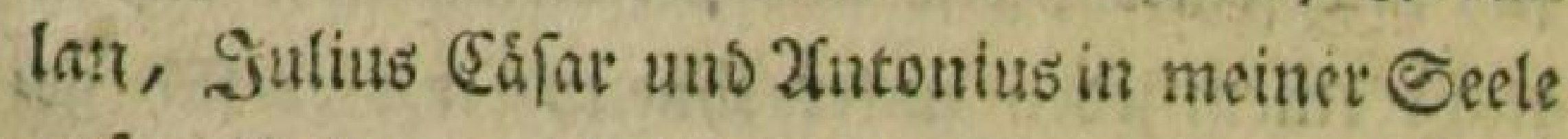
auf. Uno mag diés immer nut ein Saufelfpiel fenu, fo Enun bodf felofe citie folche Effimaire das Seerz und Den Sieife etheben.

5 lieber freuno, wein man bier fiebet, wie Det geringfte Ratrenfisteber an Dem roas vor: gebt feine Tleilnebmung bezeigt, whe bie Elein: ften Sinder fojon in Den Seift des Bolfs mit ein ffimmen, Eurz, wie ein jeber fein Siefúbl zu evs 


\section{( 63)}

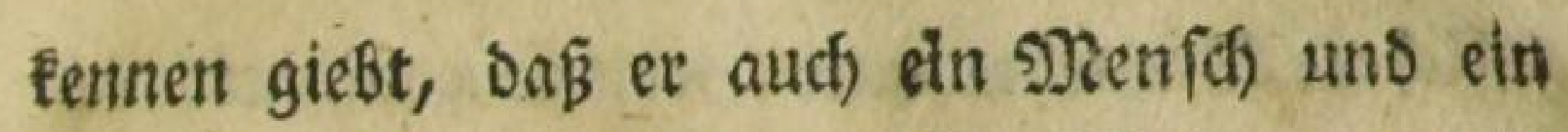
Englander Fey, fo gut wie fein sionig uno feit 2) Siniffer, Dabei wirb einem bod) ganz anders zu Nathe, als wenn mit bei uns in Serlin bie Golbaten exerciren féfen.

Zfls For, Der mit unter ben 2 Béflenden war, gleid) anfanglid) in feinem $583 a g e n$ angefafjren fam, warb ex mit einem allgemeinen frettoens geidjet empiangen; zuleşt nachoem ber 2lftus beinaly vorbei war, fiel es bem 2 olfe ein, ifln reden fu-boren, und alles fdirie: For! For! ich rief felber mit, uno er muste auftreten uno ves Den, weil witr ifn Gosen wolften. Eve trat Denn alf uno befráftigte nochmals vor Dem 2 ofte, Daß̧ ex (đ)lec)terdings nicjt als Staatsminifter, fonbern nur als Drivatmann bei Diefer 2 sabjl (Einflus gebabt babe.

शacjoem nun alles yorbei war, fo zeigte fidf)

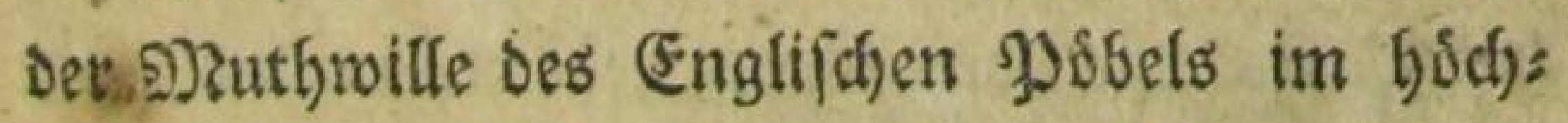
ften (Sirade. Binnen wenigen s)imuten war Das ganze bretterne SSetúfte mit Bänten unb Gtúblen abgebrodjen, und bie झlatten, romis es bedectit war, in taujent lange Streifen jers riffen, romit der Pdbel einen Sirfel JWlog, it 


\section{( 64 )}

weldjem 30 onebtme und Gieringe gefangen wat: Den, was nur in ben Siseg fam, uno fo zog das 3olf im Stiumph ourd) die Straß̈en.

1. Seier fübitt oodh ein jeoer, bis auf den (jie:

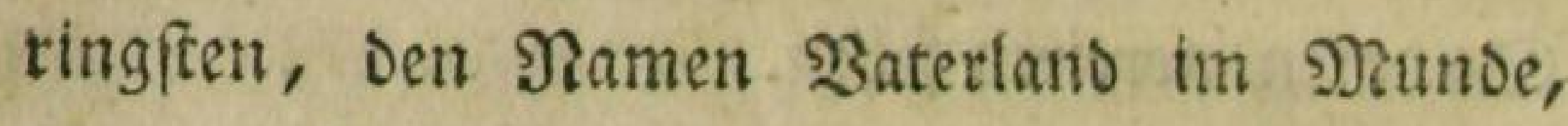
Den man bei uns nut von Dichtern nennen fortt. For my country l'll fhed every Drop of my Blood! fagt ber fleine Sackiv in unferm Staule, ein Sina: be, Det faum zrodif Sable alt ift. 23aterlands: Siebe unb friegrifase Tapferfeit if gemeiniglidf

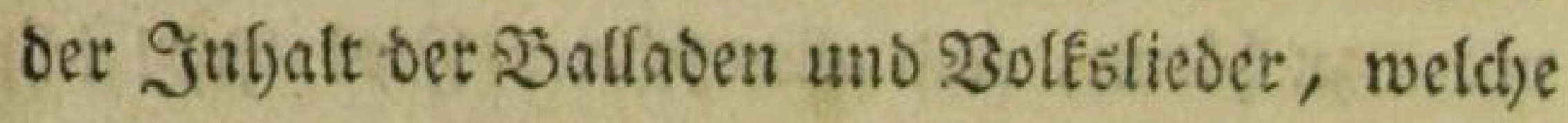
auf ben Etraf̧en von 28 seibern abgefungen uno fúr wenige Piennige verfarft wetben. Ploch) fưrz̧lich brach)te unier Jacty eins mit zu Şaufe, worinn bie (seidolidte eines atomirals etzáaft wutbe, ber nod tapfer fommansirte, als ifm fifon beide Sieine abgef fyoffen waren, uno $\mathrm{ct}$ fich muste emporfalten lafien. Die Veradstung

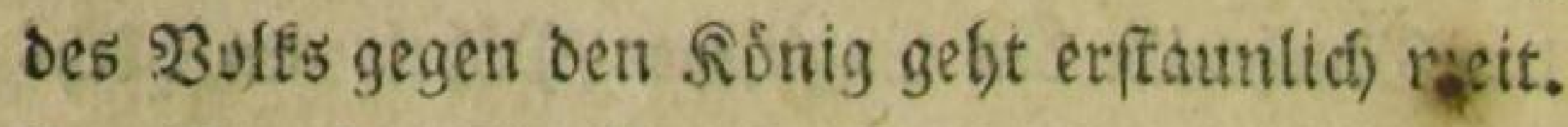
Our King is a Blockhead! bab' id́ wer weip wie oft fagen horen; indem man zu gleidfer Zeit ben

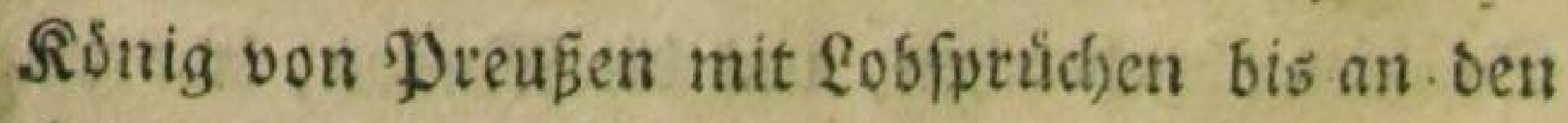
Şimmel erfob. Diefer Gabe einen fleinen Sopfs,

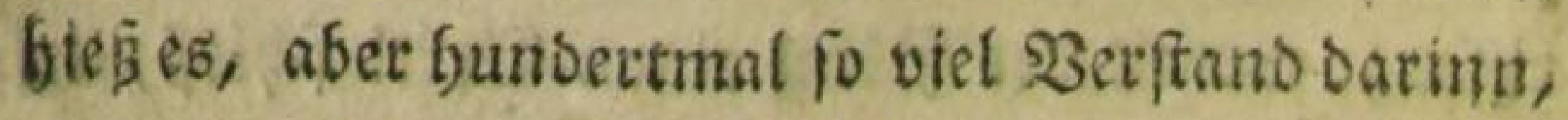




\section{(65)}

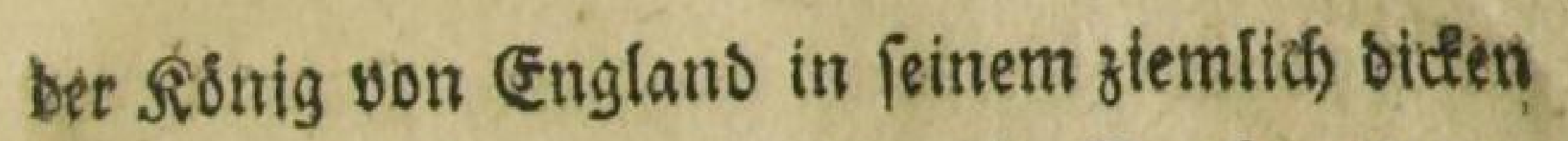

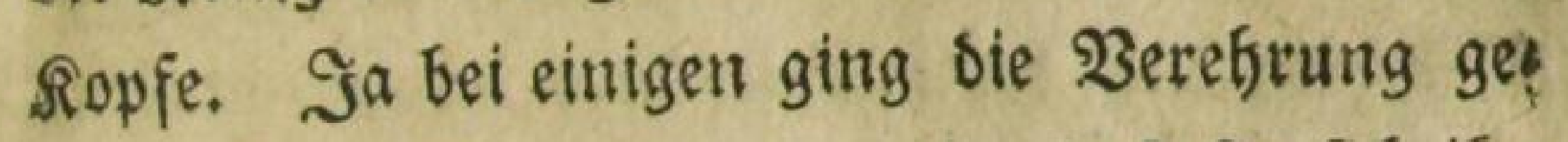
gen unfern Monard)en fo meit, Das fie fich ign im Ernff zum Rsnige wínfidten. Nur rounder: ten fie fid úber bie grope \$senge Soldaten, bie er Gált, und daß̧ allein in פ̧erlin eine fo große Aanzafl davon einquartirt find, Da fich in Eondon, ober ber eigentliden Sity, nidgt einmal ein Trupp Eoldaten von Des Rónigs Ssarde Darf blicten laiten.

Bor einigen Zagen fabe iff aud ben इug Des goromayors in Rondon, in einem ungebeus or groken, vergolbeten SBagen geféten, wels

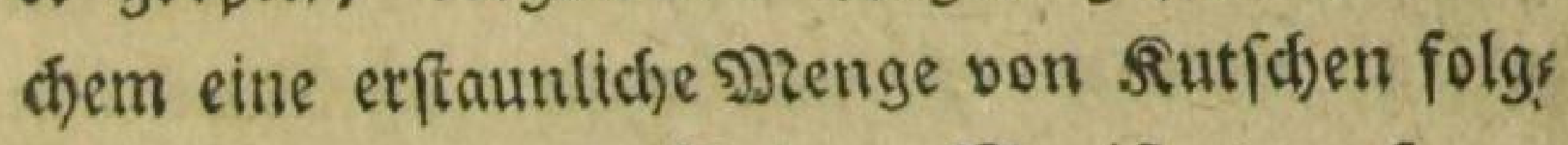
ten, in Denen bie ứrigen Wagifftratsperfonenober fogenannten alloermánner von Eonoon fir Dod) genug fúr biefesmal!

\section{Qonbort, beet 17tent Эunt.}

Tid) Gabe nuti Lonbon alle Tage nad) ver:

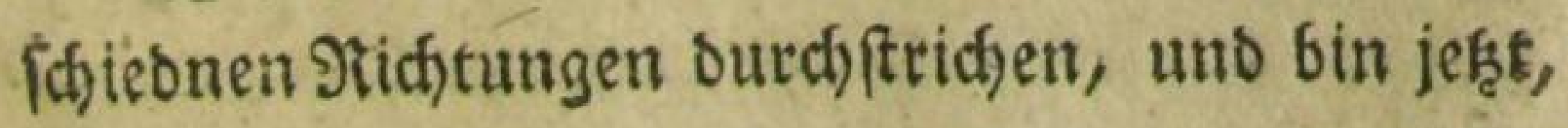
nad) meinem Sirundtí zu uttbeilen, mit biejên ssanberungen beinafe fertig. Dann folls rocis (5. 


\section{(66)}

ter ins Rand gebn, und bas, wills Sistt! in eiri Pant Tagen, Denn (d)on lange bin id) Des im= merwákbrenden Roblendampfes múde, und fefbr begierig, einmal eine reinere \&uft wieder ein: fuatlymen.

Es ift woht watht, dafi gondon, im Sianzen senommen, nidht fo fdosn wie SBertin gebaut ifi, aber es bat melgrete und fojonere große Plä:ae, sie fogenamten Gquares, beren eine ziemliche Inzabl fino, uno die benn bod) unfern (Siens 'armes: MarEt, Defnofidjen, uno Sallfelms:

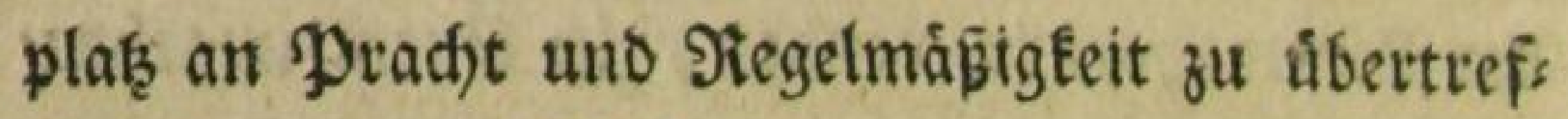
fen fafetnen. Diefe Squares oder viereckigten

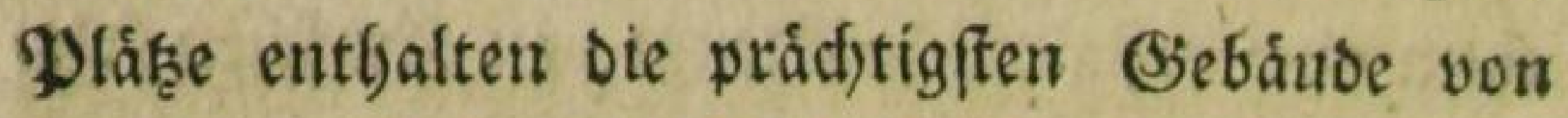
Zonoon, uns tnmerbalb derfelben ift ein runber grủner গiafenplaķ mit einem Sjelánder einge: faßst, in beffen Mittelpuntt gemeiniglid) eine Statue errid)tet ift, movon die, weldife iff ges fefen babe, zu Pferde uno vergoldet waren. In (S) fogat ein fletnes 2 Bálodjen in Der Rưnoung an: gelegt. (Finer ber längften aber auch anyeneb)ms ften wsege, oie idf gemad)t habe, ift von Pabs sington nach) Şsliugton, no man jur linter 


\section{$(67)$}

Eeite eine fobone 2fusfidjt auf oie nabegelegnent Scligel, und vorzuglid nad Dem Dorfe Scampa fread, Das an einem biefer Scugel erbauet iff; und fut vechtell Geite die Straßen Der Stadt

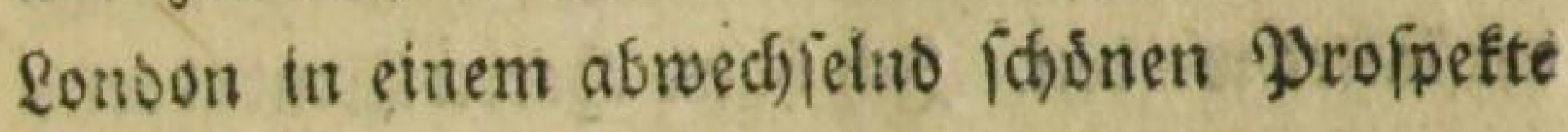
hat. Freilidf iff es gefäforlich, Gier, bejonders tit ben ग):ittags: uno 2fbendfunden allein ju gefjen: Denn nods vergangene 58 dotse if auf eben biefem 2Bege ein \$ienifh beraubt uno eridflagen rot: Den. Doch mun vott etwas andern!

\section{Das brittifuce פureum.}

Thh habe auch Szetrn Paftor 230 oide fett nent letnen, Det mit bem brittifchen פ) Berbitioung frebt, tho mir (Sjefegent)eit vers fithaft hat, baffelbe, noch am Tage vorther, ehe es gefoloffen wurbe, fa fegen; Da man fich fonft viergefon zage vorber meloen mus, ebe matl zugelaffen roiro. (sigentlich Gabe ich abet fretitc) nut bie Gimmer uno (Slasichtànfe, uno

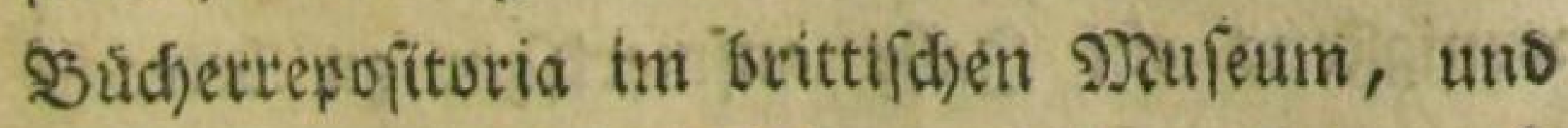

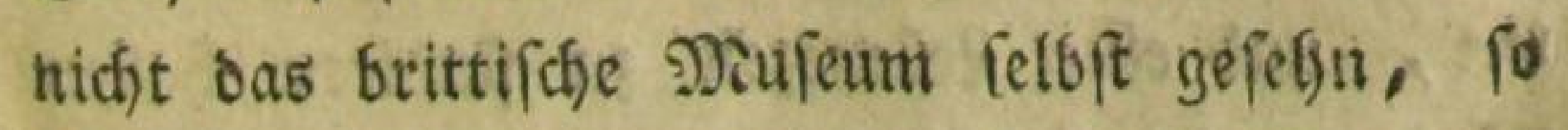
(d)nell wurben mit burch bie Stmmet ges (5) i 


\section{(i)}

fübrt. Die Gefelfficlafit beftand aus alferiet, audf' ganz niebrigen \$erfonen, beiberlei (Bess (d)lecf)ts: Denn weil es ein (Eigentlfum der פa tion iff, fo mus cinem jebreeden der Rutritt Dazu verffattet werden. Tab hatte Şerrn 23 endeborns Sbeitráge bei mir, woourch id wenigftens auf

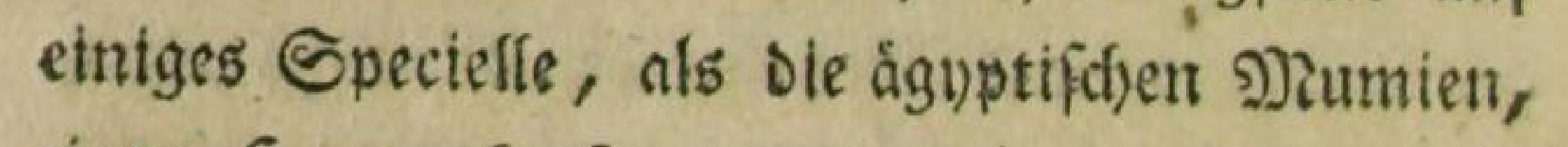
einet Şomersfopf, und einige andre Dinge aufs merffam gemad)t wurbe. Cobalo das die úbrige Befeelfichaft von Gnglåndern bemerfte, verfams melten (ie fich um midf, und id) unterrichtete fie

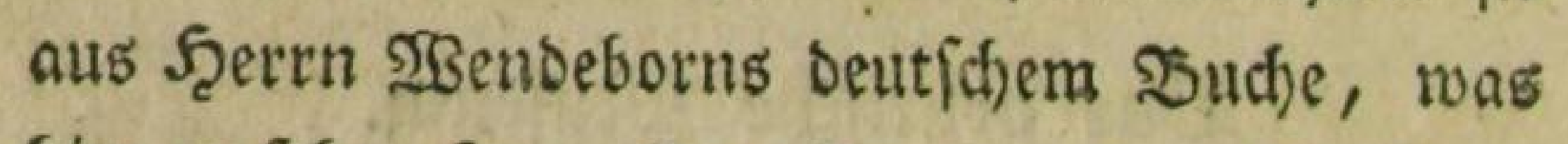
Gier zu feben fey. Der Fruffee oder Zlufferfer,

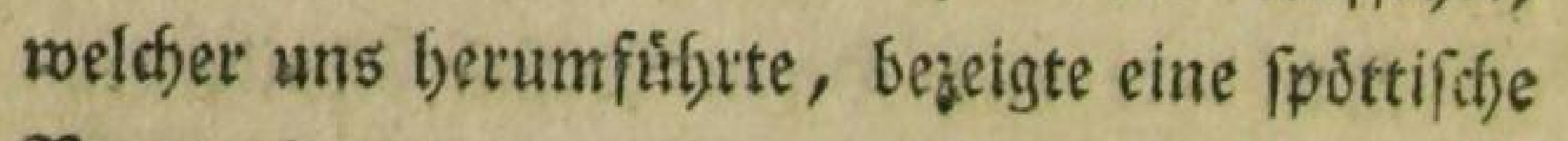
Betrounderung, oa er erfubr, Daß̧ idf eine

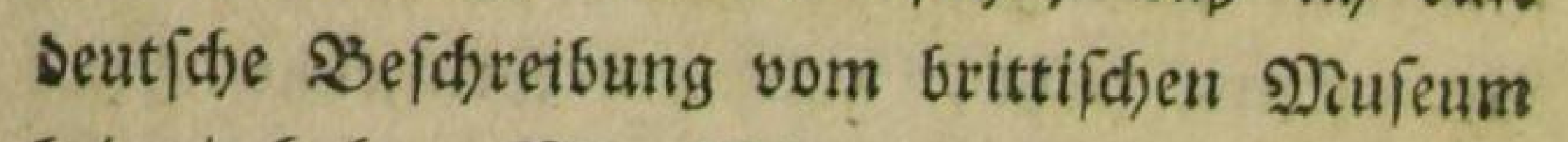
bet mir babe. Man iff in einer 2att von Betáu bung, wenn man binnen einer Stunde Durcly alle biefe simmer geft, und bie ungebeureas

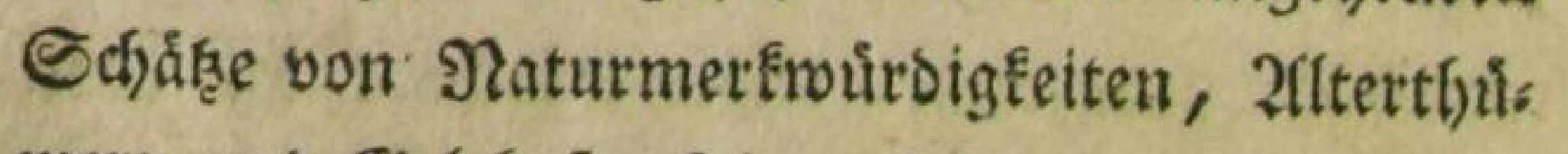
mern und Gelebrfamfeit anftaunt, woran mas swenigftens ein $\mathfrak{J a f b}$ aufmerffam ju betradjs ten, und eine Rebenszeit a frubiten baberz. múrbe. Theilmeife folf bie Gammlung yous 


\section{(69)}

son anbern weit úbertroffen werben, abet in Brangen genommen, uno fan Boffitán: Digfeit blefer Eeite gletd) fommen. Durchreis renbe Theologen pflegen fidh gern ben 2lepanbri: nifden Sioder zeigen zu lafien, un fidf mit its: ren 2fugen zu ưber jengen, ob bie Stelle: Dret find bie sa zeugen, 4. F. wo. Darinu feeft, obet nicift.

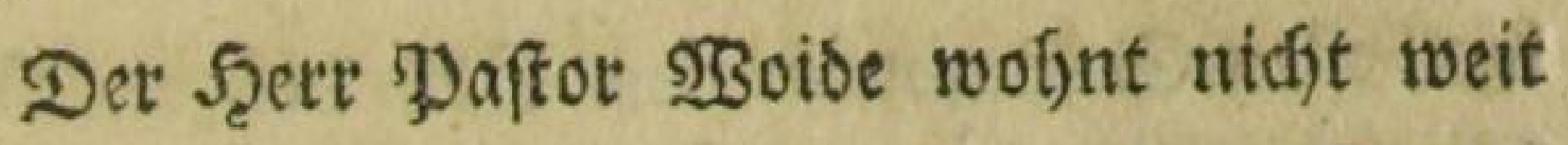
yon Wabsington, gant am Ende ber Stabt, in einet feffe angenelymen (Siegeno, wo man idjoit eine weit freiere und reinere \&uft einatbimet, als

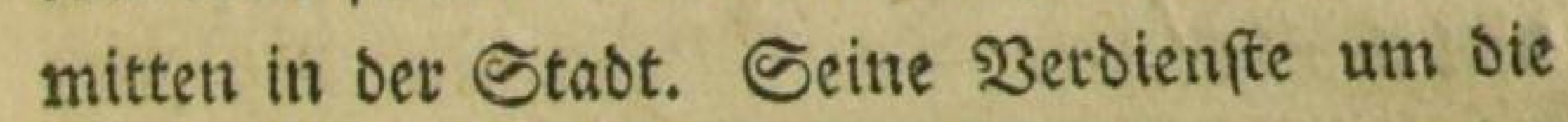
orientaliiche Ritteratur find befannt. Ert iff abet aud) ein fegr umgainglider uno otenffesertiget Nann.

\section{Das Ţ̧eater ju Scaı)market.}

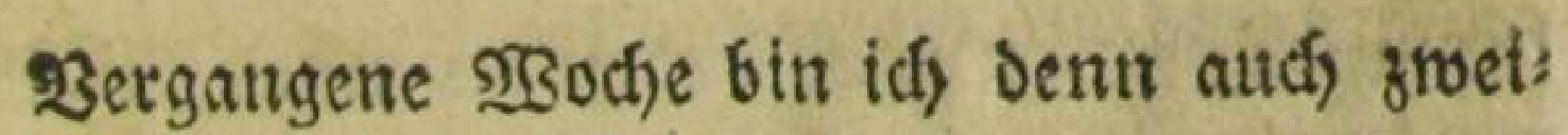
mal in ber Englitchen Somssie gervefen. Das exftemal wurbe der शabob aufgefúlyt, wovon oer vetftorbene Foot $\mathfrak{B e r f a f f e r}$ iff, und zuna Srachipiet rourbe ein fomifhes Singipiel The

E? 


\section{(70)}

Agreeable Surprife, die angenetime Heberras folfung gegeben; bas antremal aber ber (5ng, lifhe Saufmann, weldhes Stúcf ins Deutiche ůberfeß̧t, uno unter dem Titel: Die Sdjottlán: betinn ober Das Kaffeeloms, befannt ift.

Des Theater zu Roventgarden uno Douty: lane babe inh nidjt gefeben, weil auf denfeiben im Eormmer nicfit gefpielt wutbe, 2fuch reifen bie beften Sdjaufpieler vom Mian bis zum Deto: bet aufs $\mathfrak{Q} a n b$, uno fpielen nur im 2 Binter. Die Sthaufpieler, welde id) gejefyen Gabe, waten, einige roenige ausgenommen, eben nidje fon: berlich,

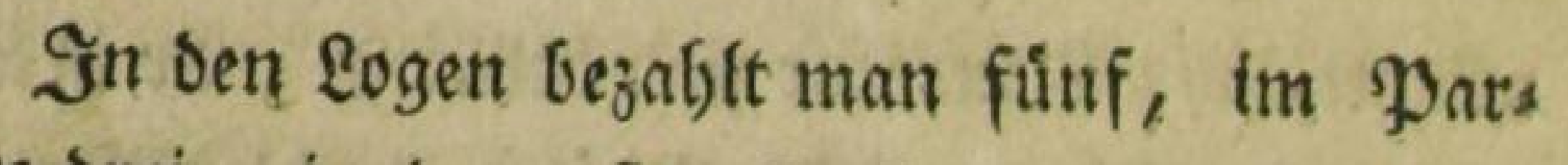
terte brei, in ber erften Galletie zmei, uno in Der leşten ober Doergallerie einen Schifling. uno gerabe biefe obergallerie macht fúr ifjeen ei: nen Sdfilfing bas meifte £erm. Joh rot im Parterre, welches bis an Das Drefjefter fofråg finuntergeft, unb von oben bis unten mit \$ån: fen verfeben ift. Lino alle 2fugenblicfe fam eine faule 2rpferfine bei mi! ober meinem शad), bat vorbei, mir auds woht auf oen Şut geflo;

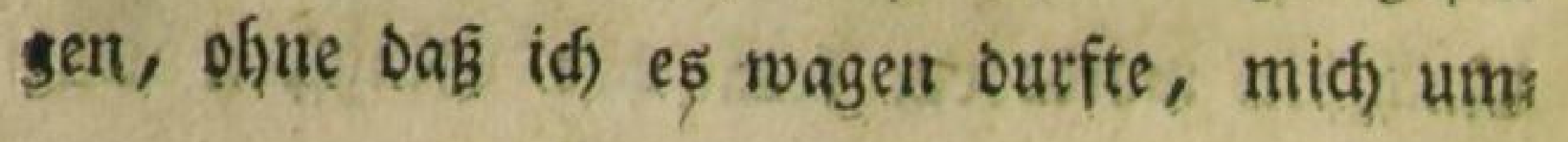




\section{( $7 x)$}

zufégen, wentt mir nidft auch eine ins Eefidht geflogen Eommen follte.

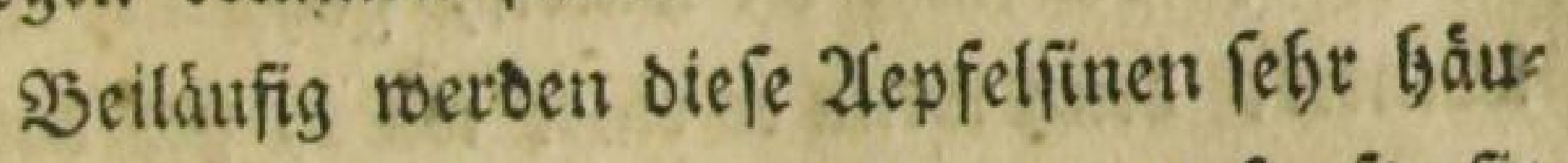
fig in Lonioon gegeten, uns man verfauft fie um einen ziemlich) woblfeilen झुeís, zumeilen eine ober gar zwety fur einen Szalfpenny, odet eitien Dreier nad) unierm (selbe. In ber Sio: móbie fingegen foderte man mir fúr eine einen Eirpence $a b$.

2luser Diejem æ3erfen von Der SSallerie bat Das Shreien und Stampfen mit Den Stoffen fein Ende bis oer ßothang aufgejogen ift. Jith

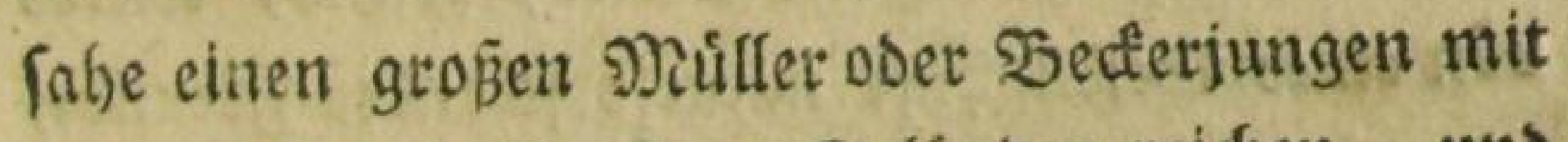
feinem Stocke úfer das Sielánber reidjen, uno immer auswendig mit allet Siervalt baran folas gen, fo daji ifn jedermann felgen founte, ofjue baßs er fich geicheuet oder gefádamt baatte. Sumbeis len horte id) auch), oaß̧ Leute aus Der untern (jals lerie mit ber obent zanften.

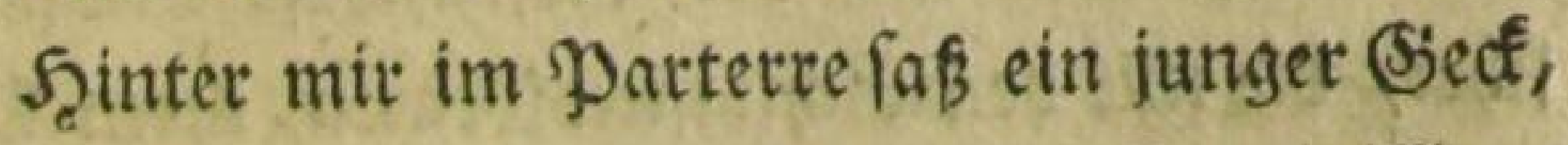
Der um feine präd)tigen Steinjofnaflen briflitels

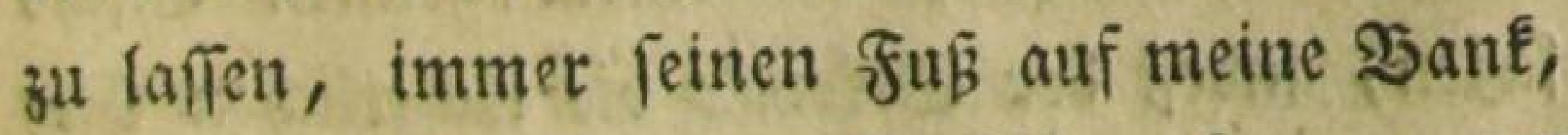
uns aud wobl auf meinen Siodidjoos ferste, wenn

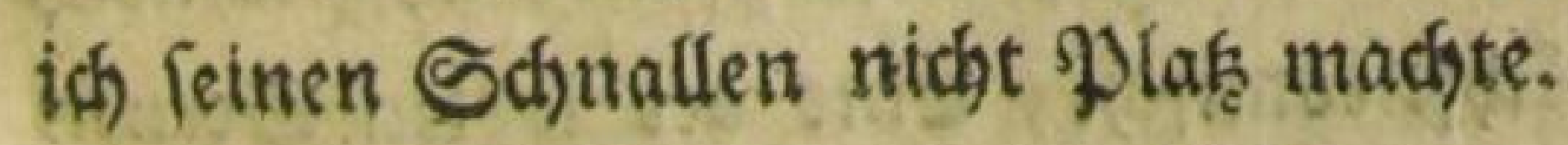

E 4 


\section{( $7:)$}

In ben Logen faß̧en die Sebienten ber Seerr fichaften, bie nidat oa waren, ganz in einem Wintel; Denn wenn es einet ragt, fid) Datinn blicfen zu laffen oder binaus zu feghen, foll $\mathrm{et}$ gleid) mit ciner ganzen \&aoung Zipfelfimenicjalen von ber Siallerie begrúft toetoen.

In Dem Nabob von foot find lofal unb per:

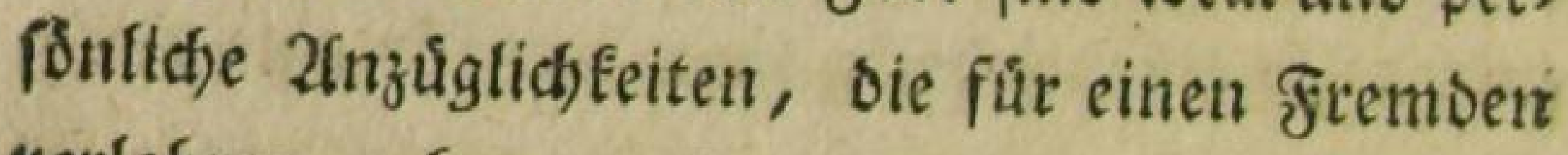
vetlobren gefen. Der Nabob, welchen eit Dit. Walmer mit alle Dem vornelymfennwollen: ben affefirter Zitr eines plóg̨lich) zu ungeheuretr Seidjthyumern gelangten Giecter, ipieite, wutbe von einer (belelfid)aft naturforidfender Freunde, von- Quáfern, uno wer weis von wem fonft, jum Mitgliede gefucht uno aufgenommen, uns eine hodfft einfáttige Siede, bie er fpottweife it bem naturiorichenden אlubb Gielt, mit Benuns Derung angehdrt. Die beiben Scenen mit ben Quáern, uno mit bet (Siefellfóaft Naturfors foher, bie mit ben widjtigften Mkinen, ibren Prás fes in oer Mitten, an einem grúnen Tifche

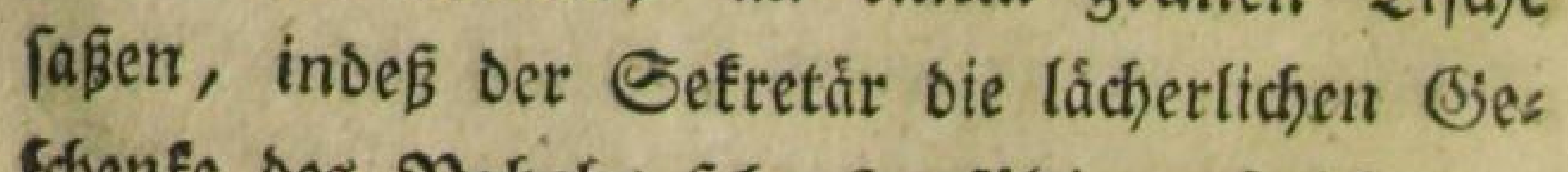
fajente bes গabobs febr forgfältig aufzeidhnete, waren bodjft fomifof. Eine der leseten Sçenen 
$=\quad(73)$

thafm fich troch am beften aus, noo bes Nabobs alter Freuno und Spielfamerad ifn befuctit, bet

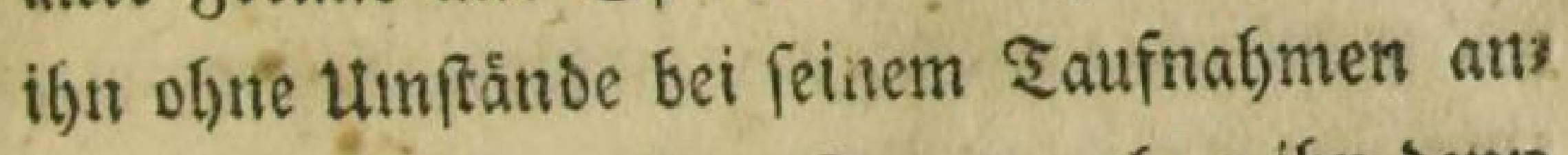
rebet, aber auf alle feine Fragen: of ev ifn Denn nidjt melyr fenne, fid) nidjt nod) jenes Eppiels; jener Sablagerei, die fie als ßinder gefabt, $\mathfrak{u}$. ケ. w. zu erinnern roiffe, mit einem falten uno

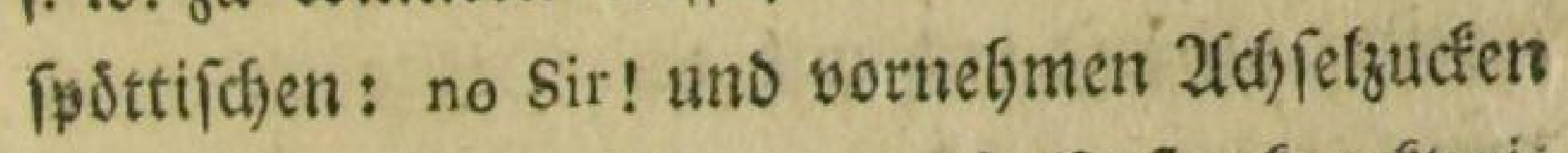

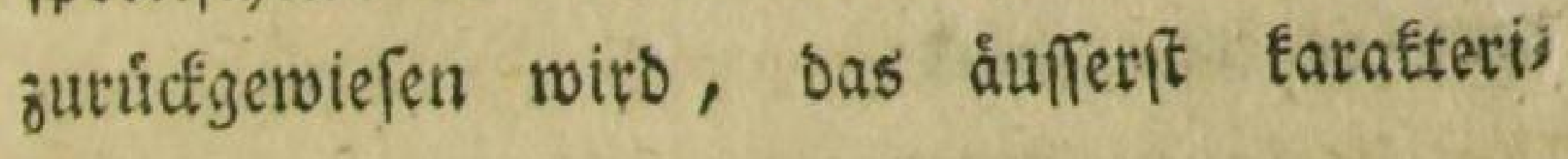
(tiiá) wat.

Das Pactipiel the agreeable Surprife, wat

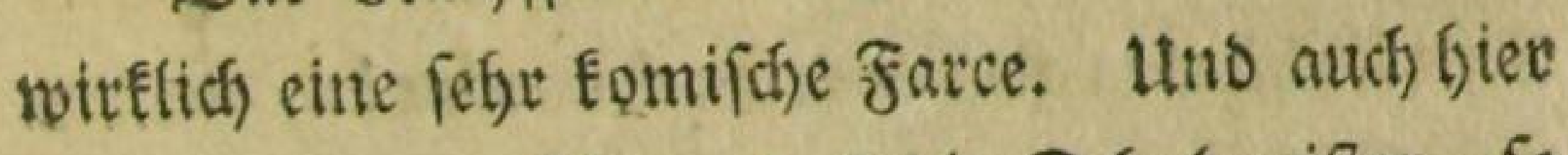
habe id bemu gefeften, Dás bie Edfulmeifter, to wie allentbalben, auf Dem Theater láchertich ges

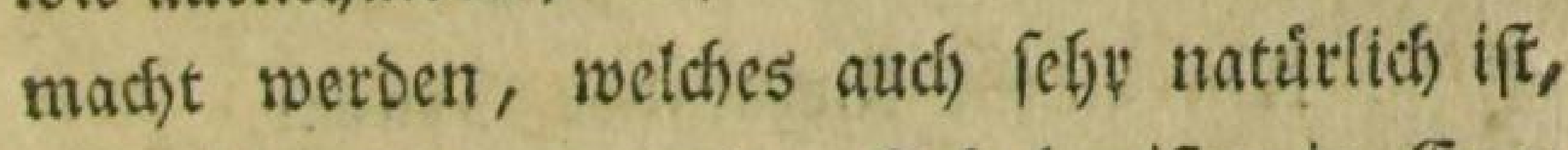
Denn bie Yeoanterie ber Seffulmeifer in Engs lant gefte fo weit, wie irgentwo. Eben ber, welder in bem vorigen Etincte, mit felyr vief Natur uno eigenthúmlidser Raume ben elyemalis gen Sofulfameraden Des פRabob fpielte, madjte

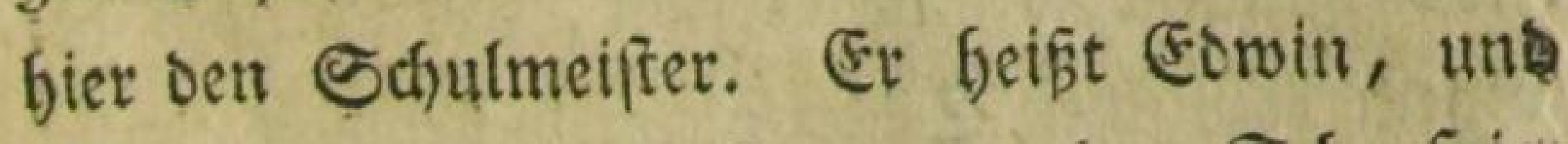

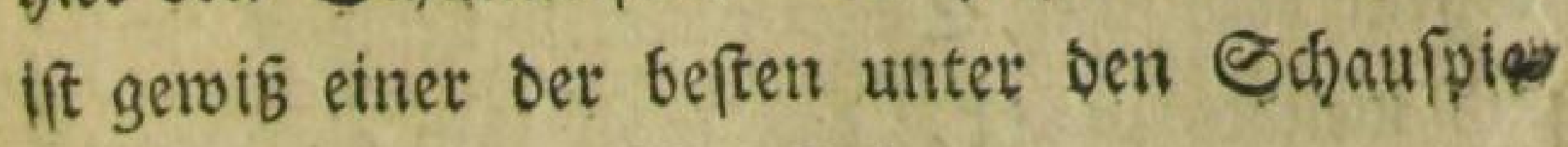
leen oir id hier gefelenen habe.

\section{है}




\section{( 74 )}

Diefer Schulmeifter tfit denn in eín gewoiffes Soutermábdjen, SRabinens Sowflip, vertiebt, Der er auf eine runderlidje mutfologifojgramma:

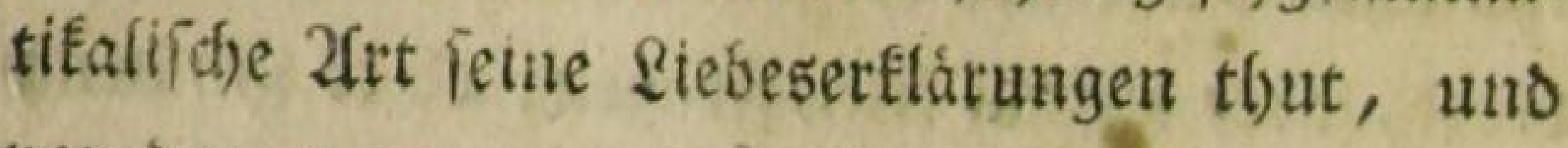
won Dei er unter andern einmal fin volfer Segei: fterung folgende afrie fingt, nobei er faft vor Shistlicyeeit jerfdymilzt, indem er von ber Sonju: gation anfängt uno mit Der Deflination uno bem Genere aufgort:

Amo, amas

I love a Laff,

She is fo fweet and tender!

It is fweet Cowslips grace

In the nominative Cafe

And in the foeminine Gender.

Das in the nominative Cafe, uno in the foeminine Gender fingt er insbefonore mit einer

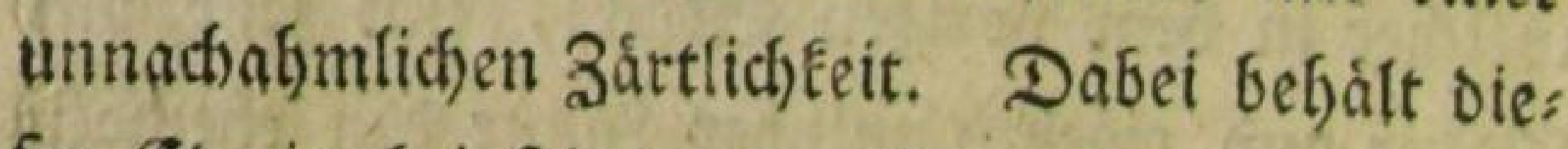
fer corwin bei feinen fomijhen Sioffen inmer etroas gutmuttsiges im (sefict)t, oas ich noch bei feinem fomifchen Sdhaufpieler fo bemertt babe, nuto welches madjt, Daß̄ man ifm ofngeachtet aller feiner \&adjerlichfeiten gut bleibt, uno fidh füt 


\section{( 75$)$}

Den Charafter, Den er vorffellt, Doppeit interef?

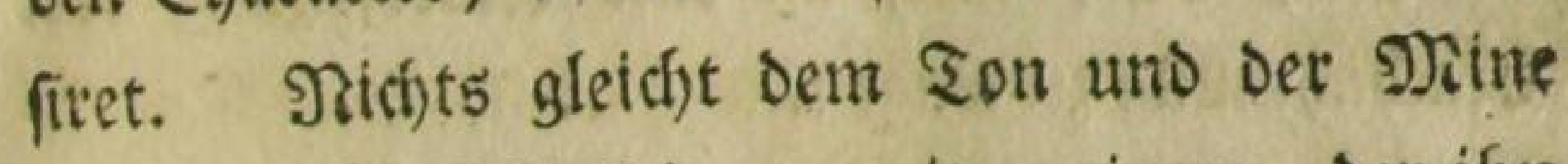

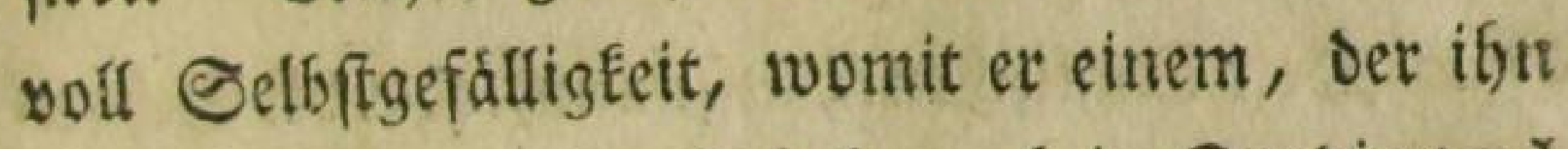
fragte, of er ein Edjolar, (ein Studierter) wáre, fut Zfntwort gab: Why, I was a Mafter

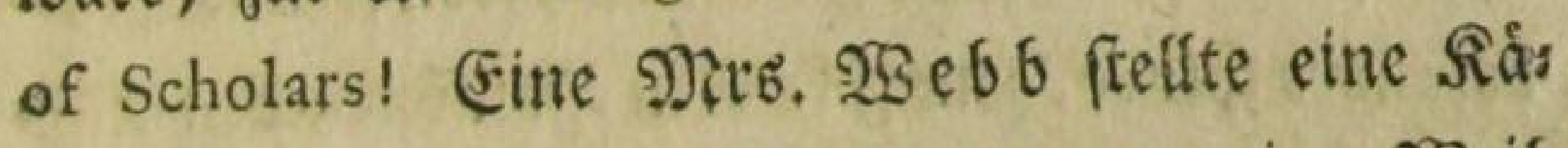

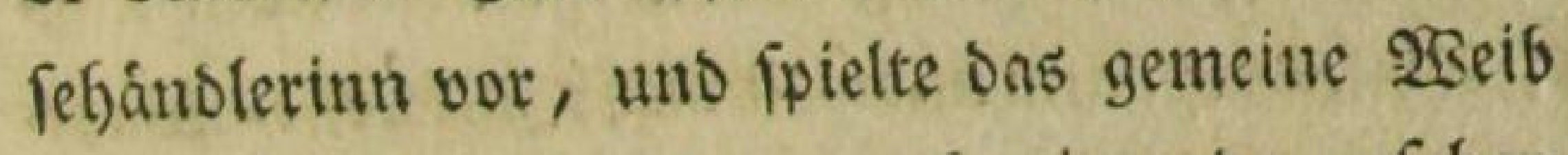
To naturllich, wie id) es nody nirgenos gefeben

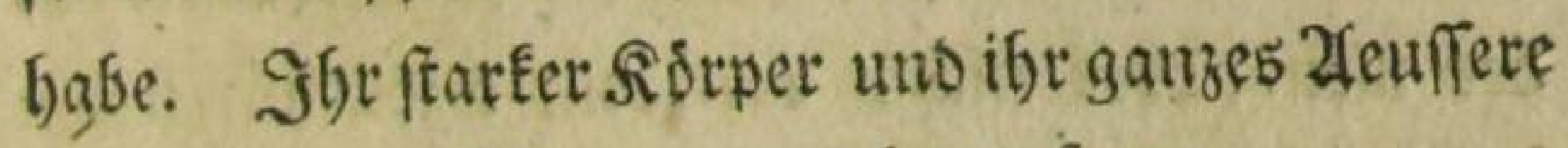
fdjien aber auch bazu gemadgt zu fenn.

Der arme Eswin mußte als ed)ulmeifer fich faft beiber fingen, indem et feine Deflinas tions: uno sonjugations: Zfrien oft groei bis oreis mal wieberloten muffte, wemn es der Sbetgalles rie beliebte encore! zu rufen, und bann muß̧te

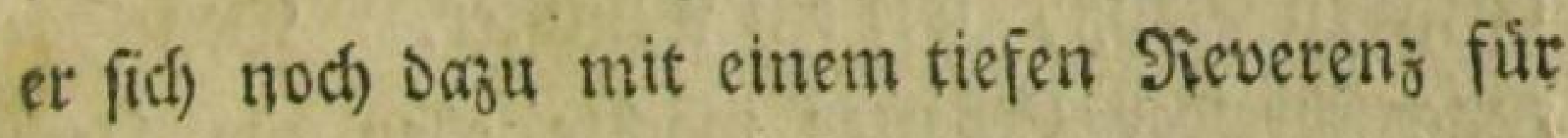
Den Goben Beifall Gedanten.

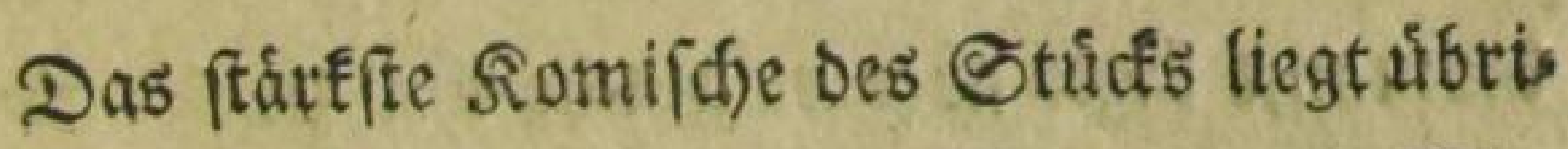

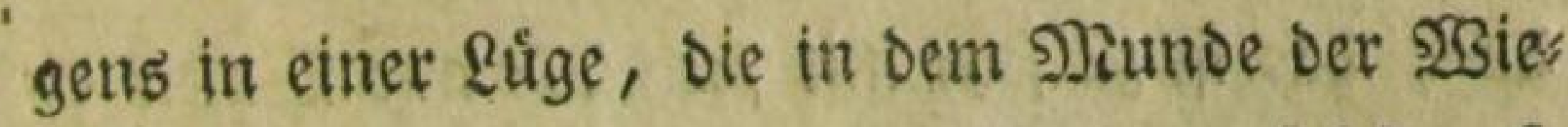
Derergáblenden immer ungefburer anmeichfis, io

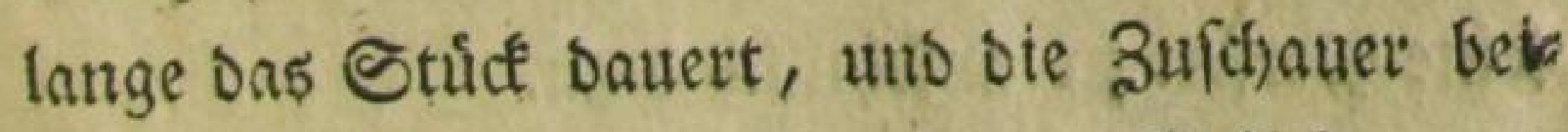
nabe in einem ununterbrod)enen (Seláshter er:

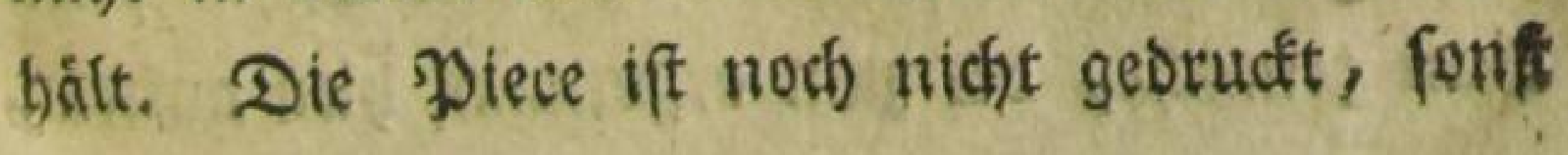




\section{$6.76 \%$}

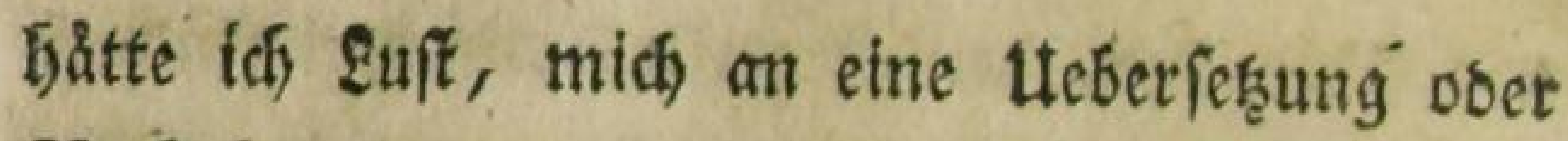
Nacjafjmung zu wagen.

Den Englifhen Raufmann, ober bie Echott:

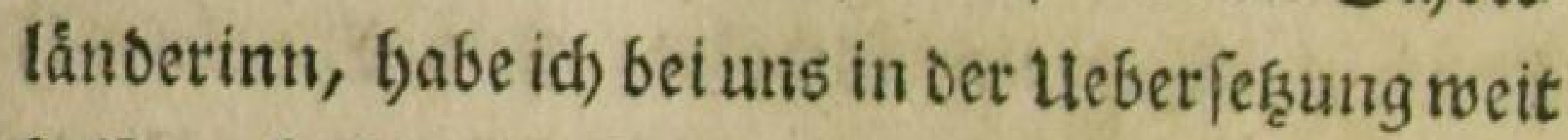
- beffer, als bier im Origtnal auffübren fehen. J̄ns:

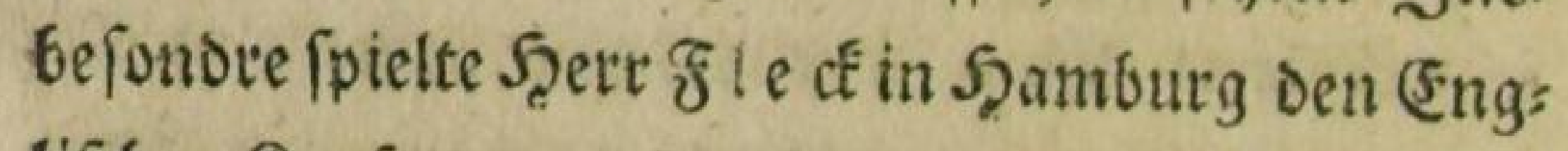
lifchen \&aufmann mit weit melyr Jntereffe, SGalft:

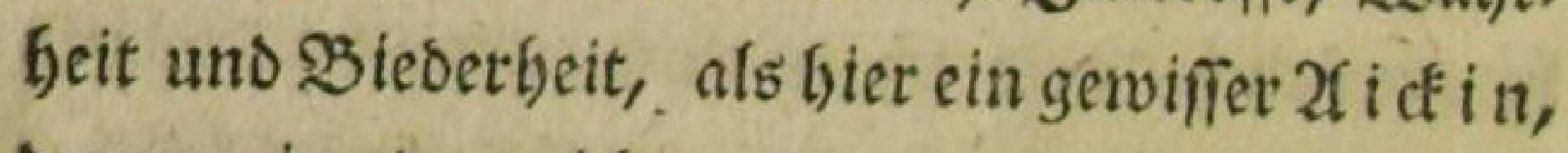
Der wenig ober nidhts von bem eigentfúmlitchett originellen 2 Seefen Des Sreeports aubbrúctete, fon: Dern itgn beinabe mit feiner abgemepurn Eprache und Gange in einen galanten Şerts verwandelt batte.

Der alte treule Şesiente, welder fút feinen Seerth das Reben lafien will, batte einen gravis

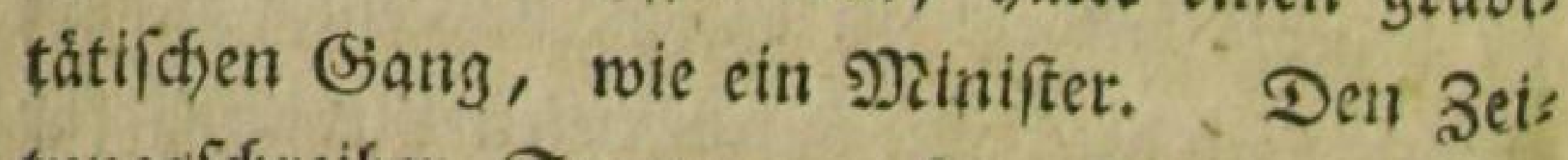
tungsfdreiber Spatter machte eben Der Şert \$almer, weldjer Den গaabob gefpielt hatte; je: bermann Yagte aber er mache ifon zu Gentlemanlike, Das iff zu Yebr mit Dem afir und 2 seefen el: nes Gentleman oder feinen Naannes: audf wat feine Đerfon zu anfergnlich daģu.

Die 2 malia murbe von einer Scfaulpieles vinn gemadit, oie zum erffetmal, bier auferat, 


\section{( 77$)$}

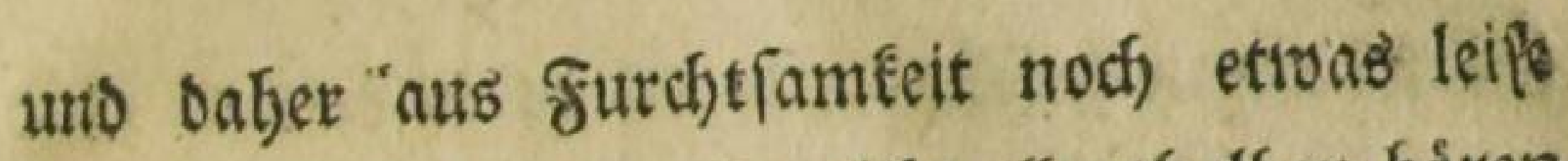
fprach, fo Daß̧ man fie nicht allenthalben horren fonnte: fpeak louder, o fpeak louder! fing ein Serl auf Der Dbergallerie an, und fie bequemte fich Den 2uigenblict lauter zu (prechen.

Neben mir im \$arterve, war man oft mis feinem ¿eifall fef)r veriahmenderifa), bei ber fleins ften oft unbedeutendften. Siebe, bié mit einigen 2lffeft gejagt waro, riefen immer einige Stims - men, very well! als wenn fie, roet weis was

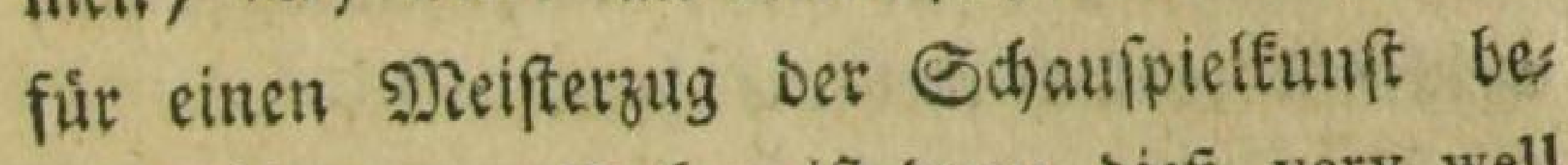
mertt bătten. Daher if benn dię́ very well aud) von renigem গadjoruct.

The agreeable Surprife murbe wiebertyofit, uno ich fate es zum zroitenmale mit $23 e r g n i g e n$. (5. if aud) ein \&ieblingsftud? geworoen, und wird immer mit ben 3 ufa angefundigt. Das Theater fdjien mir etroas grófer wie das Şamburger zu fenn, uno das Şaus war beidemal fefre voll, So viel von Der Englifenen Romodie!

Englifache Sitten uno Erjię̧ung.

Tan noch etwas die \$abagogif betreffent. 5d) Labe bie Einvichtung einer biefigen logenany 


\section{( $78:)^{\prime}$}

ten 2ffabemie gejefien, beren es in sonson eine ungebeure Mienge giebt, oie aber im Grunse meis ter nidjts, als fleine von Drivatleuten extidftete \$enfisnsanfalten furt Sitider und junge Qcute fino.

Der eine von ben beiben Englondern, die meitre Rietiegefáfrten waretl, machte mids dem Şertu Sireen befannt, Der in ber Siegeno von Pabsington moljnet, unb ein (5rziebungsimftitut für zrodif junge feute bat, beren 2 nzabler, fo twie bei uns Şert Rampe, nicht libetiffreitet, welches dort aud) meforere thutn.

จ

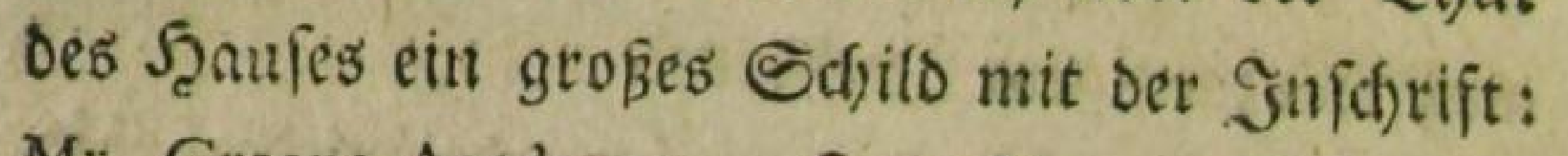
Mr. Greens Aeademy. Scert (Sireetr nalgm mid) als einen Freunden fecte freundidfaftlicf auf, uns jeigte mir feine gefrefube, welche volfig fo wie Die Rlafien in unfern sffentlidjen Scfulen, mif Eanfen uns einem Satbeder verfehen wat.

Der Unterlegter bes Sertn Green war cin jun: Jet Sseifflither der die Snaben vom Satlyeder in bet ateinifichen uno griechifchen Sprache unterrich; tete. Sin fotcher Unterlebrer beist ein Ufher, nno ift gemeiniglich ein geplagtes (Siefdfspf, gerade fo, wif er einmal im fanoprebiger son 25 


\section{(79)}

field beforteben wirto. Sndem wit in bie Silafte tratèn, Itȩ́ er gerade die Rinaben ganz nat) bem alten Edjlendorian lateini[d Defliniten, uno es flingt eittem fefor fonderbar, wetun man z. $\mathfrak{b}$. anftatt 'viri, nad) ber Englifden 2Auspprache, weirei, bes MRannes, weito, dem Mianne, a. f. w. Defliutren host,. (Eben fo ging es nad): ber aud) mit Dem (Sried if (dsen.

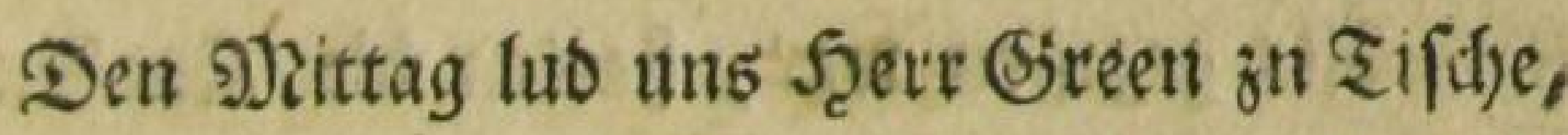
wo id) feime frau, ein fehr artiges junges 233 cib; fennen lernte, bie mit ben Sindern auf eine foldhe 2frt umging, Dá fie unter ben (Erzilefeern an biefem fleinen Shffitut vielleicht bas meifte leifrete. Die Rinber befanen blos $28 a f(e r$ ju

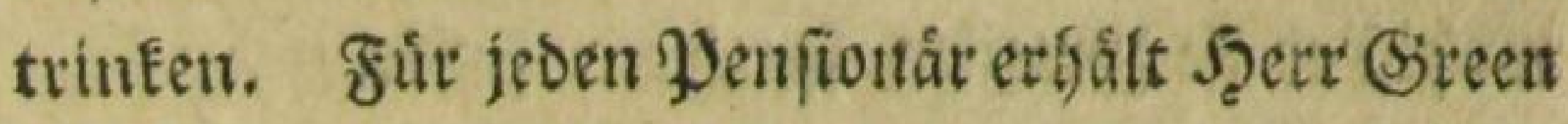

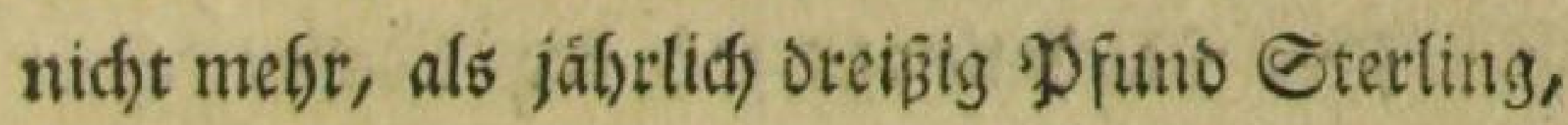
beflagte fich aber audh Darúber, baßs diejes zu wenig fen: vierzig bis funfizig Đound foll beis

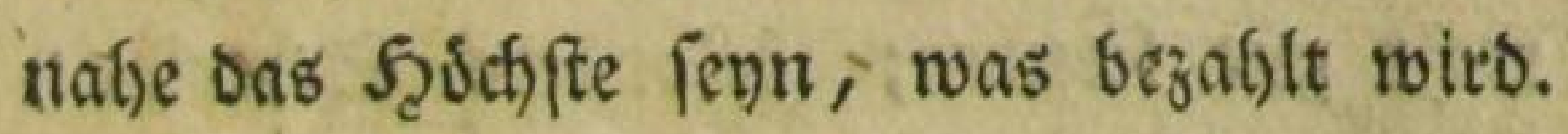

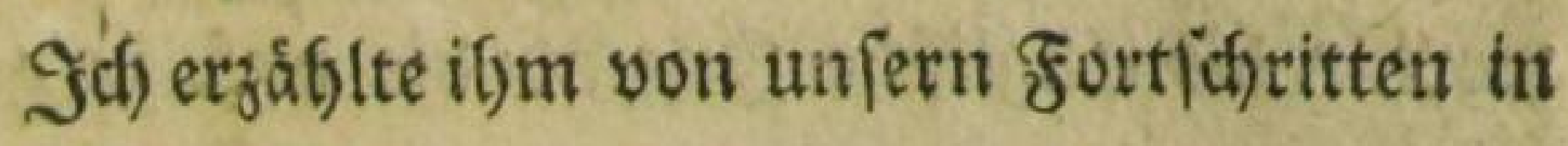
Det (Ergief)ungsfunft, und iprad) mit ifm von bet

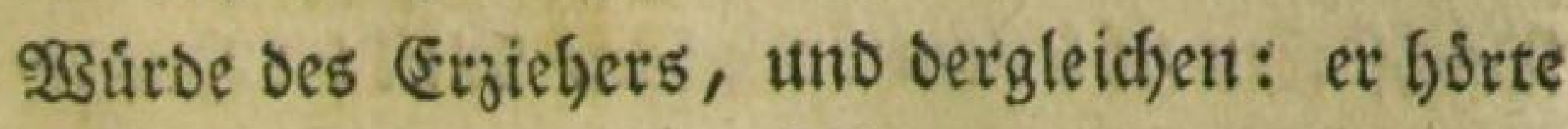
féfr aufmertfam zu, fojien aber felbft wents an bergleidjen gebadft iu Gaben. 


\section{(so)}

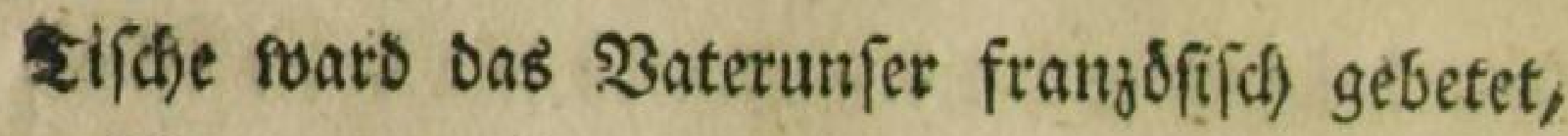
weldhes an mebreen Drten geichiefjet, Damit man, wie cs fheint, audh biefe sielegenteit zu einer Ltebung in bet franjofififjen Opracise musen, und allo einen boppelten Endjiweck erreidfen imsge. Şd Fagte ifm nadjher meine Dieinung úber diefe 2frt zu beten, weldje er mir boch nifft abel zu nebmen ichien.

Zlls gegeffen war, batten die sinaben auf einem fefir engen Şofe, Freltheit zu fuielen, weld)es benn in ben meiferr 2ffavemien in ber Stabt Qondon bas non plus ultra ifres Epiefraums in Den Erthoblungsfunden ift. Shert Gireen aber f)at aud einen Giarten am (Enbe Der Stabt, wobjin er fie zuweilen fpazieren fübrt.

Des গactmittags gab Der Maffer Şert Qureen Fetber, im Schreiben, Siectgnen uno Frangsfiichen untertidft, welches bie Rinber bei thm red)t gut letnten; befonders Sdyreiben, worinn die Englijaje Sugend die unîrige gewißß weit übertrift, viefleidjt, weil fie nur cinerlet

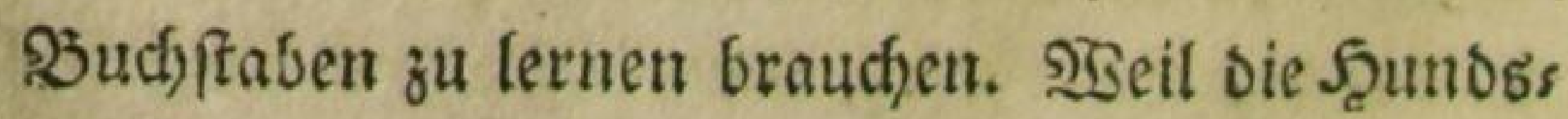
tagsferien bald angeben follten, wo bie אinder:

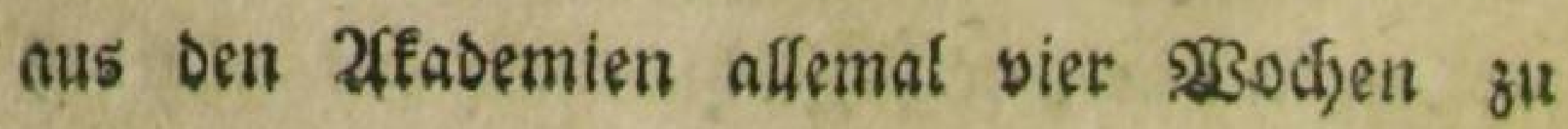

Sุaule 


\section{( 81$)$}

Şaufe gebert, fo mufte jeoer mit ber áufferffent Eorgfalt cime Boridgrift nadjicheeiben, um diele feinen Eltern zu zeigen, weil Darauf am meiften geféfen wiro. Allle Regeln des Esyntar wusten die Simben ausroentig.

Sonft teisen alfe biefe 2ffademien eigentlid) nur Baordingfchools, (Schulen, worinn manl zus gleich (peifet) einige baben aud biefen গaagmen noch beibefralten, weldje oft mefre als die foges

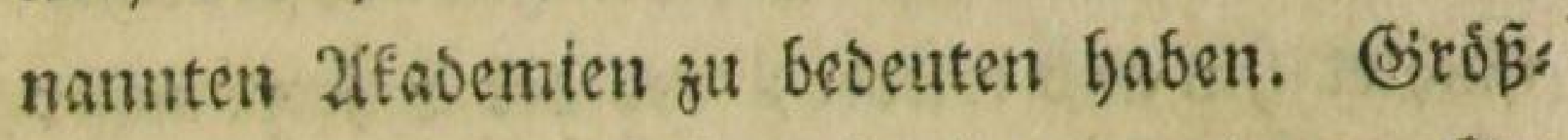
tentbeils find (s)eifftidje mit einem geringen bes balt bie Unternef)mer foldfer (Erziet)ungsinfitus te, fowoby in ber Stadt als auf bem Eanbe,

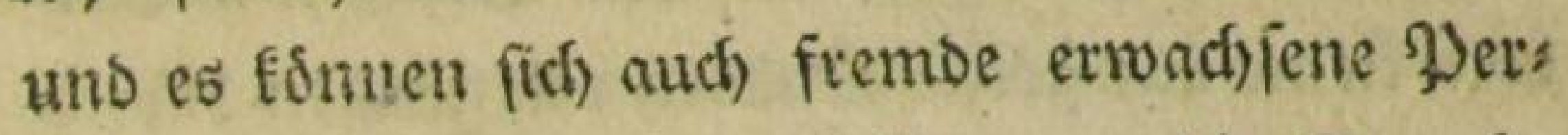
fonen bariun aufnelgmen laffen, um ble Eprache zu lernen. Scerr (SBreen nafm fưl Trobonung,

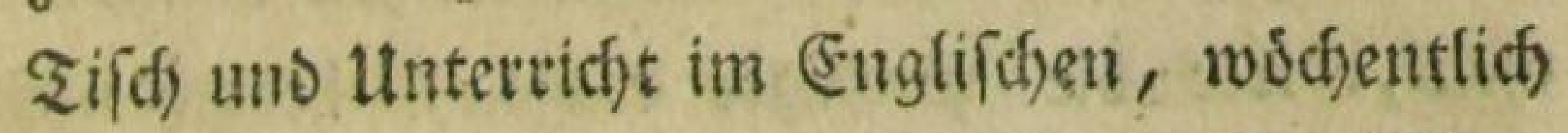

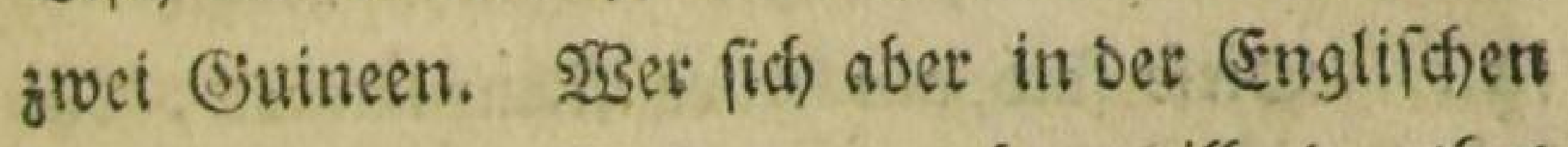
Sprache gant volfeommen machen will, ber thut am beften, wetn er weit ins gand gefft umb

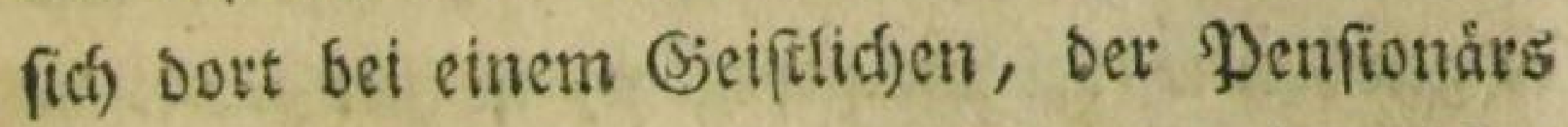
báft, in bie Roft verbingt, wo er weiter nichter als (Englifich reben fostet, und es yon jung und als bei jeber Seelegenteeit lemen fann. 


\section{( $(82)$}

(E) giebt in Englano, aufter ben beiben Hniverfitáten, mur wenige große Edsulen uno (S) mmafien. So fino in Ronoon bloz die St.

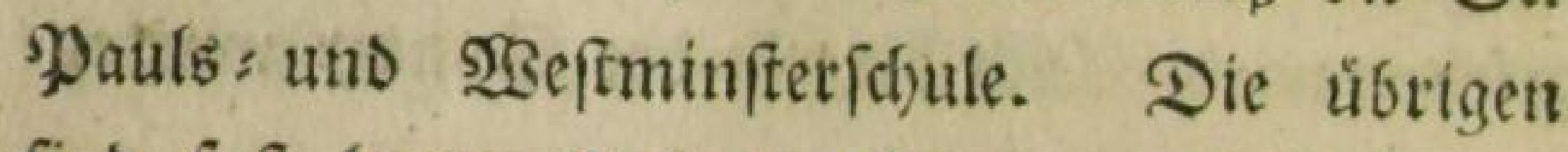
fino faft lauter Privatanftalten, worinn eine ffrt von Familienergiebung beirfdst, Die freilich wobls bie naturticffife ift, went fie nur fo wáte roie fie feun follte. Einige fogenannte Grammarfchools ober lateinifhe Sdjulen giebt es demoln: geachtet fin uns mieder, wo ber Iefoter auffer dem Schulgelde nody eine fixe כiefoloung erbaalt.

Man fieft immer auf Den Gtraß̧en in \&ons Don Eleine uno grö́ße Snaben mit langen Glauen

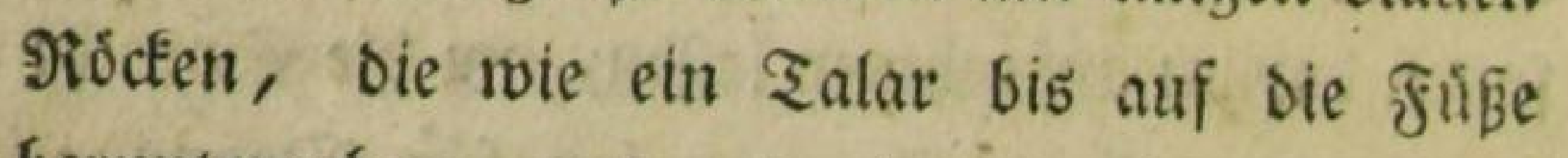
beruntergeben, und mit einem weißen Sirágel: chen, wie die \$rediger tragen, berumlau, fen. Diefe fino aus einer 2ltmennnftalt, die

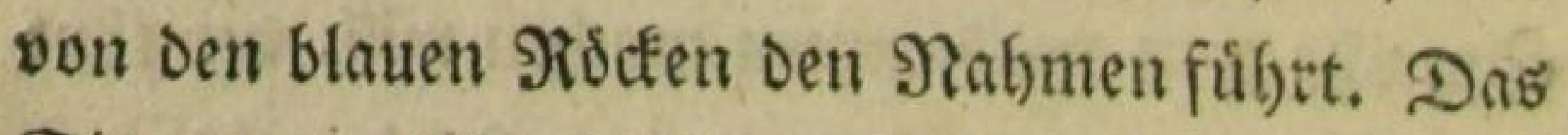
Eingen der (5horichǔler auf Den Straßien, roie

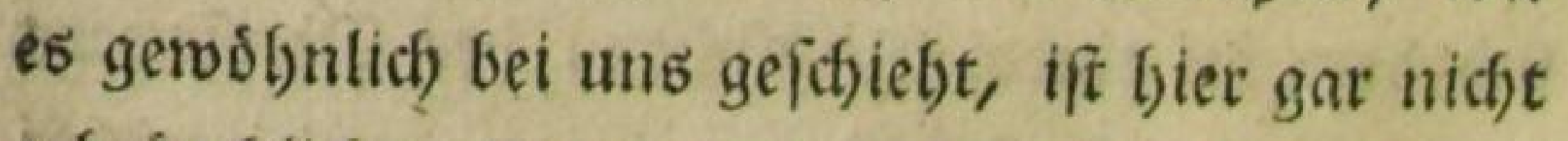
gebraiuchlich). (5E ift aud) megen bes beftándigen-

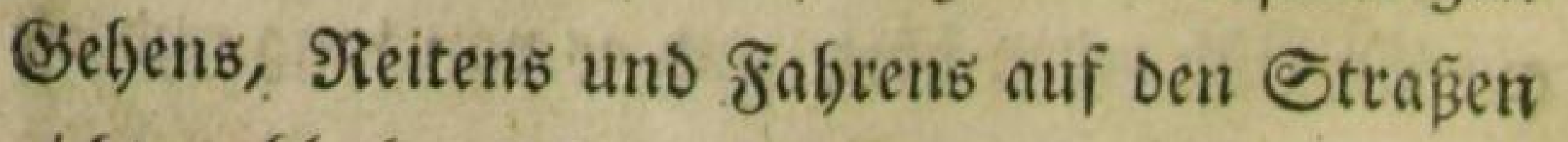
nidft wobl thunlich. Die (Eltern, aud von ge: . 


\section{$(83)$}

tingem Stanbe, fobeinen bier gegen ifyre ßinbet fefre gutig uno nad)fidjtsvoll zu fenn, uno nidft fo [efrer, wie bei uns der \$obel, mit Sdjlágen uns Sdheltworten ibren (S)eift fu unterorúcten.

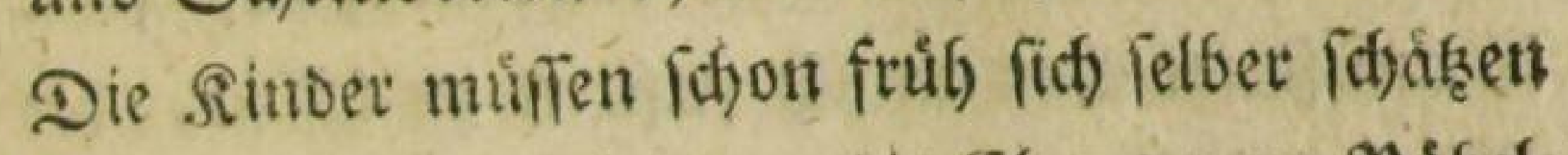
lemen, fatt Daß̧ bet uns die (5ltern vom Đosbels ftande ifye Sinder wieder zu eben ber Sflaveret erziclen, worunter fie felber feufzen.

Ofyngead)tet aller zunefmenden Modelucht bleibt man fier Denu boch Der ?atur noch trea

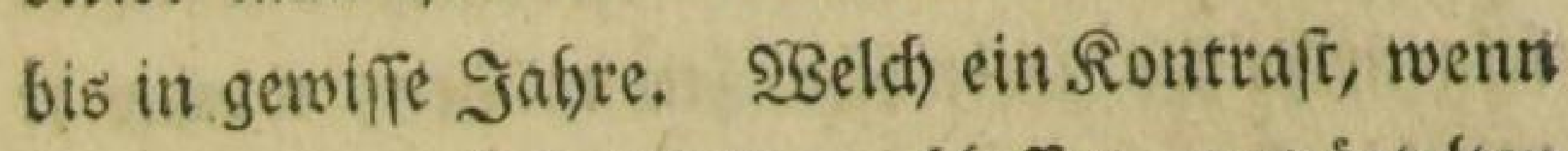

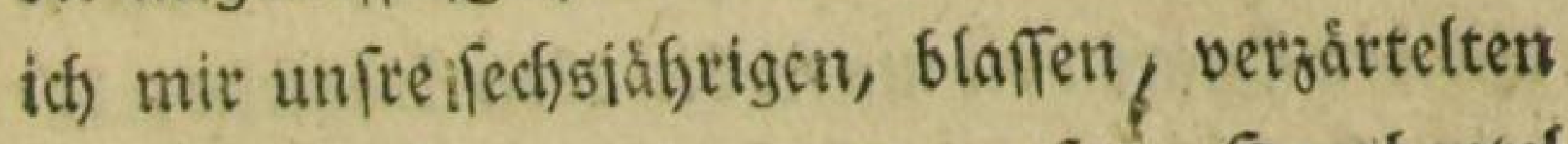
Serlimertinaben mit einem grof̧en Şaarbeutel and Dem ganzen Stante eines (5twad) [enen, wohl gar in einem verbrămtén Sleide benfe, und has gegen biet lauter blúbente, fohlante, rifftige Snaben, mit offuer Sruft uno abgefdinittnem fraar erblicfe, bas fich) von felber in naturtiche Eocfen rollt. Şier iff es etwas fébr feltnes bei einem Sinaben oder jungen Dienichen cine blaffe

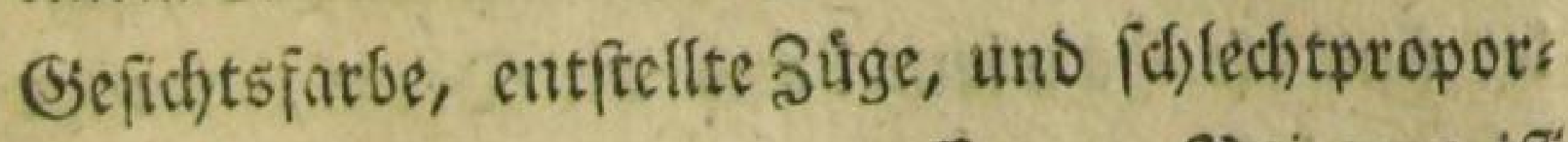
tionitte Ssliebmaßen anzutreffen. Sei uns ift wirffich Das Siegentheil etmas feltnes, fonft múrben bie (d)ónen Sjienfidgen nidjt fo auffallen. 


\section{( 84$)$}

Diele freie natúrliche Yradjt bautert oods bis ins achtzeffute aud wobl ins zrwanzigfte Jabis. Daun bort fie freilid) bei Den feinern Gtánden auf, und bauert nur noch) bei dem \$góbel fort. Dann fängt math an fide) frifiren zu laffen, Dis

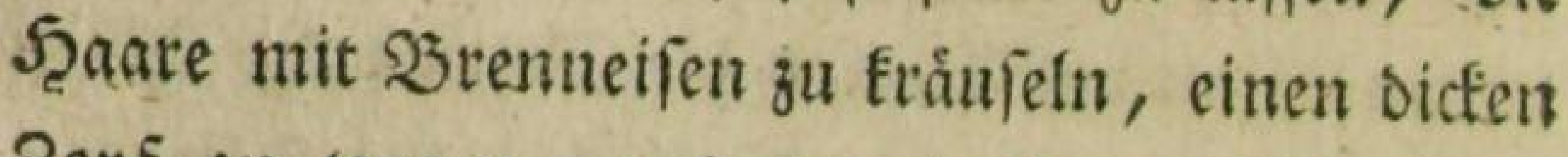
Sopf zu trigen, und ben balben গitcken mit Duber zu befrteuen. Ututer ben Seanden meines (Englifd)en Frifeurs babe id langer als unter ben Seanden eines Deutichen ausbalten, uns unter

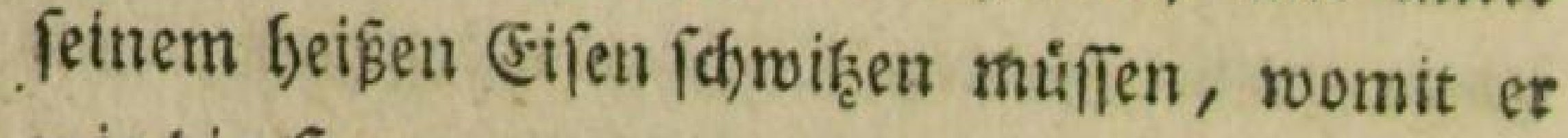
mir bie Seaare von unten bis oben frăufelte, das mit id) mid) unter (Englånbern (o Zeiten!) produciren fonnte. Shierbel bemerke idh, onş bie (Englifchen frtieur zugleid) Şarbier find, welches fie benn berslich) (d) lecht vertichten, of iff gleidf

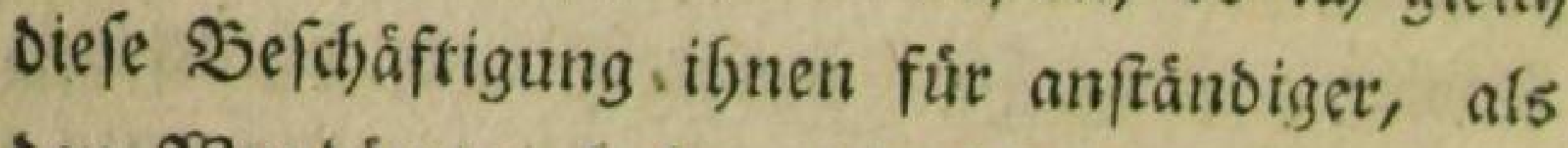
Den 2 sundárz̧ten balte, Die fich) bei uns Damit abgeben. (Frs ift unglaulich, roie bie Englánoer in Den ję̧igen Zeiten franzdfiren; was noch fef) let fino die Şaarbeutel uno Die Degen, womit id) wenigftens niemanden auf offentlid)er Straße babe gefjen feben, aber Demobngeachtet fábut man bamit zur (sour. 


\section{( 85$)$}

Des Norgens pflegt man in einet 2rte Ne: gligee (Morningdrefs) mit unfifirten bloß auf: gerotcfeltem Scaar, uno im Frrat uno Stiefeltt auszugeisen. In Siseftminfter bauert ber ग) gen bis গiadjmittags um vier bis fün libr, no man erft zu Dittage pelifet, nad) weldyem ßers băltniś fich Denn aud) bie Seit bes 21 bendeffens unto zu 2 ettzgebens ridhtet. Utm zelyn utgr miro gemeiniglich exff geitúlffúctet. Se weiter man von ber Sjegent des feofes wiederum in die Stadt formmt, Defto búrgerlidjer wiro er audh, uno mau [peist wobl zu ग)ittage um orei $\mathfrak{U t h}$, fobalo

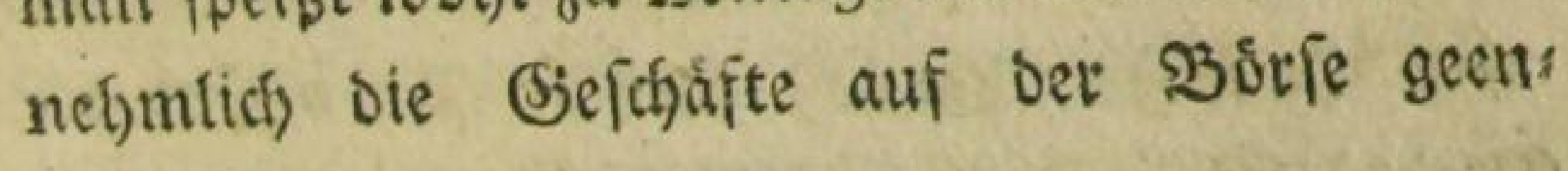
bigt fitto.

Sefergte Sileiber werben benn boch ntaft ges tragen, uno bie gewoflynlidfyfe 2(rt, fid) im @oms

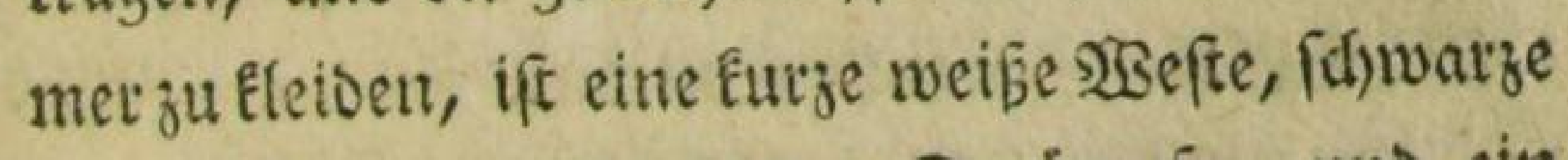
Szenteitor, meise feione Strúmpfe, und ein Srak, gemeiniglich von fef)r Dumfelotauen Tudje, oas beinabe wie fdjwar' aubficht, wentigftens bes Dient man fich immer ber Duntern Farben. 2 silf man Balla madjen, fo trágt man fofyrentz. Dfficiere gefyen nidst in Uniform, fonbern Elet:

$$
\text { ₹3 }
$$




\section{( 86 )}

Den fich bitrgerlich, und zeichnen fich blos burch eine Sofarbe am Scute aus.

Sobalo die Englander frifitt find und STals: binden tragen foreinen fie audf weicfficfer ju werden, und warnen einen bei jeber Sielegenfyeit Daß́ man fich) nicht erÉálten folle. You'll catch cold! heiß̄t es, wenn man fich mur ein wenig oem Suge ober ber \&uft ausfefet, oder nicht rwatm genug angezogen ift.

Die gewdfnficfe Ronverfation breft fich im Sommer faft immer um Den widjtigen Siegen: ftano, of otefer oder jener 2zefannte in the Country, (auf bem lanio) oder in Town (in Det (Staot) (en. Freilid) iftsoies fefyt naturtich, oa beinabe die Saalfte von dea Einwobnern der Stadt im Sommer aufs gans binauszieft, mofitr idf aud) bald wanbern werbe, ob ith gleids fein (sinmofner von gonoon bin.

Die Eleftricităt ift Das \$uppenfpiel Det

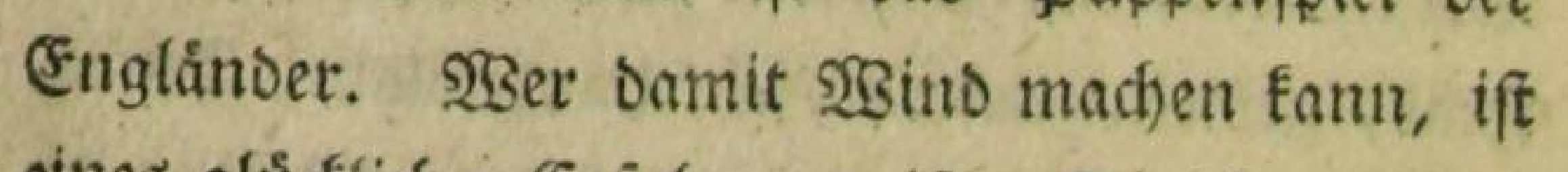

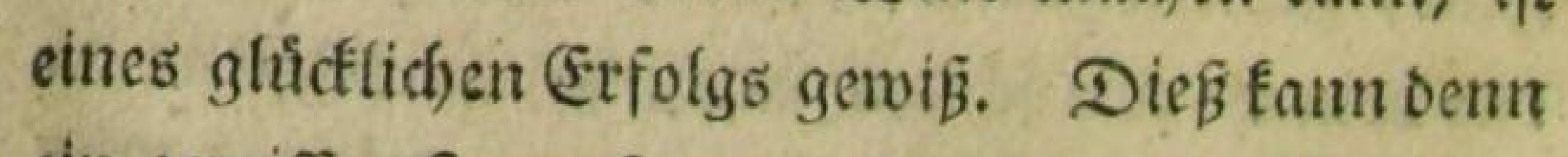
ein geniffer Seetr Rattetfello, ber fid) für cinen Ḑreusiffchen Scufarenobriften ausgiebt, fohlect)t

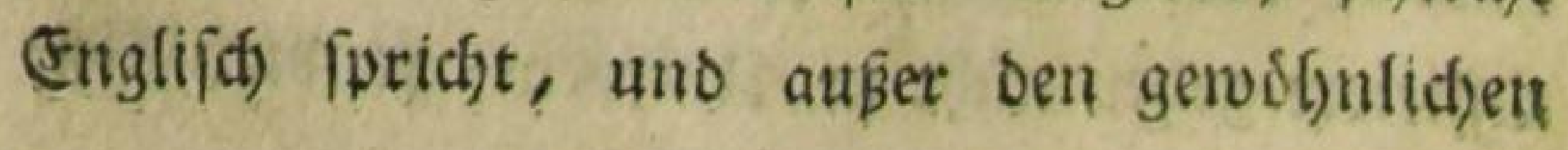




\section{( 87 )}

eleetrifichen uno andern phyfifalifthen Berfudjen nod) einige TafdjenipielerEún(te verftét), womit er, wenigftens ben Beitungen nach, bas ganje

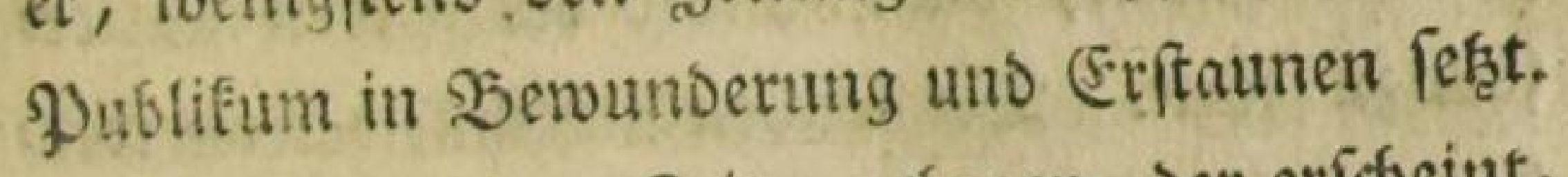
Denn faft in jesem Zeitungsfogen, ber eridheint, fetelen (sseotchte auf oen groşen Satterfello ge:

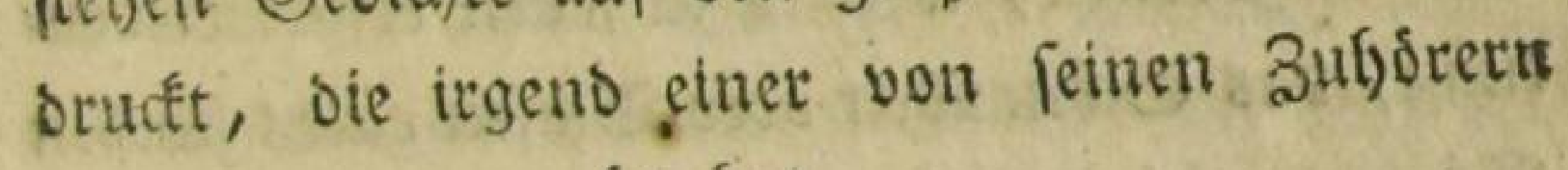
ex tempore gemadit bat.

Jeber Bermunftige bålt diefen Satterfello fír cinen 2 sinobeutel, Demolingeadtet bat er $\mathfrak{Z}$ : Iauf die sienge. (Fr l)at Den \&euten Demomftrirt, baß́ bie Snfluenza von einer 2frt L, iner JinjeE: ten berrulbre, weldbe bie \&uft vergifter, uno ein Irtanum, Das er bagegen zu haben vorgibt, wito ii) In reibeno abgefauft. Seit einigen Sagen hat et in bie Zeitung ferzen laffen: Scerr Satterfello babe jwar immer fef)r gewün (d)t, Daß Ealtes und regnigtes 2 setter einfallen móge, um bie flet:

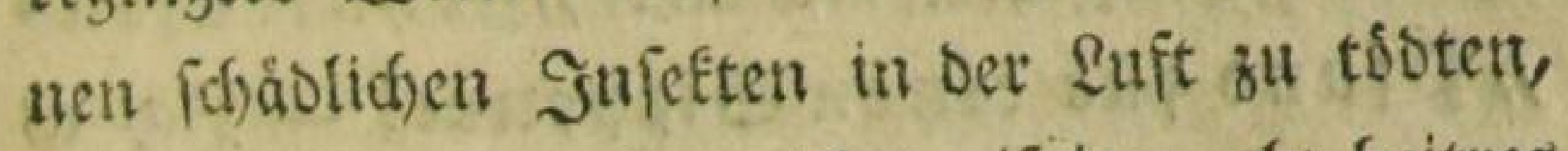
jef̧t wuniche ex aber nid)ts eifriger als beittes SSsetter, meil feine Niajeftat uno die ganze Sis: nigliche familie befálofien hátten, fobald ein:

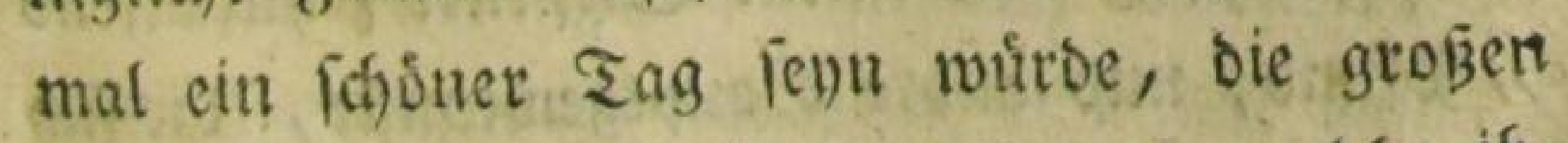

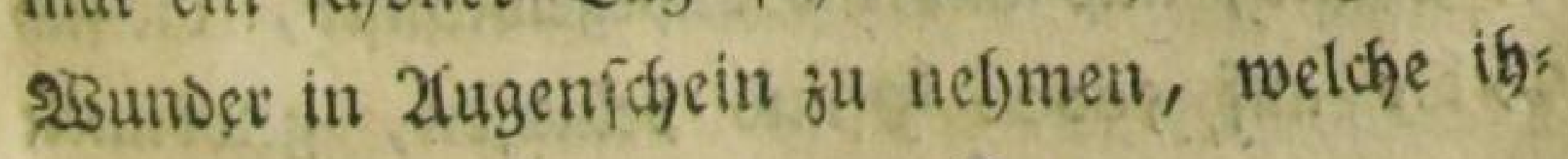

F 4 


\section{( 88 )}

nen biefer ettjabne Pbilofoph barfelfen wütbe, uns die Sosnigliche Familie forf noch) nicht Daran gedacht baben, Die SIJunder des Jerrn Ratters fellozu feben. Dergleichen Zuffidneibereien wers Den im Englifden febr fajon butch bas STsort,

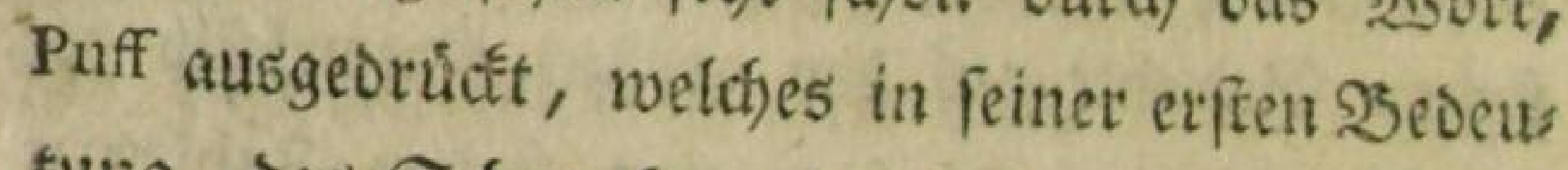
fung, das Sdfnaben oder Ṡlajen cines farten ISinves, uno in Der zweiten ober metap forifchen eine \$rablerei oder 2fuffaneiberei bebeutet.

Bon folchen \$uffi find nun bie Englifichen Seitungen tagtåglich voll. Sefonbers von Duack: falbereien uno 2(rEanis womit fid) bier f(t)on mans ther, uns unter andern auch ein Deutficher, ber unter Dem গaffmen the German Doctor befanne iff, beteichert bat. Eine 2fnfundigung von einer Sotterte in ben seitungen fängt ficf) mit grosige:

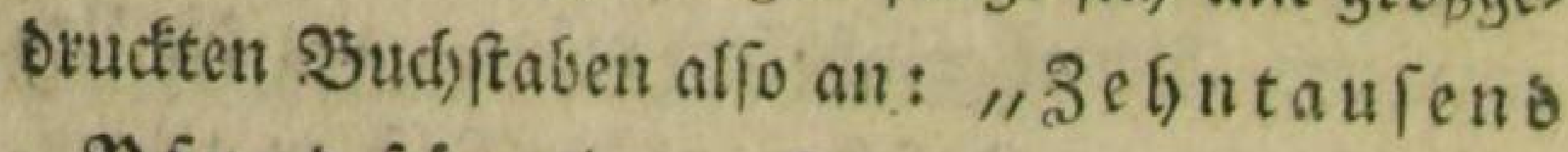
"Dfuno fúr einen Sirpence! - Ja, es "mag fo erftauntich foheinen wie es roolle, fo

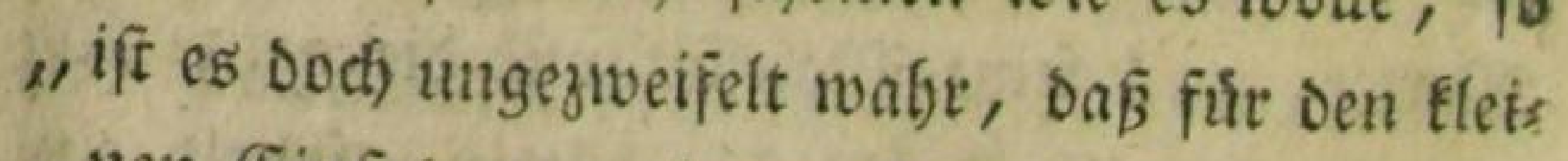
1) "nen Eirrarz von einem Sixpence zefntarfens . 4) Pfuno, uno andre IScauptgensinnfte, ote fich "bis auf 50000 \$p funb beiaufen, gemoonnete 


\section{( 89 )}

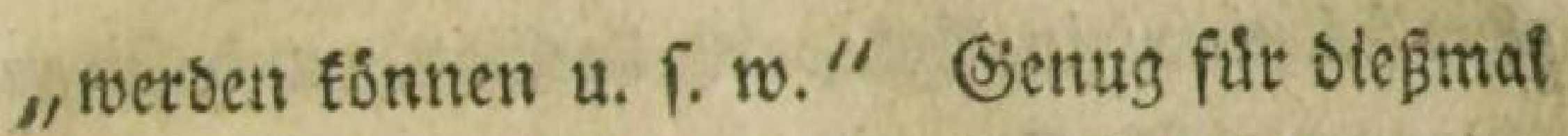
you den STsinbbentefeien der Englander!

Siefrern frabe id bei Dem Szeurn Paftor Sdjraber, einem Sthwiegeriof)ne bes fretrn

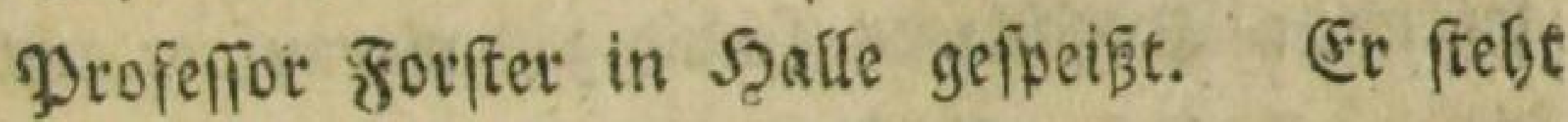
als \$yrebiger an bet St. James ßapelle, nebft einem Sollegen und einem Reftor, ber auch ors

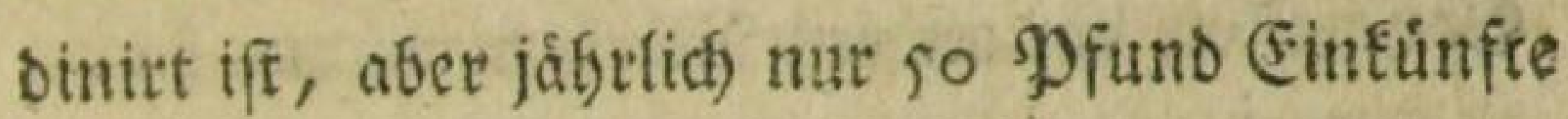

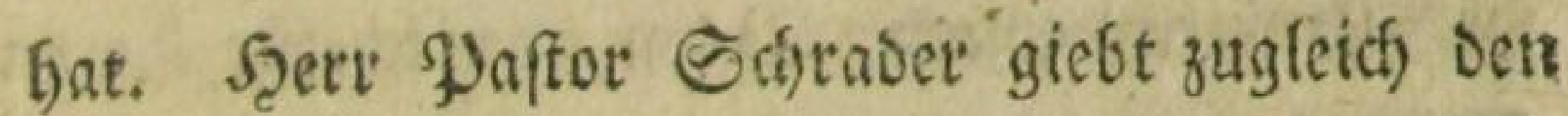

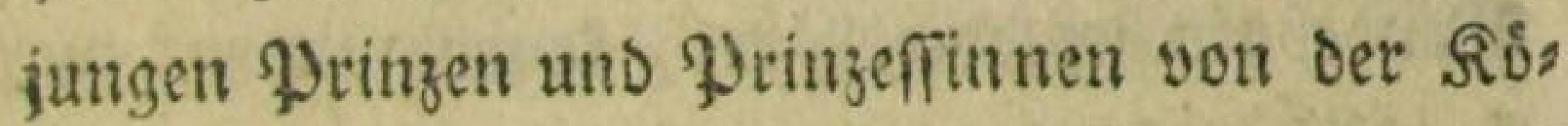
nigficfen Familie Tieligionsuntertifft. Şei

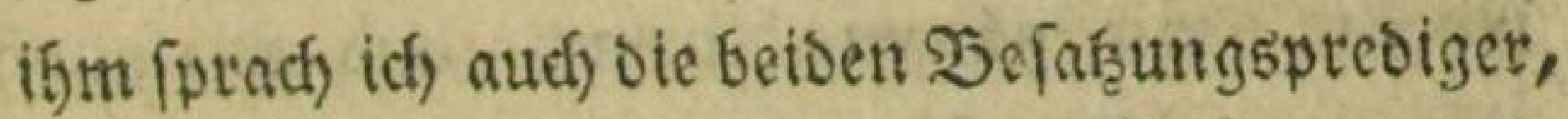
Şertm Eindentaun und Şetrn Sritter, weldye mit ben F⿻annofvif(chen Truppen nad) Dinorka

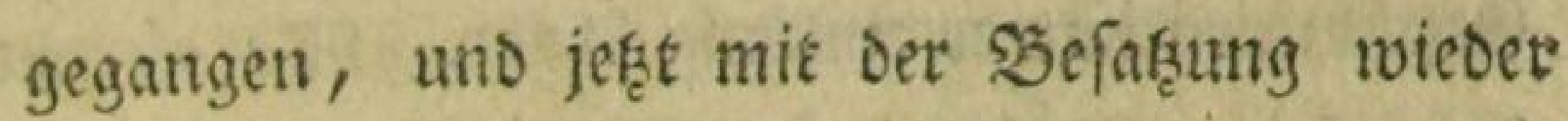
zurtichgefefert waren. Sie fino aller Giefagt mit

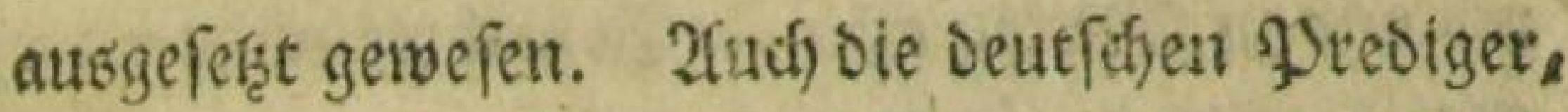
fo wie alle in sffentlitfen Sebiemungen feltyens

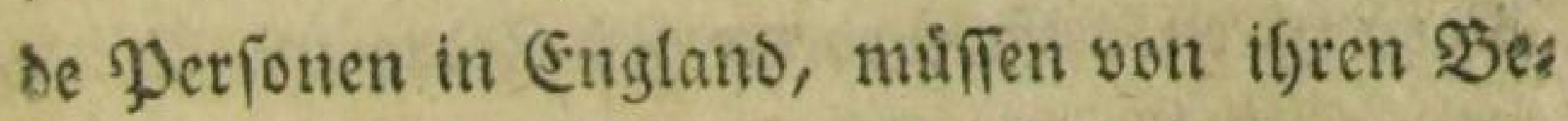
foldungen eine gewiffe fethr betrachtliche Tare be zanten.

Die Englifochen Bseiffitchen, befonders in

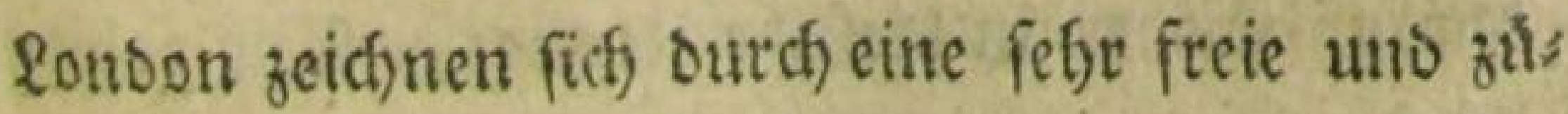
getlofe Rebensatt aus, Geit meiner 2fnwefentyeit

$$
\text { of }
$$




\section{( 90.$)$}

bat fich einer in STibeparf buelfirt, uno feinen Gienner erfafifien. Er warto von Der Jurv oder Den jrodf (S)efchwornen getifjtet, uno fie ertlatten ibn furt guilty of Manflaughter, oder Des unvor: ferglichen Toofchlages fétuldig, morauf er mit einem falten Eifen in die Sano gebtano: - marêt wurde, welches Redft Der. Zroel undidie (beifflich Eeit vor andern Miordern voraus hat.

(Seftern vor acht Tagen, oa id) filt Serrn 23 endeborn gepredigt batte, famen wir vor ciner Englifer)en Sirthe vorbei, worinn noch gepredigt rulde, wiv gingen finein, uno es fprad) ein junger gienich, of er gleich ablǟ, mit jiemliefs guter Deflamation, Die freilteh bei Den Engländern immer einto̊nig bleibt, Sצsit gingen Darauf Der Sirthe gegentuber in ein Saffel)aus,

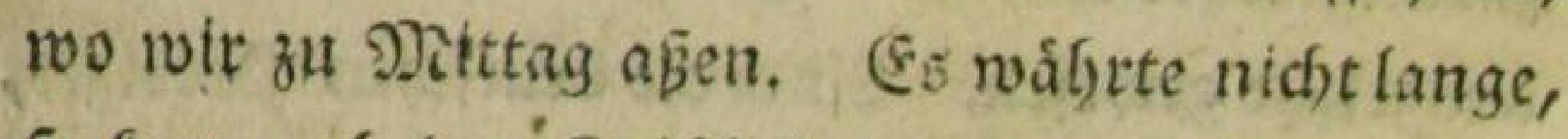
fo fam aud) Der' (Jeiffliche, Den wir hatten pres Digen Goiren. (Er forderte fich Feber uno Dinte, forries in groker (File einize Slatter voll, die er wie ein Roncept in Die Fafdye frectete, Darauf fieß $\mathrm{er}$ fich zu effen geben, uno ging unmittelbar Datauf mieber. in Diefelbe ßirche, WSir folgten 16m, uno er trat auf Die Sanzel, nabm fein Ojer 


\section{( 91$)$}

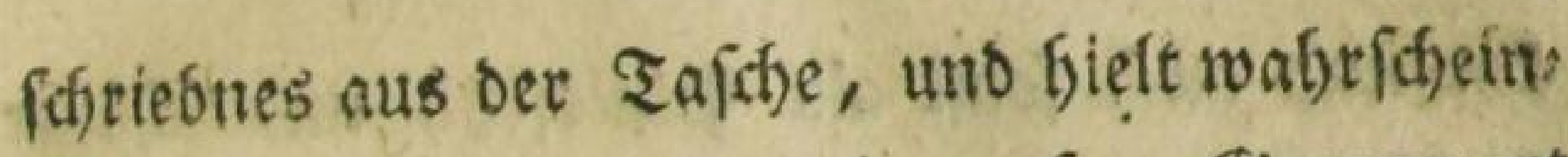
lid) Die Jrebigt, bie er in unfrer Bjegennart im Sonfeebaule perfertigt batte.

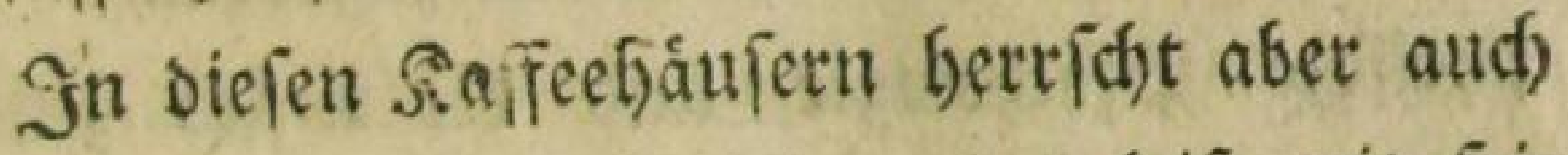
eine grope Stille, ein jeder redet leife mit feis nem গachbar, bie meiften lefen Beitunzen uno Eeiner ftort Den andern. Das Zimmet ift gleids Draußen auf Dem flur, und man tritt in Daffels be, fo wie man in bie Scausthute tritt, die Sige

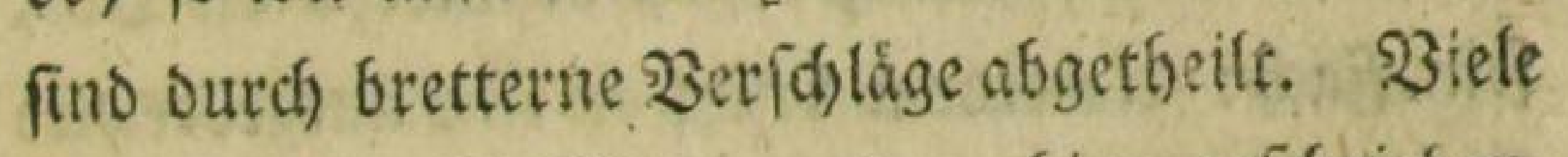
Szriefe uno 2fuffaçe weroen bier gefdrtieben, aud) foldse, bie man in ben Zeitungen geotudt lieşt, finto gemeiniglich aus irgeno einem Raffees

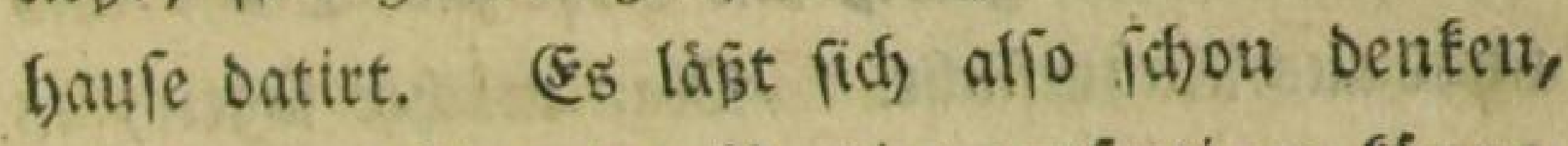
Dás jemans bier eine \$Jebigt verfertigen fónne, bie er im Segriff iff, fogletch in einer nabelies genoen Sirche zu balten.

श2od) eme weite Sour fabe idf ziemlich oft gemadht, úber Şannovetianare, und Ravendifd): quare, nad) Dufffroatfteet, Sei \$absington, wo der Dánifdje Siejande roblut, uno wo ich

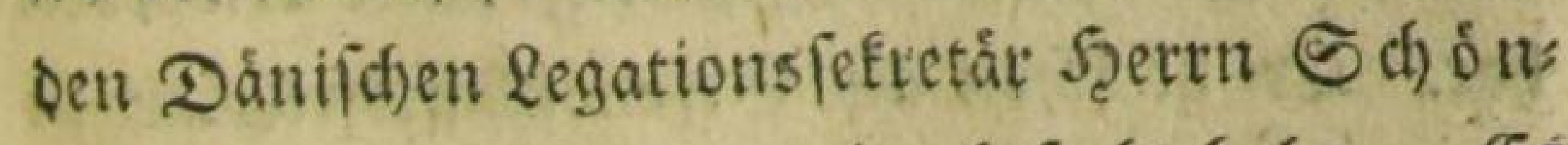
born zu veridjiconenmalen befudjt babe. (5et

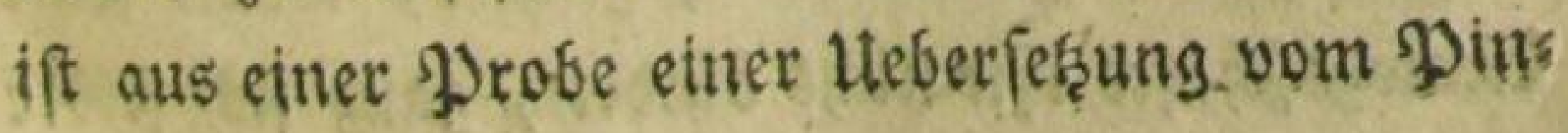




\section{( 92$)$}

bat und aud fonft als Wobilofoph und fosiner Geift in Deutichland befannt. J3it ifm babe idf Fefre angenefme Etumben zugebradit. (5m:

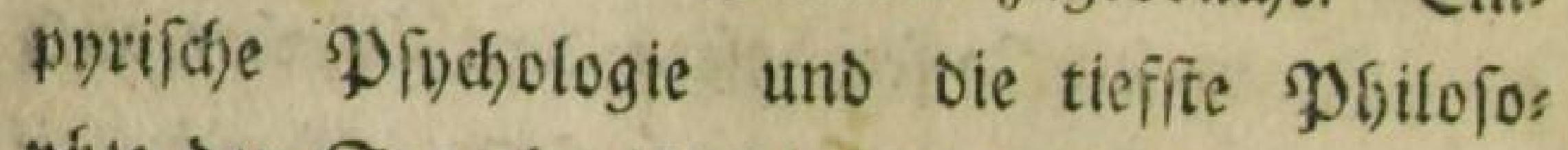
pjte der Eprache if rejn Rleotingsftudium, uns er bat Darúber vortrefflithe Eactgen in feinem Yulte ausgearbeitet liegen, von benen żu wưn

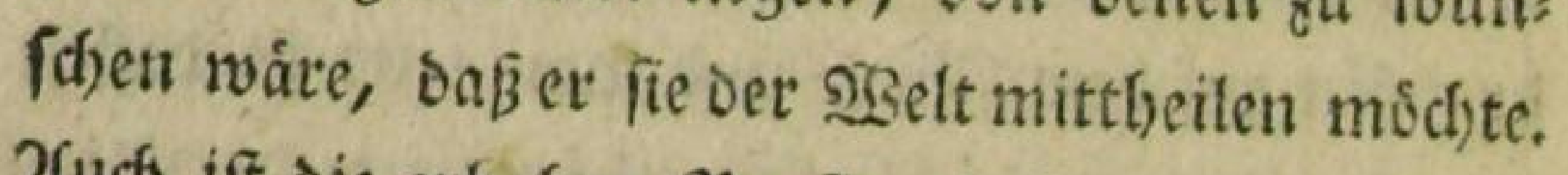
Zfuch ift die erbabue Poefie, befonders die Ode, Fein Fach: Heberdem befigt ev eine auggebreitete Belebrfamfeit uno belefenheit in den Echriften Der Bitiechen und gismer. llno alles, was et

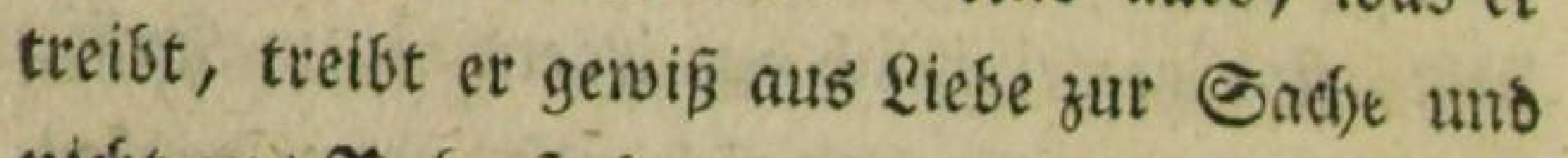
nitcht aus Tufbmfucht. - Dan modfte fagen, es fen Sthade; Daß ein fo vortteffflidher s)ann fich

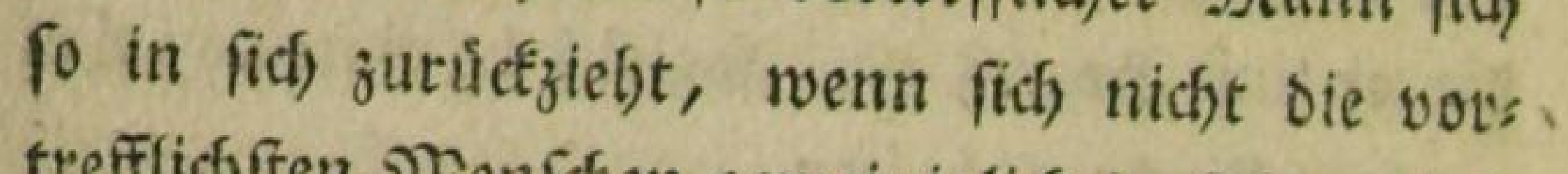

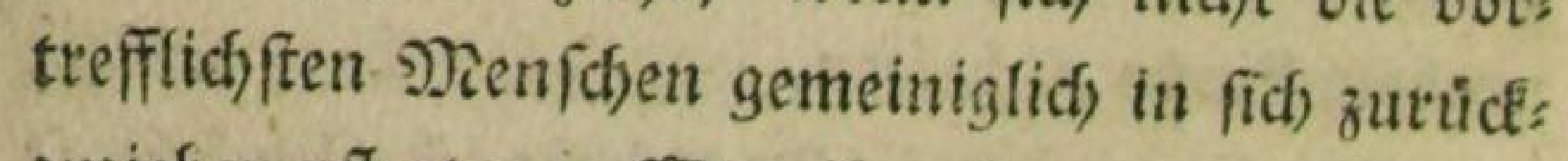
fuzziefjen pflegten. STas ifn aber úber Dieß̨ alles Thhägbar mad)t, ift feine reine ofine Geele, uno

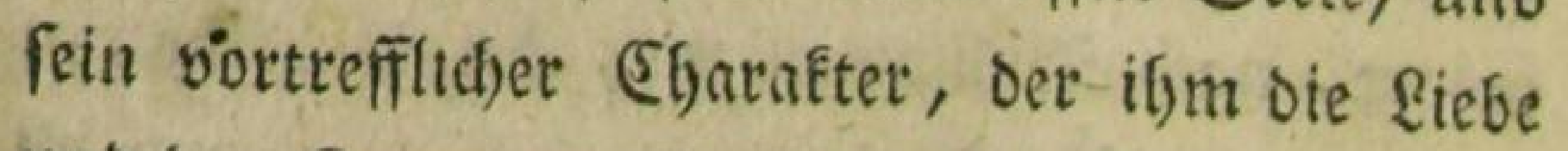
uno ons Sutrauen allet feiner sreutho etroorbert

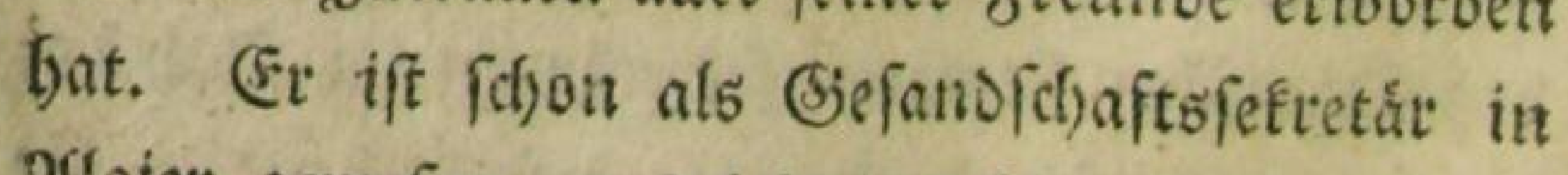
Zllgier gewe fen, uno lebt jefgt ljeer, wean feine

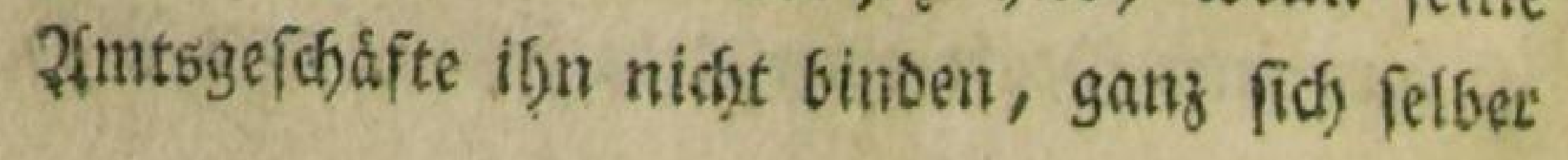




\section{( $\left.93^{\prime}\right)$}

und ben T3iffenfidaften. So angenebm mir btefe Befannt[chaft iff, fo fahwer wiro es mir wers ben, ben fieunofidaftlifjen uno lefyrreicjen ltm: gang biejes sjanmes fobald wieder jul vet: lieren.

Ja) babe bent aud ben biefigen groben Freimaunetfaal in Free Jiafons รavern gefe: bent. Diefer Saal if von einer ganj erftaunt: d)en Sçbe, uno Sreite, beinabe wie cine Sirche. Das Ordhefter für Die Dufifenten ift in bet Şo: he angebrad)t, uno man hat von demfelfen eine Leferfidjt des gamen Saals, Der fid fefyr ma: jeftatifich ausnimmt. Setne (Etbaunng bat groß̧e Summen gefoftet, wozh auth bie $Q_{0}$ gen in Deut/d)land mit beigetragen baben. Die Freimuateret wito bier ůbrigens nidjt viel meljt geadjtet, weil bie meiften Bu[ammentúnfte ein: mal zu Trinfiefellichaften berabgenurotigt find, of es gleidjwobl noch logen sebell mag, Die fid) fu einem colern und refentliffern aroed vereinigen. Der Şerzogvon Sumberland ift jeşs Sandesgropimeifter. 


\section{( 24$)$}

Sonbon, ben zoffen Juni 1782 .

Enolid) hat mein Entichlus, aufs gano zu geben, gefiegt; nodh heute Nachmittag foll's mit ber Etage coady fortgeisen, unb biefen פ)iorgen

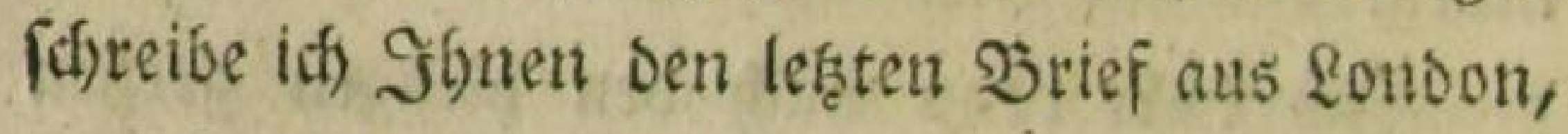
verfteft fich, bis idf von meinen sisanderungen roieder jurúcfeomme; benn, fobalo ids mur aus oen unfichern Segenden um Eonbon bin, wetbe

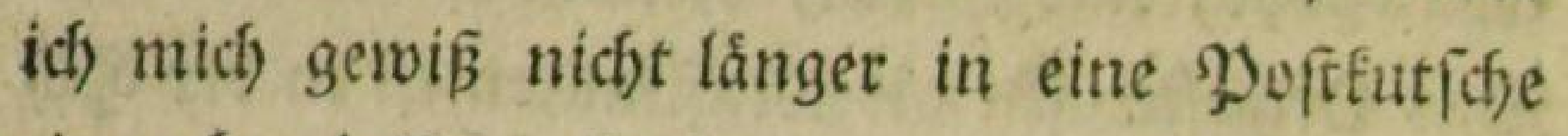
eimpacken laffen, fondern meinen Gtab ergrei:

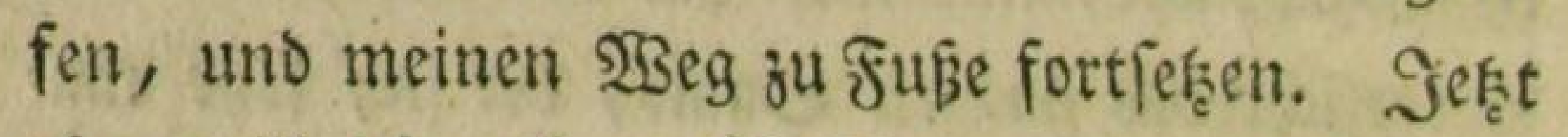
aber will ich etfit nachloblen, was idf Shtnen noch zu lid)reiben vergefien, oder leit ein Paar ₹agen noch Metfmuitoiges in Ronoon gefeben babe; und bas ift bem vor allen andert

\section{Die St. PaulsEirtche.}

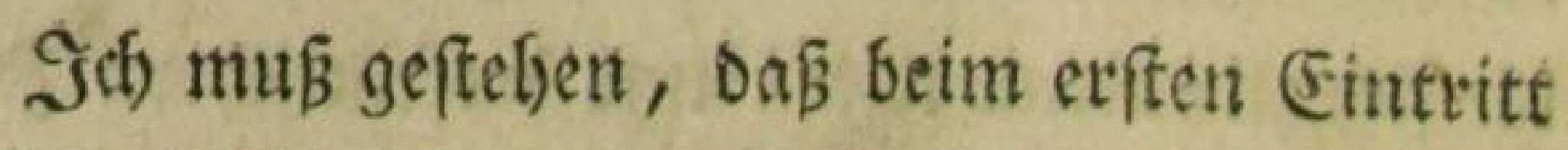

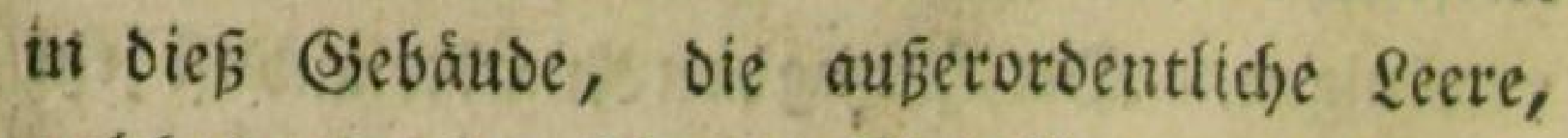

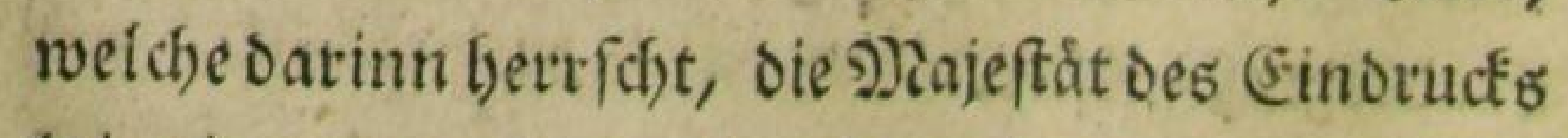
bel mir etroas hemmte, ftatt fie zal vermefjen. 1tm mich nichts als ungebeure leere গুBande und 


\section{( 95$)$}

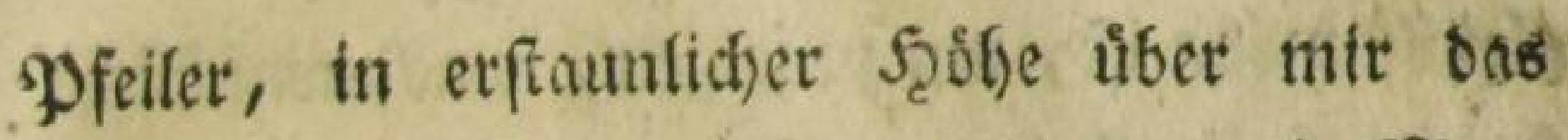
gemauerte Sserwilbe, unter mir Der mit Mar: mor gepflafterte elone flache Sooen, fein 2lltar, oder fonfir irgeno ein Beidfen, daß̧ man fich biet

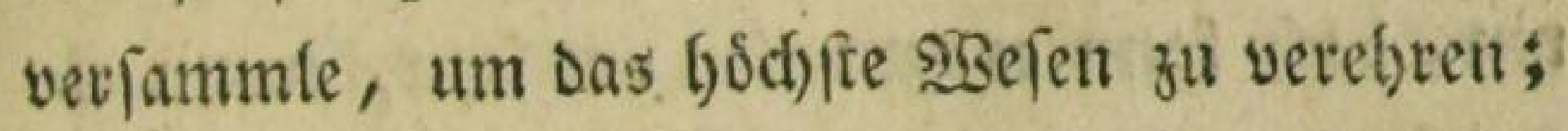
Demi das eigentlide (Shor oder Sitrche, wo bet Giottesdienft gefjalten wirb, ift nut wie anger baut, und Durd) ein (bitter von bem grojent runden Seauptgebaube abgefondert. 2Sill

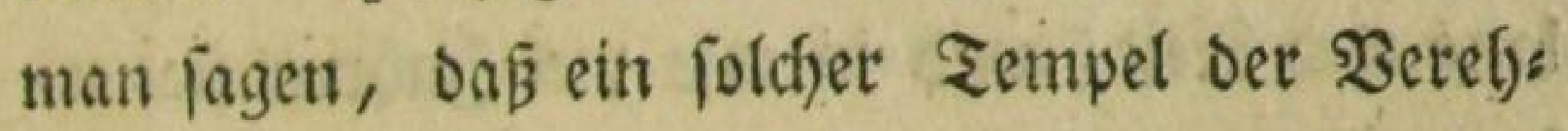

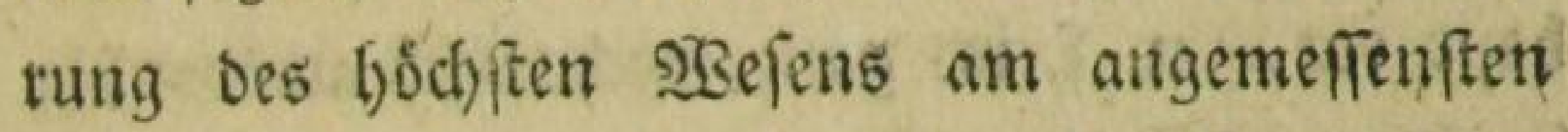
(ev), fo lobe idf mir ood) Den grosen Tempel Det 9)atur, Das blaute Sservoflbe des Şimmels, uno ben grủnen รeppich, Der Den Fußboden beflets Det, hier if ein grofirer Sempel, uno bier if: nichts iceres, alles ift hier voll von Eputen ber gottlicjen Segenwart; wollen aber Nent ichens bánoe diefen Tempel nachab)men, fo mus notb: wenoig etwas barinn angebrad)t (eyn, ons midh fúr Das Bolle uno \&ebendige in Der Natur fchads los bålt, uno midg den erljabinen (Endzrect

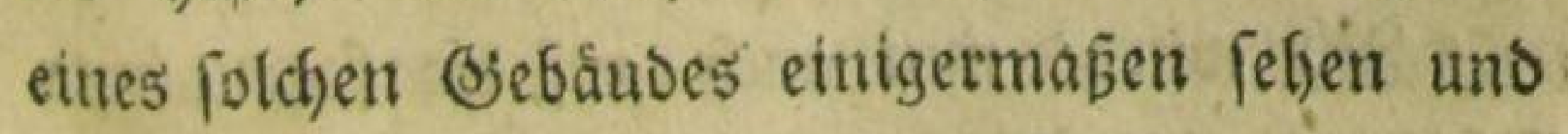
empfinden läkt. Setrad)te idf) bingegen bie

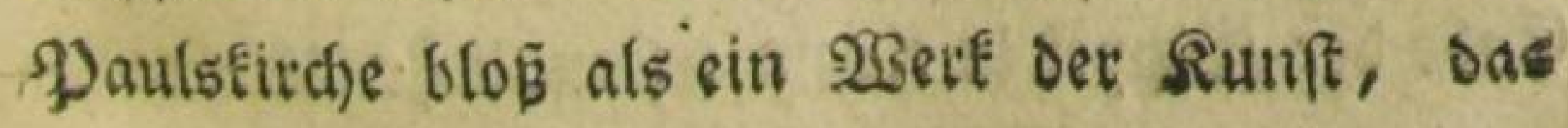




\section{( 96$)$}

gletcflam 'ba ift, um zuzeigen, was menjicfliche Rraffte bervorbringen fónnen, fo fisst fie mir freilith EGrfurcht und benounderung ein.

Fซ láft fidh ůber Dergleichen freilid) nicht oifputis ten, Doch fann es juweilen gut fenn, went el: ner fagt, wie es ifm vorgefommen iff.

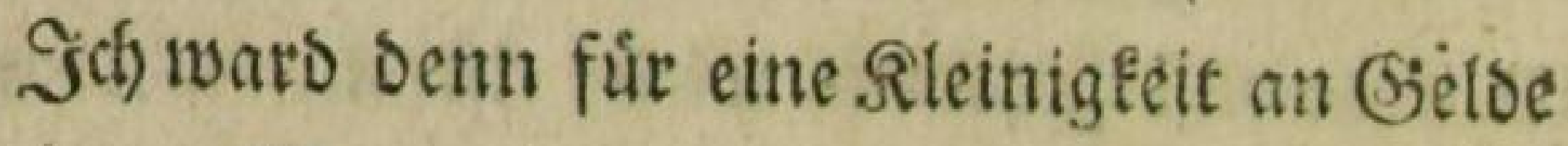
yon einem Mianne in ber Rirdje berumgefúbrt,

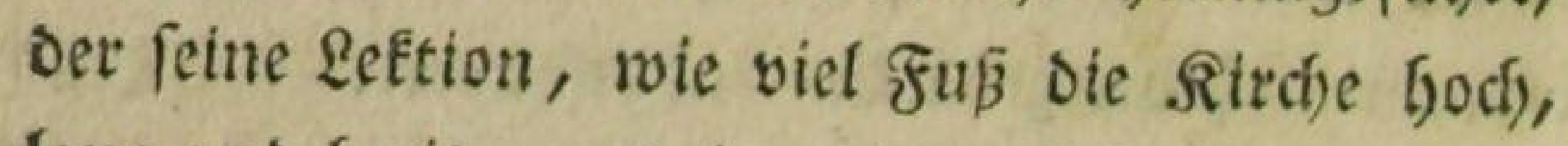
lang unb breit, uno in wie viel gabren fie et: baut [el), u. T. w. ganz mechanifif) austvendig berfagte, Das idh ifm getne gefoljentt batte. In Dem Durd) ein (s)itter von Dem Scauptgebaude abs gefonverten Egore, war benn bie eigentliche. Sirche, mit Santen uno Stúglen, Sanzel uno 2fltar verfeben; an beiben Eeiten waren bie Sił̧e für bie CGorberten, wie in unfern Dumfirtfen. Diefe Siapefle fithien recht bazu ges

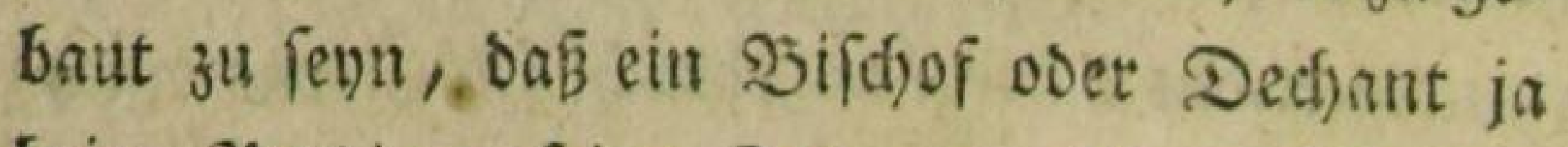
beim \$rebigen feine Stimme nicht zu fefre ans frtengen oúte.

Sif) wurbe nun aud) auf ole fogennmite 2BBbifpering: Galleric gefúbut, welche unten am (Ende Det Suppel in einem erftaunlidfin LImfteife berums 


\section{( 97$)$}

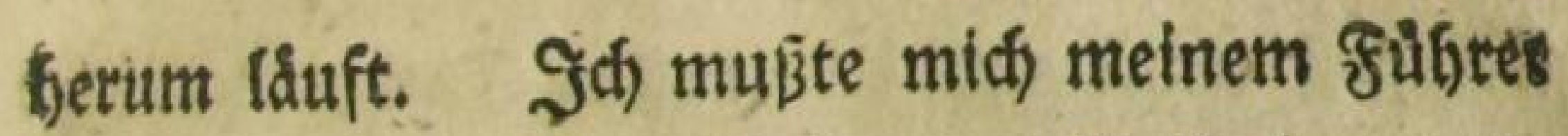
ganz auf ber, andern Seite ber Siallerie gerabe

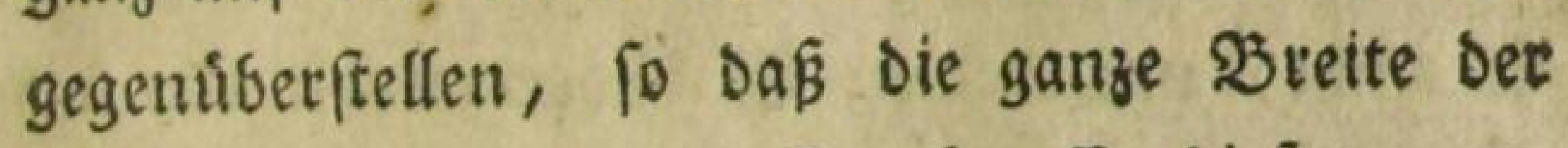
Sirdje, oder ber ganze Durdmeffer biejes unges heuren Eirfels zrwifácen uns war, uno indem ich biter frand, Fálug er bie ₹Gúre zu, weldhes vor meinen Obren einen Rnall, wie ein Donners fdjlag, verurfactite. Darauf muśte id mein Dfo

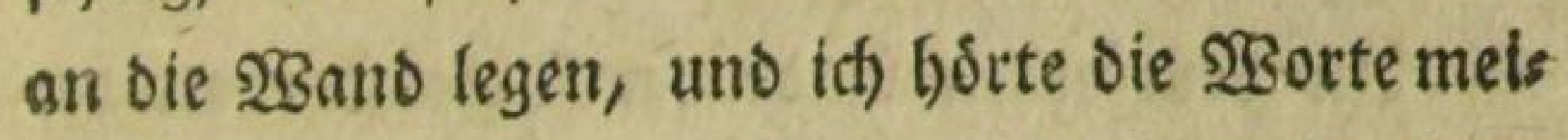
nes f̧úgrets: can you hear me? Die et, in eines fo weiten Entfernung von mir, leife gegen die 5sand (prad), mit einem farten Ssetof fe in meine Offen fallen. Diefe Berfárfung Des Edjale les in einer folften (Entfernung ift wirflid) bes roundernswurroig. Tad babe einmal etwas 2febns

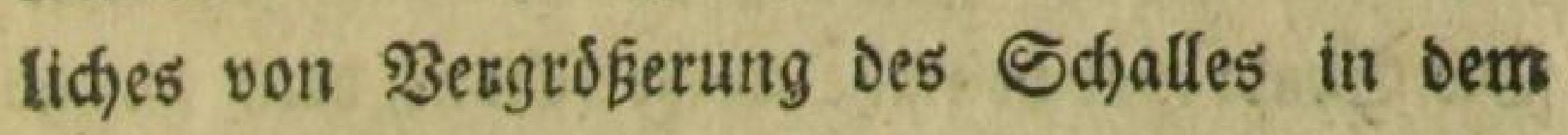
Patbsefller in Bremen bemertet, welches abes biergegen gar nidft in Betradjtung fómmt.

Nun ftieg idf noch verifiesne Treppen fins auf auf bie grobe Gaallerie, weldhe auswentig um Den gro B́en Dofgm láuft, uno bier bielt id mich beis nafe an zwei Etunden auf, weil man fidf an Dem

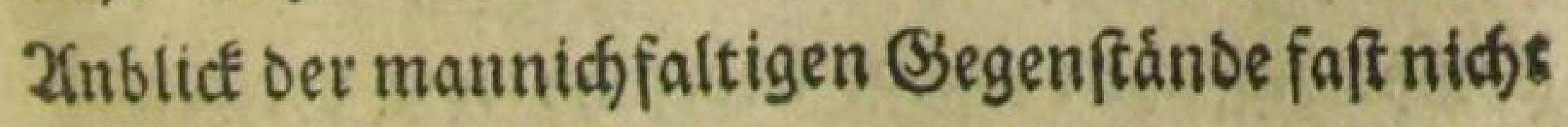
fatt fefen fann. 


\section{( 98 )}

Jid) wande midf) von einer Seite, yon einer 2Beltgegend fut andern, uno fubierte recht Die 2usficht, um meiner (Einbildungsfraft ein ims merwåbrendes Dillo bavon einzuprågen. Unter mit lagen in oer Tiefe, Thưrme, Şău|er uno Wallåfte, im dicfften Siedránge, und die Squa:

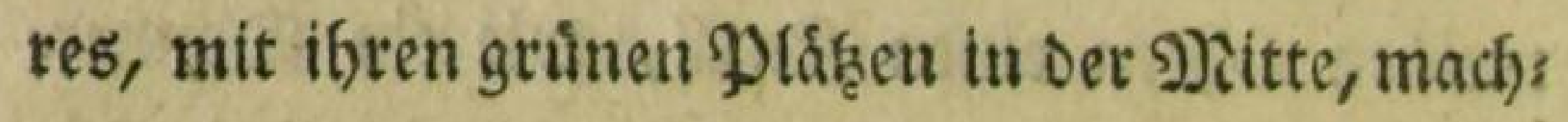
ten bazrwifden ein angenebmes Solorit.

2fit Dem einen Ende Der ₹bemfe ragte ber Touver, wie eine Stadt, mit einem 2 Salo von Dias ften binter iffm, uno an bem anbern bie sisefts minfterabtei, mit ibren ร̧นưmen, empor.

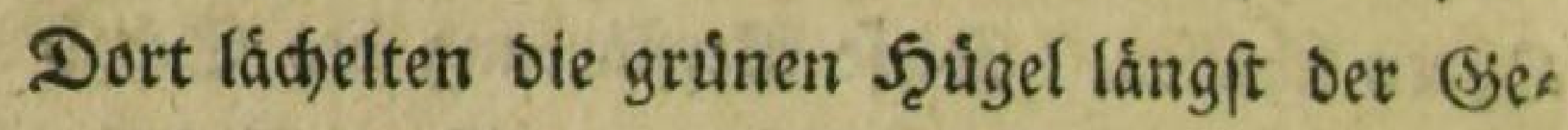
gend von Pabsington uno ЭFlington; bier lag Soutbroarf am jenfeitigen ther ber Themfe. Die Stadt war beinabe unúbet febbar, Denu wem fie idhou an fich aufbort, exftrecte fie fidh ood) faft immer nod) in einzelnen fुatuern an ben Seiten

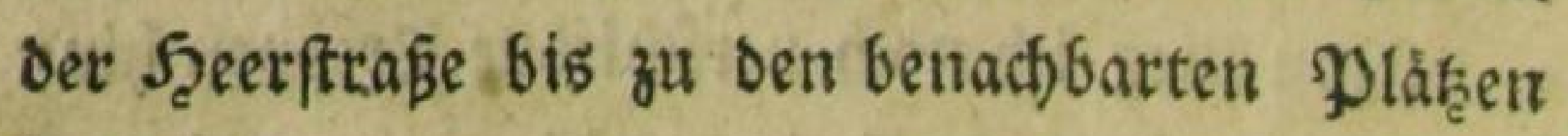
fort.

2Bie groß fam mir Serlin vor, als id) es jum exfenmal vom Sarienthurm, uno vom

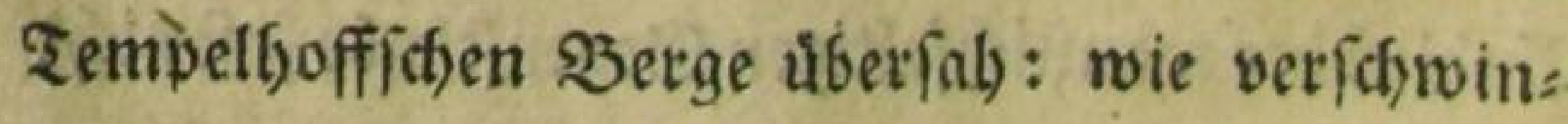
Det es ję̧t in meiner Borftellung gegen \&ondon! 


\section{(99)}

Dod), es lft yergeblich, eine foldfe 2fitsfidst

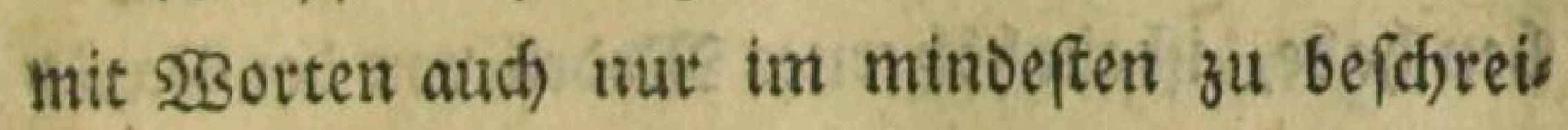
ben, uno nue cinen Sd)atten biefes (sindrucfs babutef) jut geben; wer eine 5 selt im Rleitten mit einent $\lesssim$ liaf úberiffauen will, Der fomme biefjer uno felbe!

Das Dach Der Paulafird)e felbit, mit iffrent beiben fleinetn Thutrmen, liegt unter mir, wie Der Siúcten eines nieorigen Sjebirgs, wenn mant Den Sipfel eines hoffern erfiegen bat. Bent batte id noch länger bier verweilt, aber eitt Sturmwino, der hier oben fo farf rourde, Daß̧ man fich Eaum bagegen erfalten fornte, trieb mich binututer.

Obgleich Die Sautsétirche an fich fefor bod

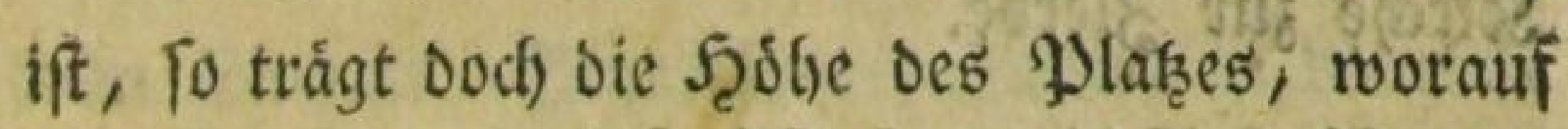
fie etbauet ift, fu ifgem hervortagen aud) fefr viel bei.

Die Ðjetrifitche in Berlin (d)eint ungead)tet Det gánzlichen Berfhiedentyeit in ber Sauntet mit

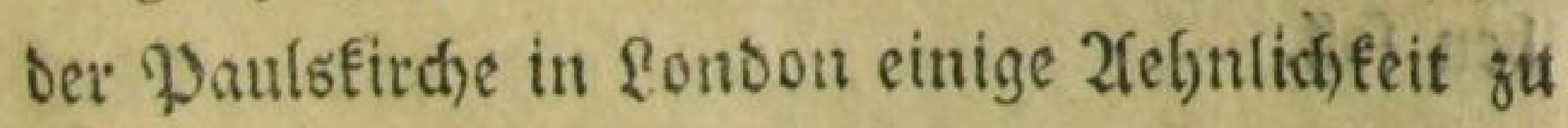
baben. 2Senigftetis ragt fie auch fo mit ifgrem gropen fdwwarzen Daft)e unter betr úbrigen (S) bálden bervor.

(5) 1 


\section{(100)}

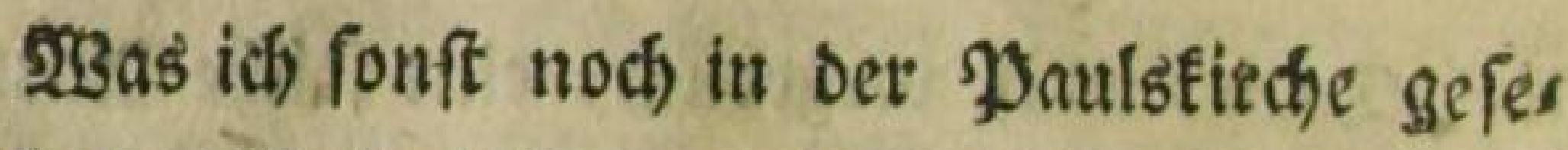

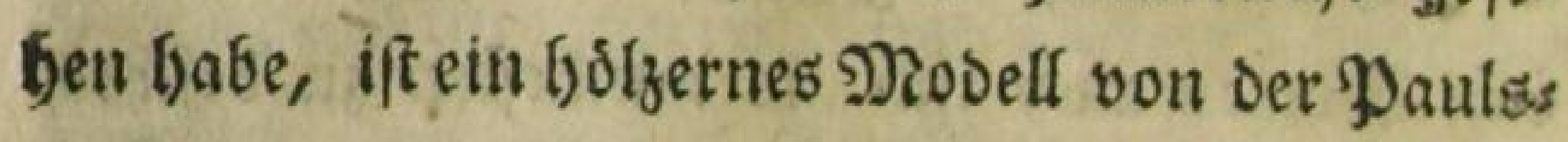
firche, bas vor ifrer (Erbaung verfertigt fenn foll, uno fid) mit Bergmigen eine $\mathfrak{W}$ seile betrach: ten lábt, menn man bas ungebeure Sjebáude dăs mit vergleicht.

Utm ben Şof Det St. Paulsfirche geft eft eifernes Sielander, unbes dáudbt einem eine ziem: lidje Strecte zu fevn, wenn man es umgetjen will. Der Dlaks umber ift aber nic)t getaumig, uno biefe pradchtige Rirdje if faft didft umber mit Şåufern umbaut.

Eine marmorne ミsilofăule ber Róniginn

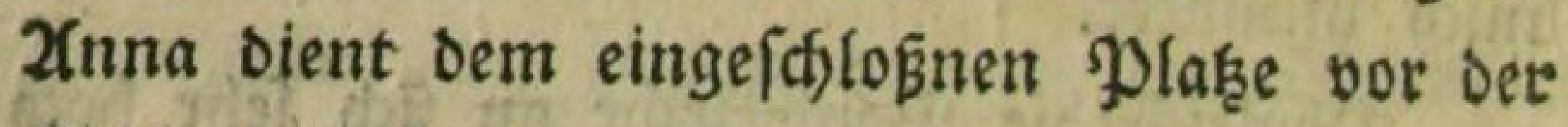
Sircje zut Sierbe.

2luch ift bie grofe SHlocfe in ber St. PJauls: firche eine Dertwúroigfeit, weil man fie unte: oie grobeften in (suropa mitzáhfit, und fie iffren Nang, wie id glaube, nach Der Fiener bas ben poll.

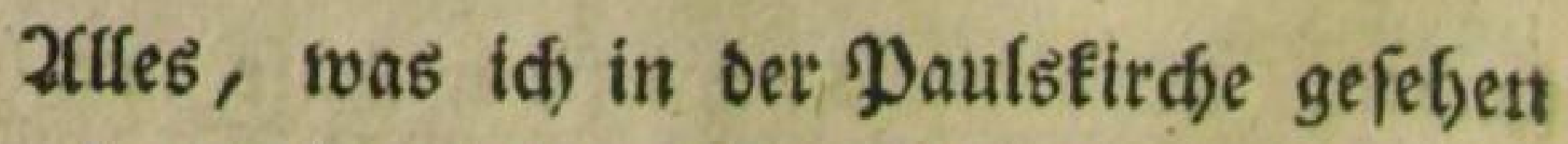
Gabe, bat mir nicht mebt, als etwas úber et, nen Sditring gefoftet, ben ich nach uno nack 


\section{( ror)}

in Dennys aud Scalfpennys, nad) einet bes frimmten ₹are, fúr oie Sehensmúrobigteiten bezablen muste.

\section{Die $\mathfrak{S E}_{\text {eftminfterabtei. }}$}

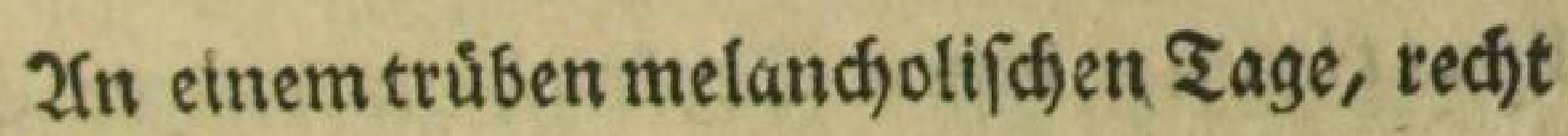

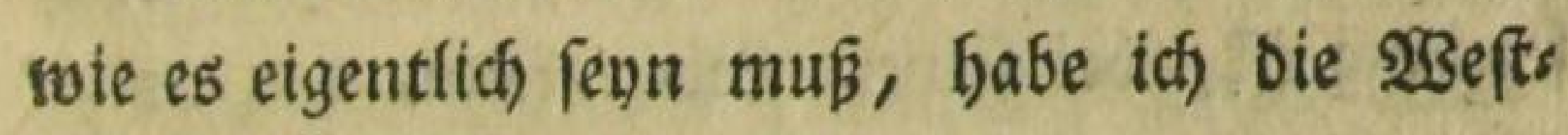
minfterabtei bejeben.

J4) gieng burd) eine fiemlid) fleine Tgut Finein, weldfe midf fogleidf in in the Poets Corner (Den Doetenwinfel) fúbrte, wo Die Dentmas

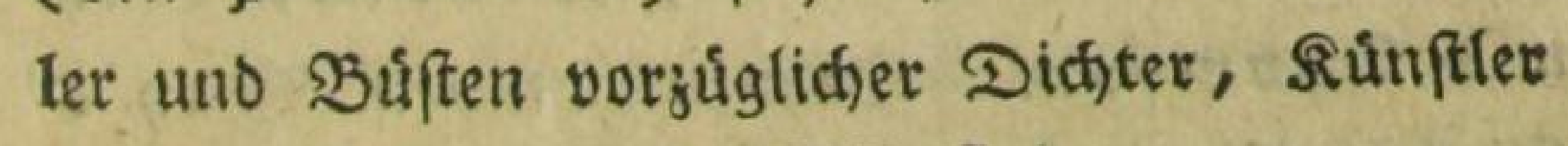
und Schriftiteller aufgeftellt find.

Nicht weit von ber Shuir etblicfte id) gleids) beim (sintritt, Schatefpears Statue in Lebenss großße mit einem Sragen um ben Fૃals u. f. w. nach Der (siemofnheit feiner Beit getleidet, und in Der Nábe deffelben Baarricts Dentmal.

Eine Stelle aus einem: Sthateipearfoben Stúcf, ber Sturm, morinn er auf eine feierlidje unb rưfrende 21tt, ben Untergang aller Dinge fafildert, ift bier fétr zrwectmábig ans gebrad)t. 


\section{- (102)}

शridjt weit von Schafe[peat ift aud gto wo en Dentmal, Daß̧ er fíd, wie etnige Beilen fagen, in biejer geliebten פadbbarfhaft feines Schate. fpears gerounfd)t hatte.

In Diefer Nachbaridhaft (ab) ich auds bes guten Solofmitl)s Suifte, Dem man, forvie Buttlern, Deffen Dentmafl in einiger (Ent: fermung iff, bei feinem geben faum Das noth: Dúrftige $5 r o d, ~ n a c h$ feinem Sode aber einen Stein geruáfrte.

- Serner fieft man bier faft in etner Fieife die 1 Dentmábler von Nillton, Druden, (b) an und Thomfon. Sebr rúbreno if (s) a 's (Grabfarift, Die er fich felbft verfertigt ba: ben foll,

Life is a Jeft and all Things fhew it,

I thought fo once, but now I know it.

Un ment, wo er in Lebensgrose vorgeftellt ift.

Juch einer Sthaufptelerim, $\mathfrak{N}$ i d) a rd, und einem Schaupieler $\mathfrak{B}$ o o th fino bier febr ebrenvolle Pronumente errid)tet. 


\section{(.103)}

New ton hat ein Fegr prádftiges Denemal etranten; es ift oben beim Eingange in das Chor, und diefem gerabe gegenúber ganl unten. in Der Sirde ift wieder ein anderes erridftet, mels des auf diefes erfe bintweibt.

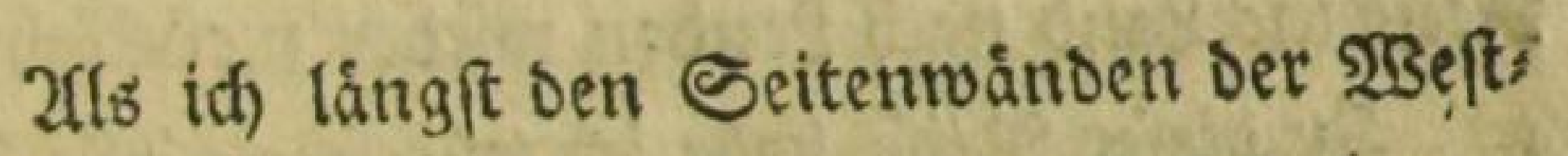
minferkfirdse binunter ging, fab ith faft lauter in Marmor gebourene Denfmáler groß̧er 2romi: rale, bie aber mit \$oracht und Biertratben viel zu fegre úberbáuft twaren, als daß̉ fie báatten einen

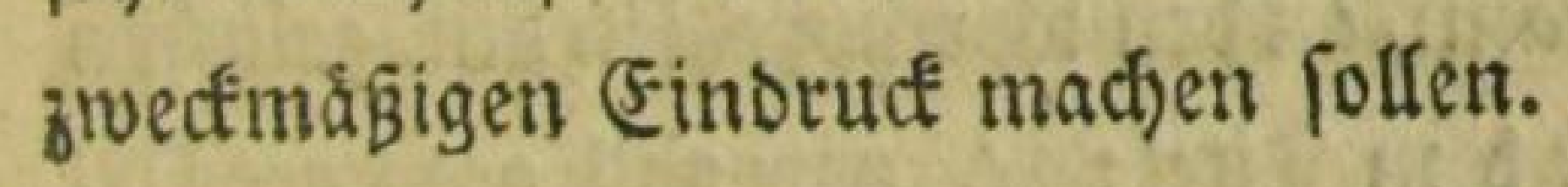

Zfm liebften verfígte ids mid immer rotes ber in Den Poets Corner, wo ids die vortrefflids) ften Sopfe aus verfchiednen Beitaltern, in vete traulid)er Sefelligfeit zulammen erblicfte, uno vorzúglid bie edle uno geld)mactvolle Simplicitát der Denfmáler auf oas (S)emúth einen erbabnen und túfrenden (Finoruct machte, inbeß oft eine lebbafte (5rimnerung an irgend cine Sieblingsftelle,

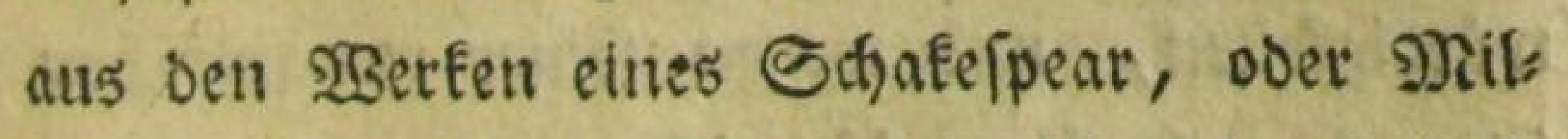
ton, in ber Soele errvadite, welthe mir bie Sieis fter diefer grofen Todten berzuzaubetn fosien. 


\section{( 104$)$}

20n 2obifon uno Pope Gabe id) feine Dentmáler hiar gefunden. Die Stråber bet 负nige, uno einige andre Merfmirdigfeiten in ber 2 Seftminfterabtei Gabe id nod) nicft gefeben. Bielleidst geichiehet diefes, wenn ich von meines Reife ins gand nad) \&ondon wieder zurúcf́fegre.

Bu Diejer Reife habe id) jesct fdoon alle 2fne. ftalt gemadjt. (Fine Speciald)arte von Englans Gabe id) in ber Tafdhe, neb/t einem vorttefflichen

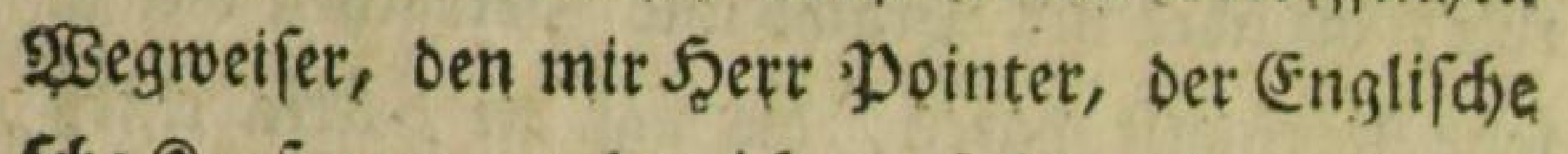
The Raufmann, an ben id) empfohlen bin, gelief)en bat, unter $\mathrm{b} \mathfrak{m}$ Titel: $A$ new and accurate Defoription of all the direct and principal $\mathrm{Cr}$ ofs roads in Great Britain. Dießß Bu(d), boffe ich, foll mir bei meinen Wanderungen gute Dienfe leiffen.

Jid) mar lange unfchlúmig, wo id) meinen

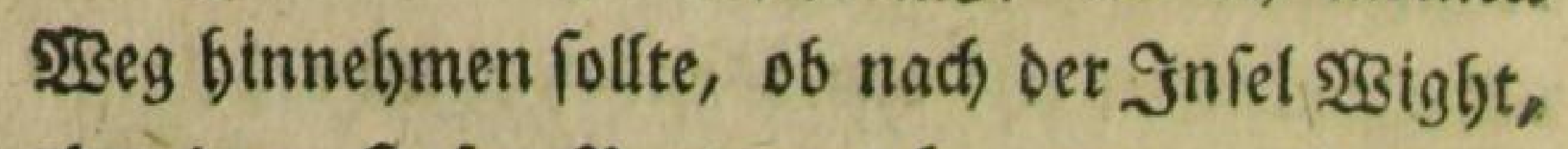
ober Dem Şafen Port6mouth, oder nad) Dars byfbire, welches wegen feiner vielen গaturmerts wúrbigfeiten, uno roegen feiner romantifchen

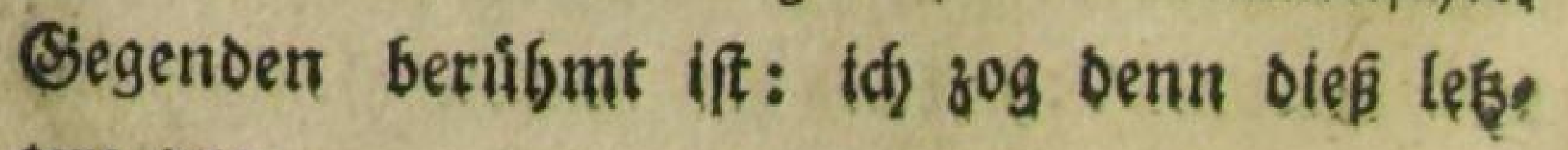
sere pQf: 


\section{( 109$)$}

Sei Setrn Pointer laffe tá sährens meiner afbrefentyeit meinen Roffer ftethen, um fein Logte bezablen ju Durfen, ofne darinn zu wobnen. Diefer Şerr $\mathfrak{P}$ ointer ift lange in Deutidjland gervejen, uno fpridjt fefyr gut und geen Deutidh. (Er lift ein fefre hofflidjer und gefâlliger गrann, ber auth Renntniffe unt Gefchmact befisct. Dabjer ift mir bie (Fmpfehs lung an ifn, von ben feerren Pe vifent und Dorner in Şamburg, weldyen idf) von bem Seerrn Sieheimenrath von Saubengetm in Serlin empfoflen war, fefre zu fatten gefommen.

Seeute werbe idf bits Frichmond fahren, wor Gin bie \$pofftutide um zroei ubr nicft weit von

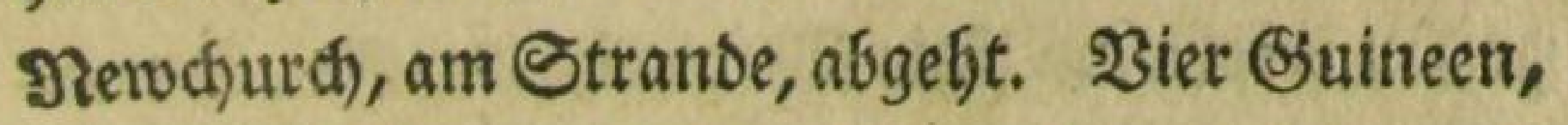

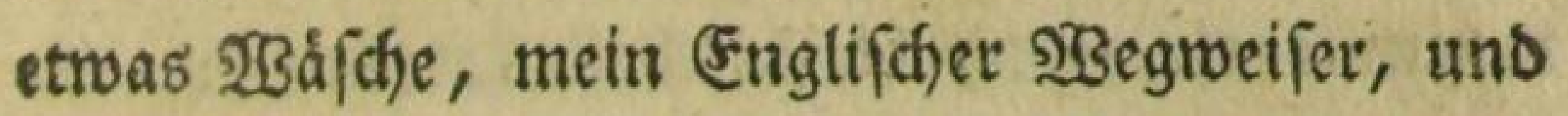
sine Landcharte uno Edjreibtafel, nebft sils tons verlofyenen Parabiefe, bas id bei mir ges frectt babe, fino meine ganze Equipage, uno id boffe febre leidft bamit zu gefjen. Doch, es fidlagt fijon balb zroet, uno es ift Seit, mids bei ber Pofteutidje einzufinden. Leben Ste

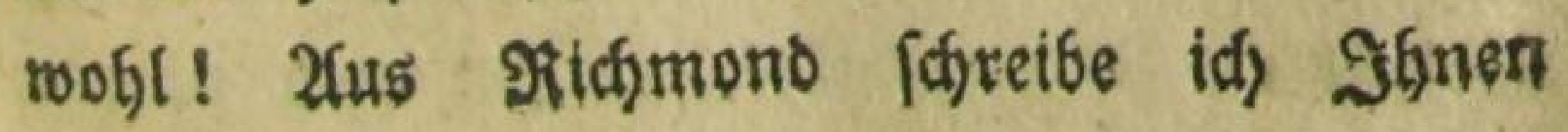
mieder. 


\section{( 106$)$}

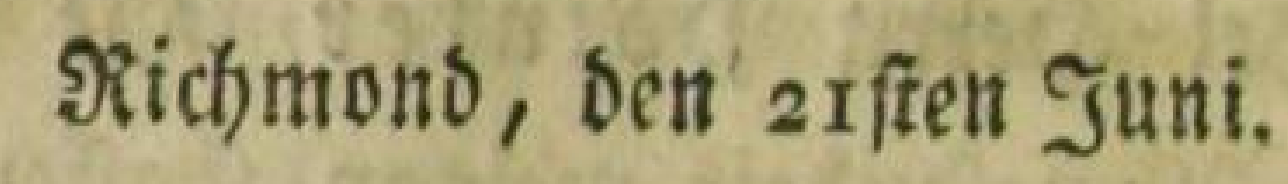

Geftern Nachmittag bin ich) Dentr zum er: ftenmale in einer fogenannten Stage ober Doft: futfche gefabien. Diefe Sutichen fino fefse ele: gant, inwendig ausgeichlagen, uno zroeificig, fur fects 'Derionen eingerid)tet, Die fidf Denn

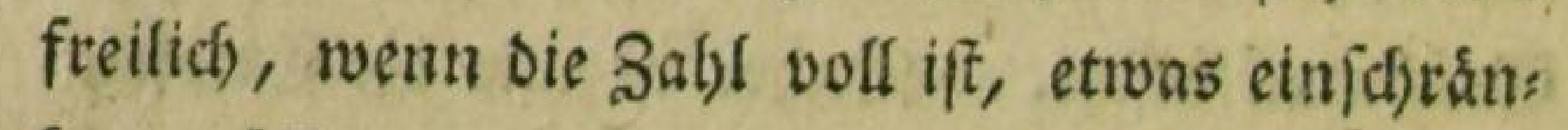
fen mútTen.

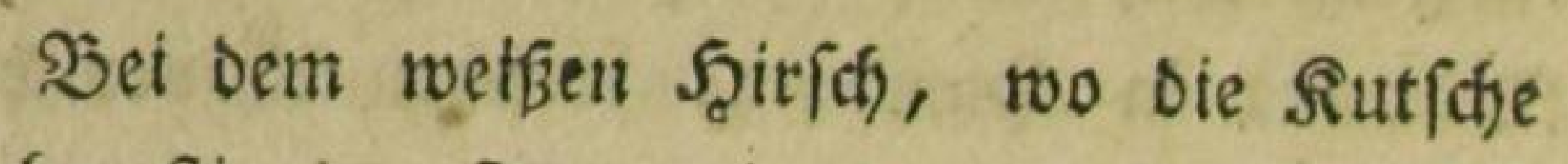
abfubr, ftieg zuerfe nur eine etwas áltlisje $D a:$ the mit binein; fo wie wir aber weiter fub): ren, warb fie ganz und gar, gróstentlyeils, mit Frauenzimmern, uno nur nod) einer Janns: perfon, befek̨t. Die (siefpráche der Frauęuam: mer unter einander, bie ficf theils faunten, waten ziemlich fade uno langreilig. Iod jog meinen

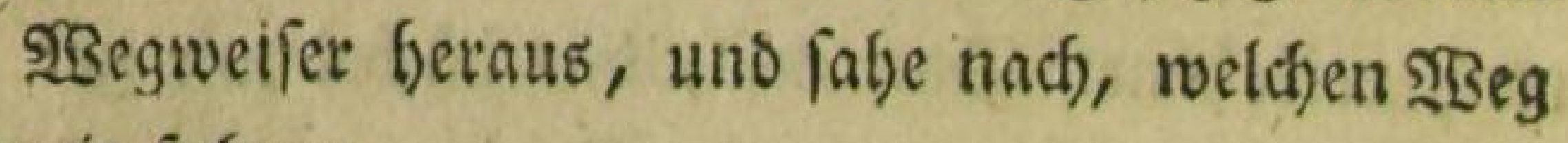
wir fubren.

El)e man meís wie man aus gonoon gefom: men iff, ift man fofon in f̧ammerimitb, Senfington, u. f.w., weil bie eluzelnen f̧åus fer voul Roubon an beiben Seiten noch immer fortbauten, wenn, Die Stadt fohon aufgebort 


\section{( 107 )}

Dat; es if beinate fo, als ween man yon \$oes lin nach Sthorneberg fábrt, obgleich in 2 Injes:

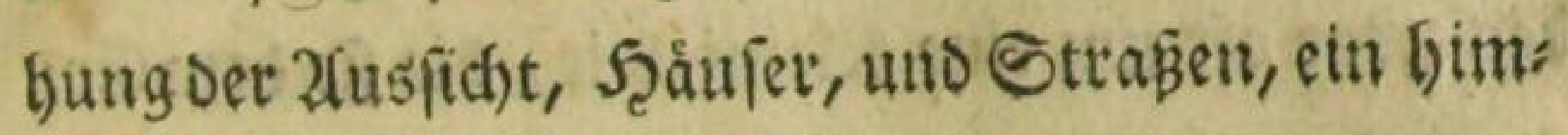
melweiter Unterfotico ift.

Es twat ein fatbner Tag, und bie hetrliffs: feen Zfusfifften von beiben Seiten, auf Denen bas Zluge gern langer verweilt bâtte, wenn unfer TSagen nidft fo neibija vorbeigerollt wáre. (Etroas fondertbat fah es mir aus, als idf) einige

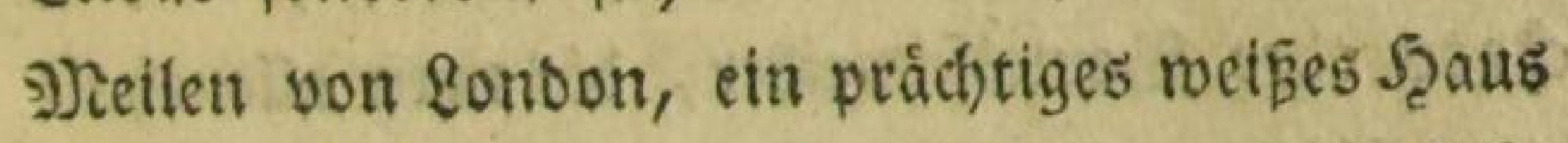
in oer Serne, und an der Şeerf(trá̧e soo woir fulfs ren, einen Szandweifer erblicte, worauf oie SGorte franden; jenes groß̈e weißße Şaus in der Serne iff eine Boardingfchool:

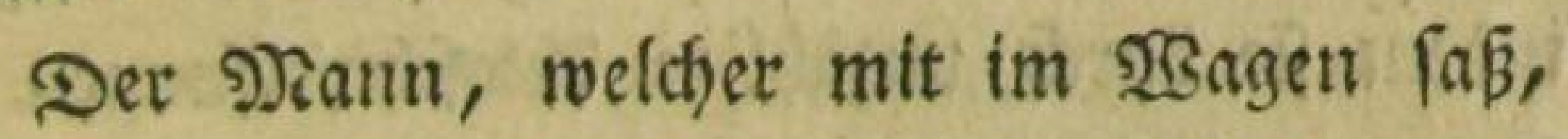

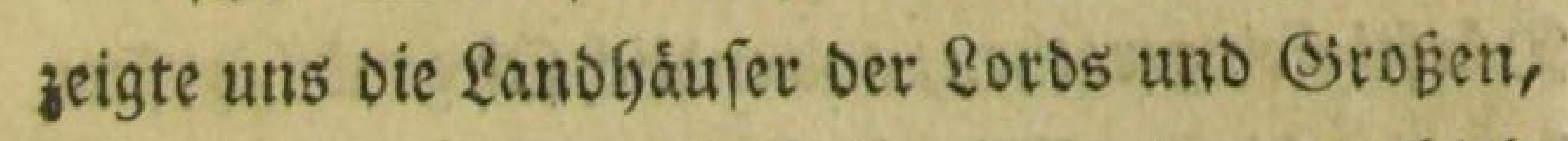
vor weldsen wir vorbeifubten, uno unterfielt

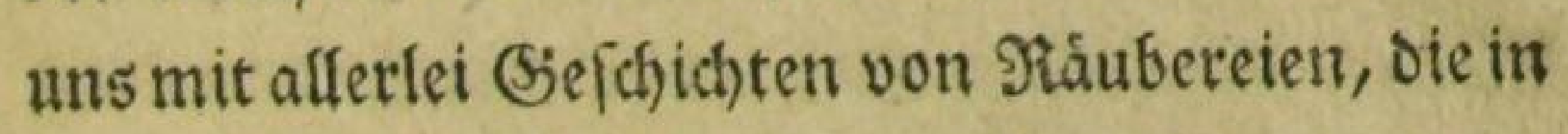
diefer Biegeno an gicienden verúbt worben waren, fo Daß Dem frauenzimmer anfing, etwas bange zu rerden. Drauf fienger an, Die Eflue der Eingtie

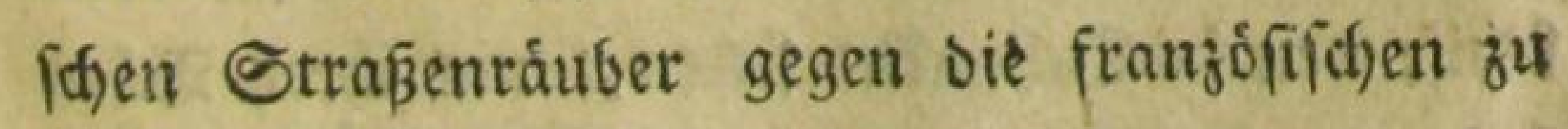
retten: Diefe raubten bod, nur, fagte er, aber jene morbeten zugleidy. 


\section{( 108$)$}

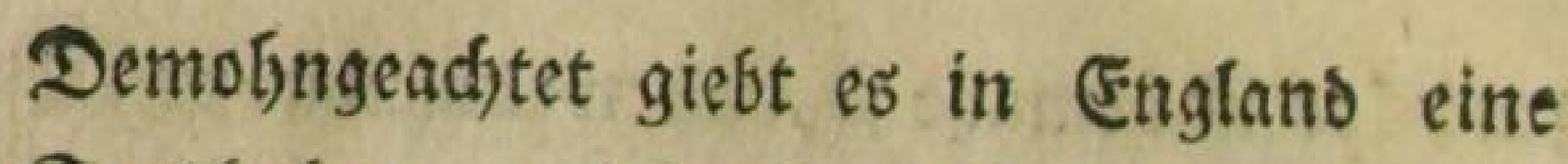
Zft Eplasbuben, welche ebenfalls morben, uno Das zroar oft um eine Sileinigfeit, Die fie Dem (5r: mordeten abnefgmen. Dieje beisen Footpaos, und find freilich Die afferniedrigfte Slaffe von ben Englijđen Spişbuben, 'unter Denen eine ges wiffe Siangordinung berejdt.

: Die vornefmfte Rlaffe fint bie pictpos cet ts ober Seutelidfneiber, bie man allenthals ben oft in den beften Giefellfidaften findet, weldye gemeiniglich féfr fein und fauber gefleibet fino, Te daß̄ man fie fúr \&eute von Stande Gált, wels des fie benn audf zumeilen wirklid) fenn mogen, tndem fie ourch unzáglige 2lusfdrweifungen in Dúrftigfeit getathen, uno enolich fich) gendthigt fin: Den, zu Diefem Dittel ibre zufudgt zu nebmen.

Nadf ifnen fommen die Ş tg frway men,

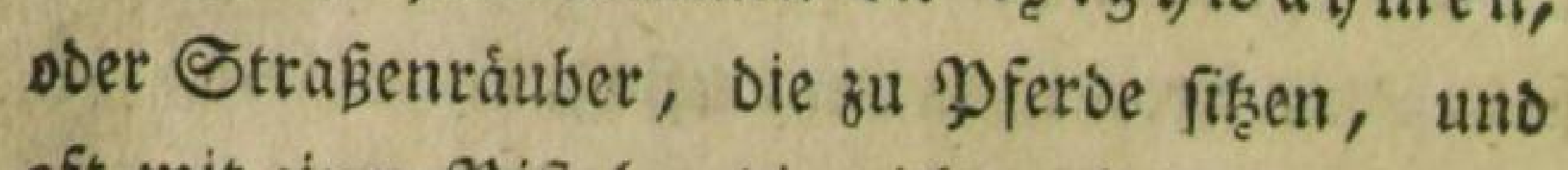
oft mit einer \$iftefe, bie nidft geladen ift, die Feilenten in Gtgrecten Fergen, um ibrer $33 \delta$ sts fen babbaft zan werden, weldhe aber autd zumeis

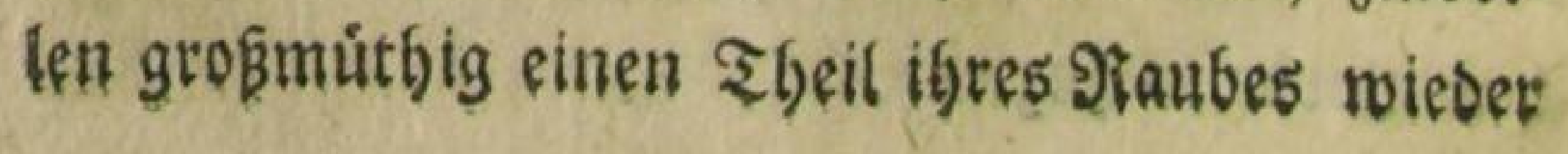




\section{( 109$)$}

zutưcfgeben, unb n(b)t leid)t eine Piotsthat bes getyen.

Dann fommt bie britte, unb niebrigfte abet aud) idjänolidffite Silaffe Der Footpads, weldre ju Supe fino, und oft um ein \$aar Sdjillinge wils

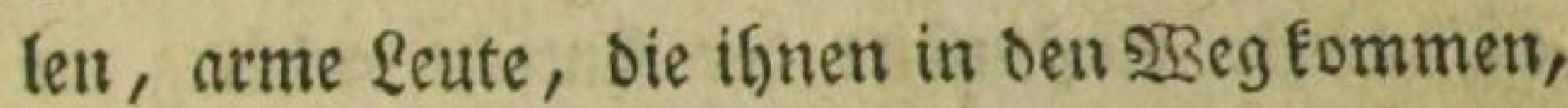
jämmerlic) ermorben, wovon in Den (Englifchen Beituugen faft táglid trautige $\mathfrak{B}$ eifpiele zu lefen finb. SGabridgeinlid) moroen fie beswegen, weil

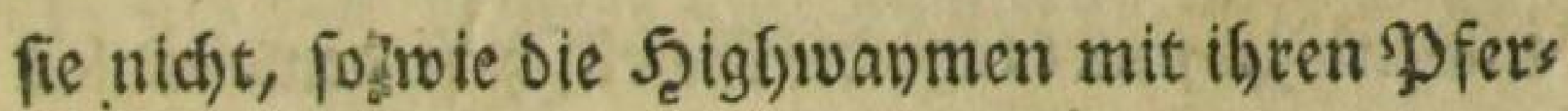
Den, Die Sflucft nefmen Esunen, uno man ifnen

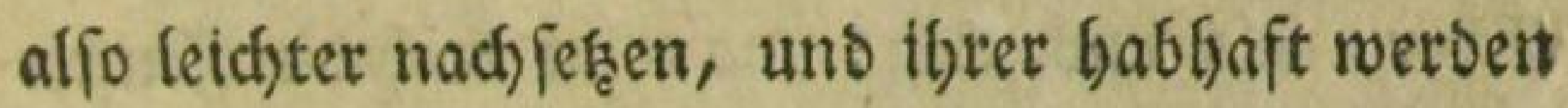
fann, wenn ber Seraubte fie angeben follte.

Dod wieber auf unire Poftentid)e zu fom men, muв ić) erinnern, daß̧ es noch eine fons Derbare 2lit nid)t in, fondern auf berfelben zut fafren giebt. (5) fiken nebmlid) Derionen von niebrigem Stande, oder bie nicft viel bezahlen fonnen, anfatt inwendig, oben auf ber Rutiche, obne dấ ein Séländer doer Sif̧e oben anges

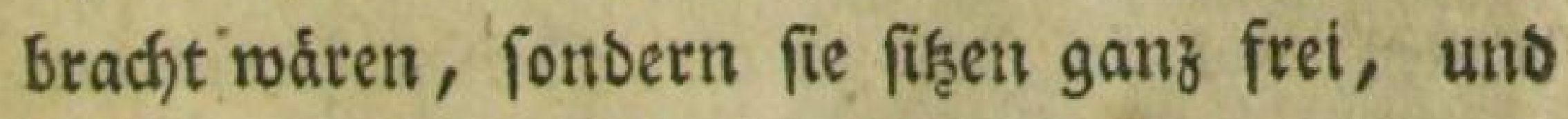
Iaffen bie Seine berunterbángen.

Diés nennt man on the Outfide (auf bet zuken(eite) fabren, wofát nur galb fo viel ber 


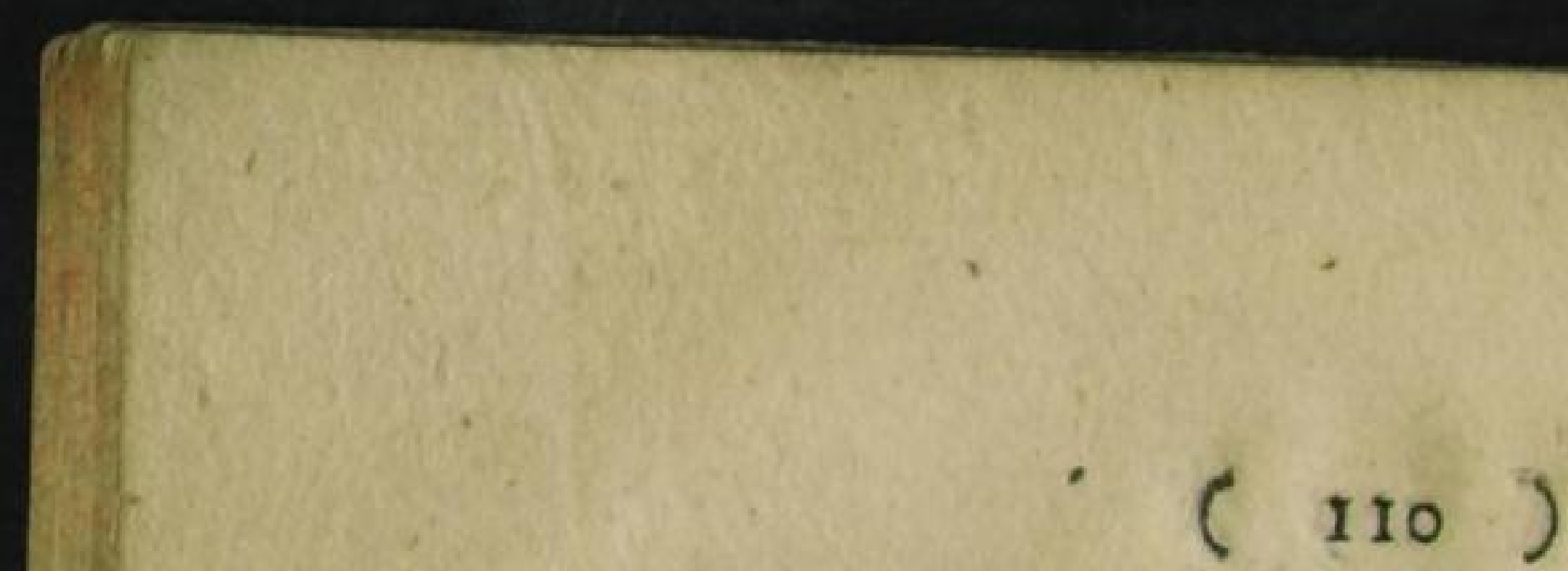

fable roitb, als wenn man on the Infide (inwer: big in ber Sutict)e) fáfrt. SBit batten alfo fechs

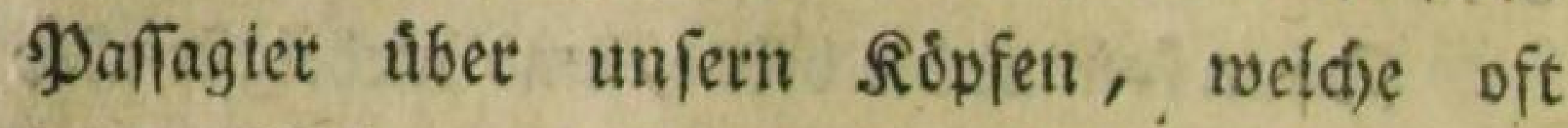
beim -2luf : uno 2fofteigen ein et/chuttternbes Seráuid) liber uns verutfachten. FBer fid) auf biefer 2fuß̧enjeite oer Rutifhe gebórig int (sileid)gervidat erbalten fann, ber first ba recht gut, und fåhtt im Soummer bei beitern Tagen, wegen ber freien 2fusficjt, faft angenebmer, als inwenoig, nut taugt oie (Siefellichaft gemeiniglidf) nidjt viel, und ber Staub ifit ebenfalls befchmers licher, als inwendig, no man bod) Die Fenfter nach) Selieben gumachen fant.

Su Renfington, wo roir anfielten, wollte ein Jube gern mitfabren, da aber inwendig fein Dolsh mefor war, fowollte er nidft an ber Outfide

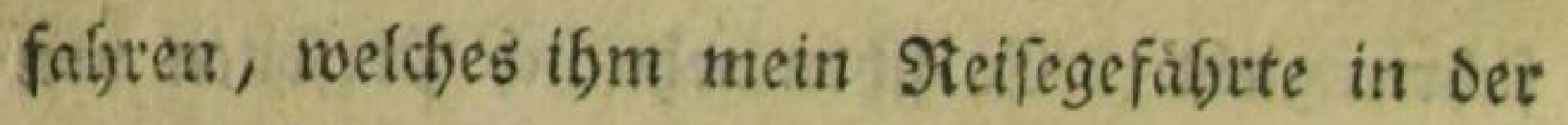
sutjọe febr úbel nafm, uno fid) gar nicht barús ber zufrieden geben fotmite, Daß̧ ein Jube fich f(bame an ber Outfide zu firsen, ba er Doch nichts weiter, als ein Jube wate. Dieles 230 urtheil unD Berachtung gegen sie Iuben babe idh úber: Gaupt bier in Englano meit foanfiger; als bei uns bemerft. 


\section{( iII)}

Bon ben prád)tigen \&andbåufert uno \&uft: fidiffern, vor weldhen roir nun vorbelfubren, fonnte ith, aus ben Fenfiern un[rer Sitticte ins mer nut fructweife und abgebrodjen einen ppro: fpeft baben, weldhes mid) winkichen lię̧, balo aus biticm rollenden Rerter befreit ju feyn.

Siegen 2(betro famen roir benn aud in Sicd): mono an. In Eonbon batte id) vor meiner 2 (b) fafyet emen Schilling bezabitt, bier aud) eiment, uno alio von fonbon bis siichmono nidft mefle als jowei Schilling.

Sobald id) in einem Siaftyofe abgetreten wat, und ein 2lbendeffen befrefit batte, sieng id) Fogleid) aus, um die Stadt uns bie Siegens unther bu bejeben.

Die Staot fieft fofon meit länolicher, ans genebmer unb beitrer aus, wie \&onboil, uno bie Şaufer fidjeinen auch nicht fo fef)r yom Robjlens Dampf gefdrwatjt fu feyn. 2fuch fam mir es fiet fhon weit gefelliger uno ritrthbaret vor. Die

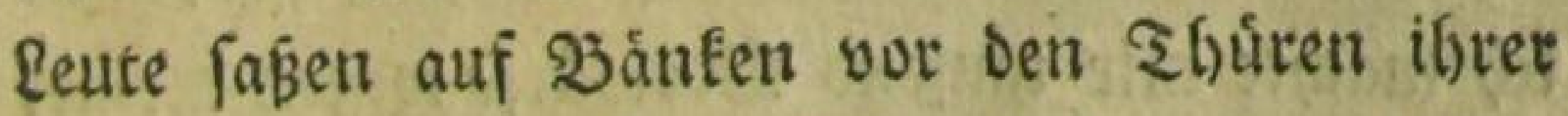

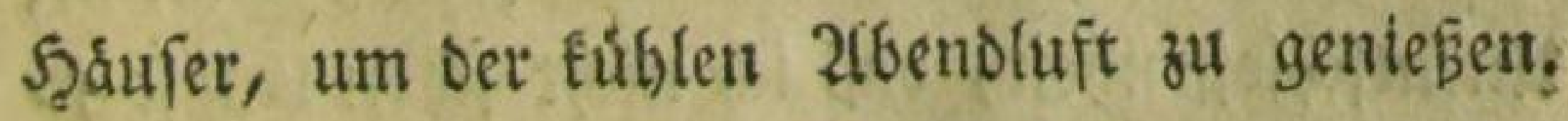
2fuf einem fobonen grunensiafenplaf̧e mitten in bex Etad ergoffte fid) ęine grobe 2(njah) Sinaben und. 


\section{( 112 )}

auch etrwachlene junge \&eute mit Saflppieleti. 2tuf ben Straken berridfte gegen das Seraulád von Sondon eine angenegrme lándliche Stille; uno man atbmete bier eine reinereiuno freiere \&uft ein.

Nun gieng ich aus oer Stabt, Ĺbet eine Soructe, die uiber bie Themfe geht, uno wo man allemal einen \$enmy bezablen mus, fo oft man Ginúber uno berúber gegt. Die Srúcfe mar feţ boch uno bogenformig gebaut, uno von ifir fieg idf rogleids in ein reizenbes $\mathfrak{s}$ gal, am ufer ber Ifemie, binunter.

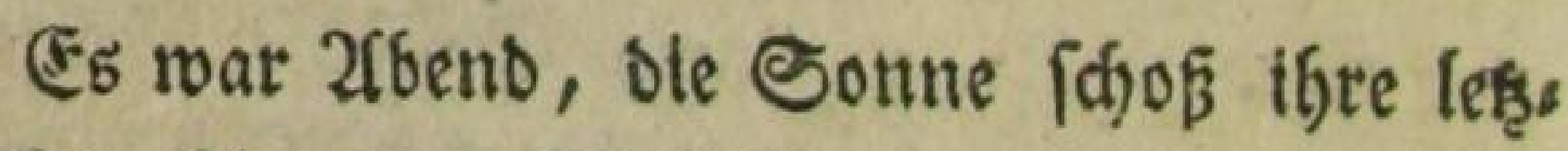
teit Strablen das ₹gal binunter. 2lber diefett abent uno diefes Thal werde iaf nie vergeffen! Dies war in feiner 2frt ber reinfte 2anblick det fojonen Natur, ben tich in meinem \&eben gebabt babe. $23 a$ as ich dabei empfant, wirb fein Febers ftridf fojilbern Eśnnen.

Tage und Stunden fingen mich an fu ges reuen, die té in Eonvon zugebracht batte, uns idf mad)te mir tou (ens Borroúrfe regen meiner Unent/d)loffentheit, Das ich nicht fobon längft jes nen groben Serfer verlaffen batte, um midh in einem Saradiefe zu verweilet. 


\section{(113)}

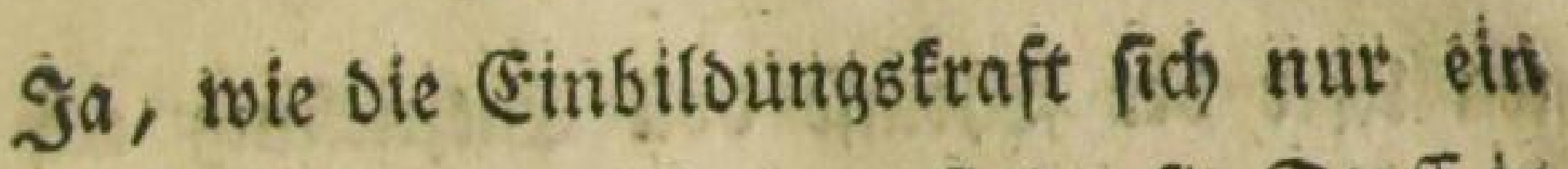

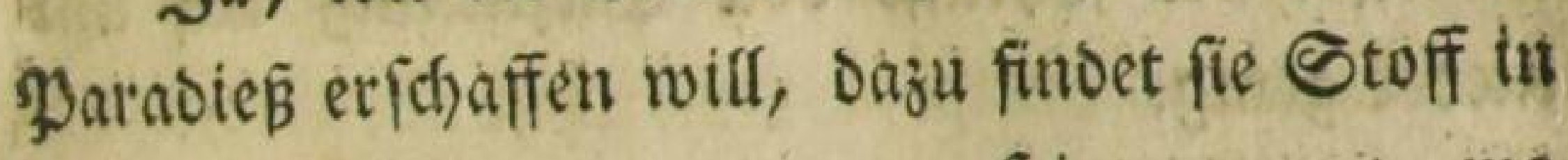
biefen bertlident Biegenden. Shier war es, wo ₹Gomfon und \$ope die reizenten Silder fammleten, woraub iffere unnadjafgmlidfen (bjes

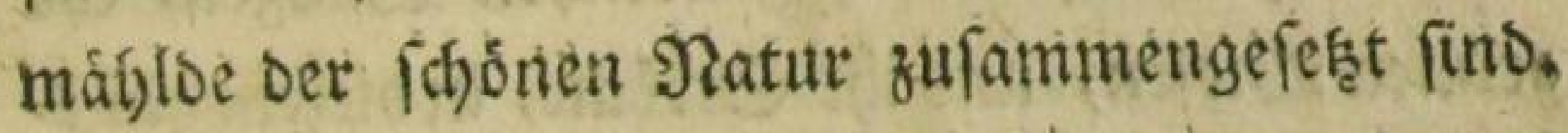

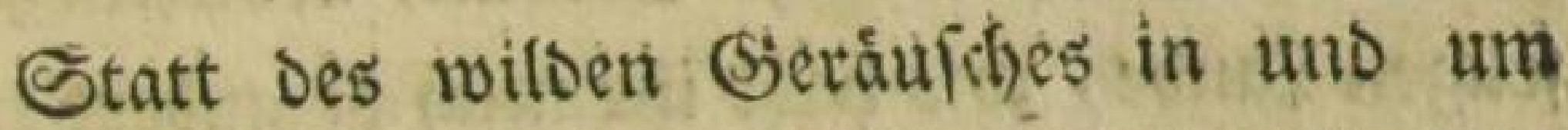
Qonoon, fabe id in ber Ferne wenige einjelne

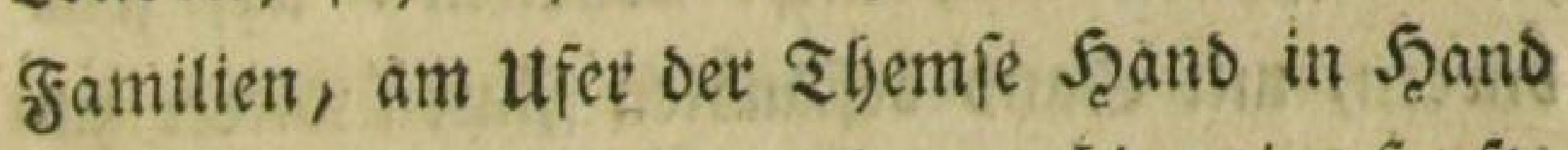
fpasieren gefen. Zllles atbmete bier eine fanfte

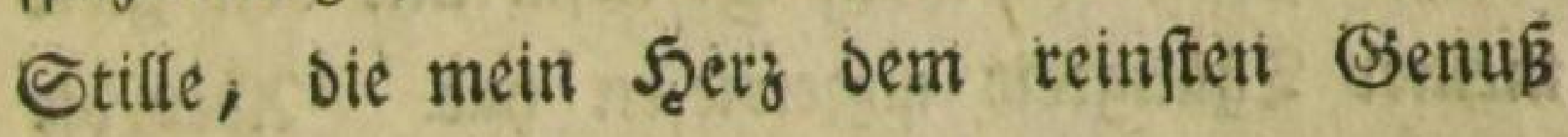
eroffiftretè.

Unter meinen Júkên Das weidfe Grün, bas nut auf Diejem Soden wádfit, an ber cinen

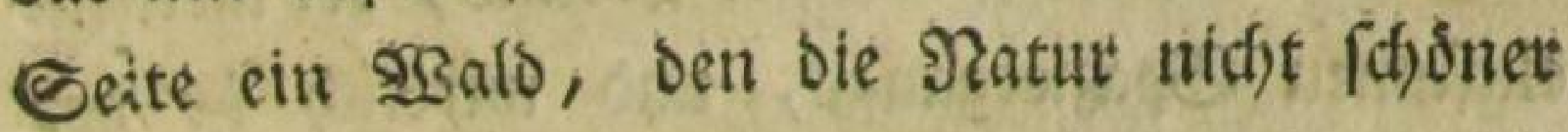
bervorbringet fann, und an ber antern bie Themie, mit igrem jenleitigen Ufeet, bas fich wie ein 2 (mmpfitfeater empor foob, und feine fyos

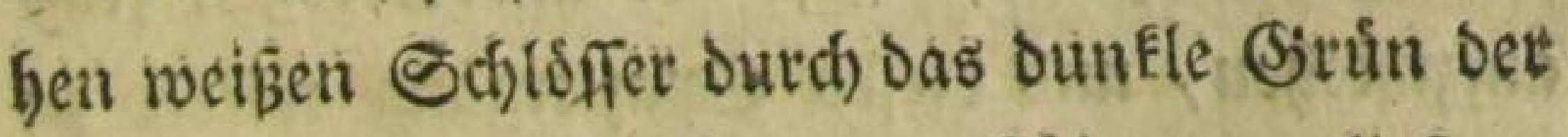

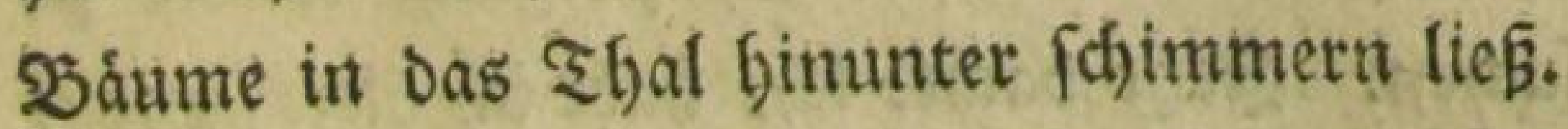

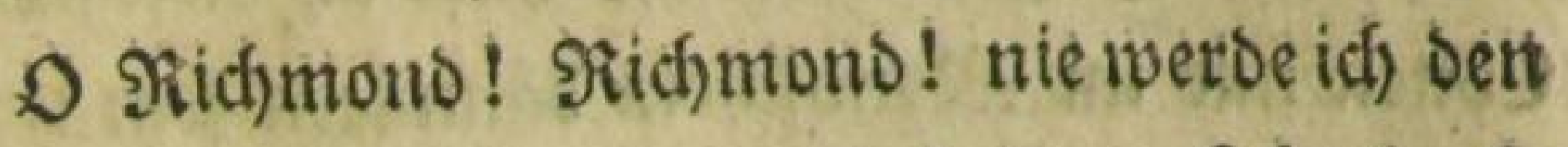
Xbento vergetien, wo bu von beinen Szugen to fanft auf mich) berabládelteff, und mich aflen Suntmet vergetient lię̧eft, Da ich an bem blumigs 


\section{( 114 )}

ten Uffer bet Themfe voll Entzuctung auf uns nieder gieng.

2Bobl mir, oaß idjijenem melandjolifchert Gemáuer nod) zu rechter äeit entfloben bin !

$\mathcal{D}$ ifgr blúbenden jugendichen 5 sangen, ifer grůnen গSiefen, uno iht Strơme, in biefem glúct: feligen Sande, wie habt iffr mid, bezaubert! aff lein bies foll mich nidjt abbalten, auf jene Durren, mit Ganb beftåubten fluren mieder zแ" rưdfufehren, wo mein Sdjicfial mir ben flect meiner ₹Gátigfeit angerwiejen bat. 2fber oie Eximnerang an bieje Scene foll mir noch mancbe Geitre Stunde gerwábren!

- So bactite ich, liebfter Freuns, bei meinem einfamen Spajiergange, uno wirflich if ' ber geftrige 2fbend ciner ber angenebmften meines gebens gerwejen.

Sd) nalsm mir feft vor am Morgen frúl, aufzufteben, uno diefen Spaziergang roieder zus befudsen. Jebst oachte ich, habe idf) diefe fanftent Ebanen nur im Mionofichein Dámmern fefgen, wie wrtoen fie bliz̧en im গorgenthau! Znilein biefe Shoffnung (h)lug mit febl. 


\section{( iis)}

Uino roie man ficf benn gemetniglith bei eititen groß̧en ßergnigen immer auf einen fleinen vera. orieşlidfen umftano gefaß̧t madjen follte, fo ging es mir aud) [ier, ba id) midf etwas ver[pátet, unt

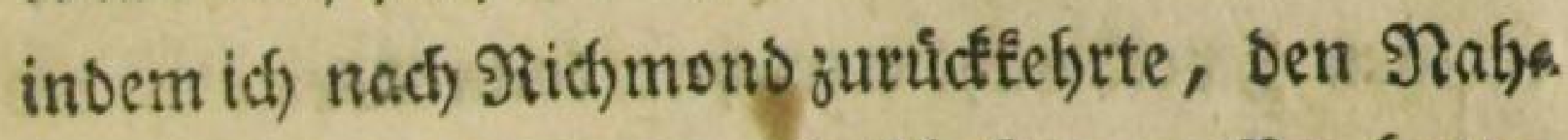
men uno das Sdyild des Sjafthofs vergeffen batte,

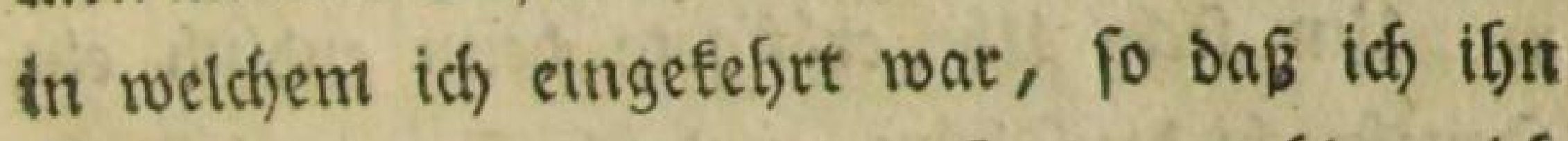
erft mit vieler Mathe wiederfant, nactbem if beinalye bie ganze Stadt Durd)laufen war.

Da id) zul Feaule fam, erzáflte tif) von meinem Spaziergange, uno man madjte mir fefr viel Siúfmens von Der 2(usfidjt von einem Şugel bei গiidjmonto, ber unter bem গafjmen Richmondhill befannt ift, und eben ber war, won weld)em id) bie weiken Şåufer hatte in bas IGal Ginunter fajimmern fefoen. Bon biefem

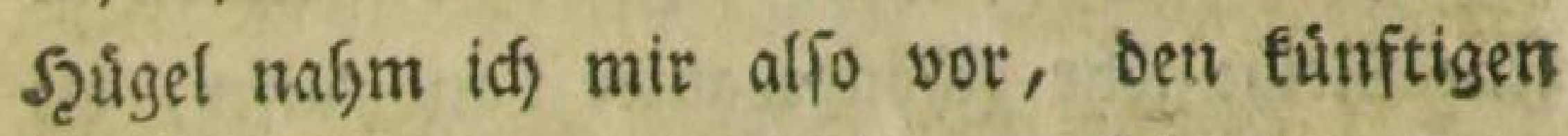
פorgen bie Sonne nufgeben zu Fefen.

Die Frau im Şaufe zanfte barauf nodf mis Dem Esefinive, worúber idf erft ziemlicf) fpát ein (c)lief, aber bod) Den Miorgen um bret Uhr fdjon wieder aufgeftanden wat. Und nun fúblte id

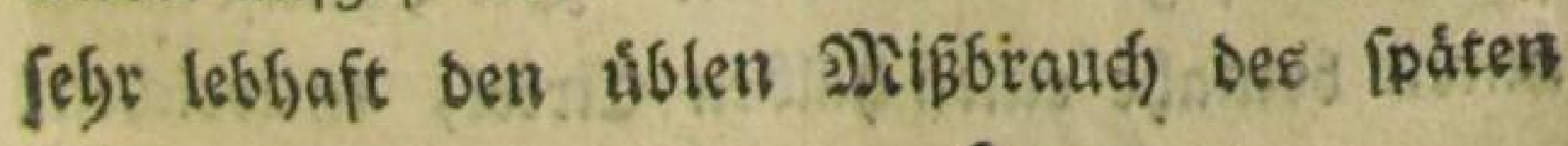




\section{(116)}

Tufitehens in England; benn weil fein Mien wad) war, fo fornte id) nidbt aus Dem Şaure fommen, uno batte orei Stundenlang bis um fechs $\mathfrak{U t h r}$ die entię̧lichfte \&angeroeile, weil ids meinen âwect nicht erreidjen tonnte.

Utm fechs $\mathfrak{U}$ )r eroffnete benn enslich ein

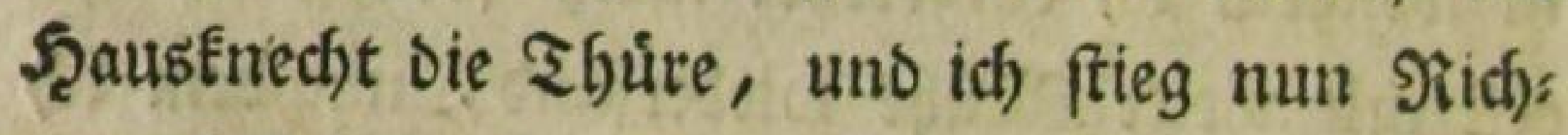

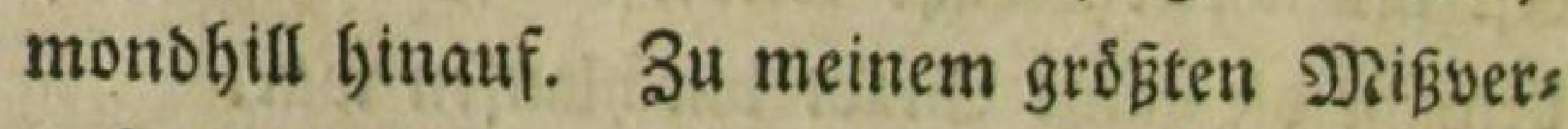
gnuigen aber hatte fich feit einer Stunde ber f̧im: mel umzogen, und es rat fo trube geworden,

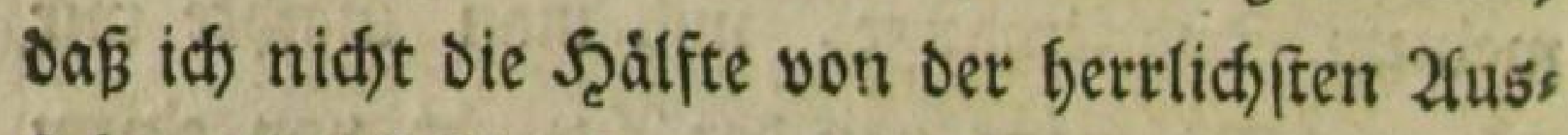
ficht, ole th) bier batte, genieben Eonnte.

Oben auf Dem J̧ügel ift eine afllee von ßafta nienbåumen, unter weldhen fin unb mieder Ranas pees zum Siken ftehen. Şinter Den afleen iff eine Fieibe febr fobongebauter Lanbjáufer, oie gerwís, wegen ber reinen $Q u f t$, Die man bier eins

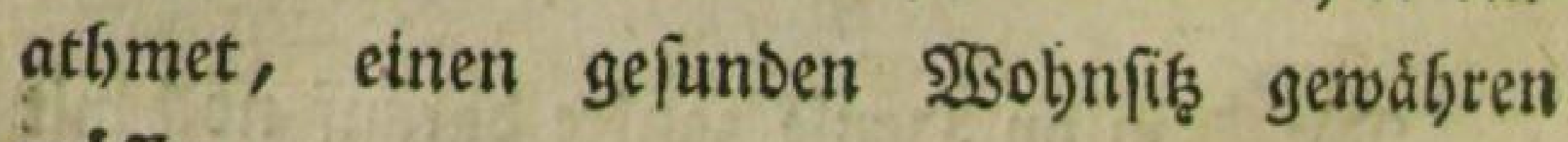
múfiter.

Der 26b̧ang des J̧ưgels bis an die Themle binunter ift grún bewadjfen. Die Them fe madjt unten beinabe einen balben (Sirtel, in velchem 


\section{( 117 )}

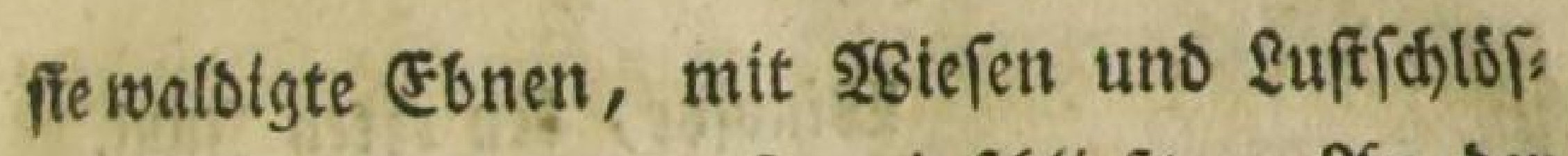

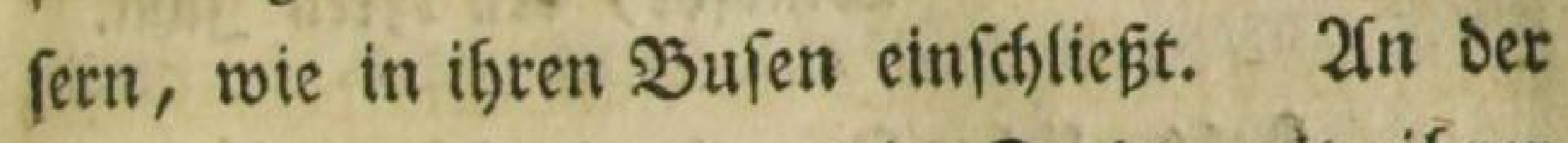
einen Seite fieft man bie Staof mit ifrer hoben 23 rücfe, und an bet andern liegt ein Dunfler Baald.

In Der Ferne fofimmerten aus bem Sirunde Der Tasiefen und $23 a$ álder allenthalben fleine Dórfer hervor, fo daßs biefe 2fusfiddt, obngenditet bes

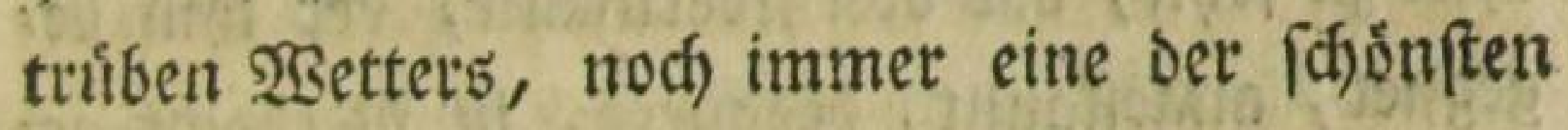
war, bie idf in meinem \&eben gefabt babe.

2lber wie fommt es? geftern 2fbend waren meine Empfinoungen weit lebbafter, uno bet Einbruct meit ftárter umo romantifecher, oa id) nuts bem Thale Diejen Şügel Ginauf bličte, uno mir ba allerlei bertiches bachte, als beute Mcot: gen, ba ich von dem Scuigel felbft das Thal úber: (chaute, und nun mußte, was ba war.

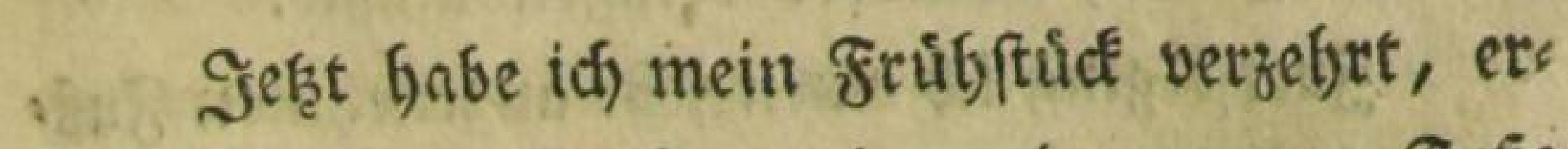
greife meinen Stab, und werbe nu zu \$uвe meine reile antreten. 24us ssind por follen Sie mefgr won mir goren! 


\section{(118)}

25inbor, ben 13ten Juni.

Sef̧t, lieber Freuno, da ich von bier ant

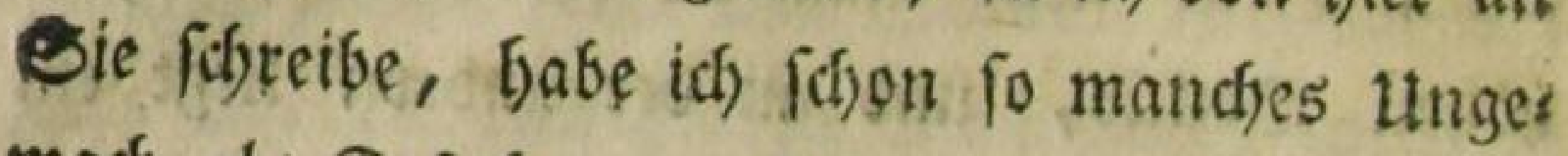
mach als Jubganger erfahten, Daß́ id) beinalge unichlúfitg bin, ob ich) meine Sieife fo fortfersen foll ober nicf)t.

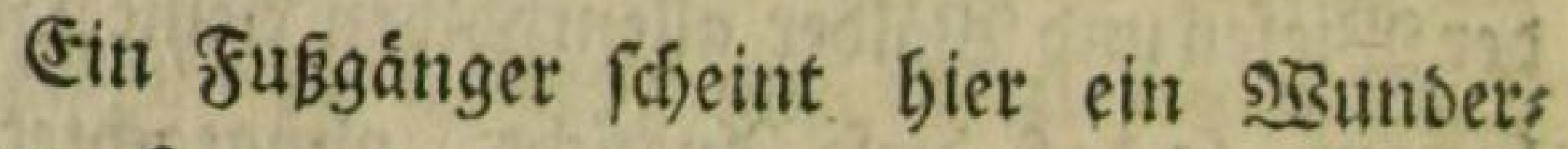
thiet zu fenn, das von jebermann, Det ifym bes gegnet, angeftaunt, bedauert, in Berdadjt ges baltent uno gefloben roiro, wentigfens if es mit

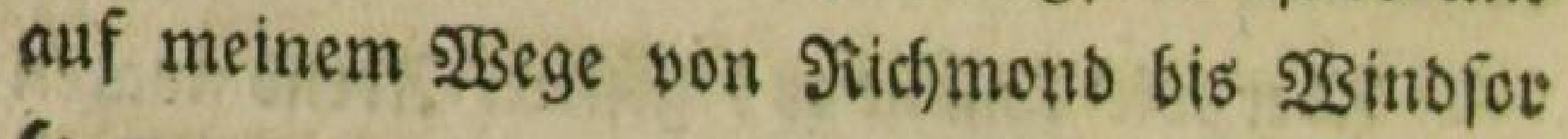
to gegangen.

Miein $283 i t t 5$ in Ridsmono fonnte fich ger ftern Norgen (d)on nicht genug verwundern, Daş idf es nagen wollte, bis orforo uno noch meiter zu бú zu gefen. Dod) gab er mir feinen 'Solnn, einen fleinen Snaben mit, oet mich auf ben 23 eg nach 5 sinofor bringen mußte.

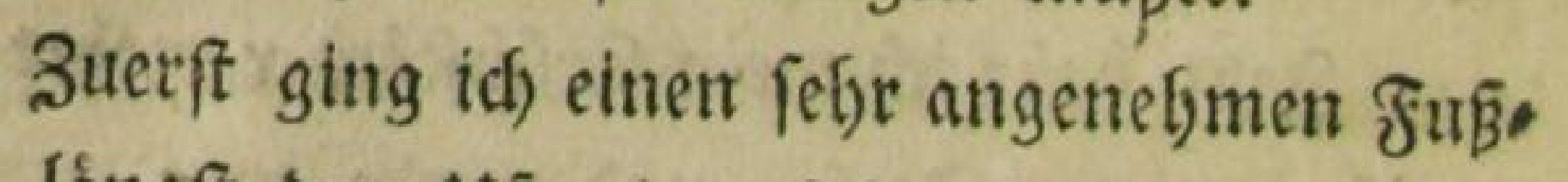
feig lángft Dem ufer der Shemfe binauf, wo bicht neken mir zur rechten Seite Des Sirnigs Sarten lag. $2 \mathrm{~m}$ jenfeitigen 4 fer ber Themfe lag Jalewort5, ein Flecten, Der fich aber burd) 


\section{(119)}

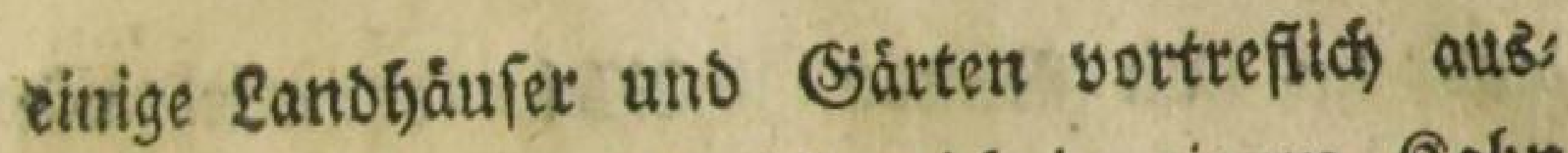
nafy. Szier muste id midy in einem Saljn überiefen laffen, um auf Drford roab, oder bie Straß̧e nad) Dxford zu fommen, weldoe zus gleid) nach $\mathfrak{S}$ intofor fúlytt.

2fls idh úbet bie Tlyemie war, fam ich, att ein F̧aus, wo id einen s)iann, ber vor bet Thur ftano, fragte, of id) auf bem rechten $233 e s$ ge nach Orforo (el)? Yes, but you want a Carriage, to bring you there, (ja, aber ifs brauds)t ein Fu(frwerf, um eud) Gingubringen) (agte er: als idg ifim antwortete, id) wúrbe zu Fußse fine getyen, fabe er midh bebeutend an, Thyutttelte ben Sopf, uno ging ins Şaus finein.

Jach war nun auf Orforbroab, einem fegr breiten und fojonen 230 ege, wo mir viele Fulst: wetíe und Pofteutiohen begegneten, Die Dentu Dod) zuweilen, wegen der fcire einen etwas bee fifwerlichen Etaub verurjadjten. Die fijonen gruinen Secten, weldje die Eandftraben in Eng: land einzăunen, tragen febr viel zur 2(nuef)m: lichfeit berjelben bet, weldjes audh bier bet fall war, und wenn id) múbe war, fescte tó) miç zumeilen in Den Sdjatten einer foldjen Sgete

$$
\text { S2 } 4
$$




\section{( 120$)$}

uno las int Milton. 2frtein es twato mit balo befdrertich, dons micf die ßorbeiret: tenden uno faffenden immer mit einer foldjen 3etrounderuitg angaften, uno joldfe bebeuteribe 9) iinen machten, als ob fie mich fúr einen खुet: rudeten bielten, fo fonderbar muste es ibnen vor: fommen, einen \$ienjoben an ber sffentlidjen Eanoftrake fisen, uno in einem suutbe le fen zu feben. Ith lat midh Daber genothigt, wenn idf micf austuben uno lefen wollte, mir irgeno:

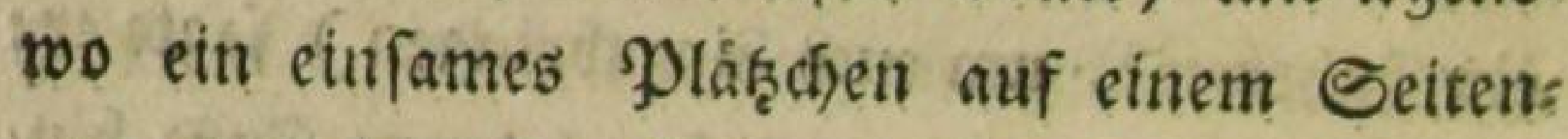
rege von der feerftraß̧e aufz̧ufuchen.

SSing iff wieder, fo rief mir jeder vorbel: fafrende Suticjer zu, ob id) nid́t auf ber Outfide Der Pofteutide mitiabren rolle; went mir nut ein baner fu \$rerde begegnete, I, fagte er mitfeidsyoil, warm walking Sir! (Es) ift felgr warm ju gefen, mein feerr) uno wenn ich Durch ein Dorf Eam bezeigte jeder alte 233 eib, ift Ṡebauren, Durdh ein God almighty!

3is founflom war ber 2 Beg felte ans genebin. Nachber roro er etwas follecflet,

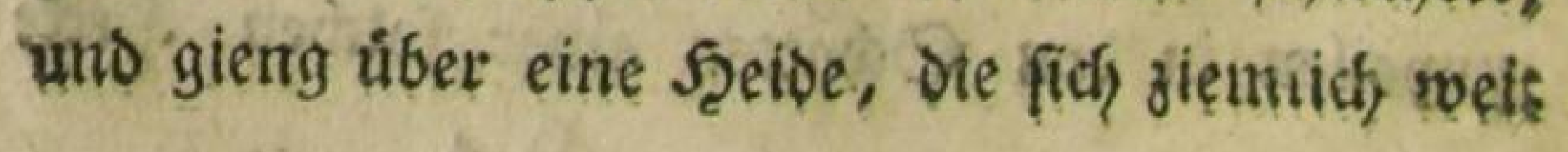




\section{$(=121)$}

erferecte, anf weldher idf) aber body hin und wies Der Gdjafe reiden fabe.

2fls id etroas mide geroorden war, fand id) auf einmal zu meiner 2 ermounderung mitten in ber Setbe einen Saum, der ganz einfam ba ftanb, uub einen Shatten, wie eine Iaube um fich ber verbreitete: unten war rund um ben

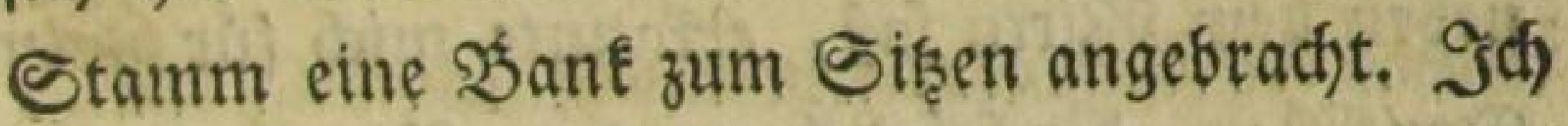
rubte in Dem Schatten diefes $\mathfrak{B}$ aumes aus, las eine SBgeile im Silton, und fofrieb in meine Sdfreibtafel, Daß̉ ich Diejes इaums, der ben miden 2 Sanberer fo wofjthjatig it: feinen wirths baven Esthatten aufgenommen babe, gebenfen molle, meldjes id) mun getban babe.

Die Englifaten Eleinen Mreilen find vors treftich zu geben; man freut fich bods, fo oft man eine Neile, in fo furzer Beit zurictigelegt bat, ob es gleich nur eine Täufdjung ift. Sgenn idh etnen ordentlidjen Sd)ritt gebe, lege id in zoei Stunden lechs Englifase Meilen zurúc:; und man fann auch beinabe fo viel auf eine berts (h)e Meile rechnen, wenn man insbejondre bie Bsite ber 2 sege mit in 2fniflag bringt. Sau \$eturiad) es einem aber eine angenebme Färs

$$
\text { S马? }
$$




\section{$(122)$}

fffung, ween man fieft, Daß mat in ein Paak Stunben zrodlf Mieilen gegangen if.

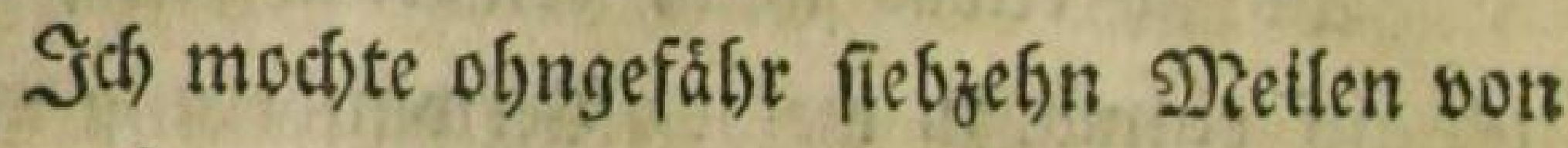
Zonbon fenn, als idi) an einen (Saftzof Eam, wo ic) fur ein wenig 2 Baffer und $23 e i n$ einen balben Schilling bezablen mufte. (rin Englander, Der

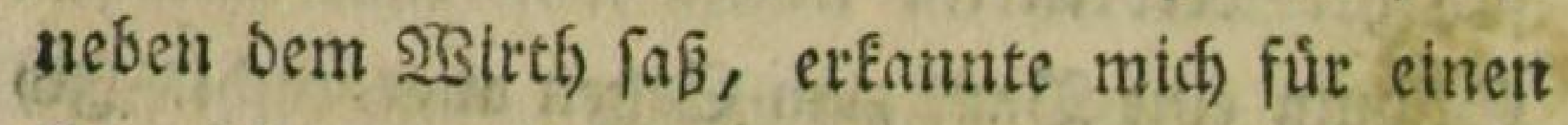
Deutichen, der folglid) aus Dem Baterlande fei: ner Sorniginn fev, Die et mit vielen Lobiprúchen rúf)mte, unb binjufesate, eine folche Sonigint Gabe (England nod) nicht gebabt, und merbe auch nicft leid)t eine joldbe mieder befommen.

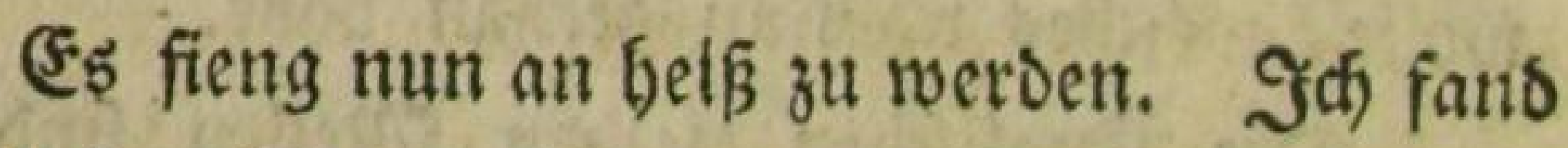
Jut linfen Seite nidft meit von der Seerftrape

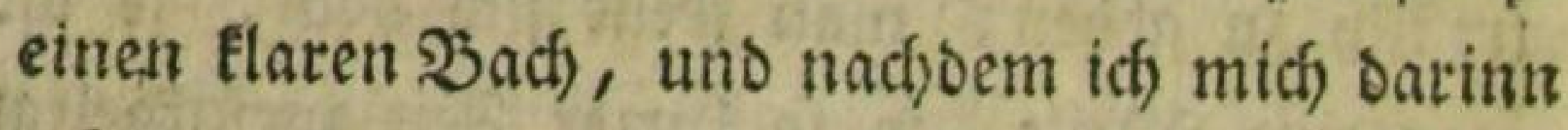
gebabet Gatte, leşte idf metnen $25 e g$ weis ter fort.

Die Secibe hatte fich verlofiren, unb es er: Iffinete fich rieder etne parabiefif he Giegento vor mir bis nach Slough, oas zlvanzig uno eine 4falbe Mieile von Sonbon, auf bem 2 sege แach Difort, liegt, und wovon zut linen Seite 


\section{( 123 )}

eitte Strape nach 2 sindor geft, beflen hohes

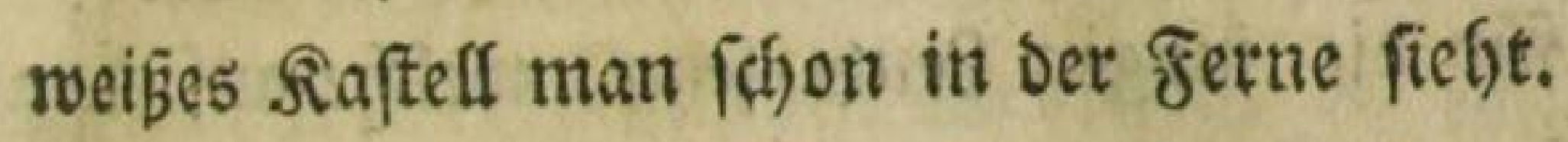

Эod) bielt mich bier nidht auf, fonderth ging gleid) recjter Şand, in einer (eb) angenefomen

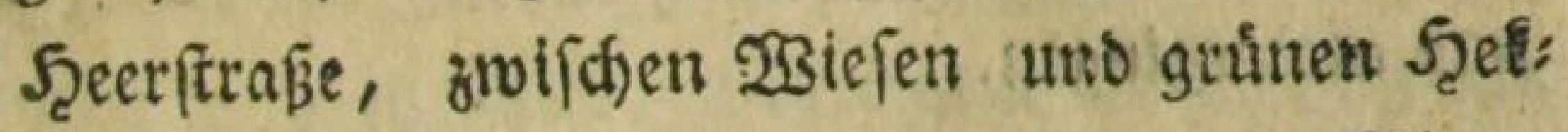
fen, nach शsinofor zu, wo idh betun um \$rittag antam.

Es iff einem Sremben fefor nuffalfent, wenta

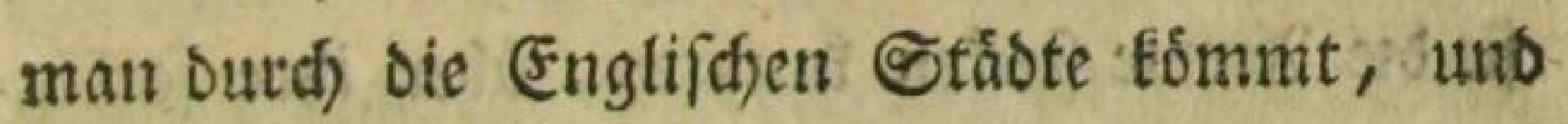
nidfts von bem bemerft, woburch fich bie Ettábte in Deutichiand von ben Dórfern untericheibet, weder STauren nodh Thore, noch fonft etwas Dergleidjen. Sieinen laurenoen $2 i$ fitator, feine brobende Sdjildwadje wirb man gewabr; fonDer frei und ungefindert geft man burd) Jlecten und Etádte, wie Durd) Die grope offine Natur:

Didft vor SBinojor liegt Eaton College, eine betúfymte sffentliçe (Erriefungsanftalt ober Syymnafium, Deren es, wie idy fichon bemerft babe, in England nur wenige giebt. Ef lag mir zur linfen Seite, uno zut Stedjten, ges rade gegenúber war ein Saffthof, in weldjen to) einfegrte. 


\section{( 124$)$}

5. Jeget mufte gerade sine Erfoblungsffun De fút bie jungen Reute fenn, weldhe auf bem Şofe vor Dem Sollegio, Det mit einer nebrigen Diauer umgeben soar, in grofer פienge auf und niedergingen.

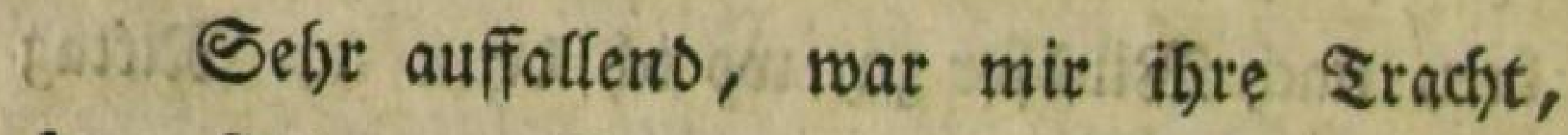
Denn fie trugen alle, vom groşten bis zum flein,

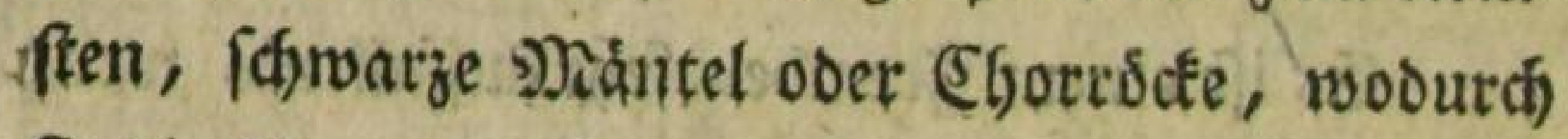
fie bie 2ferme ftecten fonnten, úber iffere farbigs ten Sleiber, nebft einem vierecfigten mit Sammt น์ Die $\supseteqq$ rediger tragen.

Sie befdáftigten fich) auf alletlei 2(rt mit uns terreden, Spagierengelyen, und einige batten aud there 2blicter in Der Şand und lafen. Dodh ich muşte mich bald ibren Zfugen entzichen, fo ftaums ten fie mich an, of ids ganz beftáubt mit meis nem Stabe gewandert fam.

2fls ids mun in ben @ifftgof, trat, unb zut ENien forderte, prophegette mir Das 2Ingeficti des Zuf fwarters iogleidf eine fegr unfveutidfidfe 2fufs naf)me. Man gab mir alfes mit \$auten und Beraditung, wie einem Bettler, uno lię naith es bodr wie einen @ientleman bezablen. Sđd glaus 


\section{( 125$)$}

be, es war dem Rerl nicht gelegen, oaß̄ et mit,

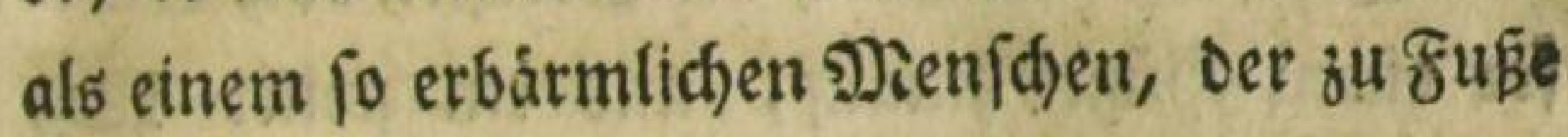
ginge, aufwarten follte. Sa war mibe unb forberte ein Bimmer zum fitlafen, und mant riés mid, midh in eines, Das einem Gefängni(iz fúc

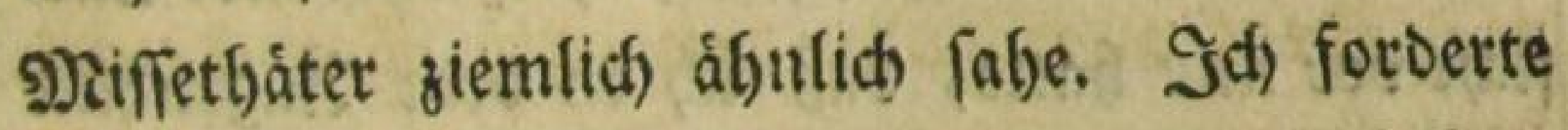
auf ote Sindt ein befferes Simmet, uno befam fur 2fntwort, Daß man gar nicht gefonnen fer), mid) Die গacht zu beberbergen, weil Eeine Sieles gentjeit Dazu wáre, id) mód)te nur nad) Slough roteder furuicfgeben, ba wurde id wohl ein Pacjtlager befommen.

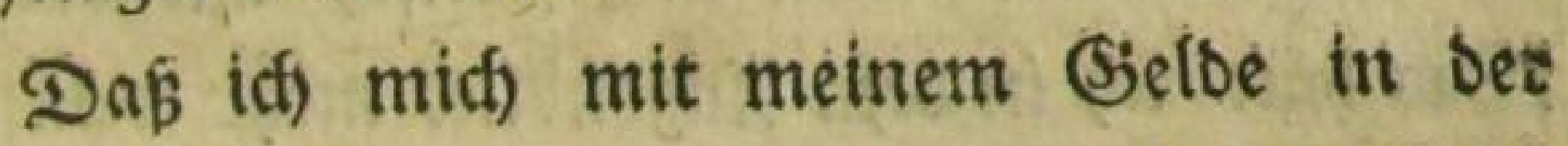
₹ajhe fo muste bebandeln lafien, blos weil ids zu Fuse gieng, brachte mich Denn boch etroas auf. Эđ) mußte furr mein Mittagseflen uno Raffee zmet Edfillinge bezablen, Die id) bin: warf, uno fachon ben Staub von meinen Früben foustteln wollte, um biejen unwirthbaren, uns

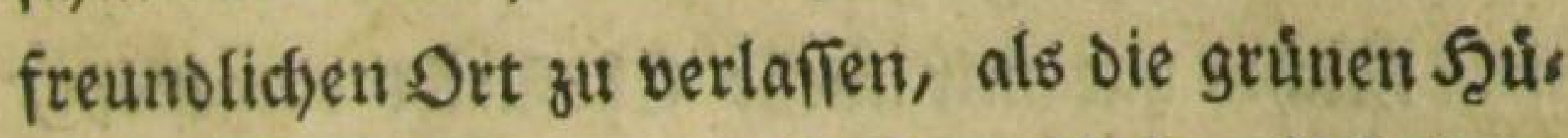
get von 2 sindior, mir fo freundlich zuládjelten, uno mid) einzuladen fdytenen, fie erft zu befudjen,

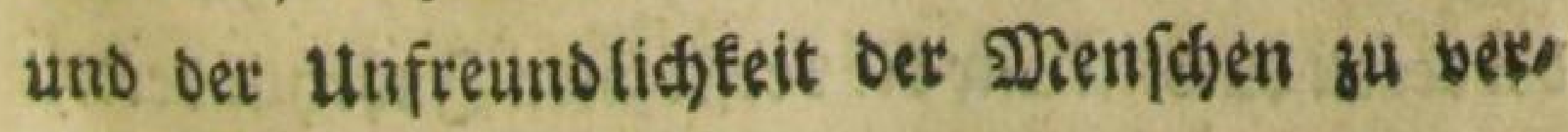
sefien. 


\section{( 126$)$}

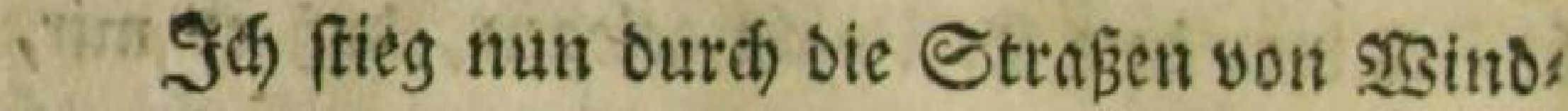
for einen Şigel Ginatf, uno ein fteiler Şgeg fúlfrte mich endidf) ganz auf oen Gipfel beffelben, bis didft an bie Miauer bes Raftells, wo id) auf einumal eine fo weite, fhjone, berzertebende 2fuss fidit vot mit batte, Daß̧ id in bem 2fugenblice jeden Siebanten an Beleibigung uno Intedft von Denfchen vergaß̂. Denn lier lag nùn bie ganje reidje, uippige Natur, eine Det (c)suften Rands

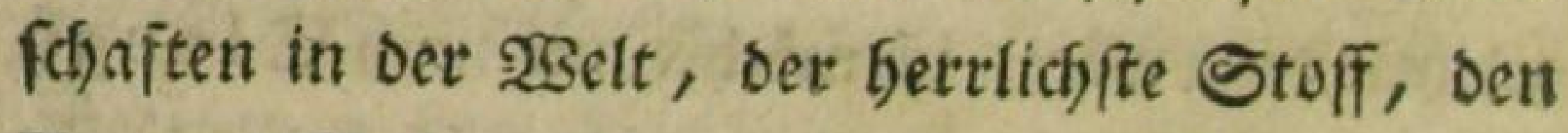

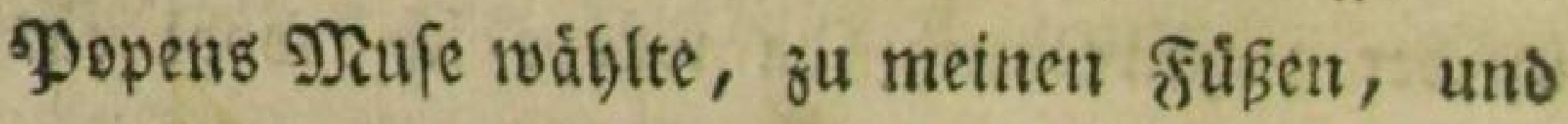
vor meinen Şlicten majeftáti (á) ausgebreitet.

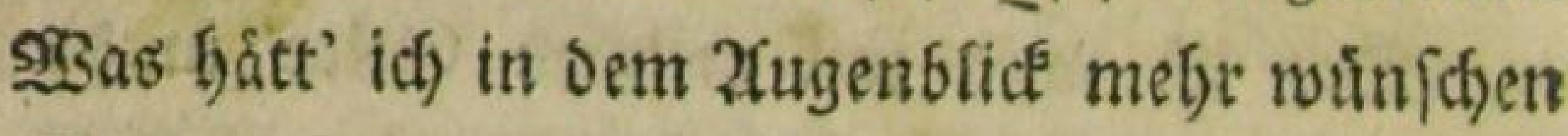
fonnen!

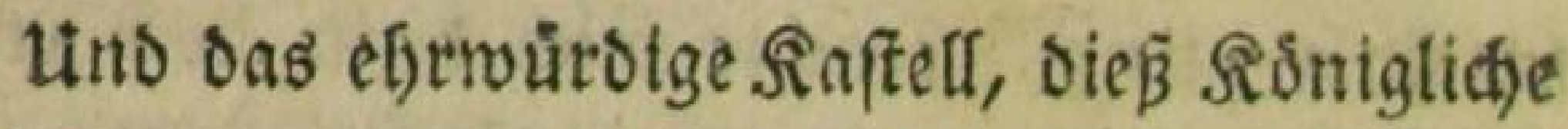
Sebande, woran alles dás Sjepriage des grauen

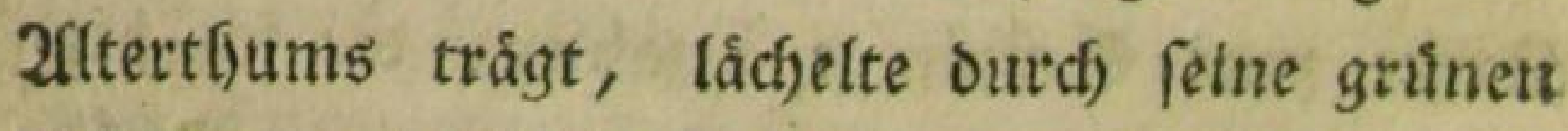
SSaume, wie die frofje Stirn des Streifes, Det Die Freute verjúngt hat.

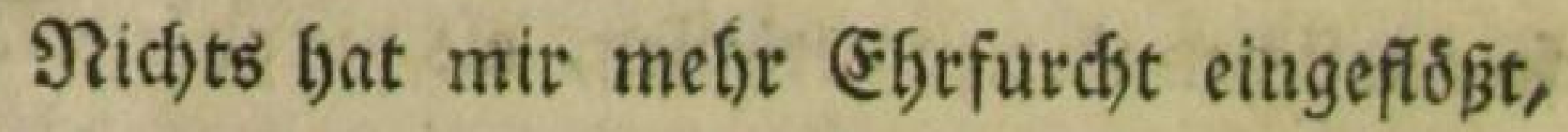
als die uralte St. Sieorgenfirthe, die im feteruns tergeben vom Saftelf zur rechten Seite liegt, uns bei deten 2 fnblicf mir die verfoßnen Safirfunderte; mieber emporzufteigen fojeinen. 


\section{(127)}

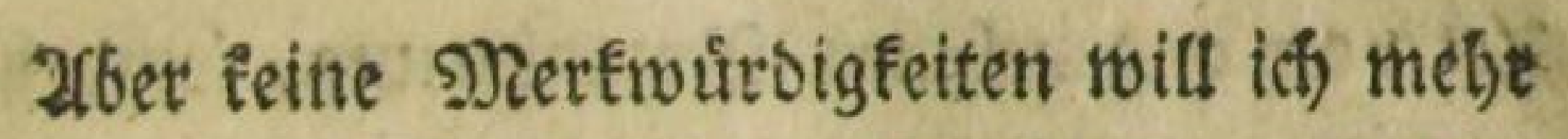

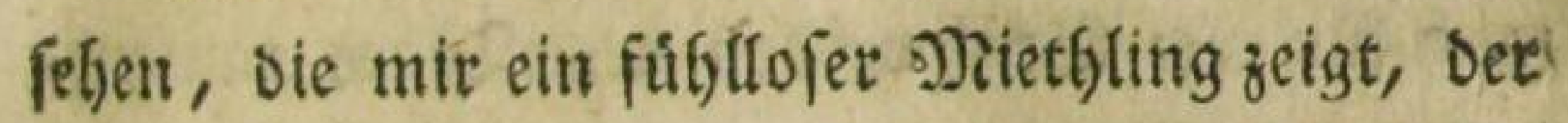
feine \&eftion auswendig geletnt bat, und fie bun Dertmal bes Tages mit $23 s i b e r w i f l e n$ berfagt. Der wibrige Rerl, weldher mich fúr einen Schils ling in ber Sirche berumfúfyte, batte mir Durdy fein Sseplapper beinabe den fósunften Eindruc verborben. Sheimtifh ber Zafte, Sart Der Erfte, uno Esuard ber Bierte liegen fier begraben. Die Sirche hat inwentig fowohl als auswendig ein

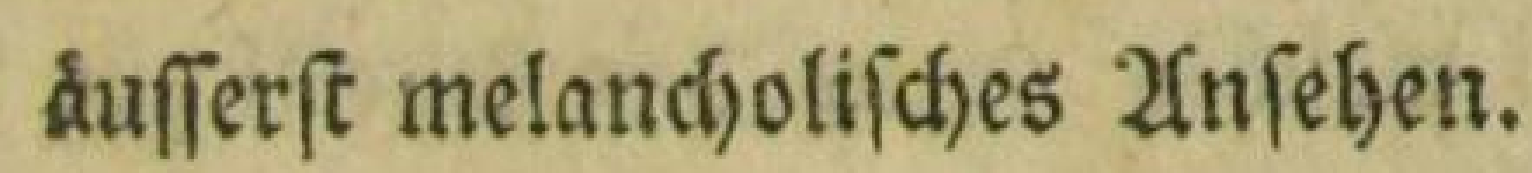

2fn Dem @óniglidfen Pallafte murbe gebauet; Ino eine शenge Steine bazu herbeigefdraft, roomit eine groвe 2(nza)l 2frbeiter befchaftiget roater.

Já) ging nun in bem berrlichen $25 i n b$ for garf, einen fanften 2(6bang Ginunter, wo es (ii) mit feinem immer zuneljmenden Dunfel von alien Seiten wie etn ₹empel eroffinete. Diefer

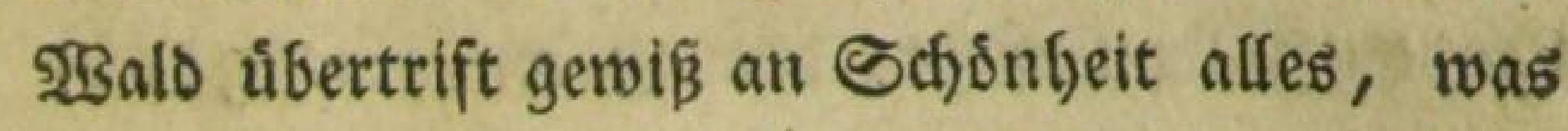
man fich nur yon ber art vorftellen fann. Dazu fam die (Einfamteit, bie Súble der 2Gbendluft, uno eine fanfte Mufit, bie in ber Ferne vom Schloffe herunteridgalfie. Sich war mie in eines 


\section{( 128$)$}

Zit von angenefmer Şezauberung, uno bielt

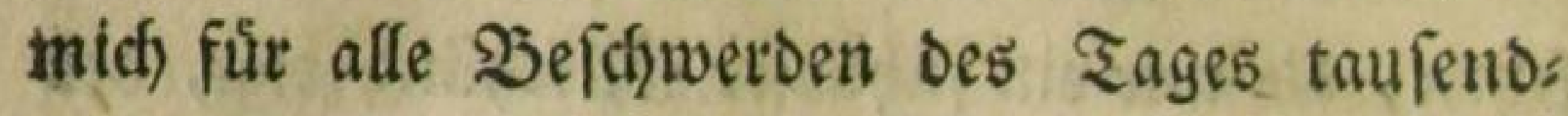
faci) belobnt.

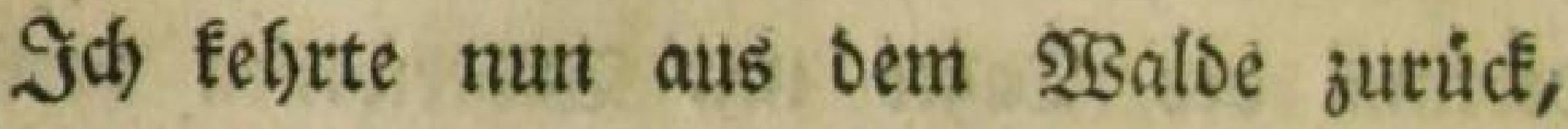
die (Sllocfe foflug fechs, und bie 2trbeiter gin: gen zu Şaufe.

No(b) babe id) Den grofen runben ₹furm, ebenfalls ein utaltes Gebaude bei dem Ronigli: డ)en Sdylofie, vergeffen. Die ausmentigen Zlufgånge auf oenfelben fino mit gruntem Sie: bưfh) bepflanzt, welches gegeu bas altertfum Des Ssemáters einen (élir angenef)men Siontraft madjt. Sianz oben auf Dem SSipfel Deffelben war Die Sabne von Sirobbrittannien ausgeftect, oie aber fpate gegen albens rwieber eingezogen wurbe.

Zlts idf vom Sdblok finunter ging, fatee id) Den Ronig in einem fimpelin $\mathfrak{T B a g e n ~ g i n a u f : ~}$ fabren. Man war hier goflicher, wie man in Eonoon zu feyn pfiegt, benn jebermann zog Dod, als er vorbeifubr, dent f̧ut vor ifsm ab.

Id) fam num roteder in bie Stabt, uno bes fand midh nidst weit vom Gchloffe, vor einem.

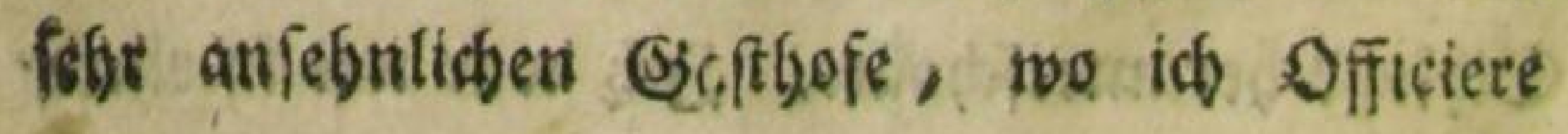
into 


\section{( 829$)$}

Atto viele anbre Qeute vom Stanbe fineingebet fafle, uno bier ward ids, wider alles פermus tien, von bem STirth, ber ebenfalls eine vot\% nebme figur fpielte, ofne Edyrierigteit aufgea nommen, ba man mich aus jenem weit feblects tern (Sinfthofe, bet Eaton ßollege, fo unfreundlid) soeggemielen hatte.

Zftein, es fajien einmal mein Edfidfal zu

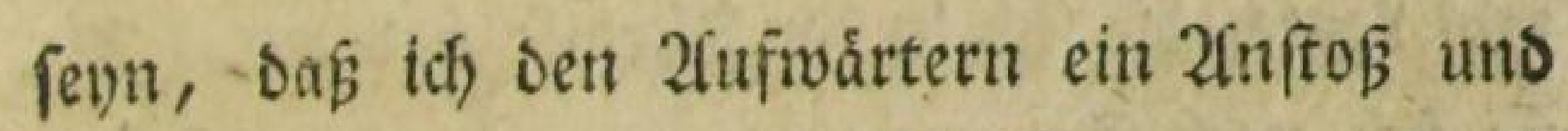
cin Dotn im 2luge war. Mit Mutren wiés mir Die ग)agd ein 3immer an, no icf) meinen 2(11zug ein wenig in Dronung bringen fonnte, uno mun ging ith wiever fimunter, in den gropen Saal (Coffee Room) ber gleid) beim Eingange im

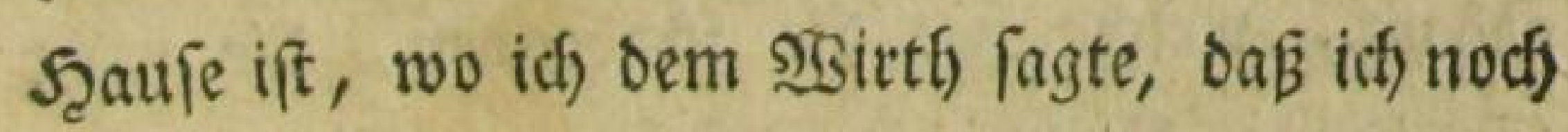
einen fleinen Spaziergang vornebmen wollte; er befdrieb mir Darauf, wie id) gleid) binter feinem $\mathfrak{S}_{\text {aut }}$ nuf cin felfr angenelymes Felo, und über baffelbe ans Ufer ber Zhemie fommen fon: ne, bafelbft wurbe id) einen felfrifichonen 20 Deplaç antreffen.

Sif) folgte feinem siatle, und biefer afbens twat beinalje noch (d) bner, als oer vorkergeljende

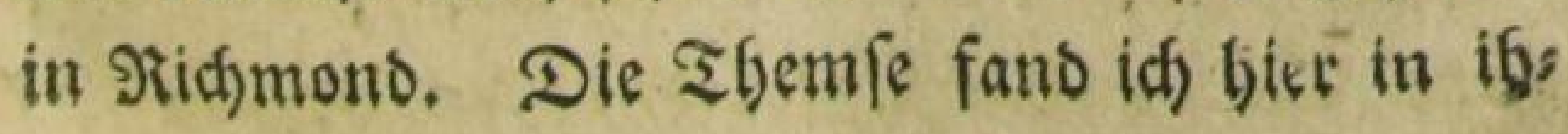

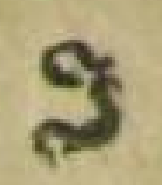




\section{( 130$)$}

ren fanften Srummungen wieber; 23 indor (chimmerte faft nod) fojoner ins grune Thal

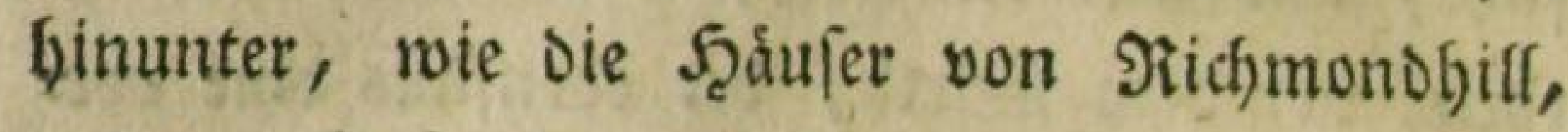
uno das SSuin Der 2 Biefe war eben fo zart uno reid). Das felo nach Der ₹bem[e zu war ets

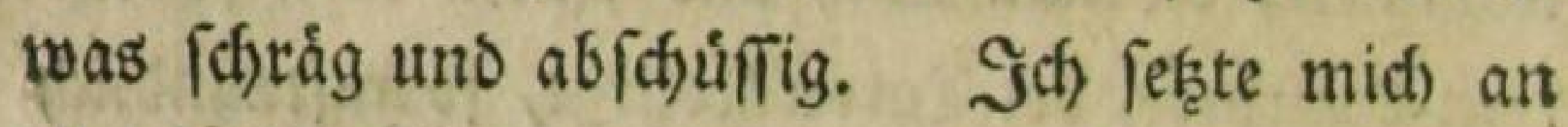
ein (Seftráud) uno erwartete Den Untergang Der Sonne. In Der Ferne faly idh eine gropie 2fins zabl ( Eeute, Die fich in ber Themie babeten. Zlls (ie fich nad) Sonnemuntergang etwas zerftreuet Gatten, nåberte ich mić) Dem $\mathfrak{u}$ fer Der Themie, uno taudfte mich bier zum erftenmale in ifore fúblen Fluthen. Das ufer mar jiemlich ab/chú: fig, aber es roar cine Treppe in den Fluß̧̧ htmunter, gebaut, melche fúr die Sabenden, die nicht

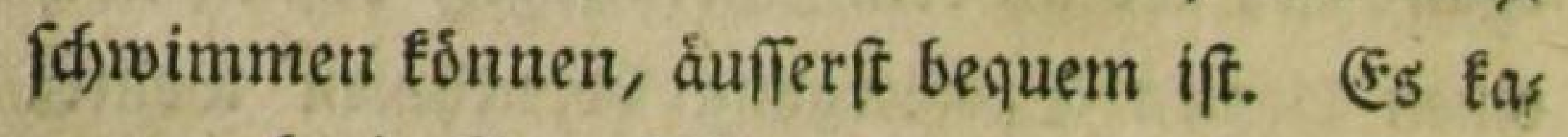
men noch ein Daar blưbende muntre Şandwer És? jungen von der Stadt Gergelaufen, Die in Der

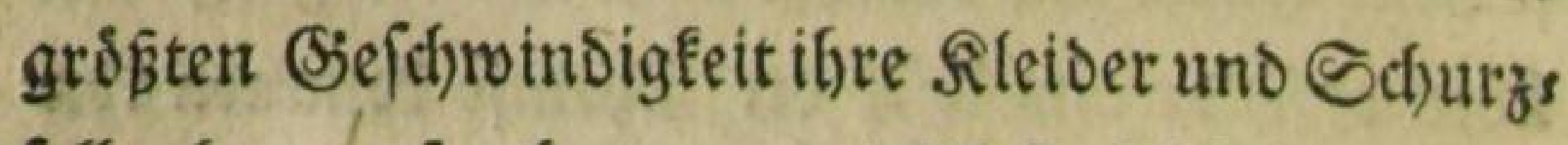
felle abgeworfen (s)atten, uno fich) Pogleich) ůber ßopf ins $\mathfrak{W}$ affer ftúrzten, wo fie mit ifren nervigten 2(rmen die fluth Durd) fdonitten, bis fie mide roaren. Sie rietben mir febr zutraulids, mein 


\section{( 131$)$}

Scaar erft loşubinsen, uno mid) Dann, tote fie, mit bem Ropfe bineinjutaud)en.

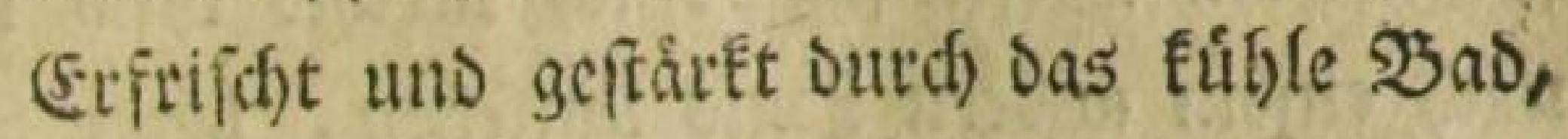

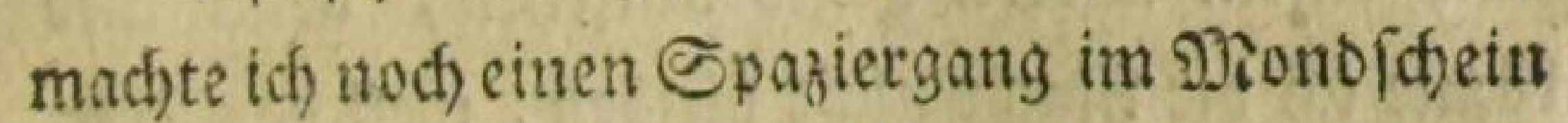
lóngff dem Ufer ber Themie Gin; zu meiner Rinfen

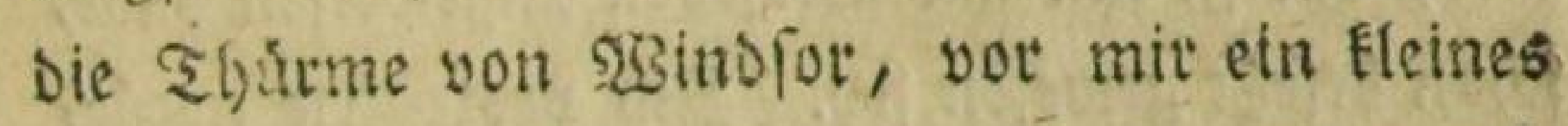
Dorf, mit einemรgurm, Deffen Spiß̨e aus den gru์ nen basumen feryorragte; in Der Ferne ein Daar reizente Şigel, bie id) mit am funftigen Diors gen zu befreigen vornalym, um mid, Das gruine 23aizenfeld ; o roie unbeldreiblid) fdson war bies fer arbento uns biejer Spajiergang! Uno in ber

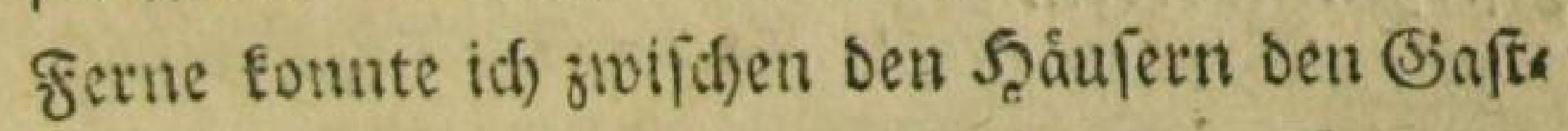

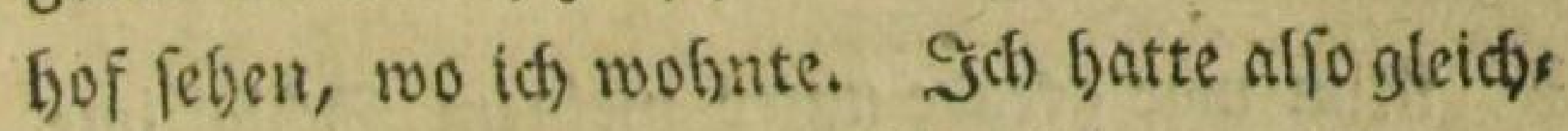
fam cine Sccimatl), wobin id jurticfefgren Eonnte, uno es wat mir, als of idf lier ju Şaufe raire, uno immer fier bleifen miste.

SBie bald verflogen bieje füsen und angeneba men Trănme, als ith ju Şaure fam, und von

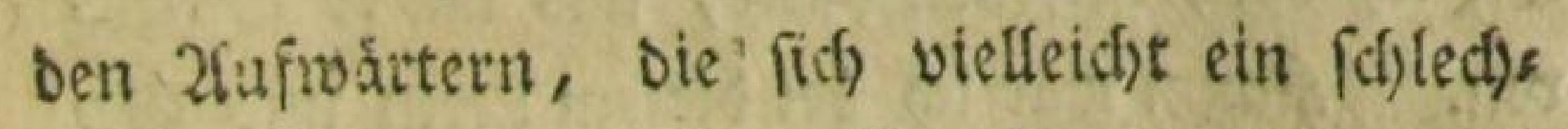
tes TrinEgeld von mit vetipradsen, wieser mic (d)eelem 3 licf empfangen nurde. Und wie groß war mein Erftaunet, on ebent die mutrifche Wags, weldje mir ein aimmer anwié, unten

$$
\$ 2
$$




\section{( 1325}

in ote Stube trat, uno mir mit einem Suir uns fpottifchem 2 seefen lagte: ich moichte mid) nut nad) einem andern Logis umfégen, denn bier Ponne id die शactst nicfjt bleiben, reif bas Bims mer, bas fie mit aus 2 Zer fében angerwiefen habe,

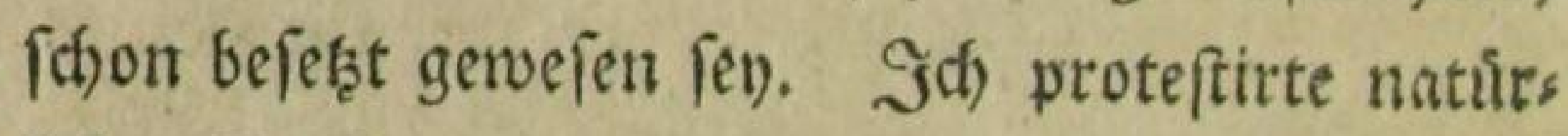

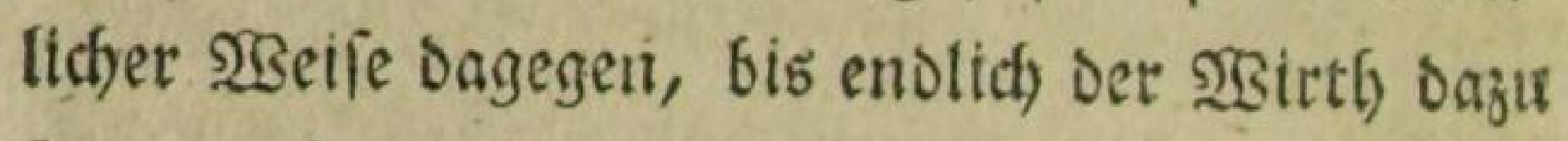
fam, auf oen idf mich berief, uno ber mir fos gleich ein Simmet anmei (en ließ̧, rootauf ict) abet felbanber fdjlafen muşte. So wáte idf aljo bier in 5 sinofot beinafe zum zreitenmal aus: geftónen worben.

গut war gerabe unter meinem Shblafă mer ein Trinkgefag, Daß̧ Der \$oden zitterte. (55

- surben Trinflieder gefungen, roorinn åfnliche Stellen mit ben unfrigen vorfamen, fo viel id) verfiteben fonnte. Die Gefellichaft beftand, wie ith vorbergefelen hatte, aus lauter Sfficies retr. Saum mat id) bei Diefem \&erm uno (sie: ráufd) ein rentig eingefdblafen, fo Eam mein Schlaffamerad, vermutblich einer aus der faus bern Trinfgefellfhaft, in bie Stube und an mein Bette getaumelt, bis ef endidi) mit vieles: 


\section{( 133 )}

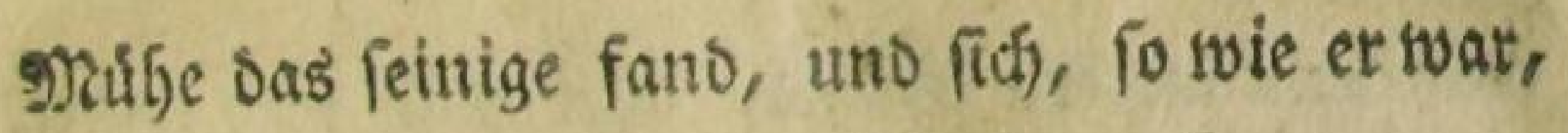
mit Stiefeln uno Rleidern hineinmarf.

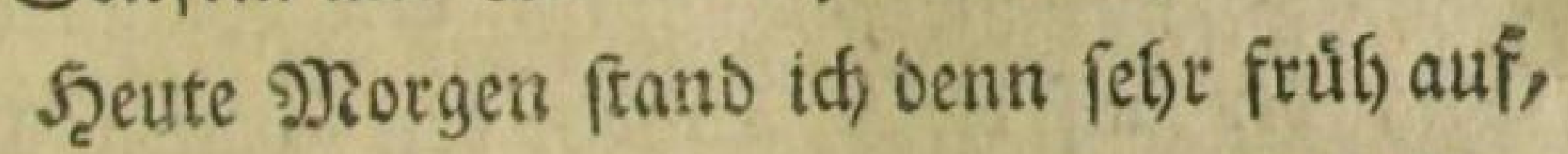
Lim, wie if) mir vorgenommen batte, bie beiben Ђ̧ugel zu befteigen, weldje mir geftern einen fo reizenden \$profpeft gaben, befonders ber eine, auf Deffen Sipipel ein bobes weibes f̧aus zwifhen Den Dunfelgrúnen Baamen hervortagte. Dev anore lag gleid) barneben.

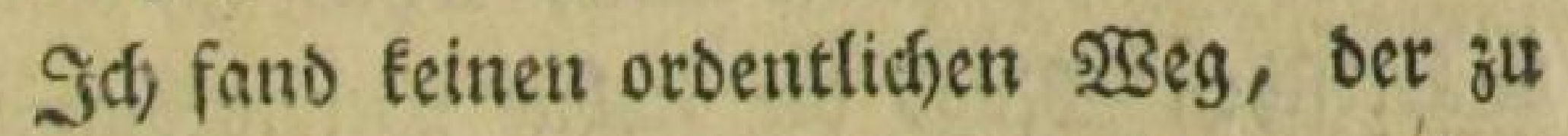
siefem F̧uigel fúfrte, ging aljo grade zu, ofune mid) an eine Straß̧e zu felyten, immer meiner einmal genommenen sichtung nach. Freilich war dießs etwas múb (am, ich batte oft einen Baun ober Sumpf zu umgehen, entich aber langte id) Doch am Fuse bes fefontich ges wưn(d)ten Şügels mit Dem boben weiß̄en F̧aule an, uns als id im Begriff war, Ginauf zuftel: gen, uno miḑ fajon auf bie Jusficht von Dem reişen Scaule freute, las idf an einev aufgeftellten Tafel Die $230 r t e:$ Take Care! Steeltraps and Springguns are laid here. (Nef)mt eud in 2(d)t, fier liegen Fußange(n!). \$ieine פ) (úlje war alfo vergebens, uno id ging nun

$$
\text { \3 }
$$




\section{( 134$)$}

Had, bem anbern Soligel, aber audh bier waret Steeltraps uno Springguns für betr sGanoter ge: legt, ber auf biefer 2fnbsife ben fobdnen Mior: gen genteß̄en mollte.

So fefrte ich, in meiner froffun ge: táưht, in bie Stnot jutilé, beinabe écen fo, wie geftern Morgen, von Sitchmond hill, bamit

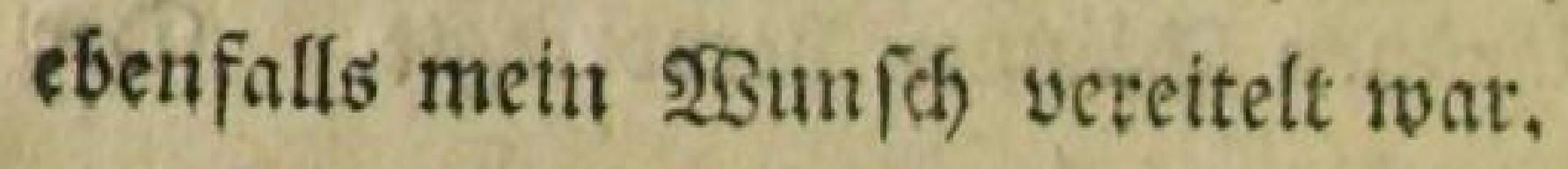

Da tch zu Scaule fam, exfiett id) von Der

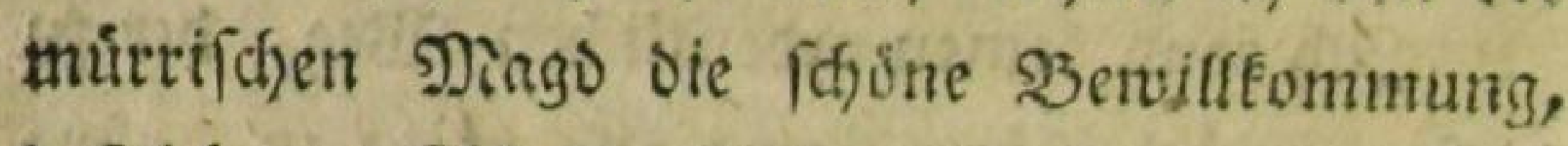

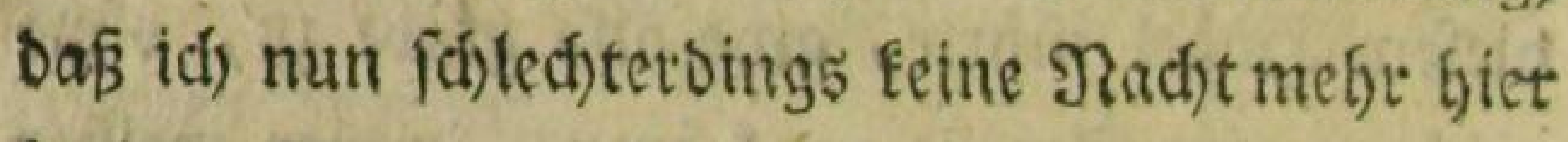
logiten fornte, welches aber auch mein sgilfe

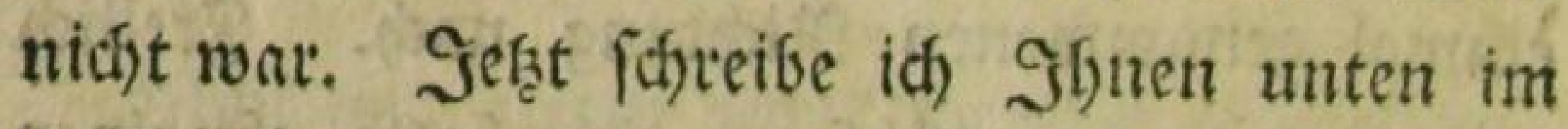
Coffee room, mo ein Waar Deutiche neben mir Tprechen, oie gemín glauben, oaß̧ ich fie nidjt vetffefe, oa idf mich alfo zu erEennen gebe, oas id) ein Deutf(f)er (et), würbigen mich Die Sierts nicht mit mir zu reben, weil ich) ein fusgangnger bin. - Ich glaube es find $\sqrt{3}$ annoveraner! - Das

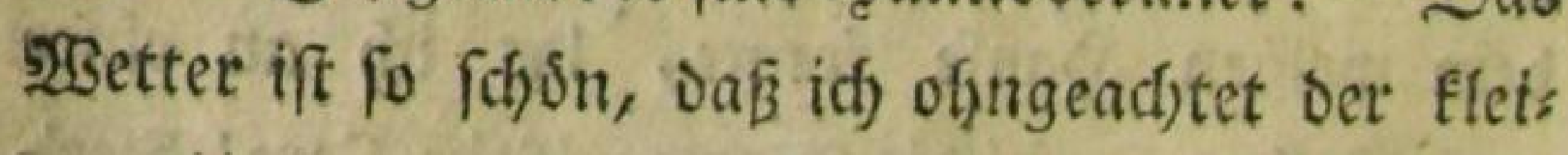
nen Unfequemlidbeiten, oenen ich ausgelefet gevefen bin, Dennod) meine Reife zu Sußse forts fergen werde. 


\section{( 135$)$}

Drford, bett 2sten Juti.

2tsas fü fonderbaren Shickfalen und 2iben:

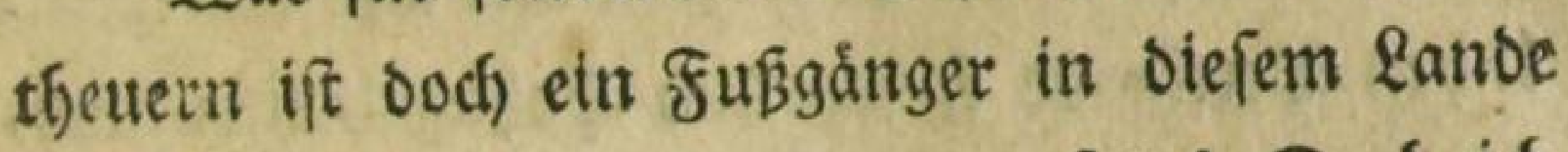
ber Pferde und Saroffen ausgeferst! Doch id will nur gleidy meine Erzáblung von vorne an: fangen.

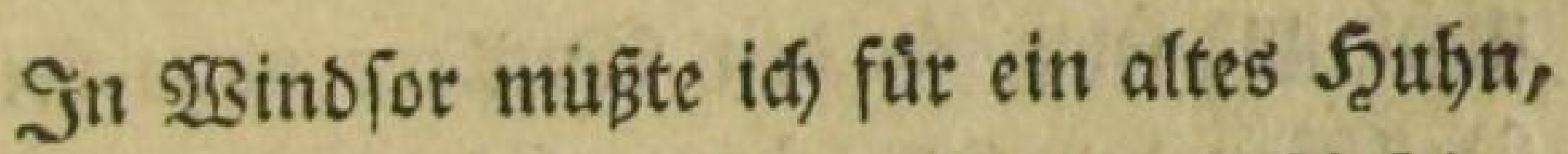
baß̧ id) Den 2lbeno verjebrte, für ein Schlafzim: mer, baß̄ man mir mit झiutren gab, uno wo (id) nod) baju von einem befoffenen Sert beuntus higt wurbe, uno fur ein פaat Taffen Thee zum Fru์lf(tưf, neun Sd)illinge bezablen, worunter Denn Das Şulyn allein Fed)s Schillinge getedhs net ward.

2lls ifh nun weggeben wollte, ftand bet Zlufwárter, welcher midf) mit Hnwillen uno \$) ars ren bedient batte, an Der ₹reppe, uno lagte: remember de Waiter! (bedenft Den 2fufwálter!)

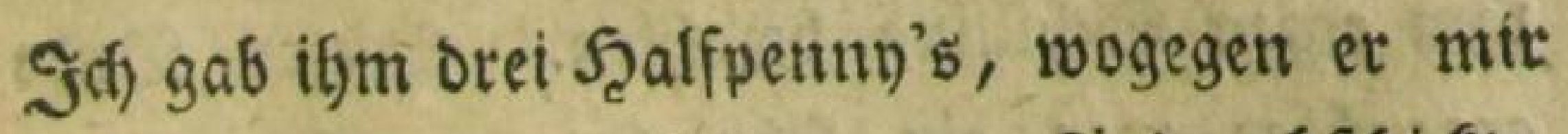
ein herzhaftes: God damm you Sir! nadj/djicfte. fln bet Thuire ftand die muitrifhe Mago, unb fagte : remember the Chambermaid ! - J'ill remember your Civility (idg werbe mid) an eure $\mathfrak{S}_{2} \delta$ ffid);

$$
\text { I } 4
$$




\section{$(136)$}

feit erimnetn!) fagt' id), unb gab iffe nichte, woruber fie iffen 2fetger in einem lauten 50 bु) geláchter erftictete. Esf folgten mir aljo im cigentz

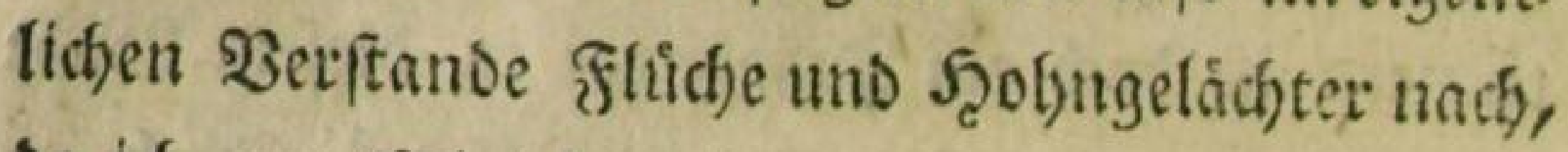
Da idf) aus 2 sindor-gieng.

WSie froh wat id) mun, oa ich Die Thíme von SSindofor wieder im Silucen batte! (F) iff nicht gut fenn fir ben SSandrer nabe bei ben Wallåften Der Sónige, Dacht' ich), uno lingerte mich) im Scljatten einet grinnen Secće, wo tín in meinem Dilton las, uno bie Seerriicyfeit ber (d)onen Satne um midf ber empfano.

Sef nafym meinen Siseg roieber burch Slough ůber Salthill naḍ Maiden: Gead. In Saltbill, weldyes boch mur ein Dorf ife, batte ganz an Ende ein Derutenma cher feine Bube, worinn er jugleich balbitte und frifitte. Dafiir Daß er mein Scaar ein wentig its Dronung brachte, und mich raffirte, muste ich ifym einen Stfilling bezablen. Diefer Sube gegentiber wat ein feft elegantes Seaus uns Garten.

Drwifden Salthill und Miaibentheab begegnete mir bas erfte 2fbentbeuer auf meiner 23 anderung. 


\section{( 137$)$}

9):ir wat bis jef̨t noch faft fein cinfiget Sügănger begegnet, bingegen rollten befandig cine grofe sienge Rutichen vor mir vorúber, weil auf Der Strafe von Drford cine farte \al: fage ift, aud begegneten mir bäufig berfonen

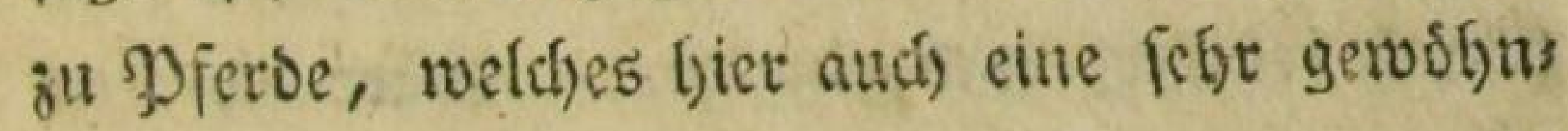
rtclye 2frt 孔u reifen ifr.

Nein SSeg fúfrte mith in einem ziemlich tiefen Brutbe zuifden bohen Saaumen ljin, fo ons̄ id) nicht weit votwates felgen fomite, als mir ein Serl in cincm braunen Frat uns run Den Şute, mit einem Gtabe in Der Scand ents

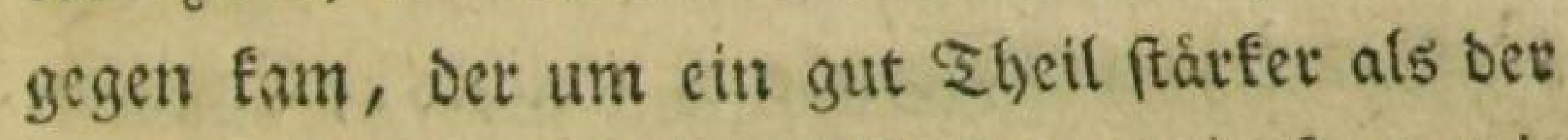
meinige wat. Seine Plyfiognomie fam mit gleich) etruas verdadhtig vor. (5t ging aber vor mir vorbet. Zaffein efje idjs mir verfal fefjute er wieder um, uno verlangte you mit reiter nid)ts, als einen Szalfpenny, wofút er fich wolle etroas Dier geben laffen, weil er nod, núdftetn (ev. Jab griff in die Tafdle, und fand, bas id) gar Eeine Supfermuinze uno nidft einmal Sirpences, fonbern lanter Séfilfinge batte. Zf(s idf mich Damit entid\}ulbigte, fagte ev mit einer fo hámifhen פine, God blefs my fould is 


\section{( 138 )}

und madite mich auf ben fauftoiden Brifif an feittem 2 Banderfabe fo aufmerefam, baj ich fos

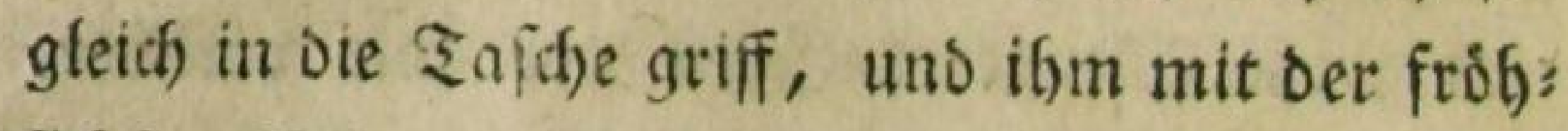

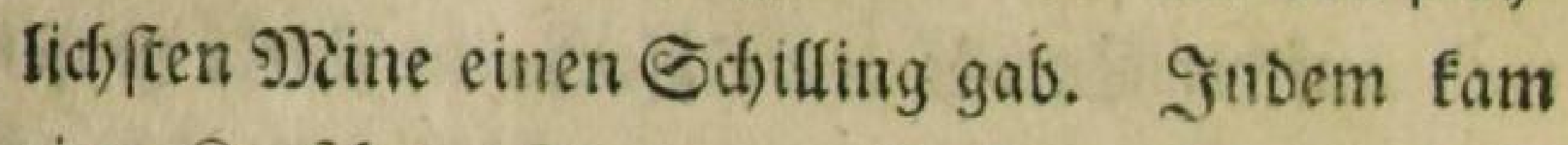

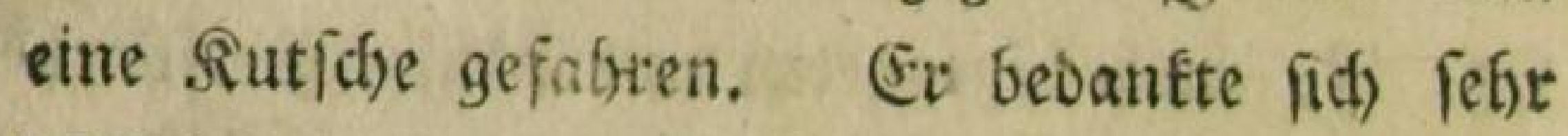
hofflich bei mir, uno, ging fort. SBăre Die Rut: fibe cinen 2fugenblict eber geformmen, fo wurbe (t) if́m ben Eibilling, Den idi) gat nicht úber:

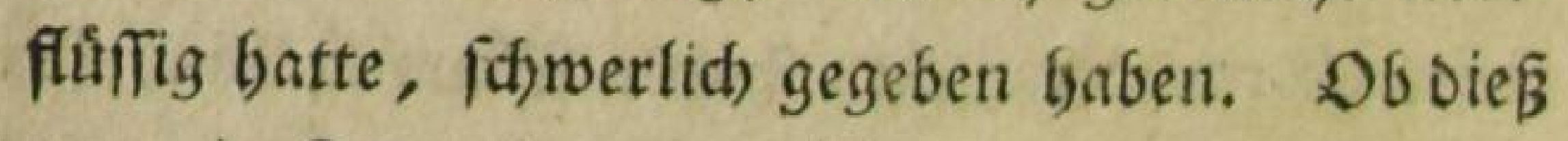
nun ein Footpao war, will idf nicht enticheiden, alles mógliche 2infiefnn batte er sazu.

Ich fam mun auf Maidenheadbridge ober Die S3rúcte von Siaidentyeab, weldjes 25 (Englijhe 2reilen von gondon ift.

Die Englifhen Mieilenzeiger fino für ben Pieifenden eine großje 2(nnebmlid)feit uno Des quemlid)Eeit. Mit baben fie oft oie Şålfte des 2reges erleichtert, weil ich immer gewis wuste, swie weit ith getommen war, und Daß̧ ich) auf Dem

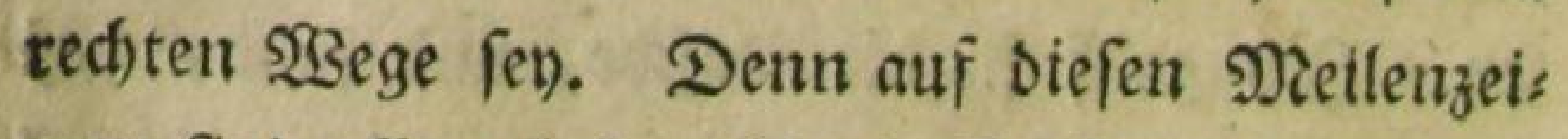
gern find alfemal forwofl oie Entfernungen von Qonbon, als bis zum nádjftliegenton orte be: zeid)net, uno no Edjeiderwege fino, if immer noch befonders ein Saanbweifer angebracht, io 


\section{( 139$)$}

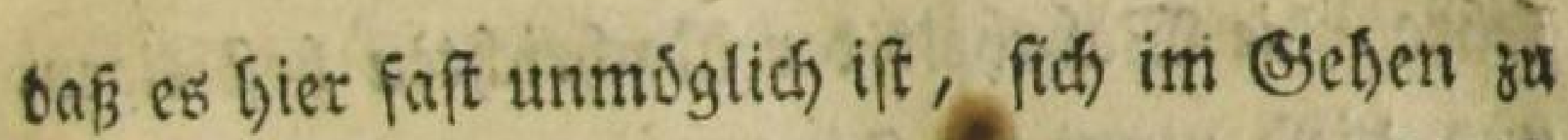
veritren. Jü muß geftetielt, Don meine Sieife faft eit beftántiger Epaziergang war.

Bon Det Stricte vor gialdenbeas if eine vorttefflidhe 2lusfidft atf einen Scigel oer

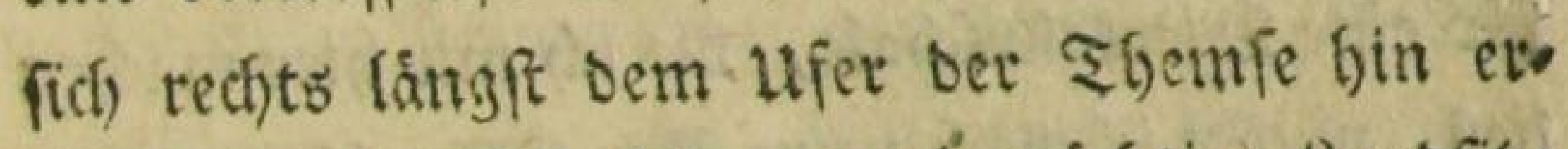
frrecte, uno auf weidsem zrvei praichtige Lanbfife mit rsiefen und parḱ befindlith find. Det erfe beist Taplow uno gefort Dem Brafen von Snthiquin, uns ein menig weiter in ber getme liegt Eliefoen, weldyes ifgm ebenfalls zugebofrt. Die Sdfloffer fohimmert mit grútten 2Siejen umgeben aus bem staten (sef)dis bervor, und geben einen reijenden 2fnblicf.

3on Diefer Strucle Gat man nidjt weit bis 9) aibenfleab, uno beim (singange in daffefbe zut finfen Seite, wieberum bie 2fusfidit auf el: nen fojonen Lanbfis, wowon ein gerwiffer Pens

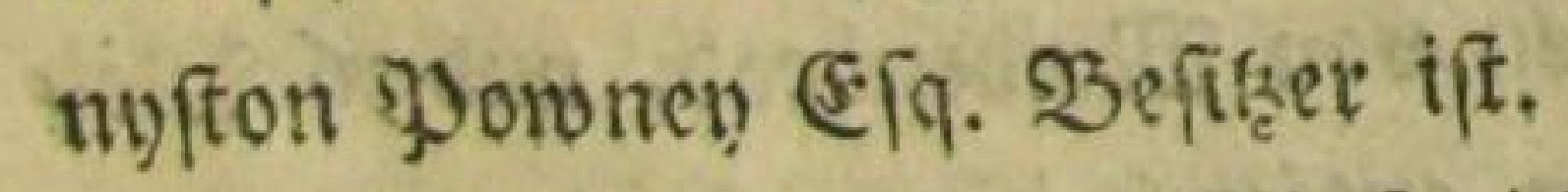

Diefe Nadjridjten idtopfe id grofstentl)eils aus meinem Englifchen 2 segrveifer, ben id faft beftandig in ber 5 ceand habe, uno wortun faft alles )ierfwurbige von Mielle zu Meile angezeigt ift. - ja) Vaffe mir von ben \&euten, bei benen id ein 


\section{( 140 )}

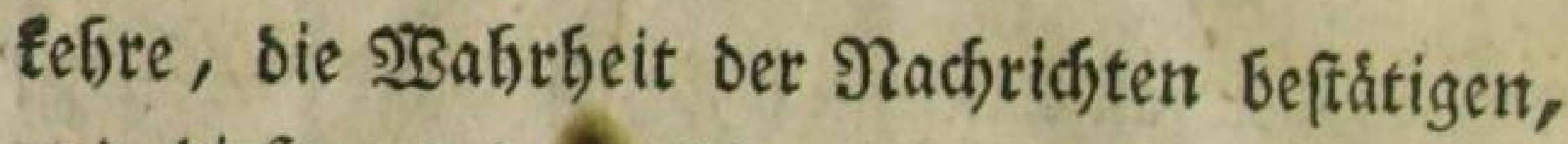
uno biefe runbew fich benn, wie idf als ein Frember, mit ifrer Esegeno to genau bes faunt bin.

Manidenthead felber ift ein unanfegnlidfer Ott : furr eine Silertaltefichale, bie id mir bier machen ließ̄. muste idh Dodh neun Jyence bezablen. T) Tan (d)ien midh audh bier nid)t fúr voll anguleben. A lufty Comrade! bort' ich im Borbcigetyen von mir fagen, uno das flang benn freilich nidft feffr eftenvoll, wenn es eben fo viel betisen follte, als wie man bei uns zu fagen pflegt: Das mag mir wobl ein luftiger Samrab, oder ein luftiger ’alfas gier fenn!

2fm (Enbe Des Dorfs batte ein Sd)ufmacher feinen gaben, fo wie am Ende von Saltbifl ein Frifeur wobnte.

Bon bier gings nun auf Şenley zu, oaß noch eilf Mieilen von Maidonlyead, und 36 शeio len von Rondon entiernt ift.

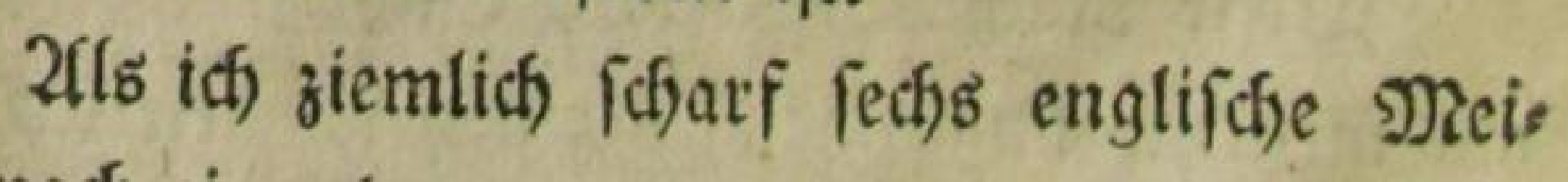
len nach einanter gegangen, uno allo nur noch fünf Sieilen von Senenley war, fam idh auf eine 2ungsbe, wo grade ein \$reilenzeiger ftand, bet 


\section{( 141$)$}

Dem idf midh nieberfefete, um eine ber bertich): ften 2lusfichten zu geniesen, of beren $\mathfrak{B e t r a d )}$ : tung id) einen jeden rathen will, ber etwa einmal auf biefen flect fommen follte.

Bor mir in Der Năbe ein fanfter Scuigel yoll gruner $S_{3}$ aizenfelder mit lebendigen Feeten eingezåunt, uns oben von einem 2 salde um: ftángt,

Uno nun in Der Serne in einem groben loal ben Sirfel um mich bet eit grưner Şúgel an Dell anbern, die fidf vom difer ber Themie fanft in bie feible erfoben, uno auf benen fid) TBăls

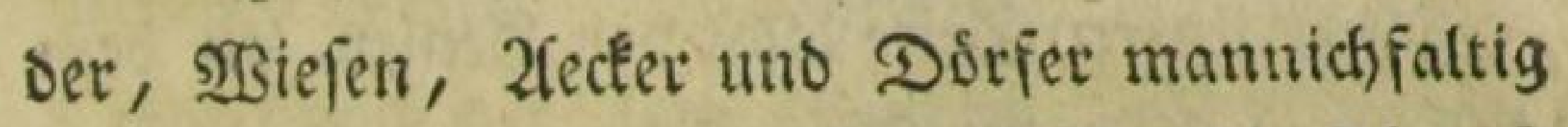

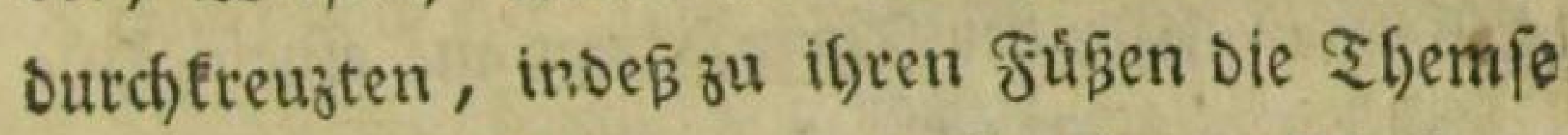

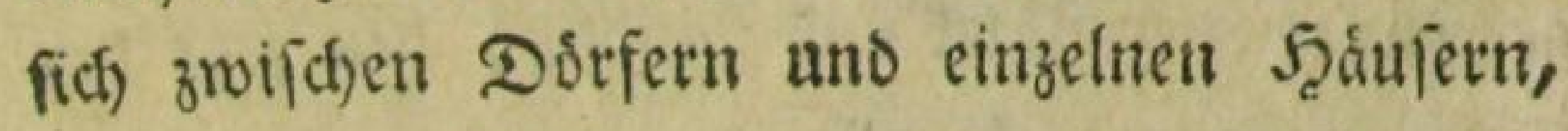
unb grůnen Thálern, in reizenden Srimmun: gen finfód)längelte.

Die Ufer ber Themie find befiandig faron und reizend; wie fús iff mir ibr 2̂nblict, wenn id) fie oft, nad) einer fleinen (Entfernung, wo id) fie aus den 2 fugen verlohten babe, plök̨lid mis allen ibren gruinen ufeen wieber felge!

Unten im Thale weideten Seerden, und bis GSlocten Thallten Den Szuggel Gerauf, 


\section{( 142$)$}

Int was eine folche Einglifd)e Siegento fo bezaus

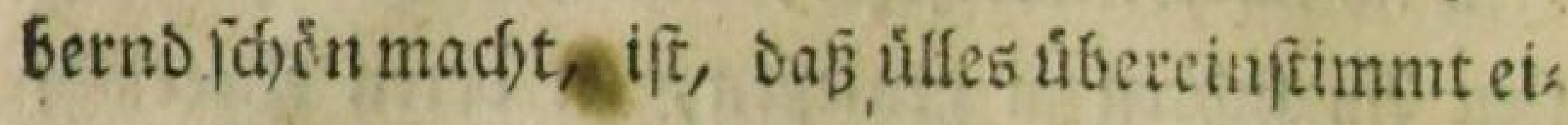

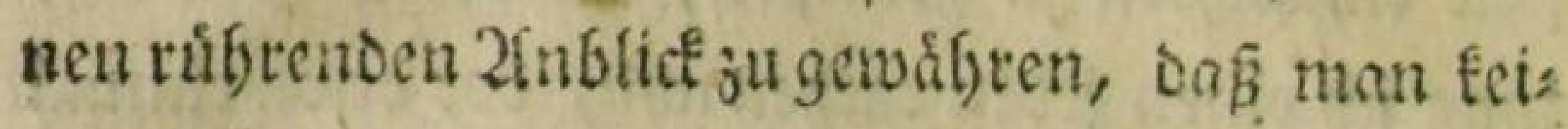
nen Flect fiebt, auf Dem Das \&uge nicht gern ruben mơd)te. Die mittelmäßigfte Giegeno vou Denen, ote ich) mun in (England gefégen babe, wurto in ber umitigen fdoon ein Parabies musmatfen.

Durch Diefe belofnende 2fusficht gleidfjam fum keten Sjange geftàtft, gings nun im fofat: fen Gchtitt 2berg auf Detg ab, Die ǔbrigen fünf Mieilen bis Scenlen, wo idf ben פadymittag of ns: gefelor um vier Utbr anfam.

Sur linten Seite Dicht vor Sentery, an bem

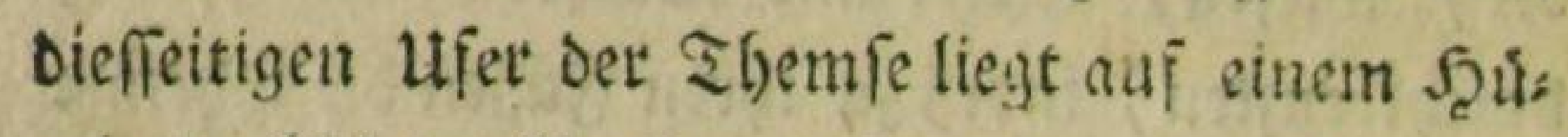

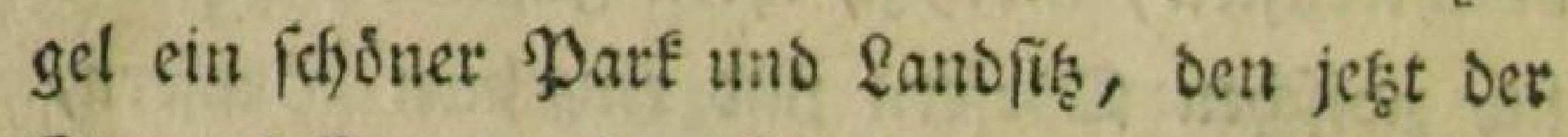
(Senteral Sonway) beroobnet.

(5.he idf in Scenlen binein gienth, fpazierte tof noch ein wenig am Ufer Der Themfe binum: ter, uno fef̧te mid́) im boben (Sirrje nieder, in: Deß am andern IIfer Der Wart auf Dem Şügel yot mir lag: weil ich etwas midoe war, foflief ich biet ein, und als ich wieder aufwadjte, fobie: nen mir gerade noch die lef̧̧ten Etraf̧len Der une tergebenden Şonne ins Geficht. 


\section{$4(143)$}

Seftånt von biefem füßen Schlummer ging idf weiter fort, und in bie Staot finein, roo es mit aber viel ju vornebm ausfabe, als baß meiner gemachten (Erjabrung zu folge, batte da bleiben follen, vielmelor ent (á)los ich mich in einem (Salithofe by the Roadfide (an Der Seeere

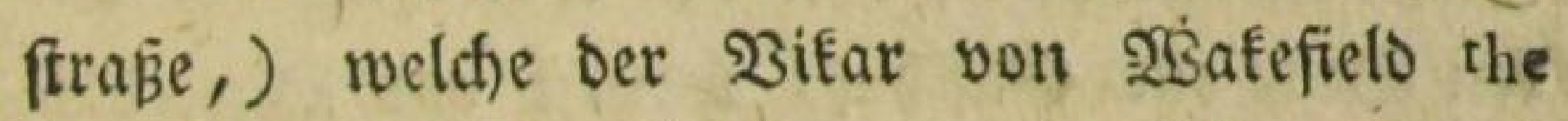
ufual Retreat of Indigence and frugality (oieger woibnliche Suflucht oer 2(rmuth ober Sparjam, feit) nenut, einzutebren.

Zlllein Das foflimmfte war, Daß̧ midh nies mand jelbft einmal in einen foldsen Bufludstsort aufnefmen wollte. (Es begegneten mir auf dies

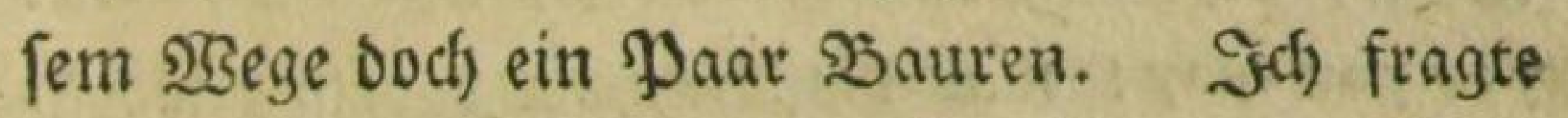
Den erften, ob idf in einem Scaule an Der Sceer: frabe, Das jof won ferne fabe, mobl Die গacjt Jzerberge finben wurbe? I dare fay you may! war feine 2fntwort. 2Allein, als id) bintam bies es: we have got no Beds, and you can't ftay here

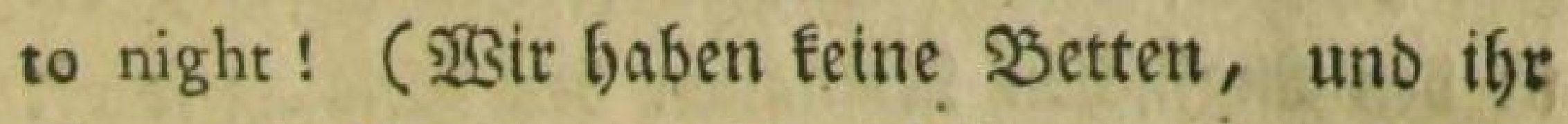

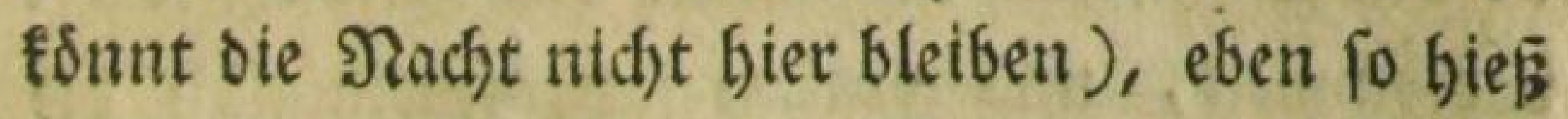
es aud) in bem folgenden Şaurle, bas idh all ber Sceerftraßje traf. Iid) muste midh alio entichlies

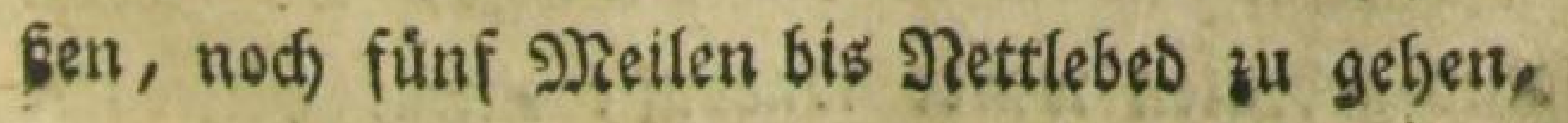




\section{( 144$)$.}

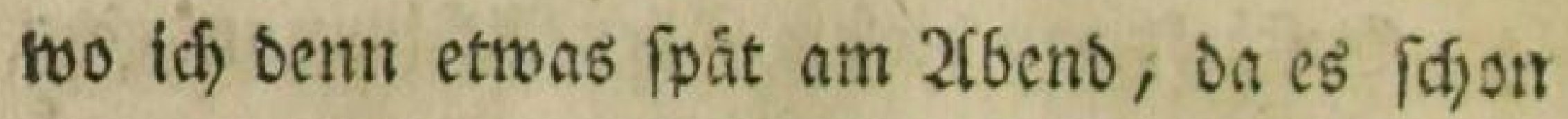
vớlig Duntel war, antam.

Es ging in Diejem Distichen nod) rectit mun: ter zu, inbem einige beurfaubte Solbaten auf thre eigene Scand muitierten. (Sileid) Geim (sin: gange in Das Dotf war bas erfe Seats zur lins fen Seite ein Gaftlof, wovon ein Queerbals fen bis zu bem gegenúberfetyenden Szanle gelegt war, an roeldiem cin erfauntict) gropes Sifild mit Dem গabmen Des Esigentbümets bieng.

May I ftay here to night? wat meine erfte Frage, Da idi) in oas Scaus trat, und cin Ealtes: yes you may! war bie 2futwort Datauf, woru ber ich) Doch fefor frob war.

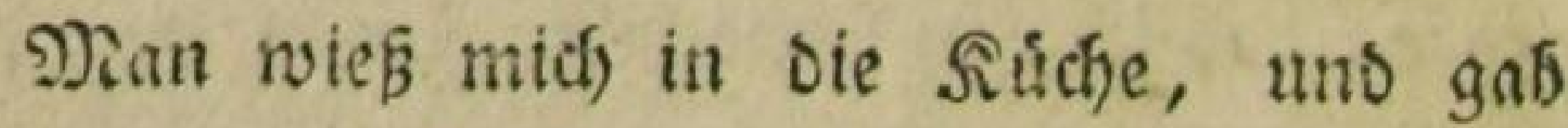
mir an einem Sijhe mit ben Golbaten uns Scaustned)ten zu eflen. Sidh befano mid) alio nun zum erftenmal in einer foldyen Suctye, Die in Den singlijchen Romanen bes Fielding fo oft vorfommen, uno roritn fid gemeiniglitg bie meifren 2lbentheuer zutragen.

Das Ramin in Diefer Rutude, wo gefodjet und gebraten wutbe wat mit eimem boflzerten 3ets 


\section{( 145$)$}

23et falage elngefapt, unb das úbrige toutbe tote

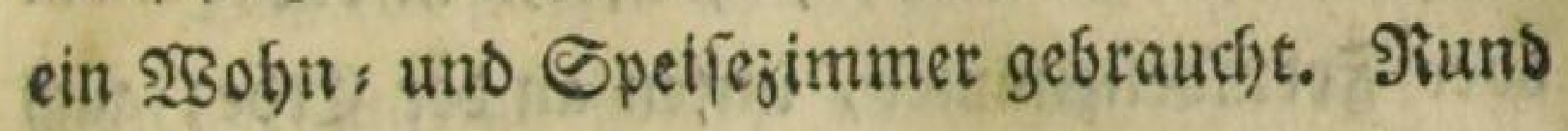
berum an den Geiten waren פorte mit jinners

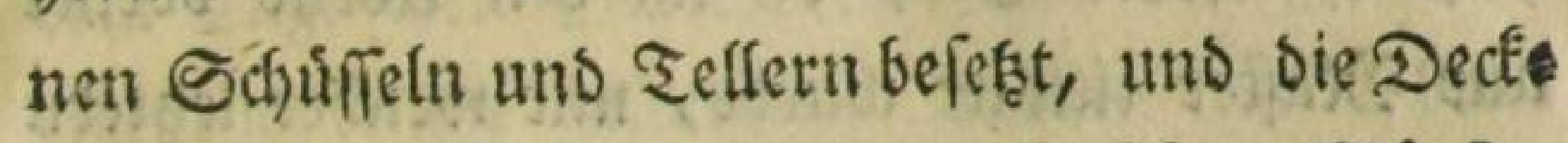
Ging voller Biftualien, als Zucferbúte, şiurfte, Epecffeiten und Dergleiffen.

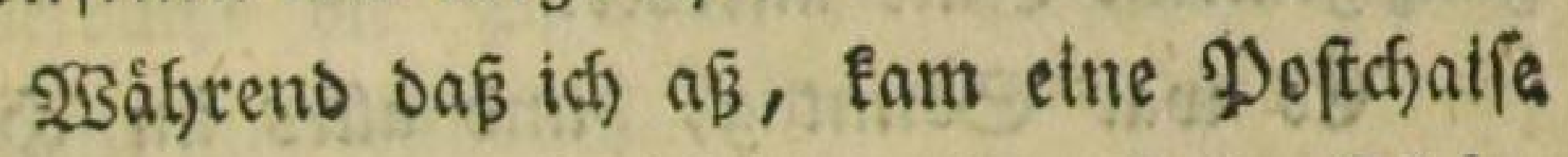
angefabren, und fogleid wutben beide Tgưts fligel eroffinet, und Das ganje Şaus in Şerve: gung gefestat, um nur biefe vornefimen Bsaffe gea Górig ou empfangen. Die Şertu ftiegen aber nur einen 2(ugenbliff aus, unb ver jef)etten nidfts als ein \$aar Sruige \$ier, worauf fie wieder fortfufteen. Dian begegnete \$ֲ̧nen mit allem

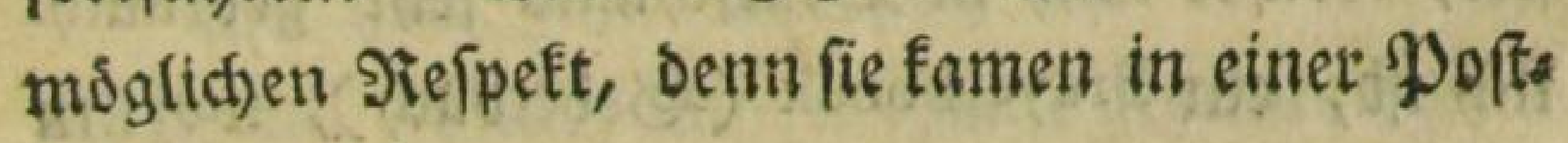
d)aile gefabren.

OGngead)tet Diés nur ein Eleines Dorf war, tunb man midh gevoí fúr feinen bornebmen (Saft bjelt, wiés man mir bier bodh ein tapegiertes Sthlafótmmer mit fefre guten \$etten an.

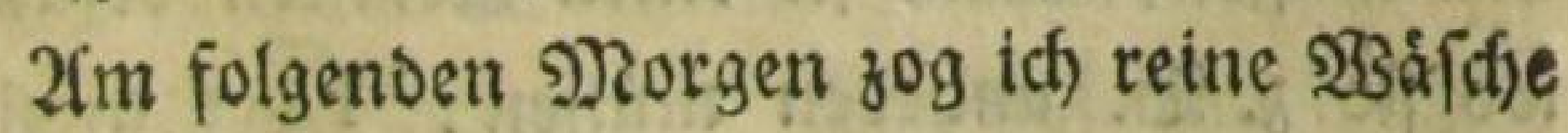
at, Die ich bei mir tritg, und puşte midf, , gut idf fonte, betaus, uno als ich nun berun ser fam, wiés man mich nicht, wie ben 2fGents 


\section{$(146)$}

vother, in bie Rúche, fonbern in oas Parlous ober frembenfimmer, unten an ber (5ibe; nut biés idf wieber Sir, ba idf den 2fbens vorber nur Jiafter titulitt wurbe, mit welcher feşteri Benenung man eigentlich nur \$auern uno ganz gemeine Qeute anredet.

Es war Sonntag, uno alles im Şaule batte fich febon feftlich angepust. (Fs fing mit an in biefem Dorfe aufferoroentlich zul gefaffen, unt idf nabm mir vor, biefen giorgen bem Siottesdienfte mit beizumofynen. au bem Ende (ief) idf mir von meinem $23 i t t$ bem Seerti Slling, biés war retn Nabme, ber mir alf? fiel, weil er auch in Deutichlano fehr gebrátuchs (id) ift, ein Prayerboock (Esebetbith), worint

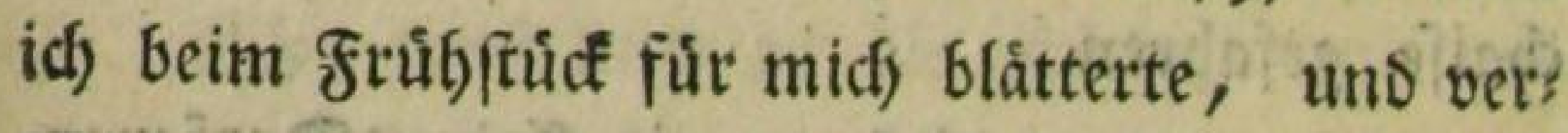
(f)iednes von ber Englifitien \&iturgie barim las. Lluffallent war es mir, ons oen prieftertit alle 23 orte vorgefachieben fino, beren fie fich beoie: nen muifen, wenn fie eitien Sranten befuchen, wo fie 子. D. anfeben múfen: Place dwell in this Houfe! (Friede fen mit biefem Saarfe) i. T. w. 


\section{(147)}

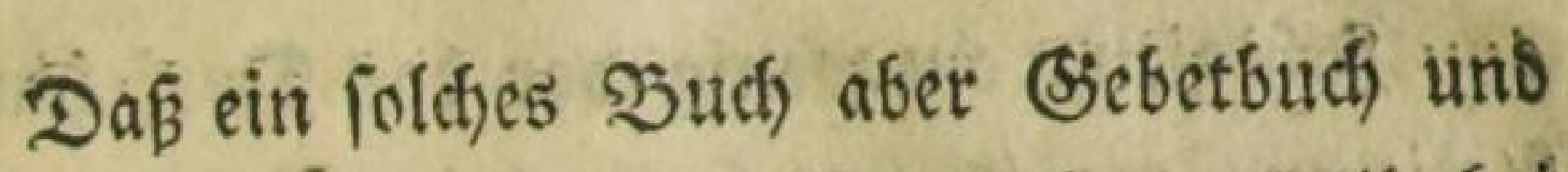
nidft (sejangbud) beist, rúbut bafer, weil bet Dem Englifden Sisttesbienf von Der Biemeine eigentlidf nitat gefungen, fonbern nur gebeted. wird. Demolyngeadjet aber fint audf in biejem

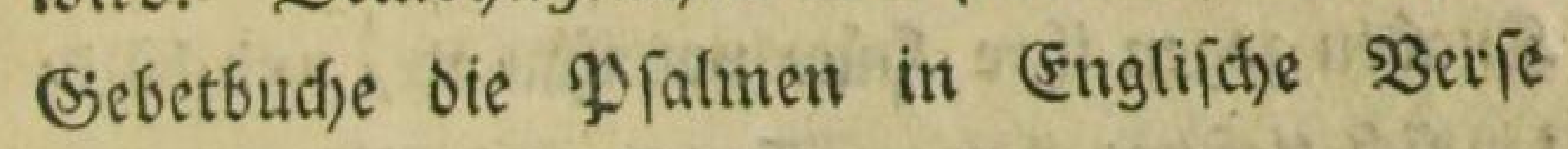
úberefest mit befindich).

Das (jebetbuch, was mit mein SBitthf liefse;

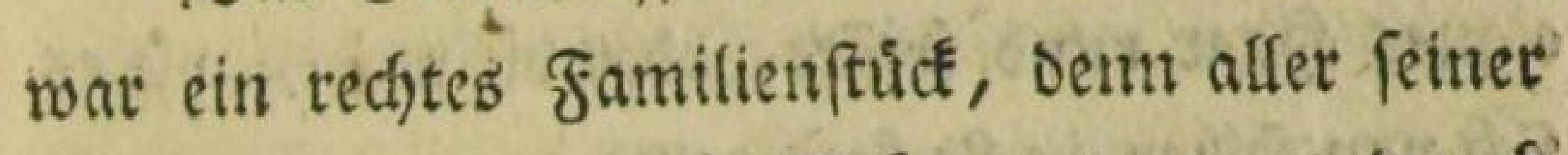
Sinber (Sefurts: und Nafimenstage, unb aucf) Der ₹ag feiner Şodjjeit waren forgfăltig Darinut verzeidfuet. Itm befto mefre 2 Seeth batte audf bię̧ Duud) in meinen 2fugen.

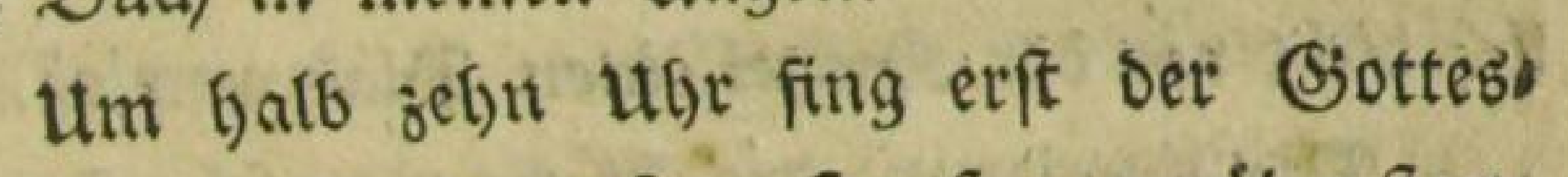
Dienft an. Brade unferm f̧aufe gegenúber frans Den bie Sinabet des Dorfs, alle blúfento unto fofón, unb fegrt nett uno fauber angezogen, ifgr rundabgefosnittnes Şaar nach Englifcher Zirt gefámmt, mit offner freiet $\mathfrak{S t u f f}$, uno bie weiken Sragen an ifren Szemben von beibent Eeiten úbergefdlagen. Eie fobienen fid biet beim Eingange bes Dorfs verfaminlet zu babeth, un Den yfarter zu erwartert. 


\section{( 148 )}

Tde gieng ein-wenig vor bas Dorf binar bazieten, mo ich von fern einige ग)ánner aus cinem andern Dorfe fommen Fabe, Die dem bies figen Gottesoienfte behobnen wollten.

Endlich Eam Der \$yarter getitten. Die. Sinaben zogen ifre Şúte vor igm ab, und búct: ten fich tief vor $\mathrm{ibm}$. (St war ein Diann von fijon etroas áttlidfem 2furefon, uno trug feitr eignes Şaar rund frifït, ober vielmegr, wie es fich von felber in gocfon rollte.

Es waro gelátet, und id) ging, mein (jis betbuch) unterm $2(r m$, mit Der (jemetne sus

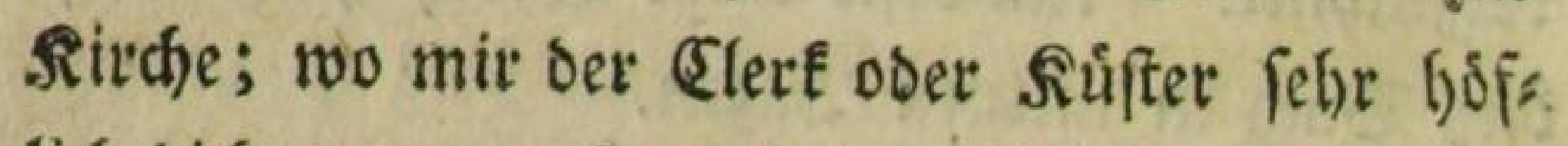
lich bidft vor ber Ranzet einen Whą̧ anwieß.

Die Zfuszierung Der Rircte war fegt fimpel. Berade úber dem 2lltat, wareen auf zwei Tafeltr

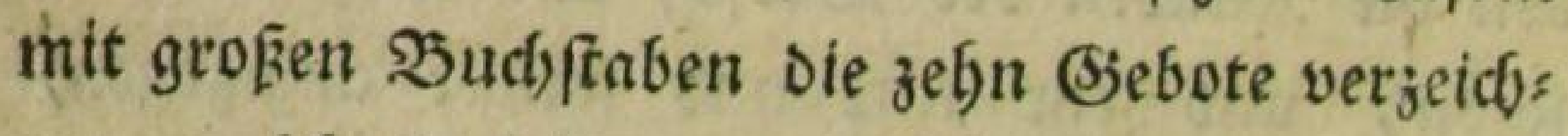
net, weldhe boct) immer ein (effr furzer uno nact)a orúctlicher Snbegrtif einer Sittenleber fúr bas 2ole fint.

Unter Der Sanzel bidjt am 2fufgange derfele ben wat cin Pult, worinn ber Prediger, vor bet Predigt, ftand, uno eine feftr lange Biturgie ablas, morauf Der Rufter jedesmal ant 


\section{(149)}

wortete, indés die ganze Semeine leife mit ein

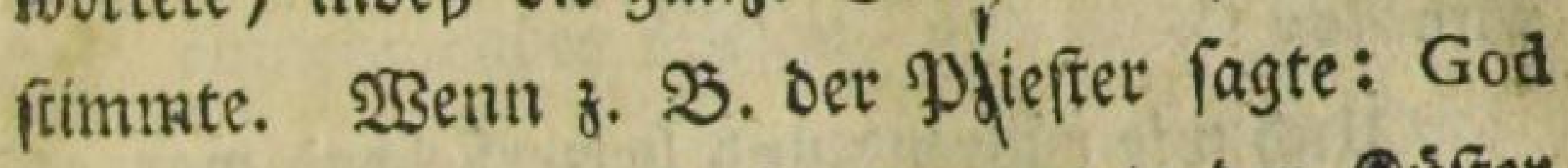
have Mercy upon us! fo antwortete ber Shiftect und bie Semeine: and forgive us all our Sins! ober Der Đriefter las ein Ssebet, und Dte ganke Bimeine fagte 2tmen Dazu.

Deeß iff fúr ben Prebiger fefte beffwets (ich), ber nifft mur, fo fange er presigt, fonbert wáhtend des ganzen Ssottesbienftes beftánotg re: Den muß. 2lbet oas Ditbeten ber ganzen Gie:

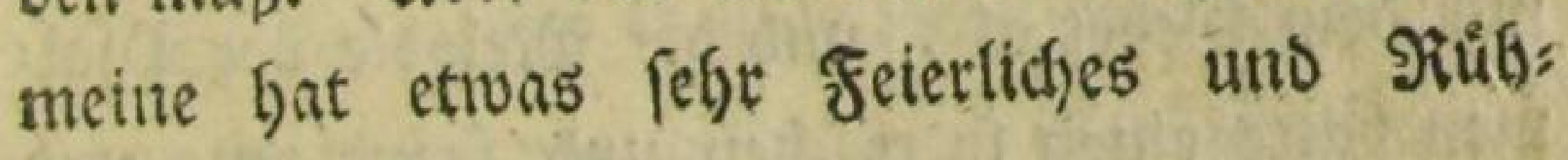
renber.

Eth Daar Gotbaten, bie neben mit fáseth, - und vermutflich in Eondon genveien raten, fdienen fijon ftarte Yjeifter fenn zu wollen, Dent fie beteten nicht laut mit,

SRachoem nun eine Slseile gebetet war, mertte 1d) auf bem Efore einige 25ewegungen, Der Eletf wat (ef)r gejdjaftig, und man f(chien fich fll its gend etruas şeierlid)em zu ruf(ten, aud erblictte

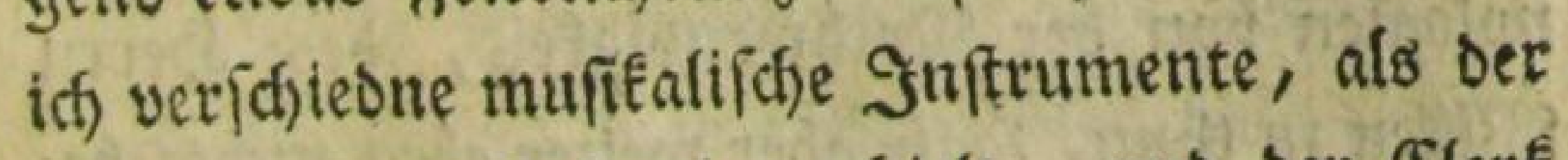
Đुrebiger mit Sefen inne bielt, uno ber ClerE vom (Shor becunter fagte: Lafit uns zur Effre Wottes fingen, Den fieben uno vietzigften $\gg$ falm, \& 3 


\section{(150?}

Der fid anfjebt, awake, our Hearts, awake with Joy!

Und wie rifbrend und herzerbebend war $\mathrm{es}$, als nun auf einmal in diefer fleinen lanotidien Sirche eitre Inftrumental : uno BofalmufiE el: id)allte, welche von feinen geoungenen Ton: funftern, Fondern von den glúcflicten 2 ewots: nern diefes Dorfes feltoft, nls ein frobbliches Opfer zut (5y)e ifres Sjottes dargebracht mutde,

Diefer Siefang medfelte num nocheinigemal mit Dem Siebet $n b$, und die Mielodie der Whal: men batte einen fo rafdjen uno freubigen, uns Dod) Dabei erfabmen Gang, Der Das Seerz unaufs baltiam zur 2(noacht mit fich fortrí, uno midh oft bis zu Thránen rúbrte.

Der Prediget trat nun auf uno bielt eine furze rede úber ben Tert: (Fs werden nidjt alle, die ju mir Seert Şerr! jagen ith f̧im: melteid) fommen, u. f. w. Er Gandelte inziem: (ich) allgemeinen 2fusorúcfen uno Drebigertermis nologien yon der Nothwendigfeit, Des Seertn 25ilfen zu thun, fagte aber weiter ebent nichts bes fonders 3roctmábiges. Die Prebigt oauețte feine balbe STtunde. 


\section{( 151 )}

Diefer Prediger batte eben fein freundi:

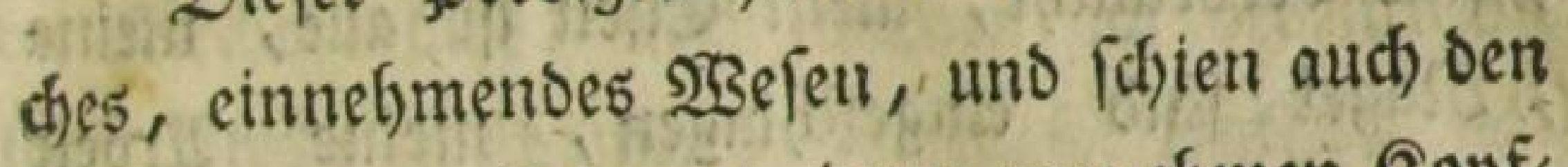
Souern etwas ftolz mit einem vornegmen Ropf: nicten zu Danfen, wetn fie ifhn grúften.

Jch blieb bis ber Giottesdienft ganz geendigt war, und Dann ging ich wieder mit ber Ssemeine

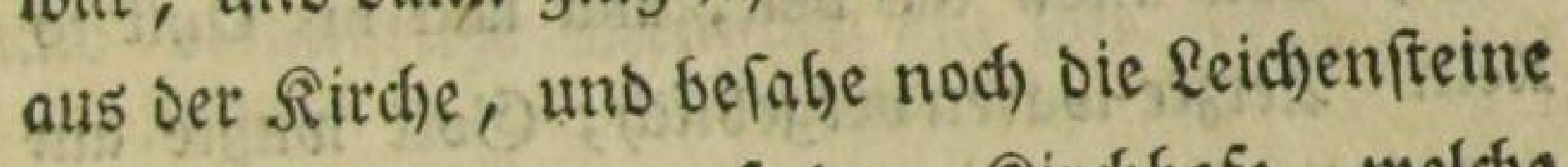
und Sirabfdriften auf Dem Sirdhbofe, weldje ooć) gróstentbeils fimpler uno gefd)mactuofler als bie unfrigen roaven.

(Finige waren freilich auch fomilds genug, morunter benn vorjuglich eine Brabjahrift auf einen Sdbmiot gebort, bie ich megen ifyer Sclts famfeit abgeidstieben gaben, und fie bierber [eß̧en will:

My Sledge and Anvil lie declined,

My Bellows too have loft their. Wind;

My Fire's exftinct, my Forge decay'd.

5. My Coals are fpent, my Iron's gone,

(1) 110 My Nails are drove, my Work is done.

sglo Miein Sd)miedefammer und 2(mbor lies "gen Darnieder; meine Slafebálge Gaben ifren "ISsino verlobren; mein feuer if verlofdien, 1) und meine Eshmiede verfallen; meine Sioblen

ऽ 4 


\section{( 152$)$}

"fint verbraucfit, mein Cilen ift alfe, meine " Nágel fino etngefolagen, meine zitbeit "ifî aus."

Biele (Srabfestiften fans ids, Die fich mit folgenton Sieimen enbigten: Phyficians were in vain; God knew the beft, and laid his Duft to Reft. Zlerzte waren vergeblid); (Sott wufte ant beften, was ifm gut jen, uno legte feinen Staub - Jur giute.

In der Sitrthe felloff folje ith das matmorne Cpitupbium eines Sobnes des betútymten $D$. 25allis, mit folgendet fimpeln uno túftention

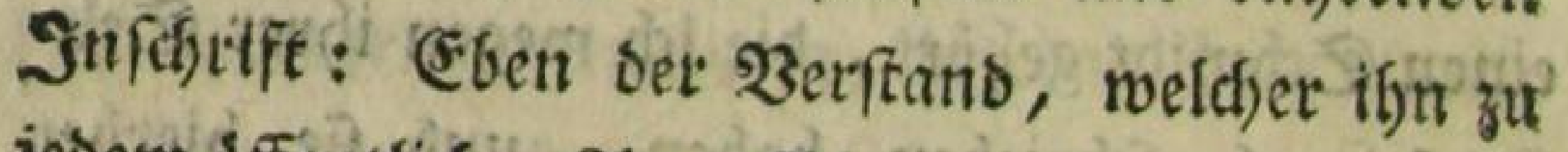

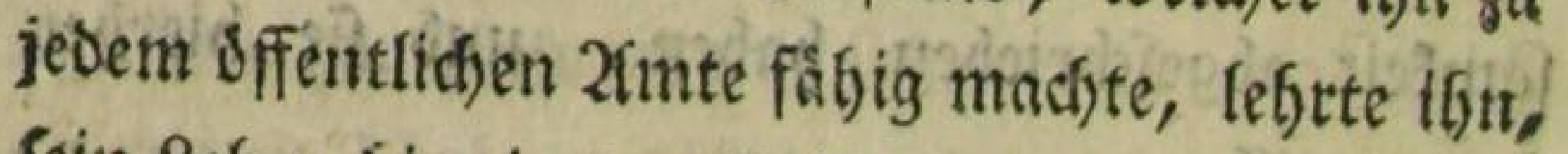
pein \&eben bier in ber Stille zubringen.

alle bie Bauetn, weldie id, bier fabe, was ren nidft, wie bie unfrtgen, in grobe Sittel, fons berti gutes feines ₹uch, auf eine gefdrmactuolfe 2frt getleibet, uns unteridjieben fich nur babuted

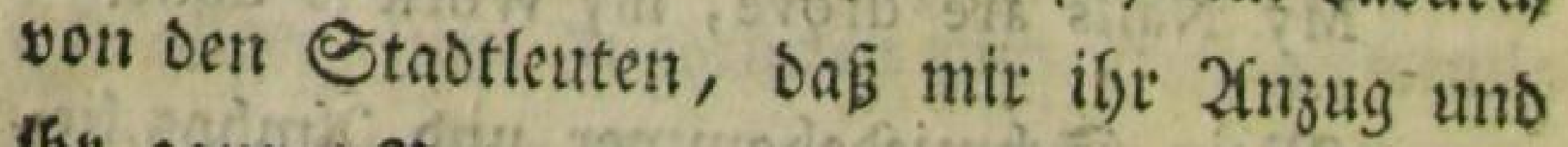
(t)e ganjes Bettagen weit natuiticher uno eples ju Fenth fébien.

Eintge von betn Soldonten, Die ftarte Sels fer fenn woliten, gefellten firf zit mir, on is 


\section{(153)}

bie Sirtibe befabe, uno fiblenen fich orbentlids itger Sirdje zn féchamen, inbem fie fagten: es (e) mut eine febr erbármliche Sirche; worúbet tof) mit bein die freiljeit nafjm, fie zu belebren, Daß̧ Ecine Sirdje erbármlich) fer, bie orbentlidje uno vernúnftige \$enf(jen in fich fasfte.

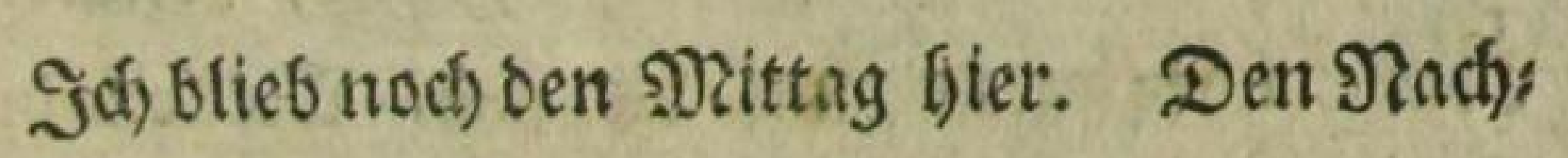
mittag war fein Giottesbienft, abar bie jungen Leute muficietten wieder für fidi), uno fangen einige ઝfalmen, wobei ein ₹fycil Der Semeine

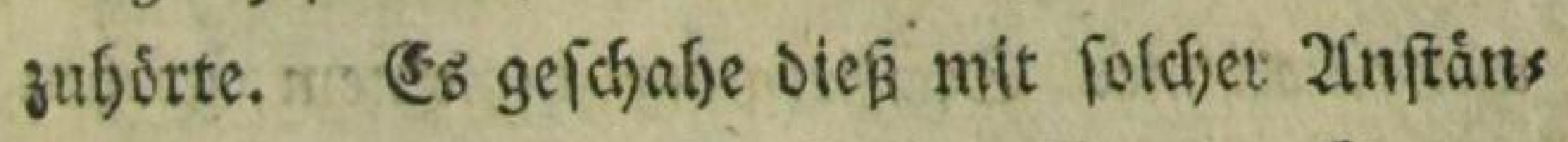

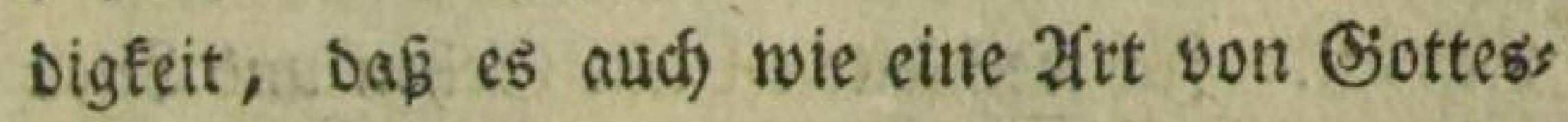
Dienft zu betradjten wat. Diefer నiz̧d)enmufite sobfinte id mieder bei. Sids wat wie an Dies Dorf gebannt. Deeimal ging idf fort, um iwei: ter zu reifen, und eben fo oft fefrte id) wieder um, weil id mit beinabe vorgenommen batte, eine 230 d)e oder langer in siefem Dorfe zuzu bringen.

Doch Der (Sebante, Daß̧ id) nur noch einige

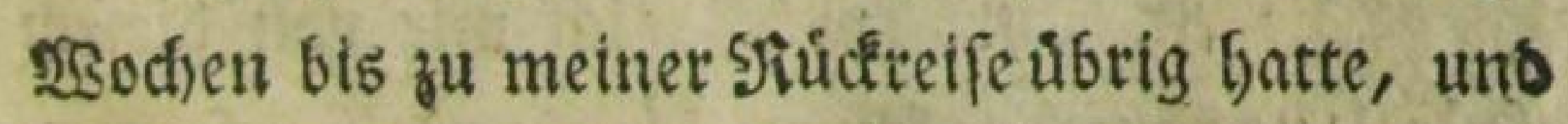
Doch nod) Derbifatire befefjen moflte, trieb michs

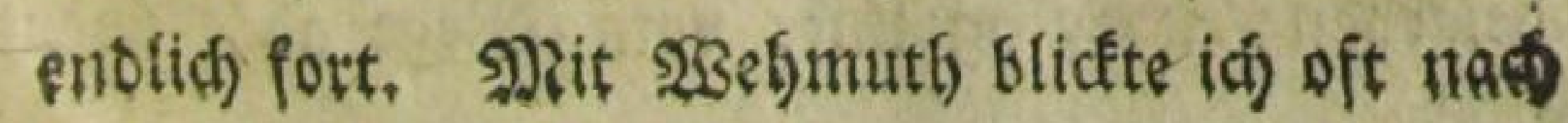

\section{\& 8}




\section{( 154 )}

Dem fleinen Sirdftlfurme uns ben friedichen f̧utten zurúct, wo ich einen \$iorgen, wie zu Şaule geweien war.

Nun war es beinabe orei Hbr গacbmittas ges, als ich von bier megging, uns ich batte nodh ndatzebn Dieilen bis Oriord. 2(llein id) nabm mir vor, nidjt bis Oxford zu gehen, fondern bie Padit úber etwa fưnf bis fectss Dieilen Davon zu bleiben, um es alsbanin ben folgenden \$ers gen noch bei guter Beit zu erveidjen.

Nein $\mathfrak{B e g}$ von Nettlebed alls war ein un: unterbrod)ener Epaziergang in einem großen

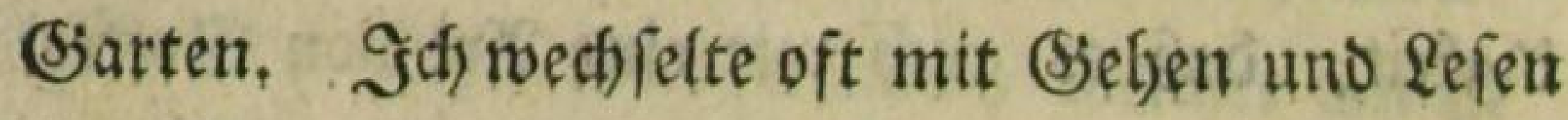

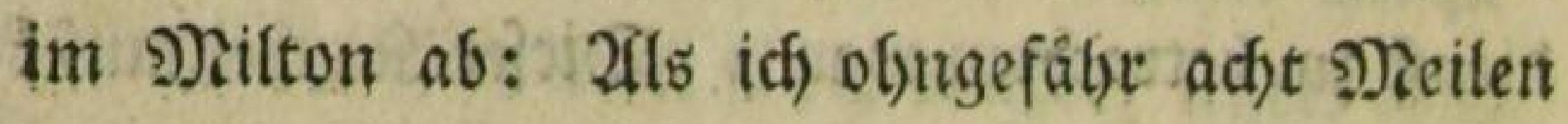
yon Nettlebes uno nid)t weit mefoe von Dorches fter war, batte id oie Fhemfe in elniger (Ent: fernung zur Qinfen, uno an ibrem jenjeitigen Ufier (â) idf) einen langen feuggel, binter weldfem ein Maftbaum berworzuragen ichien, Der mich - vermuthen liés, dafi an Der andern Seite bes Şügels auch ein Tlus (ê).

Die 2fusficht, welche ich mit von biefem frugel veriprad), fonnte idf unmoglich fo vor: beigeben; id ging lints yom $253 e g e ~ a b$, úber 


\section{(155)}

eine Brulfe úber bie ₹hemie, uno immer ben Scuigel Ginauf, auf ben गaftbaum zu. 2lls ich Den (sipfel erftiegen batte, fand ich), Dẩ alles ein Slentwerf war. Jid) Gatte nichts, als eine grope (5bne vor mir, und Der Maftbaum war in bie Erde gegraben, um vormiţige \&eute vom sisege abzuloten.

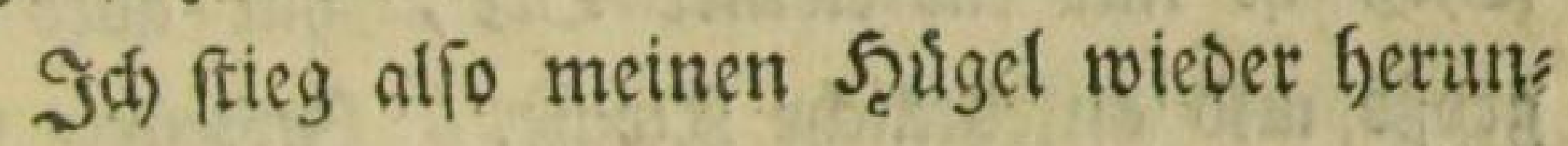
ter; am Fuß Deffelben war ein f̧aus, wo viele qeute aus bem Fenfer laben, ole mich auszus lachen (d)ienen, Daranjidy mids aber wenig fefrete, uno meine Straß̄e fortging, obue Daß̧ mich meine Tieife ju Dem गiaftbaum fefr gereuet hátte. gut war idh bod yon bem Steigen etwas ęrmúbet.

Pricht weit yon bier nabe vor Dordiefter batte ich nodh eime herrliche Scene. Die Sjes

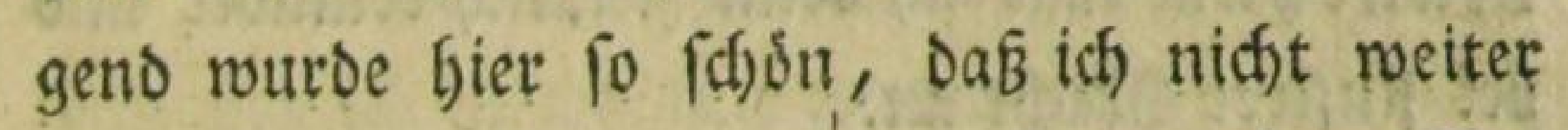
gefen fonnte, fondern milch auf ben grúnen sias fen legte, uno fie mit Entzuicten betrachtete. DeF J)ond ftand (d)on in feiner ganjen fulfe am Şimmel, bie Sonne fimmerte nod) mit' if ren

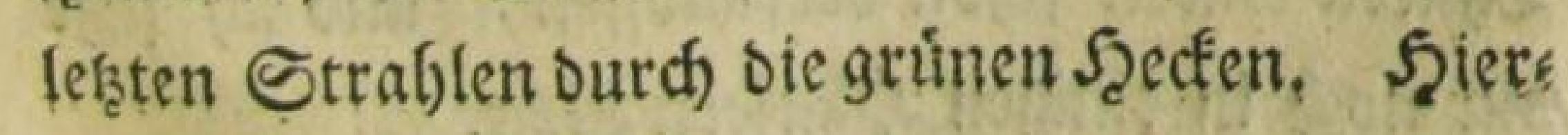
3u fam der 2 (siefe betáubender 230 hlgeruch), dẹ 


\section{( 156 )}

238gel mannichfaltiger Sejang, die Şuigel an oer Themfe, bald bellgruin, blä̧grun, oder oun: Eelgrún, mit thren fin uno ber jetftreuten \$aum. gefdrwabern. $\Im$ d) erlag faft unter ber Betlachs tung aller biejer reizenden Siegenftande.

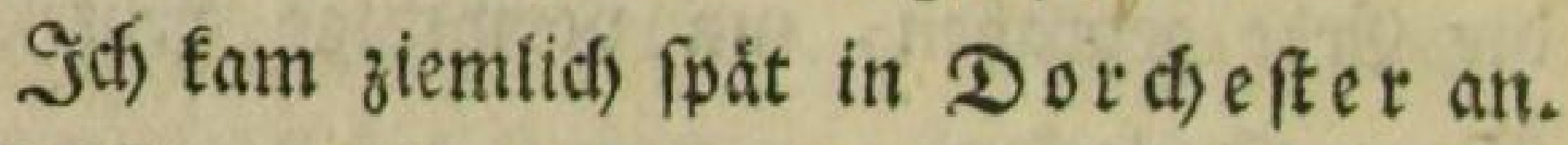
Dię if nut ein fleiner Stt, bat aber eine grofe uno anfernltidse Sirche. Snoeffen fan: Den die Damen mit frifiertem f̧aar vor betr Şåufern, wo ich vorbei ging, unb es febten mit Gier wieder alles ein viel zu vornebmes 2frifefjen zu haben, als baßs id) bier gátte bletben follen, wie ich anfänglich willens war.

Jid) entichlos midh alio, noch viertebalb פiel: Len bis sunelyam zu geben, wovon es nue noch) fưnf Meilen bis Orforo raar. Seter in Sunefam fam id, benn ziemlich ermíot uno bei finftrer Nad)t an.

Der Ort beftano aus zwei Sietben bidst ane einandergebauter f̧åufer, und war fo regelmápig angelegt, wie eine Straßje in Sonbon. 2lffe

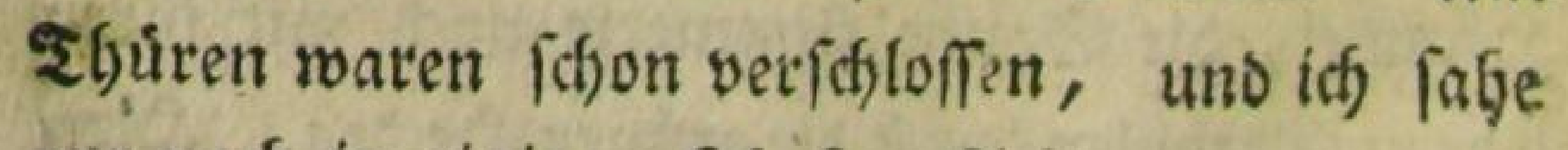
ตุเ noch in einigen Sุáuाern \&id̨t. 


\section{( 157 )}

Enblid) fal' id ganz am Ende bes Drtz, ein grofeses Edjild queer úber die Straß̧e aushants gen, uno das kef̧te Seaus an ber linfen Seite wat ber Safftlyof, wo noch alles in Serves guing wat.

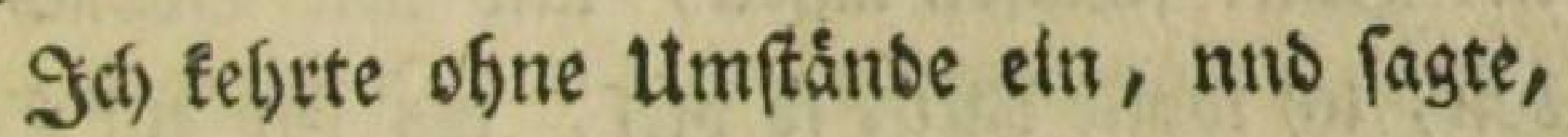
ich wolle bie शacht da bleiben. By no means? (feinesweges) bießs $\mathrm{es}$, es (ey) (d)led)teroings unmóglid); Das ganze Szaus fev voll, uno alle if)re sostten befeşt; oa ich fo meit wáre, folle tch nur noch vollends bie funf Mieilen bis Oxforo gegen.

S(seil mid) (e)br fungerte, fo verlangte idf wes nigftenr, Daß man mir etwas zu effen geben follte. Ifllein id befam zur 2fntwort, weil idf bie গacht nidjt da bleiben tonne, fo ginge es auch nidjt gut an, Daßj fie mir zu Effien geben fosnten, ids móchte nur weiter gefon.

(Englid) verlangte id einen Rrug S3ier, Den man mir fúr baare $\mathfrak{B}$ ezablung gab, aber einen DifiTen Sorodt bazu, ben id) aud) gern bezablen roollte, fhlug man mir ab.

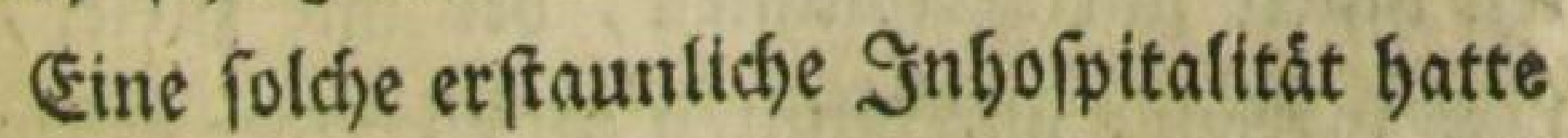
id) Denn Dod) in einem Englifhen Bafthofe nidbs 


\section{$(158)$}

etwartet. Sidh wollte aber bod) alles mogliche berfuchen, um zu féten, wie weit die \&ieblofig: feit otejer Reute gefsen wúrde.

Jif) bat allo, fie moidten midh mut autf cinet Saanf folafen laffen, uno mit Doonch ge: ben, ta) wolle baful fo viel, als für cin bette

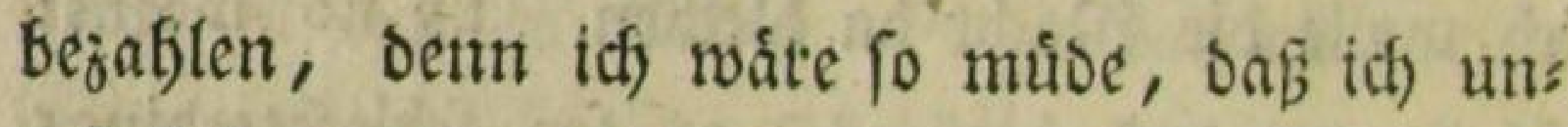
moglid) weiter geben fönnte, affein indem ich noib) biefen 2futrag madfte, fohlug man mit bic Thúr vor ber Nâe zu.

Da man mich nun fier in einem fleinen Dorfe nicht Gatte aufnelomen wollen, fo fonnte ich nod) weit weniger erwarten, ons man es itt

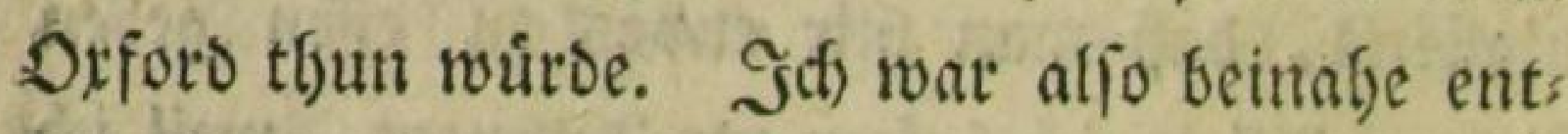
foloflen, biefe Sladt, weil es úbertoem ziemlid, war'm war, unter fretem Scimmel zuz̆bringen, into fudite mir zu bem Ende einen bequement Dlafs auf bem f̧elde unter einem Şaume aus. 2lls idf nun gerade im Begriff rat, meinen

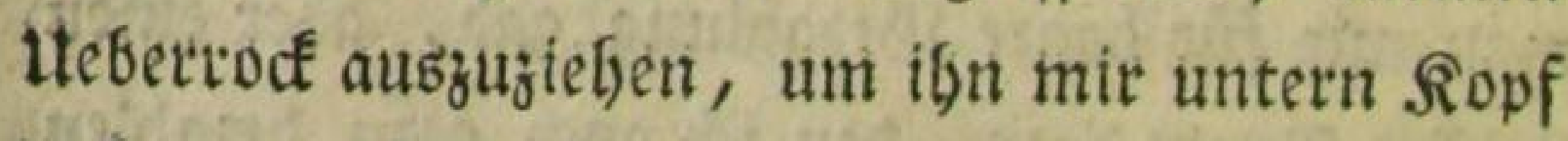

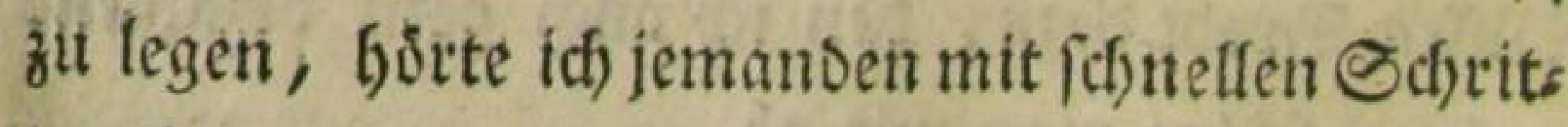
tert finter mir betfommen, Det mir zurief, idf folle watten, wir fonnten miteinander geberk 


\section{( 139$)$}

Eo wenig nun aud jemanben, ber auf bie 2seife binter einem berfommt, in finfrter ఇacbe fu trauen ift, fo wat es mir both eine freude,

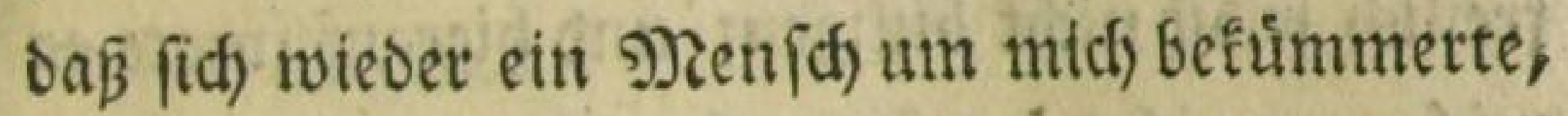
uno mit mir geben wollte, oa id vorlyer jo auj) ferfit unfreundida yon ben Nenfchen aubge: ftónell wat.

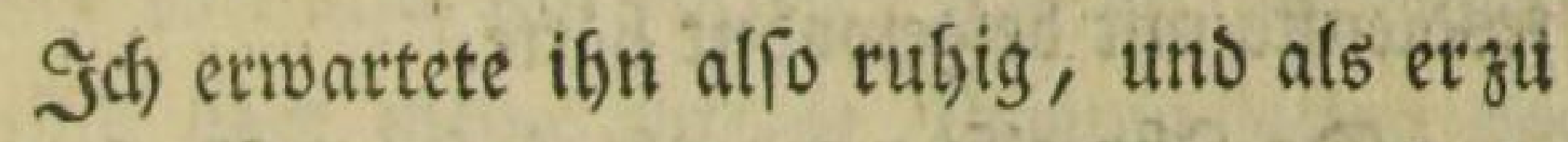
mit betan fam, fagte er, wenn tef gut zu Juße ware, fo formuten wir miteinanber geben, bent

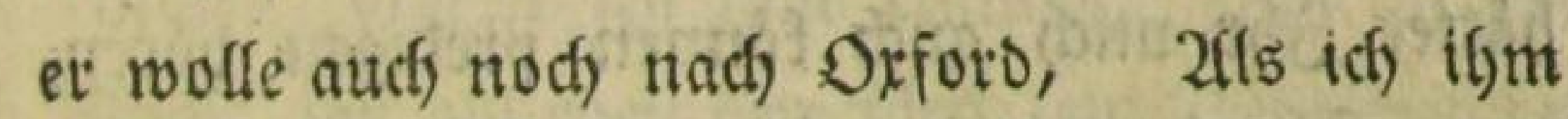

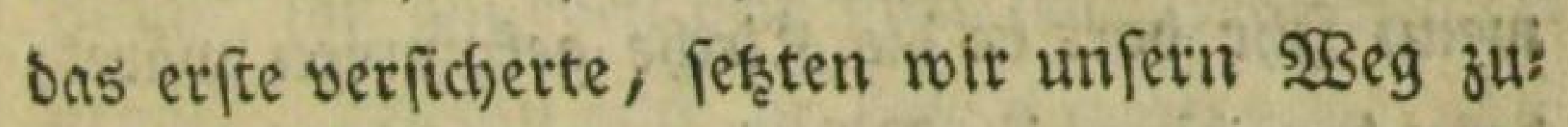
fammen fort.

Da idh nun nicht wiffen fonnte, of meinent Sieifegefábrten zu trauen fer), fo fulchte id mich (5) $m$ auf alle fălle von ciner bemitlebenswertben Seite befanth zu madjen. Uno beflagte mids รu bem Enve ûber bas Untedft, oaß man mir,

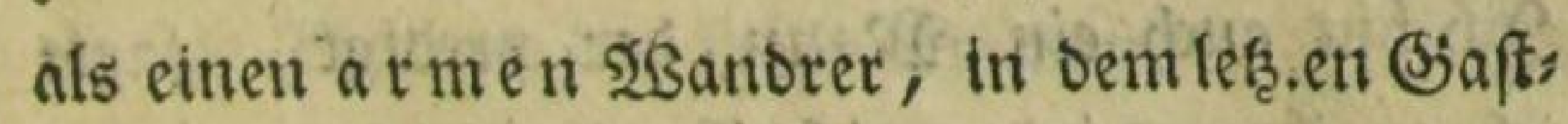
bofe nidbt einmal ein obsad) verftattet, uas mir fùr miein Sseld fogat einen siffen \$3roo berfagt babe.

Diein Treilegefábrte ent/fjulbigte bie Qeute

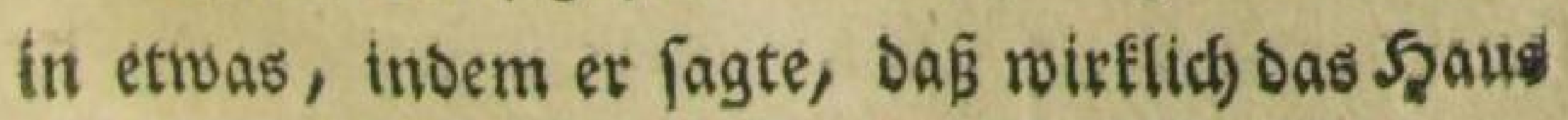




\section{( 160$)$}

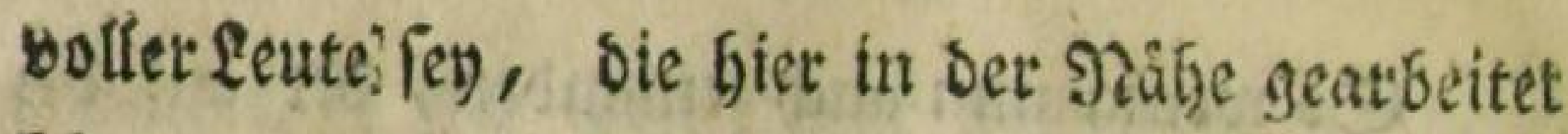
bätten, uno nun ba logierten. Daß̄ man mir aber einen \$ifien \$roo verfagt babe, föme er freilich felbft nidft billigen; nnd bierauf fragte el mich, wo id, benn Geute Gergerwandert fäme.

Sidh antroortete aus Rettlebeb, und er:

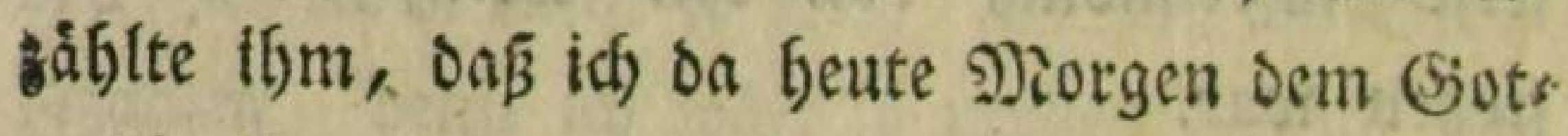
tesbienfte mit beigemobnt båtte.

Da $\Im \mathfrak{S t}$ alfo vermutblich beute Nadymittag Durch Dorchefter getommen feno, fagte er, fo

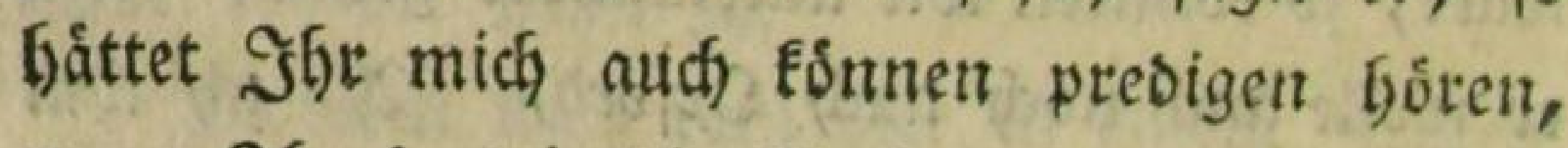

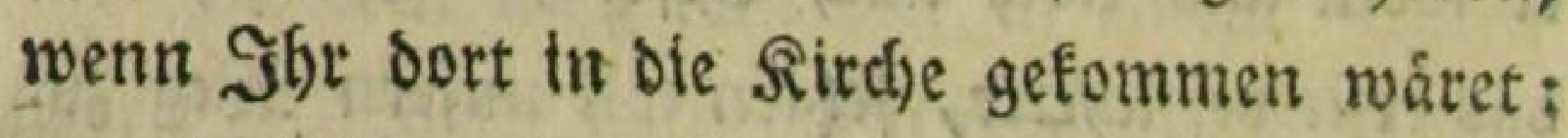

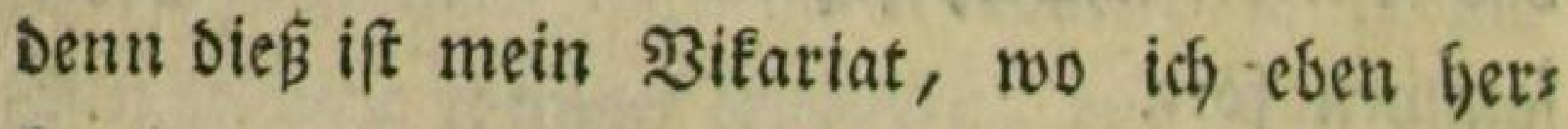
fomme, um roieder nach, orford ju gefjen.

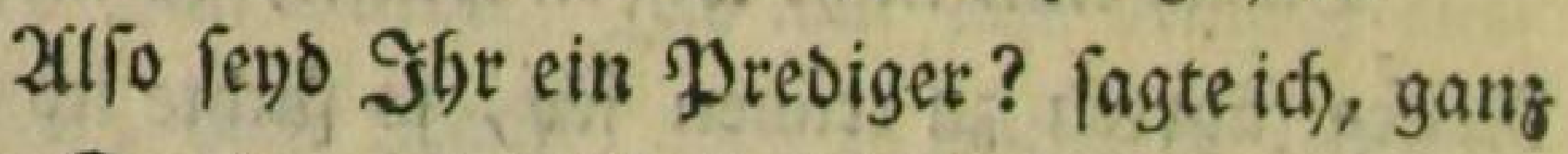
voller Freuben, Daß̧ ich in Diefer finfreen Macht, auf meinem 23 ege einen (Siefábrten angetroffen Gatte, mit bem id einerlei Befhdiftigung trieb. jo) bin aud, ejn Nann ber prebigt, lagte ich zu ifm, indem idf ifsm jugleid) zuwerftes ben $g a b$, bas ids nicht, wie ich vorber gef fogt, aus 2frmuth, fondern um Sitten uno

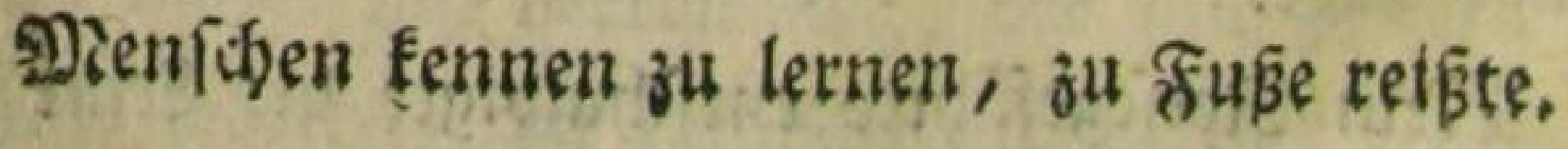




\section{(161)}

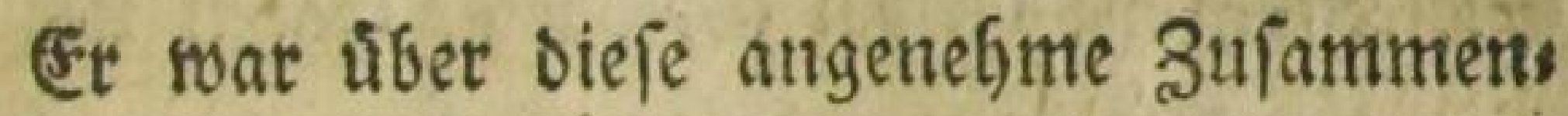
funft eben fo erfreut wie id), unb wit idfuttefs ten brưderlich Die Şånde zufammen, elge wir sweiter gingett.

Nun fing er an, einige 230 orte Latein zil res ben, uno ba ich ihm nach oer (Englifchen 2fusfprache wieber Rateinifch antwortete, gab er mir feinew Seifall úber meine rid)tige Pronunciation Des Eateinifchen zu erfenten. Denn, fagte er, vor einigen Sabren fen ifm eisumal, auth in ber S?acht, faft auf eben bem Sleck, ein Deuticher bes gegnet, Der if) aud in Latein angerebet, aber

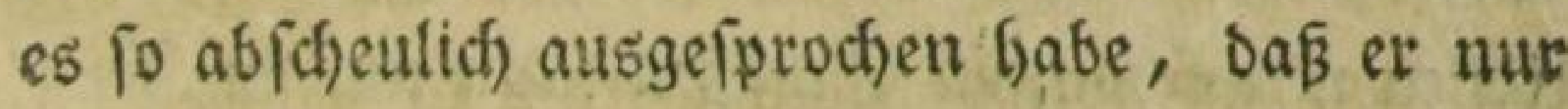
roenige 230 te bavon verftanden bátte.

Das Siefpråch lentefe fidfy nun auf theologto idie Materient, uno unter anbern auf bie neuen Eefren bes D. Prieftey, ben er bis in ben uns

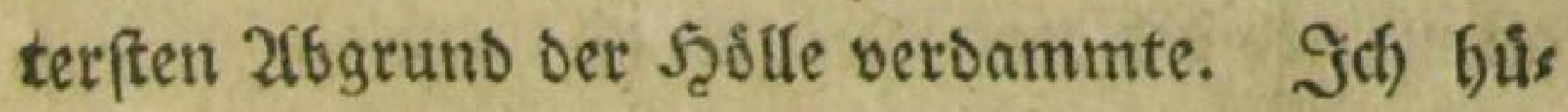
tete mich alfo mofl, mids ůber biefen Text zu tief mit ifm einzulafien, uno bifligte feine Bebaup:

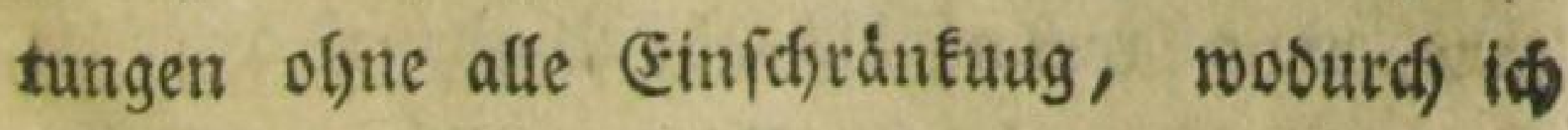
mir fefir feine Gsunft erwarb. 


\section{( 162 )}

şåfueno Diefem Siefpráche waren wir fait, olne bes 25 eges gewabr zu merden, bis nabe voe Drfort getommen.

Nun, fagte er, whitbe idf) bald eine von

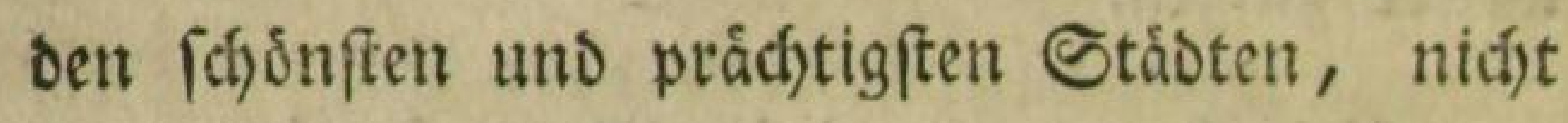
nut in Englano, fonbern in ganz Europa, feten, nur fev es S(hade, Daß̃ id), wegen ber Duin

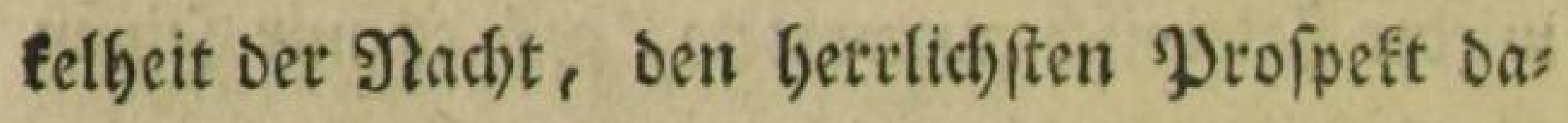
von verlieren múrbe.

Diejen verlor idf benn auds roirtlids, uns labe nidfe efer etroas von Otfort, bis wir sidft baran waren. Und mun lagte et, als wit kins eingingen, wưtoe idf eine ber láng(ten, prach): tigften uno (d)onften Straß̧en nidjt nur in Diejer Staot, fondern in England, und úberbaupt in ganz Europa Tésen.

Seben fonnte id bie Pracht und Schonbeit biefer Straß̧e nicht, aber ifje \&ánge fúblte idh an meiner ग) Díbigfeit, Denn id) merfte, Daß̧ wir immer fortgingen, ofne daj ble langfte Strẩe in (Europa ein (Ende nabm, ober Das id) genusst hátte, wo idh nun auf biejer berúlgmten Straß̧e die शad)t bleiben múrbe. Bis endlict) mein Fieires sefäbrte ftille ftans, um ron mir $2(b /$ d)ied za 


\section{( 163$)$}

nebmen, uno fagte, er wolle nun in feir Rolles gium geben, wo er wohnte.

Itno (id) will mich bie/ Iracht bier auf einen Stein Fefzen, gab id) iffm zut 2fntwort, und ben Norgen abwarten, weil ich Gier wobl fifwertidi) eine Sferberge finden werbe.

Şlor wollt (Euch auf einen Stein feçen, lagte ex, uns idjúttelte mit Dem Sopfe: Rommt lieber

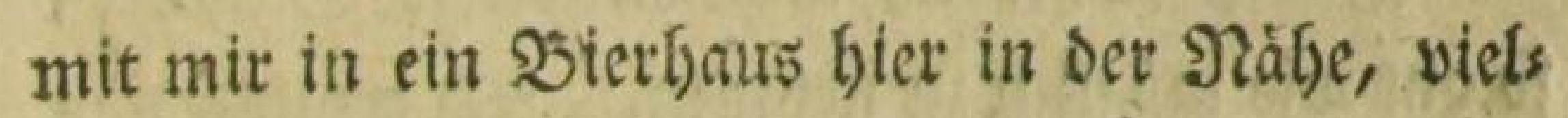
leidjt treffen wir ba nod) melyr (Siefellichaft an!

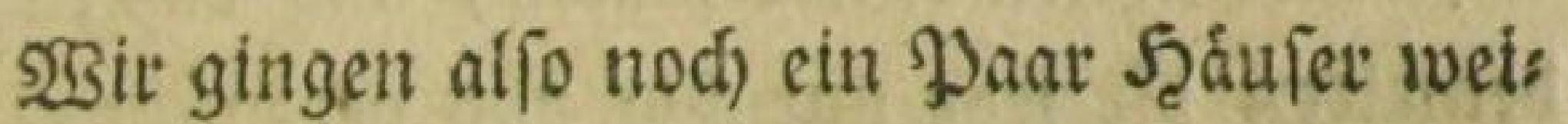
ter, und Elopften an bie Thưre. (Es gieng fá)on auf zwolf Uhr. Sian madte uns auf, und wie gró̧ war meine \$erwunderung, da wir sleich zur linten Seite in cinen Beríchlag traten, wo

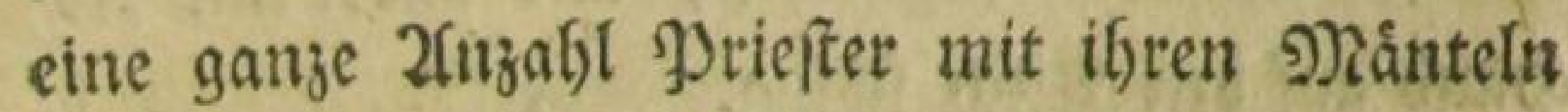
und Sitagen, um einen großen $\Sigma i j$, jeder feis nen Bierftug vor fíd, , faß̧en, benen mid) mein Sieifegefáfrte als einen german Clergyman vors ftellte, und mid) nidit genug wegen meiner richs. tigen 2(us[prache bes Lateinif(s)en, meinev Dr: thodorie, uno meines guten Sdjrittes regen, růfmen fonnte. 


\section{( 164 )}

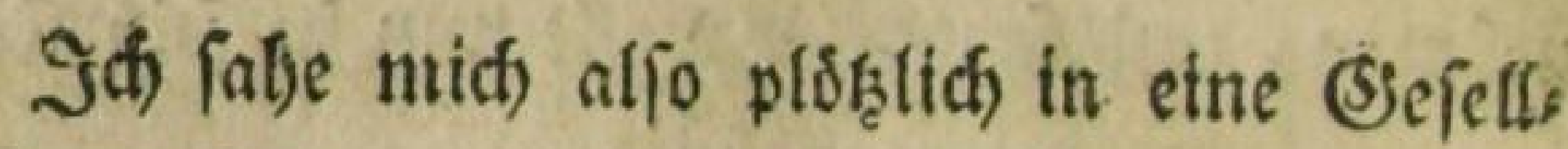
fdhaft verfegst, wovon id mir nie etrwas batte tráumen laffern; und es fam mit aufier|t fonder: bar vor, Daßs ids nun fo auf einmal, obthe zit wifien mie, nach Orford, und mitten in bet

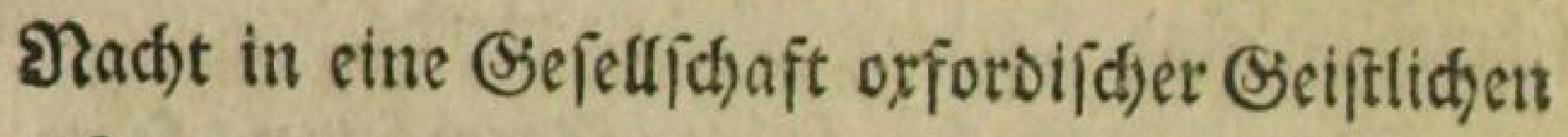
getommen war.

Sndés fuchte id mich in biefer Situation fo gut wie móglid, zu nefbmen. Ţă erzăblte von unfern deutichen Univerfitáten, unto daß́ es auf Denfelben oft fefte unrubig uno geráufdivoll zus ginge, und Dergleidfen: $\mathcal{O}$ bier gefts auch mandos: mal ferge geráufdovoll zu, verfithette mich einer von ben Gieifflicten, oer einen fráftigen süg aus feinem Sitertruge that, und dabei mit bet Şand auf oen Tifd folug.

Die Unterbaltung waro immer lebbafter: man fragte midf) autd) nad) Seerrn $\mathfrak{B} r$ un $n$, jeş̧: sen Wroferfor in Şeimftadot, den die meiften un: ter ber Gepeellid)aft gefaunt batten.

Nun war unter allen biefen Clergymen auds ein 2 Seltlicher, Nabmens (Sle r cf, der ein ftarts fer Seseift fenn roollte, uno ignen allerlei Estre mưtfe gegen die \$ibel madjte, (Er madjte ein 


\section{( 165$)$}

25sottpiel mit feinem Nabmen, weil Sletf aud) ein Sulfter heiß̄t, insem er lagte, er bleibe ims mer (Slerf, und avancire nie zum Clergyman; úberbaupt wat er, nad) Feiner 2(it, wirflids ein launigter Rerl.

Diejer madite benn unter andern meinem

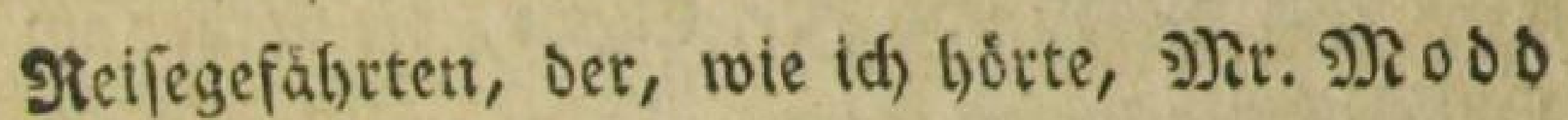

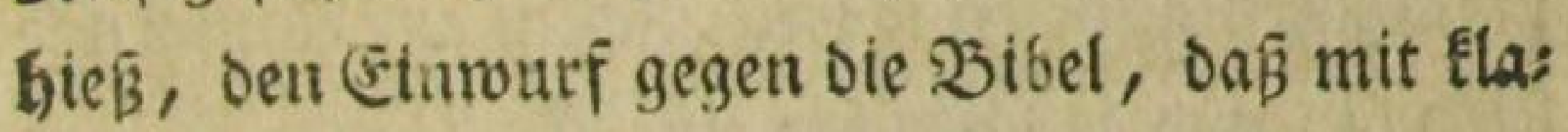
ren 2 borten darinu fúnde, Shott fen ein 2 seiny trinfer.

Datúber erefferte fich nun Mrt. MTodo ges waltig, invem ex befauptete, es fen fohlechter: Dings unmoglid, Daß̄ eine folche Stelle in ber Bibel gefunden werde. (Fin andrer (Sseiftlicier, Det Jir. Eaern bié, berief fidh auf feiten abs

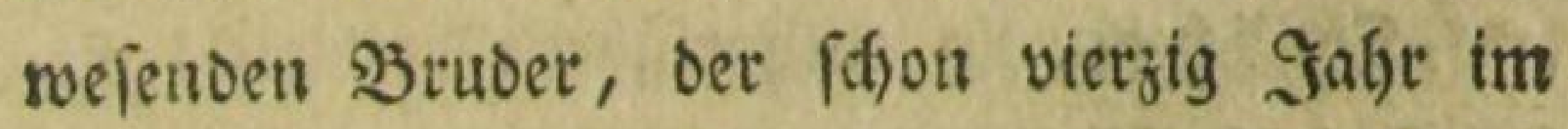
Zfmte fer), uno gewis etwas von otefer Stefle soiffen múfie, wenn fie in der Bibel fránde, er

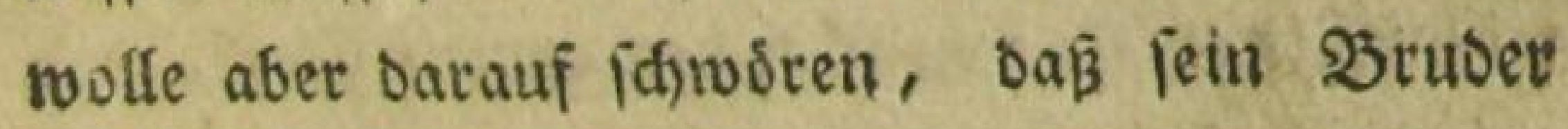
nid)ts Davon ivifie.

Waicer! fetch a Bible! (2fufioarter, bohlet

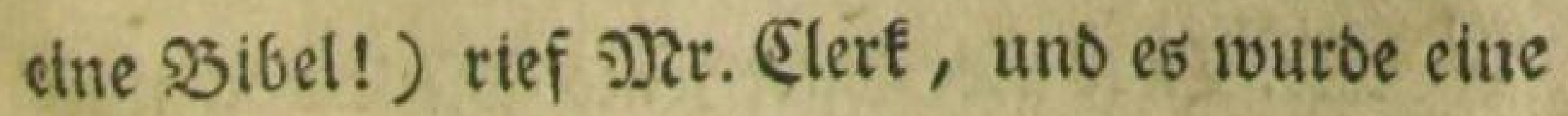
groß̧e Şausbibel gebractit, uno mitten auf bem Tiche unter allen ben 2fleftúgen aufgefohlagen.

\& 3 


\section{( 166$)$}

9). Slete bläterte ein wenig, uno las im Such ber Fichter 9, 13. Soll ith meinen 2 sein ver:

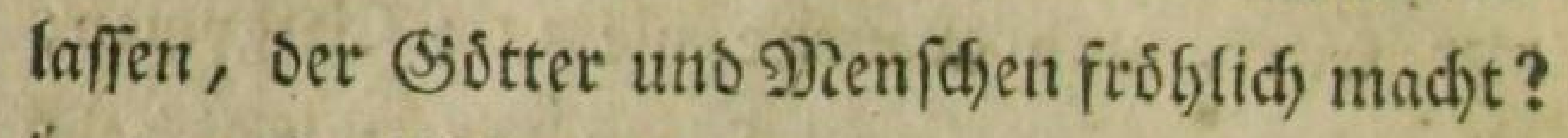
in ber Englijeben theberfersung: which rejoices the Heart of God and Man.

Mir. MLodd und Mir. (Eaetn, die vortber am muthigften gervefen waren, faßen auf einmal wie betaubt, uns es hetrfohte eine Stllfe von einigen Minuten, als auf einmal ber Sieif́t Der (5xegere ưber mich fam, uno id, fagte: Gentlemen! that is an allegorical Expreffion! (Meine Seertn, Dast ift ein allegorifher 2fusbrude, ) benn, fulfe ids fort, wie oft werden die Sonige Der Erben in Der Bibel Sidtter genannt?

- Freitich ifts ein allegorifher 2lusortud! fies

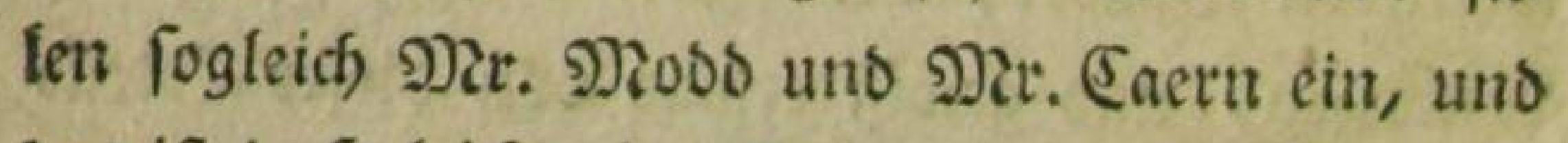
Das ift ja fo leicjt eingufelsen, rvie móglids! - po triumphirten fie un úfer Den atmen (SletE, uıo tranten mit mit vollen âkigen eine ङiefunblecit nach Der andern zu.

פar. Clerf aber Gatte feine DY feile nody nicht alle verfocofien, fondoern verlangte, fie foliten

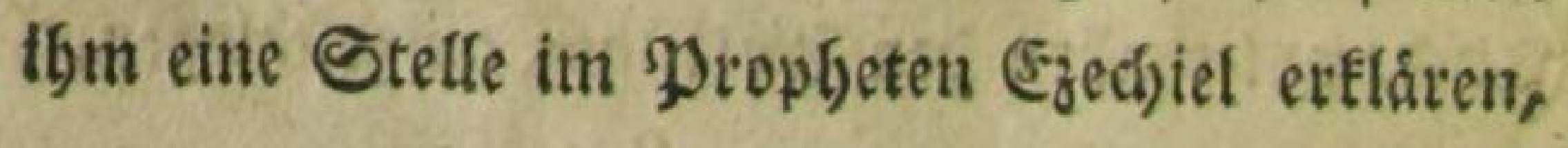




\section{( 167$)$}

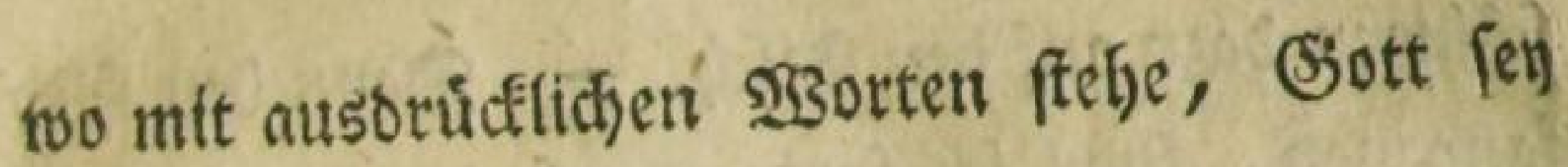
ein Saattideerer.

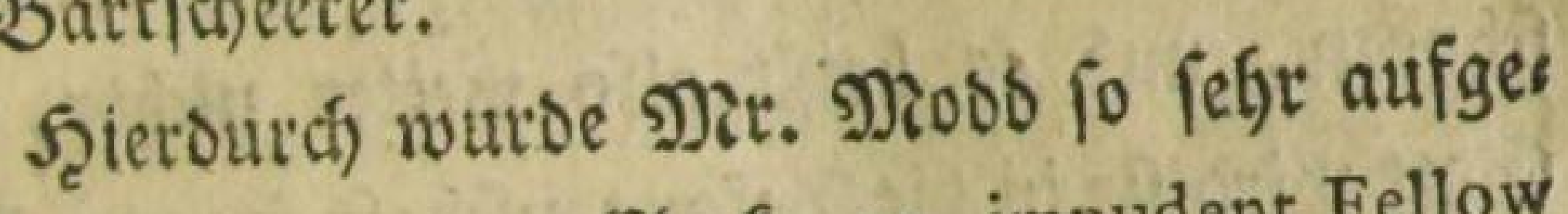
brad)t, Daßj er ben (slert an impudent Fellow (einen unveriffámten Serl) nannte, uno ग)Tr. Eaern berief fich auf feinen struber, ber fichon

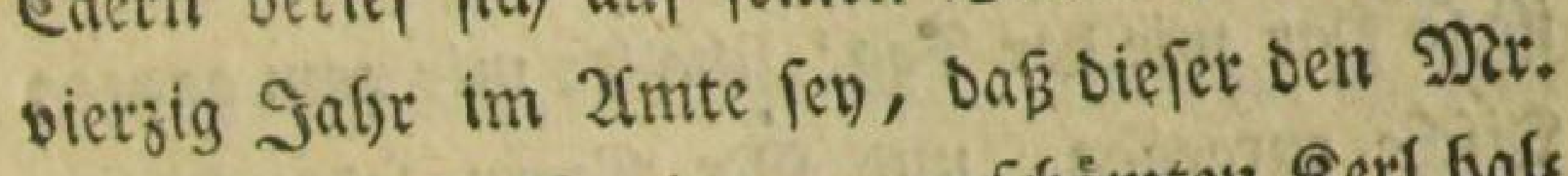

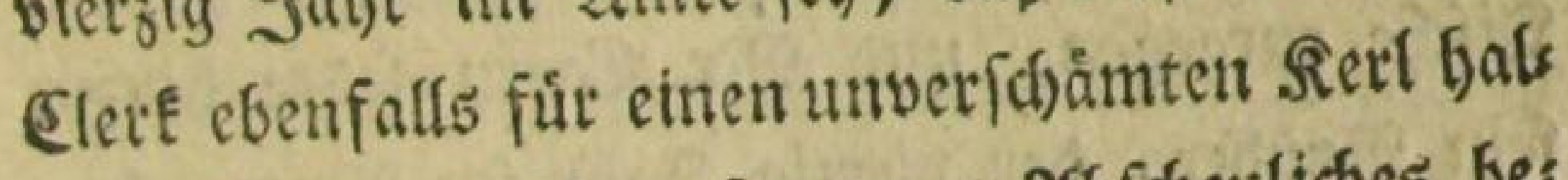
tell wuirbe, weil er fo etwas 2abldyeulidges bes Gaupten fonnte.

9): EletE aber blieb ganz rubig, uno fohling im \$roptyeten Ezechtel cine Etelle auf, Die eit jeber leeen formte, wo es von sen verftocten Sus oen fiés: God will fhave the Beard of them (S)ott wirb ibnen ben Daart abjheren). Wुaren

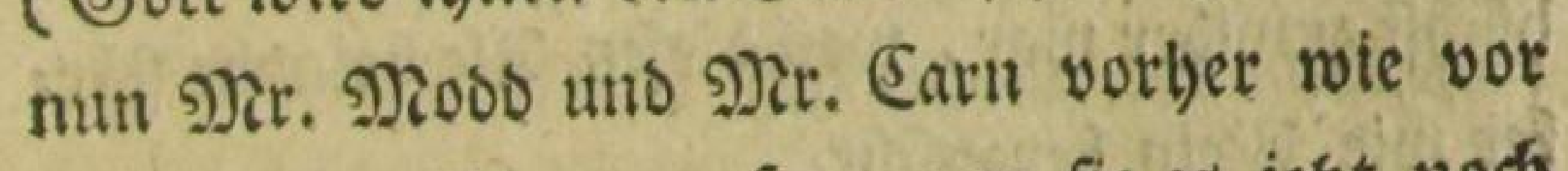
ben Sopf gefdlagen, fo waren fie es jesct nod)

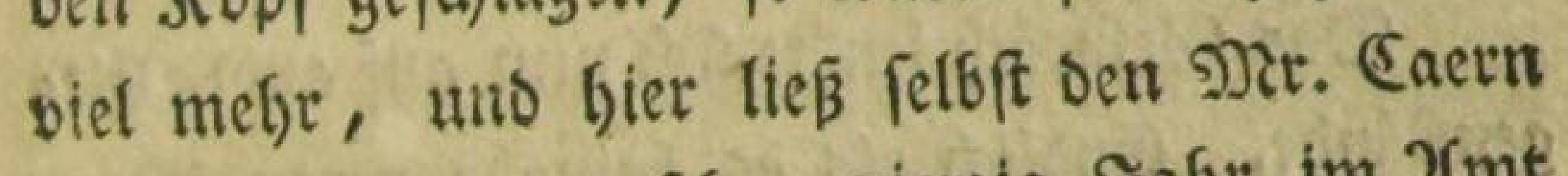
fein stuber, Det (d)on vierzig Jaf)e im 2fme war, ganz im Stidse.

इंक) (trad) Das Still(d) weigen aufs neue, und fagte! SSentlemen! Dieß̃ ift ja ebenfalls ein alles gorifa)er 2fusbruct! - Freilich ift es bas! fielen

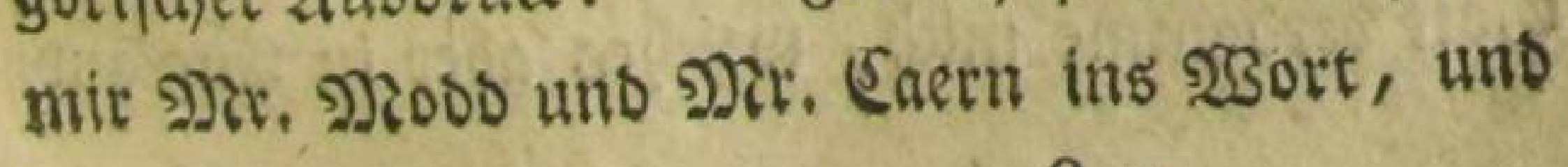




\section{( 168 )}

fohlugen bazu auf ben ₹ilf, - Denn ben bes fangenen, fube idf fort, murbe der ßart abges fehoren, und es beţ̧t alfo weiter nid)ts, als Giott wit' fie in die Siefangenfafaft frember 230 ls fer geben, die ifnen ben $23 a r t$ abjheeren! Das verffefte fich, ein jeder fieflit es ein, und es iff fo Elar wie ber ₹ag! fhallte mir vom ganjert

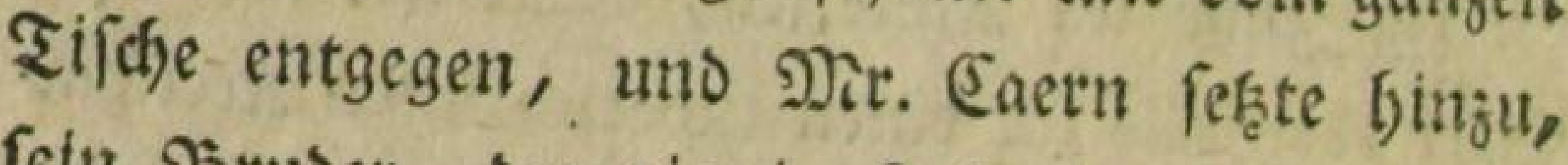
Fein \$̧ruber, Der vierżig Jabft im 2 fmte wáre, etElartte es eben fo;

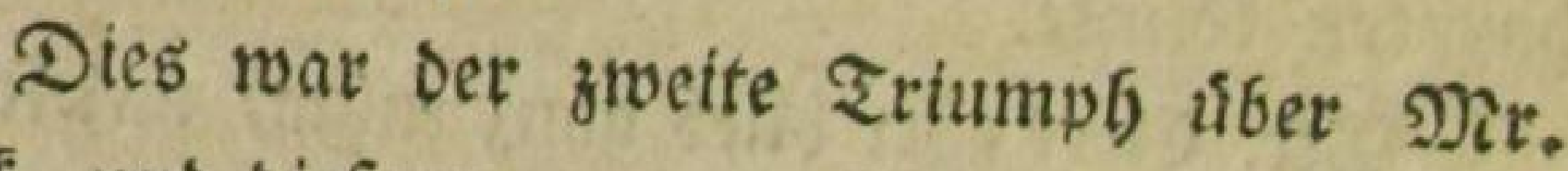
Glert, unb biefer war nun ruffig und machte feine

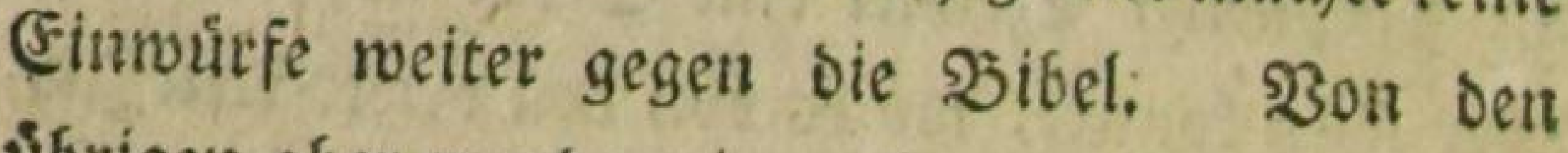
übrigen aber wutbe mit nod mandbe Gefundbeit in Dem farten 2lle zugettunfen, weld)es mit Góchjif zumiber war, weil biefes alle beinabe ftáta ter wie şBein berauldot.

Das (jefpro̊d) lenfte fid̆ mun auf anore (jes

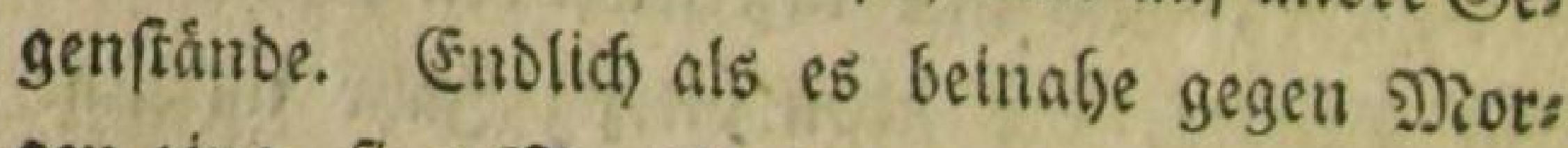
gen ging, fing Mir. Niood an: damm me! I muft read Prayers in all Souls College! (ich) mú in aller Seclen Collegio Betffunde Galten; und damm me! if eine Bertúržning aus God damm me: - Dott verdamme mich, weldhes aber in Englano 


\section{(169)}

nidft vid mebr fagen will, als bei uns, (Ei zum Şenfer! ober \Dof̧tau[end!)

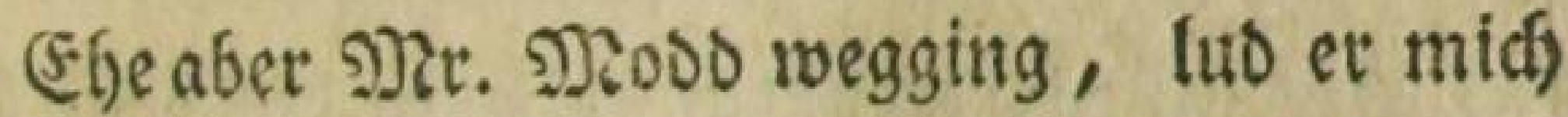
auf ben folgentoen ग्Jiorgen zu fich ein, und erbot fich (êtr Gofflid), mir bie Miettwútoigfeiten von Dxforo zu zeigen. Die úbrigen von Der Bjefells (d)aft vertofren fidf num audf. Ino ba id) eins mal, freilid) auf eine fonderbare 2(rt, in eine io

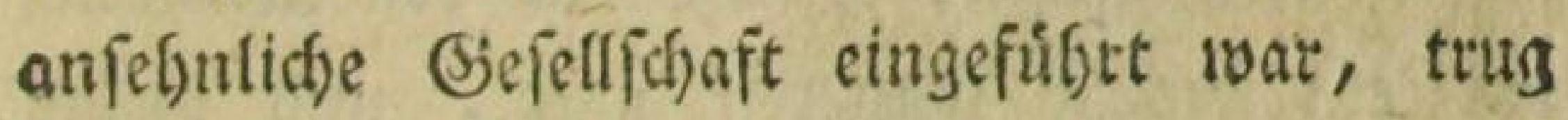
man auch im STaufe weiter fein şedenten, midg aufounefmen, uno wießs mir cin gutes Edjlafs zimmer ant.

Zflein am folgenden Norgen, ba ich aufs wadjte, hatte iif von bem geftrigen ftarten Zus trinfen der (5ftruárbigen f̧erten ein foldjes Sopfweb) betommen, daß̄ es mir nicht müglich mat aufzufteben, und noch weniger, ben Seerrn \$2000 in feituem Siollegio zu befuchen.

Der (s)aftyof, worinn idf war, Gię the Miter, (bie bifftofirmúfęe). Itno id fand bier, gegen STinb for gered)net, bie vortrefflidffte Westenung. Zllfein weil ich) Den afbent, efge idf zu sjette ging, etwas aufgetáumt war, fo fagte ich) dem 2fufwártee getabezu, er modjte nidjt glauben, roeil idh ju is 


\section{( 170$)$}

Fure ginge, oaf th) ifm beswegen ein fhlechter Srintigelo geben wurbe, fonbern verficferte iffm oas (siegentheil, modurd) id) Denn bie befte 2lufs wartung von ber 2 Selt erbielt.

S(t) nafm mir nut vor, ein Daat ₹age in Orforb ju bleiben, um zugleich) wábreno bet Seit, wieder reine 2 Sáf fje zu erbalten, Die bier dunierft nothig thut, bem als idh Den গadjmit: tag ein wenig fpajieren ging, uno meine

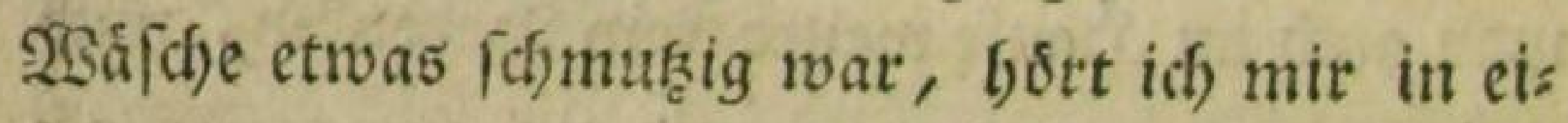
ner fleinen Strape ein Paar $23 e i b e r$ vor ber

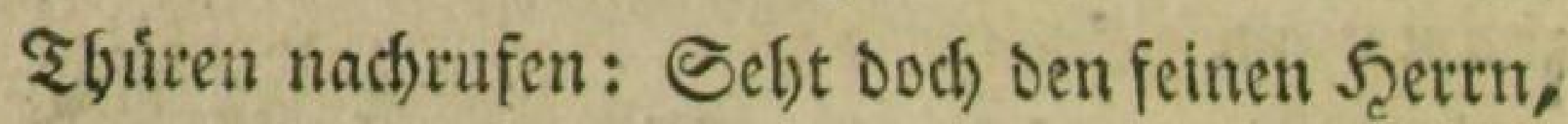
Der nicht einmal ein weißßes Şembe am \&eibe trågt !

Den Mittag af ich) unten mit Der Samilie uno nod) einigen Perionen die Da [peiß̄ten, uno unterfieft mich fefre angenebm. Sch muste viel,

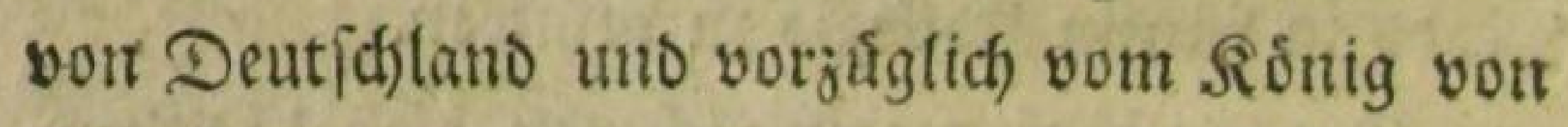

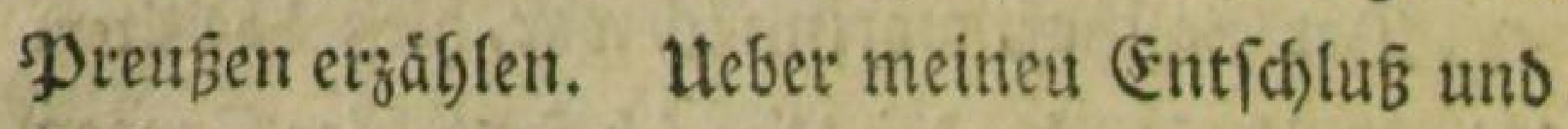

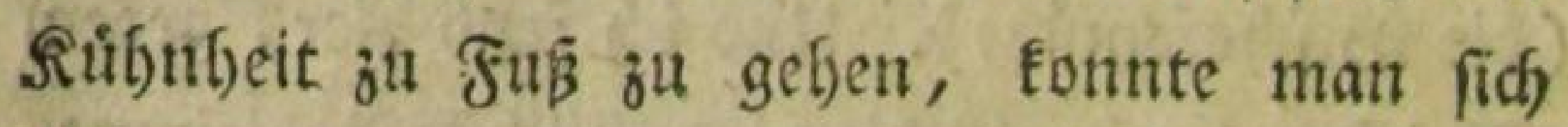
uidft genug rounbern, of man gleid) meine 216 s fidst bifligte; uns enditif geftand man mit offen: berzig, Das ich audd hier nid)t wate aufgenom: men worden, wenn es nidjt auf eine fo forber: 


\section{( $17 \mathrm{i})$}

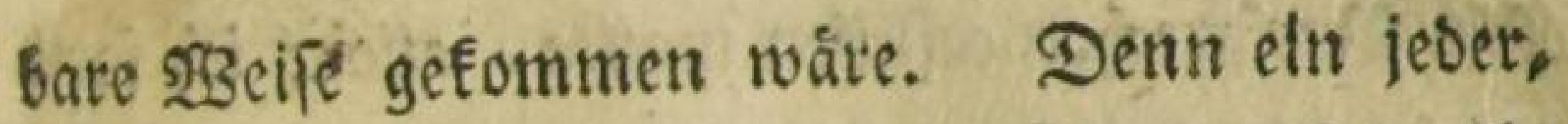
Der eine fo weite Sieife zu Fuß̧e tháte, wuirbe fúr einen Settler oder Spif̧buben gehalten , woraus ich mir bent meine 2lufnatyme in SBinb or und Nunebam leid)t eteflaren fonnte. Ob ids gleids Diefen fajectlich úbertriebnen \&urus nichts we: niget als billigen fann, vermoge beffen bie

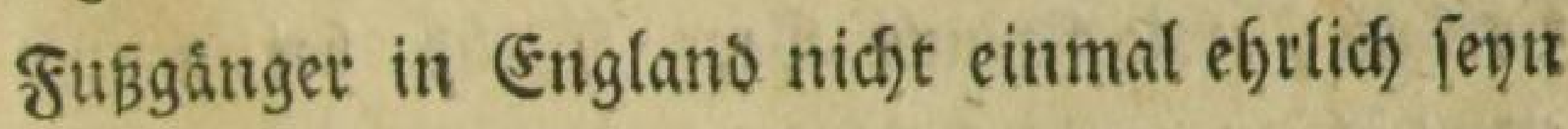
follen.

Da id mun nach Darbi) flite geben roollte, rieth man mix, wenigftens, bis idf tiefer itts \&ano fommen muirde, einen nebmen. Dern je weitet man von Lonbon ab ins Qano fame, oefto rentiger betrf(d)te Det Rus xus, und befto woblfeiler und witthbarer fen es

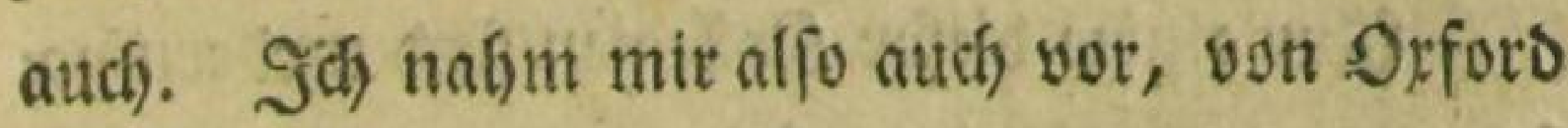
bis Sirmingham, wo ich von feeten poititer aus Lonbon at Seetrn Fothergill, eineth Raufmann empfotlen wat, in einer Dofeutiche zu faften, uns won ba erft weiter fu fuse zu geben.

Den Diontag Etadite id in Oxford wegen meines Sopfiveljes etwas mî̄vergnügt zu. Scert 22000 fam, um mid) felber abz̧ufofglen, weil er 


\section{( 172 )}

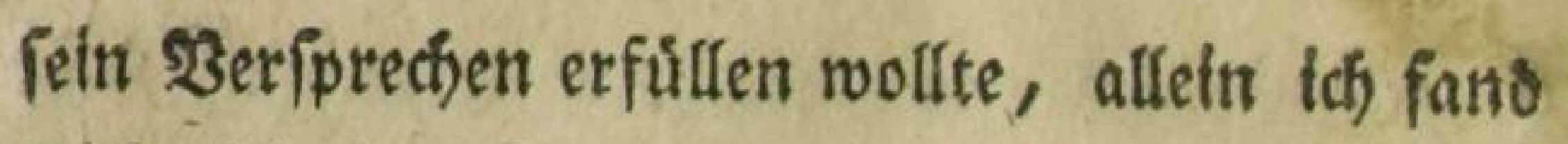
mid) nicht im Stande, mitzugeben.

Demolingeadftet madite id) gegen zibeno noch einen fleinen Spał̧iergang auf eimen Şügel, Der gegen গorden vor Orford fiegt, und von wels chem man bie gamze Stadt úberiefhen fann, bie mir benn bei weitem nidft fo fdớn und prádstig vorkam, wie fie mir Sfert Niodo bei unfrer Nachtwanderung bejhrieben hatte.

Die Rollegiengebånde fino grośtentbeils in

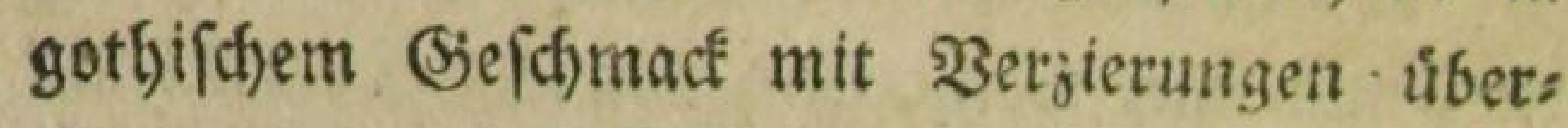
Gáft, aus einem grauen Stein erbauet, Der vielleicht, reenn er nell ift, beffer ausfiebt, abee feest die efeltbaftefte roibrigfte garbe bat, bie man fiid) nur denfen fann.

গar einige biefer Rollegien fint mobern ges

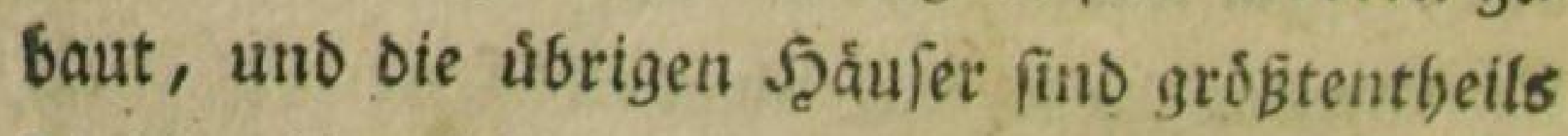

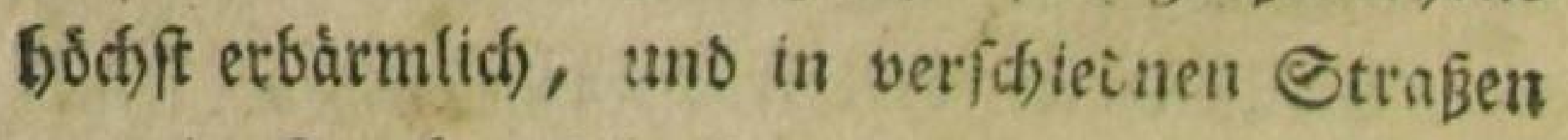
nur ein Stoctwert bod, uno mit Sibindeln ges

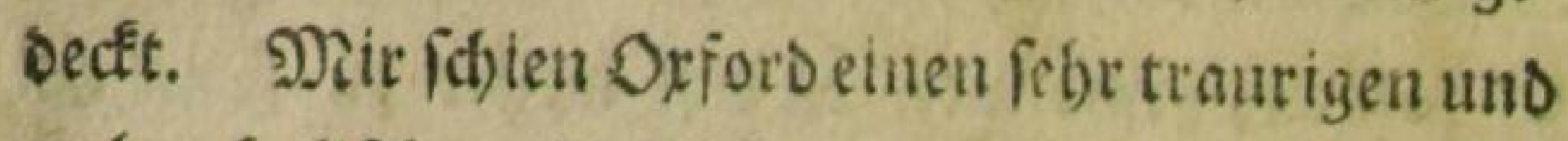
melandfolifden 2inbliaf zu baben, uno ich ber greife gar nicht, wie man es nadbft gondon fút ethe ber fogonften Stàdte in Englano Galten Eann. 


\section{(173)}

\$d) wartete auf bem Schigel, in weldhelt etne ₹reppe zu cinem unterirbifhen Şange binun: tergemauet war, bis bie Sonne unterging, und labe veríchieone Stubenten hier ipazieren gethen, die efen io role bie Schuler in Eaton: College, ůber ibrt bunten Sleider groß̧e fdrwarze Sbortóde uno platte vierectigte Scite tragen; meld)es die Tradft ift, wooutd) fidh alle, bie zut Univerfitåt geboren, mit verichiednen fleinen

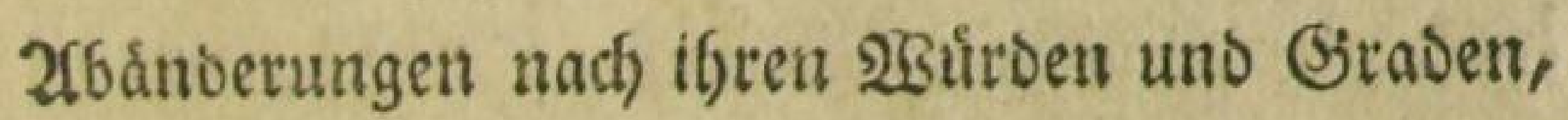
ausz̧eid)nen.

SBegen Diefer (5hortdofe werten fie aut)

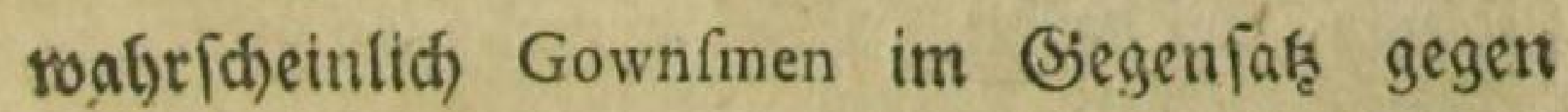
bie búrget genannt, weld)e Townfimen betīen. Ino wenn man alle sinwofner von Oriorb zus fammenfafien will, fo lagt man: die ganfe Otadt, Gownfmen and Townfmen.

Freilid) ftidht diefe Sleidung gegen bie grofen Stiefeln, Rofaroen an Den Şúten, Rollets uno

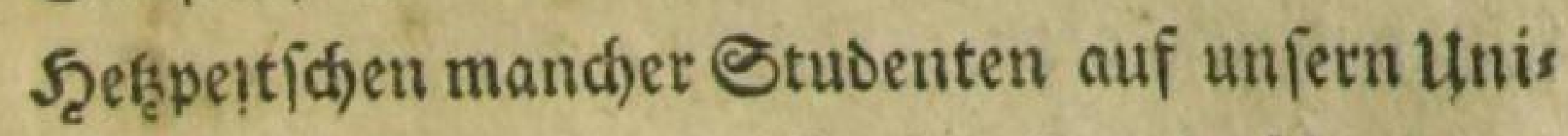
verfitáten ganz erftaunlich ab, fo wie úberbaupt Die Stille und Das fittfame SEetragen, weld)es benn boch Gier unter Den Studenten Gerridst. 


\section{( 174 )}

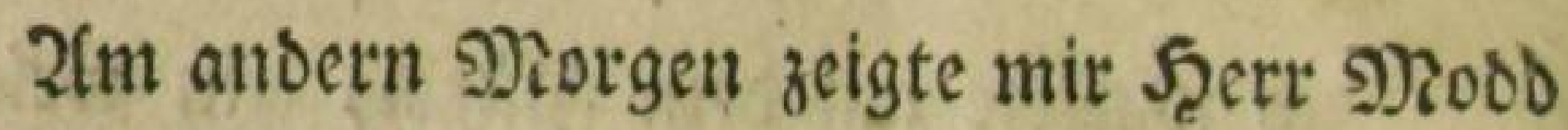
veriprochnermaß̧en einige von oen 刃erfwuir Digfeiten in Drford. Er ging erft mit mir auf feine Stube in fein Rollegium, veldje unten an Der (Eroe ziemlich niebrig uno ountel war, uno mit einer Zelle vief 2(ef)nlichkeit batte. Das

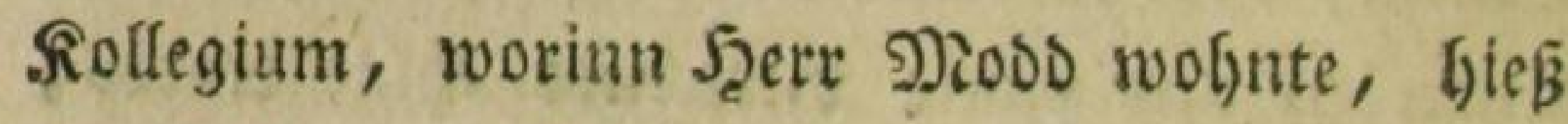
Chrift Corps College.

2flsoninn fúlgrte er mid) nach) All Souls College, ein elegantes (Siebáube, worinn aud) bie Sirche vorzuglich fchơn ift. Scerr Jiods zeigte mir biet ủber bem afltar ein Siemábloe von 2iengs, bei beffen 2(nblicf er mefre (Empfindung vertieth, als ith lifm zugetrauet batte. (Fr fagte, fo oft er diép (jemábloe fát)e, wuitoe er aufs neue Daburch gerúlgtt.

Diés Giemåblde ftellte oie Miaria Mingba: lena vor, wie fie plofslich Sefun vor fich freben

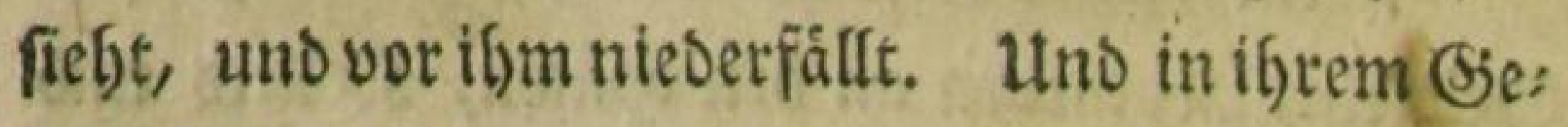

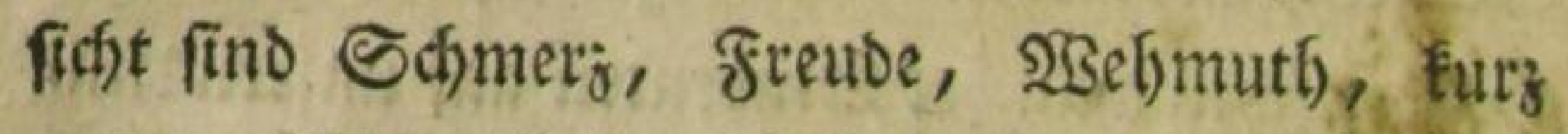
ganz verichicone \&eidenichaften, fo meiftert)aft aub:

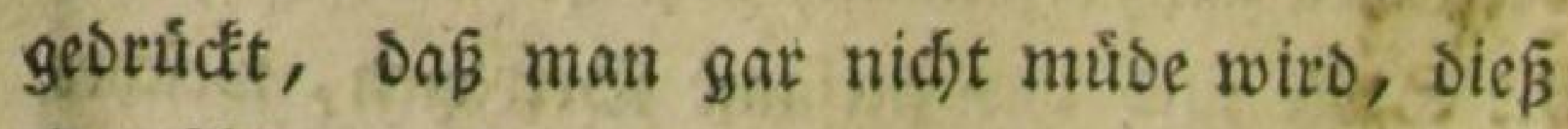
(Semáblde zu betrad)ten, und immer mebr dae ourd) getuibrt sviro, je lánger man es anfiebt. 


\section{( 175$)$}

(Ev zeigte mir mun aud die Sibliothef in bies jem Sollegio, weldse oben mit ciner Bsallerie vers

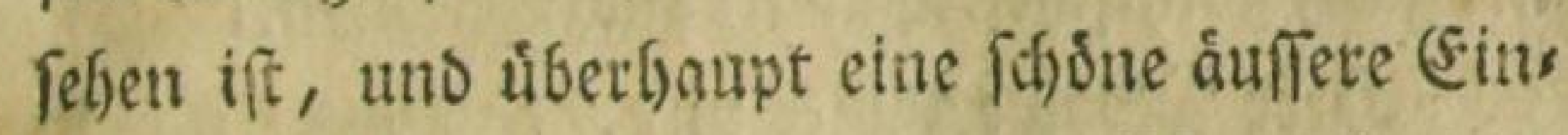
ricstung bat. Unter andern fabe idf bier eine Seffireifung von Drfort mit Siup: fern, in Folto, wo fid benn bie Thuitme uno Siollegiengebaude freilich weit faboner auf bem Yapier, als in oer Natur ansnalymen.

Şierauf fúbrte mich STetr \$rods weiter un telt auf die Sutlejanifaje Sibliotbef, weldse

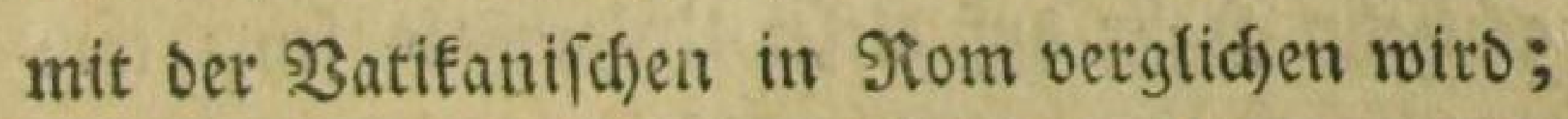
utio auf Das (s)ebáube, weldyes the Theater heist, uno wo bie siffentlichen Difputationen gejalten werden. Dieß ift ein rundes Ssebáude, worinn ein (Efor umbergeft, Das mit SánEen, eine úber Det anbern, verfében iff, worauf bie Doftoren, 刃agifter unb Stubenten fiken; und gerabe ges

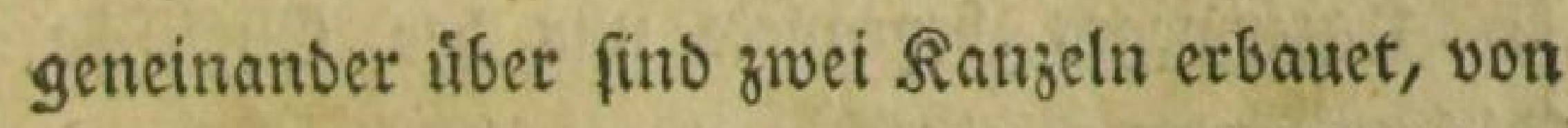
weldhen bie Difputirenden zu einanber Ginúber fprechen.

(E)riftd)urd) (Eollege und Queens (Sollege find wobl die modernfien und fojonfen, unter ben

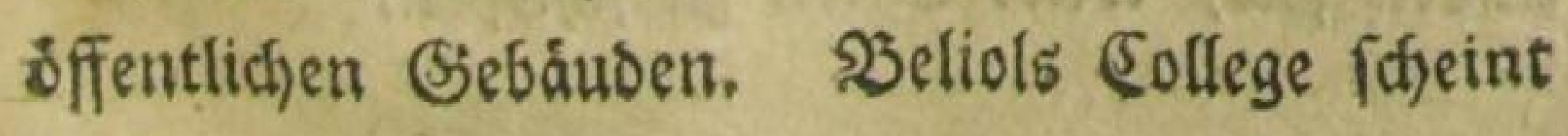




\section{( 176 )}

(id) vorzbiglid, wegen feines affeetthums utho feis

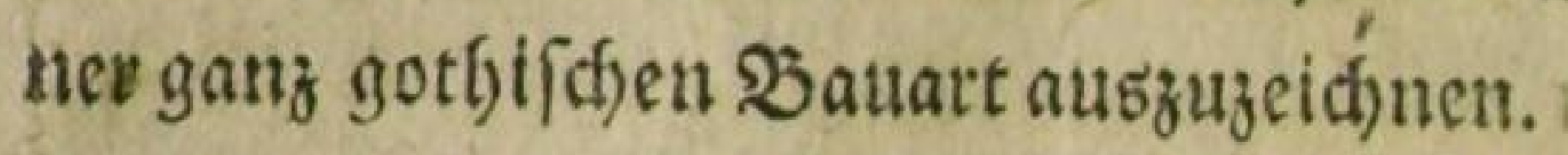

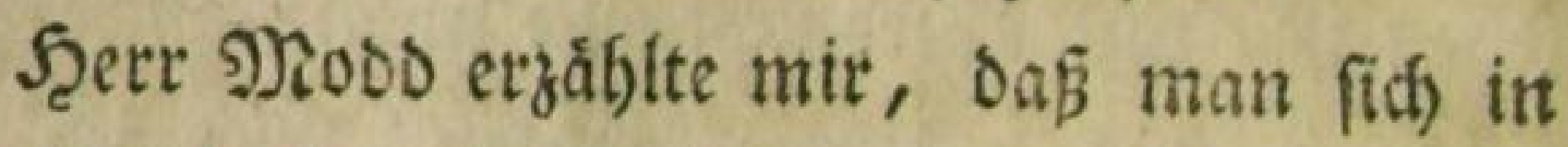
Drforo mit presigen viel verdienen forme, benn Die Studenten músten alle nadh ber Reibe, in Der Utniverfitátśtitche des Sonntags einmal pres oigen; Die meiften aber an die es Eáme, fucbten es abzufaufen: uno bejabitten fút eine \$oredigt wobl fünf bis fechs osuineen.

Z(ud) etráálte mir Şert Miodo, Daß̧ er mun adjtzebn Эabe auf obejer Univerfitát Fey, uno umfonft Doftor werben forne, fo bald er wolfe. Er wat Mafter of Arts, und bielt, wie et fagte, Borlefungen úber Elafilifó) 2futoren. Zluch war er wirfflich ordinirter \$rediger, um in eints gen Disfern um Oxford Den Giottesdienfif zu verfehen.

Unterweges begegnete unt ber (Englifone Did)ter 253 arton, ein [đon etwas åltlicfer Mann, oer bemobngeachtet two fellow oder פ) Sitglies

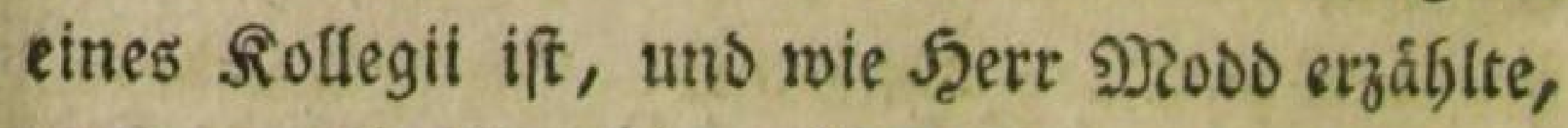

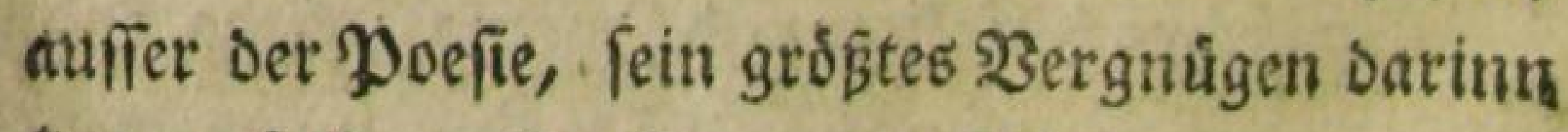
finden foll, wilbe Enten zu lólę̧en.

S2etr 


\section{( 177 )}

Şett श2000 (d)ien uீbrigens auch cin guter

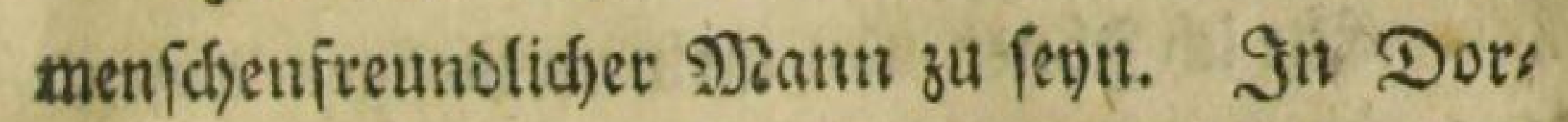
d)efter, erzáblte er mir, fer ber Slett voer Sill fter geftorben, und habe eine zablreiche framilie in grśpter Durffigfeit Ginterlaffert, nun wolle ex Sorgen binreiten, uno fu bewerffrelligen futfen, baß̧ der átefte Sobn bes פerfrorbenten,

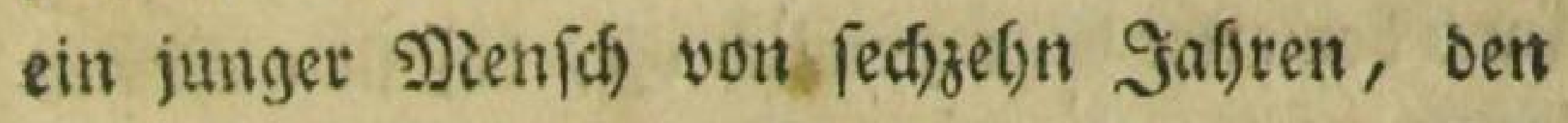
clerfoienft wieber erfyalte, um feine arme $\mathfrak{f} w$ milie ernáfren z̆ fீơnen.

In bet Miter, Dem (sjaftjofe, too id los gierte, fprachen oie Sieiflichen uno Studenten alle 2ugenblicf cinmal ein, um einen నrug afle zu trinfen, ober eine furze Ronverfatton mit bet Fochter im Scaule fu fúften, bie ein artiges Ftauengimmer war.

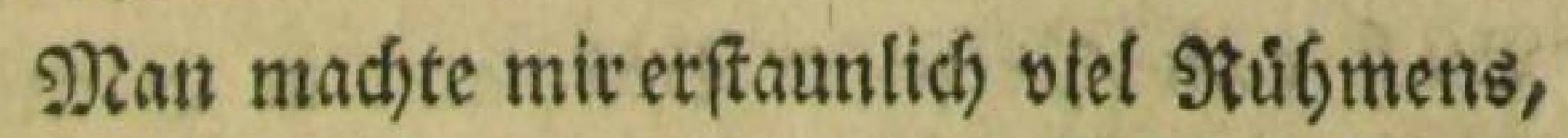

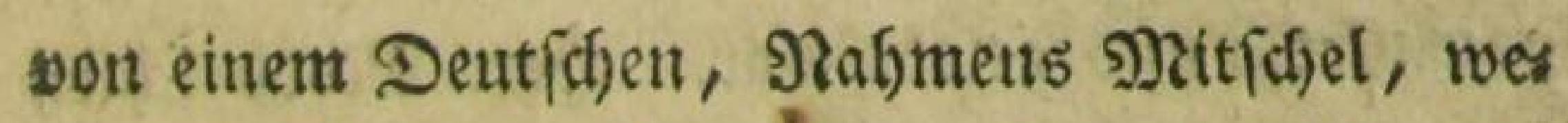
nigftents fpradjen fie feinen Nabmen fo aus, Der fidh fidjon leit viclen gatiren als Mlufifus bier berifibmt gemacht babe. Sth freute midh, yon Englánbern einen Lanbsmant lo túfgmen zul horen, wolfte ifon audj befudjen, aber traf (6) nicht zu Şaufe, .

2). 


\section{( 178$)$}

Caftleton, bent 3 offen Juni.

Che id) Shnen von meinem hiefigen 2fufents balt etroas fage, will ich) in ber (Erzăblung meiner 2lbenteuer fortiabren, und nur ba wieder anfangen, ro id) es in meinem leęten \$riefe gelaffen habe.

. Ifm Dienftage Nadjmittage fúfrte mich Sgerr ?rodo anf oie Epaziergánge bei Orforo, uno bemerfte benn ziemlich oft, Daß fie nid)t mut in Englano, fonvern ůberbaupt in (Europa nitc) foboner fenn fonnten. (5s waren wirflith

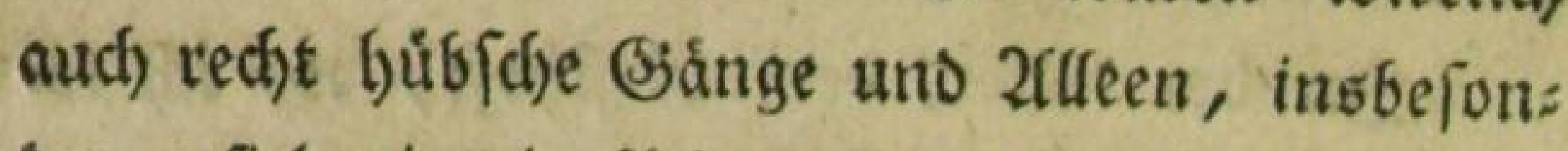
ore gefiel mir ein fleiner Spaziergang langft eis nem Sluffe, binter (Shriftcorpscollege.

5 Bir fersten uns bier auf eine Şanf nieber, uno Şert Nodo zog ein Journal aus oer Tas fole, worim unter andern audh ein beutidjes Such) vom ஒrofeffor Bectmann in sisttingen recenfirt, uno gelobt war. Şerr Miodo fdien bei biefer Sielegenteit einigen Fefpeft fừ die Deutjche Sitteratur zu bezengen. (Enofid) ichies Den wir von einander, er jur Befef̧ung der Rufterftelle in Dorcbefter, uno ich in oie Miter, um mich ebenfalls zu meiner 216 reife aus Oxfors anzu[chicfen, bie benn aut() ben गrittwoch frit) um orei Utb: mit ber Doptetut(che vor fich ging, nact): 


\section{(179)}

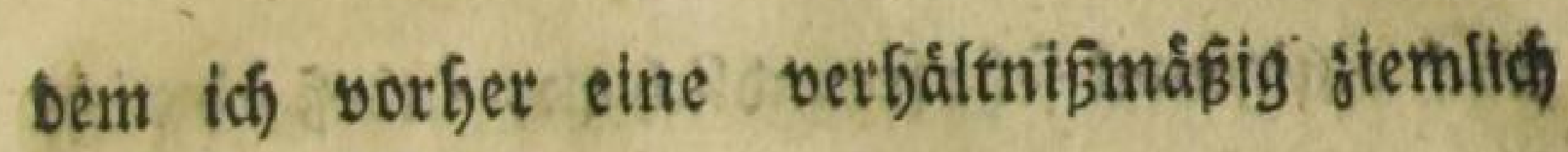
billige Siechnung bezablt batte.

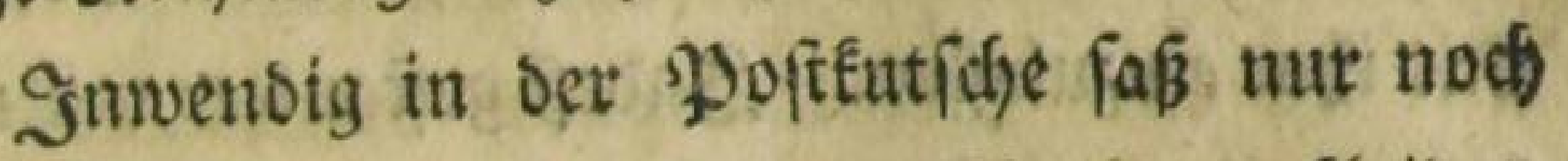
ein junger s)senich, bet zwar fohnarz gefleibet, aber nach feinet Rofarbe ani Scute fu foiliesen, ein Officiet war. Spingegen wat bie Zuffenfeite bet Sittihe mit ssseibern und Solbaten ganz bes

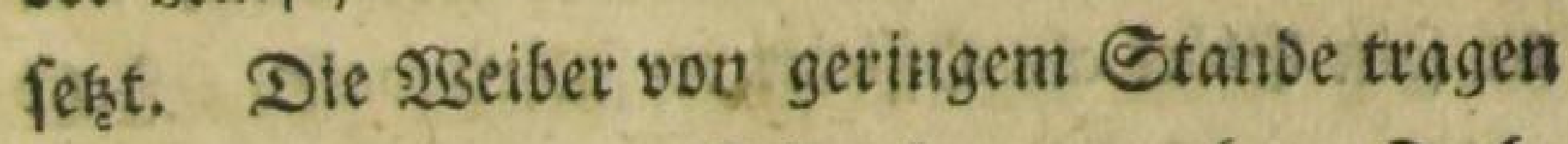
bier eine 2lit futzer s)iantel vout rotben Tuch, น์brigens Schite, joie bie शुonebmert.

Die Sradjt mit Den Scuten, weldse bei bem Englifdyen Frauenzimmer To gemein iff, Daß (ich) Die geringfte Dienftmagb therer be bient, nimmt fich, wie mir Dáudjt, weit beffer aus, als bie

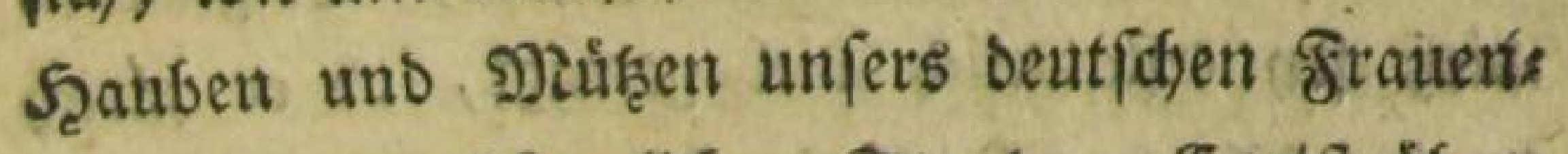
zimmers von bugerfichem Gtande, (5) lif ưbet; faupt in Englano fein fo grofer Ututerfdied in bet Sleibung zwifdien Den Bornefmen und Sis ringen, als in Deutichland.

Id) Gatte etwas Ropfrueh, uno machte ow ber bei meinem Sieifegefábrten in ber Đoftuts fide ziemfid) ben stifautberopen, weld)es viels feidjt ifjm, als bem (Englander, eljer jugetommen sáre. 2fllein bier war es ungetefot, et rebte

$$
\text { - }
$$




\section{(6) $180 \%$}

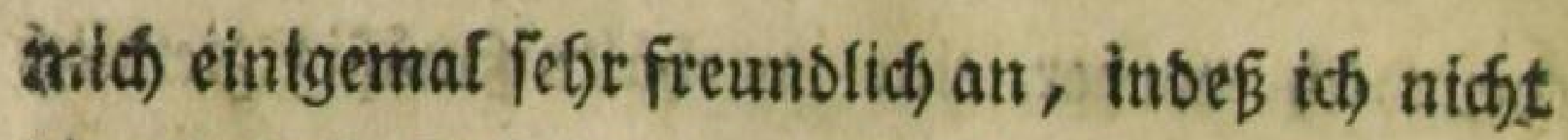
Die minbefte \&lift bezeigte, midj) in ein (jeiprách mit ibm eingulaifen. IndeE geftand er mir nad)s.

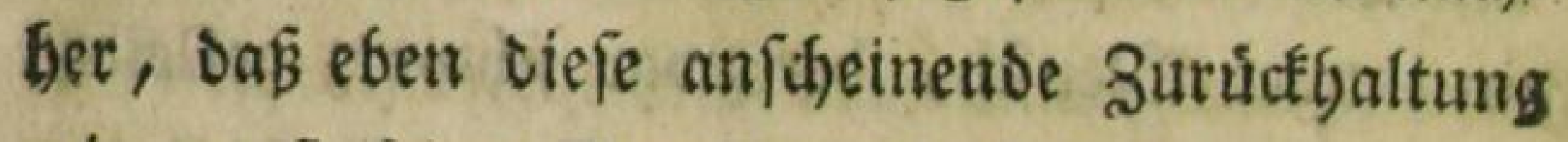
mir zuerft peine (Siunft veriá)affit babe.

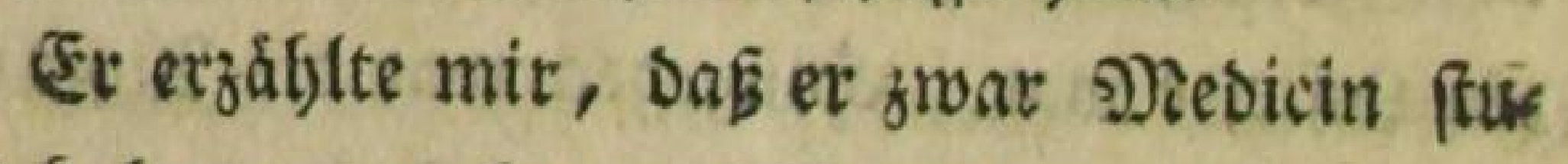
Diert Gabe, nun aber nad) Offindien reiTen, uno

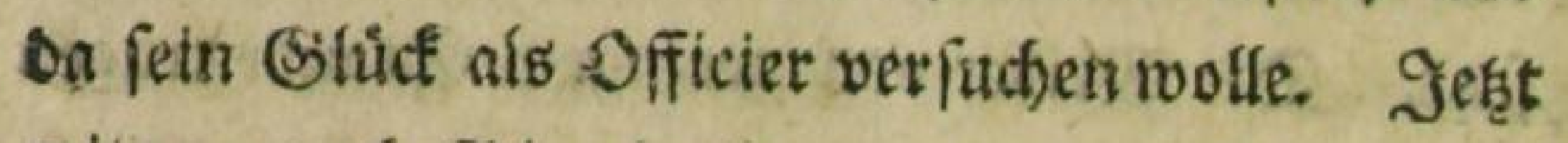
seife er nach Sirminglaam, um von feinen oret"

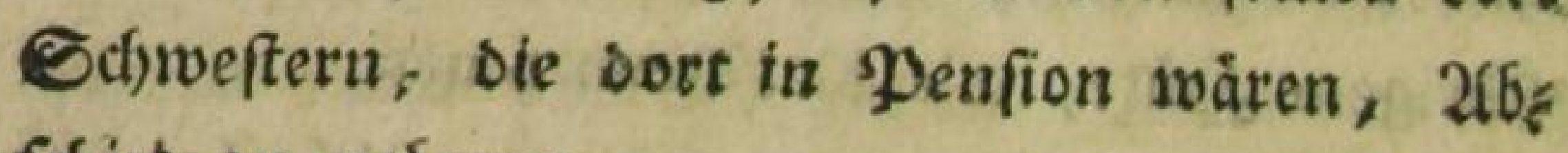
fojieb fu nebmen.

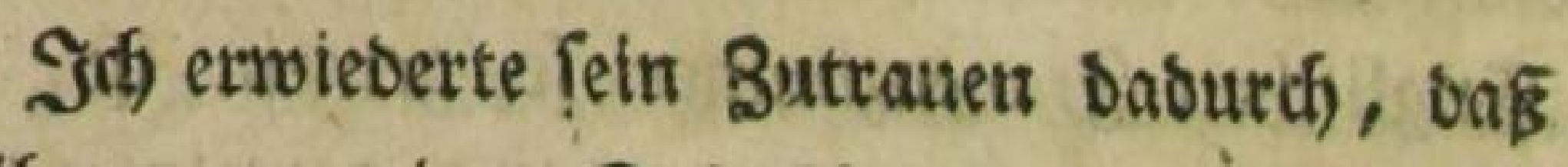
(ch) ithm von meiner Fusteife in Englano, uns won metnen 2ffentheuetn ergådflte. Er glaubte,

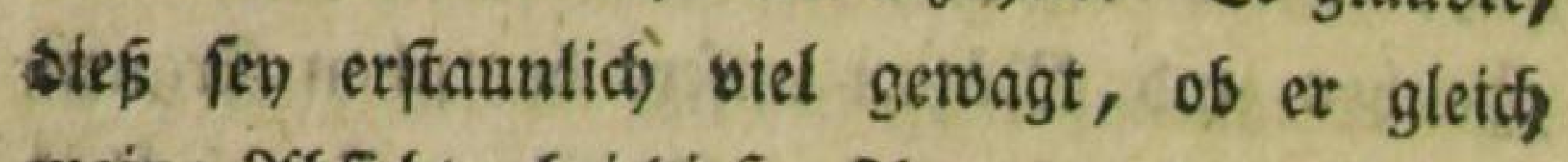
meine 2(bfisd), bei Diefer $2\left(r_{t}\right.$ ju teifen, billigte, 2uf meine Srage, warum bie Englánber benur nid)t aud) um berfellben $230 r t f e i l e$ willen mand):

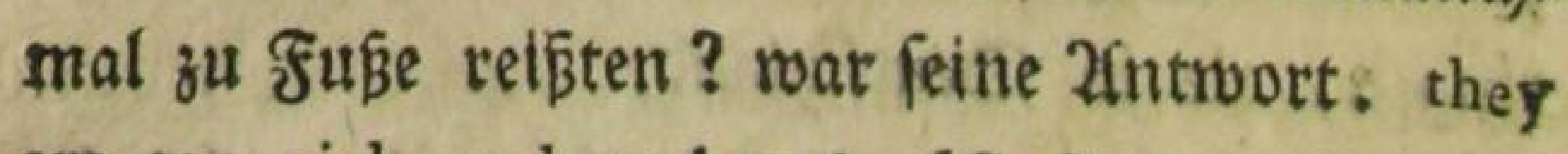
are too rich and to lazy! (fie find zu keid) uns จน tråge bazu).

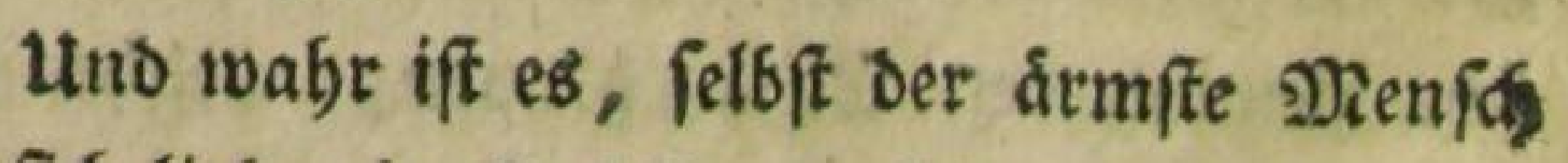
leşt fich lieber in Siefabr, auf oer Outfide einet

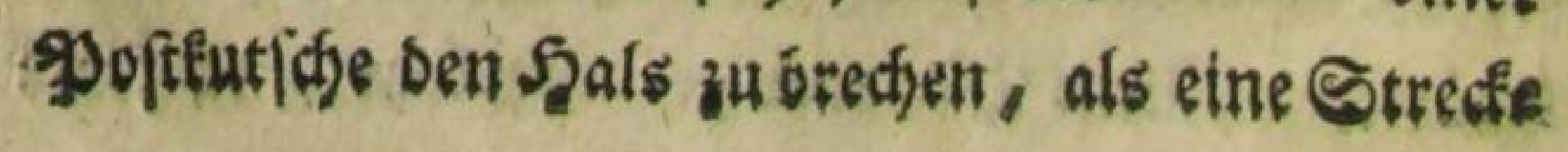




\section{( 1815}

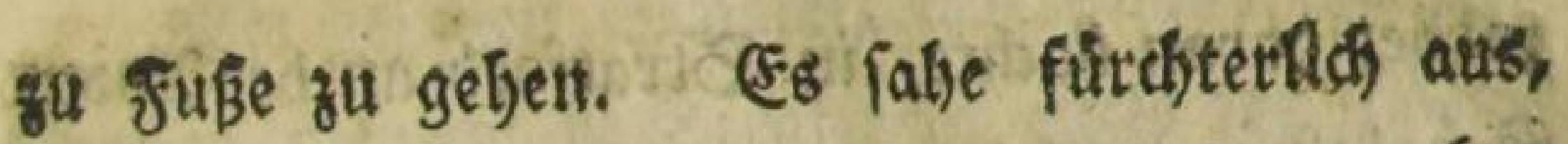
ween bie . $23 e t 6 e r$, wo wit fittle hletten, oben yon ber Rutfdhe herunterftegen, uno bie eire wat einmal rotrflid) th (Bjefafie zu fturzen, be fie eben im Şerabjteigen begriffen wat, unb bie of ferbe unver fegens fortgingen.

Bon Drford bis Birmingfiam find zhell und fedsig Neilen: allein biafe seite etrecle ging faft ganiz fût midf vertobren, weil iff wies

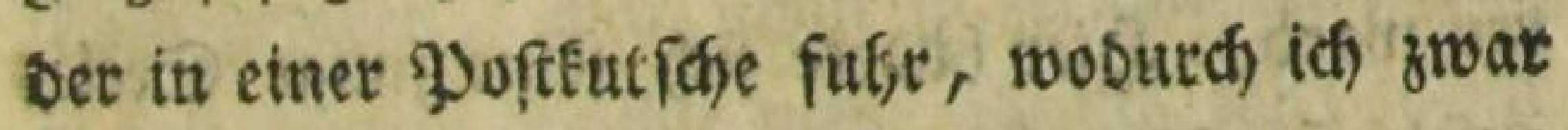
in grofer Bsefdjwindigfeit von einem Orte zun andern fam, abet nidjts weniget that, als veifen.

Micin Sieifegefaftete entichadigte midh inber

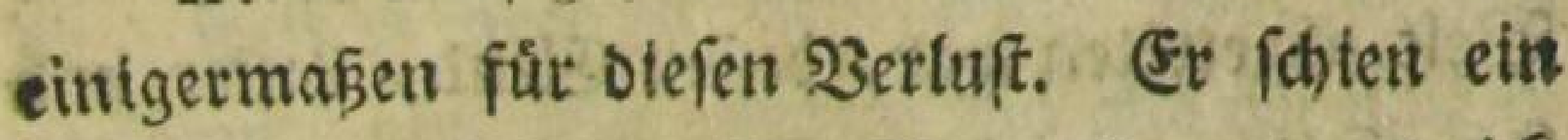

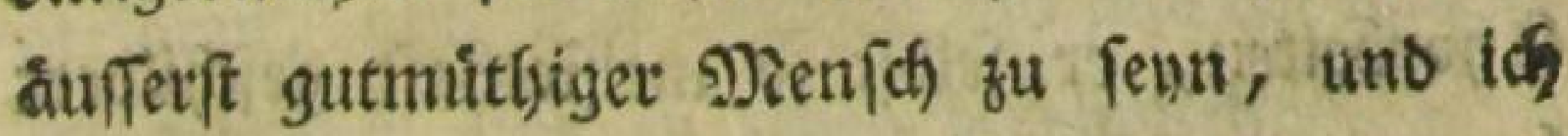
faßste in ber turzen Zeit eine 2frt von Bunetgung

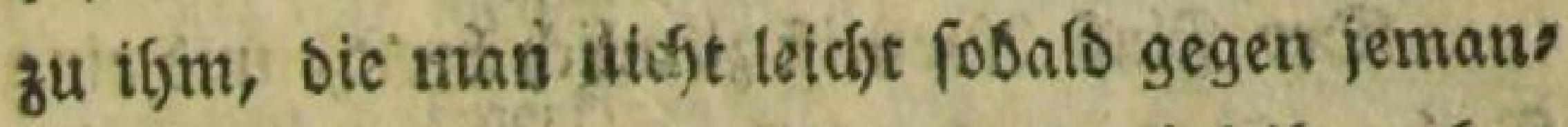
ben empfindet. Es fatien diefes bet iffm ebent bet Sall fu feun, und es wat beinafe, als wentw

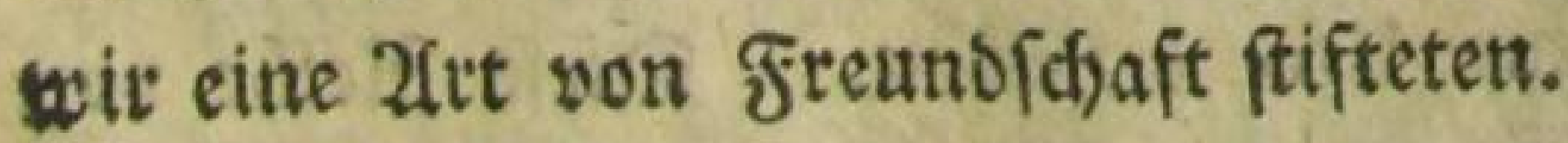

Intrem wir getabe zufálliget 2 șeife uns eine Seitlang von Shjatefpear unterbalten batten, waren wir auf etnmal, ofne daß́ einer von uns

ร) 3 


\section{( 182 )}

porther baran bactite, in Stratfots an der 2foon, Schaéfipears Gefurtsorte n mo unier SBagen fitf Glett, weil Gier eine Dofffation wat. Dieß̧ wat noch) zroei uns zroanzig Nieilen von 23 irmingbam, und vier uno neumzig 2ieiten von Ronbon.

Unfre Empfindungen theiften fid biet eits: ander fefre lebbaft mit. sid 6 :

25. Sriet mat es, mo ras grofste (Sienie, wels d)e piefleicht Die গRatur je fervorbrachte, gefors ten watb. Sgiev bilbete fidf feine junge Seele, auf Diefen fluren fpielte et als Snabe. Itno fiet in Diefen niesrigen Sçitten braxhte er vergutigs mit einigen fieunden feille lę̧ten হage ऑu nadjoem are von dem gropen Sdsmulase det 28 elt abgetreten war, defien (sleno, Rafter uno इborbeiten, er felbfit fo meifertaft gefobitoert Gatte;

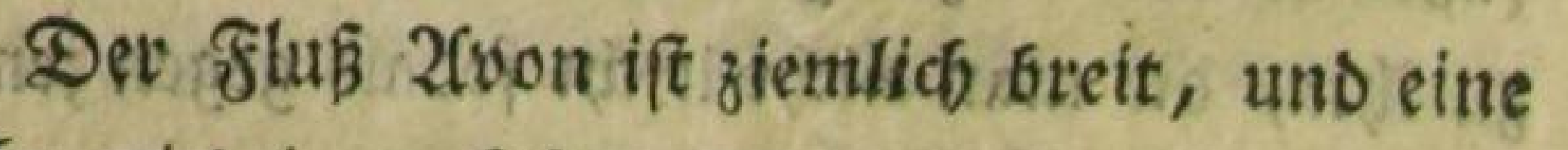
Pielge nieoriger Scutten, thur ein Stocfrert Goch) uno mit Sónindeln gedectit, erftrectit fich längft bem ufer deffetben. Diefe Sieife von

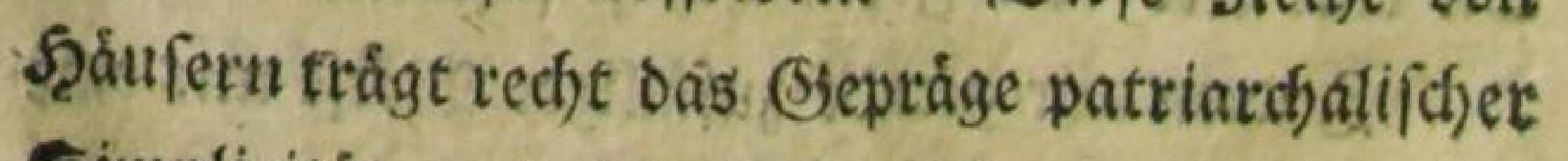
Simplicitåt uno Ssenúg/antét. 


\section{( 183 )}

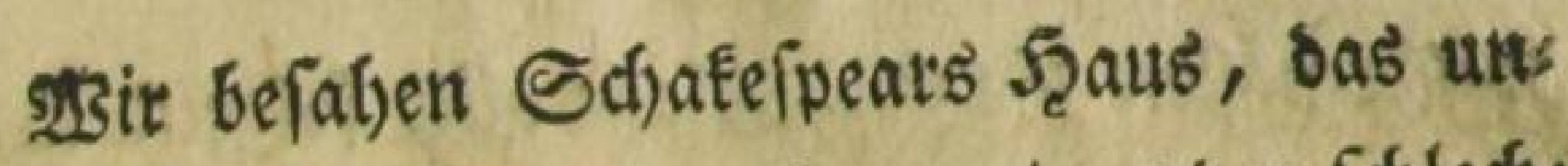
ter alfen Şáuern in Stratford, eines Der f(h)leds: teften, nieorigften uno unanfefuntichfen ift, uno unter befien niebrigem Dache er Demofingendytet Die vergnuigteften Tage zubrindte. In bielem Szaule wolnen jeşt ein spaar alte qeute, Die es gegen eine Sileinigfeit Fremben jetgen, und von Diejem sinfommen leben.

Sd)afe[pears Stulfl, worauf et vor bet

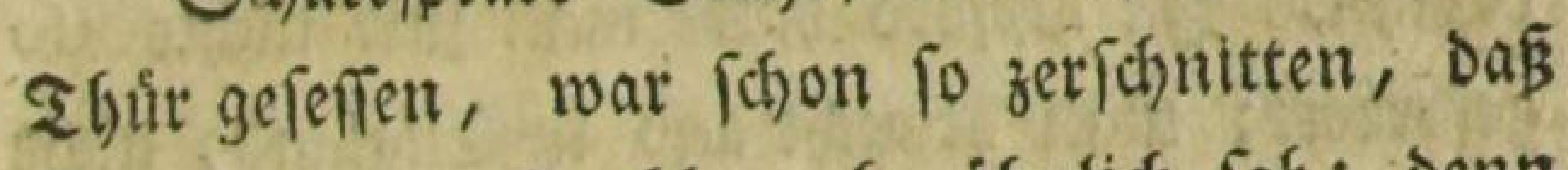
er faft feurem Stuble mefre álbnlich jab; denn jeder Durdjreifende (d)neidet fich) Jum 2Indenten einen Span bavon ab, weldyen er als eit feet: ligthum aufbervafyrt. Ioth fdyitt mir auds einen $a b$, weil ex aber zu flein war, babe ldh ifn verloren, und. Sie merben ifn aljo bei meinet 5siederfunit nidbt zu refjen befommen.

als wir weiter furbren, betrachtete id jeben Fled mit Zufmerffamfeit, wo wir vorbeifamen, wenn id Dadjte: Das iff num die Segeno, wo ein foldjer (sieift, wie Echatefpears, feine erfte Silloung Durd bie ifnn umgebende Natur exs bieft! Denn die erften Eindriffe Der Sintbeit bleiben ood immer aufferft widjtig, uno find ge:

ग) 4 


\section{(184)}

wiffermafen bie Sirunblage aller folgenbett. OB: gleid) Die Esegend bier zwat nidft vorzughtich fojon ift, fo bat fie Doch ganz etrwas (Eignes, Fiomantijoses.

Den Nachmittag um orei Htye famen wir fojon in Sirmingham an. Sechzebn Edjilfins ge fúr meinen פ̧las in ber Siutiche von Orford bis Birmingbam, batte id) (f)on in Stratford bezaflt, In Sxforo hatte man mir nidfts abs geforbett; man braucjt alfo in Englano, nicfit wie bei uns, die poft votauszubezablen.

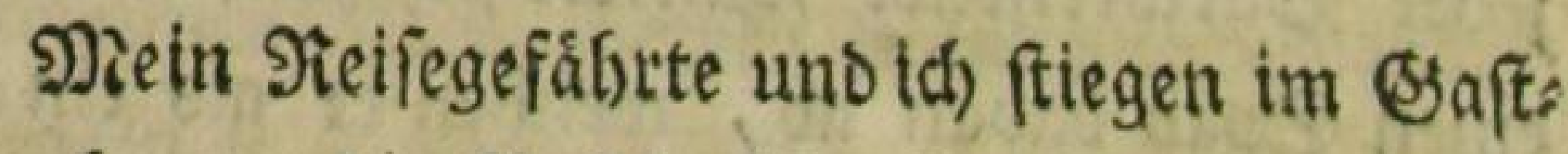
bofe $a b$, wo bie Dofteutfohe bielt. WBit trenn ten uns ungern, uns ich muste ifm verfprechen, Das idf thn nach meiner Siliffunft in Sonoon befuchen molite, zn welchem Enbe er mir feinen פantmen uno feine 230 bmung aufídrtieb. Sein 23ater war ber D. ŞBilfon in Eonoon, Der in feinem Fache ein betúf)mter Schriftftellet iff.

Эch ertundigte mich bierauf nach det 2 Ssobs mung bes Jeertu Forfjergitl, an weldjen ids empforsten war; man begeidjnete mir biefelbe,

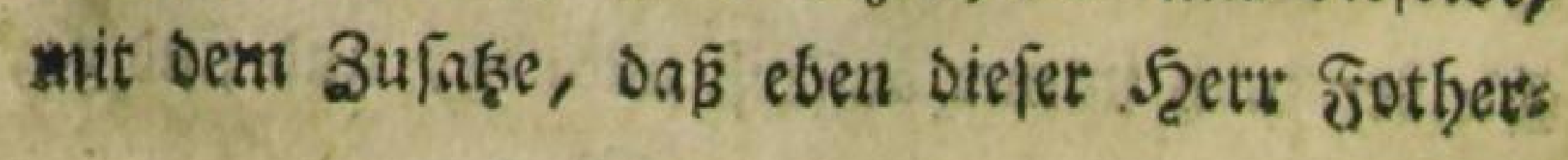




\section{( 185 )}

gif vot adft Tagen geftorben fen. Da mis allo, unter biefen Utmftánben die Empfeflung an ifsn nidft viel inufsen fonnte, fo faf) id wobl, Daß̧ meitres Sbleibens in Sirmingfjam nicjt war.

OGne midh alios bier eine Mrinute länges aufäufalten, erEunsigte idf) mich (ogleich) nad) Dem 23ege nact) Darby, uno verliés \$3irmingham, Da idf faum barinn angelangt war. Won biefer berúfmten Stabt, uno igren Fabrif: unt Ma nufafturwejen, fann id \$̧hnen alfo feine Beile (d) reiben.

Dew 23 eg von 2 tmmingham aus if nicht zum beften, fondern ziemlidy fandigt. Sich langte Denfelben afbend nod) in einem Eleinen Sorte, Nafjmens Sutton, an, worinn es mir aber aud) zum Sleiben zu wornabm aublaber bis id) ganz am Enbe einen fleinen Esafto bof antraf, bet einen Sdjwan im Scjilde fúlgws te, worunter ftand, Aulton Brickmaker.

Diefer Saffrifof fohien etruas Einlas Denbes fû́r mich zu baben, idf ging alfo Ginein, und fragte nidft gleidh fuerft, of tef die ఇacht da bleiben fonne, fondern fows

2्वेतs 5 


\section{( 186 )}

Derte mir yorfer einen Sirug Biet (a Point of Ale). Şier bieß id) nun gar nidft anders als Niafter, und man wies midh in bie Ríche, wo

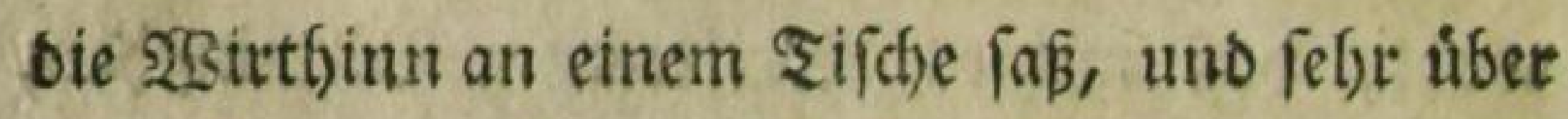

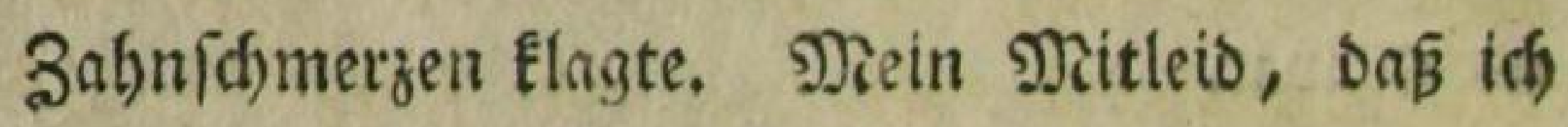
(1)t als ein frember פ)(enic) Daruber bezeigte, ver: fdraffte mir bald ifre siunft, und fie fragte mich felbft, ob ich nicht die Nadjt bier bleiben molle? weldhes idh bejabte, uns fo hatte id) Denn auf Diefe গadht wieder eine Şerberge.

Die Befellichaft, welche ids bier traf, wat eine Sd)ornfteinfegerinn mit if)ren Rinbett, veldje mir fogleich febr freunofdyaftlich zutrane, uno fich mit mir und Der $23 i r t b i n u$ unterbielt.

Sie erzáblte mir ifre (sejd)idte, Die inte, reffant genug war. Sie batte nefmitich frubjel: tig igren Mann im Rriege verlobten, uno fúr toot gebalten, worauff fie fieben gabr in Sit: land biente, ofyne daß jemano brum soufte, daß

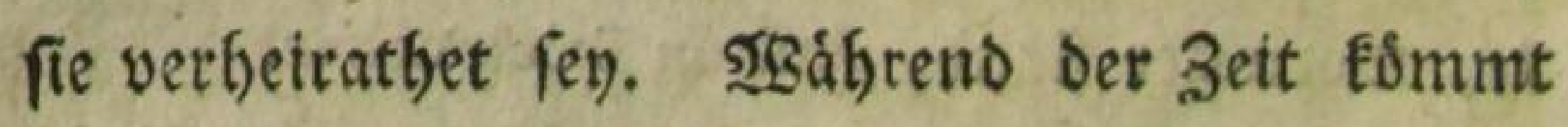
if) Mann, bet ein Sdjornfteinfeger war, wies ber nach England, und befeset fid in Sidffielo. Sobalo er fier in moblf habende tlmftánbe formmt, erfunbigt er fich allenthalben nach feiner Fraw, 


\section{( 187 )}

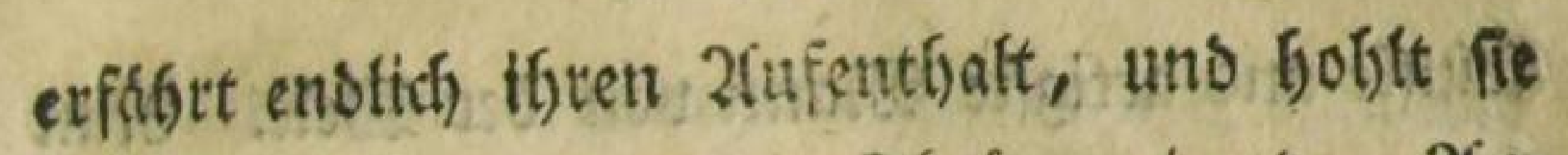

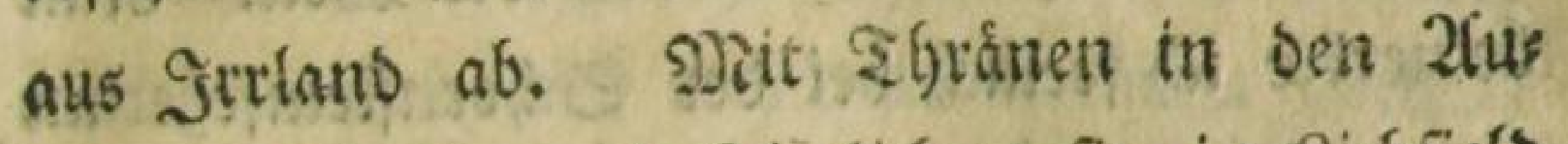

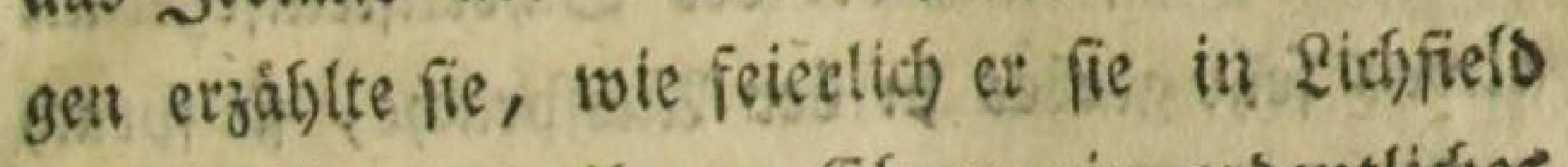
eingeboglt, und ibv zu Ebren ein orbentliches Seft geranfraltet habe. Seler in Sichfield, Das sur nod ein \$aar ग) Jeilen yon Eutton liegte, und wo id Dorgen burdifecifen wúrbe, lebe fie nun mit ifrem \$anne, uno belfe ifin fleisig arbeiten, fey aud) ben allen bornebmen Şerts fogaften beliebt und angéélen.

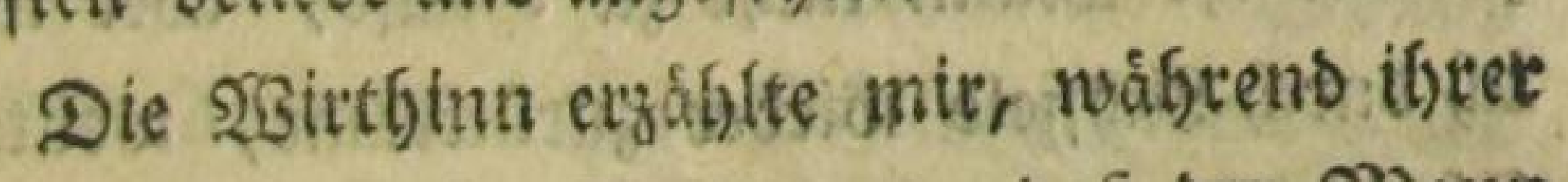

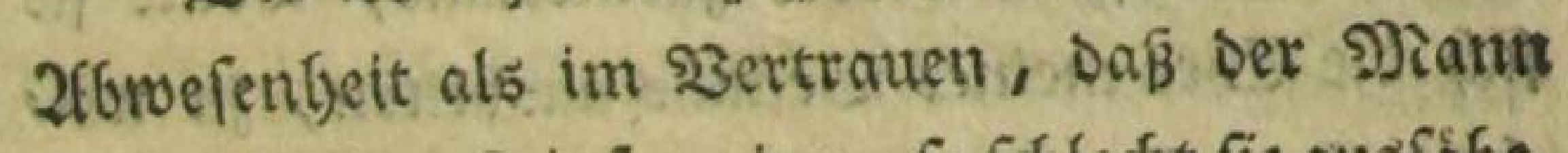

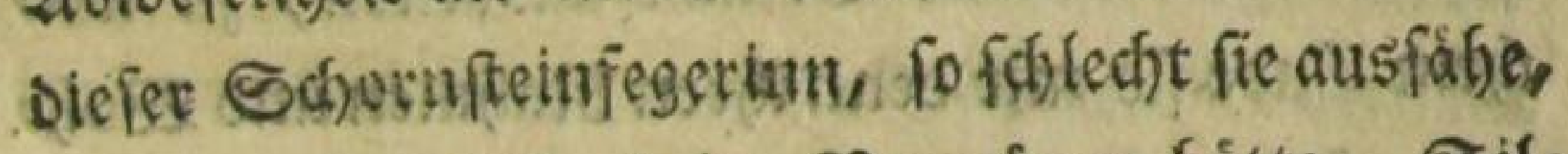

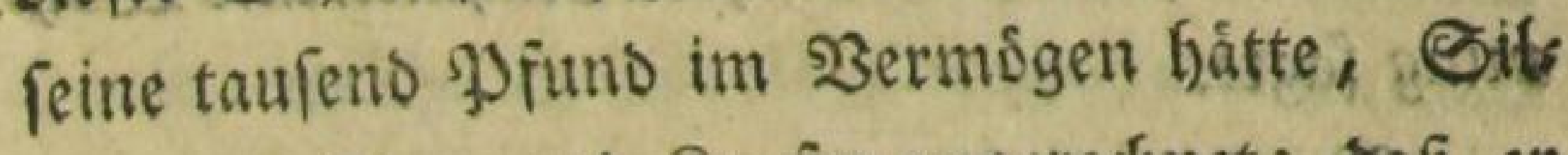

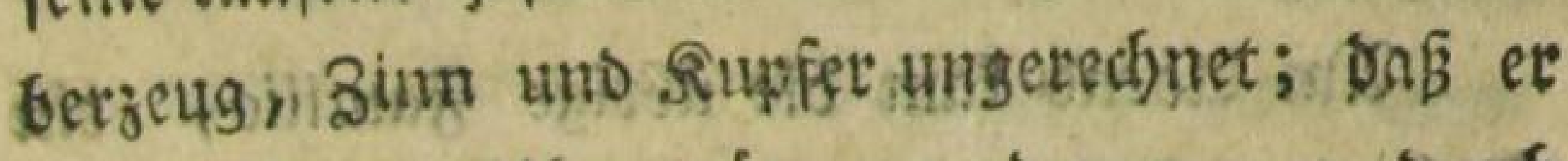

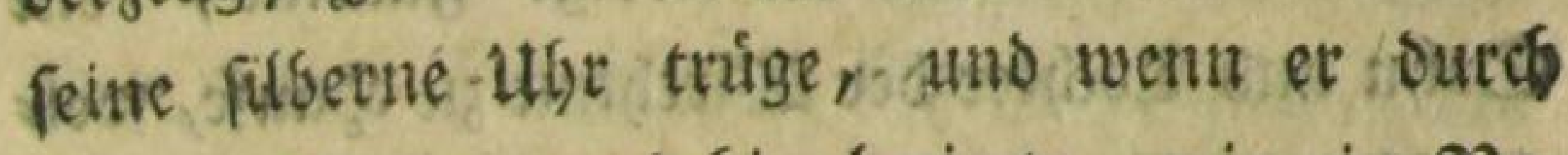

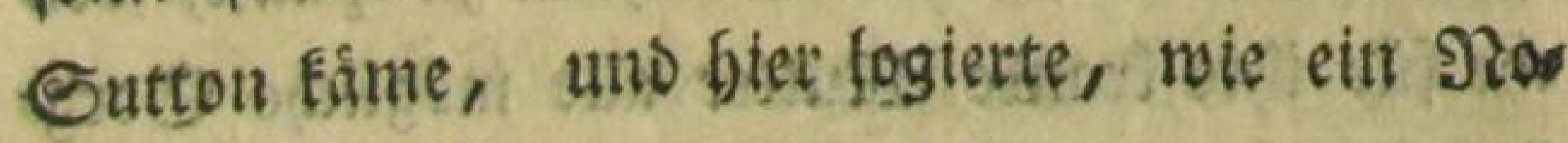
bleman begatle sat aim is C.?

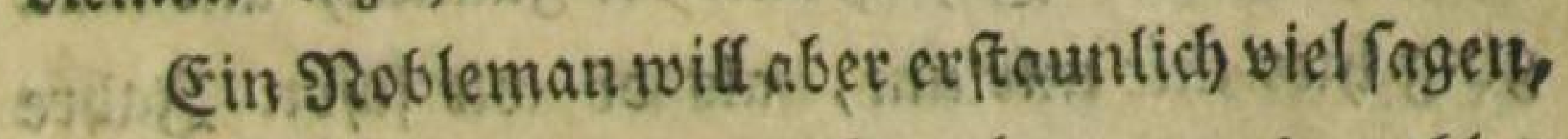
Denn in Prúcficht gegen Gienteman, Das blos

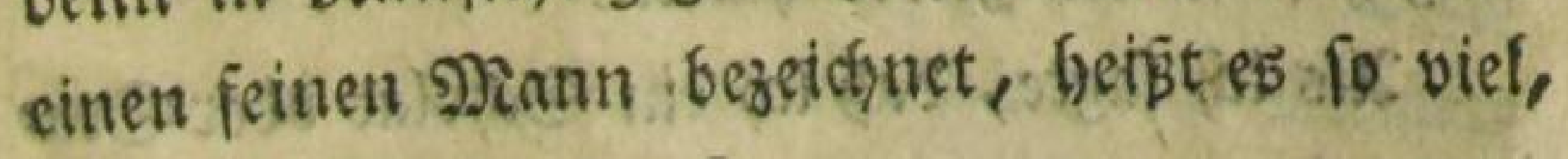

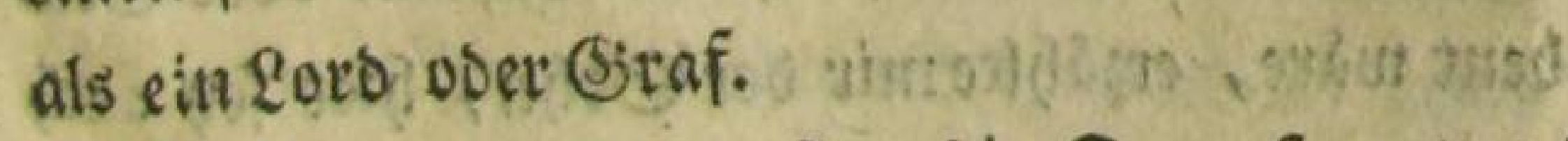
c. Serner bemerkte fie, bie Srau (ev) etwos lowlived (yon nieorigen. Sitten) ert áfer fey Def 


\section{$(288)$}

feitrfte und attigfte Xann von ber 25 elt. Nun bemerfte idf freilit) bei ber Sdjornfteinfegerint

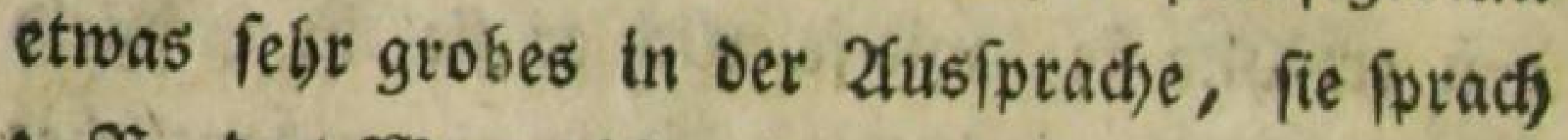
*. 23. Das 2 sort old, alt, welctes ob 10 gelefent werden mus, wie aulo aus. Sonft bemertte idf in biefer (Entfermung von gonbon nod) feine merfliche afowetchung in 2fnfefung Der 2luss firache.

Miorgen, fagte die Sdjornfreinfegetinn, fen fie und igt פiann nicht zu Şaule, aber went te) Dutch Eichfielo wieder zurúcltáme, wollte fie fith bie (st)re meines 2Befuchs ausfitten, fu wels d)em (Enoe fie mir benn thren शabmen und 2050 mung-fagte.

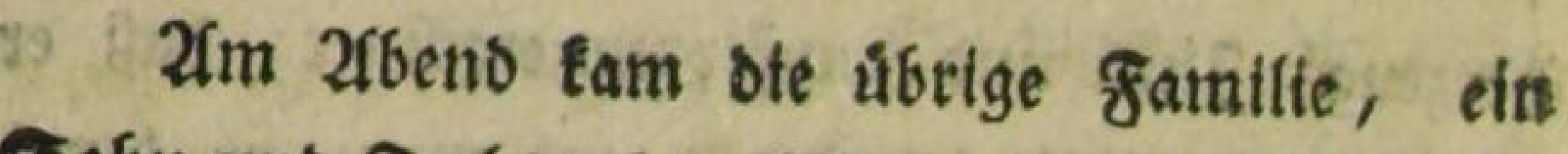

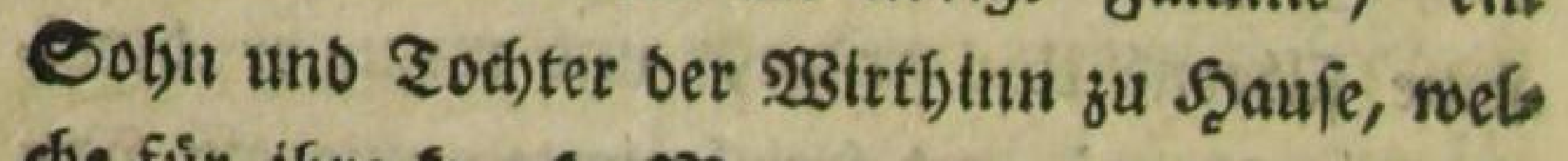
c)e fúr ifre trante Nutter alle mogliche Sorgo

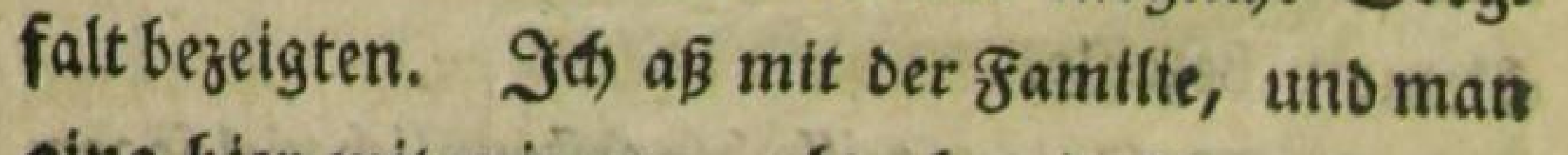
ging bier mit mir um, als ob rotr fobon gabre lang zufammen gelebt batten.

alls ith fagte, onfis ich ein Scholat ober Stus bent raare, erzáblte mir ber Sobn, bier (ên aud eine Grammar School (lateinifobe edfule) no 6) Det Schoolmafter auf zweibunbert 3y funt 


\section{( 189$)$}

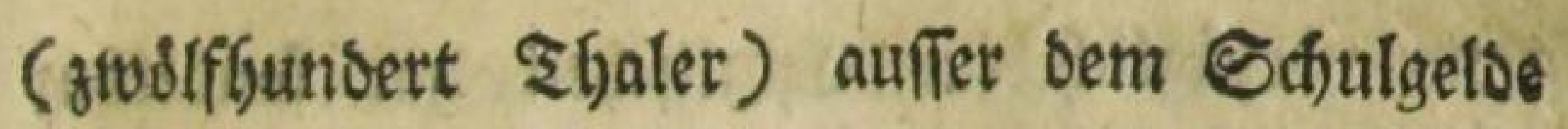
frúnde. Und biés war nur in eituem flecten, idy Dacfte Dabet an unfre Grammarfchools in Serlin, uno an bie Sefoldungen der Dafigen Schoolmafters.

2fls id) am folgenden Notgen meine Fect) knung bezafitte, merfte id Den aufferordentlichen 2l6fall gegen 23 indior, Nettlebed uno Orforb. Sn Sxjoro muste id fúr albendeffen, Sette, uno Frutbfruct wenigftens brei Edjiffinge bejablen, uno Dem 2fufwátter einen Sdjifling geben. STier

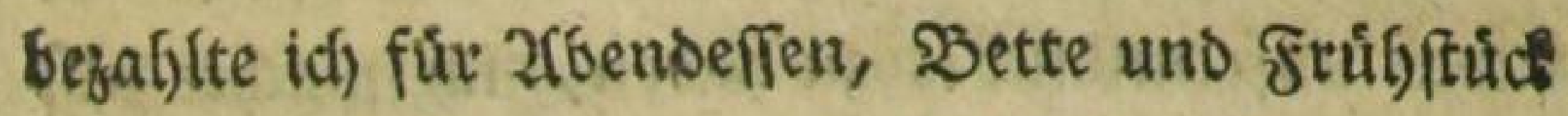
nur eimen S(bilfing, und als idb ber Fochter im Şauje, weldje idf bier als Chambermaid betradjs ten muşte, Four pence (ofngefáfre zruei Bsto. foben) gab, bebantte fie fid gar hofflid, und sab mir noch tiferdem eine fdriftliche Empfeb): lung an einen 2 sitth in Ridffield mit, bei bem id) gut wurde logieren fonnen, weil fonft sie \&eute in \&idjfielo fefre ftolz ráren. Diefe fobrif̈tliche (Empfehlung war Denn elu Deifters ftúct von orthographificher S(f)reibart im neues ften Sheidfmact, wo man nicfits (chreibt, als was man bort uns aus[pricjt, weldjes fich 


\section{(. 190$)$}

benn votzúglid, im Engliffen gat fonberbat ausnimmt.

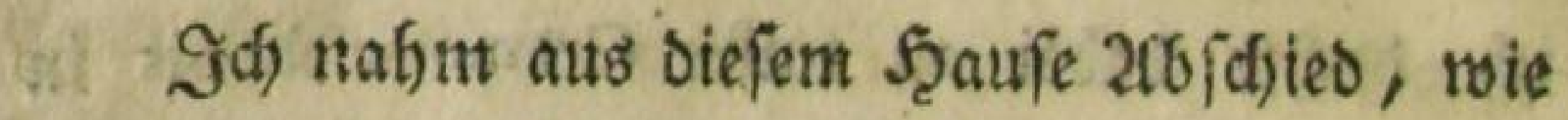
man son guten frteunden $2(6$ f chies nimmt, uns

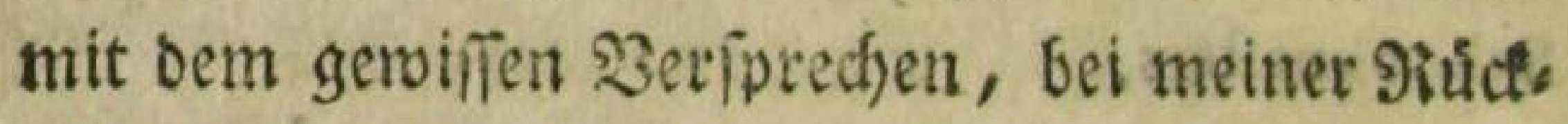
reife wieder da einzufegren.

6. Den sittag kam id nach Eicifielb, eitret fiemlich altitaitkijogen Gtaot, mit engett uno unt; faubern Sinfen, uno wo id zaerft rieber runs De Fenfterfcheiben bemerfte, bie fonft in Engs

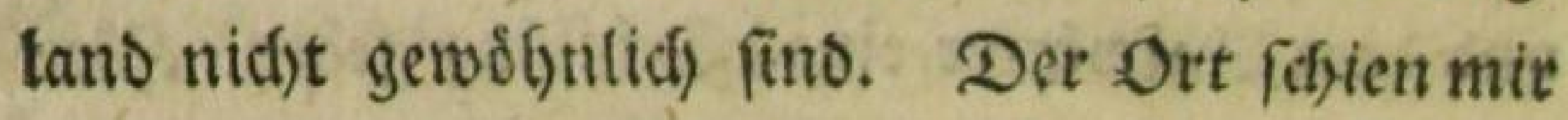
etroas unfreunditches zu haben, id madje alfo yon meiner (Empfeblung feinen (sebraut), fons bern ging gerabe ourd), uno faufte mir nur in einem Secterbause Srod, welches id mit mir nabm.

Den 26ento fam idf nach $B$ urton, wo bas berůfmte Surton 2lle gebraut virto. E(jon ebe id) an biele Stadt fam, roar id) ziemlich mitoe, uno nafsm mit alfo vor, bie গacht fier zu bleiben. 2fllein wie balo ließs ids biefen Ents ichlus fabven, ba ich nun in bie Stabt fam, und alles wieber ein fo youthebmes 2fnfegn batte, als wenn idg in nabe bei \&ondon ware. Uno 


\section{(191)}

Dod) twat es bier fo fleinftábtifa, bas man auf mich, als einen fremben, Der zu Fupe ging, faft mit Singern wies. Uno nun fam id oazu Dutch eine lange Straß̧e, moes an beiden Seiten vor allen Thuren voller Nienfacen ftand, bie mid) ordentlid) ourd) iffere neugierigen Slicfe Spiestutben geben lię̧en, und immer finter mir her żilfjelten,

2llle meine setufigungsgrtúnbe, Daß̧ id bod) ja biefe Reute nie roieder fellen wúrbe, ebent fo wenig, wie fie mich, und oergleichen, balfen nidjts; biefer âftand roard mix beinafe unets tráglid), uno bie Strape ward mir fo lang, als ob ich eine Meile gegangen wåre, uno ermus bete midh aud) eben to fel)r. Jath babe auch eine foldhe verthaşte 2lufmertfamteit auf einent Durchrei enden nod, nitgends als fier in $\mathfrak{B u x}$ ton gefunden.

23sie frob wat id, als id midh roies Der auffer ber Stadt im Freien befand, of ids gleid) nun nod) nicht muste, wo id oie Nadjt

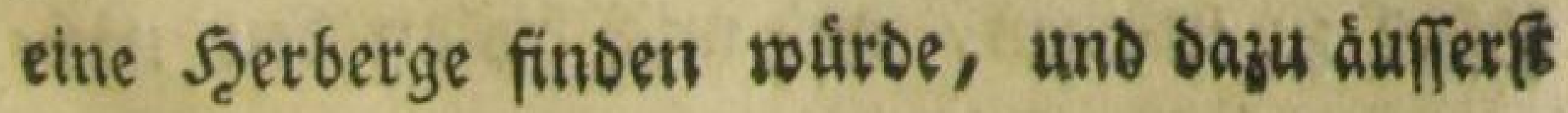
ormidet war. 


\section{(192)}

Tof ging inter immer auf ber Straße nach

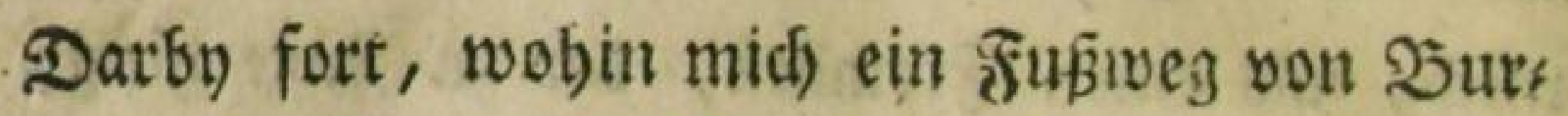
ton auts, úber eine fegr angenelgme 2 şiefe fuifts te, bie burd) Ber follage abgetheilt war, wo malt fegre oft überffeigen muste.

Ifls idf mun eine ganze Strecte gegangen twat, ofjue an Der Sacerftrabe einen Safthof arzatteffert, uns es auch folon bunfel ju wets

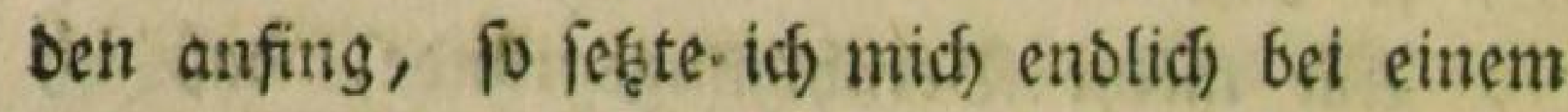
fleinen solffaule, two ein Soljlagbautm, und für Fußsgánger eine fleine Freppe zum Heber: freigen war, auf bieje Treppe niescr, um midf auszuruben, umb allenfalls zu verfuclen, of mid) Der asflner beberbergen wútoe.

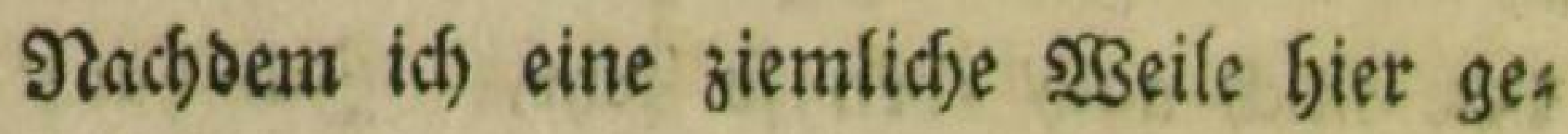
Teffen batte, fam ein Dauer geritten, uns

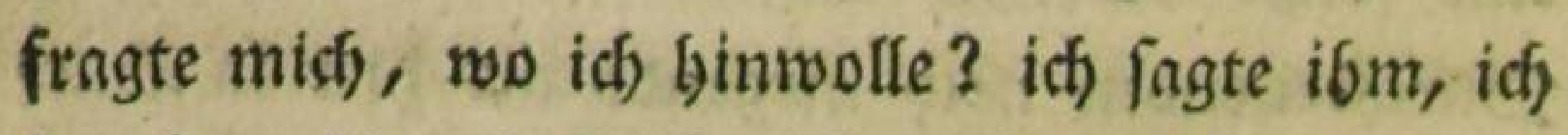

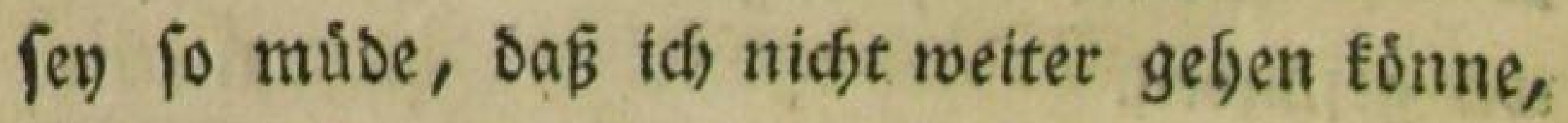
und ben Zfugenbliaf erbot fich biejer gutmuttgige eble Sauter, von freien Stiffen, ofne Das gea ringfte Mistrauen, midf) binter fich suf fein Soferb 3u negmen, uno midb bis an ben náds; ften (jafthof an bringen, wo ids bie शadist bleie ben Esune. 


\section{(193)}

Das Pferb wat ein ziemlid) bofer Staub uno als id nidft fogleid) binauffeigen founte, fain ber Boflner, ein ffeitnaltet. Mann Geraus, Dem ich faum strafte genug zutraute, fid) felb/t empotzufalten, und eben biejer Nant fabite midf mit cinem 2(rm, uno hob mich) mit einem

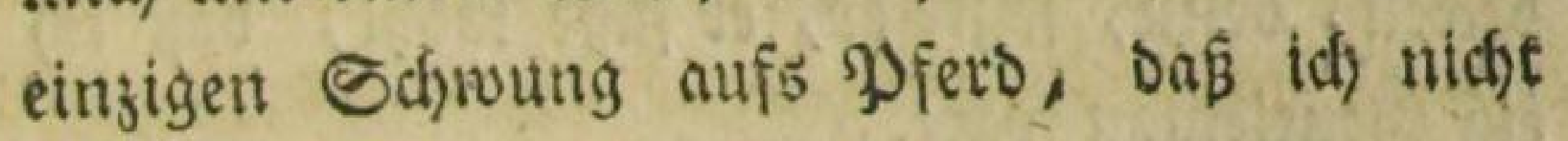
wuste, wie mir geidsatje.

Utib fo trabte id bent mit meinem vor: trefflicfen bauter fort, bet auch feine eingige neugierige frage att midh that, fondern mich vor bem Gafthofe abfereste, und barauf lints nach feinem Dorfe zuritte.

Diejer Sjaftrof ließß ber Sár, unb der şitt) ging utmbet, unt brummte wie ein Bát mit leinen $\mathfrak{Q}$ euten, fo Daß̧ id) mil anfangs feine gute 2fufuabme verfyrach, allein idf fuchte ifnth milbe zu machen, indem id) mir einen Rrug alle geben ließs, und ifm ein paarmal zutrant. Dieß̧ g) itittel balf, uno er wurbe bald fo foffich uno ges

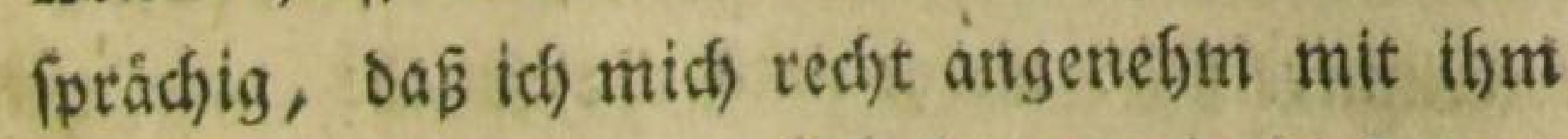
unterbalten fonnte. Jih batte mir bies vont 2Bifar von 23 afefielo abgemerft, Der aud feine

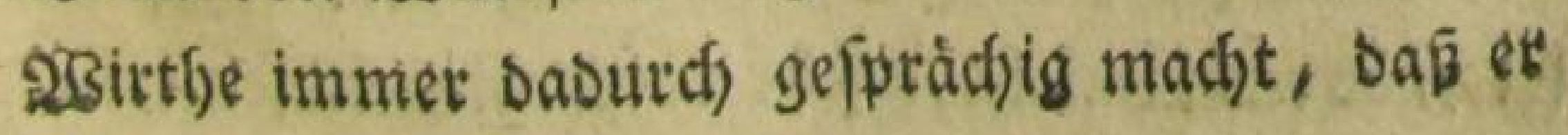
ที 


\section{(194)}

fie mit fiç trinfen låşt. Utno úberbem getwann idh Dabei, weil th) felber das ftarte alle nicht gut vertragen fann.

Diefer $\mathfrak{W}_{\text {Sirth }}$ nannte mid, nun wieder Sit, uno man muste mir mit $i$ m allein einen $T i f \mathfrak{c h}$ Decfen, denn, fagte er, er fábe roofl, daßs ich ein Sientleman waire.

TSir fprachen barauf fefre viel von Sseorg. oem Sweiten, Der fein Favoritesnig war, forwes nig Seeorg Der Dritte feine Sunft batte: unter andern famen wir auf bie Schlad)t bei Dettins gen, wovon er viel Epecialia ruste. 2(uch)

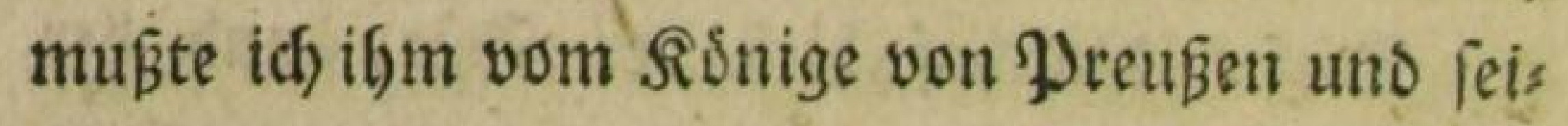
nen vielen Soldaten, uno was bei uns die Eciafe fofteten, erzáblen. Utno als wir barauf noct) eine $\mathfrak{B S}_{\mathrm{seile}}$ von politifhen Sachen gefprochen batten, fragte er midf auf einmal: of ich Das. SSalbforn blajen Eśnne? - Dießß vermutbete er Deswegen, weil ich) aus Deuticland fer, Deun et erimnere fich, als et noch ein Rnabe genefen wåke, båtte audb einmal bei feinen (S:tern in eben. Diefem Sraftyofe ein Deutfcler logiert, uns sies fer Gabe das şald born fefor wertieffich bla fen fsus. 


\section{(195)}

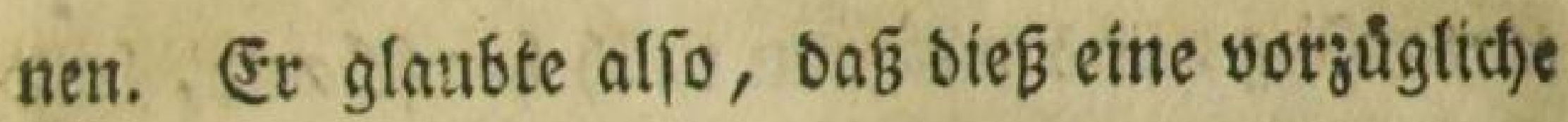
(Eigenfid)aft Der Deutichen fen.

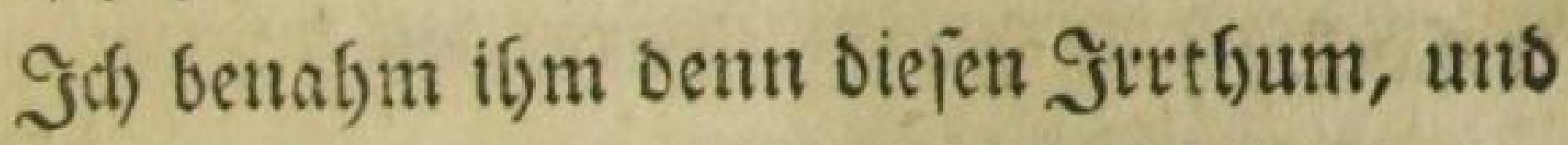
wir famen wieber auf bie politifffjen 2fngelegens beiten, inder feine Sinder und Siefinde in einis get (Entfermung mit vieler (E)trurdftunferm Şer fpráche Jutborten.

So brad)te id) bier wieder cinen feffr anger netymen 2lsento ju, und am Niorgen, oa id) ges fritbffucft batte, bettug meine Sied)mung nidft mefri, als in Sutton.

Nun fam ich endlich am Freitage Niorgen In bie Secibe vor Darby. (ss wefte eine milbe Quft, uno id) war ganj aufferotbentlich beiter und vergnígt.

Siegen Drittag begann bie hertidide romans tifdhe Siegent. Sith fam auf eine grofe 2(nthot)e,

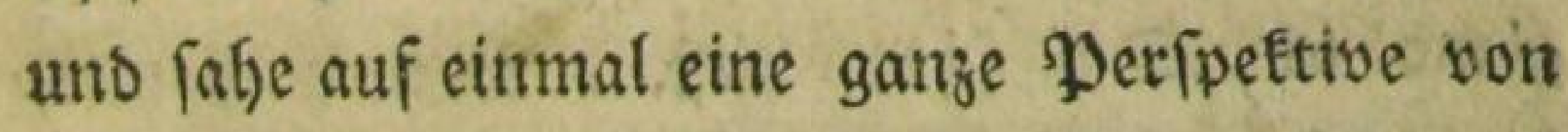
Şergen vor mir, wo immer ein \$paar náljere nodf ein गुJaar entferntere, und biefe roieder noch) ent; ferntere, zwifjen bem Praume, ber fie trennte, Durchichimmern lię̧en.

Itns num bob fich Das Qand immer wie cine 2sselle auf und nieber, nuf beten Ructen idg Eals

श? 


\section{$(196)$}

emporftieg, uno weit um mich ber fohaute, bals rieber in ben tiefen 2fogrund mit ifor hinuns terfant.

Den Nacfmittag (af) id) Darby vor mte im Tfale: Uno nun war id foundert feds und zwans zig Meilen von Lonbon entfernt. Darby ifteine fleine unanfénliche Strot. Es war bier getabe Nartt, und icl muste auds burdy viele Nien: fdjen geben, aber bier herridfte feine foldje ver: baste Neugierde, uno beleibigendes 2fmftaunen, wie in Surton. 2fuch rutbe icf von nun an, wenn id burd) ein Dorf Eam, yon ben Dauets findern immer fefre hoffic) gegrúpt.

Bon Darby fts nach Den Babetn zu æi a th loct, wo eine ber romantifoffen Segenden ift,

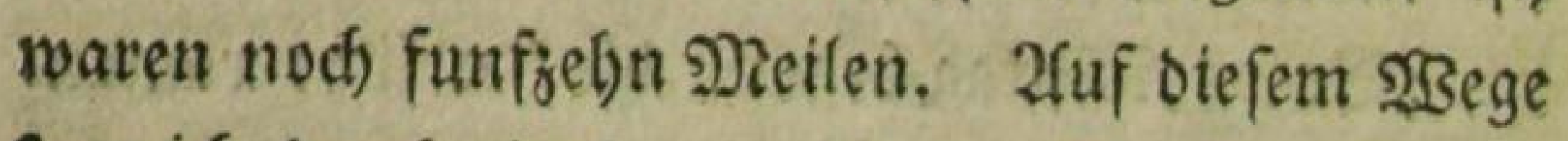
fam ich Durch ein langes breites Dorf, welches;

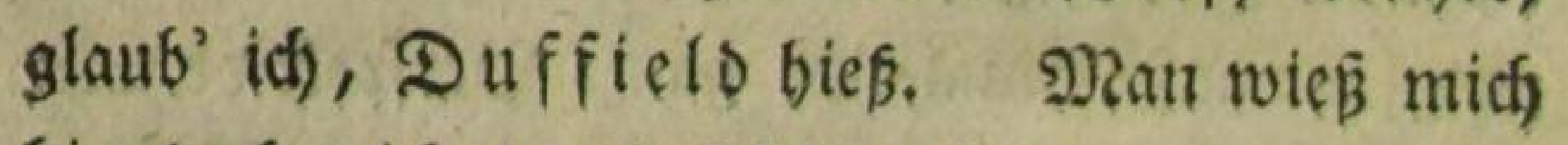
biet boch nicht tn bie Riche, fondern in ein Sims mer, uno idh â bier: eine falte Gdhale zu Mittage.

Die Supferftiche uno S3ilder, welche man gemólgntich in ben Engtichen (5iafthofen findet, fino eine 2f6biloung der ganzen Sơniglidben Fami 


\section{( 197$)$}

fie, in einer Ssuppe, wo ber Sisnig fie als eir Bater um fich ber verfammelt, oder ein Giruno,

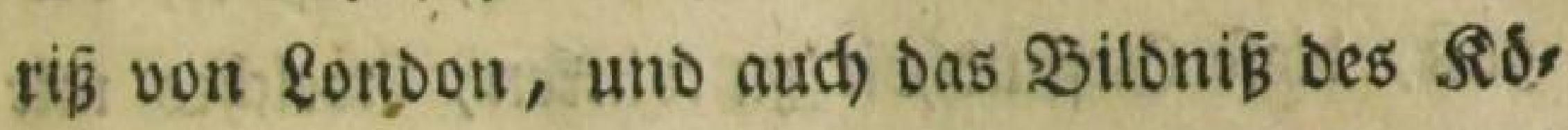
nigs von Dreusen, weldfes idh fier werichiednemal geielgen habe. 2fud) findet man zunetlen eine Ş⿻日禸 war, muşte id in Diefem Dorfe einigemal wies Der Das bemitleidenoe God Almighthy! hổrett, wooburd) man mich als einen armen Jußsgánget bedauerte.

$2 \mathrm{~m}$ 2fbend fefrte id) wieber in einem (s)aft: hofe an Det Seeerftraß̧e ein, von weldyem es nut

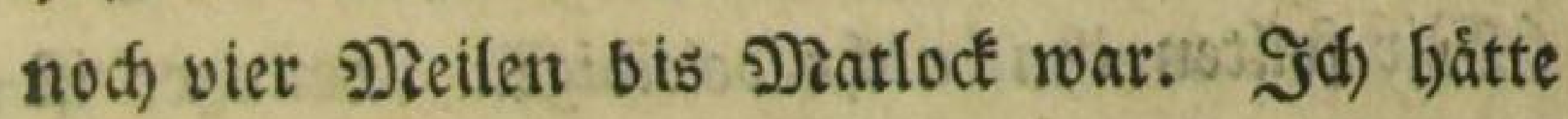
es leidft noch erreichen fónnen, aber idh mollte Den erfiten 2fnblicf Diejer Siegend lieber auf ben folgenden Norgen verjparen, als inder D âmmes rung fintommen.

Zllein in biefem siafthofe war idi? nidit io glúctich, als in ben beiben vorigen. Die Suldse

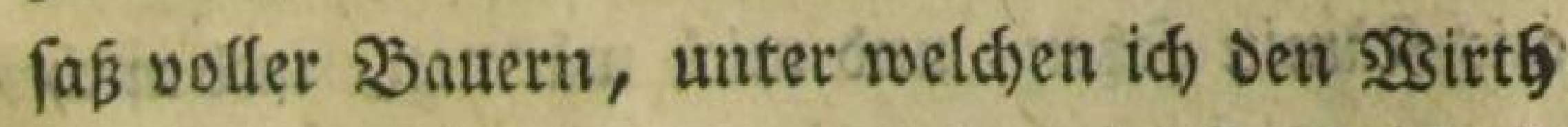
nid)t unter/heiben founte, oem id fonft gleids zugetrunken bátte. Nun forte ich woht, baß ein Bauermadhen, bie audh mit in ber Sulche war, fo oft fie trané, fagte: your Health, gentlemen all!

श 3 


\section{( 198 )}

(Eute Sefundbett, if) Şertn intgelammt!)

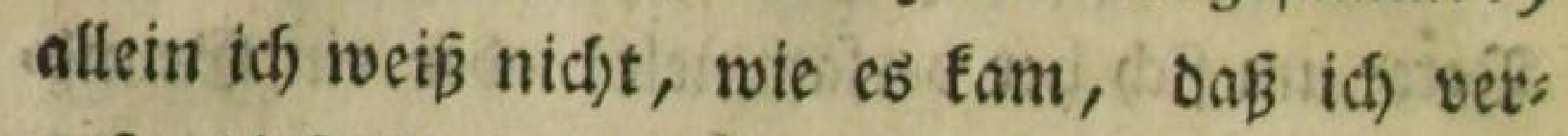
gaß́, Diefe (sefundheit zu trinfen, welches mit Denn fefr libel aufgenommen wars. Der SBitt) trant ein paramal auf eine fpittifabe 2(tet meine Siefundbeit, gletch fam, um mit meine tunbof: Lidjét zu vetweifen, uno oann fing et an, midf mit Den ůfrigen augrulachen, bie faft mit grins gern ainf mich zeigten. So muste ich) nut eine Seitlang Den Sauern jum Sefpotte Dienen, bis endicf boch einer unter ifitren mitteibig fagte: we muft do him no Harm, for he is a Stranger!

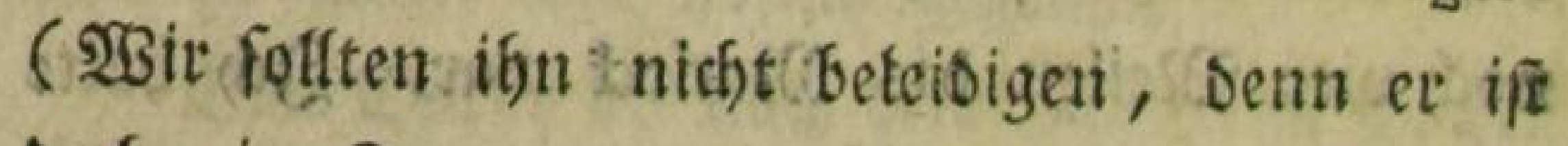
Doch ein Fremoer!) it is no Harm! fagte beo

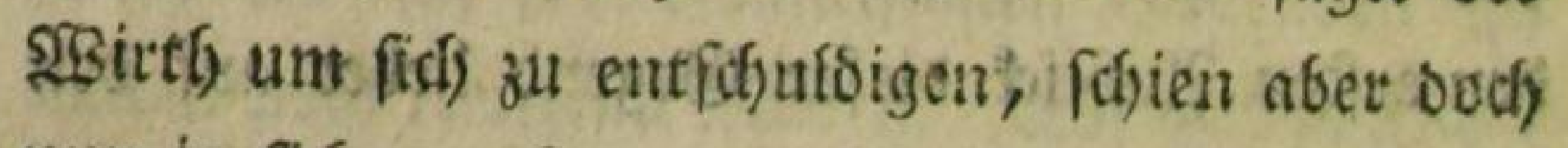
nun in fich zargeben, uno foitte mit feinen Epsts tereien auf, als ich ifjm aber mun zutrinteir

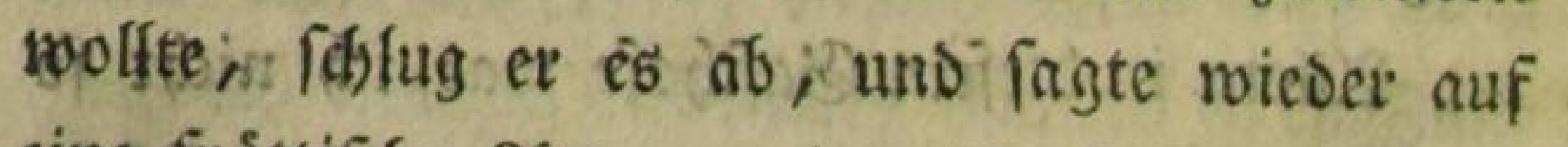

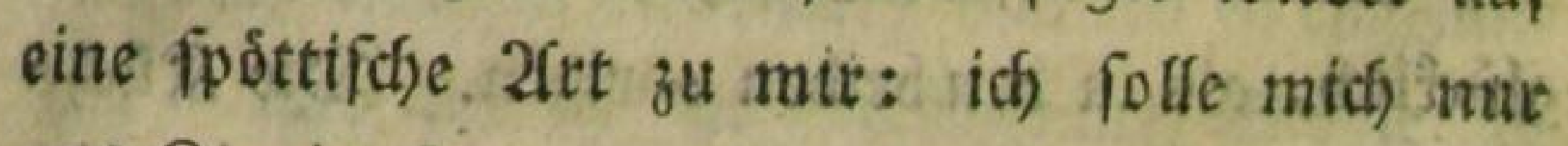
ans Samin feçen, uno mich wármen, uno midy

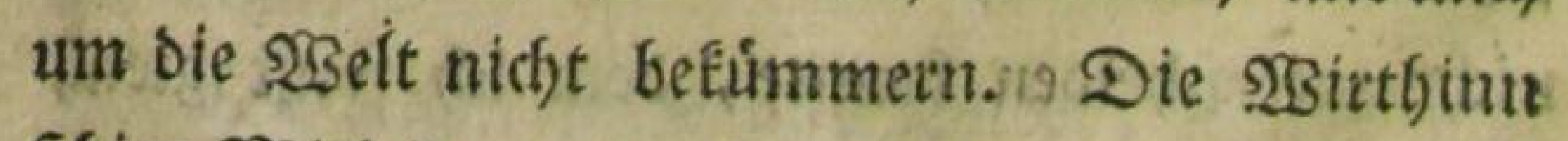
(d)ien Wcitleiden mit mit zu faben, un fúfrte mid\%, nus bet $\Omega$ ádhe in ein andres Zimmer, wo id 


\section{( 199$)$}

afteir fenn fonnte, inoem fie lagte: bas ift gott: lofes 230 le:

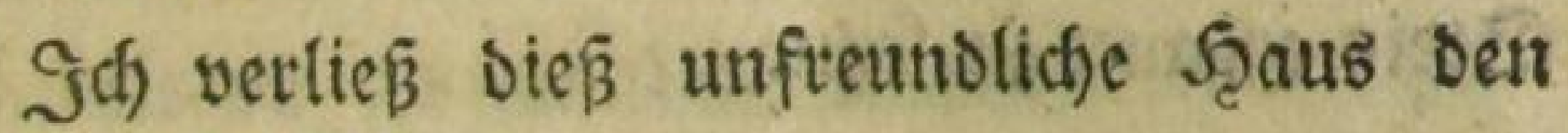
folgenten sorgen foith, uno nut ging es ouf Niatloce zu.

Dab Stel meiner Sicife, was ich) mit nun geief̧t batte, wat bie groß̧e Şdble bei Raffleton,

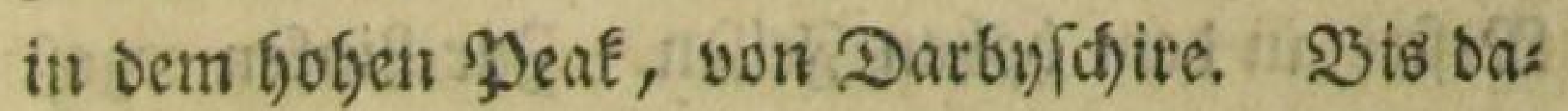

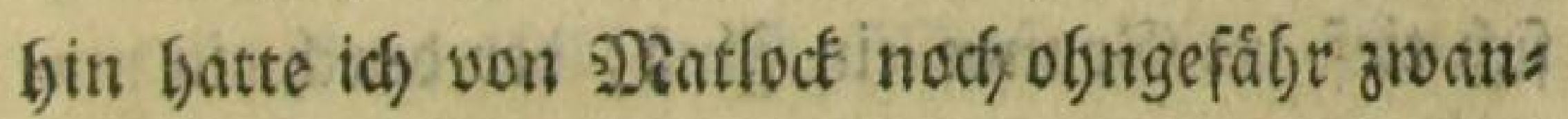
zig Meilert.

Die Erbe befam fiet eine ganz andre Ses

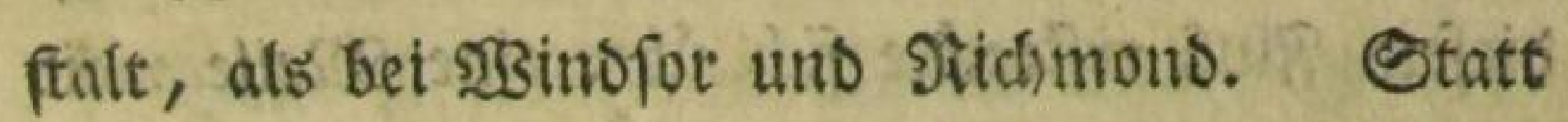

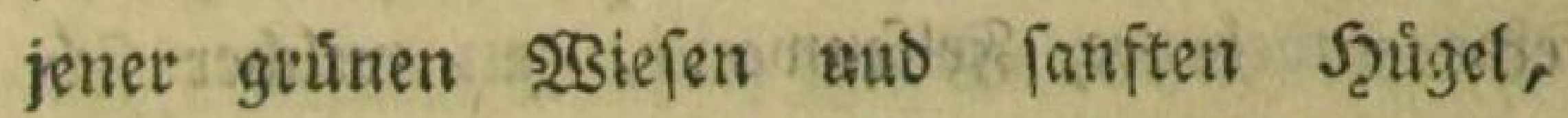
thuirmten fid) bier nacte S3evge, uno bimmel bobe Selfen; ftatt jener angenelymen guinen feets fen, waien biev bie bin umo fer zeepteuten

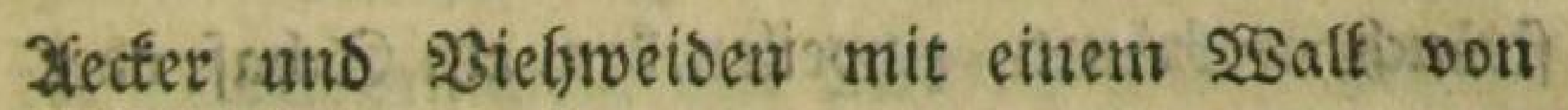
giruen Eteinen eingefdifoffen: uno yon eben Diefem grauten Stein, Der fier allentbalben ge: brodjen roitb, fins aud bie Şáufer auf eine.

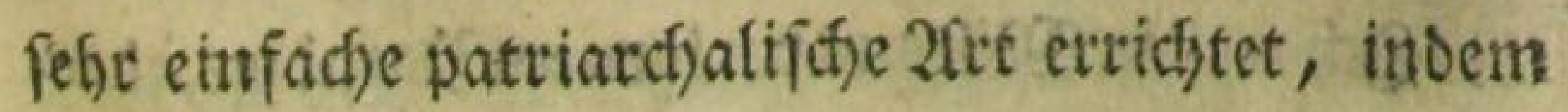
bre tolyen Steine faft obne alle Bttbeteitung auf: cinandergepact fino, tuno vier Sisainde nusmas (f)en, fo bon man fich allectifalls felber mit ieids.

$$
\text { 2) } 4
$$




\section{(200)}

ter Mathe ein folches Şaus etbauen tỏnte. In Darby fhienen bie Scáufer yon eben biefem Stein etbauet 子u (entr.

7un Die Siegend bey Matloff felbft, úbertraf nlles, was id) mir bavon vorgeftellt hatte. Sur red)ten Seite waren eintge elegante Seaufer für Die Sabegåfte, uno Eletuere Scútten bingen wie शRefter an Dem hohen frelien. Sur \&infen ergö́ fich tief im Sstunde ein Fluß, Dev Durch ein mas

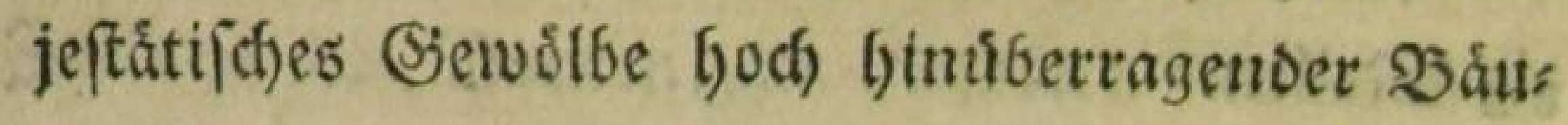
me beinalse Dem Afuge verdectit war, Lángft

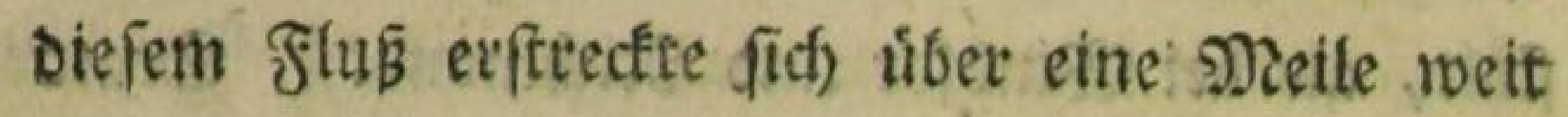
eine ungebure Felfenroans, an weldber fich. oft verftectte SSange in Dunflem Sebuich bins auffodlángelten.

Oben rat der jábe Gelien mitt grünem Sjes ftrinch) umftángt, zumetlen $\mathrm{E} a m$ etir Cobaf oder: eine Sub von ber meidenden Seeerde an den fteie len 2(6h)ang, uno blicte ourd) Das (sieftraudy Iyinunter.

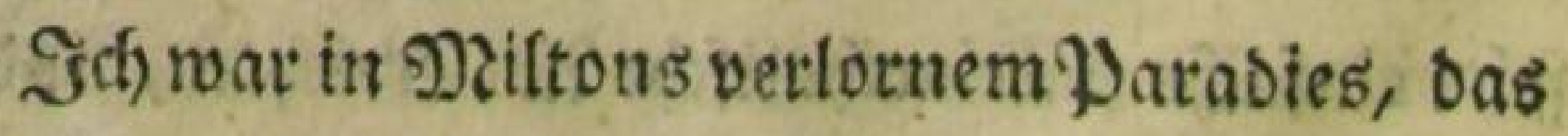

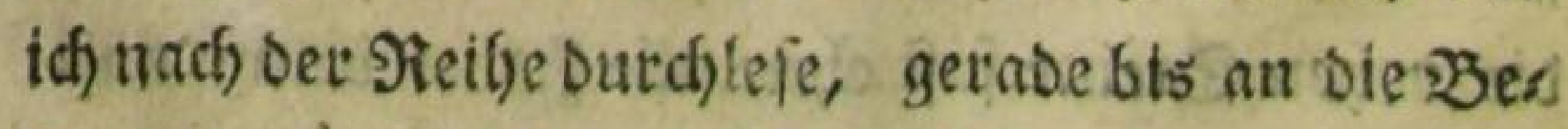
(á)reibung des Warabiefes getommen, als ich in Diefe (Segend fam, und folgende Stelle, die id) num 


\section{(201)}

im Stunde am $\mathfrak{H}$ fer des fluffes las, that eine forberbare SBirfung auf mid), Da fie auf bie Naturfene, die id bier vor mir fabe, fo felse papte, als of fie Der Didfter felbft Dayon ger nommen Gatte:

- - delicious Paradife,

Now nearer crowns with her Enclofure green, As with a rural Mound, the Champain Head

Of a fteep Wildernefs, Whofe hairy fides With Thicket overg Iown, grottefque and wild, Accefs denied. -

3on כiatlodfbade fimmt man uீber bie Matlodfutude, exft nad) Dem Stádtchen \$atloce feloft, bas eigentlid) faum eit Dorf beifen fónte, weil es aus âufierft twenigen folechten Şaulern beftebt. In diefer Ssegend ift megen

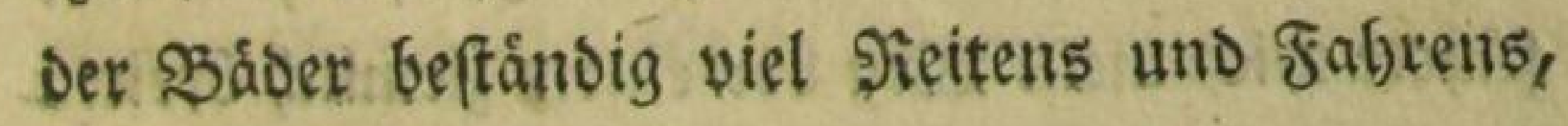
und eine farfe ઝ̧afTage.

Bon bier faum id) Durd einige Doster wies Der nach einem fletuen Stábdjen, গalsmens Bateroll. Die ganze Segend ift bier gebir gigt und romantifis). Dft fúfrte mich mein $x$ seg

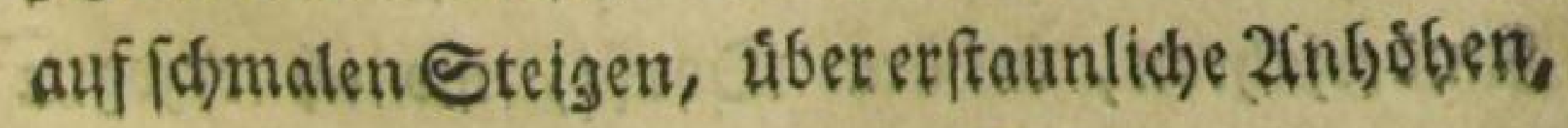
श) 5 


\section{(202)}

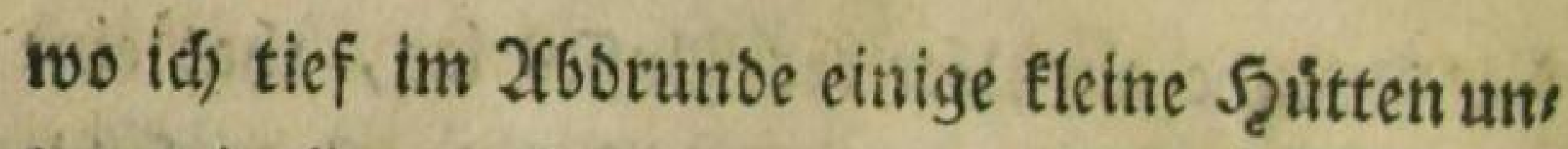
ter mir liegen fábe. Die Einjaumungen Det Felber von ben aufgemorfenen grauen Steinen, gaben liberdem ber gailzen Siegent ein wilbes

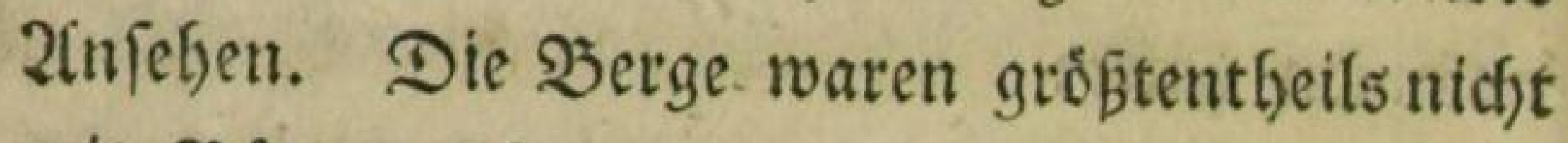
mit Şäumen berwadjen, fondern nacte, uno man fab in Der Fevne Die Seeerden auf ifren SSip: feln reiten.

2fls ich) Duth eines Det Dorfer fam, borte (d) einen großßen Sauerjungen mit vieler গeus gietbe einen andern fragen : ob ids benn nun ein Frenchman (er)? gleichjam, als ob er fojun lan: ge darauf gewartet babe, einmal ein foldjes

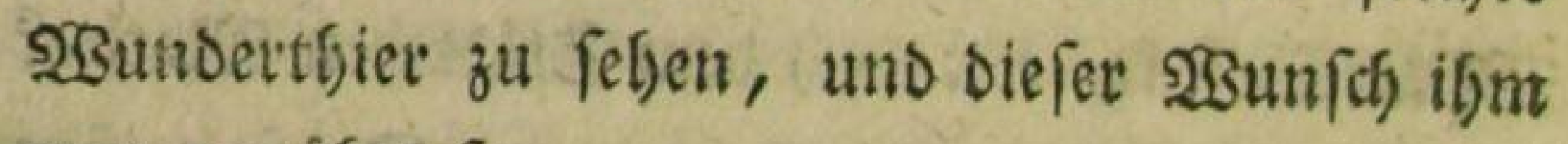
nun gervafget (et).

2lls ich) Dutch Safervelf, einen noch unans fébulichern Ort, wie Darby, gefommen roat, fúbrte mich mein $\mathfrak{I S e g}_{\mathrm{S}}$ vor einem fiemtich breiten Slufie vorbel, eine fleine atnhodge binauf, wo eit bebautes felo vor mir lag, bas einen unbes fofveiblich) angenefimen (sindrucf auf mid) mad)s te, ofne (Daß̧ icf mir erft bie Utrach Davon angeben fonute, bis idf mich erinnerte, in meinen Rinderjabren, bei bem Dorfe, mo ich erzogen 


\section{(203)}

war, eine faft ganz ábnliche Biegent gefeben zu Gaben, Die id) unu gier mitten in Englans mieder fand.

Das Feld war nefjmlid) auf beuticfe 2frt niđjt mit feecten eingejáunt, fonoern bic Saats feloer wecbfelten mit allerlei grúnlid)ten und gelblichten farben ununterbrod)en ab, weld)es ein angenebmes Folorit gab. Utebrigens aber bradjte mir biefe ganze Siegeno, uild taujent Sicinigkeiten, Deren idy mich nicft Deutlich beroufst war, bie Jagre meiner erften Sindfeit ins

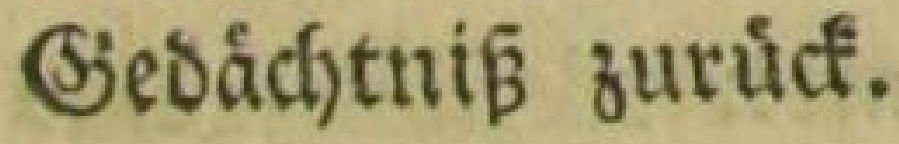

ฐd) rubete mid, bier eine 2 Seile aus, uno Da idh nun wieber fortging, badfte id) an ben Dot meines $2(u$ fentbals, an alle meine Ṡefannte, und aud) an Sie, liebfter Sreund, uno Dachte, wenn bie mich bier fo wanbern fáben! - uno in Dem 2lugenblick fúflte ich er(t eigentlich) Den (Sebanfen Der Entfernung, und Daß̧ id) nun in England war, weldjes eine ganz fonber: bare Empfinoung bei mir hervorbrachte, bie itc) nur einigemale in meinem geben ge: babt babe. 


\section{( 204$)$}

5. Sold fam nut butch nodh einen fleinen ort, Vafabmens 2fifforo, und wollte den 2(beno nod) ein fleitres Dorf, গaafmens গצardlon, bas nur bret Meilen Davon lag, erteidfen, als in ber Ferne zroet Maanner Ginter mir bertamen, bie (df) fhon in Maatloct geferfent Gatte, uno weldhe mid) anriefen, bás idf auf fie warten follte. Dies waten alio feit bem Seetrn \$iodo, bie

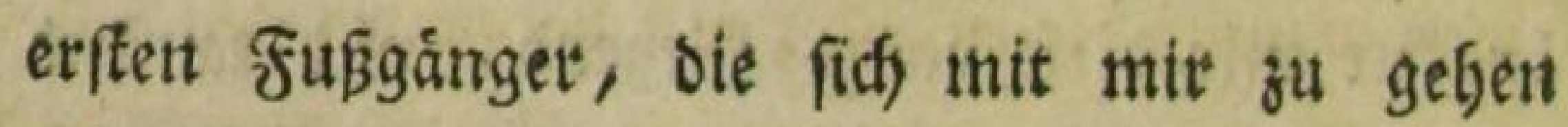
etroten.

Det eine roat ein Sattlet, uno trug eine

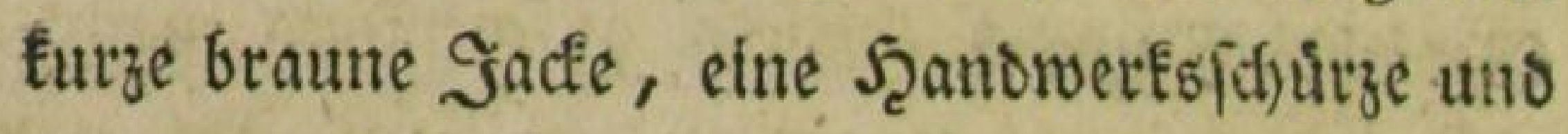
eitien rumben Saut, ber ansere wat orbentlica búgertich gefleibet, unb ein febr ftiller Diann, oa bingegen ber Sattler åuferêt gefprácbig wat.

Jah botchte bod) auf, ba berjelbe won f̧os mer, Şotaz uno \$itgil ju fpred)en anfing, unt

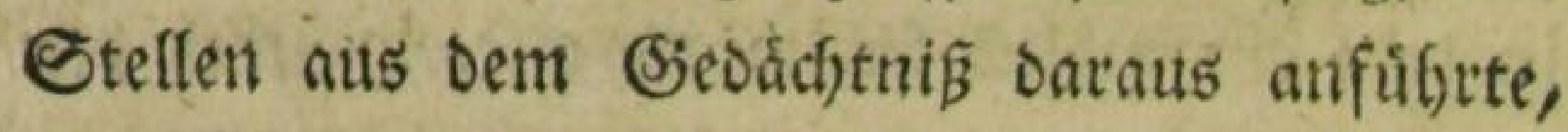
und ưberbaupt feine 2Sorte fo vortrefflic) zu fegsen wuste, als idf es vielfeidft mur irgeno von einem Doftor oder Magifter in Orforo batte erratten tonnen. (Et rietb mir, nid)t nach SBarblow, wo id (d)lechte Szerberge fittoen wuirbe, fonbern lieber mit ifm nodf ein Paat soicilen weiter nad sioejuelf 


\section{( 209.$)$}

Thefwell, ju gefen, wo er mofnte. Diefet פafjme Tibefruell miro Durd eine fonderbare ßerfúrzung roie Tiofel ausgefprodjen, ebert 10, wie man anftatt $\mathfrak{B i r m i n g h a m ~ i m ~ g e m e i n e n ~}$

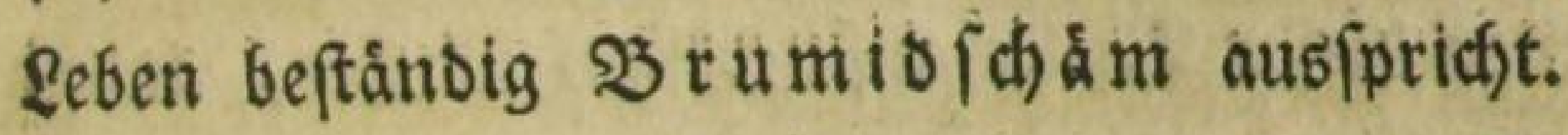

25ir febrten in einem fleinen Iflehaule an ber Şeerftraß̧e ein, wo der Sattler nidft abliéß; bis id) ifm verftattete, meine వeche zu bejafilen, weil er mid) biefen $25 e g$ mit bergenommen babe.

গicht reit von biefem Şaufe famen wir. auf eine 2(nthoshe, wo midh mein philofoptildser Sattlet atf eine 2fusfíf)t aufmerffam machte, bie freilich roofl bie einzige in ifrer 2frt fevn modjte. Wsir faben nebmlid unter uns einet tiefen 2fbgrunb, ber roie ein Reffel aus bet ume gesenden Eromaffe Gerausgefdititten twar, uns auf bem इoben beffelben ein fleines : Thal,

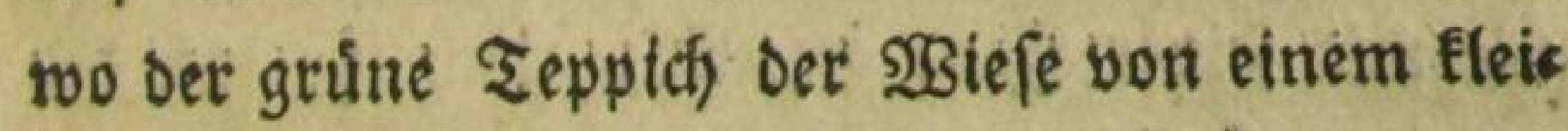

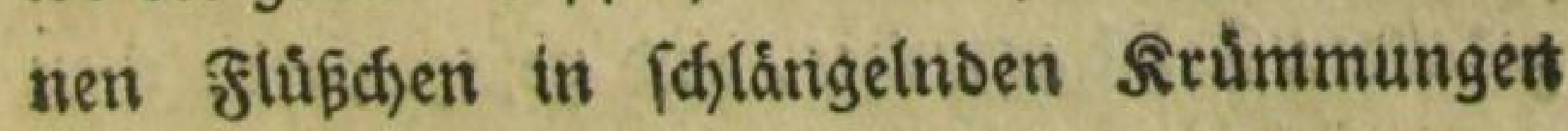
Durdjidnitten wurbe, und die reizendften Spas fietgånge warett. Şititer einer fleinen Srums mung Glicte ein Scaus Gervot, two der SBeroobs ner biefes gludetichen Thales ein großer Naturs

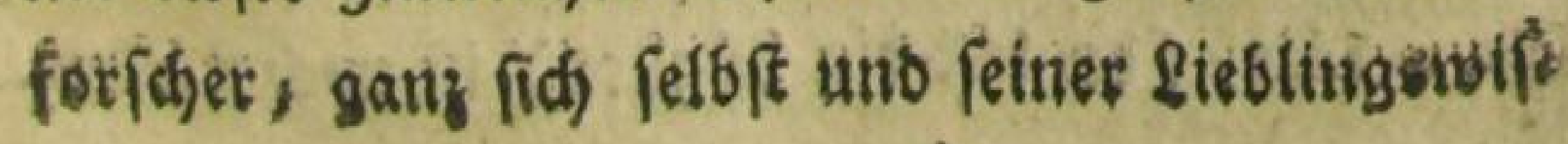




\section{( 206$)$}

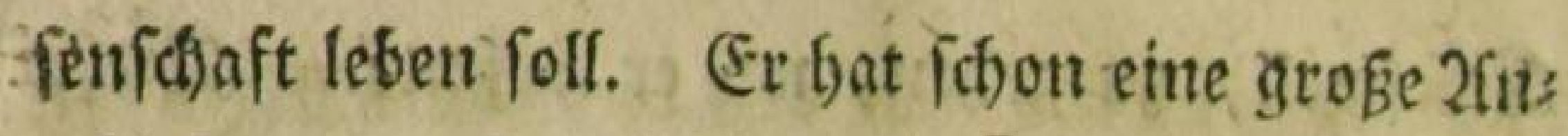

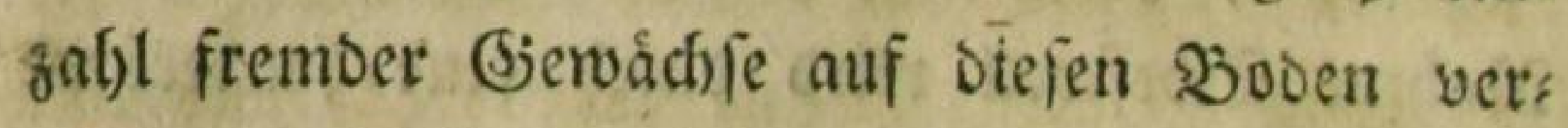
pifanzt. Nein Bzegleiter gerietb beinabe in poez

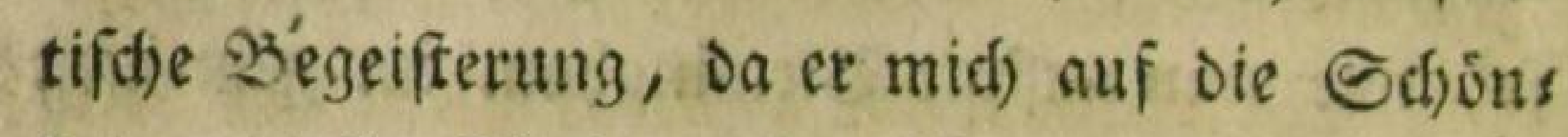
beiten Diefes Thales aufmerefam mad)te, indę unfer britter Mann, Dem dief́ zu lange Dauerte, fiber Den 2 erzug beinabe etwas unvitfig sourde.

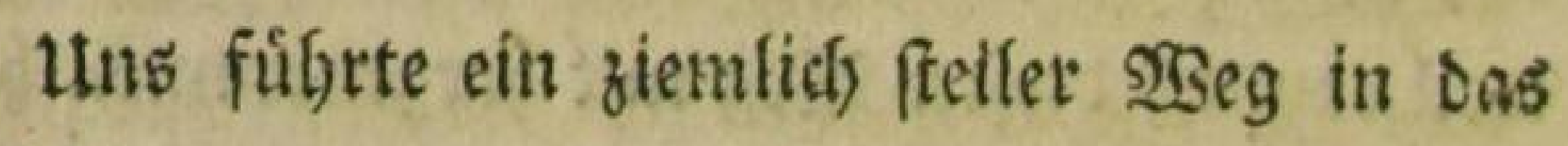
Thal (jinunter, ourd) melches wir gingen, uno auf Der andern Seite zrwifchen den ఏerben rois: Der berausfamen.

5. Nicht reit von ₹ibestwell vertię. uns unfer britter Sieifegejăbrte, oer in einem benacbbarten Orte wolnte. 2fls wir nun endici) Tibesroel vor uns lan ₹bale liegen faben, erzáblte mir Der Sattler von feiner Familie, uno Daßs er fid nie mit feiner fraus gezanft, noch ifor mit ber geballten Fauft gedrobet, uno gefagt habe: thon lieft! (Du ligift.)

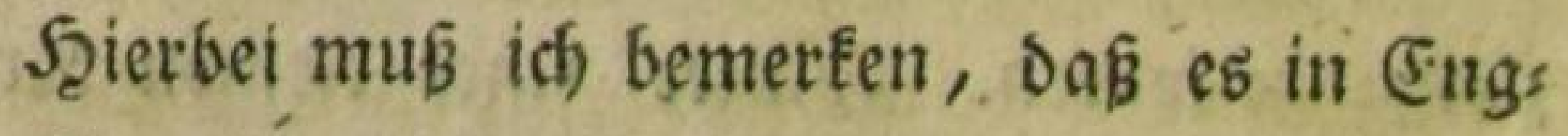
lano fưr oié grofite Seleidigung gebalten wirb, werm man zu jemanden fagt: ou lúgft! thou art a Liar, (ou bift ein \&úgner) ift noch ftạrter, 


\section{(207)}

thb thou art a dammned Liar (ou bift eitf vets bammter Luginer) ift das allerftartfife was man jemanden fagen fatin.

So wie man alfo in Deut follans fagt, einet lást feinen Scundsfott ober SchutEen auf fich firsen, oder fo wie dię bei den Zänfereien bie sofung zum Sdylagen if auth) in (England Das 2 sort $\&$ L guer, und gleid): fam ein Scerausforderungszeidjen, wobuuff Dev beleibigte Ibeil jut thatigen Siache geveigt wito.

Unier Jacin in Ronoon falje mich cinmal mit gruben 2fugen an, $\mathrm{Da}_{\mathrm{ich}} \mathrm{im}$ Sd)ev ju ifjm fagte: thou art a Liar, uno if) batte viel zutf)un, ebe id) es wieder bet ifgm gut madhte.

2ुeinn man aus Dergleichen Rleinigkeiten auf Den (SGarafter einer 9?ation foließen fann,

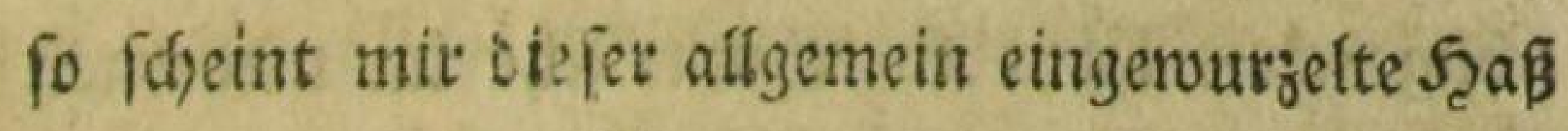

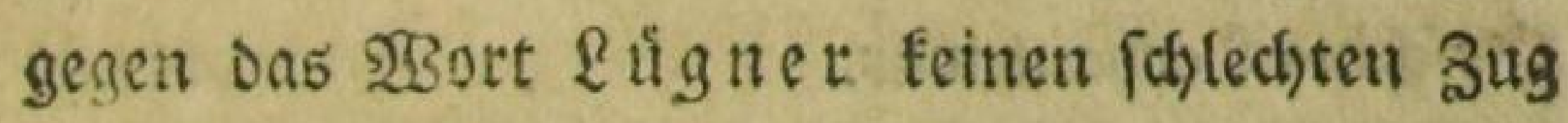
bei Der (Englifhen zu vertathen.

Dods, ids fomme wieder auf meitnen Sieifes gefábrten, ber mir ferner elzáblte, wie es fidó

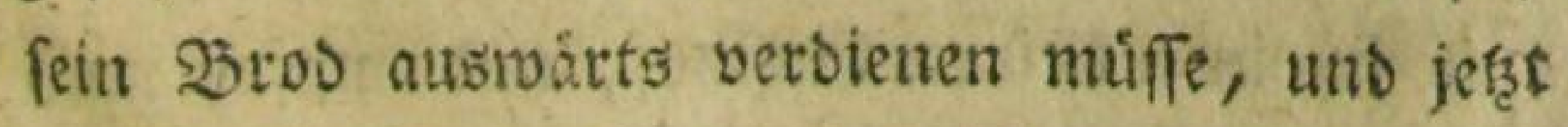

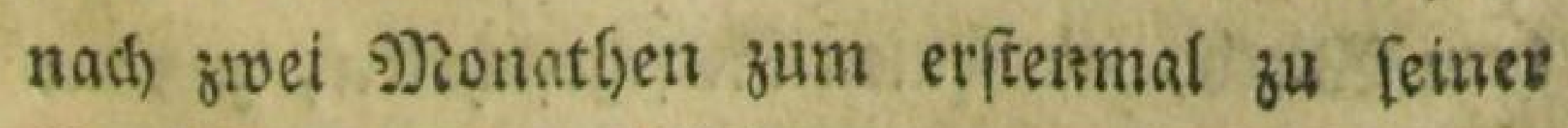
Samilie wieder zutúctétåme.

D 2 


\section{( 208$)$}

Et zeigte mit nabe an oet Stabt eine Feifye Båume, die fein Bater gepflanjt habe, uno die er nie obne গxúbrung anfebe, fo oft er von feis nen fleinen Sieifen wieber in feinen Drt zurúç

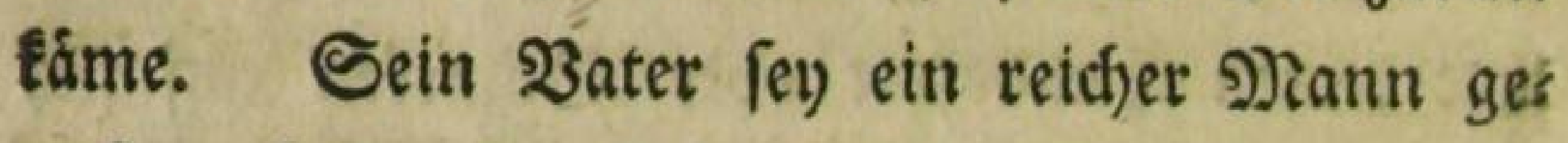
wefen, habe aber faft alle fein $\mathfrak{x e r m o g e n ~ a n g e s ~}$ wanot, um einen Sofn in 2fmerifa zu unter: ftü̧̨en, und feine ůbrigen Sinder arm hinter: laffen, bemolgngead)tet fey ibm fein 2fndenfẹn werț, uno fein Şerz getúbrt, fo oft er biefé Dáume erblicfe.

इibeswell beftand aus ein \$aar Sieifjen nies origer Şâfer, von unbearbeiteten grauen Steinen erbautet. Niein Begleiter machte mid gleid) beim (singange auf bie Sirche bes Drts aufmerffam, weldje ziemlich anfeljnlich, uno

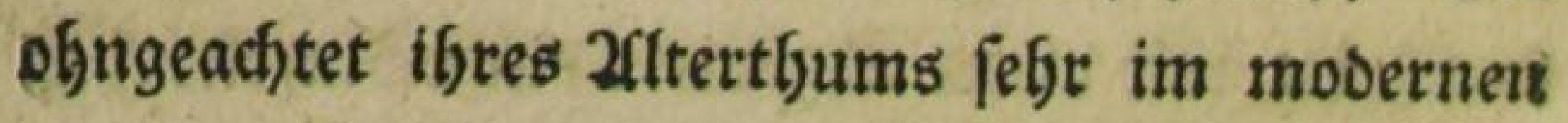
Siefchmact erbaut war.

(5r fragte mich) Darauf, of er mich in einen anféfnlichen ober woblfeilen (siafth of fúbren folle? sseil ich das lesętre verlangte, ging er felbft mit mit in einen fleinen (Safthof, und empfabl mich Dem guten 2fufnafgme. 


\section{(209)}

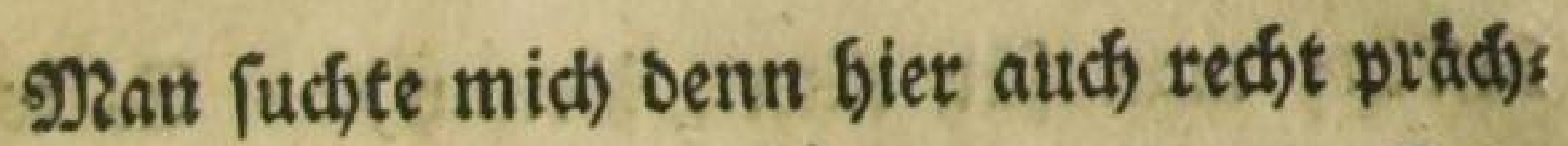
tig zu beroirtben, uno madjte mir zu Dem Ende einen Ráe toaft; Dieß r war am feuer gebratnet uno balbgefa)molzhner (Shefterfáfe, ber wobl ein recht delifates (sjeridjt fenn mag, wovon idf aber zum Unglưf feinen sifien effen fonnte, unb

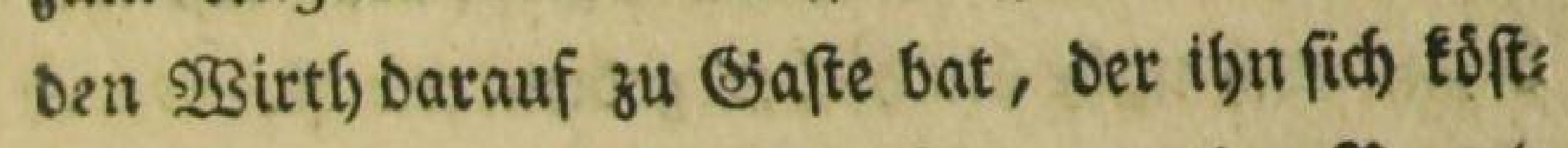
(iic) fojmecten ließs. 2fls id) nun weder \$rants weitt nod) afle trane, fagte er mir, id lebte viel

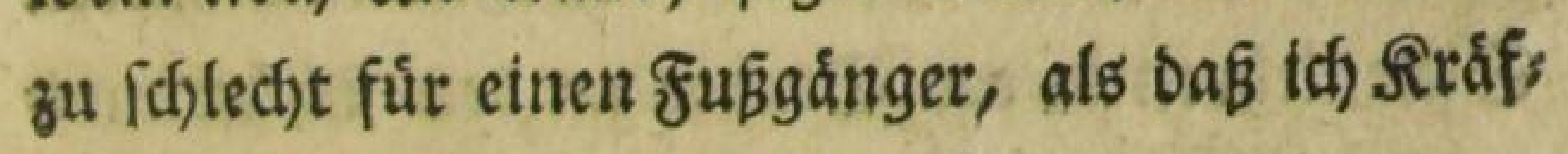
te genug zum Sieben bebalten fonnte.

Sei biefer (sielegenfeit bemerfe iah, Daßi es Die Englifhen Saftrirthe am 2lletrinfen roobl nidjt feblen laffen, uno bafjer alle von febr ftat: fer Qeibestonftitution, uno insbejonbre erftauns (id) bicf uns fett im Sieficht fino, Das ifjnen von ben vielen alle uno \$rantweintrinten ganz aufi geounfen ift.

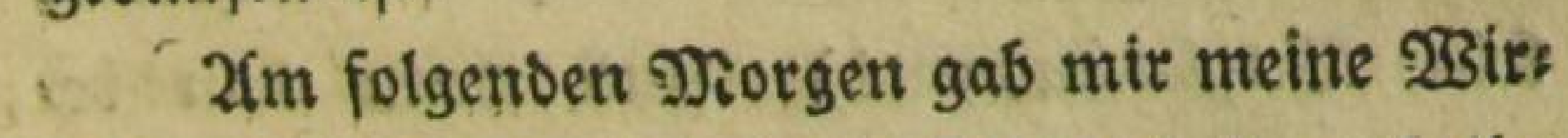
thinn bie (5f)re, mit mir Raffee zu trinfen, theilte

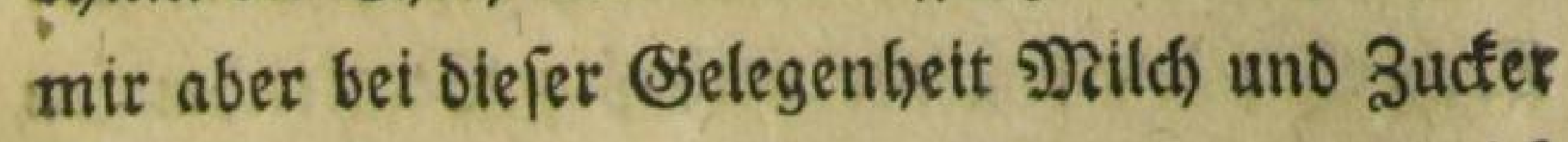
fefjr fárglich mit. (Es war Sonntag, uno id ging mit meinem 2 sitth bu einem S3arbier, an Deffen Soubeftano, Shaving for a Penny (allfier

$$
03
$$




\section{(iro)}

Bafbiett maan fúr cinen Denny). (56 forten bier viele (Cinnofiner aus bem Det verjammlet; biefe bielten midh fúv einen. Ssentleman wegen meitics feinen f̧uts, ven id, mit in gonbon fü: eine Guinee gefauft fatte; uno ben fie alle nad)

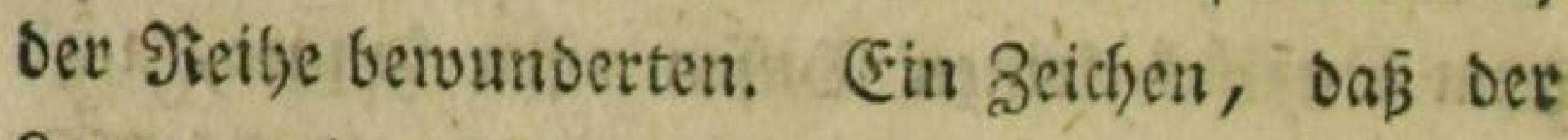
Eurtus nod) nidft bis bjeffer gebrungen iff. 3in פan, fintet in England ebenfalls bet gemeis nen Qeuten foldhe georudte $3 o g e n$ mit afferlei Eittenlegren in Den Etuben an ben Igúten ans gefhligen, wie bet uns. Nur findet man bice zunieifen auf foldsen foblechten Bogen bie vot: trefffichferen uno feinfen Sentiments, bie Dem beften moralijchen Schriftfelfer (shre machen เพx์tอen.

So las idf \&. S. Gier auf cinem folcten ges buucten Blatt an ber Stubentbur unter andert Die golone Piegel; Make no Comparifons! (madyt feine 2 Bergleidfungen!) Utn wenn man bea benft, wie viel asnfereien uno Unfeil in oer

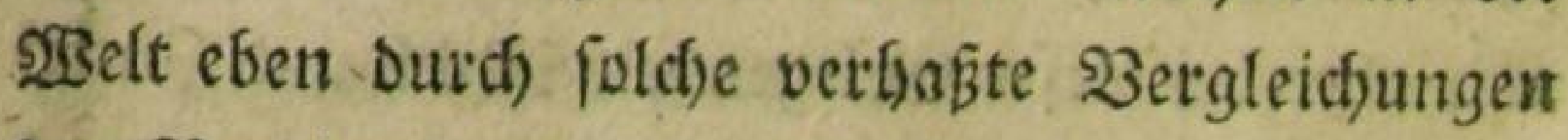

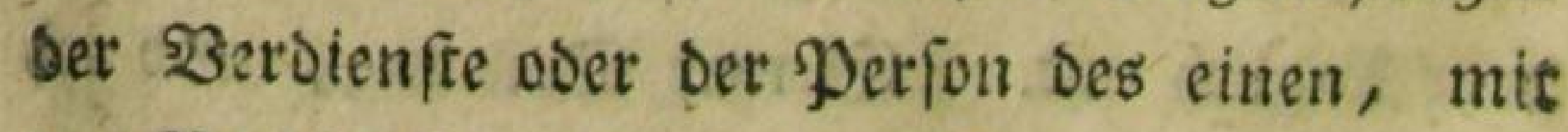
ben 2 erdienffen ober Der ЭJerfon Deธ anbern, $u$. f. w., entffégen; fo ift in Den furrefr sisorten der: 


\section{(121)}

bigen Fegel bie Gertichfte Sittenlebre zu[ants mengeorángt;

(Fin Mann, bem ich eitren Sirpence gab, benchte midf num aus der Stadt auf Den rechtert sseg nad) Eaftleton, Der neben einer foldsen S)rauer von unotdentlid) aufgervorfenen Steinen, wie id) fobon bejafrieben habe, bunging. Die galze Siegend war biet bergigt uno rauh, und Das (5roveich) mit brautren Seeideftaut bervadjfen. Şin unb wieder weibeten Edjafe.

$9 \mathrm{df}$ machte eire fleine Digreffion auf einen

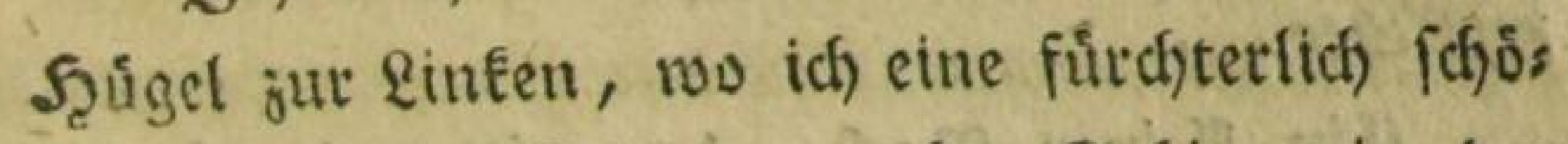
ne 2fusfid)t auf lauter nacte Sebirge in ber

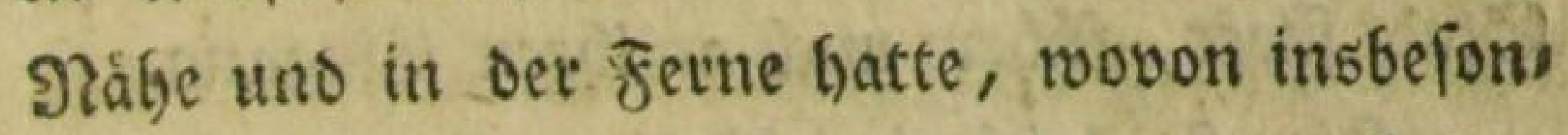
bee biejenigen, weldje ganz mit fdymatzen Seloe: fraut berwadjen waren, einen figaubervollen 2fnblict gaben.

Scunbert unb ftebenzig ग) Jeilen von Lonbon batte id) mun jutuicfgelegt, als tich eine ber fod d): fien 2(nthdben, bie vor mit lagen, exftiegen Gatte, uno mun auf einmal unter mir ein reigens

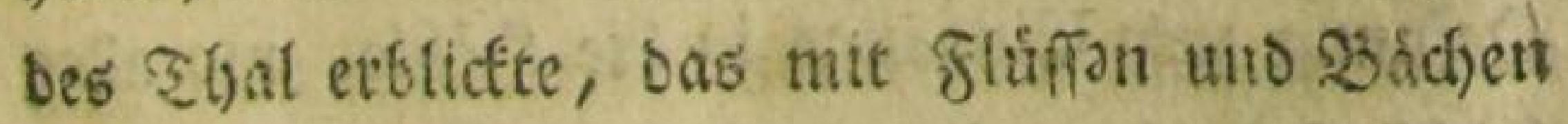
Durdichnitten, uno rumo umber von berget eitw.

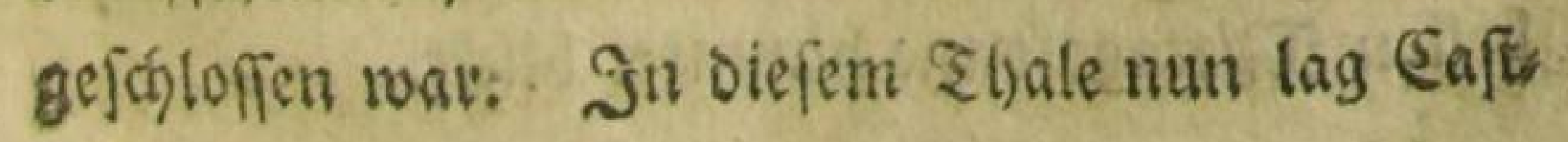

$$
\text { 2 } 4
$$




\section{(212)}

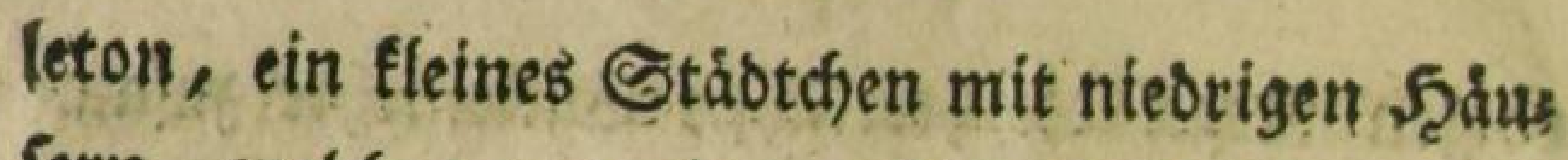
fern, reldides von einem alten Sdlofie, befien Fuinen bier nod) zu feben fino, feinen ఇabmen bat, Det eigentlich aus Caftle Town zu[ame mengerogen iff.

Ein fdymaler $25 e g$, Der fidf von ber Seite

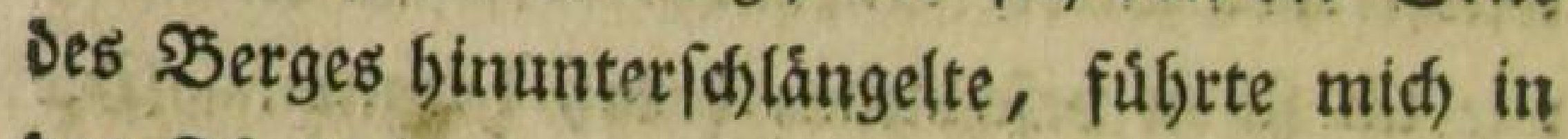

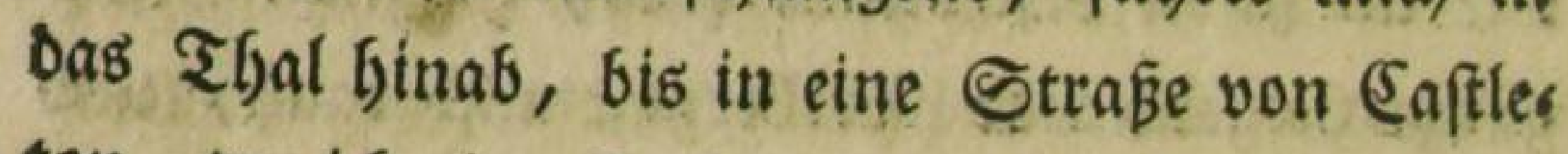
ton, wo idf eine Sererberge fand, in weldser ids gefchmind mein Dittagsmabl Gielt, uno unmits

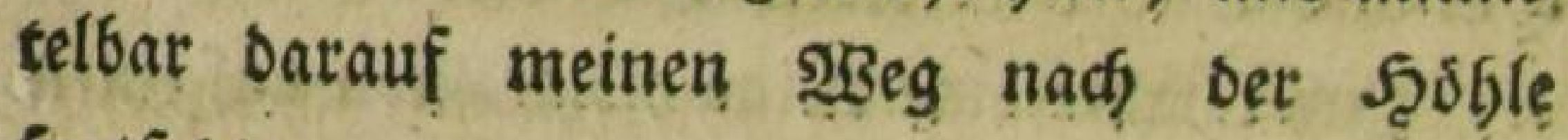
fortferęte,

Ein Eleiner $\mathfrak{b a c h}$, Der mitten ourch bie Stabt fliegrt, fübrte midh an ifren Eingang.

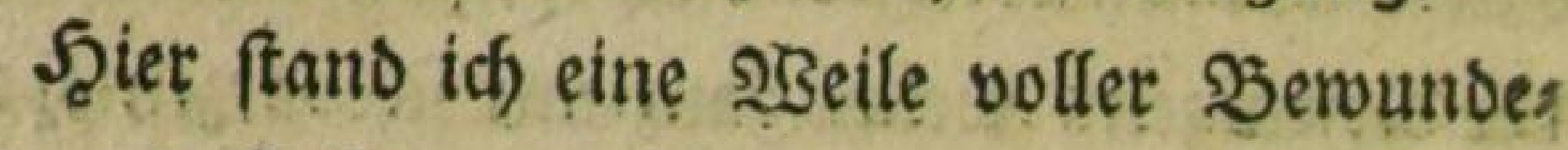

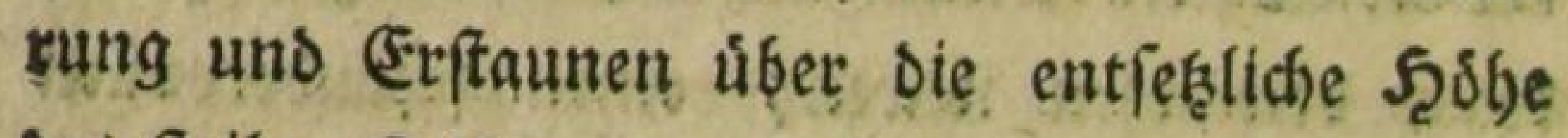
bes fteilen Serfen, ben idy yor mir etblicte, an Beiben Seiten mit grưnem (Bebülab berwach/en, Qben bie zerfallenen Mauern und Thúrme eine alten Gabloffes, das elgemals auf diefem Gelien fand, und unten an feinem Fube ole ungebeure Defnung zum Eingange in Die ŞSble, wo alles ftodfinfter ift, wenn man auf einmal von bey Bellen झittags fonne binunter bliạt. 


\section{(213)}

Sillem iff fo voll Berwounderung ba fano,

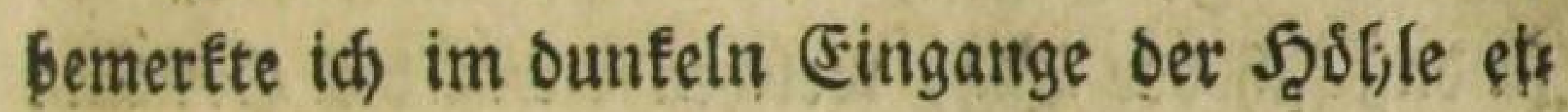
nen गann von wilben und rauthem 2 (n) fégen, Der mich fragte, ob ich die Şoble fehen wollte, wos

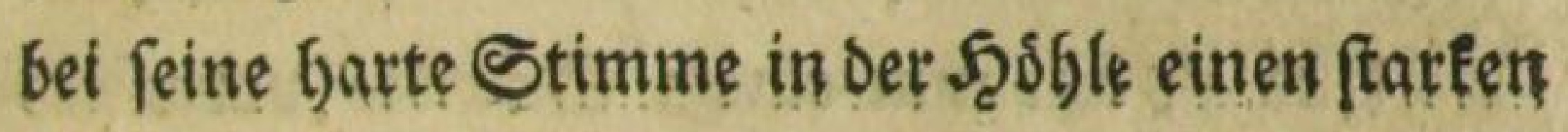
Wiedertidgall gab.

2fls idf) bieß bejabete, fragte er midh weiter, ob id) auch úber bie gluffe gefę̧t fenn mollte? uno beftimmte zugleid) eine ßleinigfeit an Sieloe, Die id) Dafúr bezablen múfiste.

Diefer গ) ftruppigten Şaar, uno fămuzigem zertịnen 2fns. zuge, ein fo milbes (5)aronșmásiges 2fnféten, meldbes feine Stimme uno feine fragen nod vermefreten, daß bie fonderbare Táficjungt

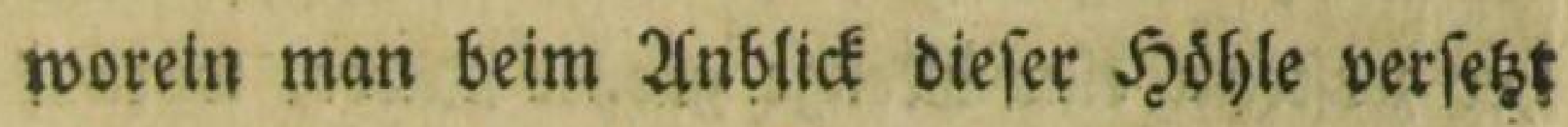
pirto, fojon bier ifgren 2fnfang nabm.

Da idh mich zu feiner forberung verftanden Gatte, fagte er, td) follte ilym uur oreiff folgen, uno wir traten zufammen in bie Şסfle.

Sur linfen Seite im Singange der Şófle, lag ein abgebautener Stamm eines Baumes, bef peldjem bie Rnaben bes Drts fpielten. -

\section{QS}




\section{(214)}

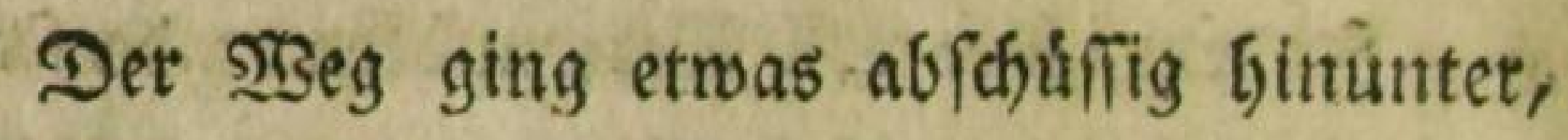

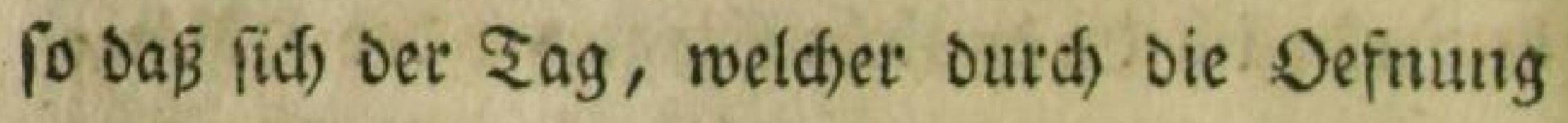
beim singange bineinfiel, allmálig in Dámmes rung verlot.

Uno als wir mun einige Schritte vorwairts gegangen waren, weld) ein 2(nblick war eธ füe midh, als id auf eiumal zu meiner red)ten Seite

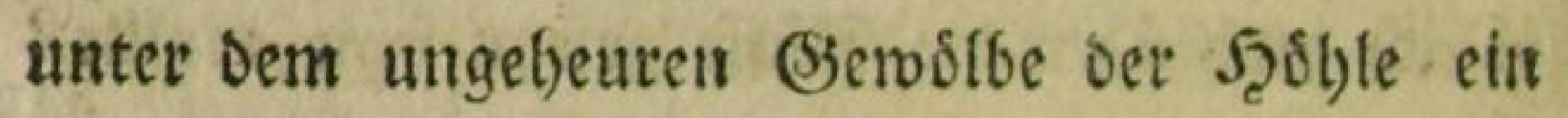
ganzes unteritroifches Dorf erblicte, wo bie Eimwobner, weil es Sonntag wat, von ifret aftbeit feierten, und vergnigt und froflicf mit its:

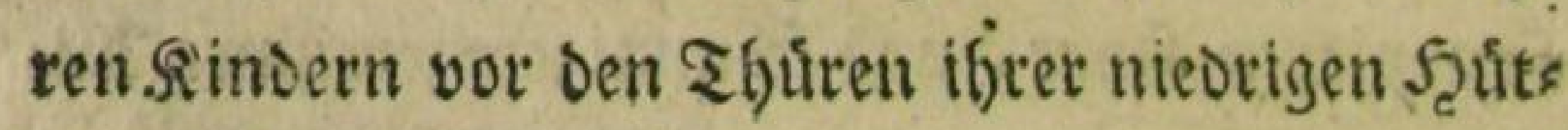
ten papen.

Saum Gatten wir diefe fleinen Şăufer hin: ter uns zuruidfgelaffen, fo erblictite ich bin uns her zerftreut eine झienge grof́er Sáber, worauf

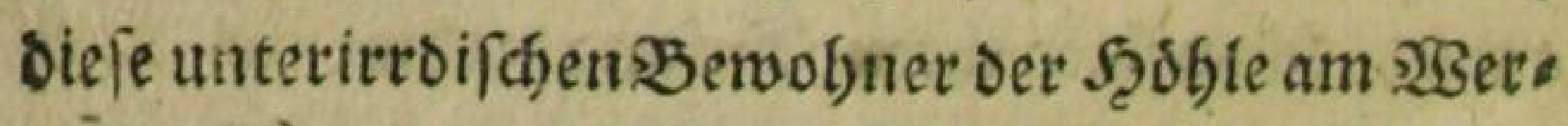
feitage Sèle verfertigen.

1. Эah glaubte bier bas भtad bes Jrion uno die unafborliche atrbeit der Danaiben zu peben.

So wie wir tiefer binabgingen, fefien bie Defnting, wobuth das Tagestidyt bineinfiel, fmmer fleiner zu merder, und die DunEelheit 


\section{(215)}

nafy faft mit jebem Scfritte gu, bis endich nue nocf einige Strablen, wie outch cine fleine Spalte bineinfielen, welche bie buinnen Siauds) wolfen fátbten, bie fid) butch bie Dadmmerung an Das Siendibe ber Sebjle emporwálgten.

Dies alfmálige 3unetrmen Der Dunfelfyeit etrocte eine fúse Jielancholie', indem man ben

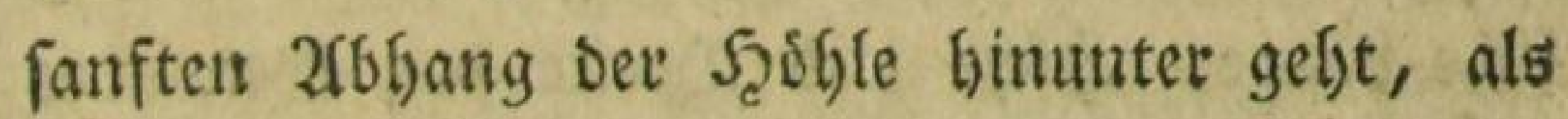
wáre of)ne S(b)mer faden abgefdinitten, uno wambelte man nun fo rubig bem ftiflen \&ande su, wo feine Duaat meljt iff. -

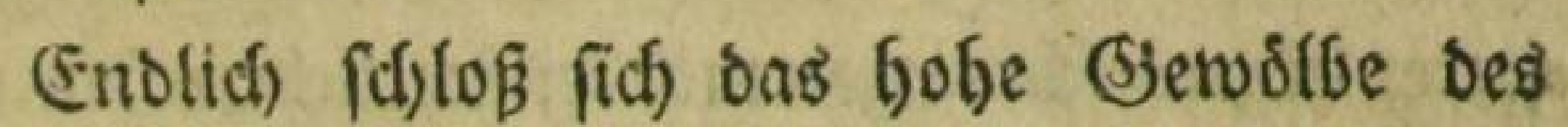
Selifen, wie fidf der Syimmel an bie (Erbe zu faslies. Ben fdjeint, als roit an eine fleine Syfoute fas men, two uns eine alte Trau aus einer. Der Şút: ten zwei \&icjter bradjte, wovon jeder van uns beiben eins in bie Scanb nalym.

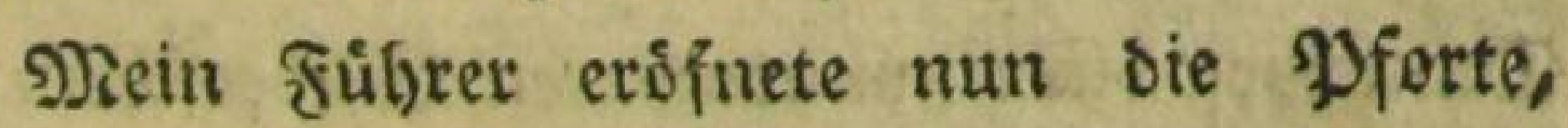
weldje bie fdiroache Dåmmerung volfends auss folofi, bie vorber noch librig war, und uns in Das Tanerfte biefes nádjtlidjen Tempels füfrte, Deffen ఇorbof wir bis jeşt nut betreten Gatten. 


\section{(216)}

Steter wat oer Felfen fo niebrig, Daßß wit uns einige Schritte ttef bucten mußten, um Gins Durdh zu fommen; abet wie grob roar mein (Frs ftaunen, ba wil uns nach olefem beflemmenden Durd)gange wieber in bie f̧ßhe ridjteten, und ich num auf einmal, to weit es bei bem ounfeln Edsein unfrer sichter moglich yoar, bie ent felss

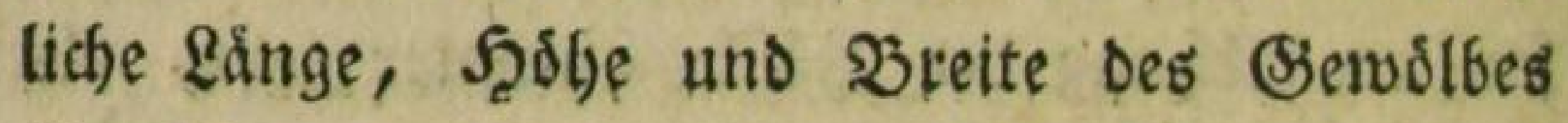
úberfeben fonnte, rogegen bie erfte ungebeure Defnung, Durch welche wir nun fdon getommen waren, gar nidht meltr in Setrachtung fam.

Nachbem wir hier eine ganze Stunde, rwie

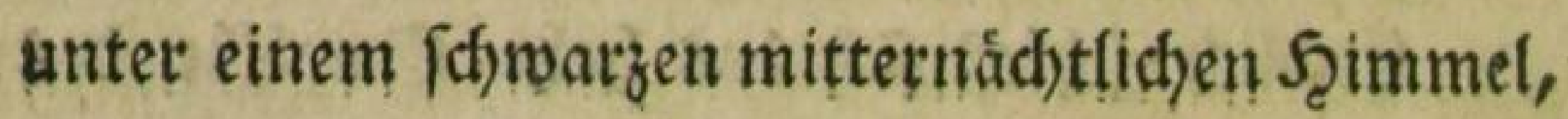
auf einem ebrten fanbigten (Erbreid) gerwanbert

- Gatten, fenfte fich enolich ber Jelien aflmálig noieber nieber, uno wir befanben uns auf eins mal an einem ziemlich) breiten Slufie, welcher, bei bem flimmern unfer gicfter, mitten in ber Dunkelfeit einen wunderbaren 2 Sieder/chein gab.

2fm Ufer wat ein fleiner Rafnn befeftigt, in weltjem Otrol lag.

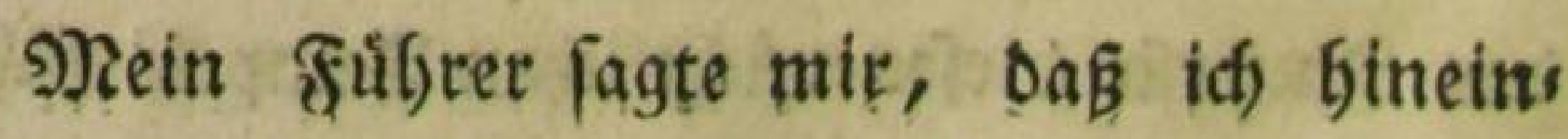
ftetgen, uno mid) ganz nusgeftrectt Darinn nie derlegen follte, weil in ber פoitte Des Fluf's 


\section{(217)}

fes ber gelfen beinabe das scaffer betuitren wuitro.

2fls id) midy niebergelegt batte, ftieg et felbft bis úber Den balben Leib ins 2 Saffer, uns 30g Das $300 t$ nad) fich.

Siund umber berrfdite eine feierlidje Toos tenftille, und fo wie bas $2300 t$ fortrúcte, fents te fidf) Der Selfen, wie eine ounfelgraue $\mathfrak{S B}_{\text {olfe }}$ tmmer tiefer nieber, bis er endid beinabe meit Eeficht berūbrte, uno ich im liegent faum noch

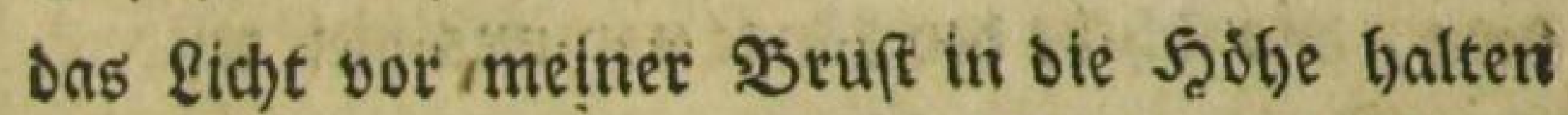
connte, fo dás idj in meinem Sojte, wie in eis nem beflommenen Sarge lag, bis wir burds biefe fúrchterlid)e (Enge famen, uno fich oer Fels fen auf ber andert Seite in bie J̧dhe zog, wo

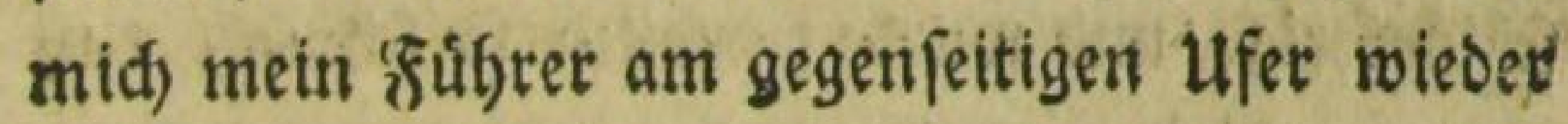
aus|êุte.

Unfer $53 e g$ wurde nun balo nuf einmal weit uno hod, und bann mieder plof̧̨lid nies orig unb enge.

2fn betben Seiten fahen wir im $30 r b e i g e s$ ben eine Menge grober und fleiner verffeinertes pflanzen und Tblere, bei benen trik uns abet. 


\section{(218)}

hid)t aufbalten burften, wenin wit nicht mely.

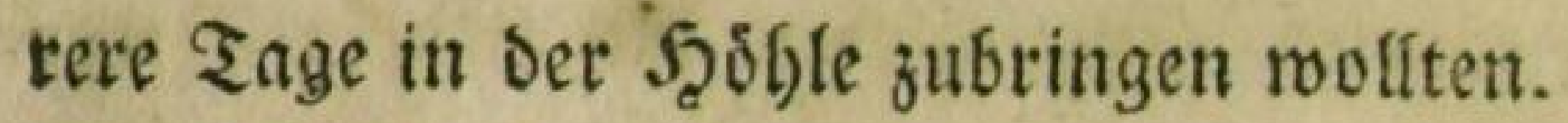

3. Itnd fo famen wir an ben zweiten Fluß, Der aber nicht fo beeit war, wie ber erfte, uno wo man gleich das gegenfeitige 1 tfer fehen forms te: úber biefen trug mich mein Trüfter auf feis nen Sdyultern Ginúber, weil fein Şoot jum Ueberfagren oa war.

3on Da aus gingen roir wenige Siffitte, als wir wieber an ein fobmales $2 B a ̈ f e r(b e n ~ f a s:$ men, Das fidf in ber Qänge vor uns bin etffrects

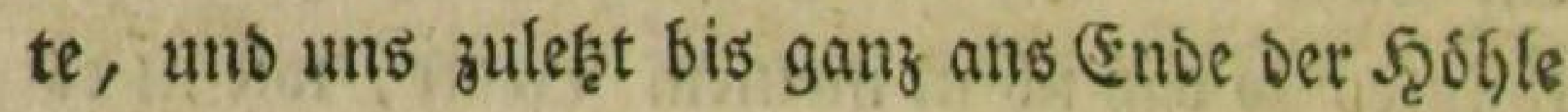
fúlgrte.

Det $\mathfrak{W}$ eg, ben wir långft bem $\mathcal{U}$ fer biefes

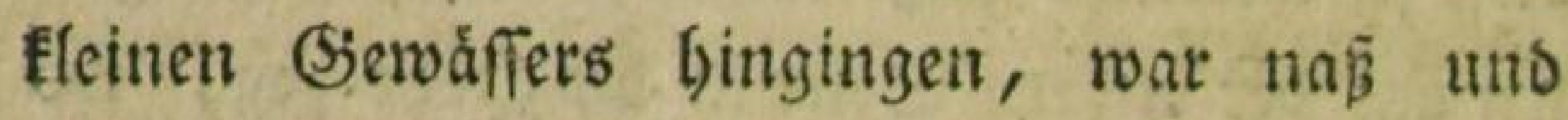
\{c) fúpferig, und rutbe zuveilen fo fotmal, Daß man faum einen Fuß bor bem anberu fortfef̧en fonute.

Demohngeadtet aber randerte ich mit $\mathfrak{B e t}$ : gingen an diejem unteritroifthen ufer bin, uns ergoffete mich an Der wunberbaren (Sictalt aflet Segenftadnoe um mich ber in Diejem sieldje Det Dunfelfeit unb bet Sdhatten, als es auf einmal yoie sine Dafuif yon fern in meine Dhten tonte. 


\section{(219)}

St) blieb yoller 2 erwunberting frebett, uno fragte meinen Fuifrer, was bieß bedeute? wor: auf er mir antroortete: Daß́ id) es bald feljen woiroe.

Iflein fo wie wir fortgingen, vertoren fich) Die Garmonifichen Tone, Das (Sjeráufel nutbe

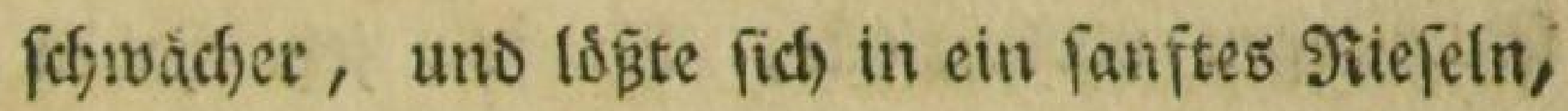
wie von berabjallenten Fegentropfen, auf.

Und wie groß̧ war meine Berrounberung, on id) auf einmal minflich einen Regen, obent aus einem Felfen, wie aus einer biffen sgolfe Gerabftrómen fahe, Deffen Tropfen, Die jef̧t im Schein unfrer sichter fiimmerten, eben

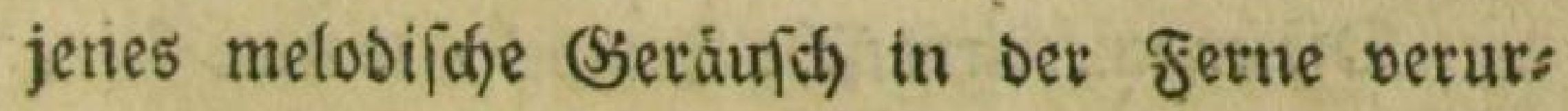
Factit batten.

Diés war nefgmlich ein Staubfad), bet fich yon oben burdh die 2loern des Felien in Dieß @ses mótbe binunter ergoj.

2Bir Durften mit unfern sidftern nicht ju nabe berangetien, weil fie leidht von Den herabs fallenden Tropfen founten ausgelofidt werben, und wir alsoann ben Firctweg viefleid)t vergebs (id) rúrben gefud)t Gaben. 


\section{(220)}

stsit fersten alfo unfern 2 seg lángft Dem Hter bes fogmalen Siewáffers fort, uno faben oft an ben Seiten folche weite Defnungen in bie

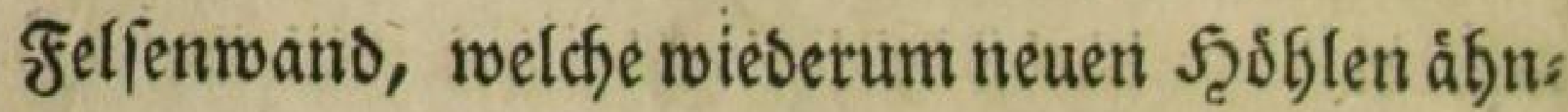
lich waren, oie wit abet alle vorbelgingen, bis mich metn Fúbrer fu einer ber prådftigften (Ft: foheinungen vorbereitete, bie wir jef̧, baben wứrbèti.

Und faum waren wir auch einige Şdyrttte gegangen, fo traten wir in einen majeftatifchen Tempel mit prádjtigen 20 ogen, oie auf fchonen Pfeilern rubten, weldje bie Şand des Eunttlidg. ften Saumeiffers gebildet fu haben fobien.

Diefer unterintotidbe Tempel, wotan feine Sienfchentario gelegt war, foten mir in bem 2lus

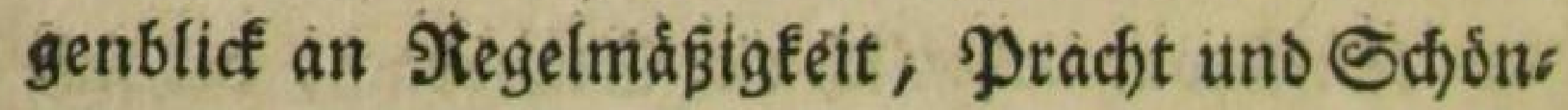
beit, oie berrlichften Gebåube zu ůbertreffen.

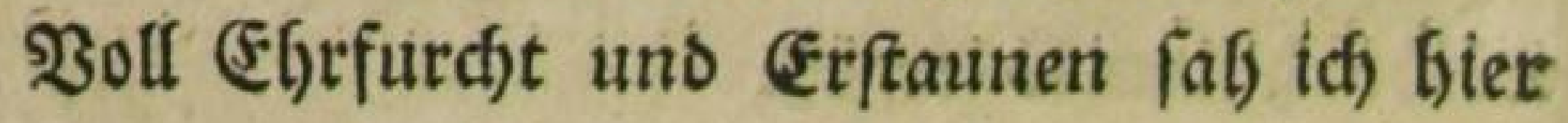
in Den innern Tiefen Der Natur bie গิajeftát Des Sdispfers enthúllt, bie ids in biefer feierlis chen Stifle, uno in biejem beiligen Dunfel ans betete, ehe id bie Şalle biejes Tempels verließs.

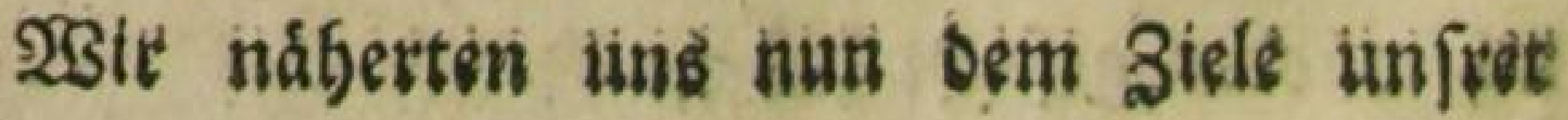
Relifer. 


\section{(221)}

Itnfer getrenes Sierwaffer leitete un outch Den úbrigen Theil der Sedfle bin, wo fid) Der Felien nod) zum leştennale wólbt, uns Damn wieber niederfteigt, bis er mit bet fluth zufammenfos̄öt, Die bier einen fleinen balben

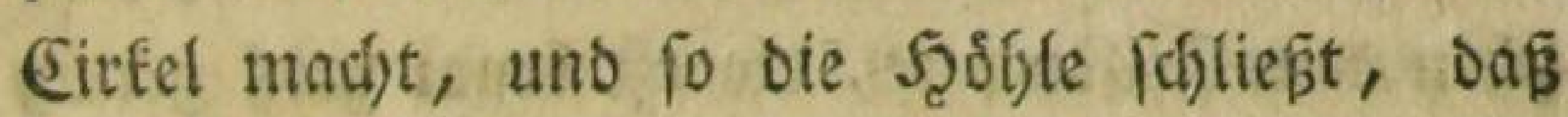
fein Sterblid)er einen ริน פ)ein Fufbret fprang fiet finein, fdyamm einige Gdyritte unter bem SGaffer uns Dem felfen fjin, uno fam ganz benef̧t zurúc, zum mir zuzeigen, ठаß ou fommen, wenn biejer Felien nidft etran ein: mal mit bulvet geiprengt, uns vielleicht eine grveite Şoble bier exdffinet wird.

Sef̧̧ glaubte ich, wưrben wir ben náchftent

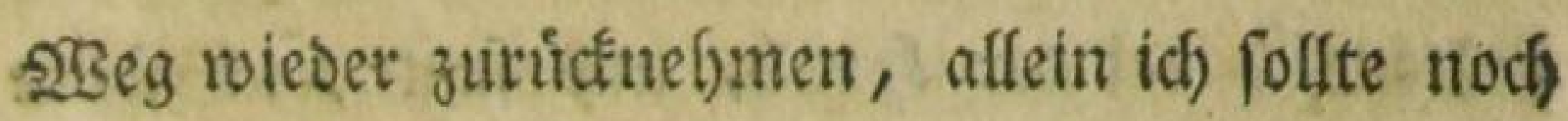
melye seiffrertichteiten erbulben, uno noch fojonere 2luftritte fehen, als bie bistherigen.

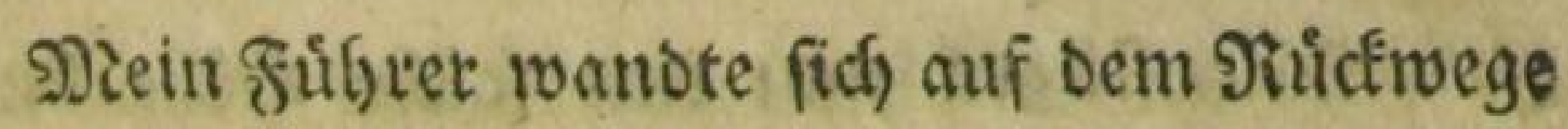

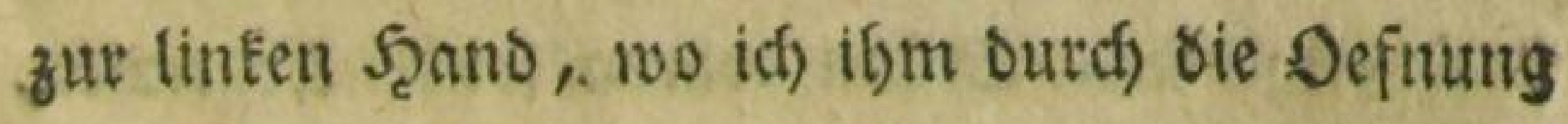
einer boben Felfenvano folgte.

Şiet fragte er mich erft, of id) mitch ents fohliefsen wollte, eine fiemliche Strecte unter sinem gelfen ourchzutriechen, der beinatge bie 


\section{( 222$)$}

erbe berůthte, unio als idf Dieß bejafyete, fagte

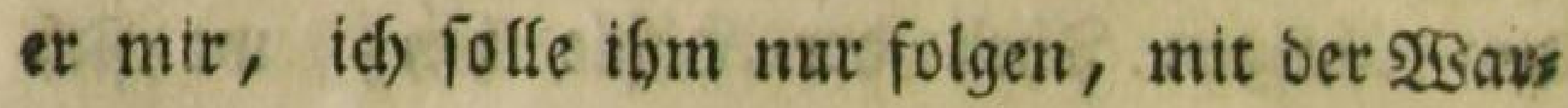

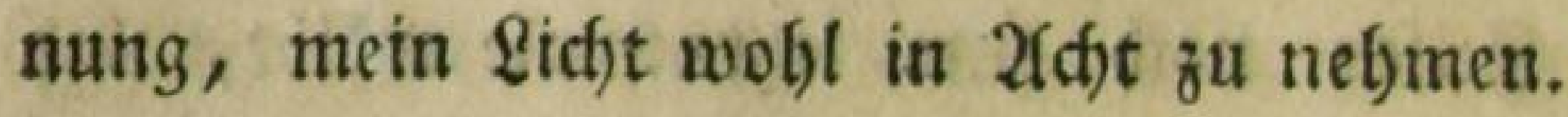

Uno fo frod)en wit nut auf Scanden uno Şißen im nafien Sanbe ourds bie Defnung zrots fchen bem Selfen fort, oie of taum grob genus mar, fid mit bem Rosper hinburdyzuminden.

2fls wir biejen befichnerlichen Durdymarid) volfendet lyatten, fabe ich in ber fedble einen fteilen Stuigel, Der fo boch war, Daß̧ er fich oben in ben hodjfen Felfen wie in einer 2 Bolfe zu ver: lieren fditer.

Diejer Schigel wat fo naß uno fdlúpfrig,

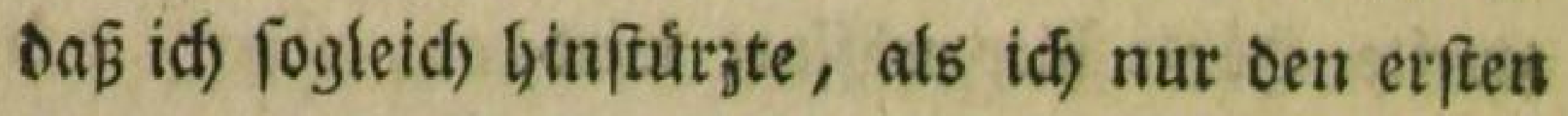
Sd)ritt binmif thun wollte. Mein Şúţer aber fafite midf bei ber Scant, uns fagte, id) follte

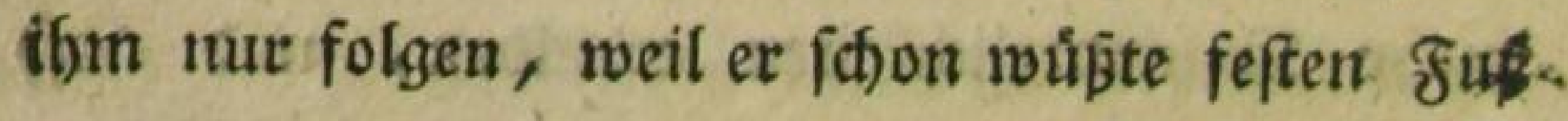
zu fafien.

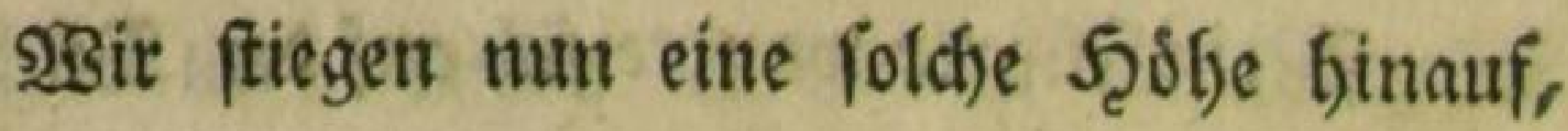
unb an beiber Seiten waren foldse 2ffogruinde, oaß̧ mir noch ichroindelt, wenn ich) Daran Denfe.

Zfls rir endlid) auf Dem ssipfel waren, wo fich Der Şúget in bem Felien verfiert, ftellte mid,

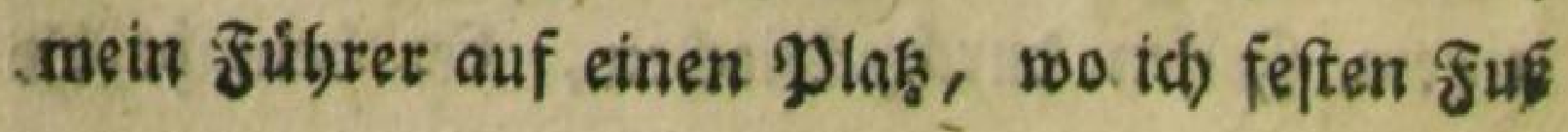




\section{(2) 223$)$}

faffen fonnte, uno fagte mir: id follte of nut ganz rubig fteben bleiben. Inbés gieng er felbft mit feinem \&ichte den Sçugel Gimunter, und fieß mich gant alleits.

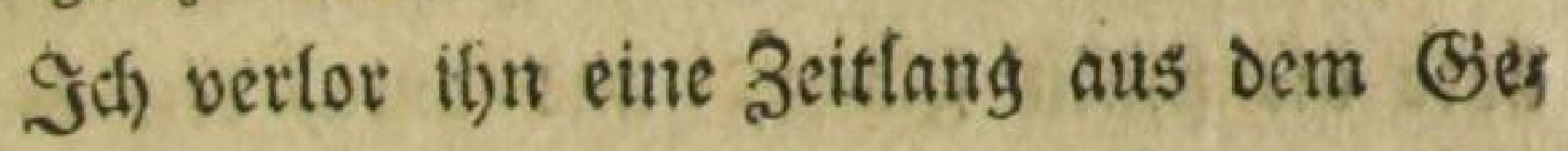
ficjte, bis id) enolidf nidjt ifju, fondern feit lidft tief im 2logrunde wiever erblictite, woraus eร wie ein fdobnet Stem emporzufteigen fóten.

Nacfoem ich mich eine $23 e i l e$ an biefen unte

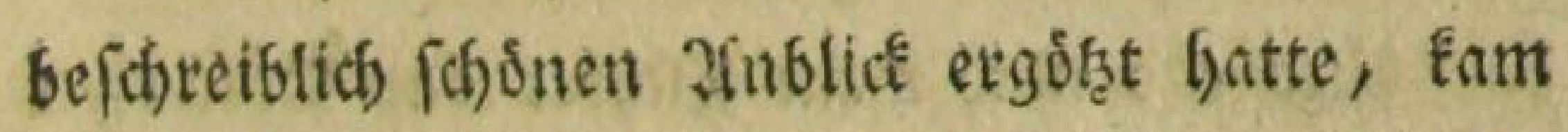
mein Fúbrer, uno brachtè midi) Den fteilen fósluppfrts

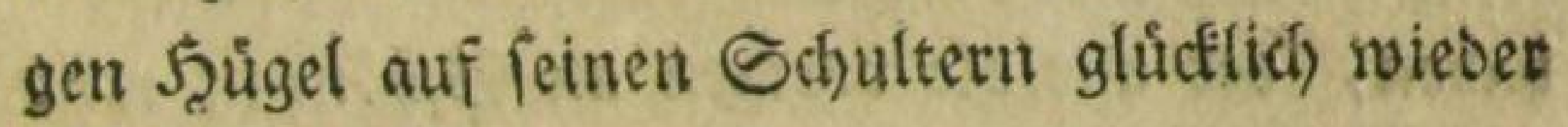
binunter. Und als idf) nun im 2agrunde fand, frieg er binauf, uno liés fein licht oben burd) eine fleine Defiung in Dem Felien binunteridsims mern, inder id Das meinige mit ber frand ver Decte, uno mun war es, als of in ounfler P) ternad)t, Dutch bicfe 250 (Eent ein Stern Ginune ter glanzte: ein zanslick, Der aller an Edjóngeit úbertzaf, was tid) gefeljen hatte.

Nun war unlte Sieife ganz volfendet, uns

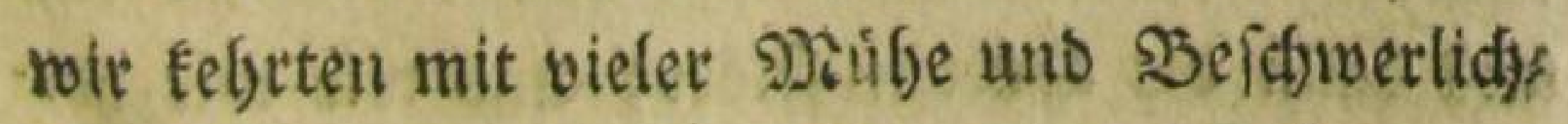
feit Durch unjern engen $25 e g$ wieder futúck. 


\section{(224)}

95ir betraten aufs neue ben Tempel, ben wir vor furjem verlafien batten; bosten aufs weue den Siegengus, lanft riejelno in Der Nåtje, und melodif̧ tônend in ber Ferne, und febrtert ůber bie ftillen flüffe, uno burd) ben weitent

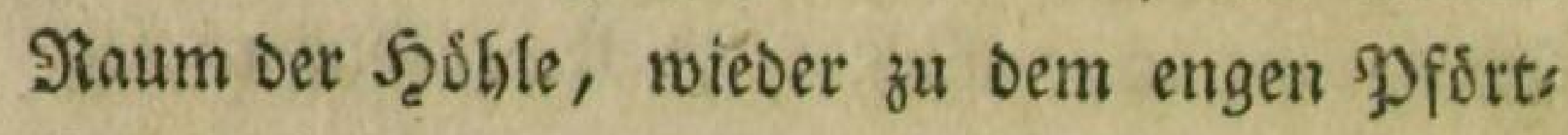
(t)en jutuick, wo wit vortber vom Tageslidfte 2ibs fd)ied nat)men, bas wir nun nad) einer langen DunEelfeit mieder begrufígten.

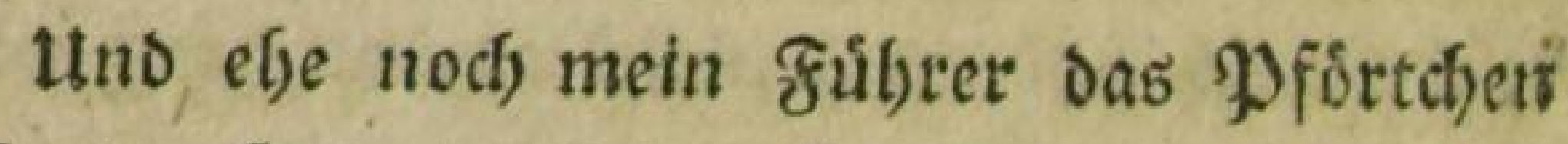
erofffnete, fagte er, jeçt mútoe ich einen In habell, ber alle bie vorigen an Shobntyeit weit

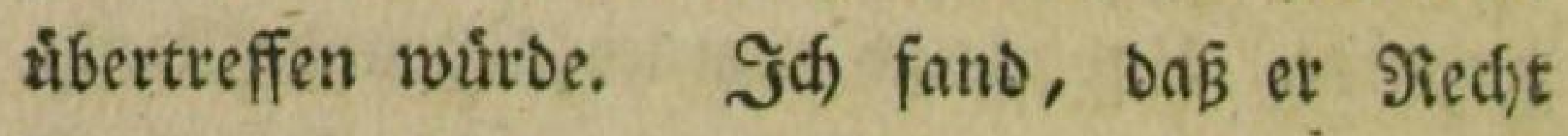
batte; Denu indem er bie Pforte erfit balb erofffs nete, war es mitr roirflich), als thăte ich einen \$blice in Elyfium, in einem folchen runberbaren ex: quictenden Dámmerlichte zeigten fich alle (Sies genfíndec.

Der' $a g$ fóten allmálig alzubrecten, uns Nacht und Dunfel fidwanden. In Der Ferne fabe man zuerft wieder Den Siauch Der feutten, uno Dann die f̧uttten felber; uno wie wir hod: ber binauffitegen, faben roir noch die Snaben bei bem abgehauenen Stamme fpielén, bis ends 


\section{(225)}

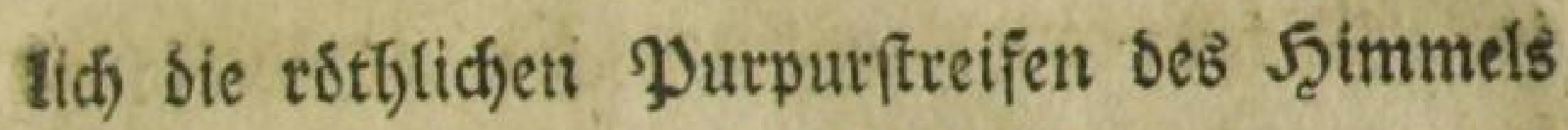
Dutid bie Defmung oet Scoble fdimmerten, und getabe indem wir finaugftiegen, bie Sonne im 23eften unterfank.

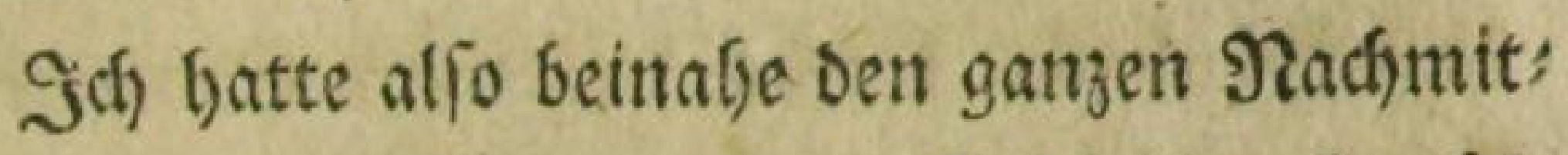
tag bis an Den 2lbento in ber Scolgle zugebrad)t, und als idf midh num betradytete, fabe id) in

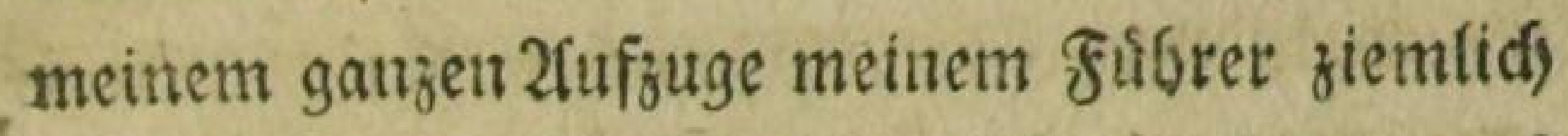
åfnlid), uno meine Sdful) bingen faum noch an ben Suffen, fo felge waren fie burds das lange Sbeljen im feuchten Sande und auf ben barten fpiß̨igen Steinen etweid)t und zerrifien.

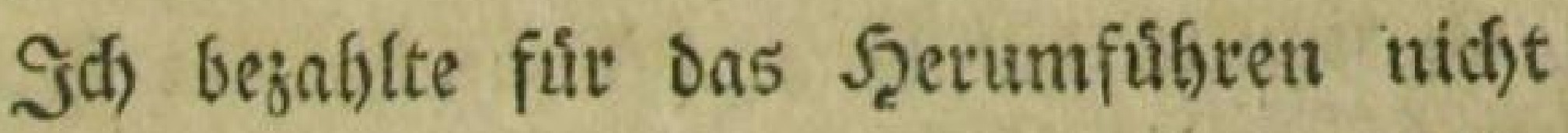
melje als eine halbe Rrone, uno meinem Sulth: rer ein Trinfgeld: Denn bie balbe Sirone befómmt er nicht, fonbern mus fie feinem Şetrn gebent,

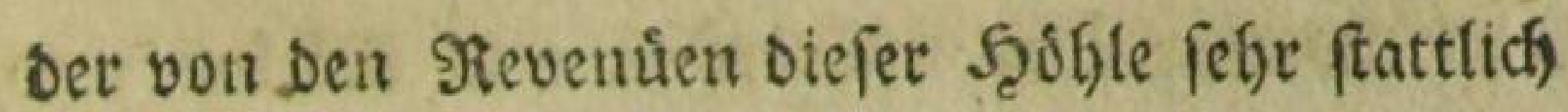
lebt, uno fid einen Rert Gált, ber oie Reute Dartiun berumfút)rt.

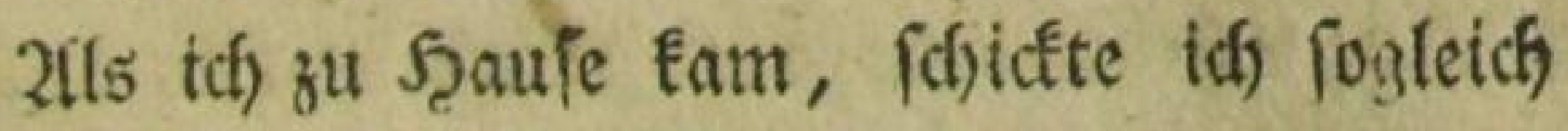
nad) einem Sd)ufter. Diefer wofnte getabe ges genúber, uno fam, um meine Silsulg in 2lugen: fdein zu nelgmen, robel er fidh nicht ghug úber bie fojlechte 2fibeit baran verwunbern fornte; 


\section{( 226$)$}

Denn iff Gatte biefe Sdfuly nod) aus Deut [thlant mitgefradit. Demolngeadftet aber, weil er ges rnde Eeine neuen fertig hatte, unternabm et es, fie fo gut rie mogglid auszubeffern.

Id machte Darauf mit diejem Sdfufter eine gat angenebme Setanntidgaft: Denn als iff ifm

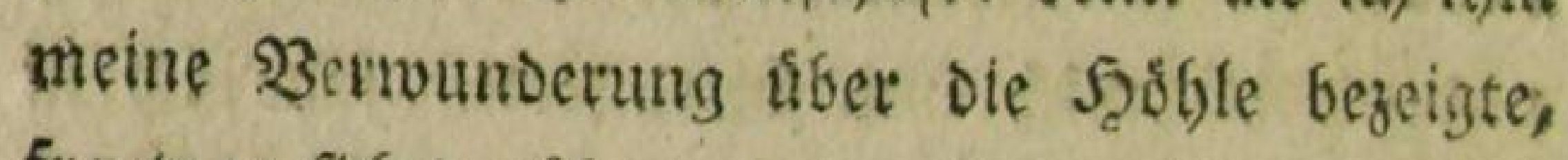
freute er fich) Daráber, Daß̧ Doch in biefem fleinen

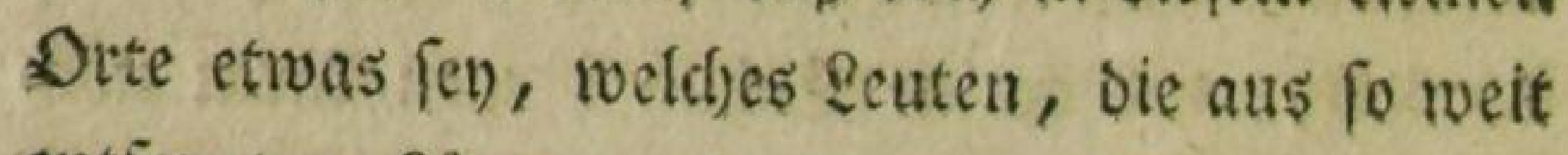
entfernten \&ånbern bertamen, Benvunderung einflópte. Utho Darauf erbot er fidd felbft, noch einen fleinen Epaziergang mit mir zu mad)ert,

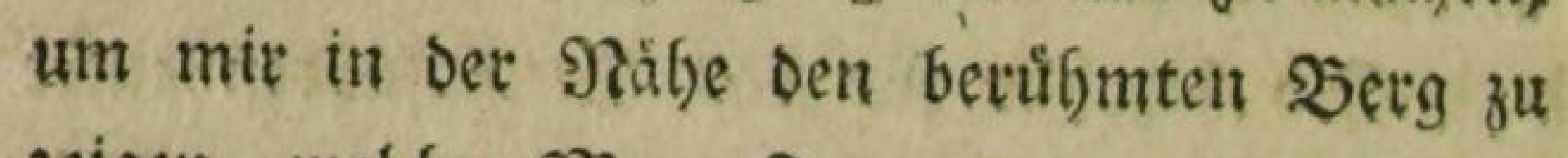
zeigen, weldser Maam For gethannt, uno unter Die Maturmerffrutrdigêtiten in Darbufdoite ges zắlరlt wiro.

Diefer serg iff auf feinem girden uno Seiten gruin berwadben, aflein an bem einetr

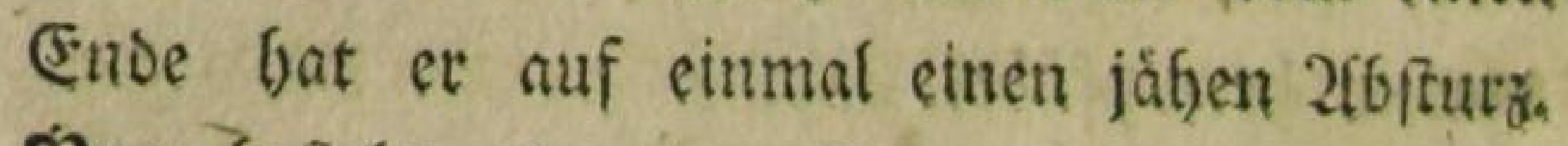

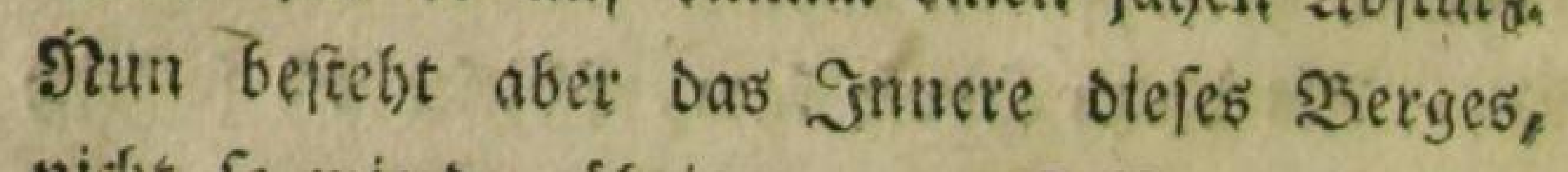
nisflt to wie ber übrigen, aus felfen, fonbern aus einer foctern (side, die fid) immer von felber

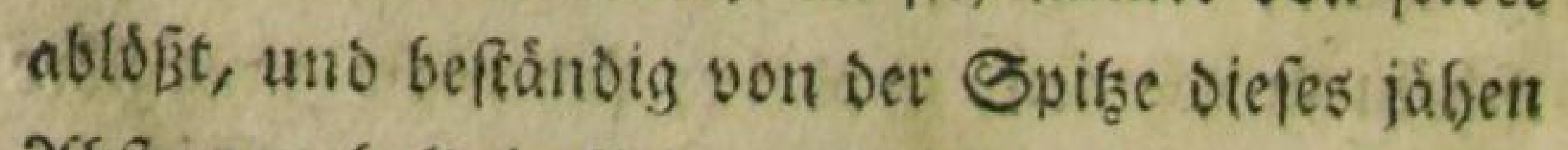
2fofturges bals in fleinen Stúden beruutertiefelt, 


\section{(227)}

Gald fich in geopen Tafien mit einem bonneen Den Sietoje losteibt, und auj die şseife neben. Diefem Serge eitren STugel bilbet, Der immer Gobler anwådhif.

Daber fosmmt auch wabrffheintich Der शab: me Dramtor, weldjer ofngefälyr fo viel jagen will, als गitterberg. Denn tor ift eine

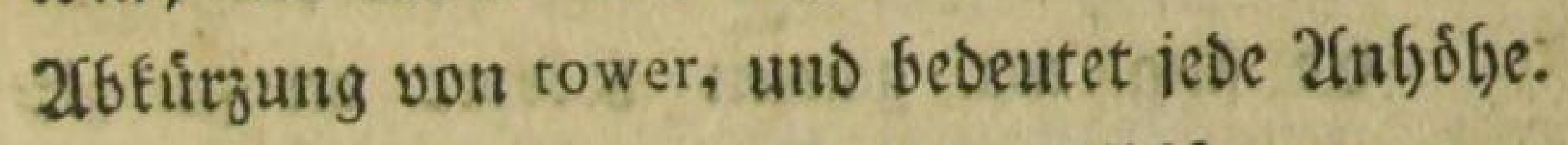
Mam aber ift cine genofbntiche 2tbefurzung vou Mother, Neutter; nun aber gebiert Diejer \$erg gleidfarm wie cine Nitter wieder fleine \$erge.

(sin 2fberglaube ift es wobl, wenn bie (sin:

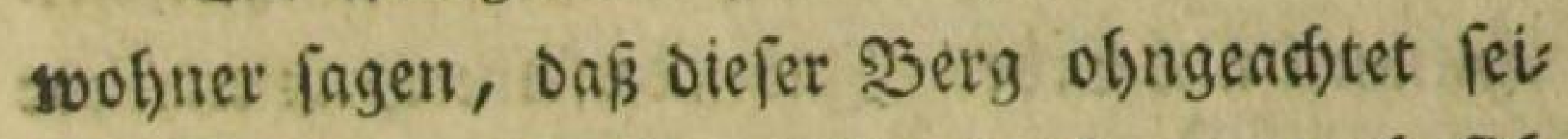
mes täglidgen Berluftes rie abnebme, nod) fid zuruidziebe, fondern immer fo bleibe, wie sorber.

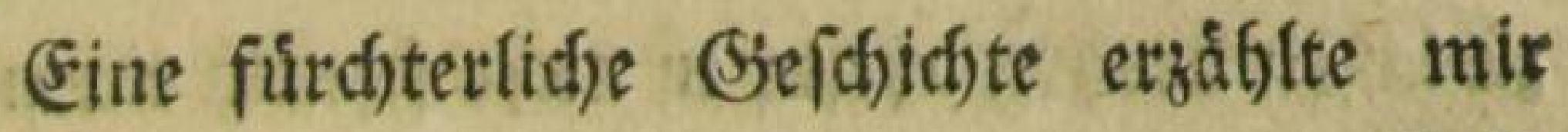
mein \$̇egleiter, von einem (Sinwol)ner von Eafts feton, Der eine $\mathfrak{W}_{3 e t t e}$ einging, dieien jäben $2 \mathfrak{b}_{6}$ ftur'; binaufălteizen.

2 geil ber 2fofury unten nidft fo gans

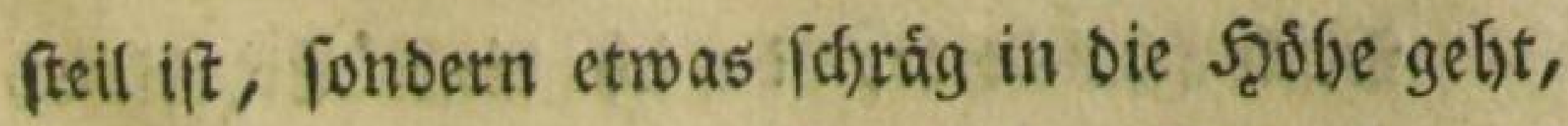
fo fonnte er in bem weidhen lofen (Froteiche gut feften Sus faffen, uno Eletterte immer Ssinan,

$$
\text { P } 4
$$




\section{( 228$)$}

ofine. fith umzufégen. (5nolich war et weit hibet Die Şálfte finaufgeftiegen, und fam babin, wo fich ber albftur bituiberneigt, nno feine cigne

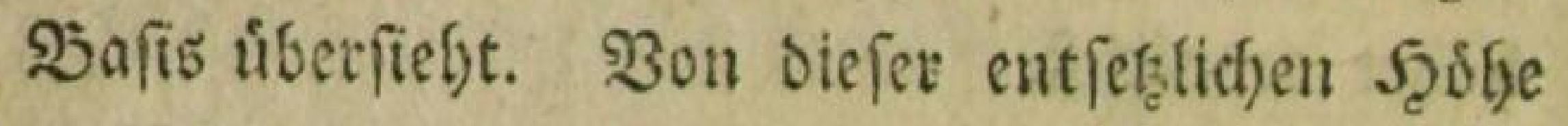
warf ber Itnglúcflidye leine 2fugen finunter, ins Dés die brobende Spifze bes 2fofutzes mit mam fenden Eromaffen ufber feinem Scaupte Ging.

Ert fing am ganzen Siorper an zu zits

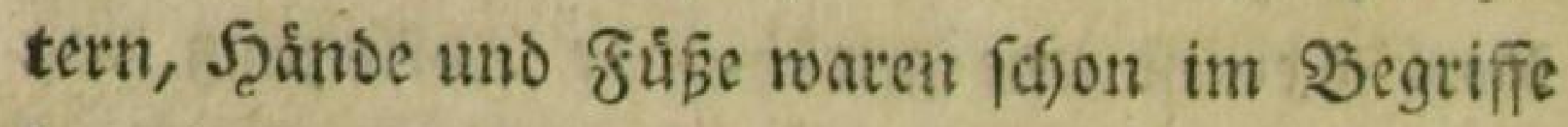
losgulafiẹn, uns er wagte es, weder sormátts

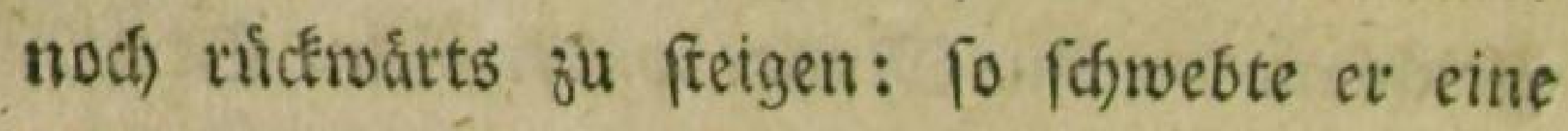
2S3eile mit Betziveifung umgeben, zrifichen

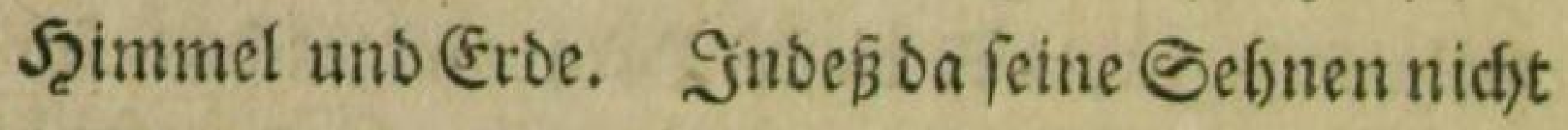
mebre balten wollten, raffte er nody einmal alle feine Sraffte Jufammen, uno ergriff einen lofen Stein nadi bem andern, wovon jeder ifn fallen zu laffen orobte, wein er nicht fofnefl einen ans Dern ergriff, auf welche SBeife er benn zu feiner uno aller Bufiffauer 3errounderung, Dem beinate

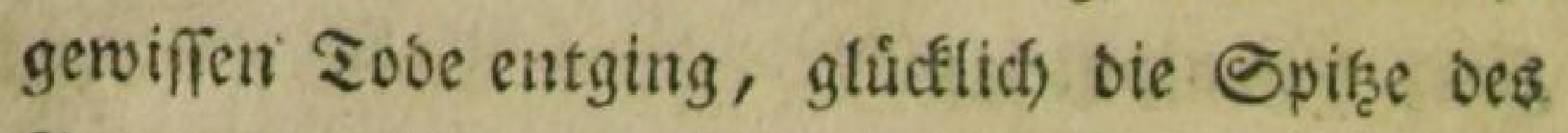

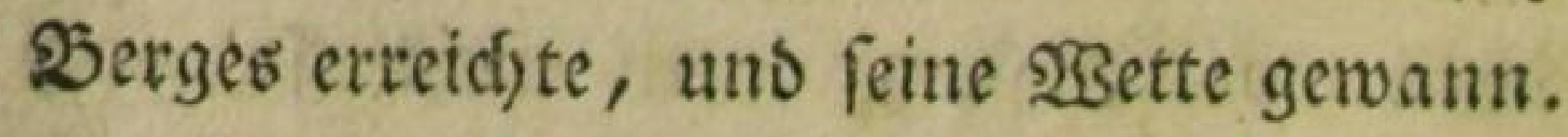

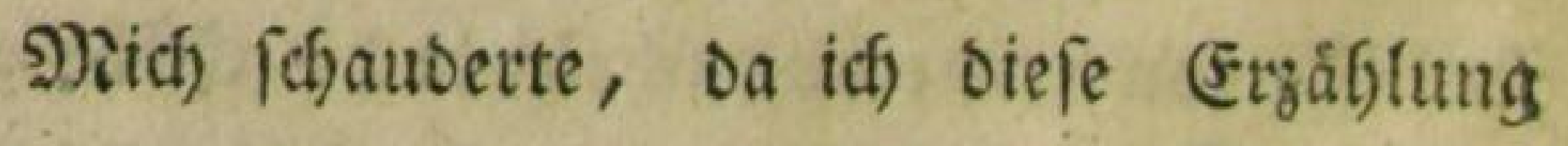
borte, unb Den Serg uno Den ungetseuren 216 : frutz, rovon die Rede wat, felfif fo nabe vot 


\section{$(229)$}

mit, und bett Siert in Siebanfen binanflet tern false.

Sicht weit von bier if Eld entgole, ein färchterfidjes god) in ber (5rbe, von to unges heurer Siefe, baß̈ went man einen Sieferffein Lineinnirft, und Das Dfr an ben Siand legt, man benfetben lange Beit fallen fort.

Sobalo bet Stein binuntertommt, ifts, nls ob man einen feufzenden \&aut borte, bis Der etfte Echlag bas obr wie ein unterirrbis fher Donner rúbrt. Diefes Donnernde Sjetsíe nimmt ab uno ju, nachsem ber Stein an bie Latten Selfenwainde fhlágt, und endtich nadjs Dem er lange gefallen ifi, Gort plof̧lich das esee tofe mit einem (Siejifich auf.

Das Bolf traigt fich audh bietvon mit allets

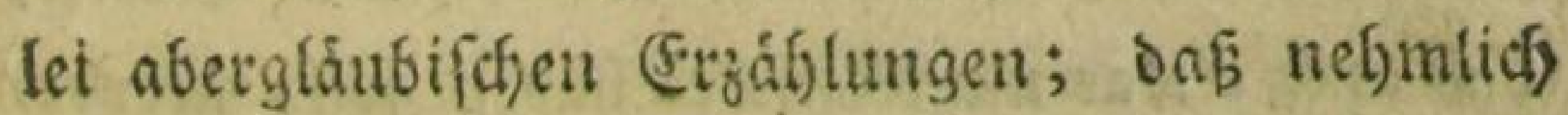
einet eine Bians hineingerworfen babe, bie froet Sceilen bavon, in ber grofien Stoble, bie ic befdyrieben babe, gauz nact uno von fredert entblis ist rieder bervorgetommen ley, und mefse Dergleidjen száburdyen.

गुร 5 


\section{(230)}

Cigentlid) jåălt man in Dortbyldsite fieben

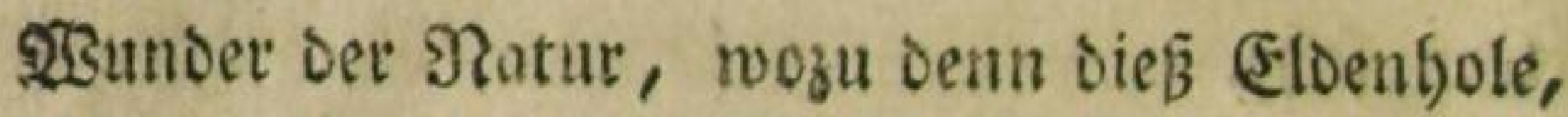

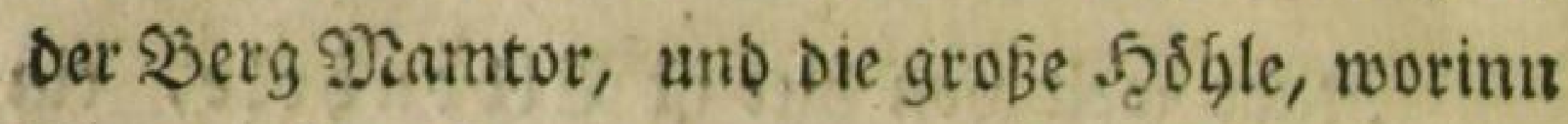
id) gewejen bin, gehofen. Dieje Scifhle wirt

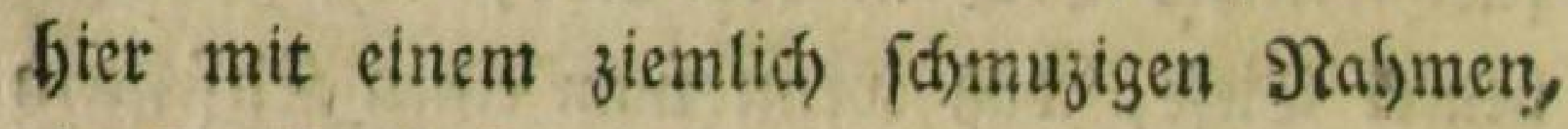
the Devils Arfe, benannt.

Die úbrigen vier $2 B$ under ber গatur find bie \oolshofle, melche mit ber meinigen ei= nige 2felynlidsteit hat, bie id, aber nidjt gejelen Gabe: ferner St, Inna's well, oder ber St. Znnenbrunnen, wo bitht nebeneinander jroet Quellen, die eine fiedent heir und die andre eis: falt, entipringen; alsbaun nod) Tibeswell, nicht weit von ber Staot, Durdh welche ich getoms men bin, eine Suelle, bie fich Die mebreite Seit faft ganz unmertlich ergiefst, uno bann auf eins mal mit einem ftarfen unteritroifden Setofe, - Das aud etroas mufifalifhes faben foll, hervors briab), uno there Ufer úberid)wemmt; endich (E) at froorth, ein Dallaft am Fus eines Der: ges, Der oben mit Sdfnee bedectt ift, uno ben traurigften $\mathfrak{B}$ sinter Darftellt, indeß̧ zu feinen

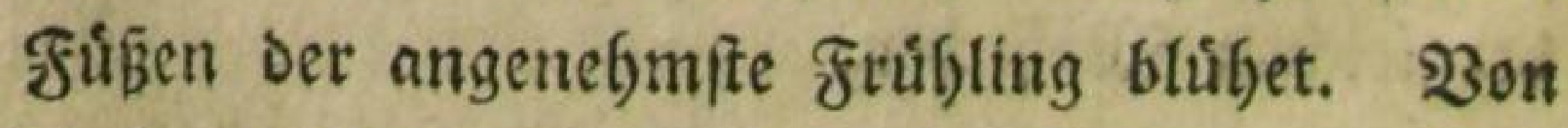

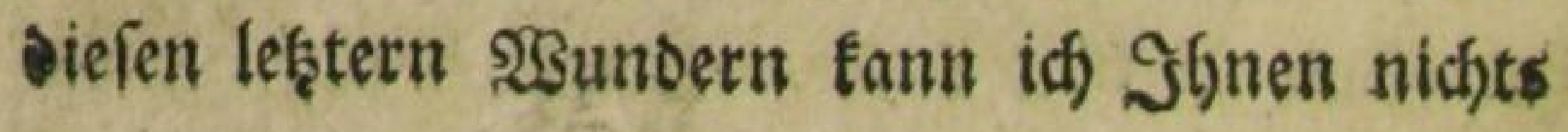




\section{(231)}

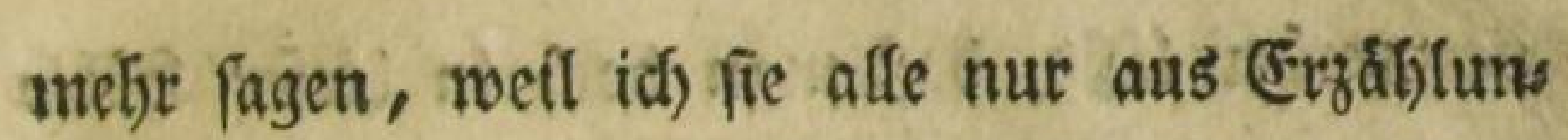
gen fenne, womit midh theils aud) mein Begleitet Det Sd)ufer, wábrend unjers Spazierganges unterfielt.

S̄ndem mid) biefer Siann Gier Gerumfúfyr: te, unb erwágte, wie weit id) mun fobon in ber sgeft getommen fen, und was fur wunberbare Dinge ich weit uno breit ju fefen betomme, ers regte biés bei ifm eine fo lebrafte Begierde zum Sieifen, Daß ith genug ou thun Gatte, fie then wieber ausaureden: Dent ex Eomte den ganzen flgent nid)t davon aufgoren, und betheuerte,

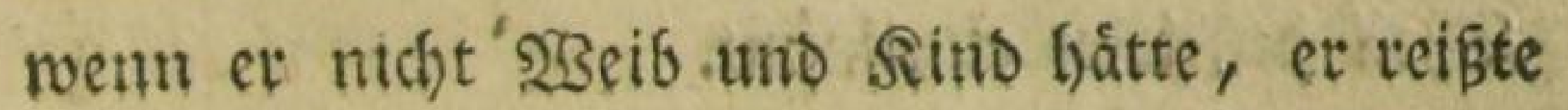
Siorgen in sage fort; bent bier in Cafteton fery fo nidft viel zu verdienen, und fefre faledite

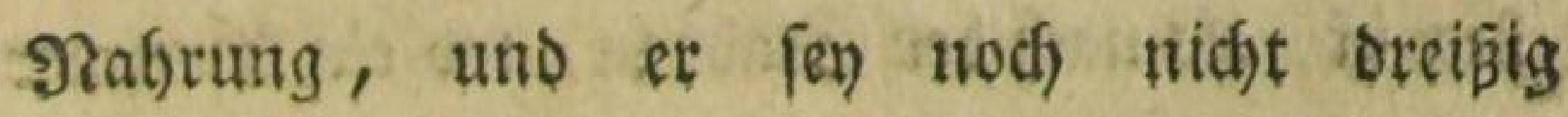
Jatge alt.

2luf Dem sildivege wollte er mir noch die S3leiminen zeigen, allein es mar fdyon fu fpat. Er fellte mir ben afbend nod) meine Sthuf) auf seine meifterbafte 2frt wieber hor.

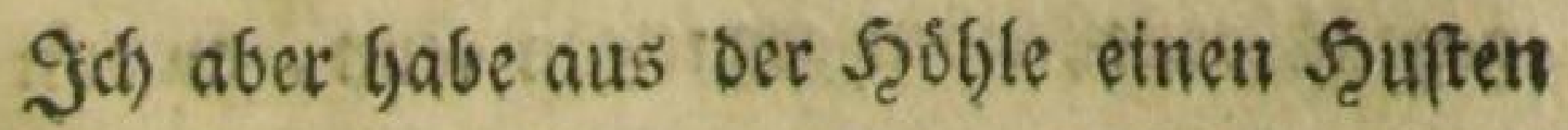
mitgebradjt, oer mir gar nidjt gefálft, uns mie viel Sejdprerlidfeit verurfadst, welche midj 


\section{(232)}

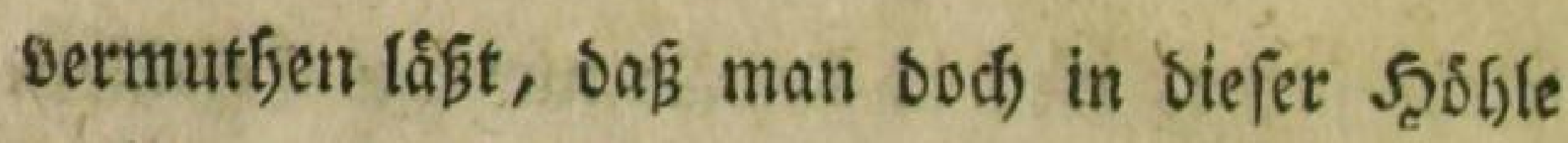
wobl ungefunbe Dámpfe einatfmen múfie, abet benn begreife ith nut ntdt, wie bet (shaton es fo lange aushalten fann.

Seute Miorgen bin id folon fríh aufgeftan: Den, un die Stuinen zu befelgen, und einen bas nebentiegenden feftr boben serg zu befteigen.

Die Siumen ftelen gerabe liber Dem Ein: gange ber fejble auf Dem Scügel, Der fić) noch weit binter den Siuinen ůber die ScdGle hin et: ftrect, uno immer breiter wotro, fier vorn aber fo

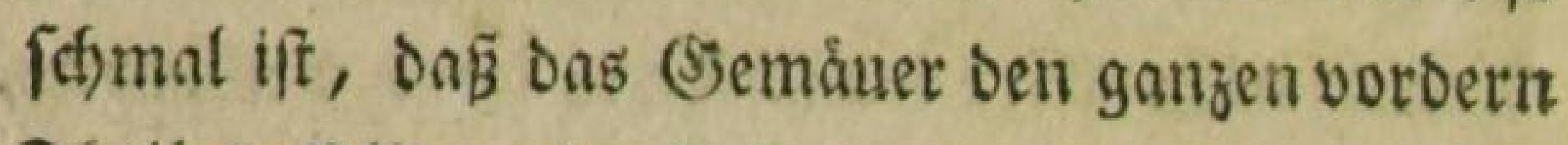
Ibeil beffelben einnimmt.

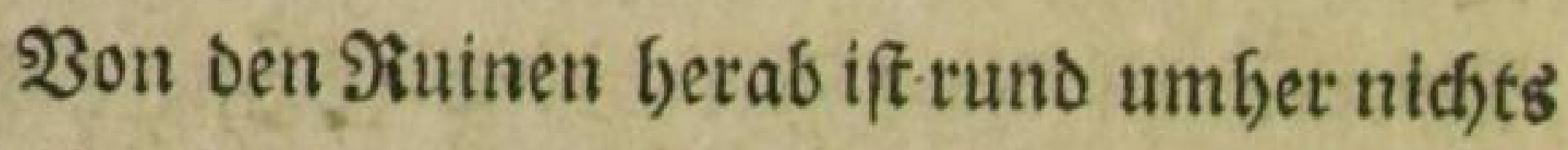
als fteiler Felien, fo dấ fein Zugang zu demielo ben ift, als nach ber Stabt zu, wo ein frummer

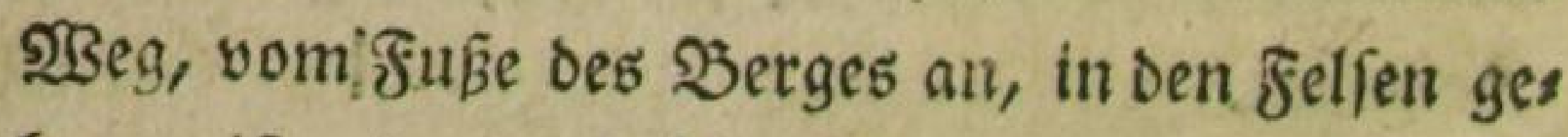
bauen ift, Der auth febt fteil binaufgebt.

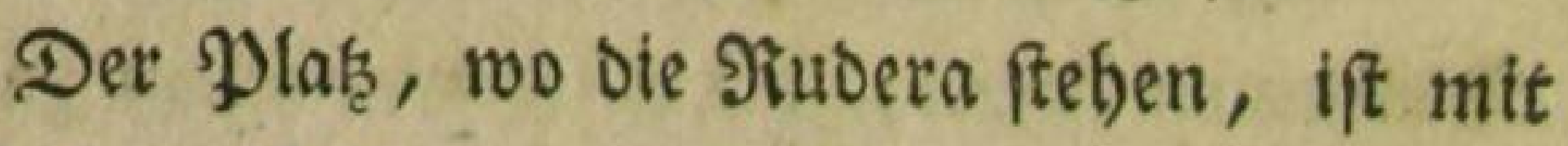
febr holjen Neffeln und Difteln berwachien. (5hes mals foll eine Sruicke von einem felfen zu ben gegemúberfretgenten gegangen fevn, wovon man noch Epuren entoect, indem man in Dem Thale, Das die beiden, Felfenfpişen trennt, 


\section{(233)}

Die tteberbleibfel von $230 g e n$ findet, auf weldsen Diefe sructe geruft baben foll.

Diejes Thal weldfes finter ben Stutnen bed findlich ift, und rabridjeinlid, oben uber bet

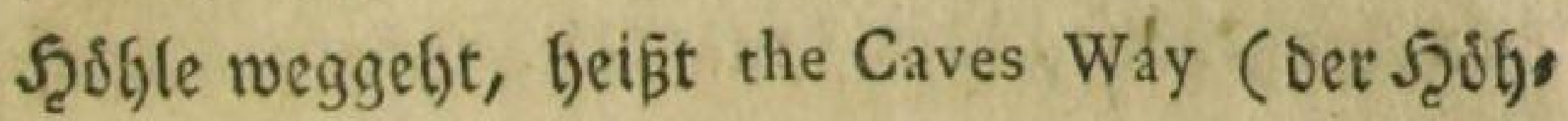
lenweg), uno ift eine der ftatkfen Paffagen zu Der Stabt; uno 100 es in ber Ferne anfängt,

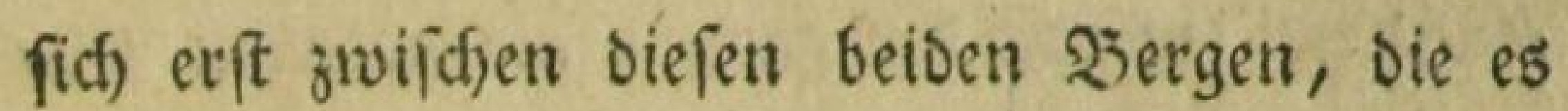
von einander trennt, zu fenten, lajpt es fid) fo

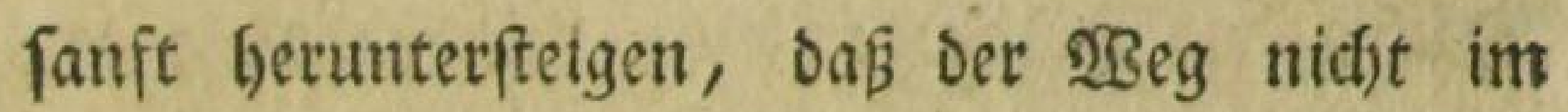
mindeften ermúbet. Berfefft man abev biefen Weg zwifhen den beiben Detgen, uns geft oben

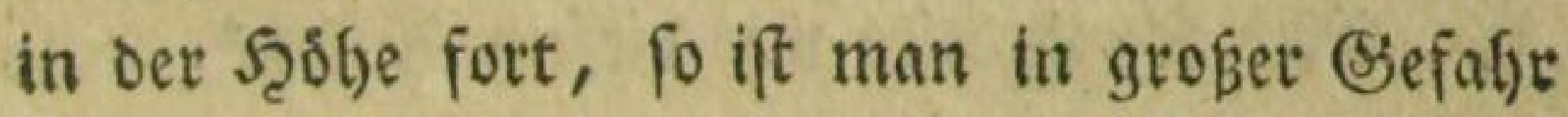
von bem immer fteiler werdenden Selfen Ginun: ter zu fturzen.

Der Derg, worauf oic Fituinen fteten, ife allentlyalben felfigt, Der anbre aber linfer feano Danefen, wether burdh bas That abgefonbert wiro, ift úberall grún, und oben auf oem SSipfer Deffelfen find die 3 ief)weiden, outch) nach 2fit ets net )auer aufgerworfne Steine, abgetleilt. DeF gruine $\mathfrak{B e r g}$ aber ift wenigftens oreimal fo boch, mie der, auf Dem bie शiuinen fteben. 


\section{(. (234)}

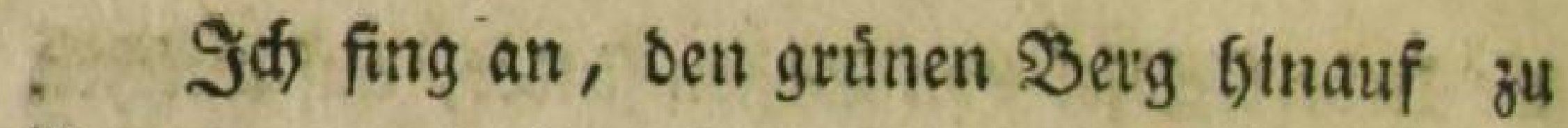
flettern, Der Doch auch ztemlich (Eetl ift, und als (id) mun weit úber bie Şálfte gefommen war, of Dem 2 isagefalie, Der betr गaamtorberg binauf: fletterte: Denn als idf mich umlabe, war mein

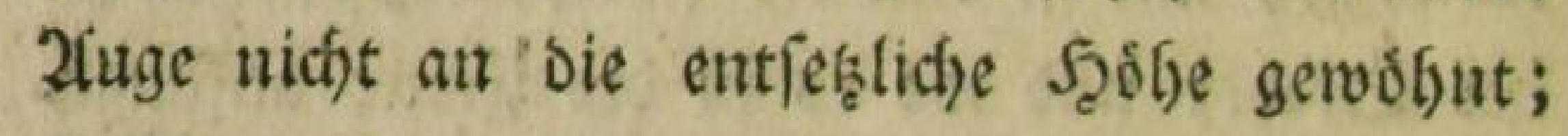
Caffleton lag mit Der ganzen umliegenden bies genb, wie eine Randegarte unter mir, die Dáctjer oer Şáufer fatienten beinabe oidft auf Det Erve, uno Det Shuinenberg felber zu meinen ร̛น์

פitr fabwinbelte vor biefem 2lnblick, uno

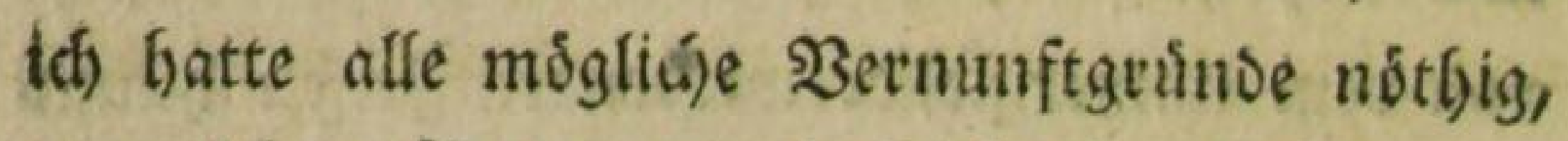

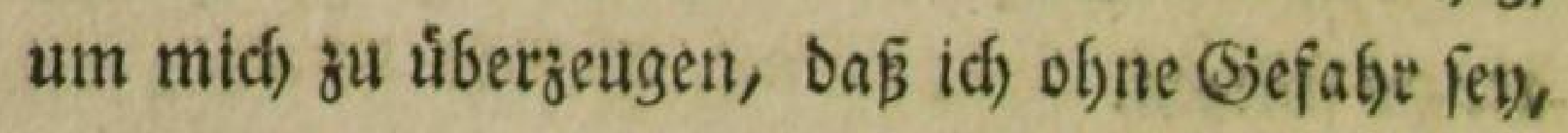
benu idh fornte ja auf alle żăle, ben grúnen Siafen, weldfen ith hinaufgeftettert war, nus

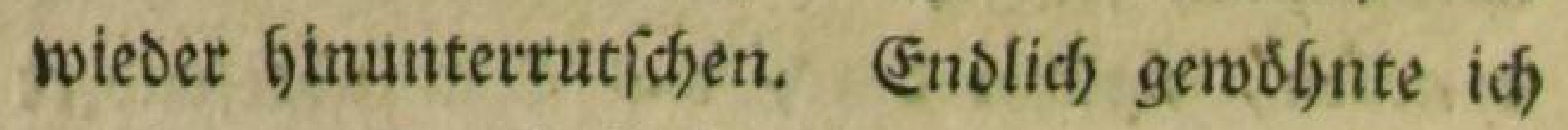

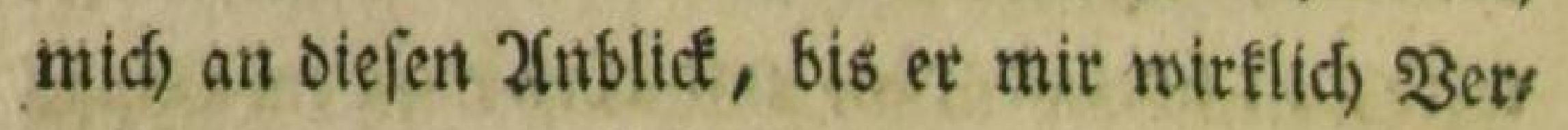
gnigen machte. Sid) fletterte mun ganz bis auf

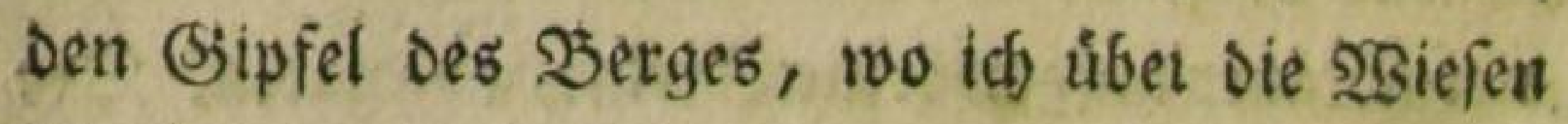
binging, uno endlid) an den 2 seg fam, ber fich zwifhent ben beiden șergen allmálig binuv terfenft. 


\section{(235)}

Oben auf Dem Sipfel Des grùnen Sorges melften Die Sirtiunen if)re Rúbe, uno famen Dann mit ben silldyeimern auf Den $\Omega$ Spfen eben biejen 2 Seg bertuter:

Eine fichone Struppe wat eร, on fich einige biefer Mabdhen, indem es alt zu regnen fing, mit ifgren Drildjeimern unter ein úberbangendes Felienftúct am 2 sege geflichtet batten, worunter fie auf natútliḑen fteinernen Şånfen fạ̄en, und vertraulid) mit einander (d)

Jiein $23 \mathrm{eg}$ fúbste mich) wieber in bie Stabt, wotaus id Stgnen idfreite, uno bie teh mun im SBegriff bin zu verlaffen, un meine Pixctereife nach Sonoon anzutreten, wozu idh aber moblnidjt ganz denfelben 2 seg wieder nelgmen merbe.

Sortbbampton, Den sten Jult.

Da id) von meinem Sd)ufter in Eaftetcr, ber gar zu germe mit mir gereišt ráre, 2ffichied genommen batte, to ging id nun nicht auf Tis $^{2}$ Deswell, fondern Wardlow, welches náber ift, roieder zuricf. 


\section{( 236$)$}

14 Ŝn Diefer Giegent traf ich einen citzelnen Bafthof, wo mur die Frau zu Scauje roar, die

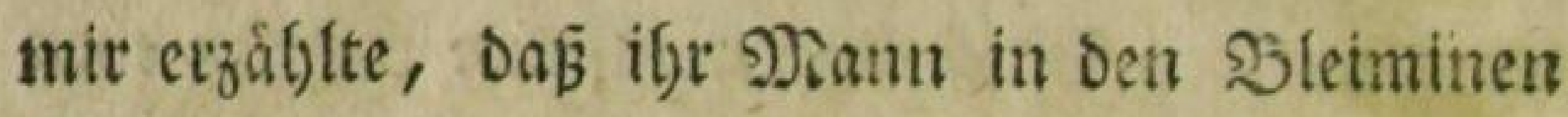
(Lead Mines) arbeite, uno oá̧ bie Şoble von (Eaftleton, unb alles mas idf) geieljen babe, gegen Diefe Reabmines gat nicht in Sietrad)tug fomme. Sor Mann fonne mich Darim Gerumfiffect.

Da ich ifor mein sittagseffen bezabsen wollte, madjte fie mir ben (Einuurf, baß̧ idh Eeis nen afle uno feinen Sranntwein getrinten Gabe,

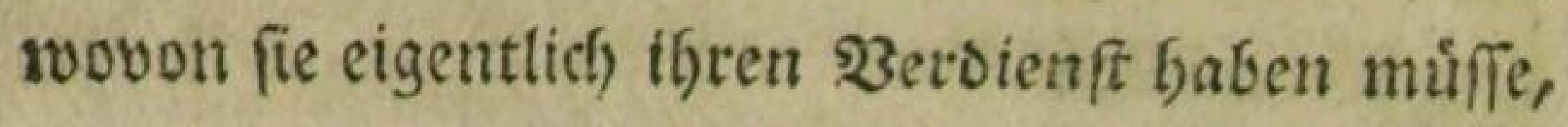
und mir alio nicht gut bie Fiechnung madjen fonte, worauf ith mir benn einen Sirug afle geben ließ, ofjne ifn zu trinfen, um igre Siech) nung zu beridgtigen.

In eben diejem (Safthofe befam ich) meinen Isirtl) aus ₹ibeswell wieber fu feben, Der aber nicht, wie ich ju $\mathfrak{F} u[$ gegangen, fonbern fefhe frol geritten fam.

Da idf nun von ba weiter ging, uno bie SBerge wieber vor mir auffiegen, welde mir von mel; ner J̧inreife noch, befannt waren, las idh gerade (im Milton bie Schopfungsficene, welche det cengel Dem 2loam fabiloert, wie fid) Das IJaffer 


\section{( 237$)$}

Fenft, uns ofe nackten Djerge ifren breiten Situdeth emporbeben.

Immediately the Mountains huge appear

Emergent, and their broad bare Backs upheave

Into the Clouds, their Tops afcend the Sky,

Neir war $e^{5}$, indem ich biefe Stelle las, als ob alles, was um mid) ber war, erff wurde,

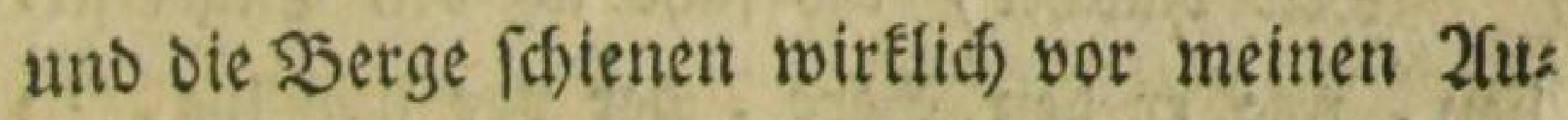
gen emporjufteigen, to leb gaft rourbe mir biefe Siene.

(5twas åthnliches empfand id bei meinet Scertetie, ba idf) gerabe einem Serge gegenuiber

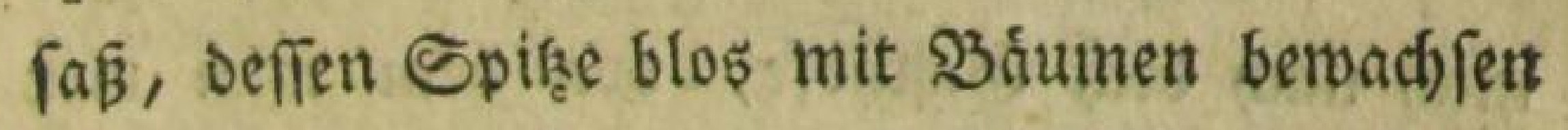
war, und im stilton bie folofialif be Sejhrei: buttg vout bem Streit Der (sngel las, wo bie abe gefallenen (Engel ifye Begnet mit einem ftartent Dombardement angreifen, biefe fid) aber bages gen vertheidigen, inbem eit jeber einen Serg gleichlam oben beim Schopf ergreift, ifjn mit Der Şutzel austeist, und fo in Feinen Scánden aufget)aben traigt, um ifsn auf bie Feinbe zu folleudern.

๑. 


\section{(238) \\ wo. - - they ran, they flew}

From their Foundations loof'ning to and fro

They pluck't the feated Hills with all theit Load,

Rocks, Waters, Woods, and by the Chaggy Tops

Uplifting bore them in their Hands، - -

Sir Dauclite, als lâbe id ben (Enget fies ben, wie er Den Serg, ber vor mir lag, in ben Eúften (c)ưttelte.

als ich ben afbend, ba es fdhon bunfel war, in bas lef̧te Dorf vor Miatloct fam, ent/d) ich mid) bie शacht ba zußleiben, uno etfunsigte mid) nach Dem (jaftrofe, von dem man mir fagte, Dafier am (snoe bes Doris fey. Zlllein id) ging beinabe bis um Jitternadt, ehe ich art Das (snde des Dorfí fam, das faft gar fein (snde zu haben fahien. Sei meiner Serreife muste idf entweber nicht auf oteß Dorf zugefommen, obet: auf leine Qaunge gar nidht aufmettian gewes fen leyn.

(Ermúbet uno balb frant fam idy endich in Dem Giafthofe an, wo ich mich in ber Sưdhe ans 


\section{(239)}

Gener forgtê, unt zu effen verlangte. 2 2fls man mir [agte, id fosme fein Dette Gefommen, ließs id) mich foflecteterdings nicht wieoer wégtreiben, fondern [agte, id) wolle Die Nad)t beim Ramin feter firfen bleiben, welches id) bem aud that, und midh mit bem sopfe auf Den ₹ifal legte, um ju (ajlafen.

Da man mun g'aubte tof fogliefe, gorte th in ber suidje úber midj beliberiten, was iff roobl für ein Meniá fern móge. Eine frrau nafm meine bुartfyel, und [agte: I dare fay, he is a well bred Gentleman, (id) glaube er if ein Nien [af von gutemstanbe); eine andre wiberlegte fie bamit, $\partial a \hat{B}$ idf zu Fuß̧e ginge, uno fagte : he is a poor travelling Creature! (et if ecin atmes hets

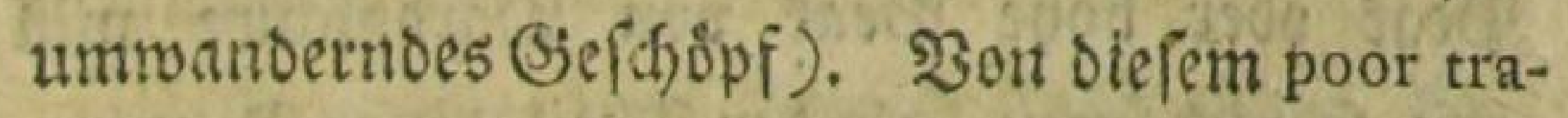
velling Cręature geflen mit nodi) die Obren, wenn id) Daran benle, Dent es faheint mir alles (Eleno eitres Nenichen, Der nirgends eine Szeimath bat, utio bie Seradjtung ber er aubgeferst ift,

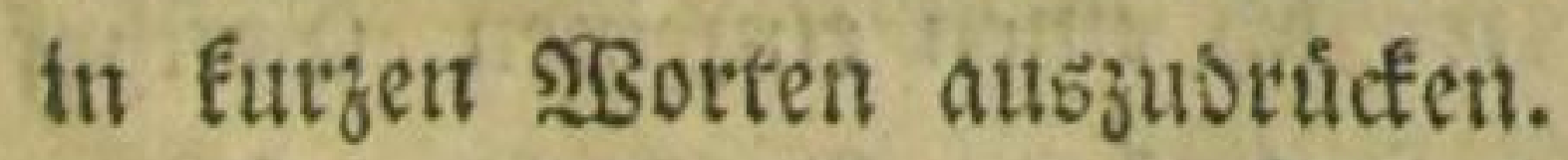

Enolich, als man fáte, oâs ich roch ein: mal ba bfieb, gab man mir sin 2jette, als id es

$$
\text { 2. } 2
$$




\section{- (240)}

gar nidjt meft vermutbete. Utro da man an )2orgen einen Schilling von mir forberte, gab id) ifhen eine balbe Rrone, worauf id) mir nidits wieder herausgeben lię̧, um das poor travelling Creature von mir abjuwálzen. Nian entlię mich Darauf mit vieler Sçfflid)éeit uno (5ntichuldigut: gen, uno ich) fef̧te nun vergmigh meinen 2 (3eg peiter fort.

2lls id) ourch Natlock gefommen war, ging ich nicht roieder auf Darby, fonoern linfs auf গlottingham 孔u. Fૃier verlobren fich allmálig

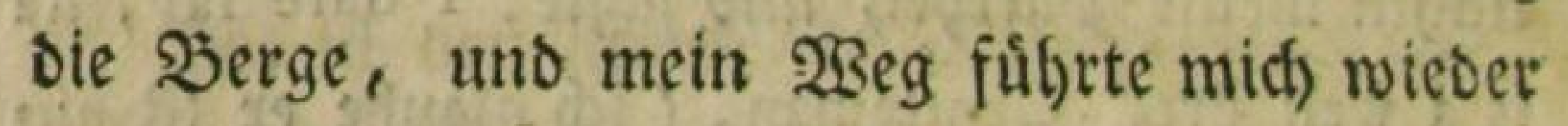
ứer $\mathfrak{x}$ sejen uno Felder.

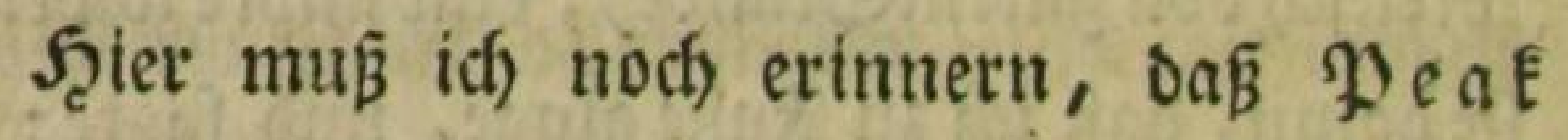
eigentlich eine Spize oder SSipfel beiß̈t; Der Deaf oder lobe Peaf von Darbyifhire will alfo fo viel jagen, als Der Theil diefer Provinz, wo fie am gebirgigften iff, oder ifre SBerge am bodffen fino.

Siegen Mittag fam ich boch wieder auf eine $2(n b j b j e$, wo ich einen einzelnen Safthof traf, ber efine fonderbare Infchrift auf bem Schilde fúfrte, oie in Sieimen war, uno fich mit ben ssorten entigte, refrefh, and then 


\section{(24I)}

zo on! (etfrifache bich), und bann reife weiter.

Oben über bem Edfilbe frano, Entertainment for Horfe and Man (Detwits tgung für Miós uno Mann), welches idh an mebs: retu Sdjilben gelejen habe. Sonft if Dealer. in foreign Liquors oie gewosgnlich) Ine Snfdutift an Den fleinen Gafthofen.

Эa) aß bier zu Mittage, uno befam ein Stuid Ealtes fleijh) und Sallat. Diejes ober Eier und Sallat, war mein gewosfynlidjes 2fbends. und s) Rittageifen, in Den (Safthofen wo ich ein Eefyrte, felten erfielt ich einmal etmas warmes. Den Sallat, woz̧u id) alle Sngrediengien bes fam, muste (d) mir immer felber madhen, wels d) 2 b) fier fo geftáuchlich ift.

Deein 2 seg wai jiemlich angenefm, abet sie (jiegeno bier eben nidjt leftr abrech felno.

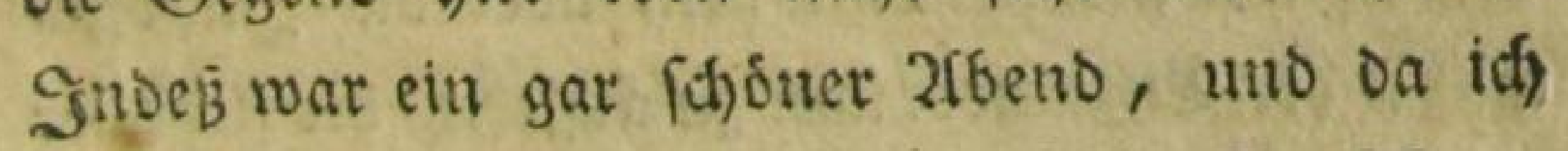
fur; yor Sonmenuntergang ourd) eiu Dorf fam, grúbiten mich veridjiedne Qeute, ole mir begegs neten, Damit, onß fie fagten: fine night ober fine Evening! ( Ein fdofner 2foend!) Eo pflege id, aud) zumeilen von \&euten, bie mis

$$
\text { 2. } 3
$$




\section{(242)}

begegneti, gegrúst zu werben, inbem fie fagen: how do yo do? ( $25 a s$ madit ibs?), worauf man benn antroottet: I thank you! - Dicie 2tt zu grůsen muß einem fremben fefr fonderbar vortommen, ber von einem sienidgen, ben et in feinem \&eben nicht gefefen bat, auf ein: mal gefingt wit's, was er mache, ober trie et ficf) befinde?

2fls iá) ourch ons Dorf war, fam ich uiber ein guines Jelb, mo ici) an ber Seite wieber eis nen einzelnen Safthof antraf. Die 2 Bittbint

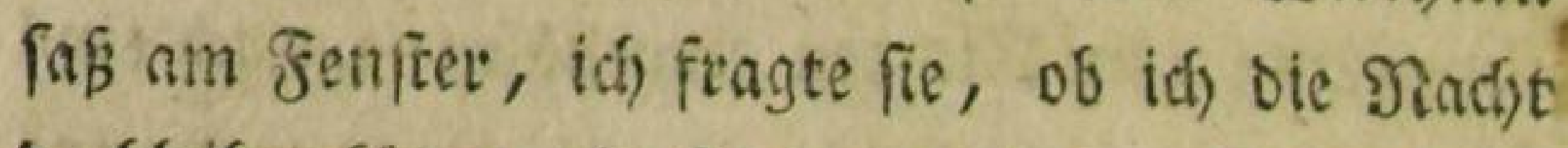
ba bleiben fsome, fie fagte, nein! uno fojob mis Dab Fenfer vor Der গare zu.

Seietbei fielen mit alle die Negegnungen voin ber 2fit wieber ein, Denen ich bier fofon ausges fefet gervefertwar, und tif) fonnte mich bier niche entbilten, meituen unviffen úfer die Intyofpis talitåt ber (Englánder laut zu áußern, Der fić) abee boch balb wieder legte, oa ith weiter ging, uno oie Faffe, wo iff gut aufgenommen war, ons gegen redsnete.

(Enblidf) Eam ich nodi) frúl) genug an eitren mbern Gaftjof, auf beffen Schilde ftand: Na. 


\section{( 243 )}

vigation Inn (Sd)ifferferberge), tweil bie

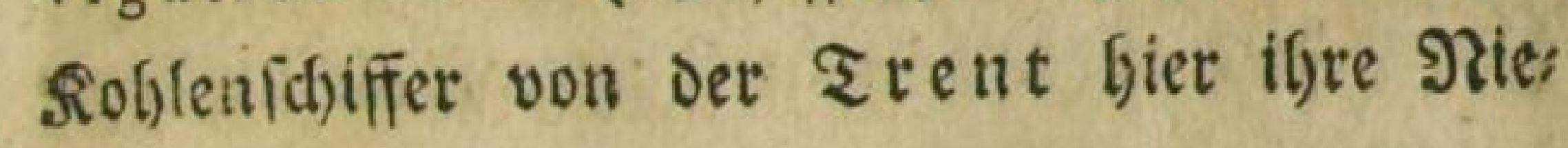
Derlage laben.

Eine wilbere, raufere 2lit von MenfGen Fabe id Denn nod) nie gejeflen, als biefe fioblens

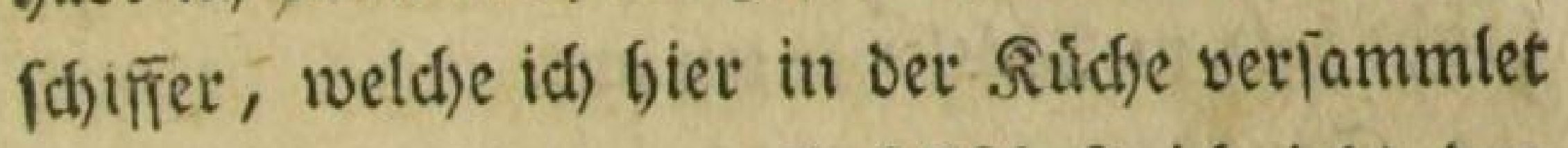

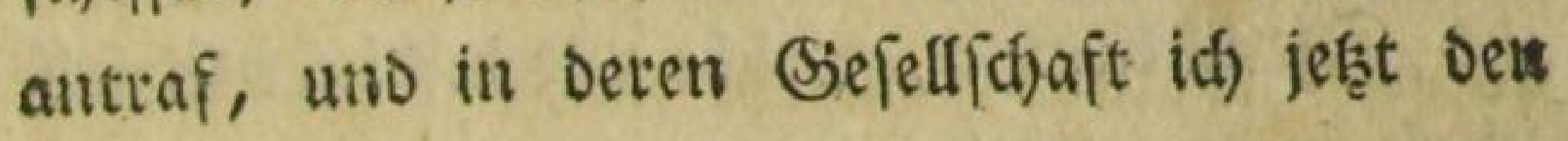
26 eno fubringen maß̧te.

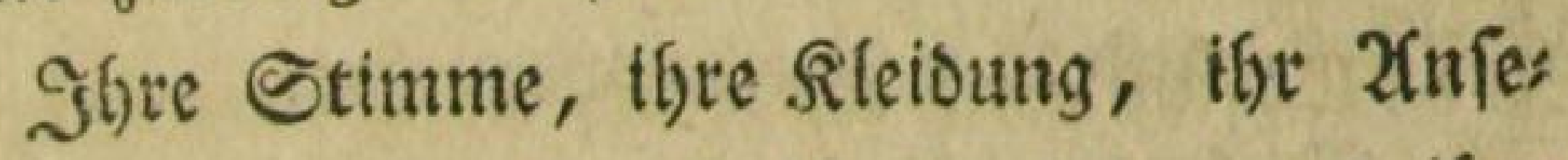
flen, alles war raub) uno fúrdtertich, uno igre

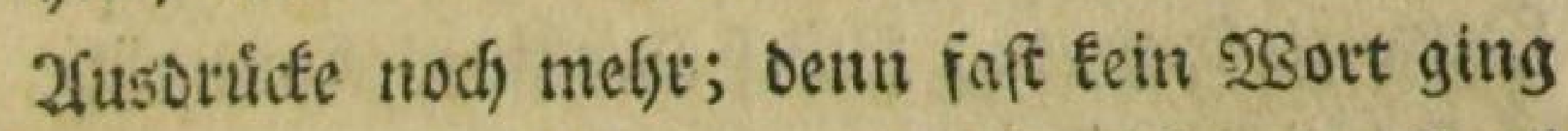

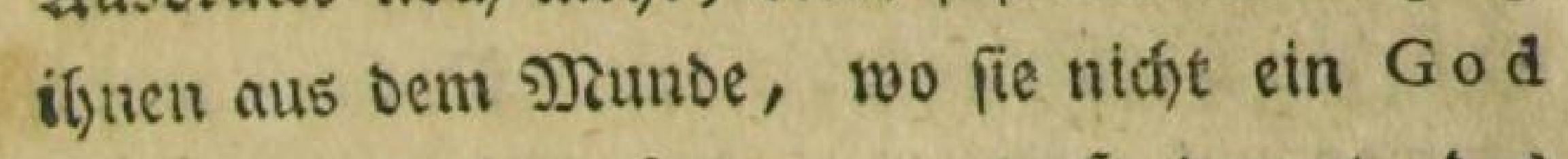
damm me! finzulefgrten, und fo bauterte bas Sludjen, Banten und edowsten in einem fort, mir aber that feiner von ifhnen etwas zu leide, fondern jeder trank meine (Sefundbeit, und idf

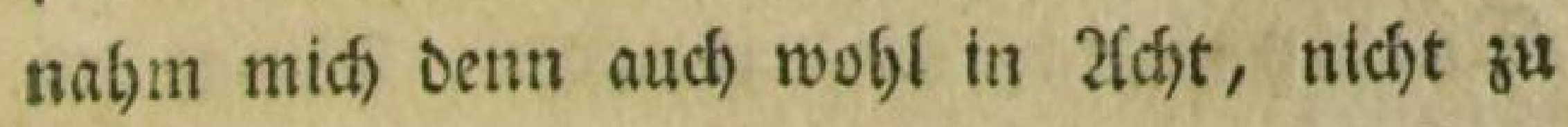
vergeffen, wieder ifre Gefinnobeit jut trinfen, Denn meine Begegnung von Dem গIBittl) in Dem esaftrofe bei Miatloct war mir noch im frifthen afnoenten; fo oft id) alio trank unters llé̉ (id) nicht fu lagen: Your Heàlth Geno lemenall!

\section{4}




\section{(244)}

25enn fich ein ઝaar Englánder zanten, fo Theint bod, alles mehr in Thaten, als in 230 r: ten zu beftelyen, fie fpredjen wenig, uno wieberbos lent oft bas Siefagte, mit einem linzugefungten God damm you! Ifre Sorn foct)t inwendig, uno bricht bals in ₹gátliçéteiten aus.

203 Die รBirthinn, weldhe mit in biefer Siefell fohaft in ber Súche fā̧, war bemofingeadjtet Eoeffitt, und that ziemlich vornetsm.

Nactidem idf gegeffen batte, eilte idf, 3u Bette zu formmen, fohlief aber ziemfich uniubig, weil bie Schiffer faft bie sanze Iacht hindurth fermten und tobten. - 2(m Niorgen, ba idf) auffand, war Eeiner mefye von ibnen ju goren und ful fegen.

Jch) batte mun nux noch einige Mieiten bis Notting bam, Das id) gegen Wittag ev reidjte.

Dię fofien mir unter alfen Stabten, bie id) auBer Eonoon gefégen babe, oie fidonfe uns nette[te zu ferti. Zllles batte bier ein modernes

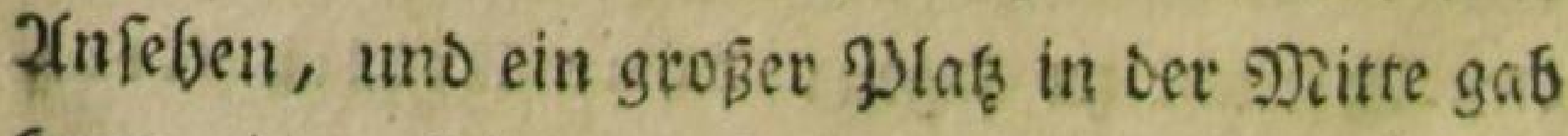
faum einem \&ondner Square an Schonbeit eta mas nach. 


\section{(245)}

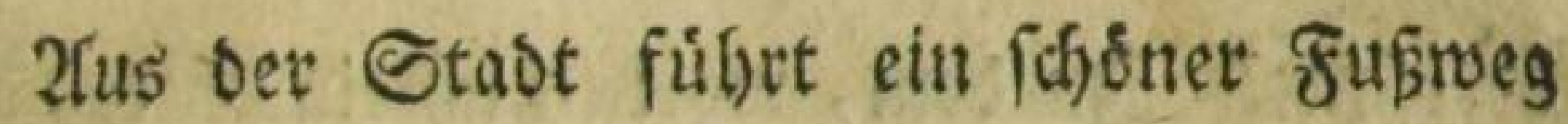

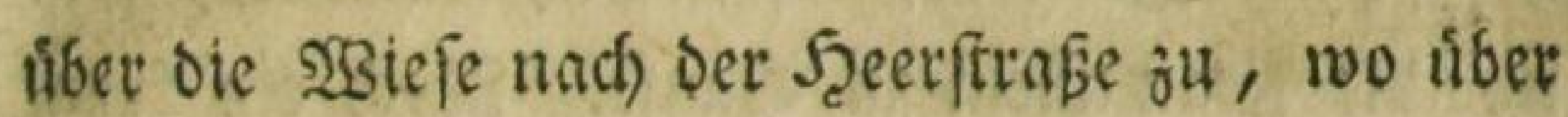

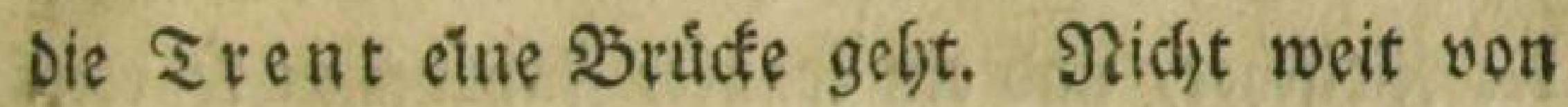
Diejer Struffe wat cin (Safthof, wo id) zu 2it:

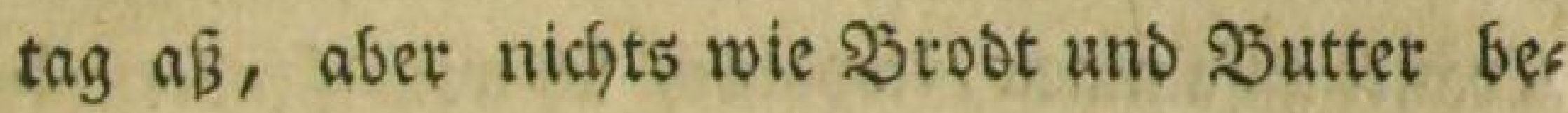
fommen founte, wovon idf) mir benn einen Toaft machen ließ.

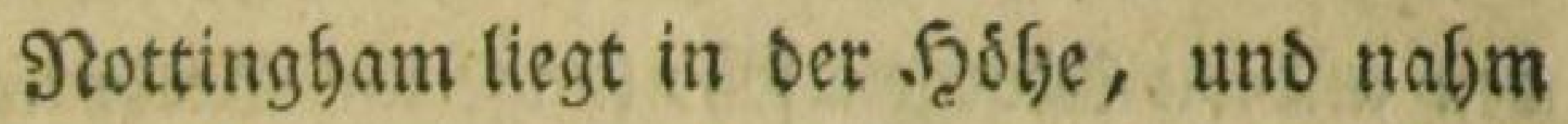
fich in ber Ferne mit feinen netten bofjen Seak fern, rothen Dádjern, und Thuirmen ganj vor, trefflid) alts, STod) von Eeiner Stast in (Engs Lano habe id einen fo (d)onnen 》rofpett gefeljen.

Sch Eam nun ourd) viele Dofrfer, als Fi ut

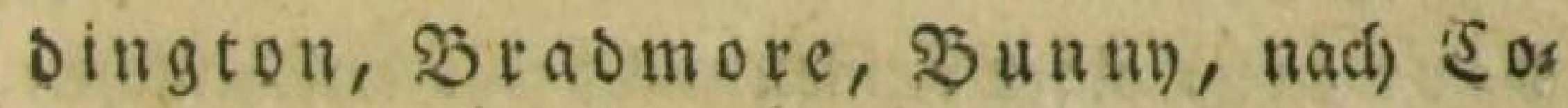
fial, wo ich Die Siadjt blieb.

Diejen ganjen Nacf)mittag gorte iff von

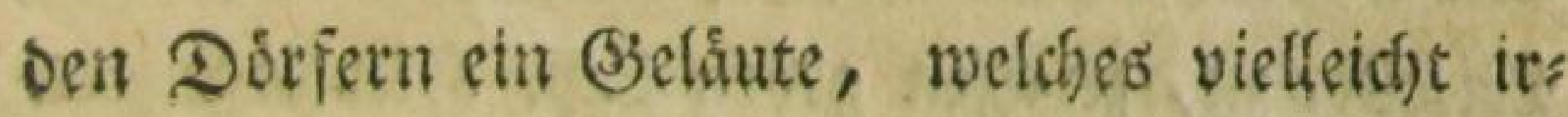
gent ein Feft anzeigte, Das hier gefeiert rurbe. (Es war ein trúber Seimmel, ich) fúblte mich et: was franf, uno diés Sielåute machte mich nodh Daju forvermitgig uno melandjolifab.

In (Eaftol waren bre: Gafifgofe Dicht neben einander, in weldjen, fdjon nach Dem áuseen

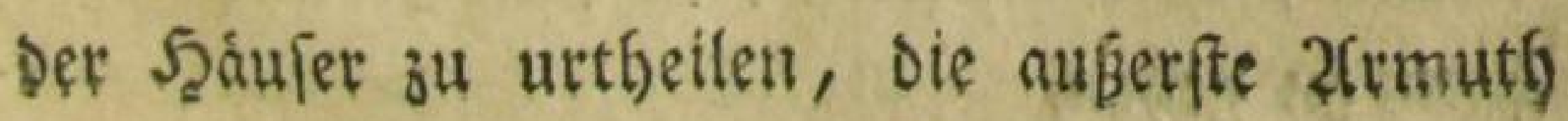

ก. 5 


\section{(246)}

bertiffec. In bem, worinn id einfefyte, wat mut bie Frau allein zu Feaule. Nod) ein frans

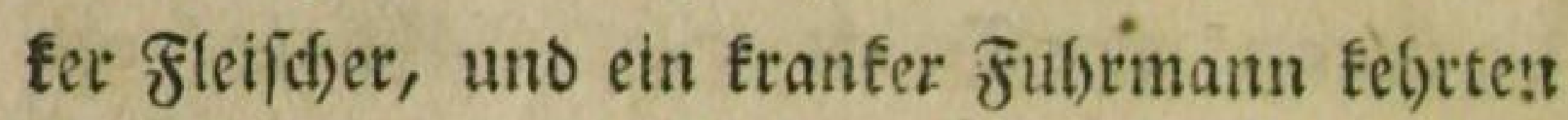
bier ben arbend ein, alfo éamen Gier lauter Sitanfe zufammen, woourd) ich nod) fohwermu:

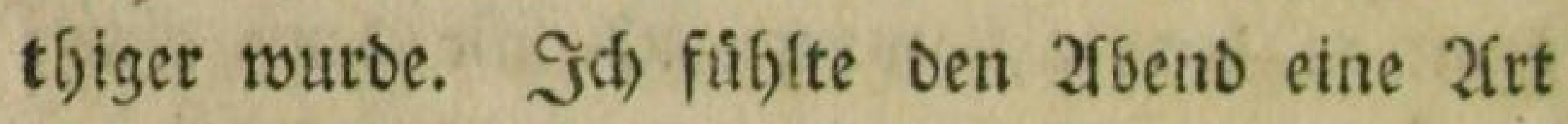

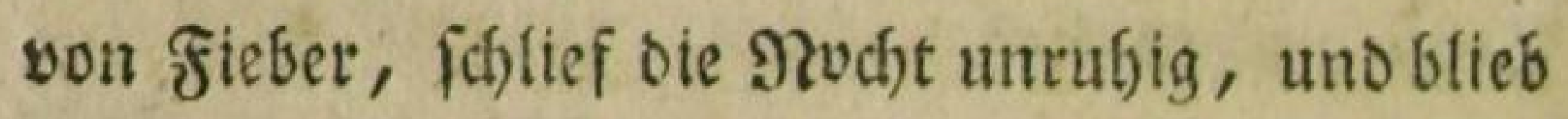
Den anbern Mrorgen ferje lange im Şette liegen, bis mid) bie 2 situtfimn wectite, indem fie laste, fie fen meinetwegen beforgt gewefen. Nun nafm (id) mir aud) vor, von Letcefter aus, mit oet \$olftetitche zu fafren.

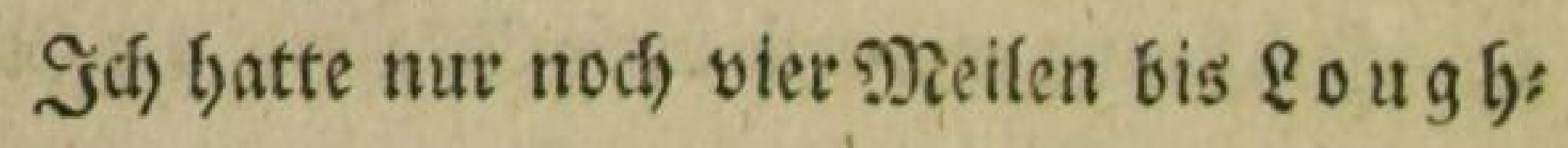
borough, einer fleinen nidst fegre anjefinlident Stadt, wo id erft fpat um s)ittag anfam, uno mir in bem leşten siafthofe auj bem 2 sege nach Qciceffer zu, zu effen geven lię. Şier begegnete man mir wiber $\mathfrak{B} e r m u t h e n$ jum erffenmale ries Det wie einem (sentleman, uno ließs mich) in dem Parlour ober Sremoenzimmer effen.

Son gougboorough) (gofoorro) bis Eeicefter (fefter) warell nut nod zeben Dreilen, aber Der $253 e g$ feg)t fandigt uns. unber quem zu gegen. 


\section{$(-247)$}

I(i) fam ourch cinen flecfen, গRafmens De ountiorrel, ber vielleidft von einem flei: nen Şugel am Ende beffelben feitren গat)men bat. Uebrigens war bis Qeicefter cine grofe Es bne:

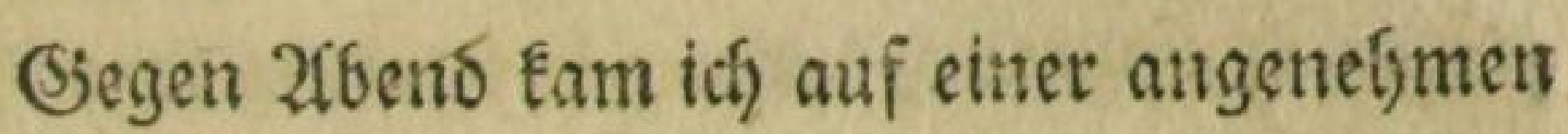
şiefe yor Retcefter an, liber welcje midj ein

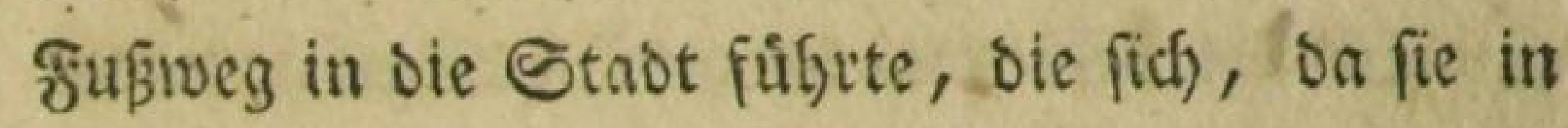
ber \&ănge vor mir lag, recijt gut australym, uno groserer fósien, wie fie wirtlich iff.

Jic) ging eine lange Strafe binnuf, che idh an Das Scaus fam, wo bie \$offEutichen abges hen, und reeldyes zugleid) ein Siaftyof ift. Soth erfufy: bier, Dafi Denfelben abend noch eime Sta: ge nad, \&ondon abginge, bie aber inwendig fojon be fergt (ev), allem auswendig (ev) nod) plati.

Da ich) jeşt eilen muşte, um roieder zurutat nach Iondon zu fommen, weil Die Zeit herans rucite, wo ber Sfambutger Sd)iffer, mit Dem id) zurúcfifabren will, feine 2fbreife beftimmt gat,

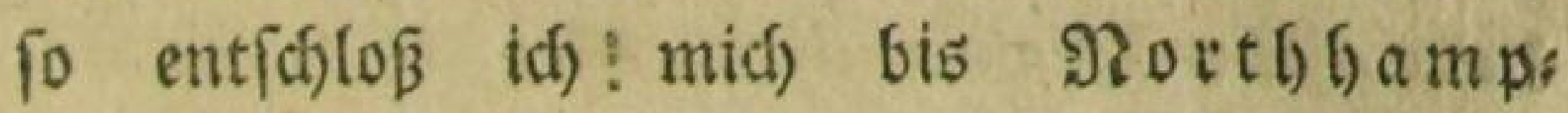
to netnen Plats aurmendig auf ber Sutidhe zu nef)men.

2(ber an biefe Fabut von \&eicefter bis शoutfy bampton roifl idf Denten, fo lang id) leber. 


\section{(248)}

Die Sutidfe fubt vom Şofe outch bas Şaus.

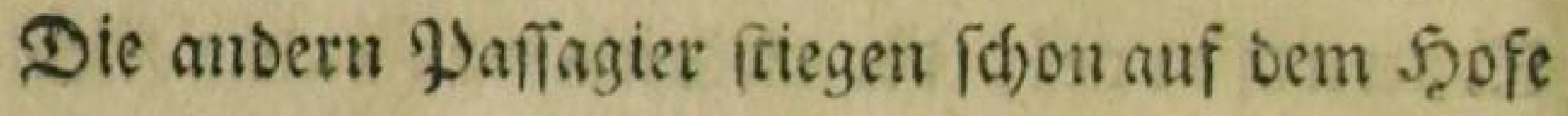
ein, wir an oer 2lufienfeite aber musten auf ber sifentlichen Straje erft btnaufelettern, weil noir fonft mit unfern ßoppfen nidjt unter Dem Thor: wege Durd)getommen wáren.

Miehre Siefábrten oben auf ber Rut fde roaren ein Bauer, ein junger Mienfá) oet nod) ganz orbentlid) gefleidet war, und ein Mrobrenjunge.

Das Scinaufflettem allein war f(h)on mit gebensgefalge vertmipft, uno als ich num oben rar, Eam idh getade an eine (Ede auf oer ßuttiche fu firsen, wo ić) mich) bloß mit einer Scano an einem fleinen Grifif balten fonnte, ber an Der Seité ber Sutiche angebradit war. Gidh fas bem Diabe am nåchften, unb fobald tch Gerunter fainz: te, fath ich einen gervifien Soo vor 2lugen. Utm Defto fefter Gielt ich mich) an den (Sirifi, tuns um

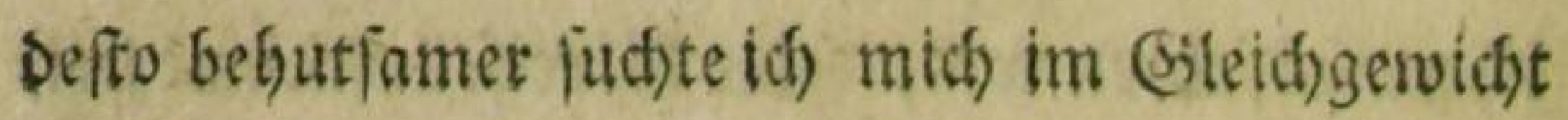
ou erbalten,

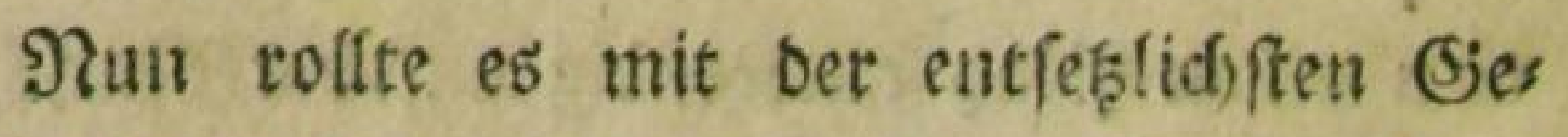
fahmindigfeit in Der Stadt auf Den Steinen fort, und wir flogen alle 2lugenblict in bie scoble, fo Dé̄ es beinabe ein 23 under war, oaß̧ wir immer 


\section{( 249 )}

wieder auf bie Sutjdje jutút, uno nidjt einmal nebentyer fielen. So ging es num auch, fo oft wir Durd) ein Dorf oder eine 2(níbóbe binunter famen.

Entilich, waro mir Diefer Buftanto, in beftảns oiger Rebensgefahr zu (d)weben, unertráglid), und als es einmal bergan, und aljo etwas lang: fam ging, frod tif) oben von ber Sutid)e hintent in oie Schoßífelle, welche bier the Bafket heist.

In the Bafket you will be fhaken to Death! (in ber Schofifelle werdet ifr zu Tobe geíd)uttelt werden!) [agte ber siofyrenjunge, uns id) nafym Dieß fút cine Şuperbel an.

Sergan ging es auch recht fánft uno gut, uno id) war zroifhen ben Soffern und Siepacte beinabe eingeichlafen; aber wie erfdyract idh, ba es auf einmal wieder bergunter ging, uno bie Soffer und alles fofwere (Siepsict um mith an zu taingen uno an zu leben fing, wobet id) alle 2 fus

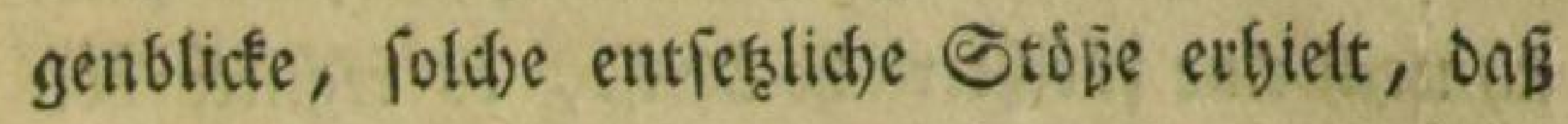
td) glaubte, mein lebensende (el) gefommen, und

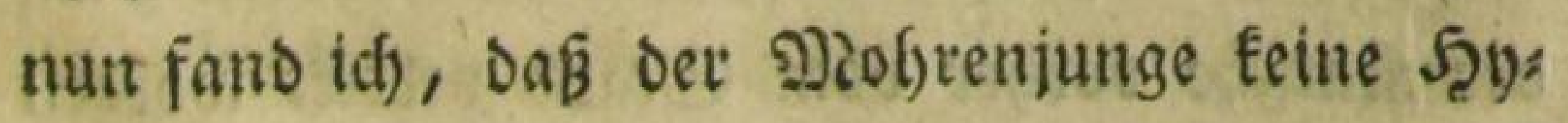
berbel gefagt batte; alles mein Schreien balf nicjts, id muste beinabe cine Stunde ausbals 


\section{( 250$)$}

têt, bis es wteber betgan ging, wo idj oenn gailg múrbe uno zerfhlagen wieber oben auf bie Ruts fole froch, und meinen vorigen Sifs eimnafm.

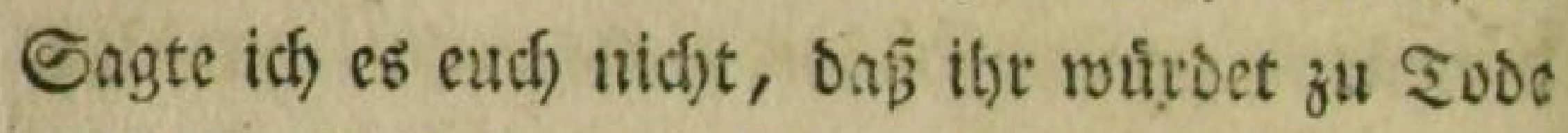
geiffúttelt werben? rebete mid, ber sobofrenjunge ait, als idf wieber beraufgetrodjen fam, uno idf fonvieg ganz ffifl, - Dieß fofreibe iff einem jeden fur $\mathfrak{S}$ Sarnung, Dem es etwa citumal ein fallen follte, ofne es gewobnt zu fenth, auf bet Outfide einer Engfichen pooffutiofe, ober gat in bem Bafket ou fafjern!

(Segen פitternacht fament wir in Scar 6 or rough an, wo idf midf mur ein wenig nustuhen fornte, und bann gings wieder im vollen Gagen Durd) cine Dienge Dofree fort, fo Daß wit in eints

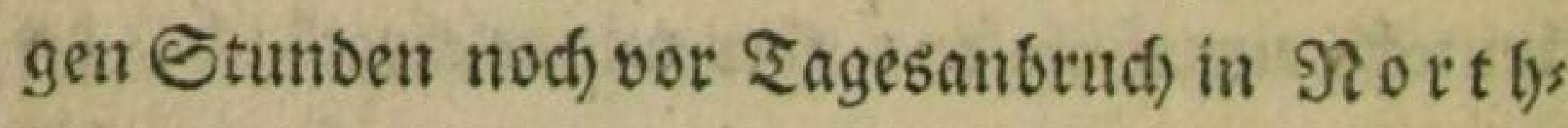
b) a mp to nt antamen, oas boch orei uno breibig Dreiten von Reicefter ent fernt iff.

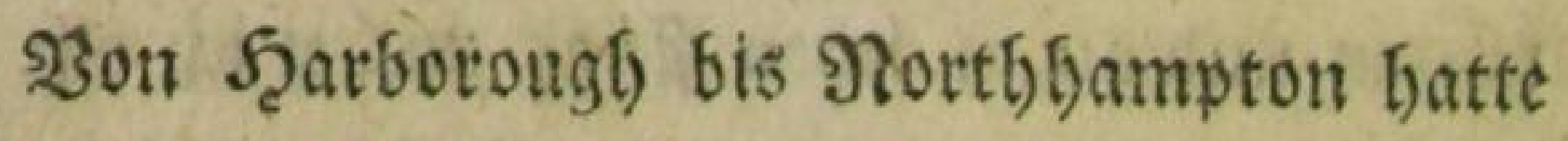
(d) nod) eine fúrcheertidbe Sieife, es regnete beis nabe in einem fort, und fo mie wir suswendig auf ber Sutfide vorlfer vom Etaub besectit worden waren, fo wurben wir nun vom Siegen outd)nefigt.

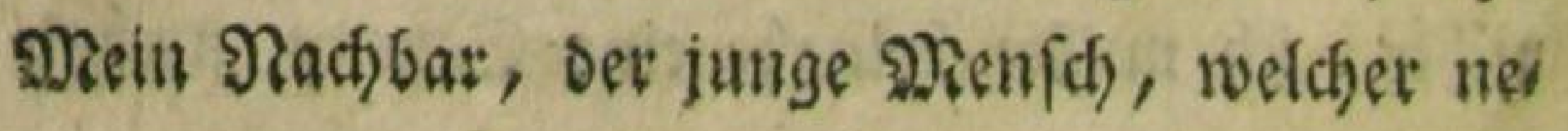




\section{$(251)$}

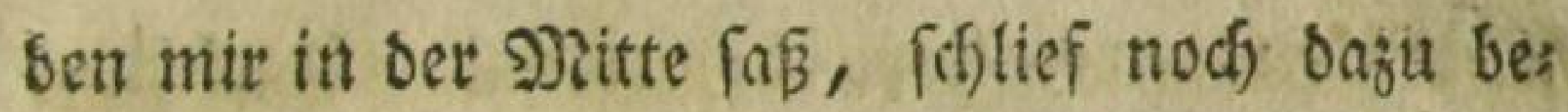
franoig ein, uno indem ex alle 2ugenblicfe mit Der ganjen $\mathfrak{L} a f \mathfrak{t}$ feines Sisters auf mich fiel, fefite wentig, bnß er mid) ganz von meinem Sif̧ binunterorángte.

Endich Eamen wit dent in Northgampton an, wo idf mich fogleich zu Szette legte, uno beinabe bis an ben Mittag gefhlafen labe. 9) গुofteutidje meine Sieije nad) Sonbon weitev fortzuferenen.

Lonbon, Den I 4 ten Эult.

Die Fieife von Portlyampton bis fonbon fann ich urederum feine Sieife, fonbern nut eine Servegung von einem Drte zum andern in einem zugemadhten Siaften, nenten, wobei man etwa mit ein Paar \&euten, Die fid) auf eben bie 2fits fortbervegen lafien, wenn bas sslüct gut ift, fons verfiren fanu.

Sei mir war das sllúc fo gut nidjt, benn

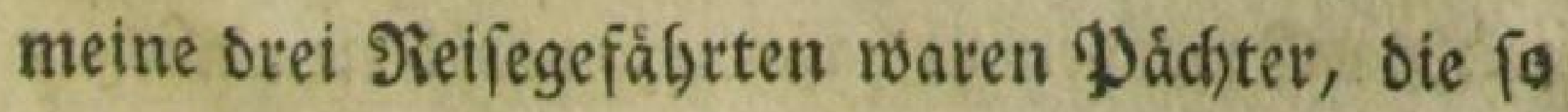
feff fobliefen, Das fie Durch bie beribafteften 


\section{$(252)$}

Sopfitiose, womit fie fid einanber begrufsten, nidyt aufgetúttelt wurben.

Şge von \$ier uno Şrantwein aufgedunf:

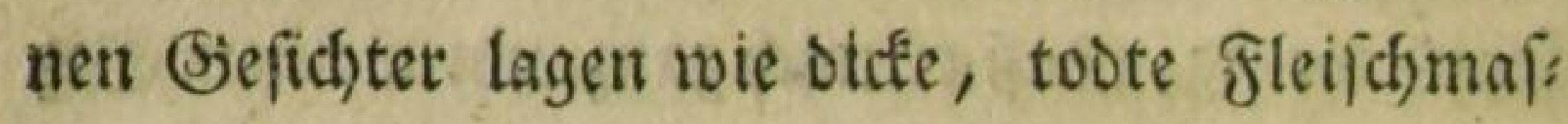
fen vor mir. - Utno wenn fie einmal erwads):

1.ten, fo waren $\mathcal{S c h}_{\text {afe, }}$ womit fie bandelten, iffr erftes und ifyt lef̧es şort.

Det eine unter ifnent aber wat von ben úbrigen beiben fébr verfifieden: fein (Sieficht wat getb uno bager, feine 2lugen tief eingefallen, feine langen gelben finger follotterten an feinen Seanden, er labe aus roie Sieiz und Nien: (d)enga的.

Das erftre war er, bent er weigette fiid) auf

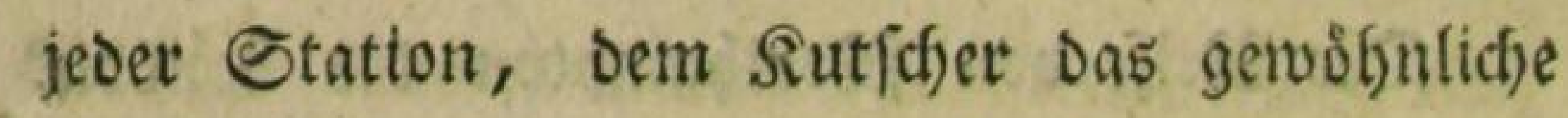
Erinfgeld zu geben, was bod) alfe gaben, uno jeder Sceller, oen er bezablent muß̈te, preß̄te ifgm ein God damm! aus Dem Sectzen.

$23 e n n$ er im $23 a g e n$ fá̧, (d) Sidjt, uno mad)te, wo et nut fotmte, alle Fens fter zu, wenn idf) nidjt zumeilen eitts wieder auf: ríß, um gleidffam nut einen 2fmblict von ben tets jenden Segenten zu Gafchen, vor Denen wir im fluge vorbeifubren. 


\section{( $253 \quad$}

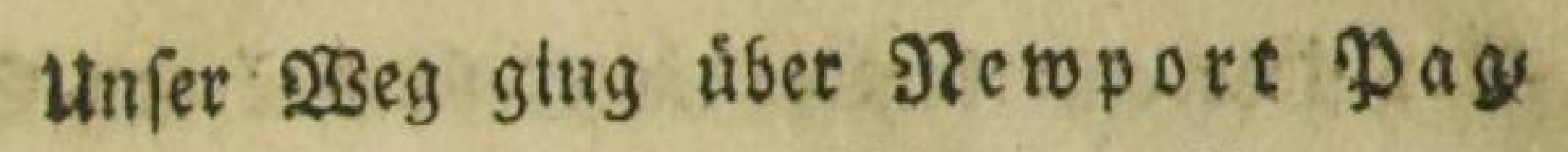
nel, Dunfable, St. 2llbans, sarnet, bis Siltington oder vielmegr gonoon feloft. 2fber bie शalimen find aud mun alles, roas ich won biefen Dertern zu Fagen weis.

In Dunftable, wo mit recht ift, fruits: fficten wir, uno es roato bier alles, wie es auds bei uns auf Den Poftwagen gebráudjlich ift, von Den Paffagiers gemeinidaftlich bezahit. Jas batte mir, meil idf bief nidgt wuste, befonders Saffee beftelft; allein neil er einmal ba roar, tranten bie brei Đaáchter mit, uno ließ̧en mich roieber von ibrem ₹Gee mittrinten.

Sie fragten midf, aus weldsem ₹beile

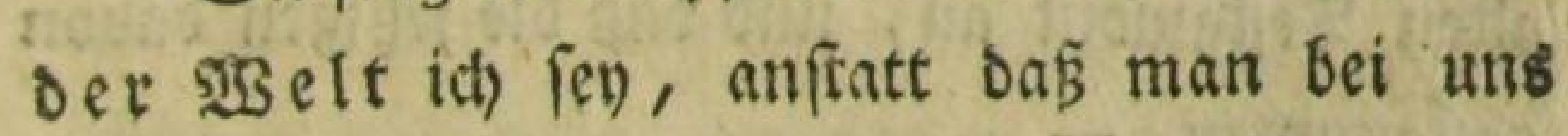
frågt, was fứ ein $\mathfrak{a} a n \delta s m a n n$ einer ift.

Da wir nun gefrúbftuctet Gatten, und wies

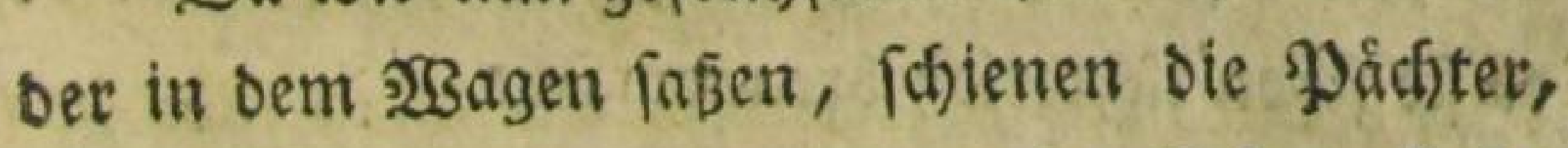
Den bagern ausgenonmen, orbentlid aufzule: ben, uno fingen Sieligions s uno politifge Difcourfe an. 


\section{( 254$)$}

- Der eine bradjte bie Geidjidjte von Sims fon aufs Tapet, weld)e fein \$farter neulidf ew flårt batte, uno madite fich bod) jelbft alierlet Broelfel gegen das grobe Thor, mas Simjon getragen, uno bie Futaje mit oen Feuerbianden zrwifhen ben Schroanzen, ob er gleid) fonft in fetnem slauben feft war.

Sie erzåblten fich Darauf allerlel (s)efhich) d)en aus ber sibel, nicht als of fie olefelben fidon als befant vorausfergten, fondern fie is: gendwo als angenébme Scliftorien Gátten erzáblen boren, Das meifre batten fie aud von ifsem Pfarrer gebort, und nicht felbft gelejen.

Der eine fing Darauf von ben Juben im alten Teftament an, und daßs die jef̧igen Davon abftammten. -

Sie fino in Enigfeit verdammt! - Fagte bet andore fo faltblutig und zuverficjtlidh, als ob or fie fichon fichterlob bremen fábe.

2Bit befamen nun fefor oft neue \$affagier, Sie zureilen nur etne Strecte mitfubren, uno Dann roteder abftiegen. Unter andern eine Brants weinsbrennerinn aus gondon, Dis uns mit sines 


\section{(255)}

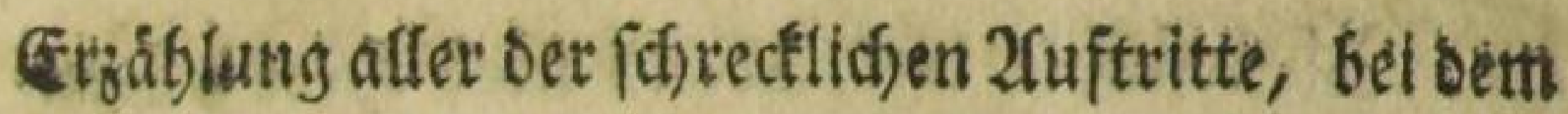
lefecten 2(ufrubr in London unterbielt. Beforts Dets nuffalleno war mir, wie ein Serí iffem Şaule gegenúber to rotityend war, baß̄ et auf Der Daaue eines fhon Galbabgebranten Şaules ftand, und noch mit eigenen Scănden bie Stet ne loszuteísen fuchte, weldje Das Feuer batte fethen lafien, bis er erfdjoffen warts, uno rúcs lings in bie Flamme fiel.

(Endich) Eamen wit Denn im volfem Fiegen

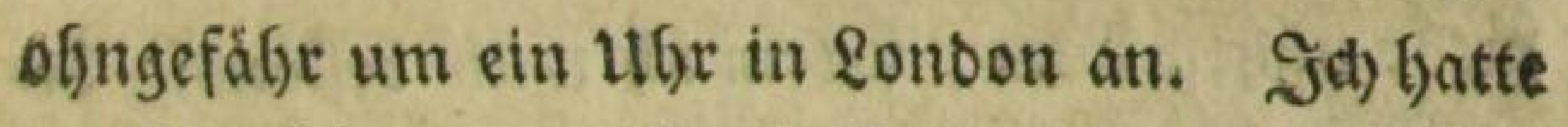

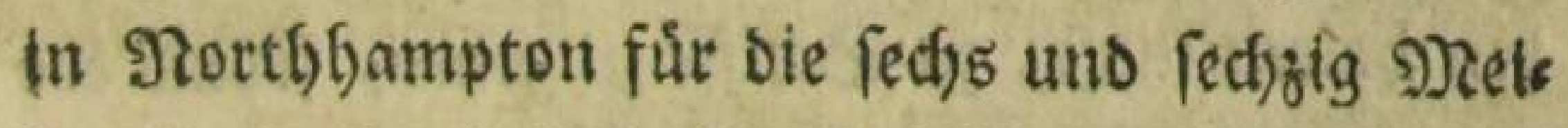
len bis Rondon, fectzefnn Schillinge voraubbezabs.

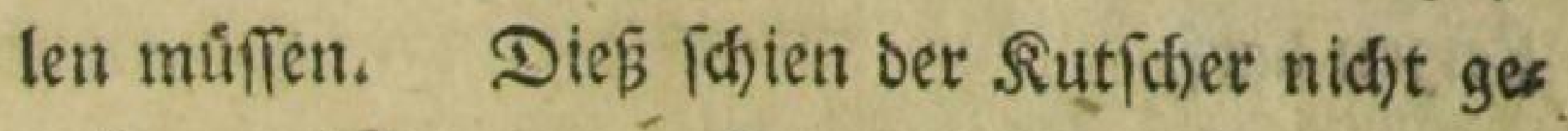
wís zu wifien, utio fragte mich Dafer, of ids jchon bejablt babe, welches er mit bod) nun auf mein 2 sort glauben mußte.

Ich) (ab)e nus, wie ein halber 2 silber, on id) in Sonbon wieder anfam; Demobngead)tet nabm midh Seert Pointer, bei bem mein Soffet f(ano, febtr freund fd)aftlich auf, uno lię̧ fid) úbes

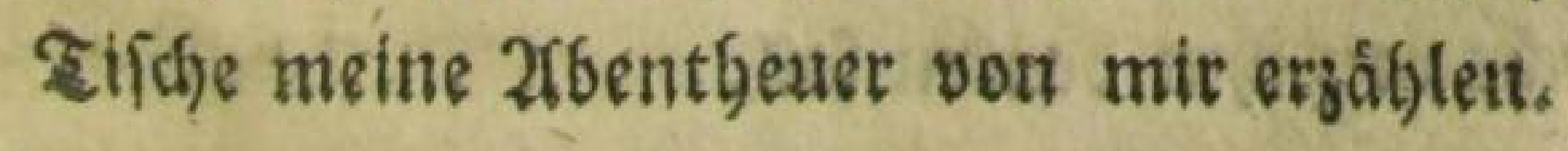




\section{( 256$)$}

Эक) befuchte ben 216end nod) feertn Reons baroi, welcher mich, weil id, wegen ber गुar Fage, bie id) etroa nod auf guten গgins warten muste, fein Logie miethen rooflte, bts babin in Freemajons Tavern unterbradjte.

ZCllein bies in Freemafons Tavern warte if nun iffon acht Tage, und ber SSimb refyt noch

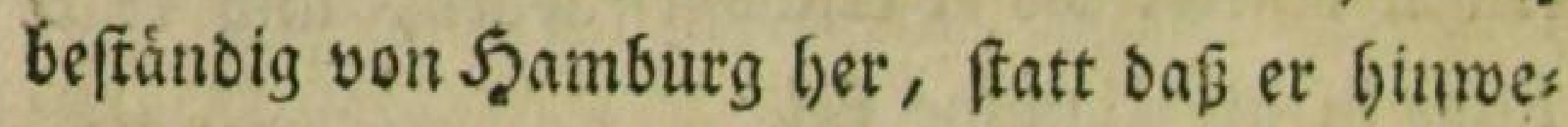

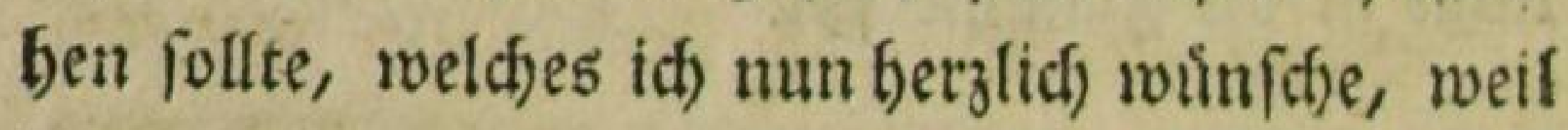
idf) boct) Den biefigen 2(ufenthalt faft gar nicfts mebr núkęen fann, invem id) micl beftándig bes reit Galten mus, zu Echiffe zu geben, fobald der

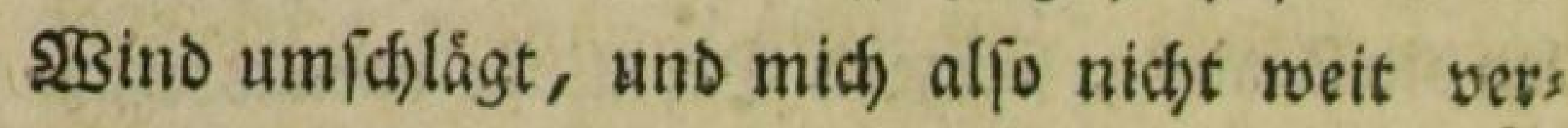
feigen Darf.

2ffes ift jeţt woll von Focfinghams Tobe, unb der barauf erfolgten Beránderung

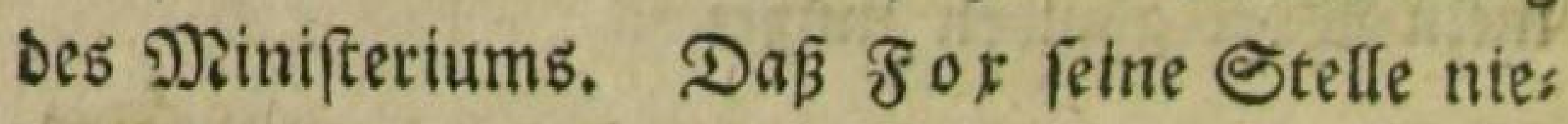
Dergelegt bat, Darůber ifí jedermann aufgebrad)t, uno boch iff es fonderbar, alles nimmt Theil ans

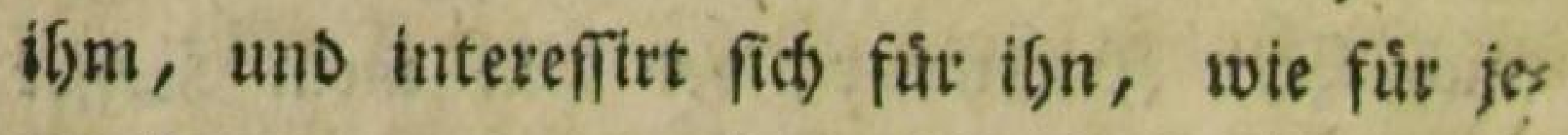
manben, von demes etnem letb tjut, wenn mas foflecht von ibm denten forf. 


\section{( 25t)}

If Dienfitage war eine ber wichtigften De: batten im \arlamente. For war aufgefordert, Feine Grúnde Der Pation Darghtlegen, warum ex refignitr habe. Um eilf Uhr war bas Şaus von

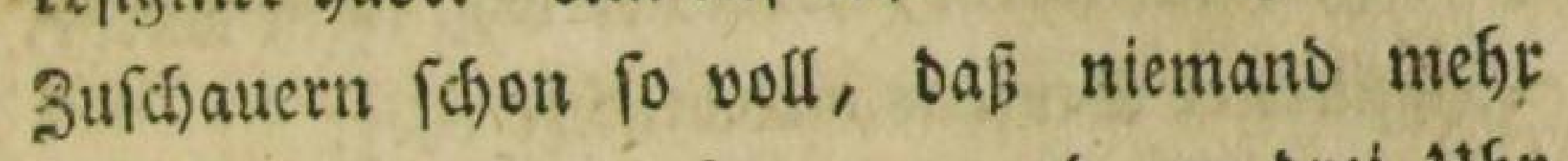
bariun Plaf finden fonnte; unt um oret Uthr gefyen boch erfit die Debatten an, die biefimal bis

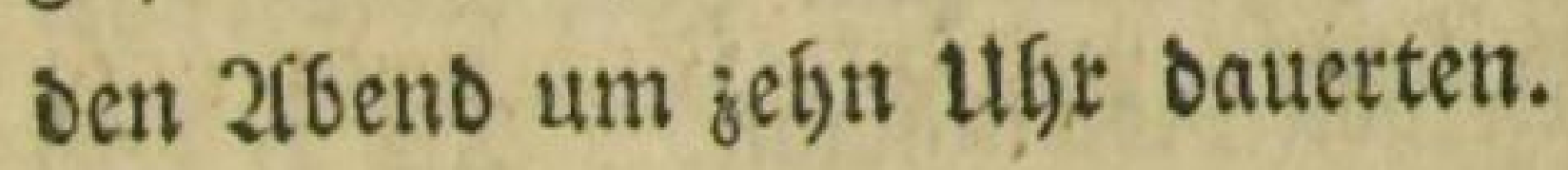

Giegen viet $\mathfrak{H}$ )r Eam For. 2flles war voll Erwartung. (Ev fprac) mit groper Sefeftigfeit, ließs es aber bennodi) merten, wie lef)e er bieje Şeftigéeit måß̧ige, uno als er nun ben 厄d)titt beit er getban, mit allen Srúnben vertbeloigt fatte, uno mun lagte: now I fand here again, poor as I was. \&c. nun frete idh blet wieber, arm wie id war! u. F. w. To war bieß wirelidh fút sen Subơter rúfreno uno erf́chútterno.

Der Sieneral Sonway fagte barauf feine Sirinde, worum er nicht abdanfte, ob et gleids mit Şerten for uno Surfe einerlei politifose

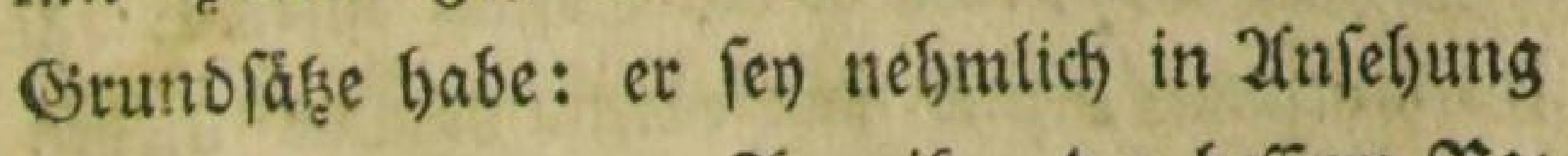
Der Jitbependenz von ZImerita, ber beffern Fies pråfentation bes ३olfes im \arlamente, uno भ 3 


\section{( 158 )}

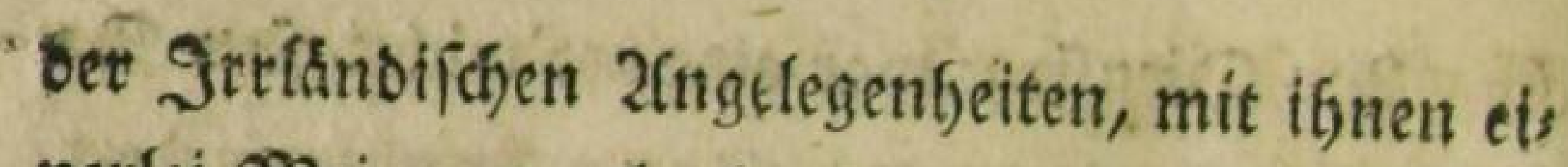
netlei Nieinung, glaube aber nicht, baśber jef̧ige Minifter, Srow Sdjelbutn, gegen biefe (Stund:

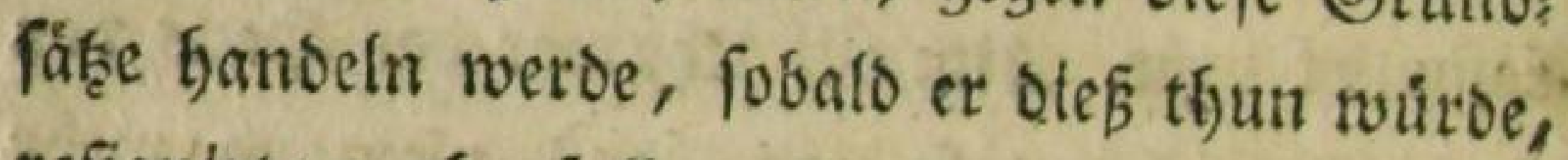
refignite er ebenfalls, aber nicht eber.

Nun fand $\mathfrak{B}$ urfe-auf, uno rebete in feff blumenteichen 2fusorticten jum Iobe bes verftor: benen Marquis von Rocfinglam. 2lls er Eetn binlanglidjes(Siebor fand, uno viel um ficf plauben uno murmeln borte, fagte er mit grober Seefs

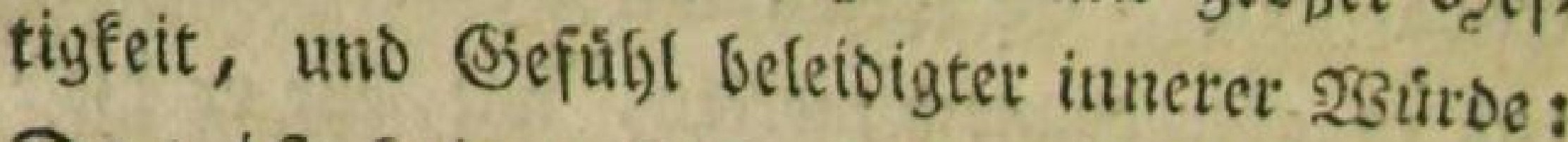
Das iff feine Szehandlung fure ein io altes Darlamentsglied, als ich bin, Hno idf will gebort leyn! - morauf for gleid) eine allgemeine Stifle bertidfte.

- Radjbemer nun nod) fér vieles zu Stodfing: bams lobe gefagt batte, fing er an: 'was ben

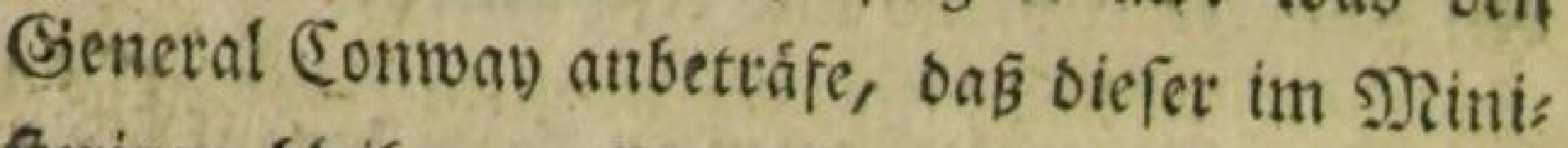
ferium bleiten wofle, fo erinnere er fich Dabei einer శ̧abel aus feimet Sindfyeit, wo oer 230 off vorgeffellt wirt, wie et die (Seftalt eines. Edja: fes antummt, uns von einem samme in ben Stall gelaffen wito, weldjes z̧war zu $15 \mathrm{~m}$ fagt; Mama, we babt ibr die grofien Nagel une die 


\section{( 259)}

fogarfen ådine ber? Demolngencaditet aber the

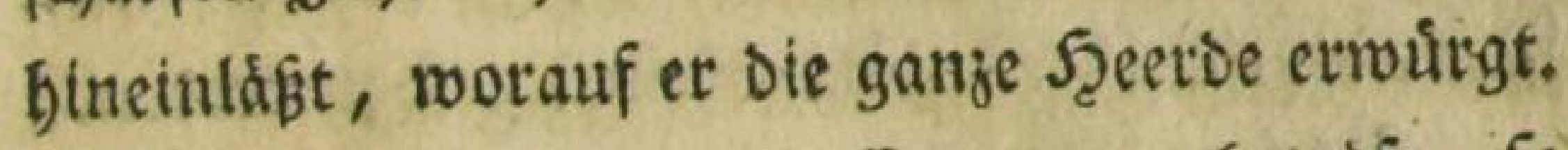
25sas nun ben Sseneral Conway anbetráfe, fo fáme es ihm gerabe fo vor, als ob bas eftraf

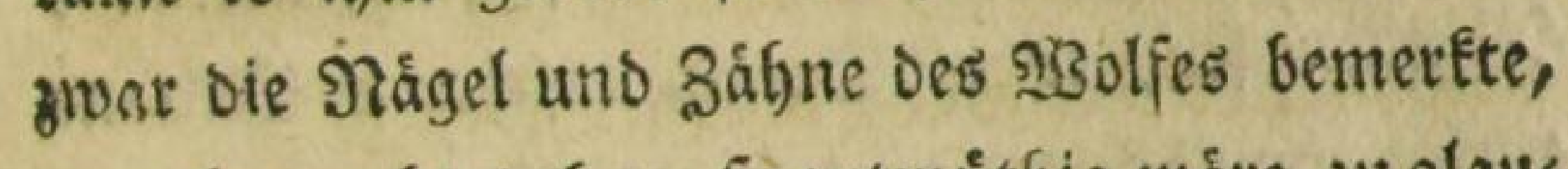
bemofngead)tet aber, fo gutmútbig wåre, zu glaus ben, Der 2 Solf werbe wobl feine Patur ánbern, und ein Eamm werben. Er wolle bamit gat nicht auf ben (Graf von Schellburn zielen, nur

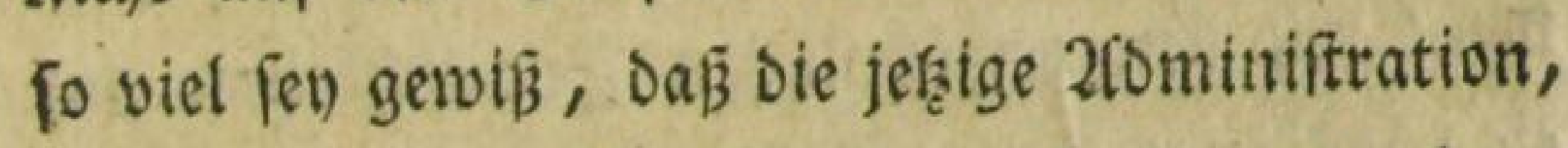
noch taufenomal fidfectiter fen, als fie unter bem Lord North) (Dee Gier gegenwarttig faß́) gerwe: fen wáre.

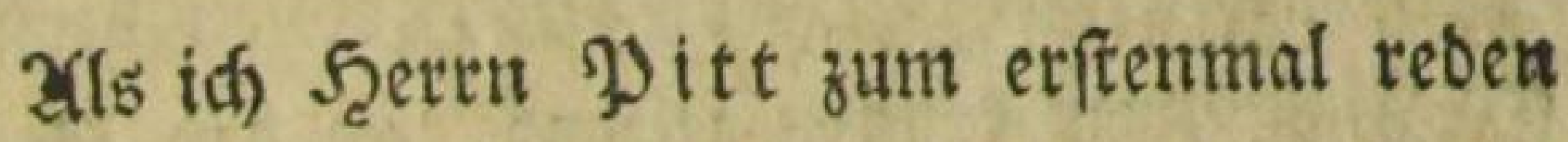
Gobrte, erffaunte ich, Daß̃ ein Diann vou fo jus genolicjem 2 (n) fefjeir auftrat, uno inbem er (prad), fo viel 2fufmerffamfeit auf fich erregte. (Ex

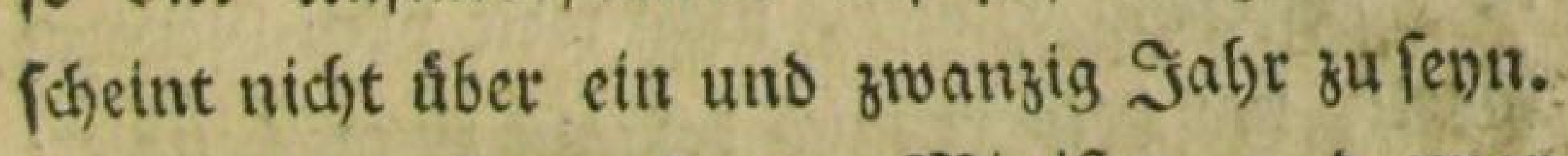
Eben Diefer Moitt ift inum s)iniffer, und fwar Chancellor of the Exchequer geworden.

Ess iffe erfartectlidh, was in ben Seitungen, wovon bier táglid) zroslf uno mebrere beraus: zommen, die es theils mit der Mainifterial theils

$$
\Re 4
$$




\section{(260)}

mit ber 2fntiminiffertalpartbei Galten, bei biefer

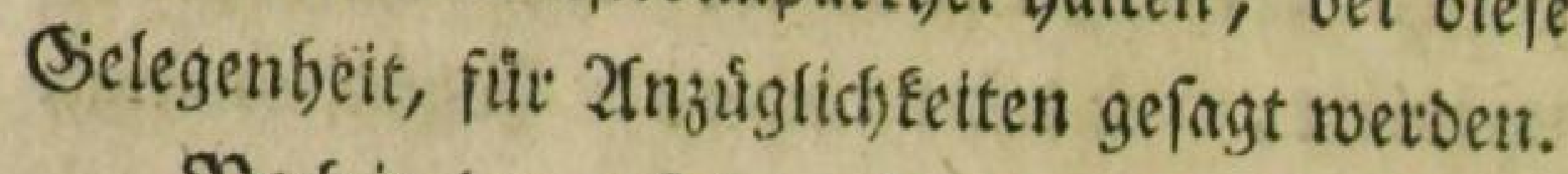

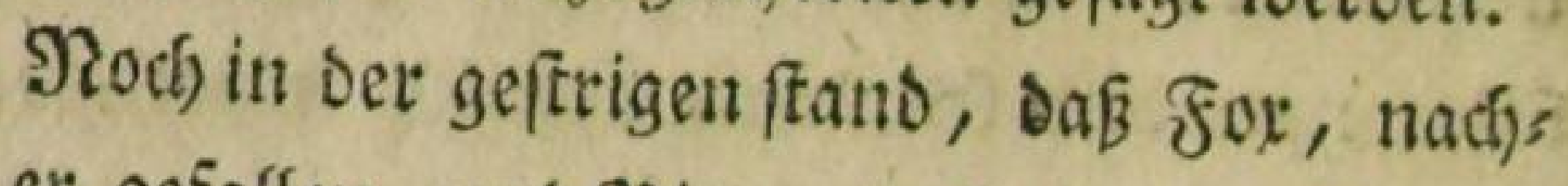
bem er gefallen, und $\mathfrak{\text { Ditt, }}$, cin fo junget Mann, Minitifer (ev), er mit Satan, weldyer in Doittons vertortiem Daradiefe, oen vou (Bott beguinftigs ten Dienlitien erblicft, austufe: O hatefull Sight.

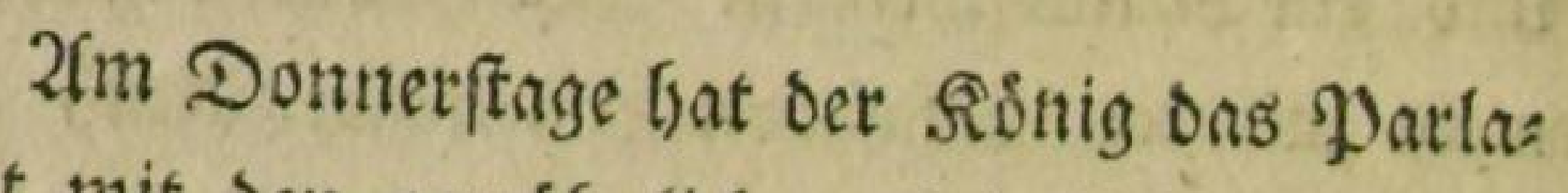
ment mit Den gerodfunfichen Feierticfeeiten auf

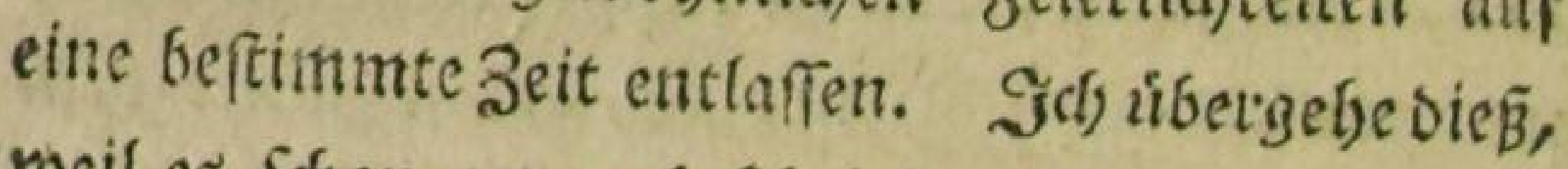

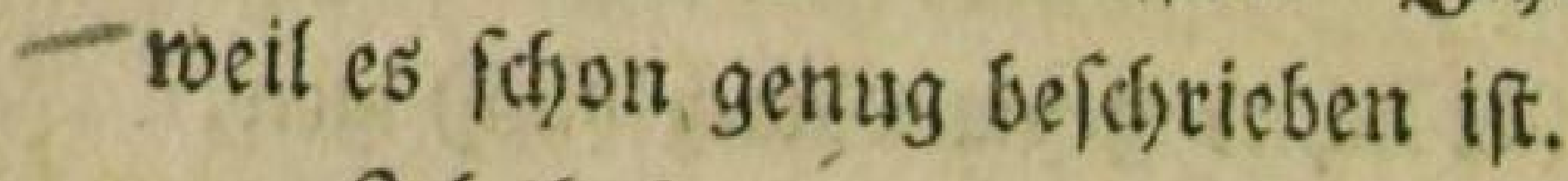

Jith lyabe audh noch in biefen Eagen ben. Şerrn Baron Sirotgaus, Diefen berúfms ten FuBganger fennen geleunt, ail ben id) von

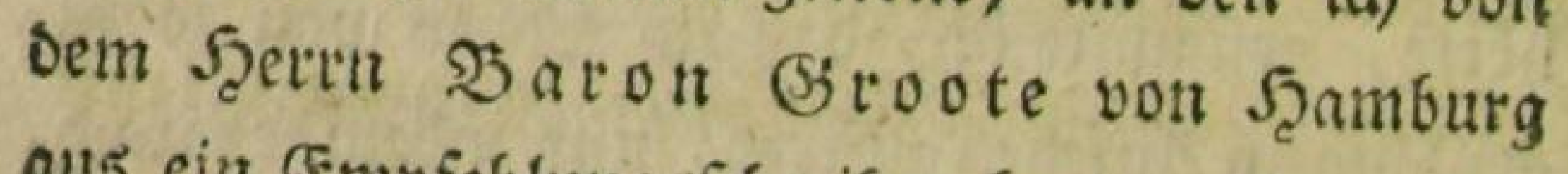
aus ein Empfeblungsfdyreiben batte. Ert wobnt in CGefterfielo Seaure, nidft weit vom (seneral Daoli, mit bem er mich befannt ou madhen vers fprodhen bat, wenn idf Beit babe, iban nod) ein: mal ju befudeet.

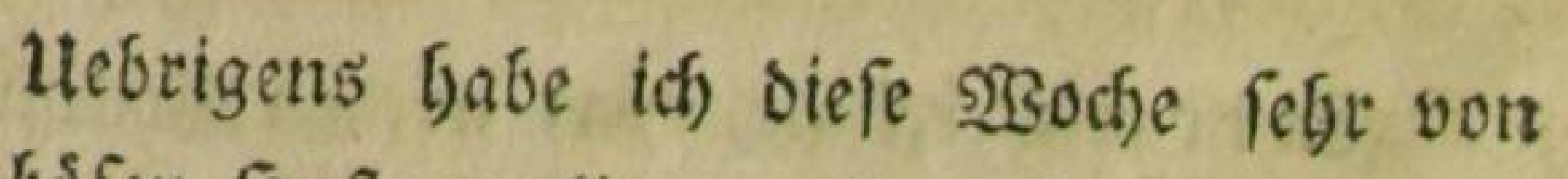
Den boffen SYuffen gelitten, ben if) mit aus dee Szoble gebradjt babe, fo oak :d, einige ₹age nicht 


\section{( 261$)$}

Gabe ausgeben durfen, wo mich bie Scetrh Schonborn und geonfyardi fieisig befucht, uno zu meiner 2fufmunterung fefre viel beige: tragen baben.

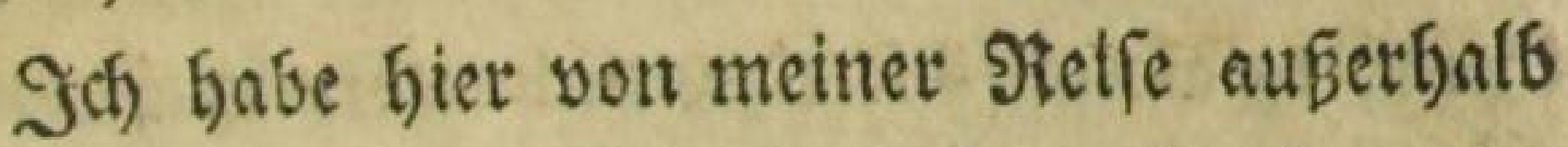
Eonbon fo viel zu cezáblen gebabt, als tid wabts (d)einlid in Deutichland von (England ufbert)aupt werbe erjáglen múfen. - Den meifren \&euten, betren iff biet in Eondon von meiner Sieife ex" zálgle, ift bas, was ich gefelgen babe, gallz ets waร กอนеร.

(siniges muE (đa) Dod) nun noch nachbolen, was idf in 2fnfefoung Der Giefigen Deflamation, 2fus[prache, uno Dialeft, bemeift, uno Şgnen zu f(f)reiben vergefien habe.

Die Englifd)e Deflamation fobeint mir latt: ge nicht fo vieler 2fowed) felungen fábig zu fenn, als bie unfrige. In ben Pुartamentsreden, Srebigten, Theaterreden, ja felbft im gemeinen Eeben, werben bie sjorioden am Enoe immer mit einem gewiffen fonberbaren, etutónigen frall ber Stimme begleitet, Der bei afler feiner Wios notonie, boch etwas folioes uno nacjoriceflidses fat, uno ben ein 2luslánder folmertich nact)afys

$$
\text { भi } 5
$$




\section{( 262 )}

men lernt. Şert \&eongard fhien mit in

- einigen Stellen, oie er aus dem f̧amlet befla, mitte, biejen Fall der Stimme felor gut gu trefs fen. Ferner wiro Der $2($ ccent faft mebre auf Die Epytheta als auf oie eigentlidjen Gubfrantive ges

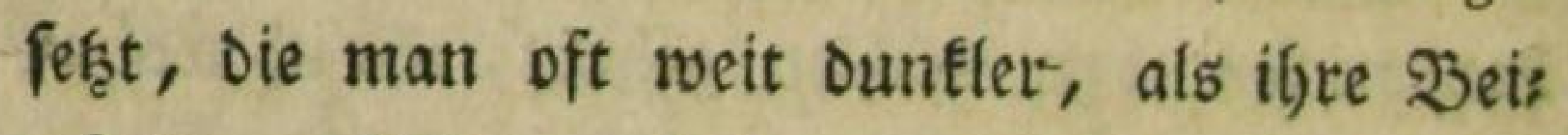

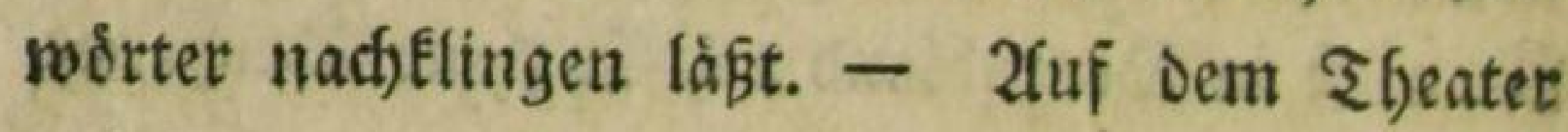
brúct man bie Snfben und2580tter aufferorbentlich beutlich aus, fo Daß man fier immer, in 2fnjebung Der Englif̧chen 2lusipractie uno Deflamation, wohl am meiften lernen fauth.

(Es gibt in Eonoon aud eine 2att von bejon: berm Dialeft: fo fagt man $8, \mathfrak{Z}$. it a'nt, anffatt it is not, es iff nicht; I do know, anftatt I do not know, ober I do'nt know, id tweís nidjt; 1 do know him, idf fenne ifn nidft; weldjes

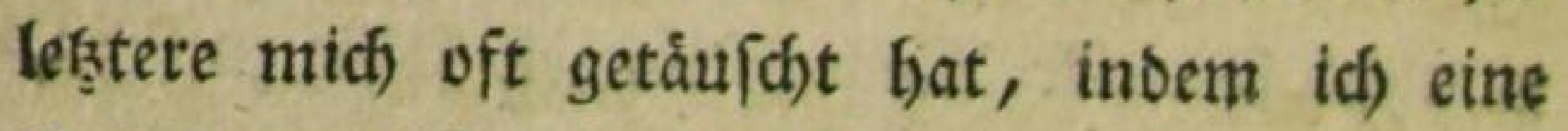
Berneinung fúr eine \$ejafung nabm.

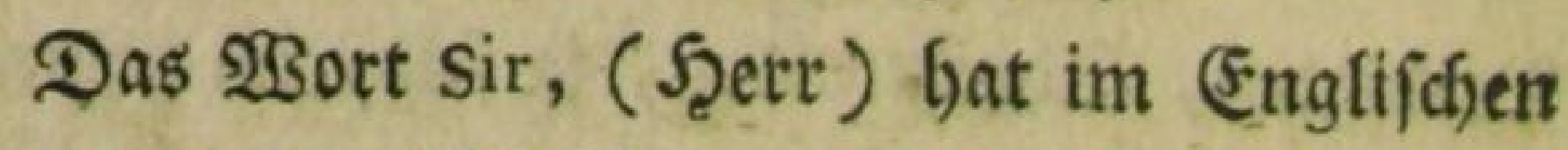
einen gar mannidffaltigen Gebraudf. SJit Sit

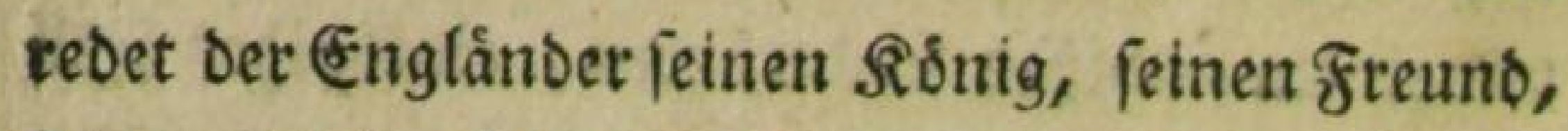

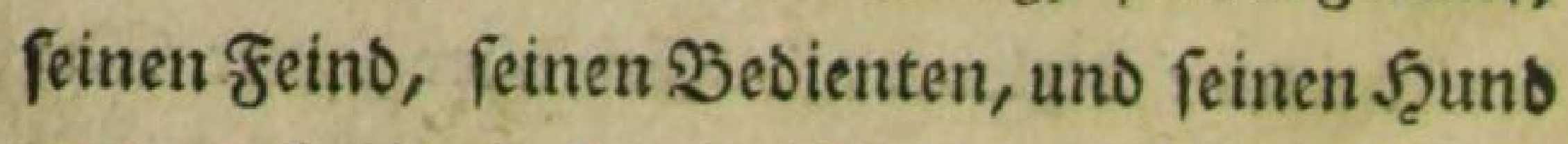
an; er bedient fiith beffelben, auf eine fosfliche

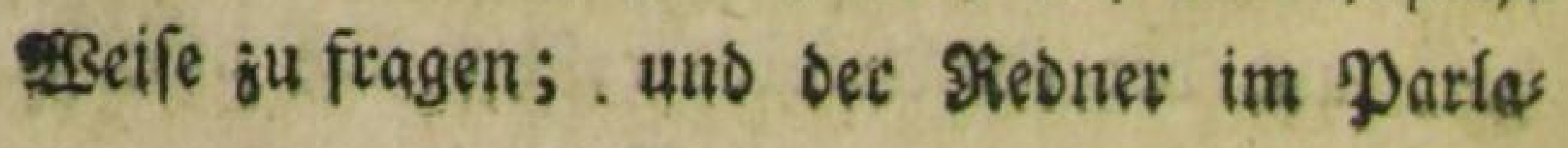




\section{(263)}

ment, ben Utebergang Damit zu machen, went er nicht weiter fann.

So beift alfo Sit? in einem fragenden इone: was befehlen Sie? - Sir! in einem Demútbigen Tone: gnåbigfer Sonig! - Sir! in etuem trofsigen Tone: es ftehen cin \$aar Oht: feigen zu Dienfre! - zu einem Scunde gefagt, bebeutet es eine Tracht \ruiget - uno in bent \$arlamentsreden mit einer \aufe begleitet, beißßt e5: (ic) faum mié) nicht fogleid) befinnen.

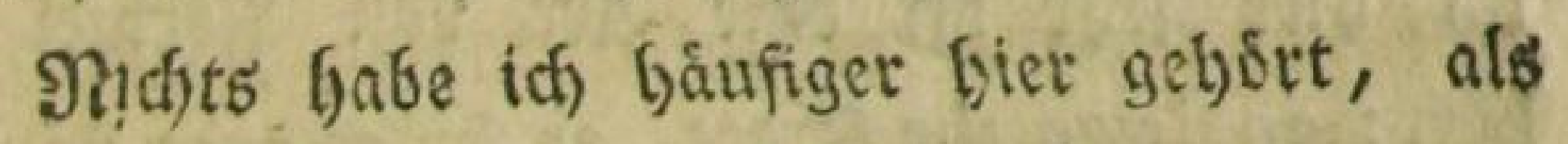
ben 2fusbrutef: never mind it! Eajpt Das gut fenn! - (sin Träger frürte, uno fiel fich auf Dem 'Jffafer Den Ropf entzwei: never mind it! fagte ein Englanber, der vorbei ging. 2fls id, yom

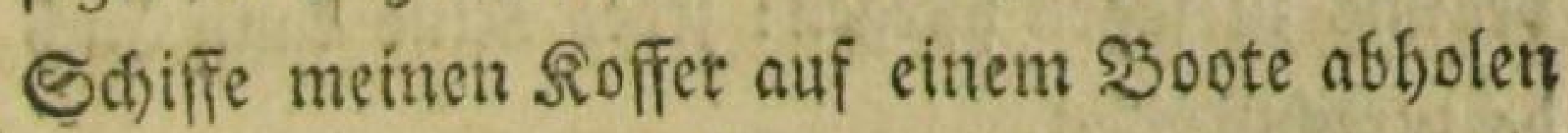
lié, ruberte Der Gdjiffer zroifojen bie Săbne, uno fein Jange ber vorn ftand, Befam Die ent:

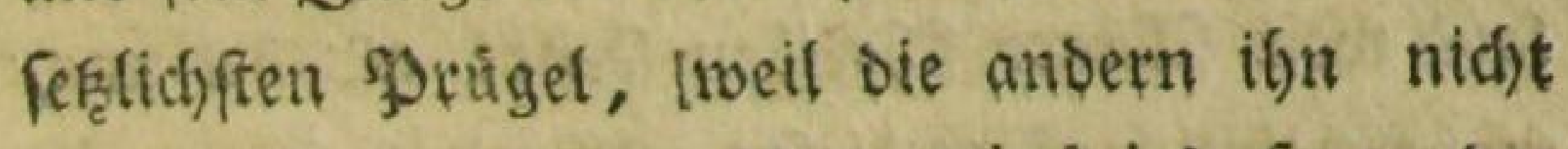
butulfaffen wolften: Never mind it! fagte bes 2lite, und ruberte inmer zu,

Die Deutfanen, weldye lange bier gewefen find, reben faft in lauter 2finglicifmen, als: es nif nicot thun, anfatt, es iff nisht bins 


\section{( 264$)$}

fơngliff, and bergletchen. İa einige lagen

- Pogar: idf babe es nidft geminded, id babe midg nifft baran erinuert, ober baran gebactst.

Englander, Die Deutich) fprectien, Eennt man bald an ber 2fusfpradje bes $w$ nach Englis fifer 2(rt; anftatt: id) befinde mid) wobl, fager fie, idf befinde midf) u obl, indem das wo faft fo sweich, wie ein iffnell ausgefproffines u flingt.

Feim Buredjtroeifen auf den Straß̧en babe idh bier fegrt oft eine 2frt von formel ges Gortt: go down the Street, as far as ever you can go, and afk any Body, geft Die Strake binunter, fo weit igr fommen fonnt, unb fragt, wen ifr wollt! - fo wie wie bei uns zu lagen pflegen: jedes Sind Eann (5uch on zureditweifen.

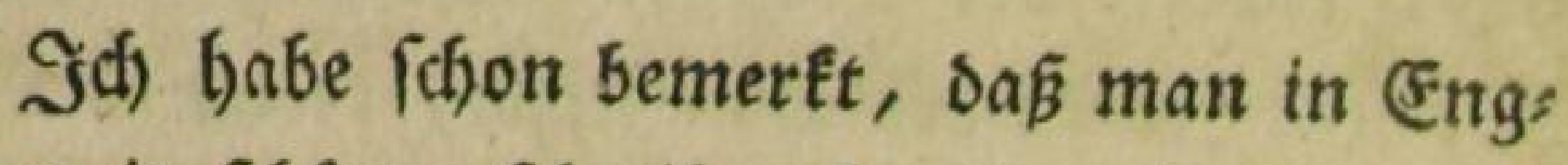
land weit fojosner fogreiben lernt, als bet uns, svabreicheinlidh rưlget biefes auch mit Dafer, weil

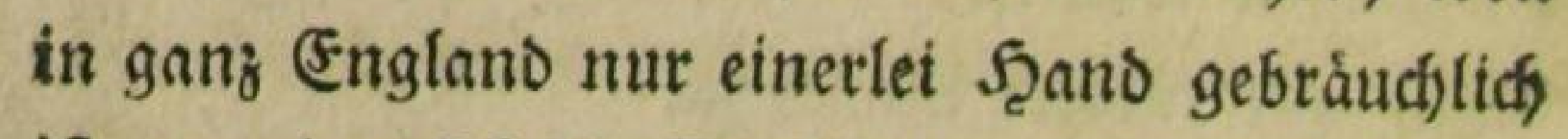

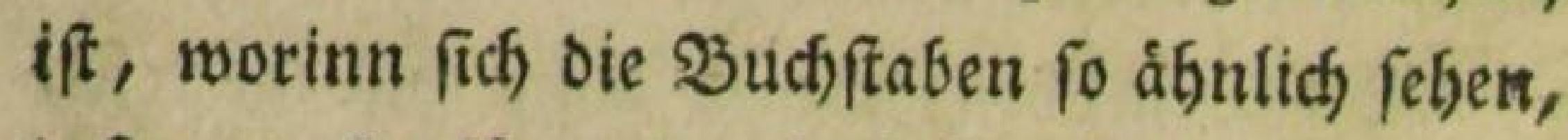
Daßs man fie fúr geoructit balten foulte. 


\section{(26;)}

Heberbaupt (d)eint Rede, Schrift, 2fubs orud und Sd)reibart, in (England meit mefs fixirt zu fenn, als bei uns. Der gemeinfte

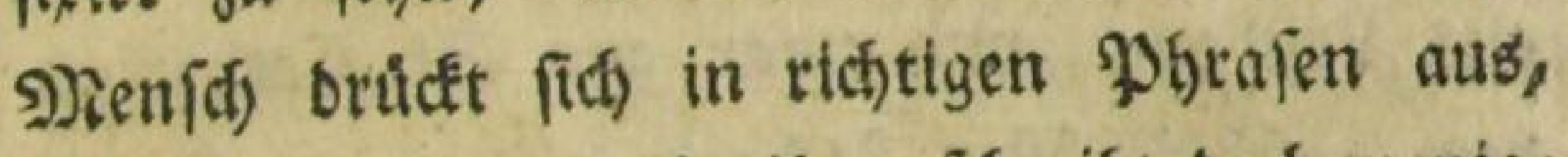
uno wer ein Sudf (d)reibt, fafreibt Dod) wenigs: ften forreft, wenn bie Sachen audb nod fo (d) fecht finb. Denn über ben guten Stil facheint nan bock in (England einig geworden zu (enn.

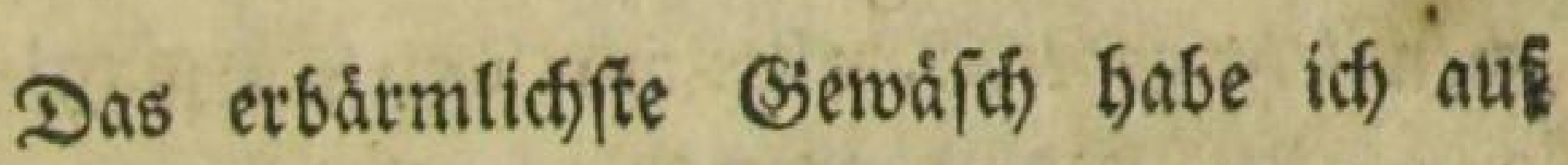
Den Sanzeln gebort. Sids bin beute in einigen Rirchen gewejen, wo bie prebigtent aus Dogs matijajen feeften genommen ju lenn fobienen. (Es foll bier ein Jude roognen, von dem fich bies fige Eseiftlidge ifre Presigten fur Geld verfew tigen lafien. 


\section{(266)}

Lonbon, ben 18tent Gult.

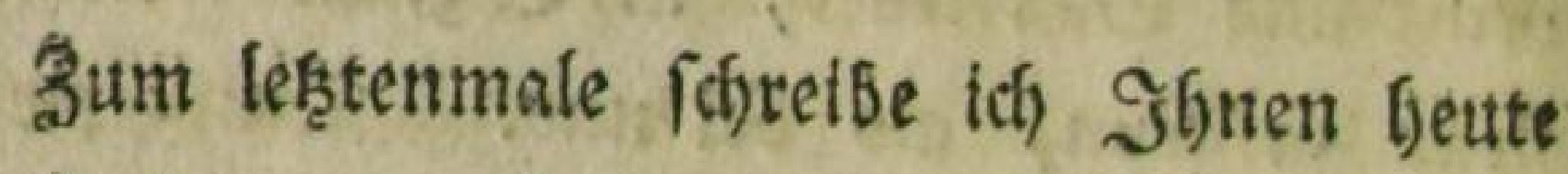
aus Sondon; und zwak aus St. Eatbatins, oem abféfeutichfen godje tn Dex ganzen Stadt, wo id) mich aber besroegen aufbalten mus, weil bie groben Sthiffe auf Der Shemfe bier anlan: Den, und abgeben, und wir fobalo ber 25 ind fich oreft, fortfeegeln werben: Der bat fich num ebén jeşt georebt, aber wir feegeln erif g) orgen fort. Seeute Eanu ich Shtnen alfo noch, fo viel ids toeí, erzánflen.

2(m Miontag Miorgen fog idf aus freemas fons Tavern bieber in einen (Safthof, worinn ein beutficher SSirth ift, und in weldhem alle Seams butger Schiffer einfefren. In Freemnjons Tavern betrug meine Siecfinung fút adjt Tage

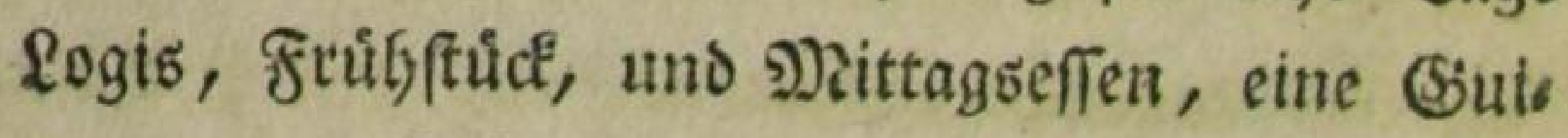
nee, neun Schifling uno neun ঐence, alio beis

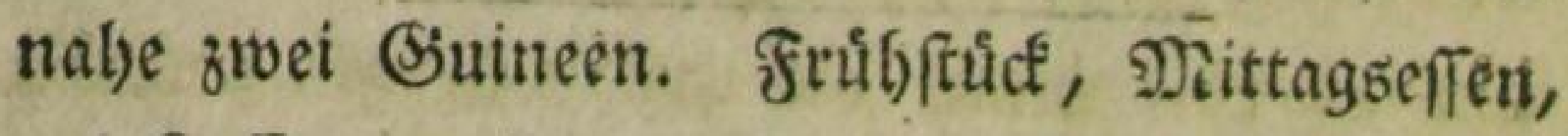
und Saffe, war intmer obne Utnter fdied jebes einen Sdfilling getecfnet. Fưr oas Iogis bezablte id nicht mefre als zrodlf Sdjillinge fúr bie \$Bodje,

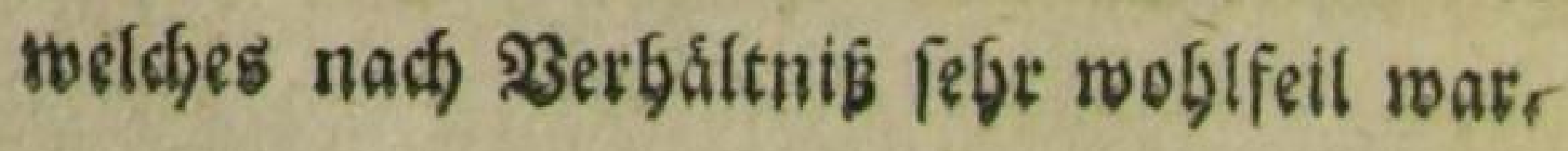




\section{(267)}

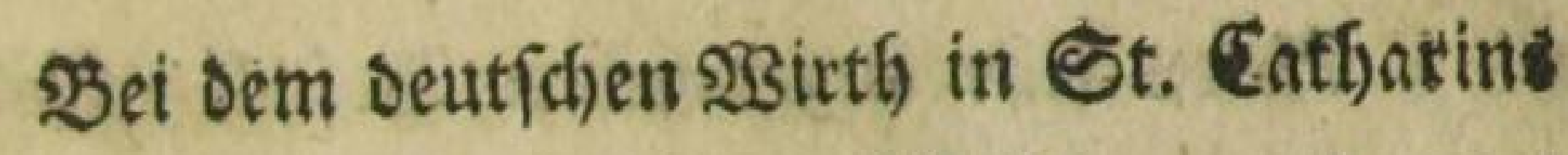
gingegen iff alles viel woblfeiler, uno mant tist, trinft, und wobnt bier wodtentlich furr eime balbe Ssuinee. Iidh móchte aber Demohngeadhs tet feinen rathen, bier lange zu logiren, wet fich in Qonoon umiefen will; benn St. (athos rins if einer ber abgelegenf̧ten uno unbequemften Oláge in bet ganzen Stadt.

SBer fier vom Stifife ausfteigt, beformmt biefe jămmerlidje enge fómuzige Straß̄e, ins diefe den Einfturz orobenden Szüuer von \&ondon zuerfizufeben: und alio gewis beim exften anblia feinen fehr vortbeilfyaften (Eindrua von diefer pråd)tigen uno berúlymten Stabt.

Bon sulftruatiftreet ober Cavendifa) quare bis Et. Eatharins ift beinabe etne balbe $T_{a}$ gereife. Demofhngead)tet hat mich Jeerr $S$ d) $\delta \mathrm{ns}$ born, feitbem id bies wobre, táglida befudt,

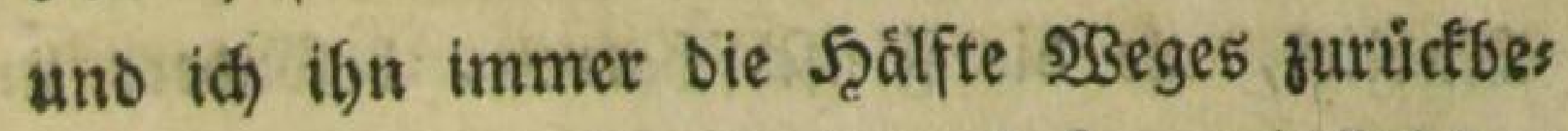
gleitet. Şeute Nachmittag baben wir bei Der Paulsfirche von einanber $2(6)$ ffied genommen.

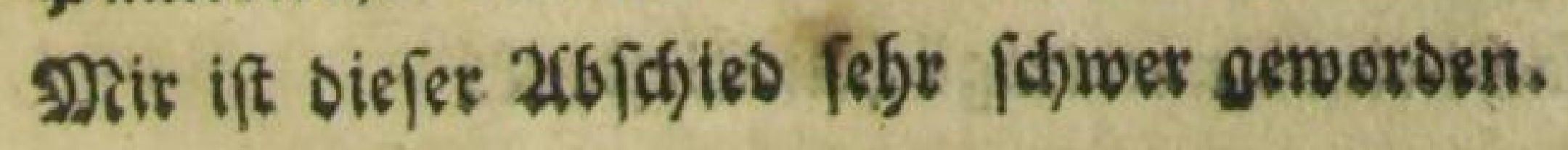




\section{$(268)$}

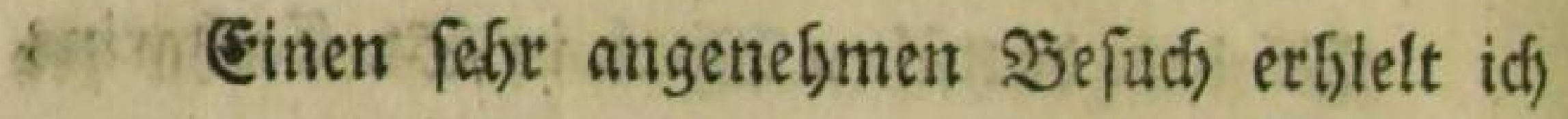
eben biejen Rachmittag von Şetrn Şanjen, einem Mitarbeiter an bem Zodfnetidyen Lefe: buche fúr alle Stánbe, welcher mir einen Strief

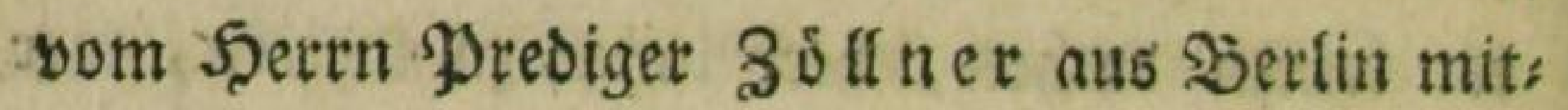
Gradjte, uno gerabe in Lonbon aneam, Da tch abveifen wollte. Er gefgt in Scandlungsgeftgaf: ten nad) giverpool.

Dieje Tage thber habe if benn noch aus 'Langetrueile cinige Gegenden von Eonown butch: frtichen. Sich fuchte geftern Das weftliche Enve Der Stabt zu erteichen; allein fie onuette einis

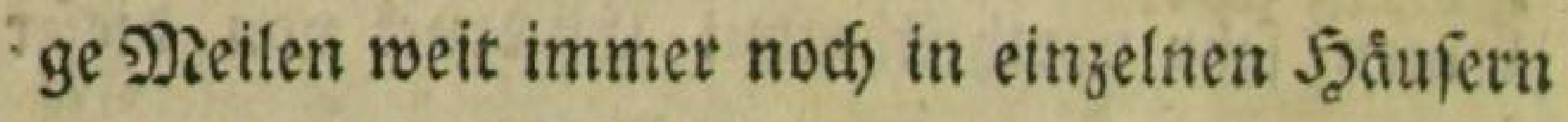
fort, die aber bods eine Strabe autmadten, bis ich) endlich, ba es fichon bumeel war, gall ermu: Det zuridiféfrte, ofne meinen swed elteicht zul Gabetl.

Nichts macht in Ronoon einen beşlidjern Inblict, als bie Fleifhicharten, befonders in

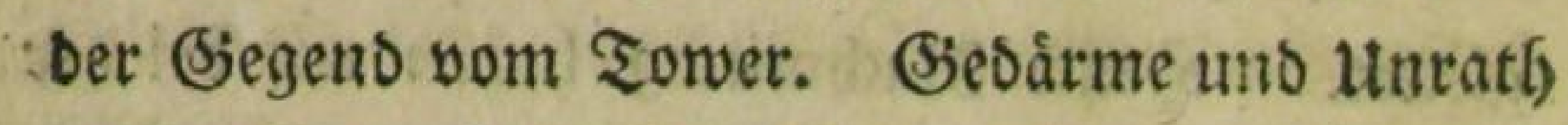
wiro alles auf die Stzaß̧e geroorfen, uno verur, facht einen umertrágliçển Sieftant. 


\section{(269)}

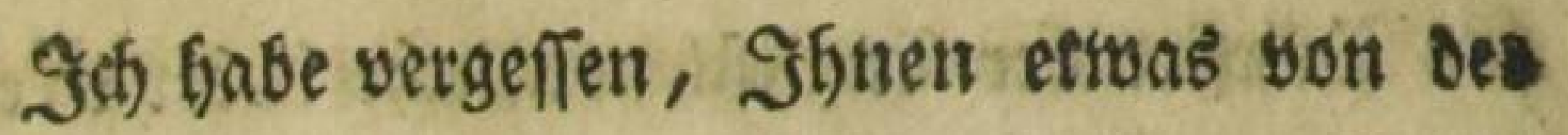

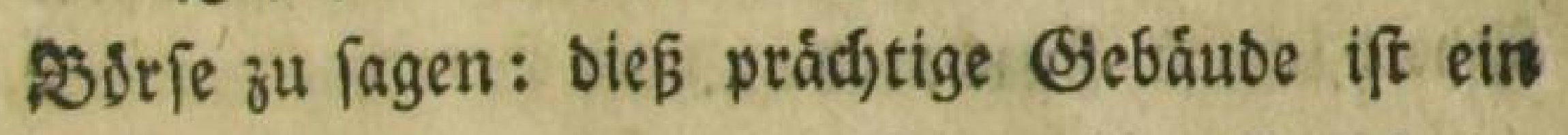

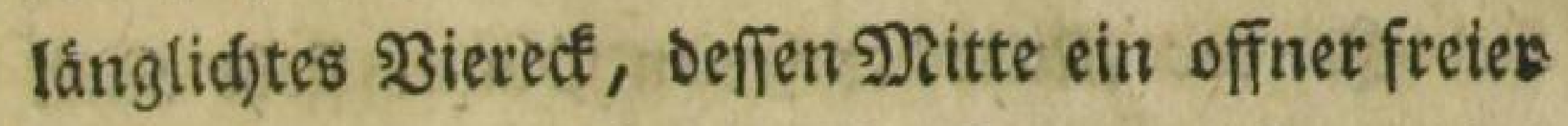
ઝlafe ift, wo fid) Die Raufleute vetfammeltr. gruno berum fino bedectte Såulengånge, uno an

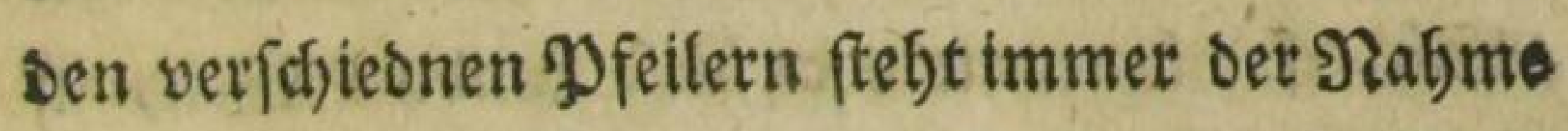
Der Gandelnden פation verzeichnet, welche man Gier treffen will, Damit man fich unter ber \$) ge von- Menidjen einanber finden fsune. Zfud finb unter ben bebecten (Săngen fteinerne șánte

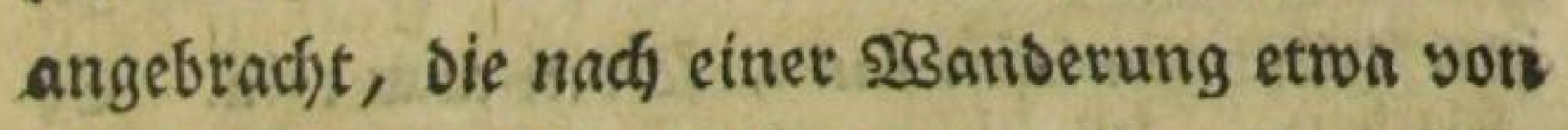
St. Catbarins bis bieger zum 2fustuben fẹs bequem fint.

Tiund umber an bet 2 banden fint allerlet Zivertifiements auf grofen, gebructen \$ogen angelchlagen, wotwnter ich) eins von ganz fonber barem Inbalt las. (5s ermafnte nefmlid ein

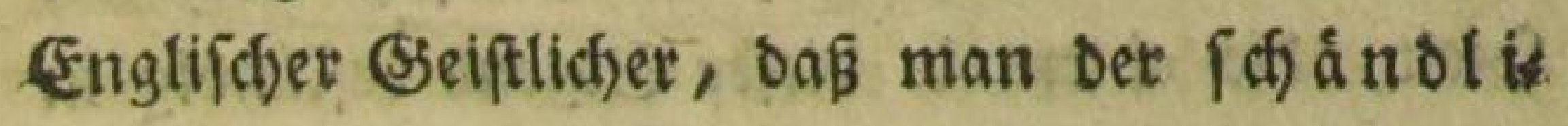
d) en Darlamentsafte zur Dulbung ber (Eattjos. Sicfen nid)t barurd) beiffimmen follte, Daßi man etwa feine Rinder, 子u ifrem ewigen ßetberben, bon ifgnen unterridsten und erzlefgen ließe; font Dern man folle Dod) ifin, als sinem red)tgláubi: 


\section{(270)}

gen Driefter ber Engfichen Ritche liebè bie fen Berdienft fumenden.

asit In Der Ditte Des freien Whakes fteft Sart Des anvern feituerne Silofaule. - פBenn iff

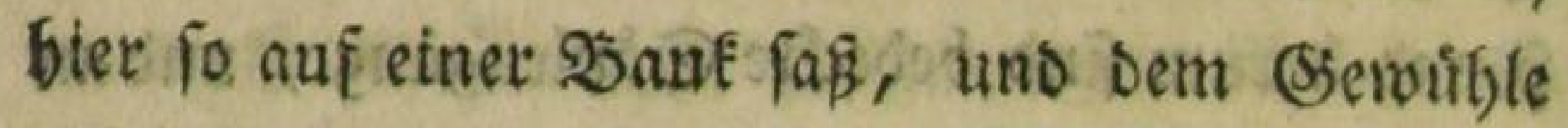
zufals, fo Eam mit bod Diefe gononer 2 Belt, in

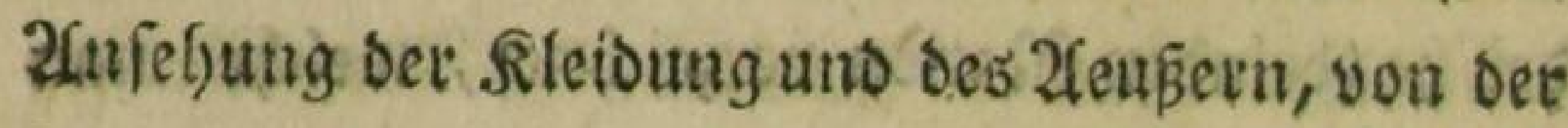

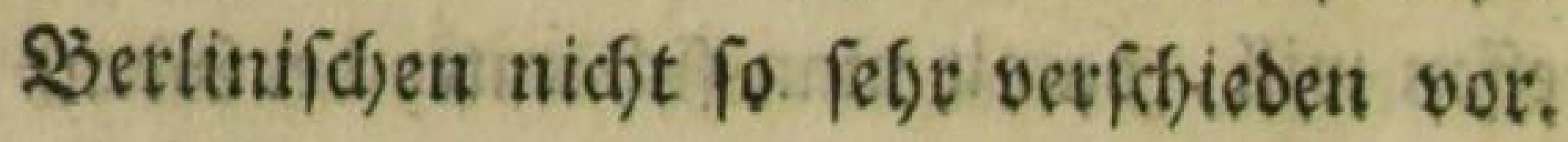

(1) Didft bei bet $3 \delta$ befe ifo ein Laben, wo matt får eitzen Penny oder Scalfpenny im :3otbetge: ben Beitungen lejen Eanu, fo viel man will. (5)

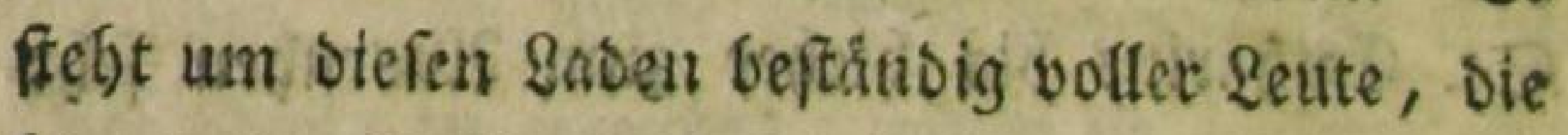

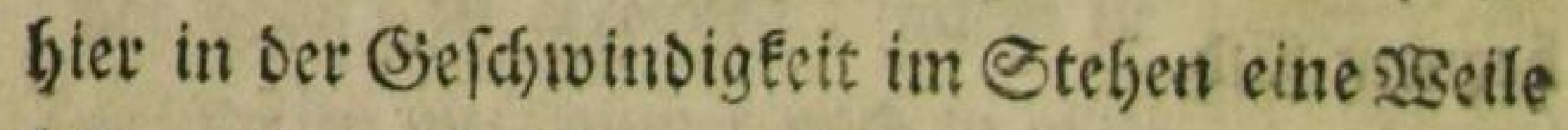
lefen, ifyen Scalipenmy bez̧ablen, uns baum nei:

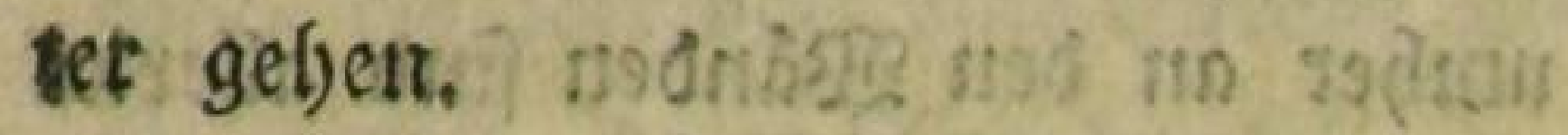

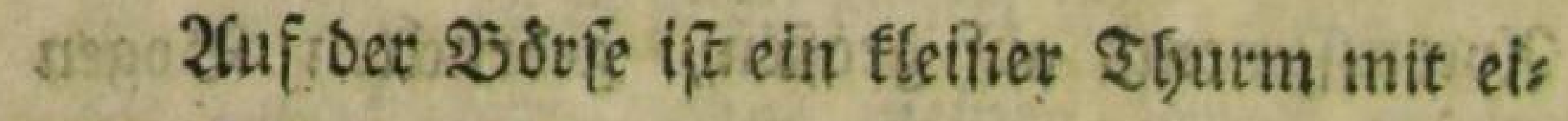
nem Silocfenfipiel, Das fefor angenefun flingt; abor nid)t megt als eine jiemfich Ituftige \$ielobie fotelt, Die einem in biefer. (Siegens beftandig in Deth Obrem fdjalle.

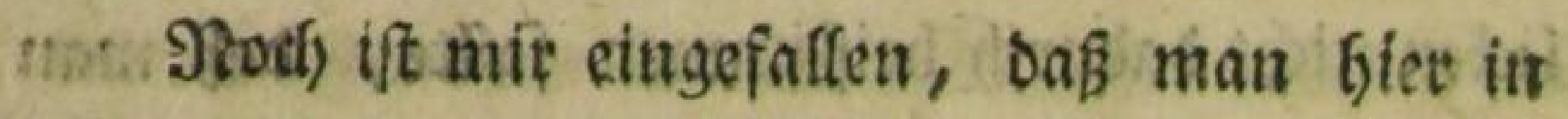
fonbon feures Elementainerts un feiner Supfers tafeln zuin Alnterticht fúr Sinber bedirfte: mat brauchte fie mur in die Straßen Der. Stadt zu 


\section{(271)}

fübren, uns ignen alle bie Dinge feloft, roie fie wirtelich fino, zu zeigetr. Denn bier ift bafúr ges forgt, Daß̧ alle ઝrodufte ber Sinffte uno Des

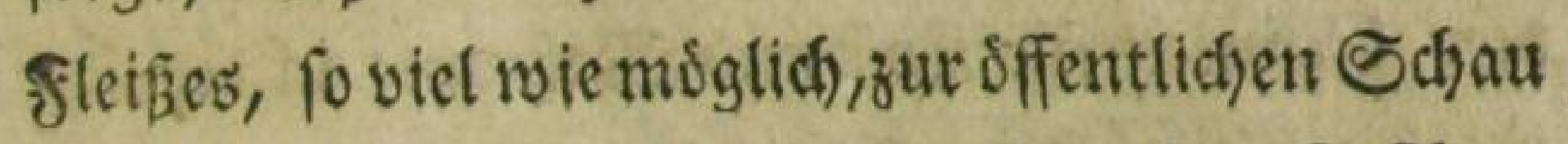
geftellt fiub. Ssemábloe, Runftwerte, Roftbar: feiten, alles jeigt fich binter den groß̧en Şlass fajeiben unb bellen Fenftern bet Gienoslbe im vortbeilfafteften \$rofpeft. (5: feblt auds nie an Sufchauern, wefdhe hier ober ba mitten auf ben Straß̧en, vor irgend einem Runftrette ftill ftes ben, uno es betracten. Oft foseint eine foldse ganze Straß̧e einem wohlgeotoneten Sunfteabi: net zu gletifien.

Die Squares aber, wo bie prádtigften Şáas fer finto, veridsmáben bergleicfen Bierreatl), ber nut ben Raufsmannsfaufern anfeft. 2(ud) iffs fier lange nicht po volfteidf, wie in ben úbris gen Igeilen bet. Stabt. Brwiffyen Dem Strande uno ben Squares in Ronbon ift ofngefeft, in 2fa:

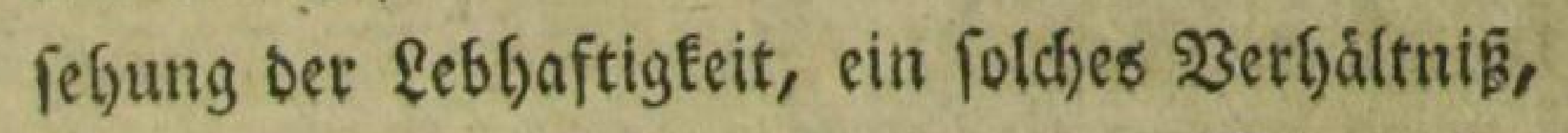
als zimichen Dem?lifhlendamm und Der Friedrichs: ftabt, in Bertin.

Nun, lieber Freuno, fâlft mir niç)ts merfe

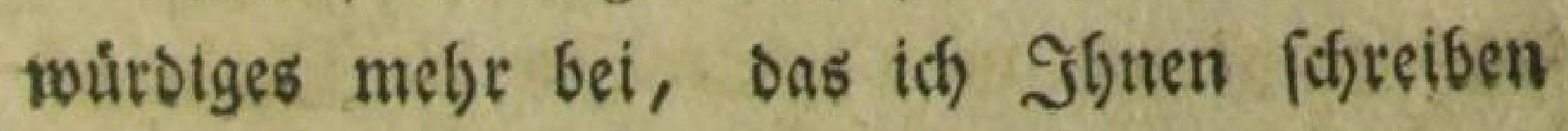




\section{(272.)}

Bormte, als Dak" alles zu unfrer motgenden $216=$ veife fertigift. - Dem Serrn Eapitain Şilte es, mit bem idf yon Şamburg berfubr, mußte idf

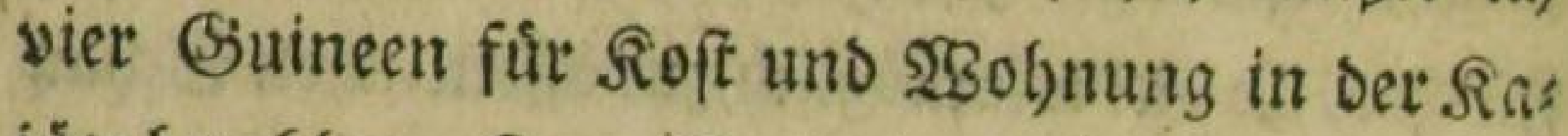
jüte bezablen. Sert (Eapitain Ş raun [d weig aber, mit Dem iff wieder zutúcffabte, nimmt fünf

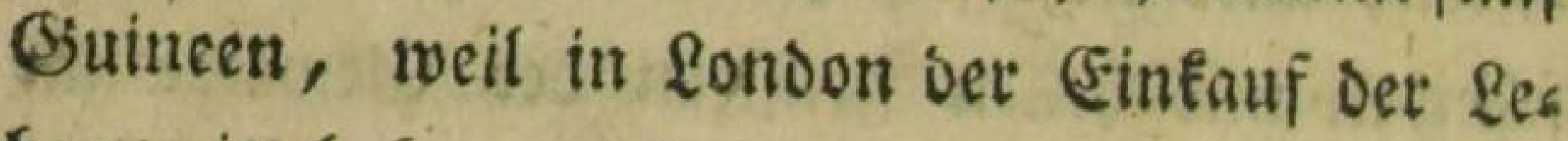
bensmittel theurer iff.

Utno mun batte id) Şfthen benn alle meine Fata unb 2lbentbeuer, von bem 2fugenbliff an,

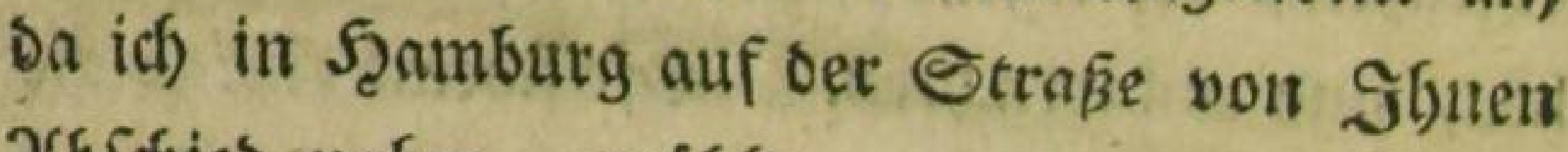
2(b)ófied nabm, ergáblt; auggenommen meine Şetreife mit Şetrn Şilfę. Bon siejer bes vidfte denn noch, Daß fie zu meinem bodyften Mišergnigen vierzethn Tage Dauerte, uno ith brei Tage leeftanf war. $3 o n$ bet Scinreife

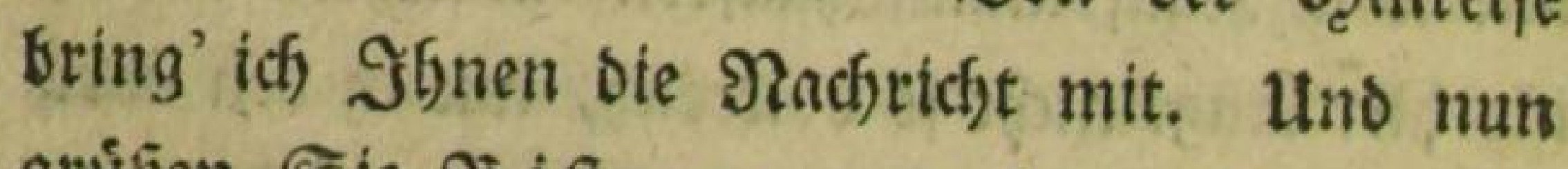
griben Sie siftern, und leben Sie robly bis wir uns wiederfefjen! 

7 8. 302.1982

pa Nov 1984.

4. 7. VII. 1985

$2-t \cdot x_{2}=$ 

